Portland State University

PDXScholar

$7-1-2020$

\title{
CE-QUAL-W2 Hydrodynamic and Water Quality Model of the Cedar River Municipal Watershed
}

Amory Spencer Cervarich

Portland State University

Follow this and additional works at: https://pdxscholar.library.pdx.edu/open_access_etds

Part of the Environmental Engineering Commons

Let us know how access to this document benefits you.

Recommended Citation

Cervarich, Amory Spencer, "CE-QUAL-W2 Hydrodynamic and Water Quality Model of the Cedar River Municipal Watershed" (2020). Dissertations and Theses. Paper 5523.

https://doi.org/10.15760/etd.7397

This Thesis is brought to you for free and open access. It has been accepted for inclusion in Dissertations and Theses by an authorized administrator of PDXScholar. Please contact us if we can make this document more accessible: pdxscholar@pdx.edu. 
CE-QUAL-W2 Hydrodynamic and Water Quality Model of the Cedar River Municipal Watershed

\author{
by \\ Amory Spencer Cervarich
}

A thesis submitted in partial fulfillment of the

requirements for the degree of

Master of Science

in

Civil and Environmental Engineering

Thesis Committee:

Scott Wells, Chair

Chris Berger

Gwynn Johnson

Portland State University

2020 
(C) 2020 Amory Spencer Cervarich 


\begin{abstract}
The laterally averaged, two-dimensional model CE-QUAL-W2 was used to develop a water quality model of the Cedar River Municipal Watershed as a reservoir management and climate change scenario tool. The 90,638-acre watershed, located 56 kilometers southeast of Seattle, WA, provides drinking water to over 1.4 million people. The watershed relies on two waterbodies for storage, Chester Morse Lake and the Masonry Pool. The Masonry Dam is the main storage structure in the watershed. The Cedar River flows downstream from the Masonry Dam for 57 kilometers to Lake Washington. The reservoir model simulated Chester Morse Lake and the Masonry Pool. The river model simulated the Cedar River from the Masonry Dam for 21 kilometers to the Landsburg Diversion Dam. Model inputs included bathymetric data, stream inflows and temperatures, outflows from the Masonry Dam, water quality constituent concentrations, and meteorological data. The system was modeled over two separate time periods: January 1, 2005 to December 31, 2008 and January 1 to December 31, 2015. Water level calibration was completed by comparing observed water surface elevations in Chester Morse Lake and the Masonry Pool. Flow calibration was completed by comparing streamflow gages in the Cedar River. Water temperature calibration used temperature data from twelve locations for the 2005-2008 model and six locations for the 2015 model. Water quality calibration used data from five locations for the 2005-2008 model and ten locations for the 2015 model. The model simulated water temperature on the hourly timescale with an RMSE of $0.60-0.65^{\circ} \mathrm{C}$ in the reservoir
\end{abstract}


models and an RMSE of $0.48-0.71^{\circ} \mathrm{C}$ in the river models. The model simulated dissolved oxygen profile concentrations in Chester Morse Lake with an RMSE of $0.51-0.66 \mathrm{mg} / \mathrm{L}$ in the reservoir models and dissolved oxygen discrete sample concentrations in the Cedar River with an RMSE of $0.32-0.36 \mathrm{mg} / \mathrm{L}$ in the river models. Other water quality parameters were simulated within observed ranges for all parameters.

Three climate change scenarios considered changes in meteorological data and inflow data. Two reservoir management scenarios considered changes in reservoir storage and spring refill level. The scenario with the greatest predicted impact was Scenario 1, in which air temperature and water temperature were increased by a uniform $3^{\circ} \mathrm{C}$. Temperature change of the average monthly temperature at noon increased by $1.0-2.6^{\circ} \mathrm{C}$ across the watershed. Dissolved oxygen concentrations less than $6 \mathrm{mg} / \mathrm{L}$ were predicted 9 percent of the time for the reservoir from May to September compared to 0 percent in the base model and all other scenarios. Other water quality parameters did not experience significant change under any of the modeled scenarios.

The impact on fish habitat under each scenario was determined for the reservoir model and the river model. Non-lethal growth conditions for bull trout in Scenario 1 decreased by 2 to 20 percent of reservoir volume from June through October. Core summer salmonid habitat decreased by 1 to 13 percent of river volume from mid-June through mid-September under Scenario 1. 
The calibrated Cedar River Municipal Watershed model provides a watershed management tool to help implement new management scenarios and prepare for the impacts of climate change. Current model limitations include a reliance on the historically observed Masonry Pool water levels to control outflows from the reservoir in management scenarios. Operation logic that de-couples the model from the historically observed water surface elevations should be developed. This would allow the model to be a more useful management tool based on operation logic rather than observed operation strategy. 


\section{Acknowledgments}

I would like to thank my thesis committee chair, Dr. Scott Wells, for his endless support and insatiable curiosity. I would also like to thank my committee members, Dr. Chris Berger and Dr. Gwynn Johnson, for their encouragement and guidance along the way. Special thanks to Jamie Thompson, John Edgerly, and Lynn Kirby from Seattle Public Utilities for their watershed expertise and data contributions. And to my fellow graduate students in the Water Quality Research Group Laboratory, tel jensen and Corina Overman, thank you for all the sanity-inducing conversations, puffin burrow highlights, and animated discussions. 


\section{Table of Contents}

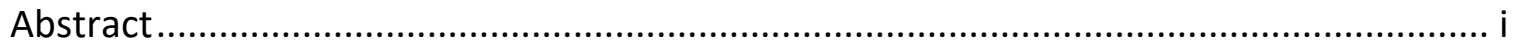

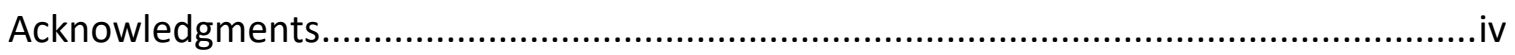

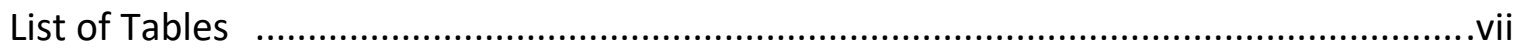

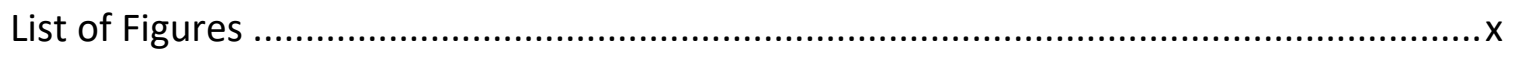

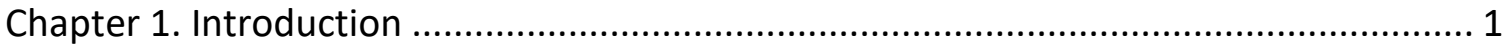

1.1 Site Description, Basin Characteristics, and Hydrology ..................................... 3

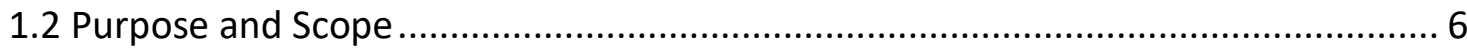

Chapter 2. Previous Modeling Work on the Cedar River Basin ....................................... 7

2.1 Water Quality and Fish Bioenergetics.................................................................. 7

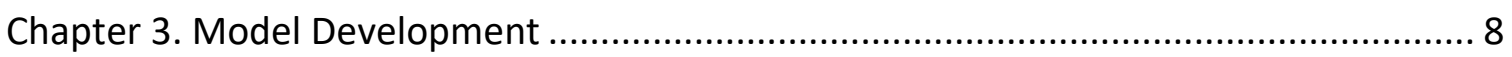

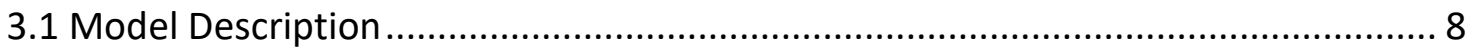

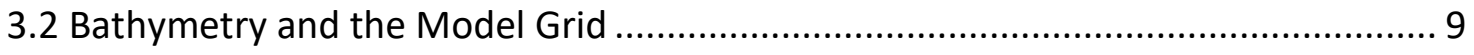

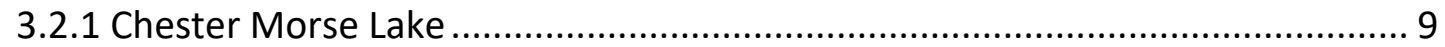

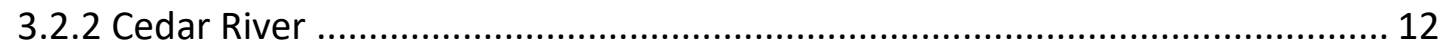

3.2.3 Chester Morse Lake and Cedar River Model Linkage..................................... 16

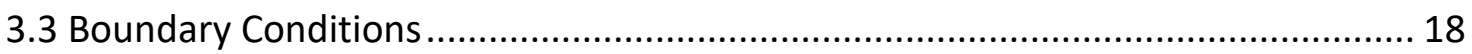

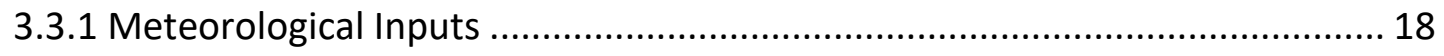

3.3.2 Streamflow and Stream Temperature......................................................... 25

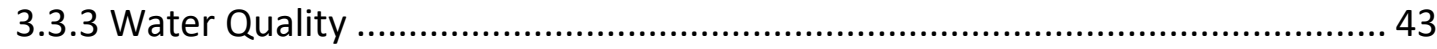

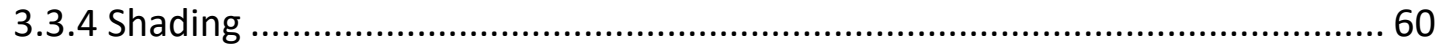

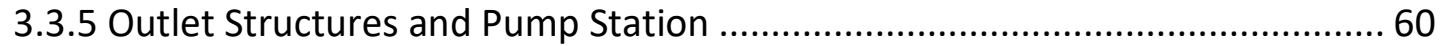

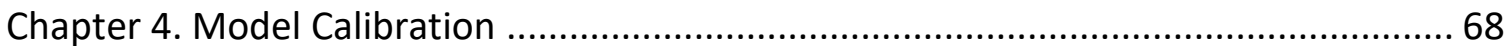

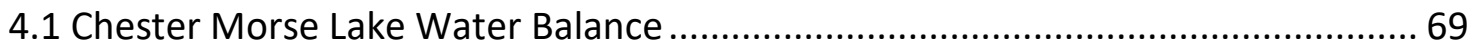

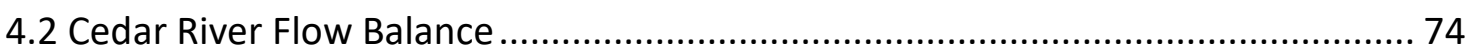

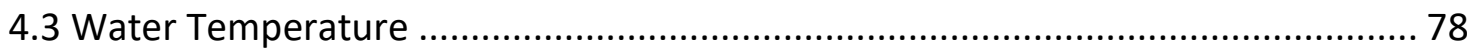

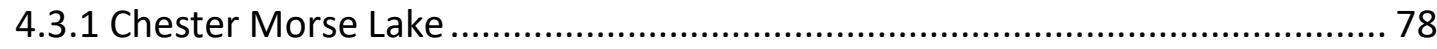

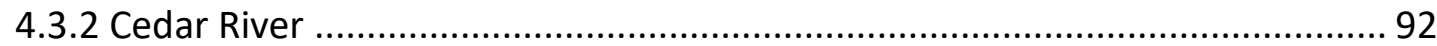

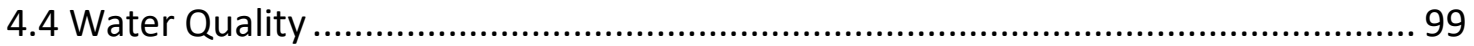

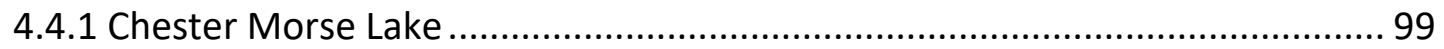

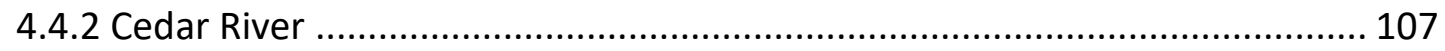




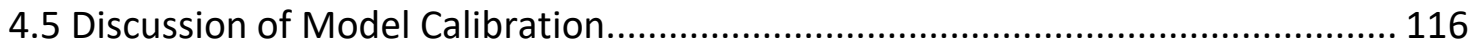

4.5.1 Chester Morse Lake Water Balance .......................................................... 116

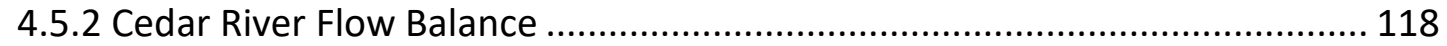

4.5.3 Water Temperature Calibration Discussion ............................................. 118

4.5.4 Water Quality Calibration Discussion........................................................ 121

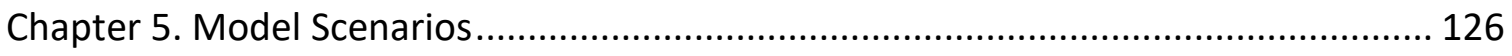

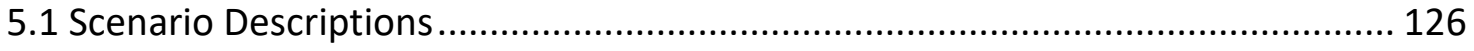

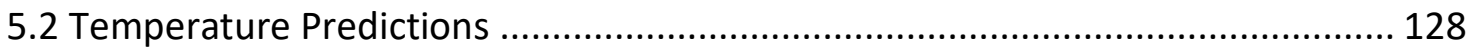

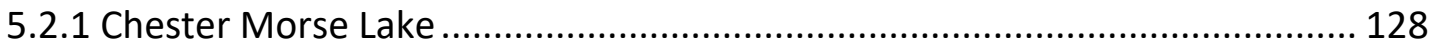

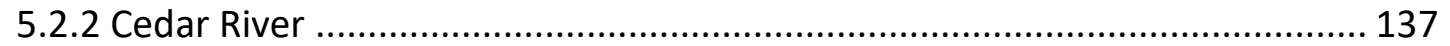

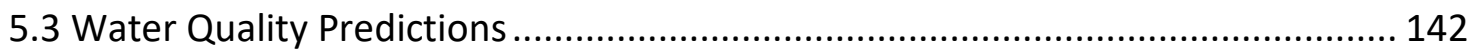

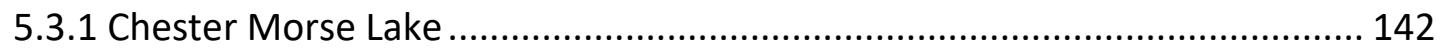

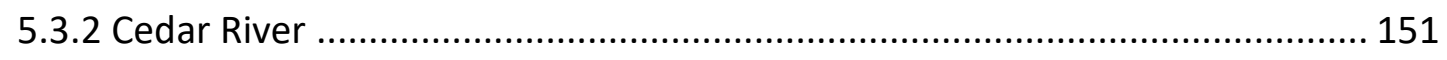

5.3.3 Water Quality Discussion and Conclusions ............................................... 152

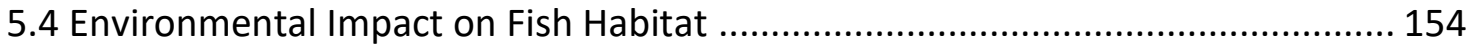

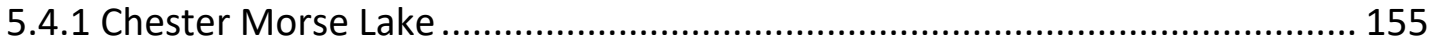

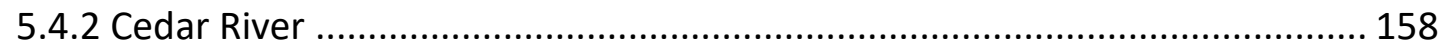

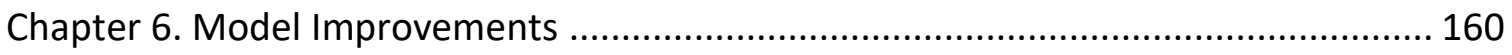

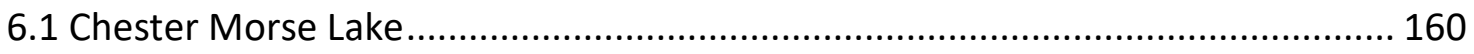

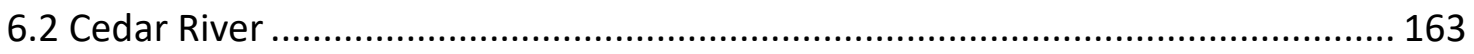

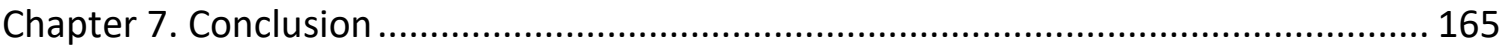

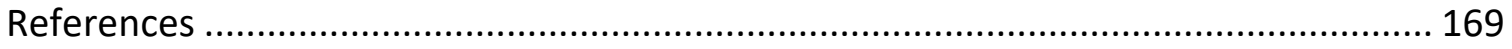

Appendix A. Temperature Profiles: Buoys, 2007-2008 ............................................. 172

Appendix B. Water Quality Constituents: Reservoir Model, 2005-2008....................... 190

Appendix C. Water Quality Constituents: Reservoir Model, 2015 .............................. 200

Appendix D. Water Quality Constituents: River Model, 2005-2008............................. 206

Appendix E. Water Quality Constituents: River Model, 2015 ................................... 209

Appendix F. Change in Dissolved Oxygen Concentrations under Scenarios, Cedar River 216

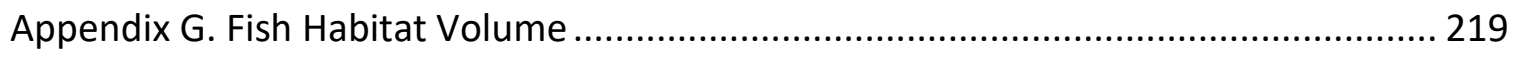




\section{List of Tables}

Table 1. Summary of the Chester Morse Lake model grid characteristics. ....................... 12

Table 2. Summary of the Chester Morse Lake model branch segments......................... 12

Table 3. Summary of the Cedar River model grid characteristics. ................................. 15

Table 4. Summary of the Cedar River model branch segments. ..................................... 15

Table 5. Summary of drainage areas and corresponding location in the Chester Morse

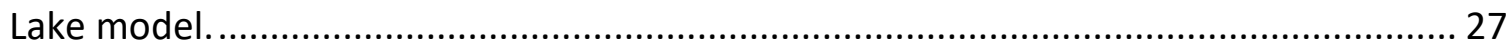

Table 6. Summary of the drainage area of river tributaries, the percent of drainage basin

area, and corresponding location in the Cedar River model........................................ 38

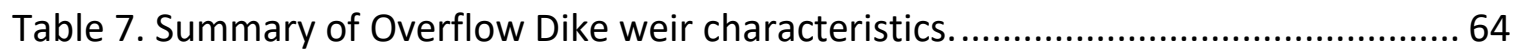

Table 8. Summary of the underflow structure characteristics at the Overflow Dike. ..... 65

Table 9. Water surface elevation error statistics for the main reservoir (USGS 12115900)

and the Masonry Pool (USGS 12116060), 2005-2008................................................. 74

Table 10. Water surface elevation error statistics for the main reservoir (USGS

12115900) and the Masonry Pool (USGS 12116060), 2015..................................... 74

Table 11. Summary table of daily average flow error statistics at USGS 12116400, USGS

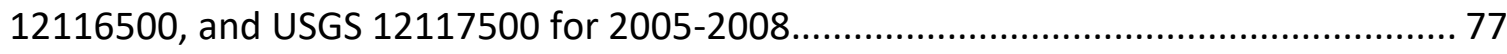

Table 12. Summary table of daily average flow error statistics at USGS 12116400, USGS

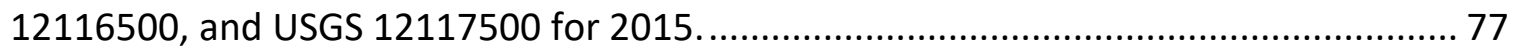

Table 13. Summary of temperature buoy location and corresponding model segment. 81

Table 14. Summary of vertical profile temperature error statistics for CM1A and MD,

2005-2008.

Table 15. Summary of vertical profile temperature error statistics for CM1A and MD,

2015. * indicates that some data were excluded from analysis.

Table 16. Summary of vertical profile temperature error statistics for the seven

temperature buoys, 2007-2008.

Table 17. Summary of daily average temperature error statistics for USGS 12116500 and

USGS 12117600, 2005-2008.

Table 18. Summary of daily average temperature error statistics for USGS 12116500 ,

WSDE 08C110, and USGS 12117600, 2015

Table 19. Summary of water quality error statistics for chlorophyll a and dissolved oxygen, 2005-2008 and 2015. * indicates that some data were excluded from analysis.

Table 20. Summary of observed and modeled concentration ranges at CM1A in 2005-2008 and 2015. 107

Table 21. Summary of weighted average concentration error statistics in the Cedar River, 2005-2008. 110

Table 22. Summary of weighted average concentration error statistics in the Cedar River, 2015. 
Table 23. Summary of weighted average daily temperature error statistics comparing the final calibration to the boundary condition temperature sensitivity analysis model runs for the 2015 Cedar River model.

Table 24. Comparison of Pearson correlation coefficients for water quality parameters, 2015. Coefficients were calculated for the relationship between parameters at CM1A and the Masonry Dam (MD).

Table 25. Summary table of modeled scenarios. ........................................................... 126

Table 26. Summary of the average monthly temperature in degrees Celsius at noon in the Chester Morse Lake base model and the change in the average for each scenario modeled at CM1A (segment 27). Weighted averages are calculated for May through September and annually.

Table 27. Summary of the average monthly temperature in degrees Celsius at noon in the Masonry Pool base model and the change in the average for each scenario modeled at MD (segment 64). Weighted averages are calculated for May through September and annually. 134

Table 28. Summary of the average monthly temperature in degrees Celsius at noon in the Cedar River base model and the change in the average for each scenario modeled at all segments. Weighted averages are calculated for May through September and annually 138

Table 29. Weighted average change in percent of reservoir volume from May 1 to September 30 relative to the Chester Morse Lake base model for all segments on all days. .....

Table 30. Summary of the average monthly dissolved oxygen concentration $(\mathrm{mg} / \mathrm{L}$ ) at noon in the Chester Morse Lake base model and the change in the average for each scenario modeled at CM1A (segment 27). Weighted averages are calculated for May through September and annually.

Table 31. Summary of the average monthly dissolved oxygen concentration $(\mathrm{mg} / \mathrm{L})$ at noon in the Masonry Pool base model and the change in the average for each scenario modeled at MD (segment 64). Weighted averages are calculated for May through September and annually. 148

Table 32. Summary of the change in weighted average concentration at noon relative to the base model for all segments calculated for May through September (M-S) and

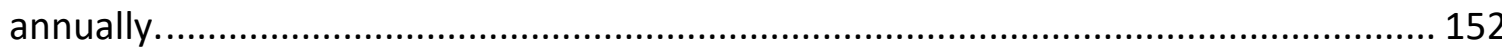

Table 33. Summary of growth potential zones for bull trout in Chester Morse Lake.... 156 Table 34. Summary of the average monthly percent of reservoir volume with non-lethal growth potential for bull trout in the Chester Morse Lake base model and the change in the average for each scenario. 157

Table 35. Summary of the average monthly percent of reservoir volume with optimal growth potential for bull trout in the Chester Morse Lake base model and the change in the average for each scenario. 157

Table 36. Summary of WAC 173-201A-200 aquatic life temperature and dissolved oxygen criteria for fresh surface waters. 158 
Table 37. Summary of the average monthly percent of river volume with core summer salmonid habitat aquatic life use in the Cedar River base model and the change in the average for each scenario.

Table 38. Summary of the average monthly percent of river volume with salmonid spawning, rearing, and migration aquatic life use in the Cedar River base model and the change in the average for each scenario............................................................. 159 


\section{List of Figures}

Figure 1. Map of the Lake Washington/Cedar River Watershed, showing the locations of

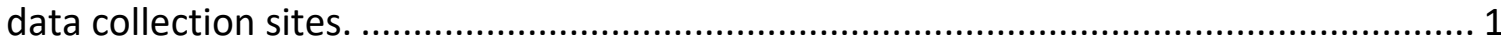

Figure 2. Overview map of the upper Cedar River Municipal Watershed. Major tributaries include Rack Creek, Boulder Creek, McClellan Creek, Rex River, and the North and South Forks of the Cedar River.

Figure 3. Overview map of the lower Cedar River Municipal Watershed. Major tributaries include Steele Creek, Williams Creek, Rock Creek, and Taylor Creek. 5

Figure 4. Original bathymetric data for Chester Morse Lake and the Masonry Pool (Wells V. I., 2012). 10

Figure 5. Schematic of the Chester Morse Lake model grid with branch boundaries indicated. 10

Figure 6. Side view schematic of the reservoir model grid showing the four model branches, horizontal model segments, and vertical layers. Each layer was 0.61 meters deep. Segments ranged between 250.2 and 276.3 meters in length.

Figure 7. Vertical model segment slices: segment 2 (left), segment 27 (middle), and segment 64 (right). Segment 2 was the beginning of the model domain. Segment 27 was located at the SPU CM1A sample station. Segment 64 was the end of the model domain at the Masonry Dam.

Figure 8. Cedar River transects and USGS DEM coverage of surrounding area.............. 13

Figure 9. Schematic of the Cedar River model grid with branch boundaries indicated... 14 Figure 10. Side view schematic of the Cedar River grid showing the five branches, horizontal model segments, and vertical layers. Each layer was 1 meter deep and segments ranged between 252.7 and 258.3 meters long.

Figure 11. Vertical model segment slices: segment 2 (left), segment 74 (middle), and segment 95 (right). Segment 2 was the beginning of the model domain. Segment 74 was located at the WSDE 08C110 sample station. Segment 95 was the end of the model domain at the Landsburg Diversion Dam.

Figure 12. Detail of linkage between Chester Morse Lake and the Cedar River. Outputs from the reservoir model were used as inputs for the river model...

Figure 13. Locations of tributary inflows, USGS gaging stations, and water quality monitoring sites located within and in immediate proximity to the model domain....... 17 Figure 14. Location of meteorological stations used to develop boundary conditions for the reservoir and river models.

Figure 15. Chester Morse Lake air temperature and dew point temperature for the 2005-2008 model (top) and the 2015 model (bottom).

Figure 16. Cedar River air temperature inputs for each waterbody in the 2005-2008 model (top) and in the 2015 model (bottom). Air temperature was adjusted by the US Standard Atmosphere lapse rate when field data were not available. 
Figure 17. Chester Morse Lake wind direction model inputs for 2005-2008. Adapted from Google Earth, earth.google.com/web

Figure 18. Chester Morse Lake wind direction model inputs for 2015. Adapted from Google Earth, earth.google.com/web.

Figure 19. Wind speed data from USGS 12115900 relative to wind speed model inputs for 2005-2008 (top) and 2015 (bottom).

Figure 20. Fraction of model period with indicated cloud cover for 2005-2008 (left) and 2015 (right).

Figure 21. Solar radiation data from USGS 12115900 relative to solar radiation model inputs using the Meeus theoretical solar model for 2005-2008 (top) and 2015 (bottom).

Figure 22. Map showing the location of USGS gaging stations within the Cedar River Municipal Watershed.....

Figure 23. Regression analysis of flow at USGS 12115500 and USGS 12115000 using 15-minute data from January 1 through December 31, 2015 ( $n=28207)$. Periods impacted by backwater were excluded from the analysis.

Figure 24. Regression analysis of flow at USGS 12114500 and USGS 12115000 using hourly data from January 1, 1988 to December 31, 2017 ( $n=220252)$. 28

Figure 25. Observed streamflow at USGS 12115000 and USGS 12115500 relative to the branch 1 modeled inflow in 2005-2008 (top) and 2015 (bottom). Modeled inflow was corrected for backwater affects.

Figure 26. Observed streamflow at USGS 12115700 and modeled tributary inflow for Rack Creek. All reservoir tributaries not shown follow the same trend as Rack Creek adjusted by their respective scaling factors.

Figure 27. Regression models for water temperature in Boulder Creek (left, $n=12220$ ) and Rack Creek (right, $n=29168$ ) as a function of observed temperature at USGS 12115000.

Figure 28. Regression model for water temperature in Rex River (left, $n=38530$ ) as a function of observed temperature at USGS 12115000. Regression model for water temperature at USGS 12115000 as a function of observed temperature at USGS 12116500 (right, $n=1415$ ).

Figure 29. Observed water temperature at Boulder Creek and model input developed using regression analysis, 2005-2008.

Figure 30. Observed water temperature at Rack Creek and model input developed using regression analysis, 2005-2008. 33

Figure 31. Observed water temperature at Rex River and model input developed using regression analysis, 2005-2008.

Figure 32. Observed water temperature data at USGS 12115000 and model input. Water temperature data at 6 meters from a buoy in close proximity were used for the later part of the model run, 2005-2008. 
Figure 33. Water temperature inputs for all reservoir inflows in 2005-2008 (top) and 2015 (bottom). Inflow temperatures for tributaries lacking field observations were assumed to be consistent with USGS 12115000.

Figure 34. Observed streamflow below the Masonry Dam (top) and modeled outflows from the Masonry Dam (bottom), 2005-2008.

Figure 35. Observed streamflow below the Masonry Dam (top) and modeled outflows from the Masonry Dam (bottom), 2015.

Figure 36. Larger inflows to the Cedar River in 2005-2008 (top) and 2015 (bottom). The dam releases were generated by the reservoir model. USGS 12117000 is the observed streamflow at Taylor Creek.

Figure 37. Smaller inflows to the Cedar River in 2005-2008 (top) and 2015 (bottom). USGS 12116100 is the observed streamflow at Canyon Creek. All other tributary inflows were estimated using the flow difference and drainage-area ratio method. Tributaries not shown follow the same trend as Rock Creek adjusted by their respective scaling factors.

Figure 38. Observed water temperature in the model domain for 2005-2008 (top) and 2015 (bottom).

Figure 39. Simulated water temperature from the lower outlet release, the powerhouse release, and the spillway in the reservoir model for 2005-2008 (top) and 2015 (bottom).

Figure 40. Map of water quality monitoring site locations within the Cedar River

Municipal Watershed.

Figure 41. Monthly percentage of occurrence of observed algae groups in Chester Morse Lake, 2015.

Figure 42. Constituent concentrations for phosphate, ammonia, nitrate-nitrite, and dissolved oxygen, 2005-2008.

Figure 43. Constituent concentrations for LDOM, RDOM, LPOM, and RPOM, 2005-2008.

Figure 44. Constituent concentrations for LDOM-P, RDOM-P, LPOM-P, and RPOM-P, 2005-2008....

Figure 45. Constituent concentrations for LDOM-N, RDOM-N, LPOM-N, and RPOM-N, 2005-2008.

Figure 46. Constituent concentrations for algal group 1, algal group 2, algal group 3, and zooplankton, 2005-2008.

Figure 47. Constituent concentrations for phosphate, ammonia, nitrate-nitrite, and

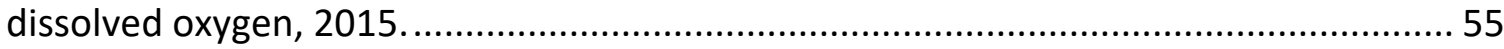

Figure 48. Constituent concentrations for LDOM, RDOM, LPOM, and RPOM, 2015...... 56 Figure 49. Constituent concentrations for LDOM-P, RDOM-P, LPOM-P, and RPOM-P, 2015.

Figure 50. Constituent concentrations for LDOM-N, RDOM-N, LPOM-N, and RPOM-N, 2015. 
Figure 51. Constituent concentrations for algal group 1, algal group 2, algal group 3, and zooplankton, 2015. 59

Figure 52. Aerial view of the Masonry Dam (Seattle Public Utilities, 2014). 61

Figure 53. Overflow Dike at high water levels (left) and low water levels (right) (J.

Edgerly, personal communication, July 12, 2019). 61

Figure 54. Chester Morse Lake Pumping Plant (Reid Middleton, n.d.) 62

Figure 55. Schematic of Overflow Dike as modeled in CE-QUAL-W2. The weir was modeled using an overflow dam (section A) and a notch with flashboards (section B). The underflow structures were modeled as pipes.

Figure 56. Schematic of the Chester Morse Lake floating portable pump station (Vail, Ochiltree, \& Bishop, 2016).

Figure 57. Schematic of the Overflow Dike and Masonry Dam. The schematic is not to scale (J. Edgerly, personal communication, July 7, 2019).

Figure 58. Main reservoir distributed flow (branch 1) and Masonry Pool water balance flow (branch 4) for 2005-2008.

Figure 59. Main reservoir distributed flow (branch 1) and Masonry Pool water balance flow (branch 4) for 2015.

Figure 60. Comparison of the SPU water management equation for seepage loss in the moraine to the water balance flow (distributed tributary, branch 4), 2005-2008. ........ 72 Figure 61. Comparison of the SPU water management equation for seepage loss in the moraine to the water balance flow (distributed tributary, branch 4), 2015. 72

Figure 62. Comparison of modeled and observed water surface elevations in the main reservoir (USGS 12115900) and the Masonry Pool (USGS 12116060) in 2005-2008 (top) and 2015 (bottom). 73

Figure 63. Modeled flow predictions compared to observed flow for 2005-2008 at USGS 12116400 (top), USGS 12116500 (middle), and USGS 12117500 (bottom). 75

Figure 64. Modeled flow predictions compared to observed flow for 2015 at USGS 12116400 (top), USGS 12116500 (middle), and USGS 12117500 (bottom).................... 76 Figure 65. Flow inputs used for Rattlesnake Prairie and the distributed flows in branch 4

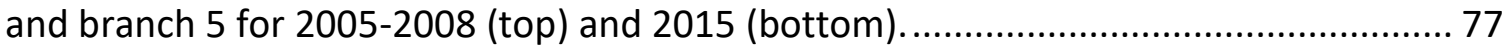
Figure 66. Temperature profiles from CM1A (segment 27), 2005 through 2008........... 79 Figure 67. Temperature profiles at MD (segment 64), 2005-2008. ............................. 80 Figure 68. Temperature profiles from CM1A (left) and MD (right) during 2015. Grab samples were collected 2 meters below the surface and at the elevation of the lower level outlet at the Masonry Dam. The lines are for visual aid only in the MD figure....... 80 Figure 69. Continuous temperature collected at Buoy 1, Cedar River confluence (segment 9).

Figure 70. Continuous temperature collected at Buoy 2, Green Point/McClellan Creeks (segment 17).

Figure 71. Continuous temperature collected at Buoy 3, Rex Delta drop-off (segment 47). 
Figure 72. Continuous temperature collected at Buoy 4, Cedar Della drop-off (segment 13).

Figure 73. Continuous temperature collected at Buoy 5, Chester Morse Lake - Deepest

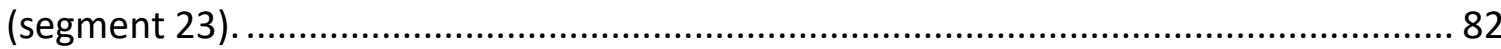
Figure 74. Continuous temperature collected at Buoy 6, MLPP intake (segment 34).... 82 Figure 75. Continuous temperature collected at Buoy 7, Masonry Dam (segment 64). . 83 Figure 76. Wind sheltering coefficient as a function of time for the Chester Morse Lake model in 2005-2008 (top) and 2015 (bottom).

Figure 77. Simulated temperature at noon at CM1A (top) and the Masonry Dam

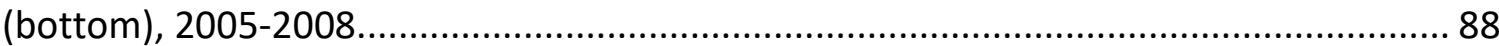

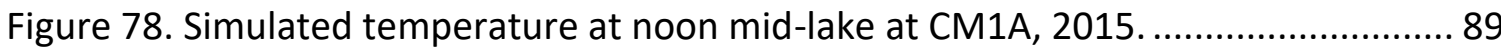

Figure 79. Simulated temperature at noon at the Masonry Dam, 2015........................ 89

Figure 80. Comparison of model temperature simulations to observed temperature data

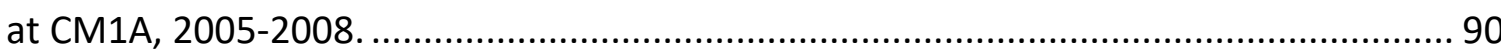

Figure 81. Comparison of model temperature simulations to observed temperature data

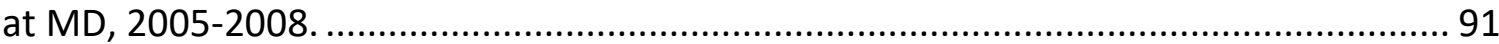

Figure 82. Comparison of model temperature simulations to observed temperature data at CM1A, 2015.

Figure 83. Comparison of model temperature simulations to observed temperature data at MD, 2015.

Figure 84. Water temperature inputs used for model tributaries in 2005-2008 (top) and 2015 (bottom). Upper Cedar tributaries included Lost Creek, Fish Creek, Canyon Creek, and Rattlesnake Prairie. Middle Cedar tributaries included De-Horn Creek, the unnamed left-bank input, Steele Creek, Williams Creek, and Taylor Creek. 93

Figure 85. Simulated daily temperature at noon in the Cedar River, 2005-2008. Model segments indicate the domain boundaries, USGS gaging stations, and water quality monitoring sites.

Figure 86. Modeled daily average temperature predictions compared to observed daily average temperature from 2005-2008 at USGS 12116500 (top) and USGS 12117600 (bottom).

Figure 87. Simulated daily temperature at noon in the Cedar River, 2015. Model segments indicate the domain boundaries, USGS gaging stations, and water quality monitoring sites.

Figure 88. Modeled daily average temperature predictions compared to observed daily average temperature from 2015 at USGS 12116500 (top), WSDE 08C110 (middle), and

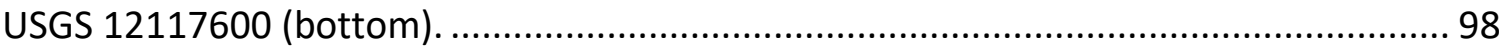

Figure 92. Comparison of modeled chlorophyll a concentrations to observed chlorophyll a data at CM1A, 2015. 102

Figure 89. Simulated dissolved oxygen concentrations at noon mid-lake at CM1A (top) and at the Masonry Dam (bottom), 2005-2008. 103

Figure 90. Simulated dissolved oxygen concentrations at noon mid-lake at CM1A, 2015. 
Figure 91. Simulated dissolved oxygen concentrations at noon at the Masonry Dam, 2015.

Figure 93. Comparison of modeled dissolved oxygen concentrations to observed dissolved oxygen data at CM1A, 2005-2008.

Figure 94. Comparison of modeled dissolved oxygen concentrations to observed dissolved oxygen data at CM1A, 2015.

Figure 95. Simulated dissolved oxygen concentrations at noon in the Cedar River, 20052008. Model segments indicate the domain boundaries, USGS gaging stations, and water quality monitoring sites.

Figure 96. Comparison of modeled dissolved oxygen concentrations to observed concentrations at WSDE 08C110 (segment 74), 2005-2008.

Figure 97. Comparison of modeled total nitrogen concentrations to observed concentrations at CPR1 (segment 95), 2005-2008.

Figure 98. Comparison of modeled nitrate-nitrite concentrations to observed concentrations at CPR1 (segment 95), 2005-2008.

Figure 99. Comparison of modeled ammonia concentrations to observed concentrations at WSDE 08C110 (segment 74), 2005-2008.

Figure 100. Comparison of modeled total phosphorus concentrations to observed concentrations at CPR1 (segment 95), 2005-2008.

Figure 101. Comparison of modeled phosphate concentrations to observed concentrations at CPR1 (segment 95), 2005-2008.

Figure 102. Comparison of modeled total organic carbon concentrations to observed concentrations at CPR1 (segment 95), 2005-2008.

Figure 103. Simulated dissolved oxygen concentrations at noon in the Cedar River, 2015. Model segments indicate the domain boundaries, USGS gaging stations, and water quality monitoring sites.

Figure 104. Comparison of modeled dissolved oxygen concentrations to observed concentrations at WSDE 08C110 (segment 74), 2015

Figure 105. Comparison of modeled total nitrogen concentrations to observed concentrations at CPR1 (segment 95), 2015.

Figure 106. Comparison of modeled nitrate-nitrite concentrations to observed concentrations at CPR1 (segment 95), 2015.

Figure 107. Comparison of modeled ammonia concentrations to observed concentrations at WSDE 08C110 (segment 74), 2015

Figure 108. Comparison of modeled total phosphorus concentrations to observed concentrations at CPR1 (segment 95), 2015.

Figure 109. Comparison of modeled phosphate concentrations to observed concentrations at CPR1 (segment 95), 2015.

Figure 110. Comparison of modeled total organic carbon concentrations to observed concentrations at CPR1 (segment 95), 2015.

Figure 111. Comparison of observed daily average temperature at WSDE 08C110 to calibration model runs using different temperature inputs for the Middle Cedar 
tributaries and the branch 4 distributed flow. In the Upper tributaries model run, the Upper tributaries temperature file was used for the Middle tributaries. In the Rock Creek run, the Rock Creek temperature file was used for the Middle tributaries. In the mean air temperature run, the mean annual air temperature for waterbody 2 was used as the temperature value for the branch 4 distributed flow.

Figure 112. Correlation matrix of water quality constituents mid-lake at CM1A, 2015. Negative numbers indicate a negative correlation and positive numbers indicate a positive correlation. Insignificance is indicated by a blank.

Figure 113. Correlation matrix of water quality constituents at the Masonry Dam, 2015. Negative numbers indicate a negative correlation and positive numbers indicate a positive correlation. Insignificance is indicated by a blank.

Figure 114. Change in percent of reservoir volume from May 1 to September 30 within the indicated temperature range relative to the base model for all segments on all days.

Figure 115. Comparison of the base condition daily temperature at noon to Scenario 1, CM1A (segment 27). 131

Figure 116. Comparison of the base condition daily temperature at noon to Scenario 2, CM1A (segment 27).

Figure 117. Comparison of the base condition daily temperature at noon to Scenario 3, CM1A (segment 27). 132

Figure 118. Comparison of the base condition daily temperature at noon to Scenario 4, CM1A (segment 27). 132

Figure 119. Comparison of the base condition daily temperature at noon to Scenario 5, CM1A (segment 27).

Figure 120. Comparison of the base condition daily temperature at noon to Scenario 1, MD (segment 64). 134

Figure 121. Comparison of the base condition daily temperature at noon to Scenario 2, MD (segment 64). 135

Figure 122. Comparison of the base condition daily temperature at noon to Scenario 3, MD (segment 64). 135 Figure 123. Comparison of the base condition daily temperature at noon to Scenario 4, MD (segment 64). 136 Figure 124. Comparison of the base condition daily temperature at noon to Scenario 5, MD (segment 64). 136 Figure 125. Change in percent of river volume from May 1 to September 30 within the indicated temperature range relative to the base model for all segments on all days. 137 Figure 126. Comparison of the base condition daily temperature at noon to Scenario 1 for all segments on all days, Cedar River. 139 Figure 127. Comparison of the base condition daily temperature at noon to Scenario 2 for all segments on all days, Cedar River. 139 Figure 128. Comparison of the base condition daily temperature at noon to Scenario 3 for all segments on all days, Cedar River. 140 
Figure 129. Comparison of the base condition daily temperature at noon to Scenario 4 for all segments on all days, Cedar River.

Figure 130. Comparison of the base condition daily temperature at noon to Scenario 5 for all segments on all days, Cedar River.

Figure 132. Change in percent of reservoir volume from May 1 to September 30 within the indicated chlorophyll a range relative to the base model for all segments on all days.

Figure 131. Change in percent of reservoir volume from May 1 to September 30 within the indicated dissolved oxygen range relative to the base model for all segments on all days.

Figure 133. Comparison of the base condition daily dissolved oxygen concentration at noon to Scenario 1, CM1A (segment 27).

Figure 134. Comparison of the base condition daily dissolved oxygen concentration at noon to Scenario 2, CM1A (segment 27).

Figure 135. Comparison of the base condition daily dissolved oxygen concentration at noon to Scenario 3, CM1A (segment 27).

Figure 136. Comparison of the base condition daily dissolved oxygen concentration at noon to Scenario 4, CM1A (segment 27).

Figure 137. Comparison of the base condition daily dissolved oxygen concentration at noon to Scenario 5, CM1A (segment 27).

Figure 138. Comparison of the base condition daily dissolved oxygen concentration at noon to Scenario 1, MD (segment 64).

Figure 139. Comparison of the base condition daily dissolved oxygen concentration at noon to Scenario 2, MD (segment 64).

Figure 140. Comparison of the base condition daily dissolved oxygen concentration at noon to Scenario 3, MD (segment 64).

Figure 141. Comparison of the base condition daily dissolved oxygen concentration at noon to Scenario 4, MD (segment 64).

Figure 142. Comparison of the base condition daily dissolved oxygen concentration at noon to Scenario 5, MD (segment 64).

Figure 143. Correlation matrix of water quality constituents and input parameters changed in scenarios. Negative numbers indicate a negative correlation and positive numbers indicate a positive correlation. Insignificance is indicated by a blank. 


\section{Chapter 1. Introduction}

The Cedar River Municipal Watershed is Seattle's main water supply. The 90,638-acre watershed is approximately 39 kilometers (24 miles) long and 16 kilometers (10 miles) wide and provides drinking water to over 1.4 million people (Figure 1). The watershed begins in the mountain crests of the Cascade Range approximately 56 kilometers (35 miles) southeast of Seattle. The Landsburg Diversion Dam forms the westernmost boundary of the system. From the Landsburg diversion, the Cedar River flows 21 kilometers (13 miles) northwest to its terminus at Lake Washington.

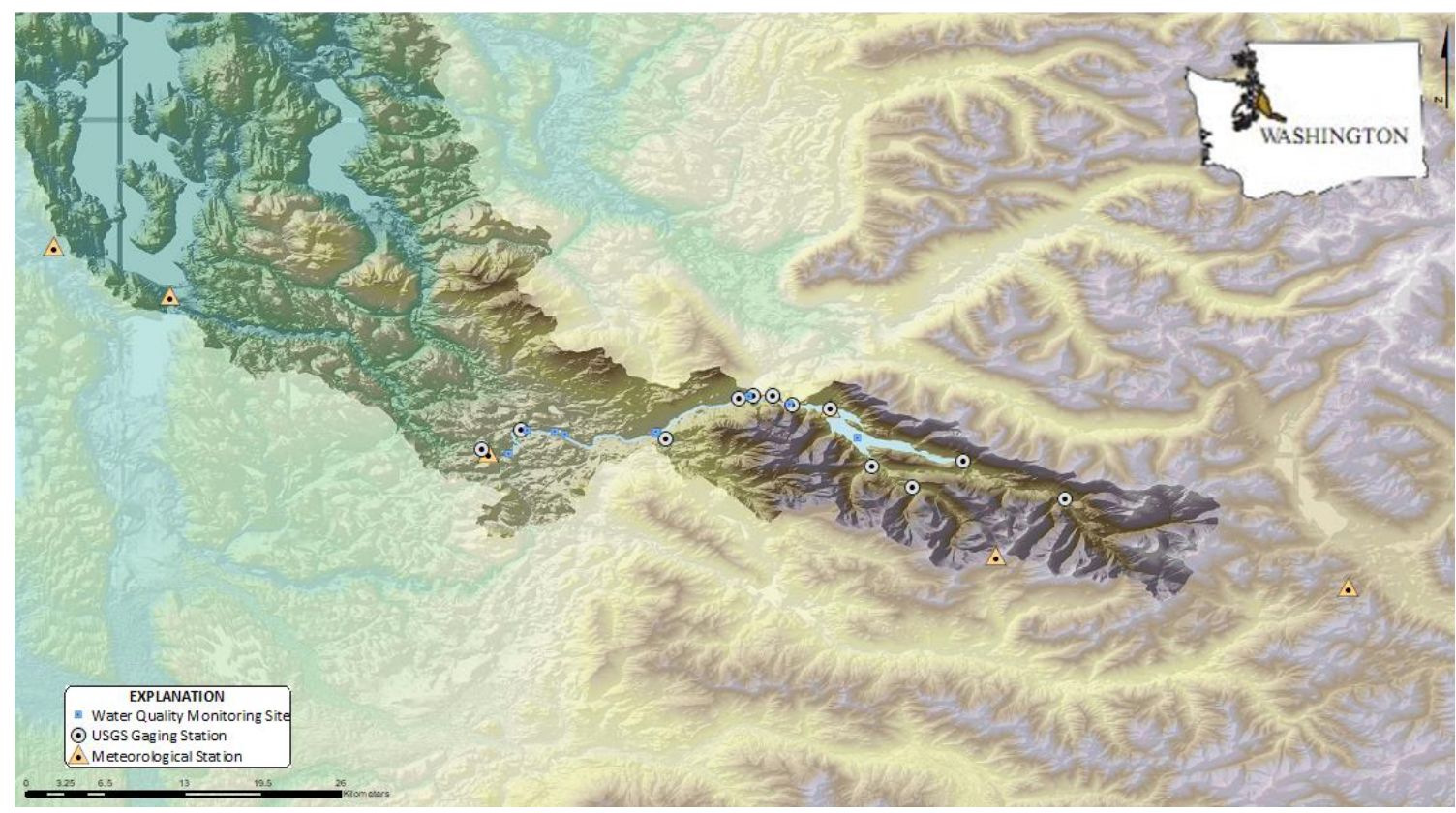

Figure 1. Map of the Lake Washington/Cedar River Watershed, showing the locations of data collection sites.

The City of Seattle owns the entire watershed, making it one of the largest forest acreages owned by any city in the United States (McDonald, 2017). The watershed is managed by Seattle Public Utilities (SPU) for water supply and hydroelectric utilities. 
Seattle began using the watershed as its main source of drinking water in 1901 after the completion of a dam at Landsburg. A timber crib dam was then built on Chester Morse Lake, raising the natural elevation of the lake 5.5 meters (18 feet) from 466.3 meters (1530 feet) (Stein, 2000). A hydroelectric power plant, the first publicly owned hydroelectric project in the United States, was constructed in Cedar Falls in 1902, with the first power provided to Seattle in 1905 (McDonald, 2017). Today, the Cedar Falls hydroelectric plant currently generates up to 30-megawatts of power and provides about 1 percent of the electricity for the city of Seattle (City of Seattle, April 2000). By 1910, construction began on the Masonry Dam to increase water storage, decrease the distance to the power plant intakes, and increase pressure head (Hirsch, 1975). Against the recommendation of consulting engineers, who expressed concern over the glacial moraine and soil suitability, the dam was built 49 meters (160 feet) above the stream bed elevation. The Masonry Dam is located 2.4 kilometers (1.5 miles) below the timber crib dam. Water storage began in December 1914. By May 1915, seepage from the dam had flooded the town of Moncton, which was condemned by the City of Seattle the following year (Savor Snoqualmie Valley, 2017). Rattlesnake Lake now marks the previous location of Moncton, and its water levels continue to respond to reservoir water levels. The reservoir has never been filled to capacity, as seepage through the glacial moraine has caused large landslides (Landau Associates, 2019).

From 1900 to 1924, the watershed was heavily logged with nearly 30,000 forested acres removed (Stein, 2000). The City of Seattle hired a forest manager on a permanent basis 
beginning in 1924 to strengthen logging regulations and control of the watershed. In 1962, current landowners signed the Cedar River Watershed Cooperative Agreement. The agreement created a process to transfer land, ultimately giving the city complete ownership of its watershed by 1996.

In 1988, the timber crib dam was replaced by the Overflow Dike. The current watershed infrastructure includes a roller compacted concrete dam (Overflow Dike), a 210-foot tall cyclopean concrete gravity dam (Masonry Dam), and a power tunnel and penstocks that carry water to the powerhouse located 3.2 kilometers ( 2 miles) downstream of the Masonry Dam (Association of State Dam Safety Officials, 2020). Chester Morse Lake provides approximately 75,000 acre-feet of storage to the Overflow Dike, with the Masonry Dam adding an additional 18,900 acre-feet of storage (WSDE, 2018). A narrow outlet channel connects the two waterbodies. The Overflow Dike, the control structure located in the outlet channel, allows the system to operate as one waterbody at high water levels with Chester Morse Lake flowing over the dike or as two separate waterbodies at low water levels. This minimizes seepage through the moraine at lower water levels.

\subsection{Site Description, Basin Characteristics, and Hydrology}

The Cedar River Municipal Watershed has a temperate marine climate and is characterized by mild, wet winters and warm, dry summers. The mean annual air temperature over the basin area is approximately $8.4^{\circ} \mathrm{C}$. Average annual precipitation 
over the area is approximately 255 centimeters with nearly 75 percent of the annual precipitation occuring between October and March (USGS StreamStats, n.d.).

Chester Morse Lake, formally Cedar Lake, was formed during the last glaciation of the Puget Sound lowlands (Northwest Hydraulic Consultants Inc., 2007). When the glaciers receded, the lake was formed by a glacial moraine deposit of alluvium. Chester Morse Lake is primariliy fed by the north and south forks of the Cedar River and the Rex River. The rivers enter the lake across broad deltas. Most of the smaller tributaries in the upper watershed are charactierized by steep gradients with cascade and step-pool habitat (Seattle Public Utilities, n.d.). The major tributaries include Rack Creek, Boulder Creek, and McClellan Creek (Figure 2).

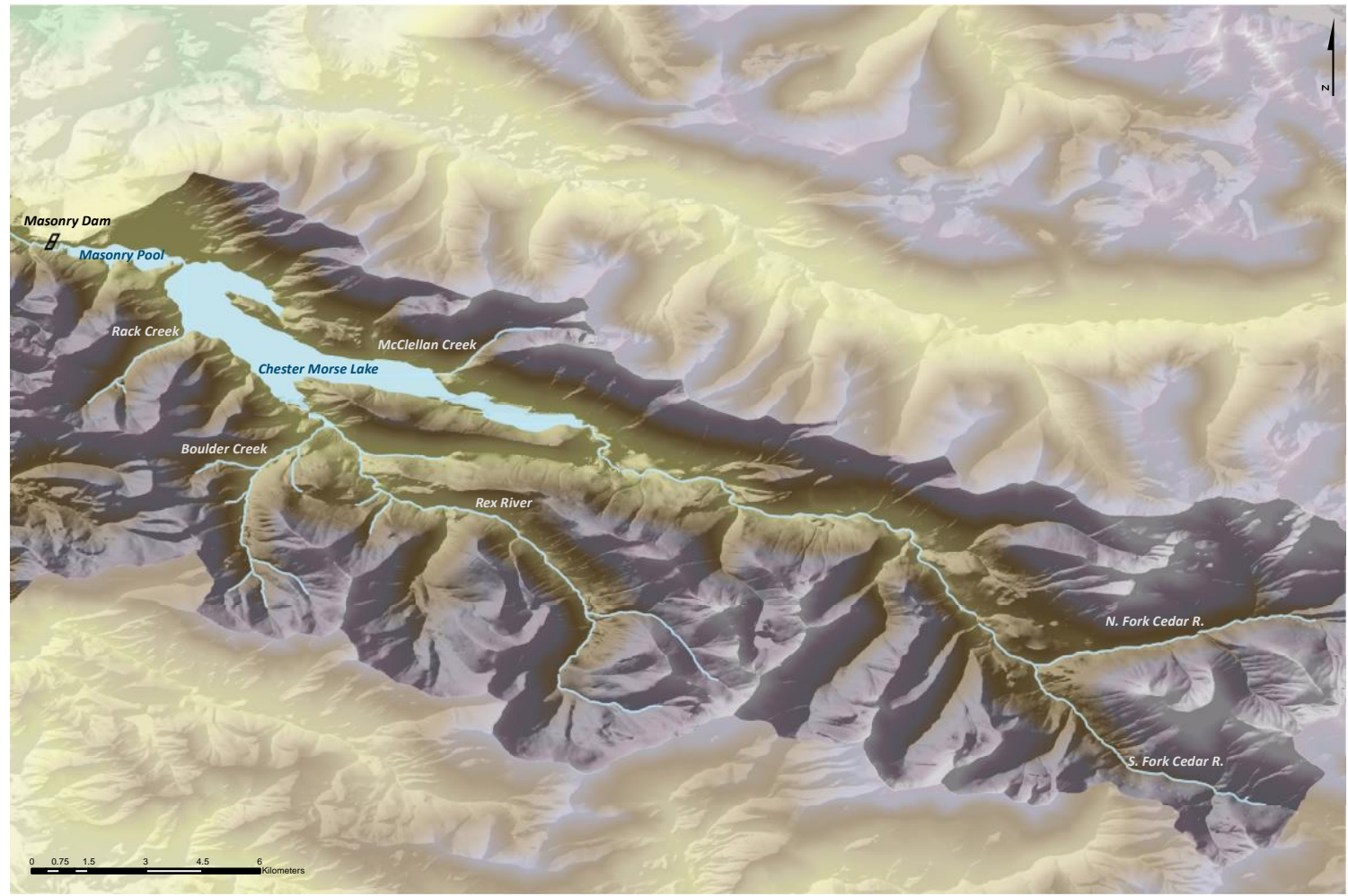

Figure 2. Overview map of the upper Cedar River Municipal Watershed. Major tributaries include Rack Creek, Boulder Creek, McClellan Creek, Rex River, and the North and South Forks of the Cedar River. 
The Cedar River below the Masonry Dam was formed by the downcutting of the glacial outwash deposits. As a result, the river is characterized by narrow floodplains with sections of smooth water interrupted by boulders and waterfalls (Seattle Public Utilities, n.d.). The lower watershed has numerous tributaries, with Taylor Creek, Rock Creek, Williams Creek, and Steele Creek comprising the larger inputs (Figure 3). Between the Masonry Dam and Cedar Falls, a large portion of the reservoir outflow is diverted for power production. Flows in this stretch are maintained at a minimum of $0.85 \mathrm{~m}^{3} / \mathrm{s}$ for fish habitat (Seattle Public Utilities, n.d.).

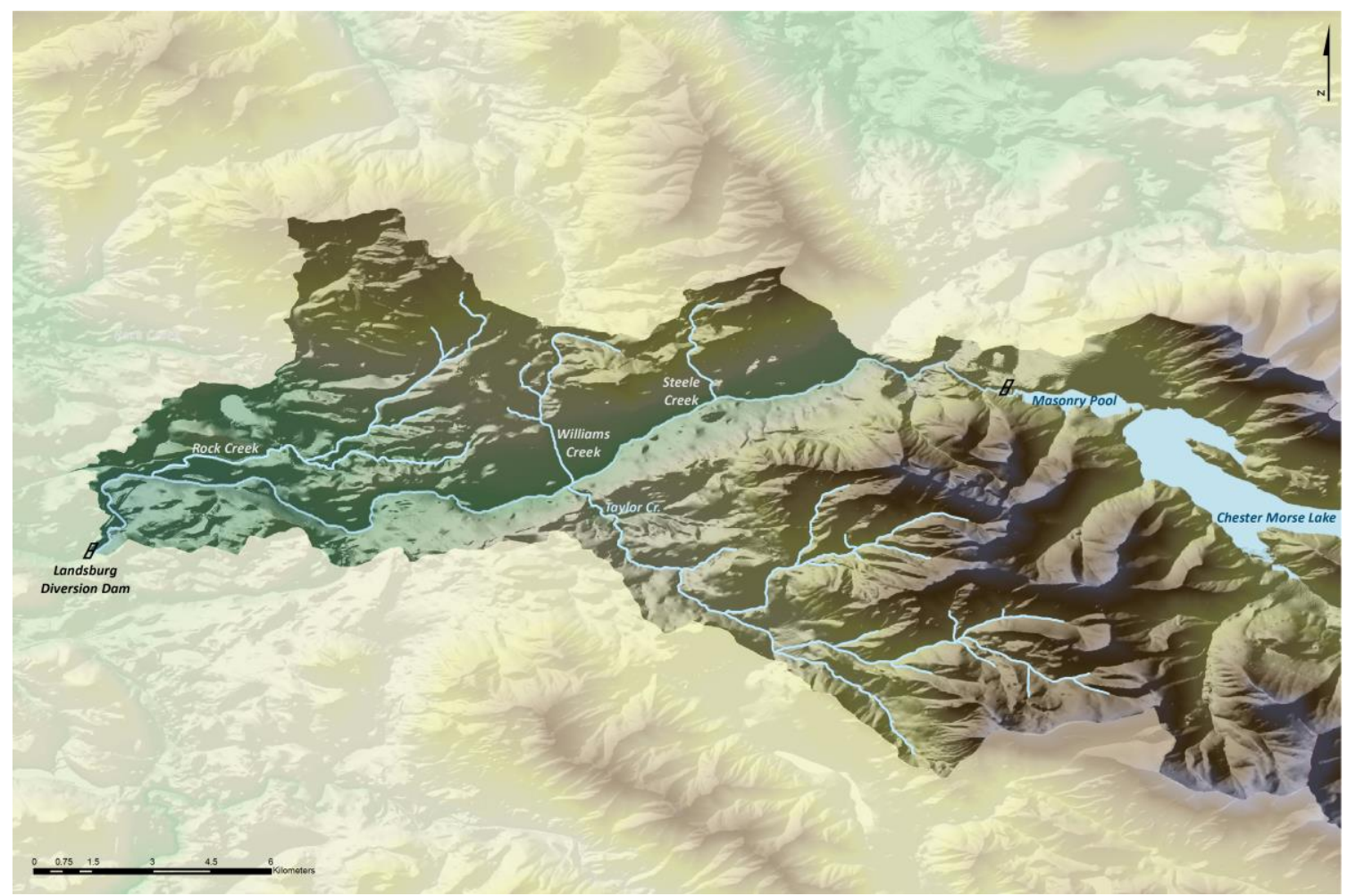

Figure 3. Overview map of the lower Cedar River Municipal Watershed. Major tributaries include Steele Creek, Williams Creek, Rock Creek, and Taylor Creek. 


\subsection{Purpose and Scope}

The objectives of this study were to (1) simulate sub-daily streamflow, temperature, and water quality conditions in the Cedar River Municipal Watershed for 2005-2008 and 2015; (2) document all components of model development; and (3) use the calibrated models to understand potential changes in temperature and water quality due to climate change and reservoir management strategies.

The model domain included Chester Morse Lake, the Masonry Pool, and the Cedar River from the Masonry Dam to the Landsburg Diversion Dam. Unless explicitly stated, this report uses Chester Morse Lake in reference to the main reservoir and Masonry Pool as one waterbody and Cedar River in reference to the Cedar River below the Masonry Dam. 


\section{Chapter 2. Previous Modeling Work on the Cedar River Basin}

2.1 Water Quality and Fish Bioenergetics

A Cedar River Municipal Watershed model using CE-QUAL-W2 version 3.7 was

developed by Portland State University for the calibration years 2005 to 2008 . The model development was summarized in CE-QUAL-W2 Water quality and fish-bioenergetics model of Chester Morse Lake and the Cedar River (Wells V. I., 2012). The model included a hydrodynamic and temperature model of the Cedar River Municipal Watershed and a habitat analysis of the Chester Morse Lake model. The absolute mean error ranged from 0.5 to $0.8^{\circ} \mathrm{C}$ at most temperature sampling locations within the model domain. The habitat analysis focused on bull trout impacts caused by proposed climate change and reservoir management scenarios in the main reservoir. 


\section{Chapter 3. Model Development}

\subsection{Model Description}

This study used the public domain model, CE-QUAL-W2. CE-QUAL-W2 is a two-dimensional water quality and hydrodynamic model for rivers, lakes, reservoirs, and river basin watersheds. The model is capable of simulating longitudinal-vertical hydrodynamics and water quality characteristics including water surface elevation, velocity, water temperature, nutrients, dissolved oxygen, organic matter groups, and algae, zooplankton, periphyton, and macrophyte species. The model generates predictions across longitudinal segments and vertical layers using finite-difference approximations to the laterally averaged equations of fluid motions.

The grid resolution is user-defined, with typical longitudinal resolution between 100 and 1000 meters and typical vertical resolution between 0.5 and 2 meters. The model was developed by the Water Quality Modeling Group at the Corps of Engineers Waterways Experiment Station in 1986 . Today the model is maintained by and primarily updated by the Water Quality Research Group at Portland State University. The current model release is version 4.2, which includes a multiple waterbody cascade model that allows simulations to run in parallel.

CE-QUAL-W2 is used extensively throughout the world. In a study that evaluated eight different water quality models, CE-QUAL-W2 was the most widely used model with over 300 hits in ScienceDirect and 148 hits in Web of Knowledge with the second highest hits 
of any other model at 196 and 65, respectively (Mateus, da Silva Vieira, Almeida, Silva, \& Reis, 2018). CE-QUAL-W2 was chosen for this study for multiple reasons. It allowed the watershed to be modeled as one system, with the outputs from the reservoir model used as inputs to the river model. The modeling approach was therefore consistent across the entire watershed. The model was also capable of capturing the complex hydrodynamic connection between the main reservoir and the Masonry Pool. Additionally, this study was able to leverage the 2012 efforts (Wells V. I., 2012).

\subsection{Bathymetry and the Model Grid}

The model grid is composed of interconnected longitudinal model segments along the direction of flow. Model segments are divided into vertical layers with a user-defined depth. The width of each vertical layer is defined based on the waterbody's cross-section. This allows the model grid to create a two-dimensional representation of the system. Branches are composed of model segments grouped together by a common factor, such as channel slope or location. Waterbodies, the largest structure in the model, are comprised of any number of branches.

\subsubsection{Chester Morse Lake}

The model used the bathymetry files developed in the previous model effort with minor adjustments to cell widths for model stability (Wells V. I., 2012). Bathymetric data for Chester Morse Lake was provided by SPU (Figure 4). A three-dimensional rendering was generated using USGS digital elevation map (DEM) coverage and the bathymetry data. A 
two-dimensional grid was developed based off of the three-dimensional rendering (Figure 5). The reservoir model was composed of two waterbodies divided into a total of four branches. A side view schematic of the grid is illustrated in Figure 6. Representative vertical slices of three model segments are shown in Figure 7. Grid characteristics are listed in Table 1.

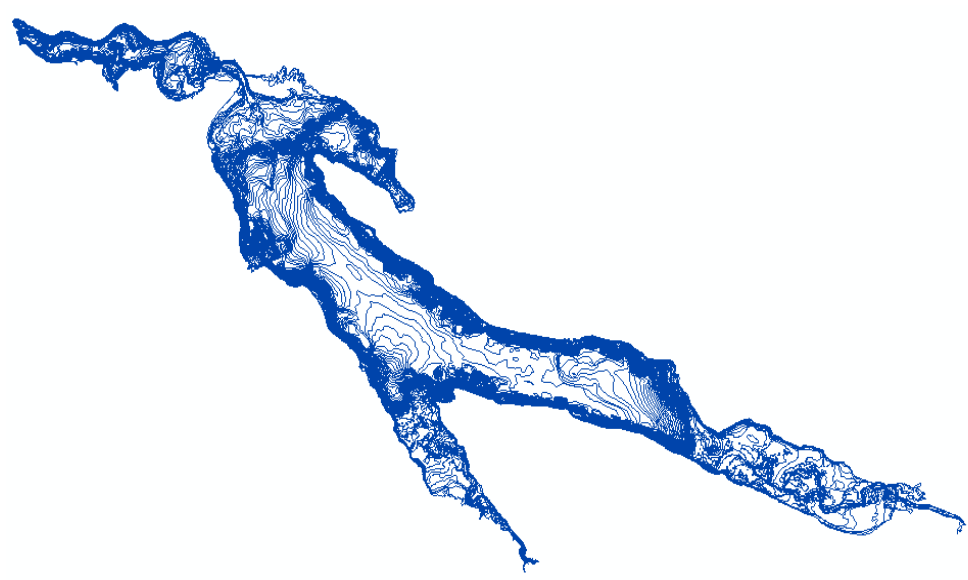

Figure 4. Original bathymetric data for Chester Morse Lake and the Masonry Pool (Wells V. I., 2012).

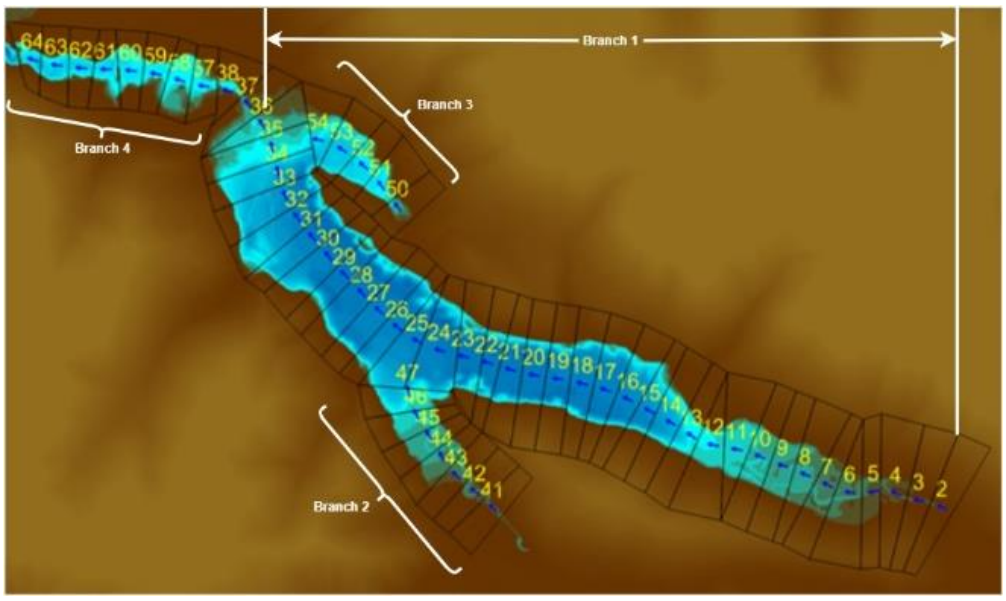

Figure 5. Schematic of the Chester Morse Lake model grid with branch boundaries indicated. 


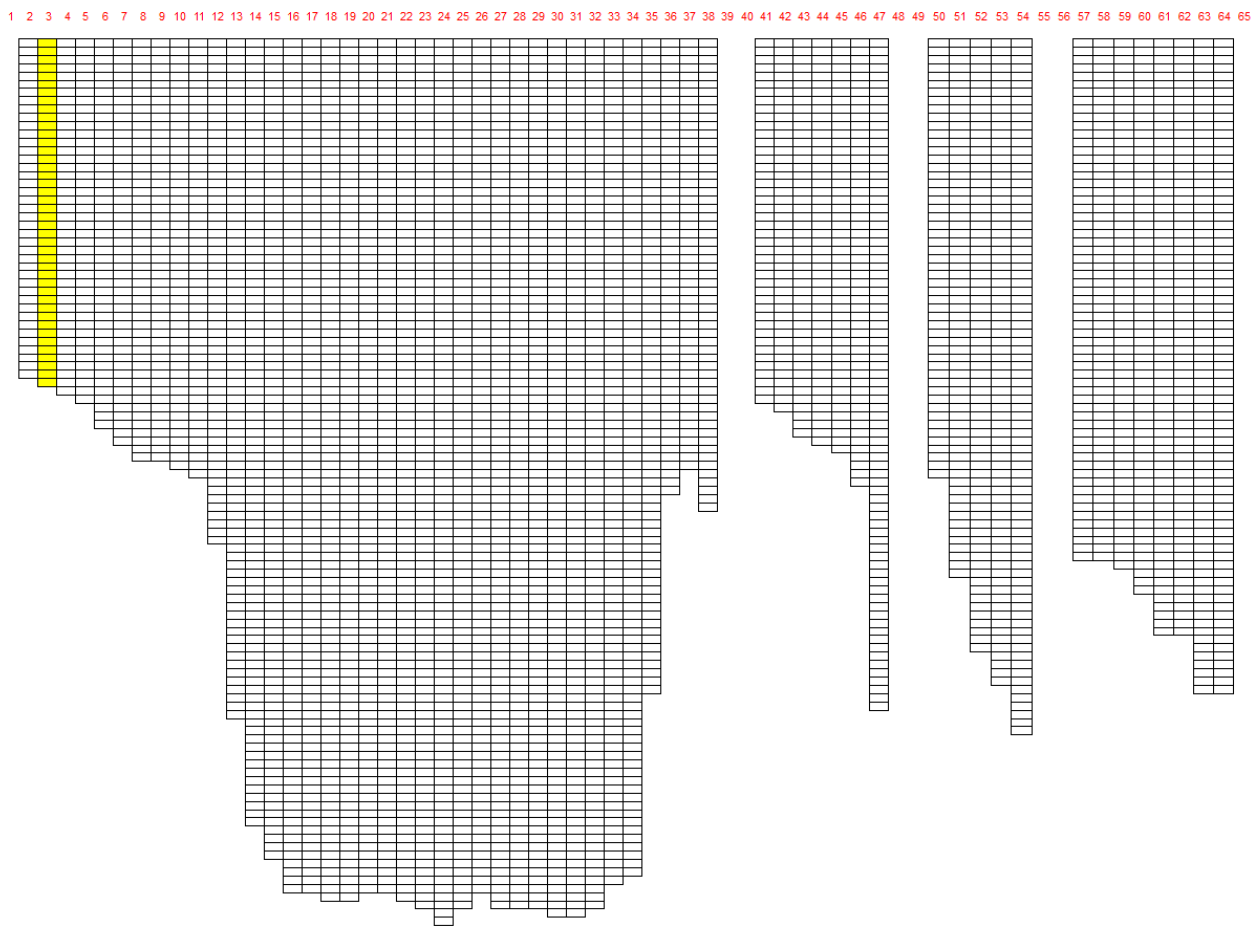

Figure 6. Side view schematic of the reservoir model grid showing the four model branches, horizontal model segments, and vertical layers. Each layer was 0.61 meters deep. Segments ranged between 250.2 and 276.3 meters in length.
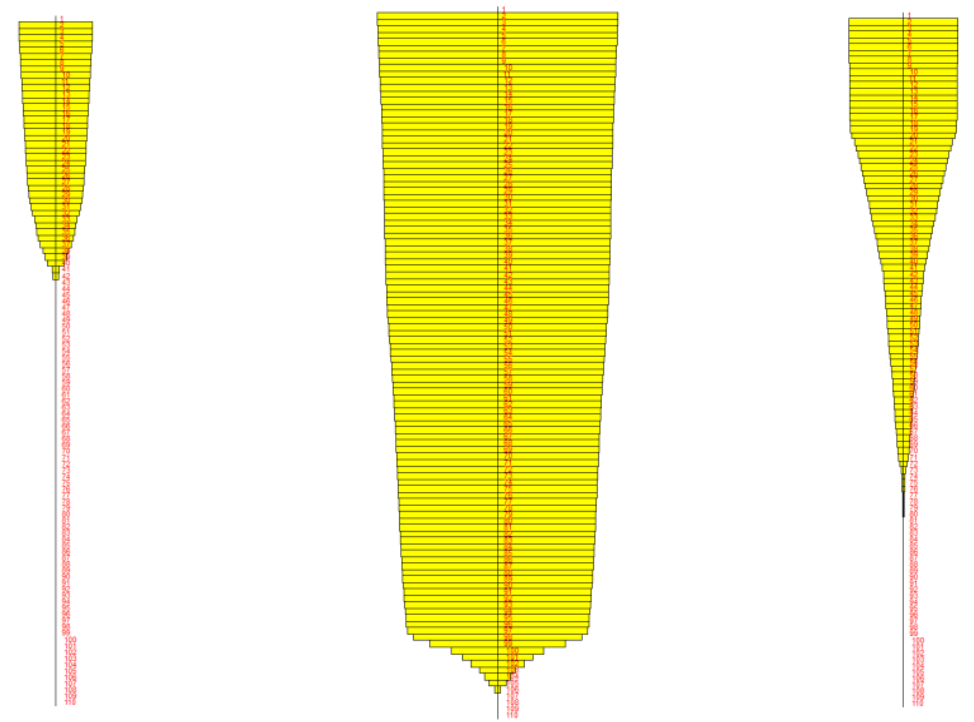

Figure 7. Vertical model segment slices: segment 2 (left), segment 27 (middle), and segment 64 (right). Segment 2 was the beginning of the model domain. Segment 27 was located at the SPU CM1A sample station. Segment 64 was the end of the model domain at the Masonry Dam. 
Table 1. Summary of the Chester Morse Lake model grid characteristics.

\begin{tabular}{lc}
\hline Parameter & Chester Morse Lake \\
\hline Mainstem (branch 1) centerline length & $9256.3 \mathrm{~m}$ \\
Number of active segments & 57 \\
Longitudinal grid spacing & $250.2-276.3 \mathrm{~m}$ \\
Number of branches (br); waterbodies (wb) & $4 \mathrm{br} ; 2 \mathrm{wb}$ \\
Number of active layers & 107 \\
Vertical layer thickness & $0.61 \mathrm{~m}$ \\
\hline
\end{tabular}

The four branches included the reservoir mainstem (branch 1), the Rex River arm (branch 2), the Otter Creek and Damburat Creek arm (branch 3), and the Masonry Pool (branch 4). Table 2 lists the model segments included in each branch.

Table 2. Summary of the Chester Morse Lake model branch segments.

\begin{tabular}{cccc}
\hline Branch & $\begin{array}{c}\text { Upstream Active } \\
\text { Segment }\end{array}$ & $\begin{array}{c}\text { Downstream Active } \\
\text { Segment }\end{array}$ & Description \\
\hline $\mathbf{1}$ & 2 & 38 & Mainstem \\
$\mathbf{2}$ & 41 & 47 & Rex River arm \\
$\mathbf{3}$ & 50 & 54 & Otter/Damburat Creek arm \\
$\mathbf{4}$ & 57 & 64 & Masonry Pool \\
\hline
\end{tabular}

\subsubsection{Cedar River}

The Cedar River model used the bathymetry files developed in the previous model effort with minor adjustments to cell widths for model stability (Wells V. I., 2012). The bathymetry was developed using 93 cross-sections taken between Cedar Falls, WA and Landsburg, WA by SPU (Figure 8). A three-dimensional rendering was generated using USGS DEMs and the transect data. A two-dimensional grid was developed based off of the three-dimensional rendering (Figure 9). In the absence of transect data, the three-dimensional rendering was used to estimate the river bathymetry between the Masonry Dam and Cedar Falls, WA. The river model was composed of three waterbodies 
divided into a total of five branches. A side view schematic of the grid is illustrated in Figure 10. Representative vertical slices of three model segments are shown in Figure 11. Grid characteristics are summarized in Table 3 . The five branches are differentiated from one another by changes in slope. Table 4 lists the model segments included in each branch.

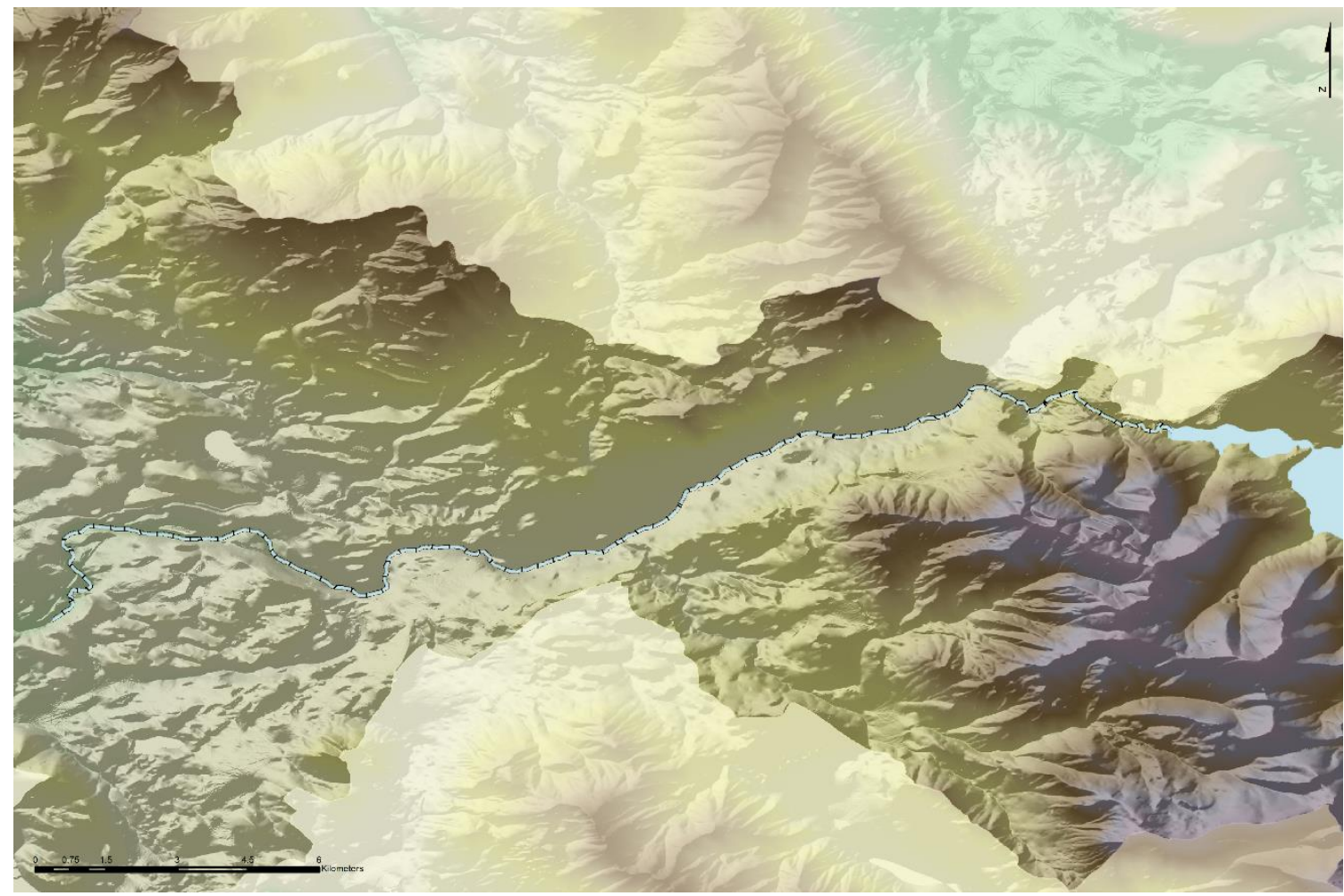

Figure 8. Cedar River transects and USGS DEM coverage of surrounding area. 


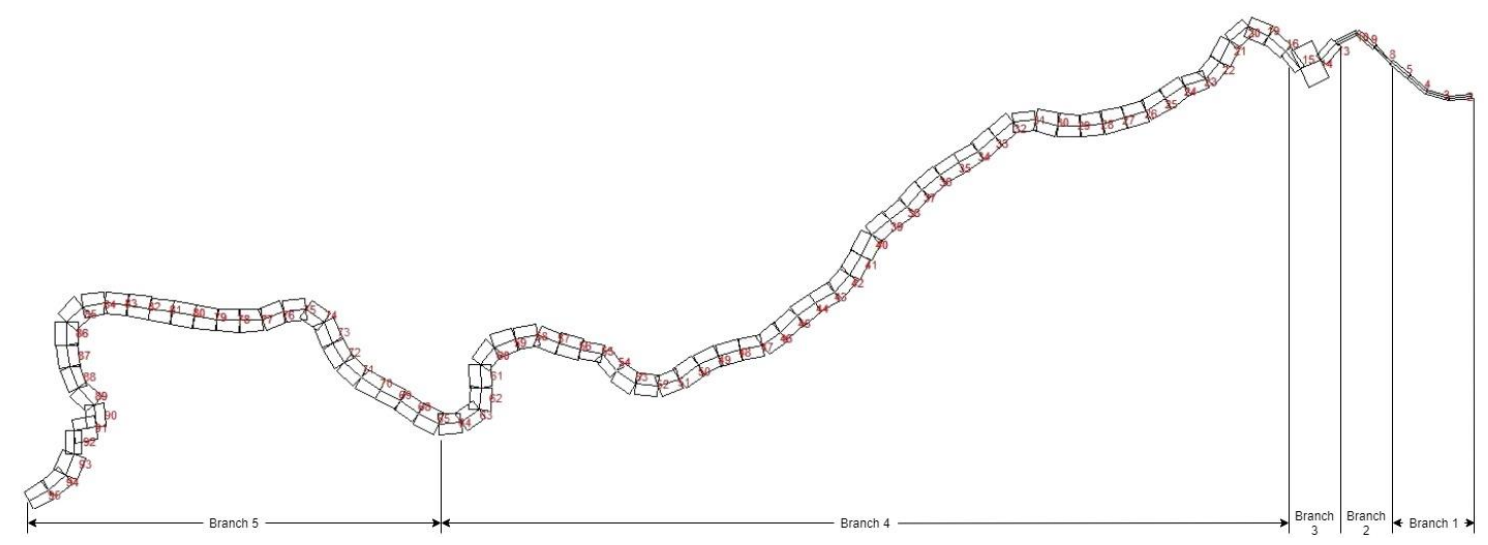

Figure 9. Schematic of the Cedar River model grid with branch boundaries indicated.

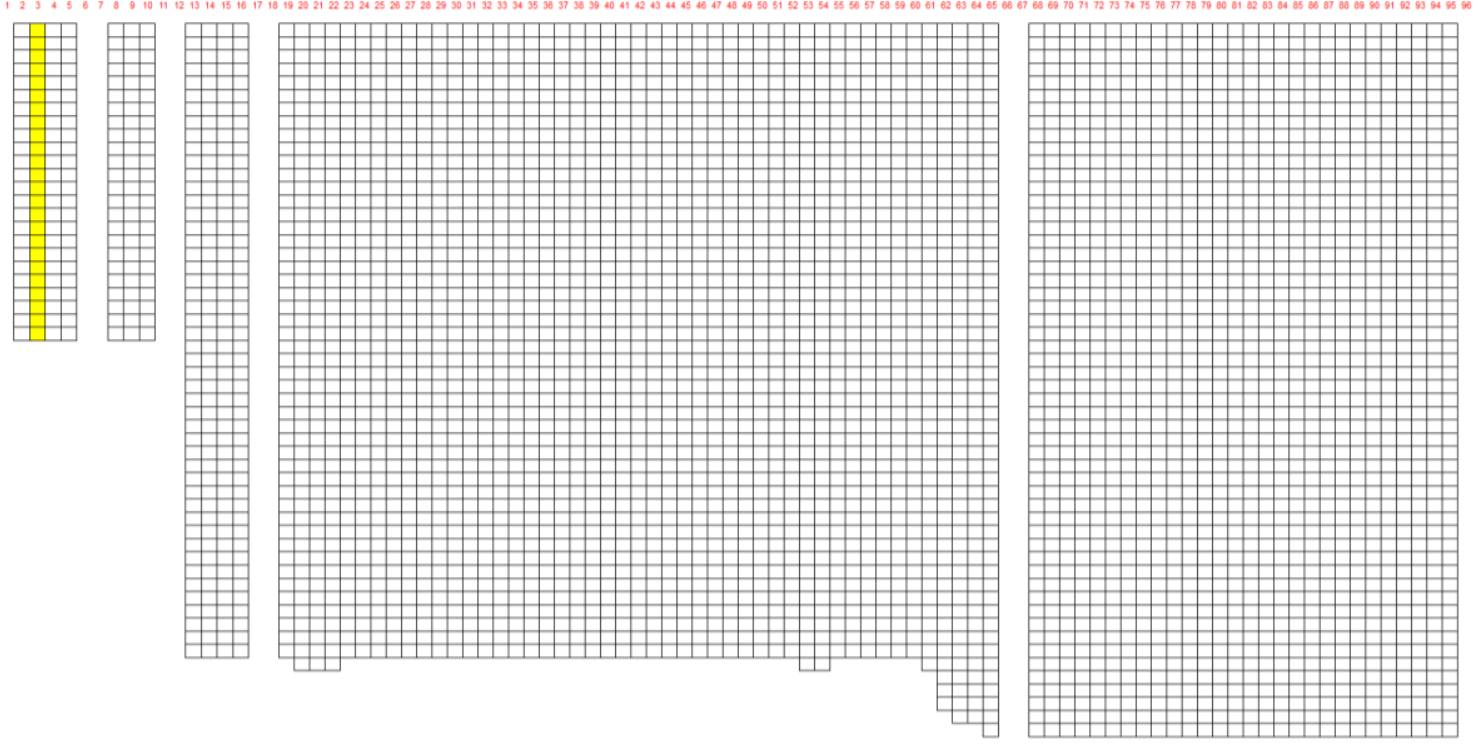

Figure 10. Side view schematic of the Cedar River grid showing the five branches, horizontal model segments, and vertical layers. Each layer was 1 meter deep and segments ranged between 252.7 and 258.3 meters long. 


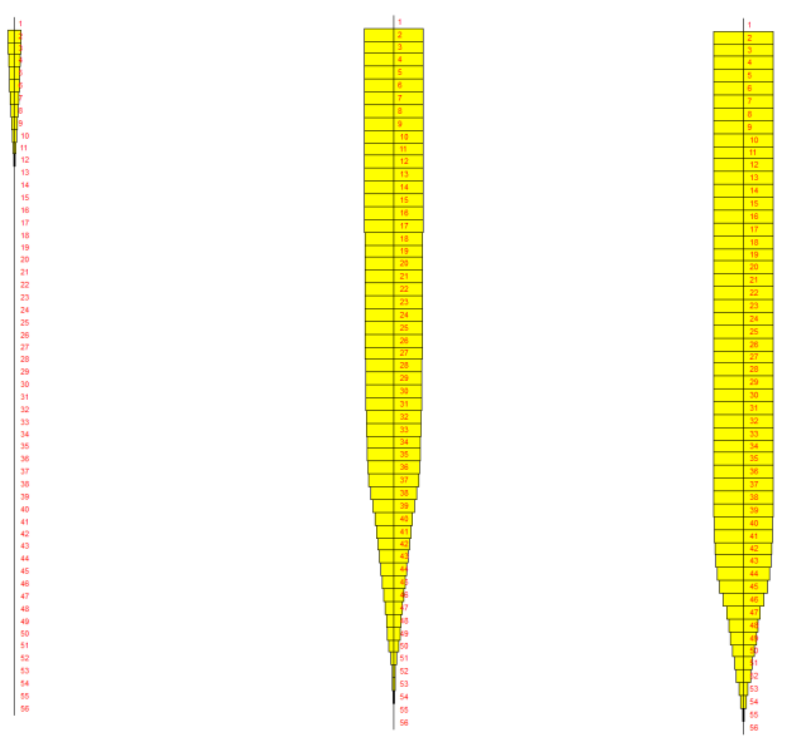

Figure 11. Vertical model segment slices: segment 2 (left), segment 74 (middle), and segment 95 (right). Segment 2 was the beginning of the model domain. Segment 74 was located at the WSDE $08 C 110$ sample station. Segment 95 was the end of the model domain at the Landsburg Diversion Dam.

Table 3. Summary of the Cedar River model grid characteristics.

\begin{tabular}{lc}
\hline Parameter & Cedar River \\
\hline Grid length & $21.8 \mathrm{~km}$ \\
Number of active segments & 57 \\
Longitudinal grid spacing & $252.7-258.3 \mathrm{~m}$ \\
Number of branches (br); waterbodies (wb) & $5 \mathrm{br} ; 3 \mathrm{wb}$ \\
Number of active layers & 54 \\
Vertical layer thickness & $1 \mathrm{~m}$ \\
\hline
\end{tabular}

Table 4. Summary of the Cedar River model branch segments.

\begin{tabular}{ccccc}
\hline Branch & $\begin{array}{c}\text { Upstream Active } \\
\text { Segment }\end{array}$ & $\begin{array}{c}\text { Downstream Active } \\
\text { Segment }\end{array}$ & $\begin{array}{c}\text { Branch Centerline } \\
\text { Length }(\mathbf{m})\end{array}$ & Branch Slope \\
\hline $\mathbf{1}$ & 2 & 5 & 1033 & 0.026 \\
$\mathbf{2}$ & 8 & 10 & 775 & 0.115 \\
$\mathbf{3}$ & 13 & 16 & 1033 & 0.023 \\
$\mathbf{4}$ & 19 & 65 & 11876 & 0.007 \\
$\mathbf{5}$ & 68 & 95 & 7075 & 0.003 \\
\hline
\end{tabular}




\subsubsection{Chester Morse Lake and Cedar River Model Linkage}

Chester Morse Lake is connected to the Cedar River by the lower outlet release and spillway of the Masonry Dam. The Masonry Dam outflows from the reservoir model were used as inputs in the first active segment of the river model. The powerhouse outflows from the reservoir model entered the river model downstream of the other two outflows at a segment that corresponded with the physical location of the powerhouse (Figure 12). The current version of CE-QUAL-W2 allows the models to run in either series or parallel with the addition of the multiple waterbody module. Figure 13 provides an overview of the full model with the locations of all included inflows and data sites.

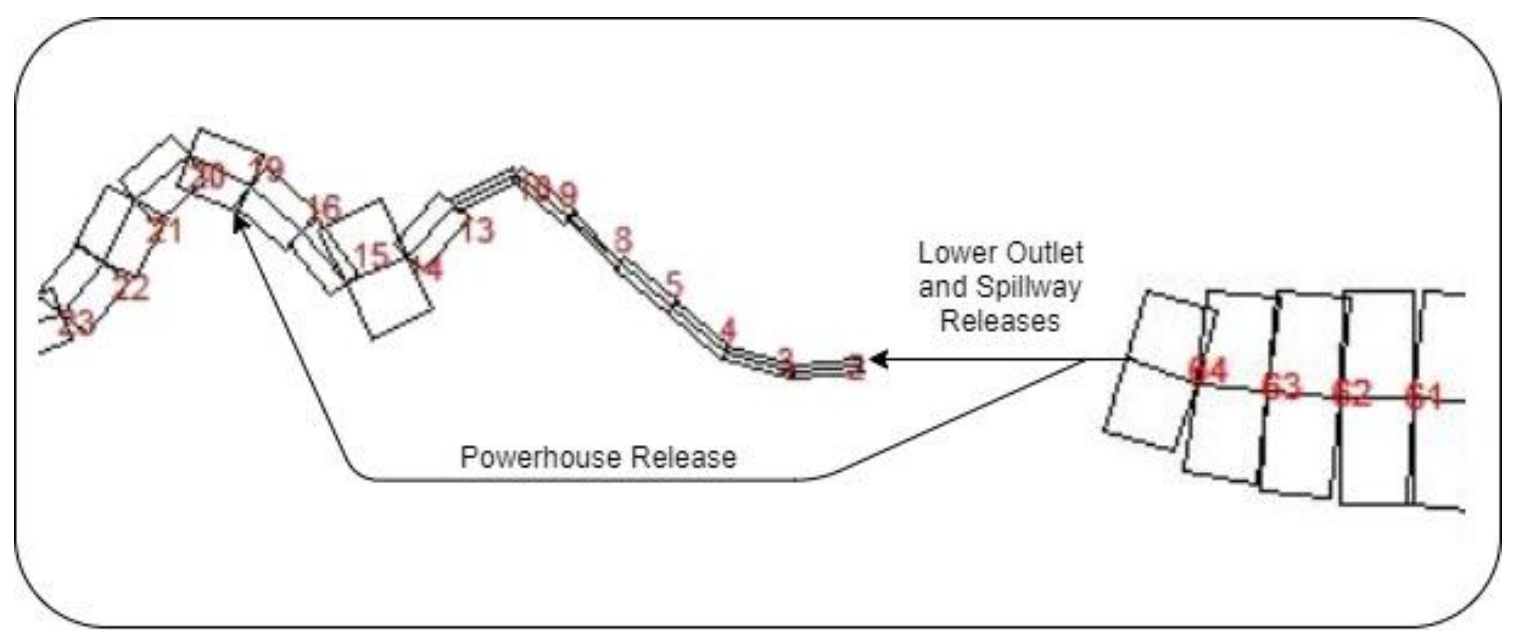

Figure 12. Detail of linkage between Chester Morse Lake and the Cedar River. Outputs from the reservoir model were used as inputs for the river model. 


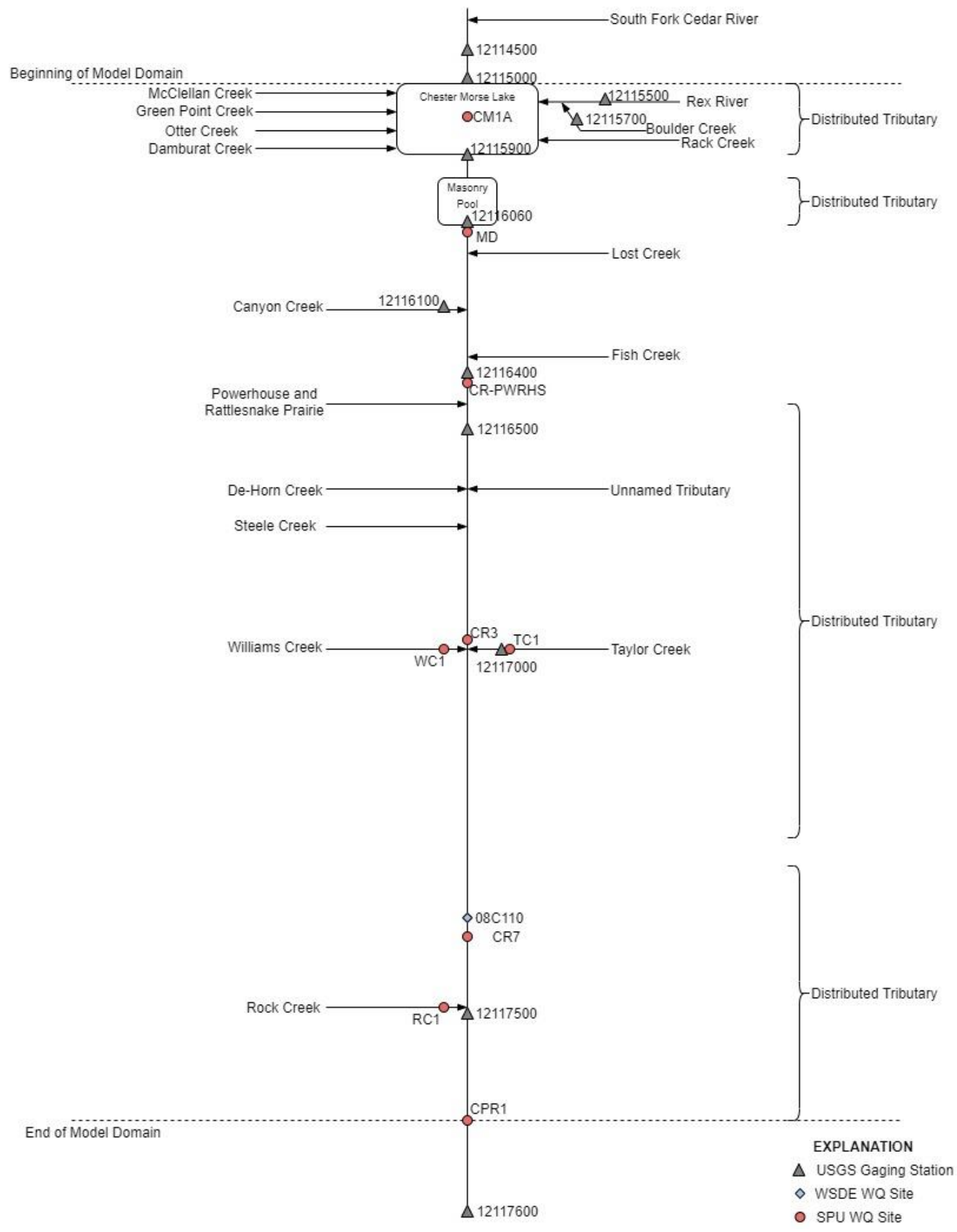

Figure 13. Locations of tributary inflows, USGS gaging stations, and water quality monitoring sites located within and in immediate proximity to the model domain. 


\subsection{Boundary Conditions}

\subsubsection{Meteorological Inputs}

The meteorological data required for the model included air temperature, dew point temperature, wind speed and direction, cloud cover, and solar radiation. Model inputs were obtained from six local meteorological stations in combination with model estimations of parameters (Figure 14). The USGS gaging station located at Chester Morse Lake, USGS 12115900, was used preferentially based on data availability.

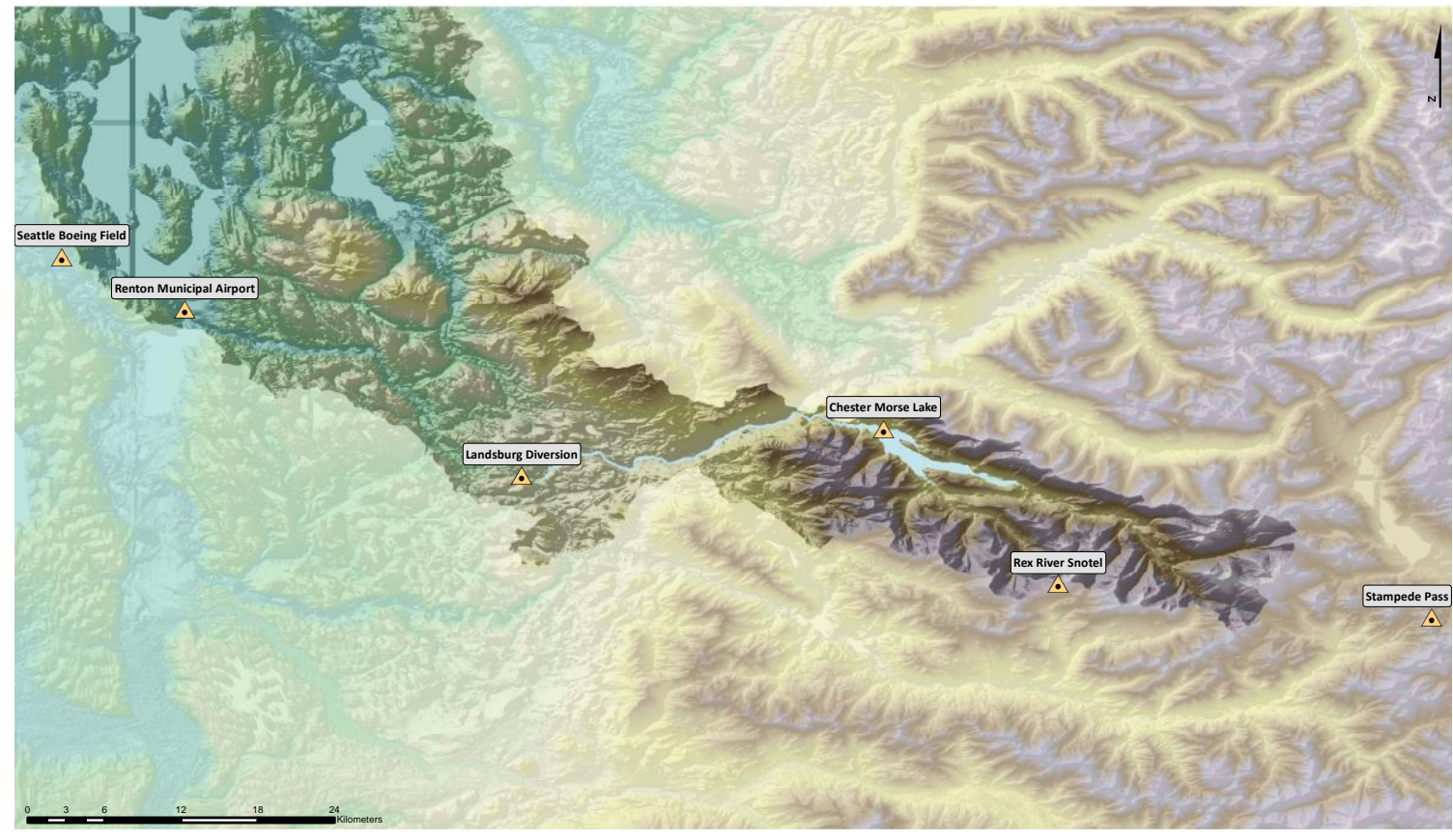

Figure 14. Location of meteorological stations used to develop boundary conditions for the reservoir and river models. 
Air temperature data were available from USGS 12115900 located at Chester Morse Lake. For the 2005-2008 reservoir model, hourly data were available covering 98.2 percent of the model period. Gaps in hourly data were filled using the SPU hourly air temperature model at Cedar Lake (J. Edgerly, personal communication, March, 19, 2019). For the 2015 reservoir model, 15-minute data were available for the entire model period. Data were used on the hour, as other meteorological data were available hourly. Dew point temperature and relative humidity data were available at Stampede Pass (WBAN 24237) and Renton Municipal Airport (WBAN 94248). Hourly relative humidity data from Renton Municipal Airport with gaps filled by Stampede Pass was used to calculate dew point temperature for the 2005-2008 and 2015 model. The following relationship between air temperature and relative humidity was used to calculate dew point temperature using respective air temperature for each waterbody (Equation 1) (Singh, 1992). Air temperature and dew point temperature model inputs are presented in Figure 15.

$$
R H=\left(\frac{112-0.1 T_{\text {air }}+T_{\text {dew }}}{112+0.9 T_{\text {air }}}\right)^{8}
$$



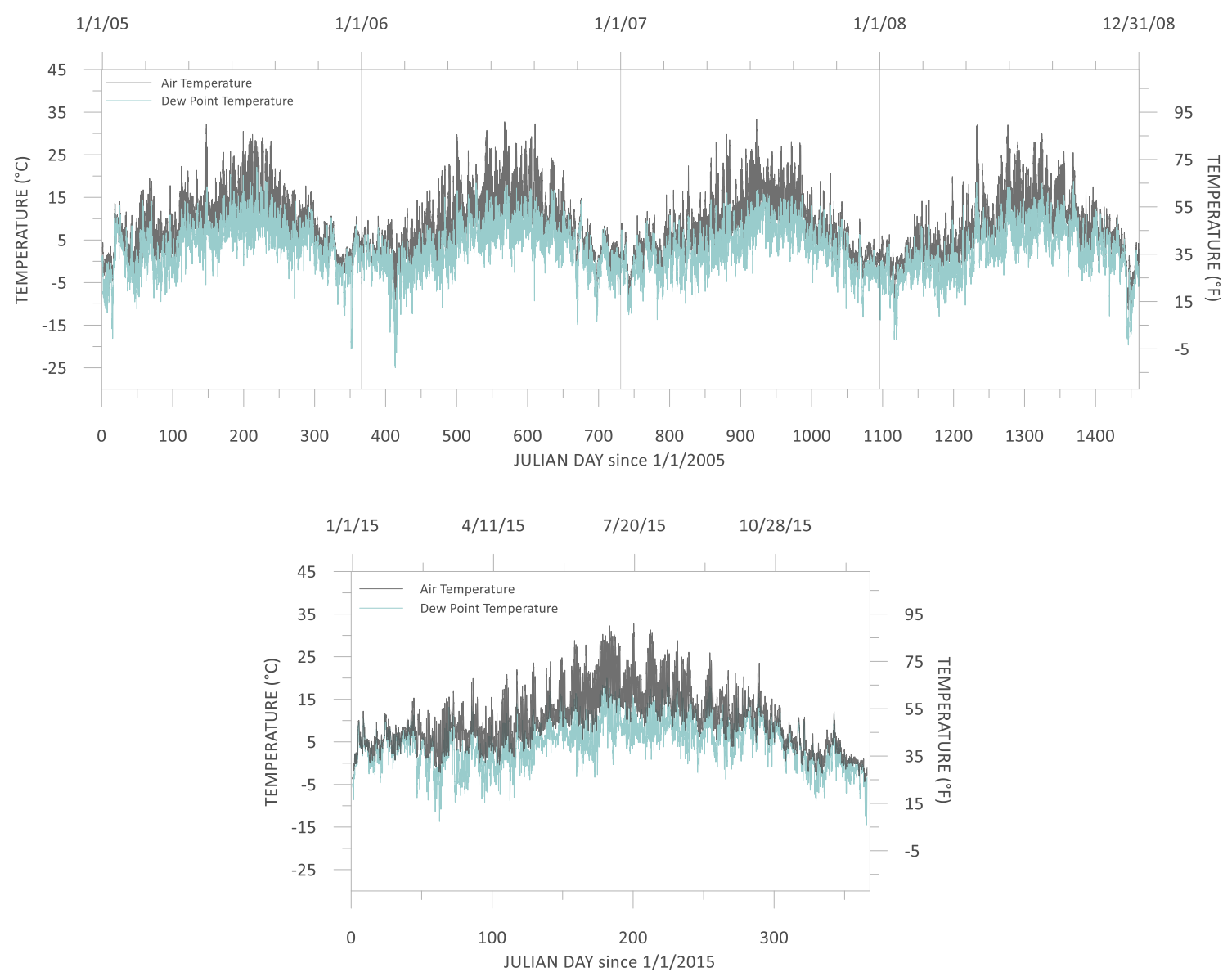

Figure 15. Chester Morse Lake air temperature and dew point temperature for the 2005-2008 model (top) and the 2015 model (bottom).

In the river model, air temperature inputs for waterbody 1 were consistent with the reservoir model. Waterbody 2 used the SPU hourly air temperature model at Landsburg Diversion Dam adjusted by the US Standard Atmosphere lapse rate. Waterbody 3 used the SPU hourly air temperature model at Landsburg Diversion Dam (Figure 16). 

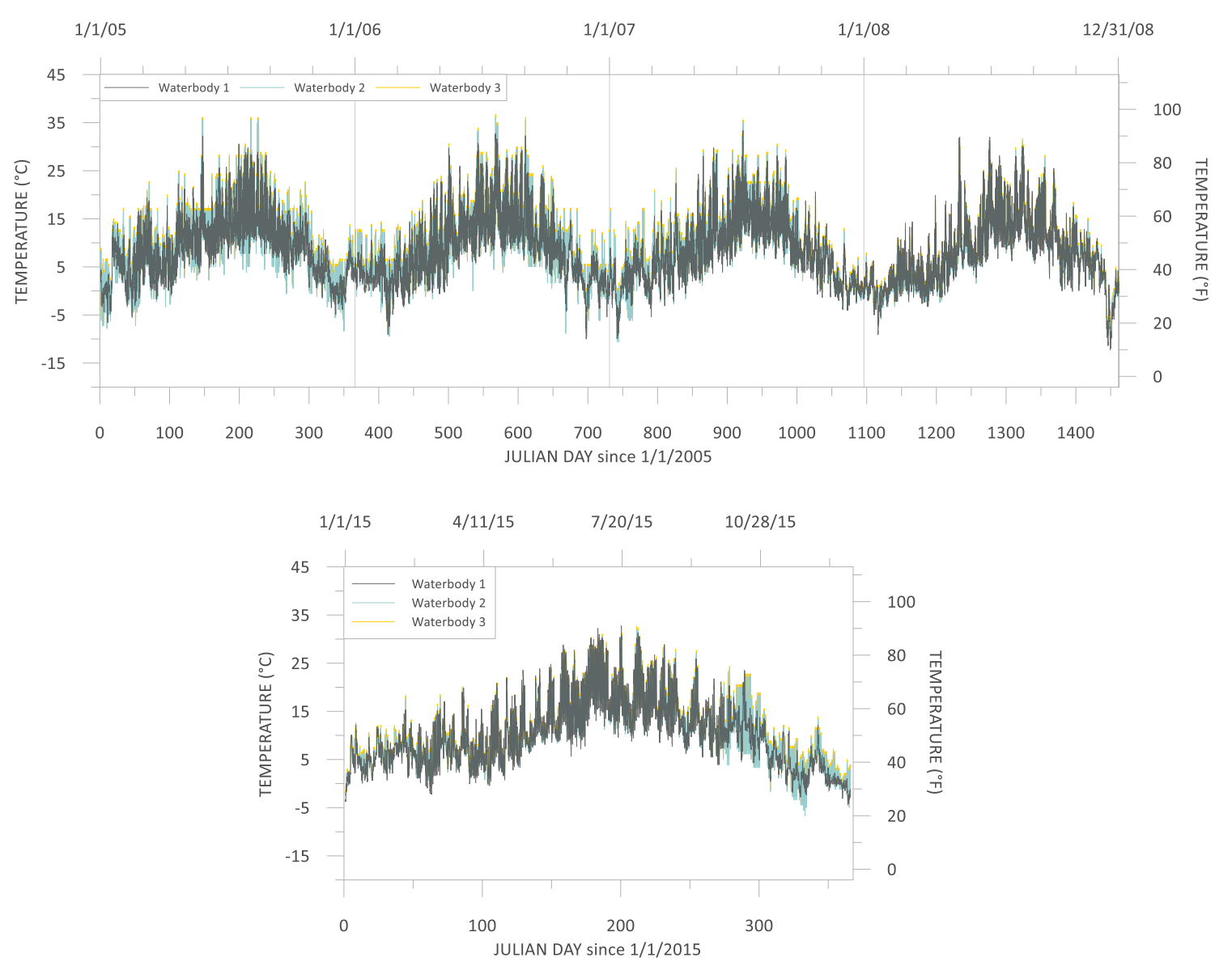

Figure 16. Cedar River air temperature inputs for each waterbody in the 2005-2008 model (top) and in the 2015 model (bottom). Air temperature was adjusted by the US Standard Atmosphere lapse rate when field data were not available.

Wind speed and wind direction data were obtained from USGS 12115900. Wind speed data gaps were filled using wind speed data from the Rex River SNOTEL (site 911). Wind direction data gaps were filled using wind direction data from Stampede Pass and Renton Municipal Airport. The data quality screening rules developed by Meek and Hatfield were implemented for wind direction and wind speed due to data irregularities (1994). The wind direction model inputs are shown in Figure 17 and Figure 18. The wind speed model inputs are shown relative to the USGS data in Figure 19. 


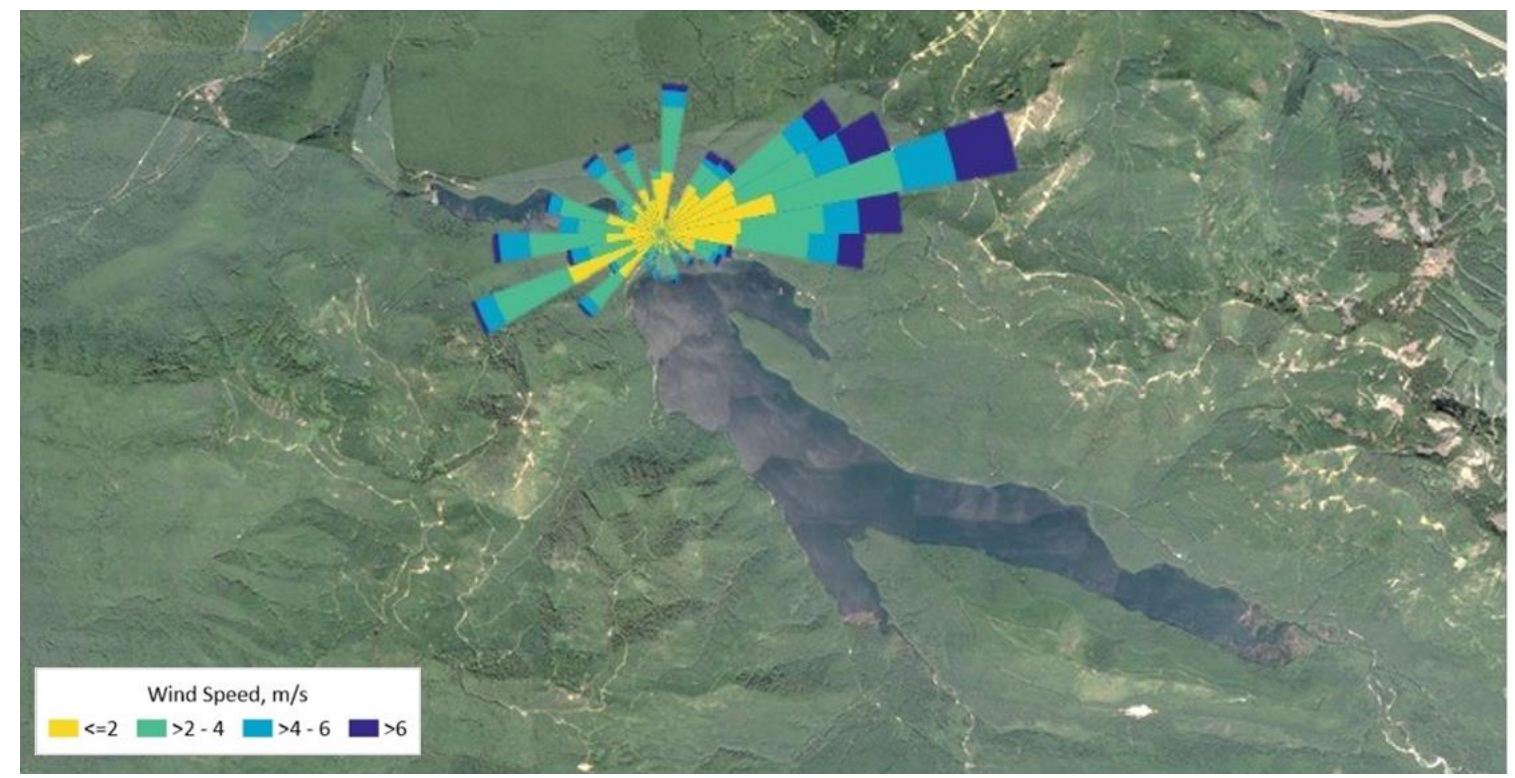

Figure 17. Chester Morse Lake wind direction model inputs for 2005-2008. Adapted from Google Earth, earth.google.com/web.

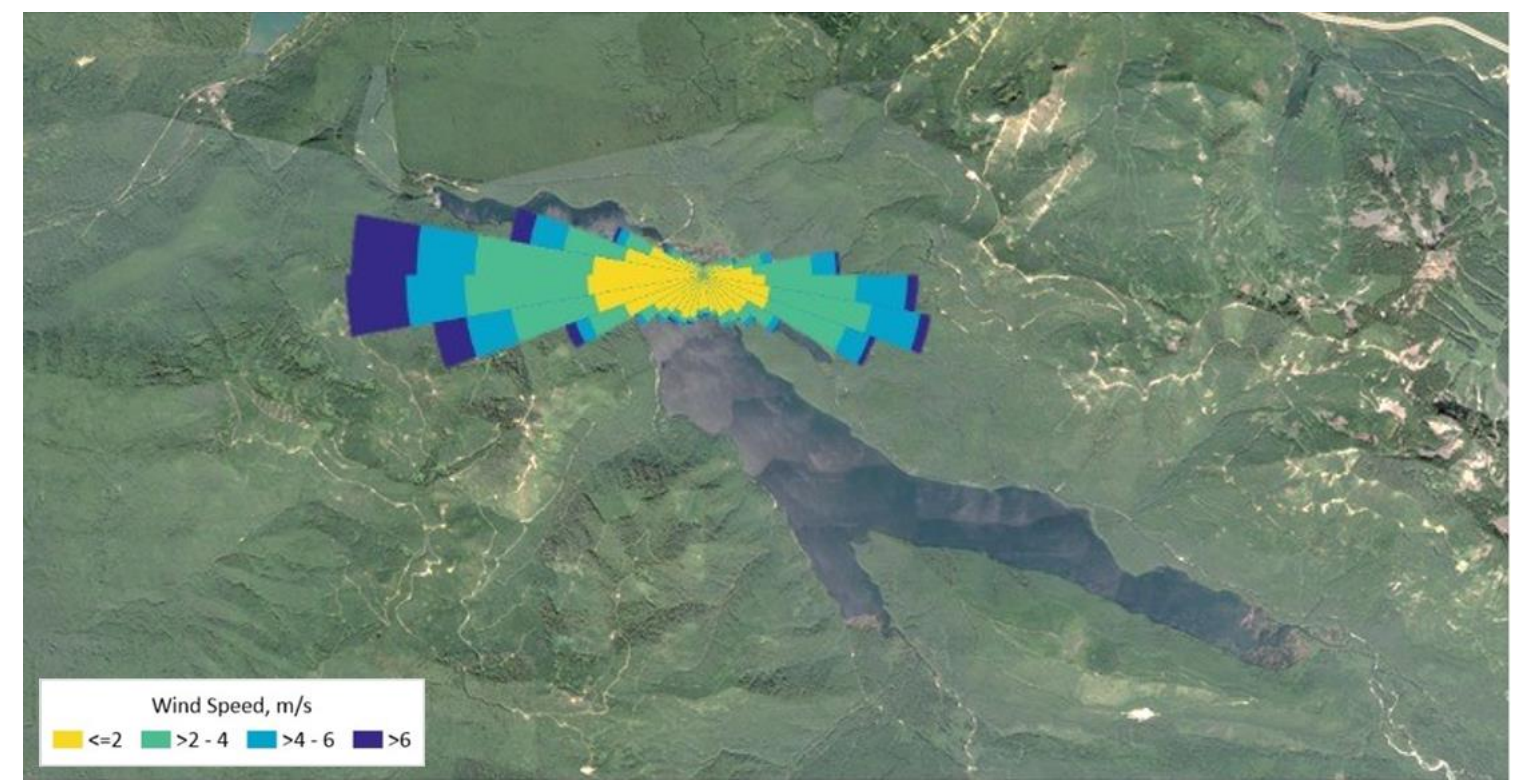

Figure 18. Chester Morse Lake wind direction model inputs for 2015. Adapted from Google Earth, earth.google.com/web. 


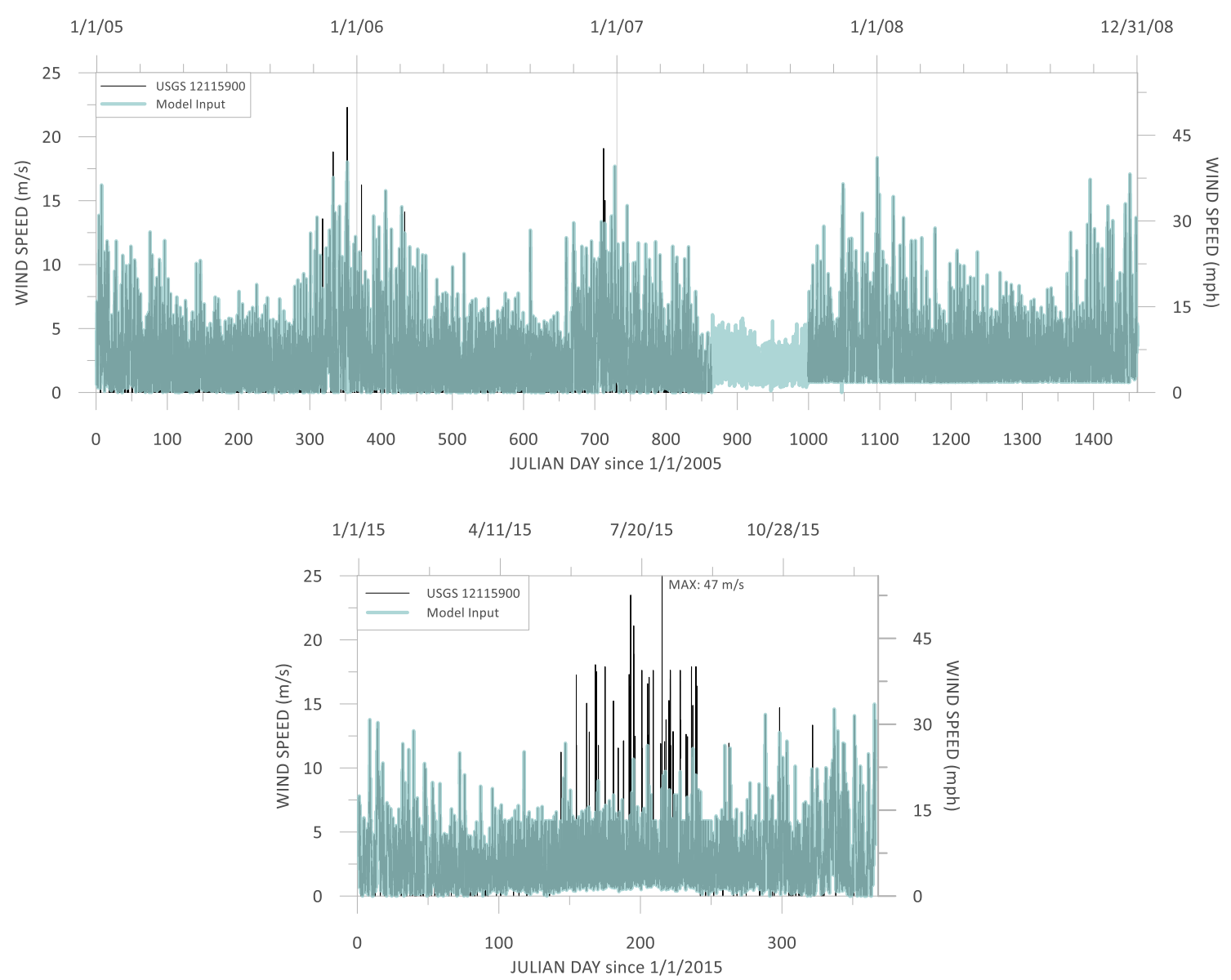

Figure 19. Wind speed data from USGS 12115900 relative to wind speed model inputs for 2005-2008 (top) and 2015 (bottom).

Cloud cover data from Renton Municipal Airport were used for the model inputs with gaps filled from Stampede Pass and Seattle Boeing Field. Cloud cover at three observation levels was reported in oktas, a unit of measurement that estimates how many eighths of the sky have cloud coverage. The highest observed sky condition was used as the model input. Oktas were scaled proportionally to tenths. In the event of multiple sky observations over a given hour, the average of all reported values was used. The fraction of model period at each observed cloud condition in tenths is presented in Figure 20. 

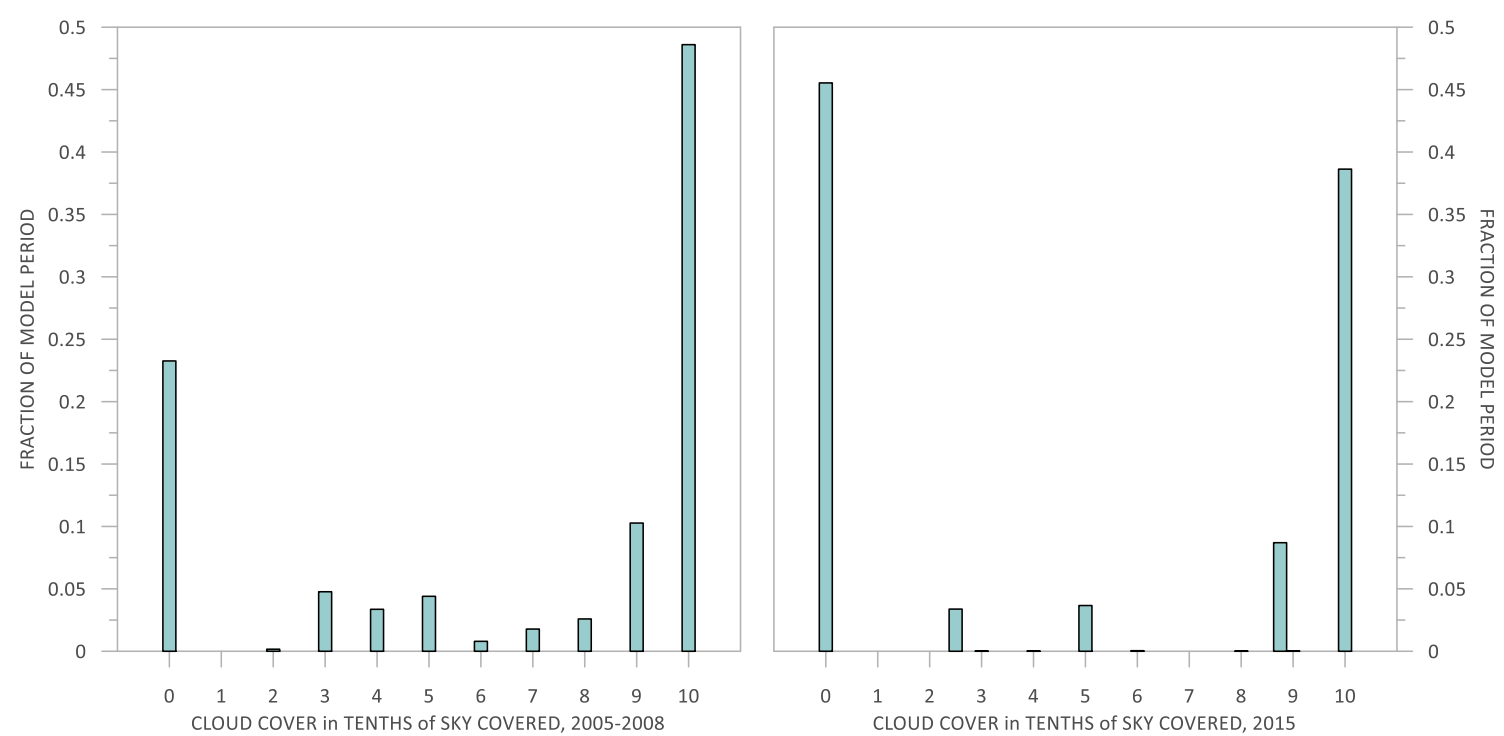

Figure 20. Fraction of model period with indicated cloud cover for 2005-2008 (left) and 2015 (right).

Solar radiation data were available at USGS 12115900 . The data were compared to five theoretical models of solar radiation. The data displayed a significant low bias relative to the theoretical models. According to Pluhowski (1970), the heat energy budget is one of the most critical factors impacting stream temperature and that diurnal temperature changes are directly correlated to the amount of solar energy absorbed. The model was calibrated using the Meeus method as it best approximated observed water temperature. The Meeus method calculates the position of the sun and the attenuation of radiation using latitude, longitude, time of year and elevation (Annear \& Wells, 2007). The USGS solar radiation data are compared to the Meeus method in Figure 21. 


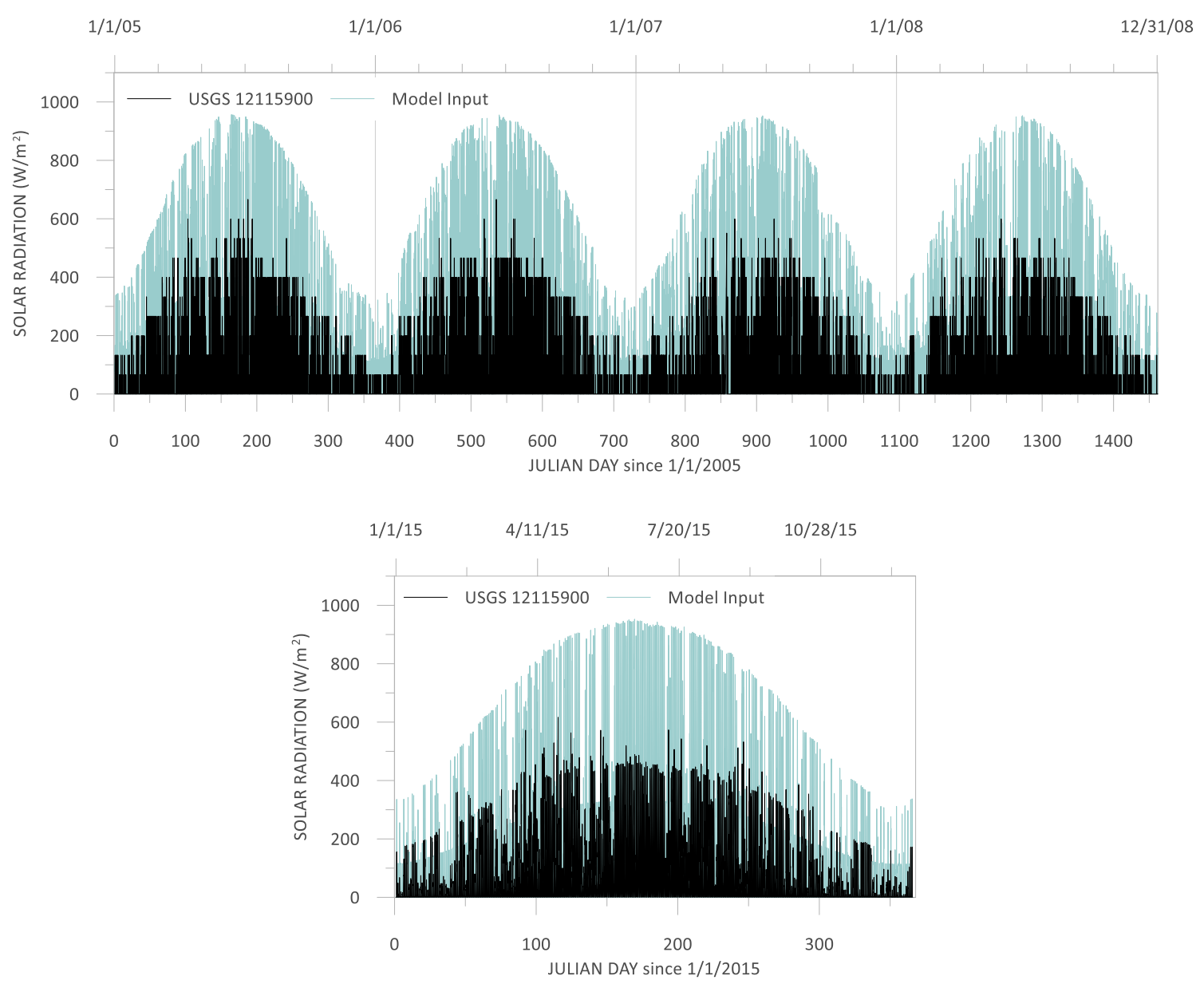

Figure 21. Solar radiation data from USGS 12115900 relative to solar radiation model inputs using the Meeus theoretical solar model for 2005-2008 (top) and 2015 (bottom).

\subsubsection{Streamflow and Stream Temperature}

The Cedar River Municipal Watershed covers approximately 366 square kilometers. The watershed is monitored by twelve USGS gaging stations. Data from the USGS station network were used as streamflow and temperature inputs for the model (Figure 22). 


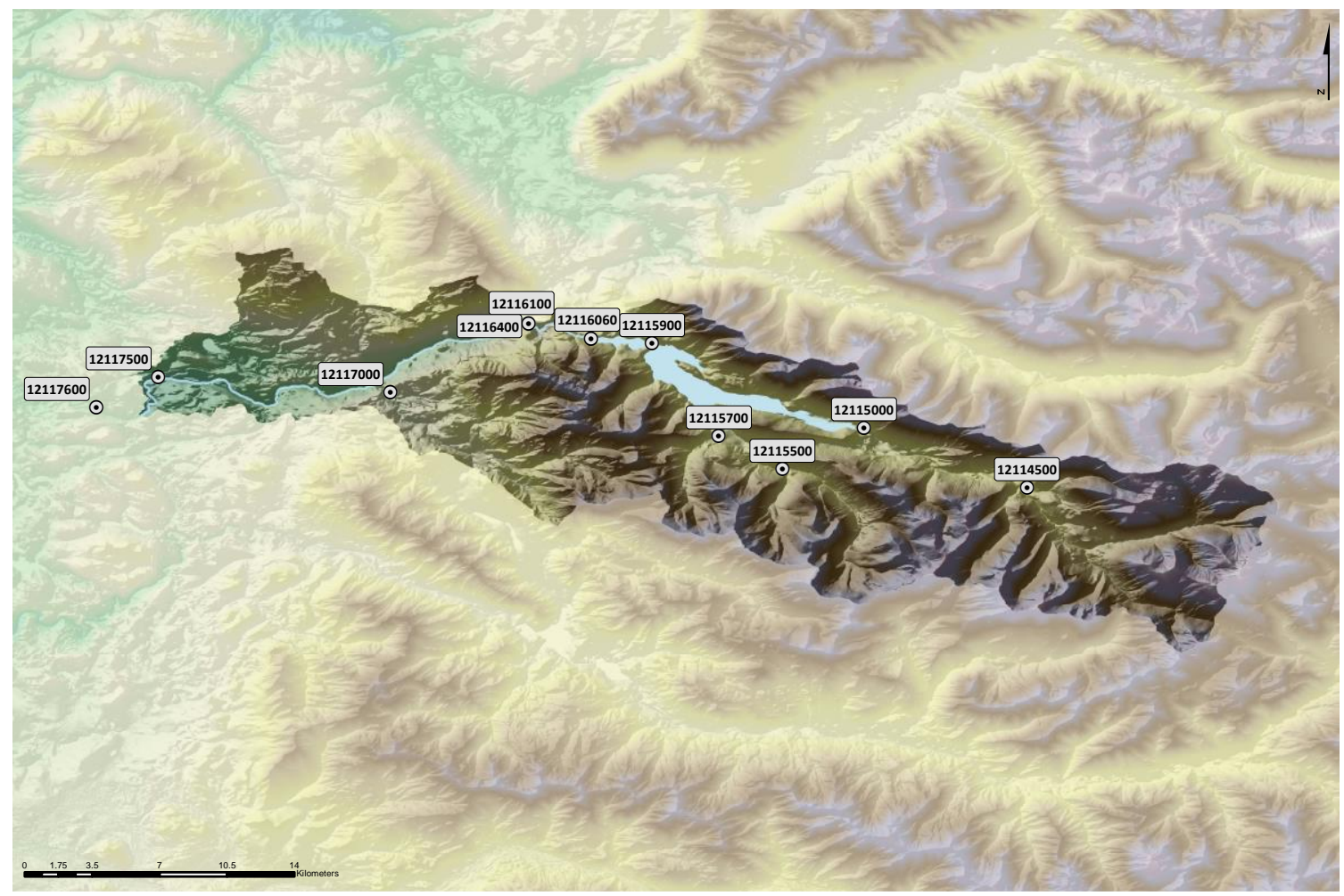

Figure 22. Map showing the location of USGS gaging stations within the Cedar River Municipal Watershed.

\subsubsection{Chester Morse Lake}

The Chester Morse Lake drainage area accounts for 60 percent of the watershed with a 212-square-kilometer drainage area, and is monitored by six USGS gaging stations. The Chester Morse Lake watershed receives three main inflow sources from the Upper Cedar River, the Rex River, and Boulder Creek. Collectively, these three streams drain approximately 77 percent of the watershed area. A USGS gaging station is located at each major stream. The remaining 49 square kilometers of the watershed are ungaged. A summary of the drainage areas and the corresponding location in the reservoir model is presented in Table 5 . 
Table 5. Summary of drainage areas and corresponding location in the Chester Morse Lake model.

\begin{tabular}{lccc}
\hline Stream & Area $\left(\mathbf{k m}^{2}\right)$ & \% of USGS 12115000 & Model Segment \\
\hline Upper Cedar River to USGS 12115000 & 106.8 & 100 & 2 \\
McClellan Creek & 3.9 & 3.61 & 15 \\
Green Point Creek & 2.3 & 2.11 & 19 \\
Rack Creek & 5.7 & 5.31 & 32 \\
Damburat Creek & 1.2 & 1.09 & 37 \\
Boulder Creek & 13.3 & 8.89 & 41 \\
Otter Creek & 1.9 & 1.75 & 52 \\
\hline Rex River & 43.0 & 39.88 & Branch 2 \\
Distributed flow & 34.5 & 32.29 & Waterbody 1 \\
\hline
\end{tabular}

\subsection{Streamflow}

The confluence with the Upper Cedar River defined the upstream boundary of the model (Figure 13). Data from USGS 12115000 on the Upper Cedar River, located just upstream of the model domain, were used as inflow boundary conditions. USGS 12115000 is impacted by backwater from Chester Morse Lake at water surface elevations above 476.0 meters ( 1562.5 feet). During periods impacted by backwater, flow was estimated using regression analysis with USGS 12115500 on the Rex River (Figure 23). Missing flow data were filled using regression analysis with USGS 12114500 on the Upper Cedar River below Bear Creek (Figure 24). The data from USGS 12115000 and USGS 12115500 are shown relative to the branch 1 modeled inflow corrected for backwater and missing data periods (Figure 25). The USGS 12115500 observed flow was used as the model inflow for Rex River, branch 2 of the model. 


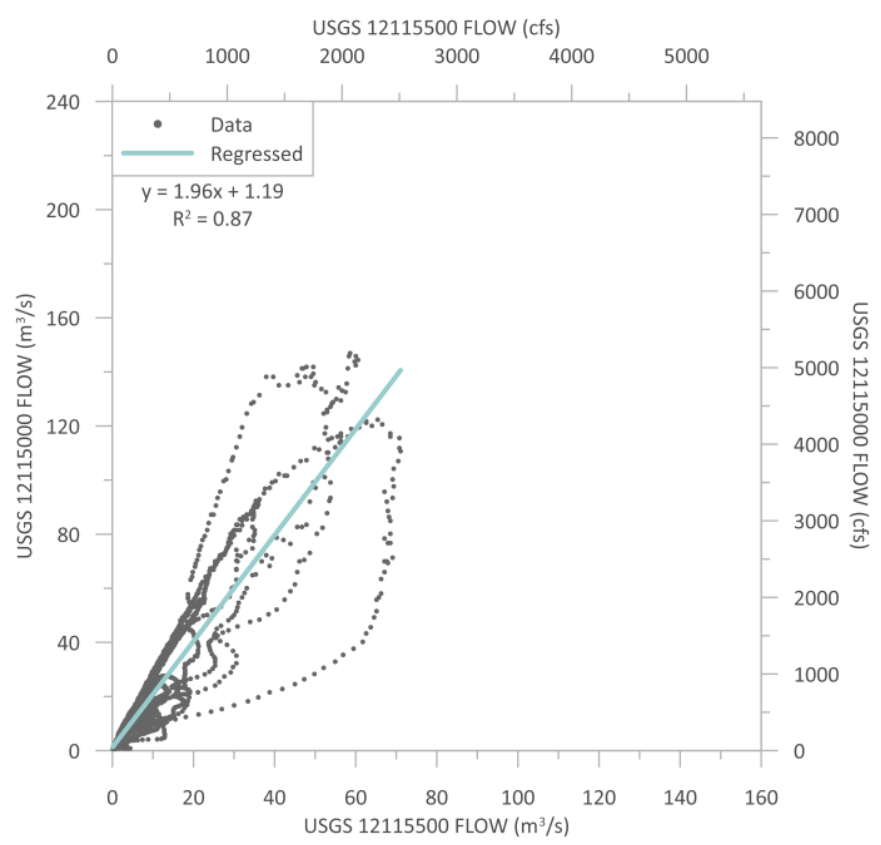

Figure 23. Regression analysis of flow at USGS 12115500 and USGS 12115000 using 15-minute data from January 1 through December 31, 2015 ( $n=28207)$. Periods impacted by backwater were excluded from the analysis.

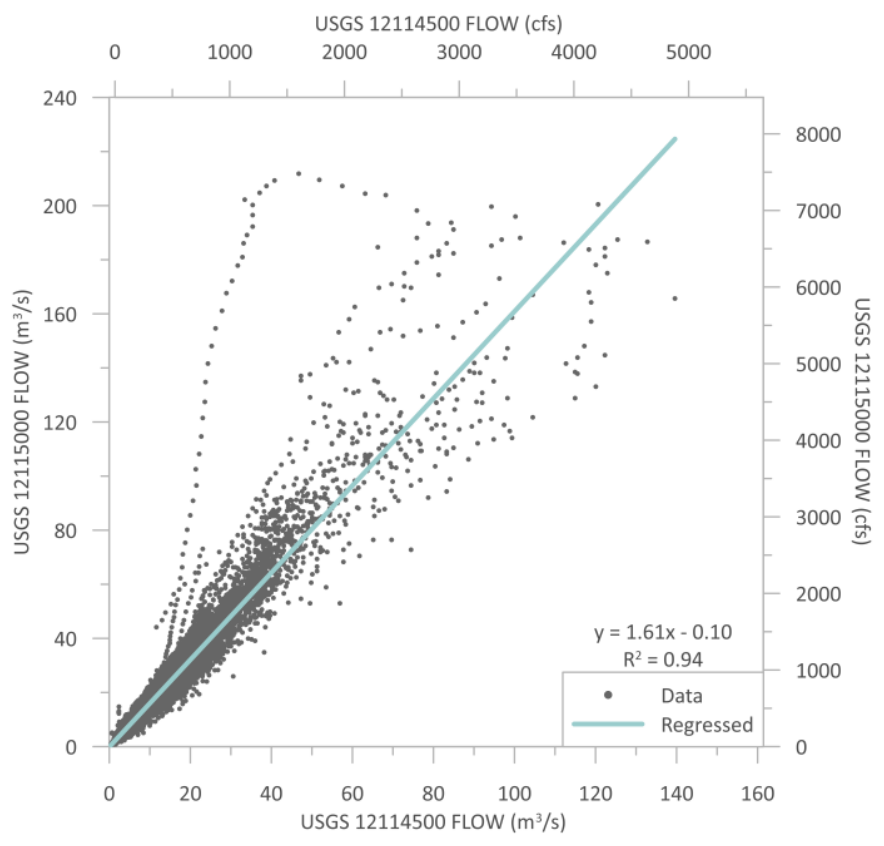

Figure 24. Regression analysis of flow at USGS 12114500 and USGS 12115000 using hourly data from January 1, 1988 to December 31, 2017 (n=220252). 


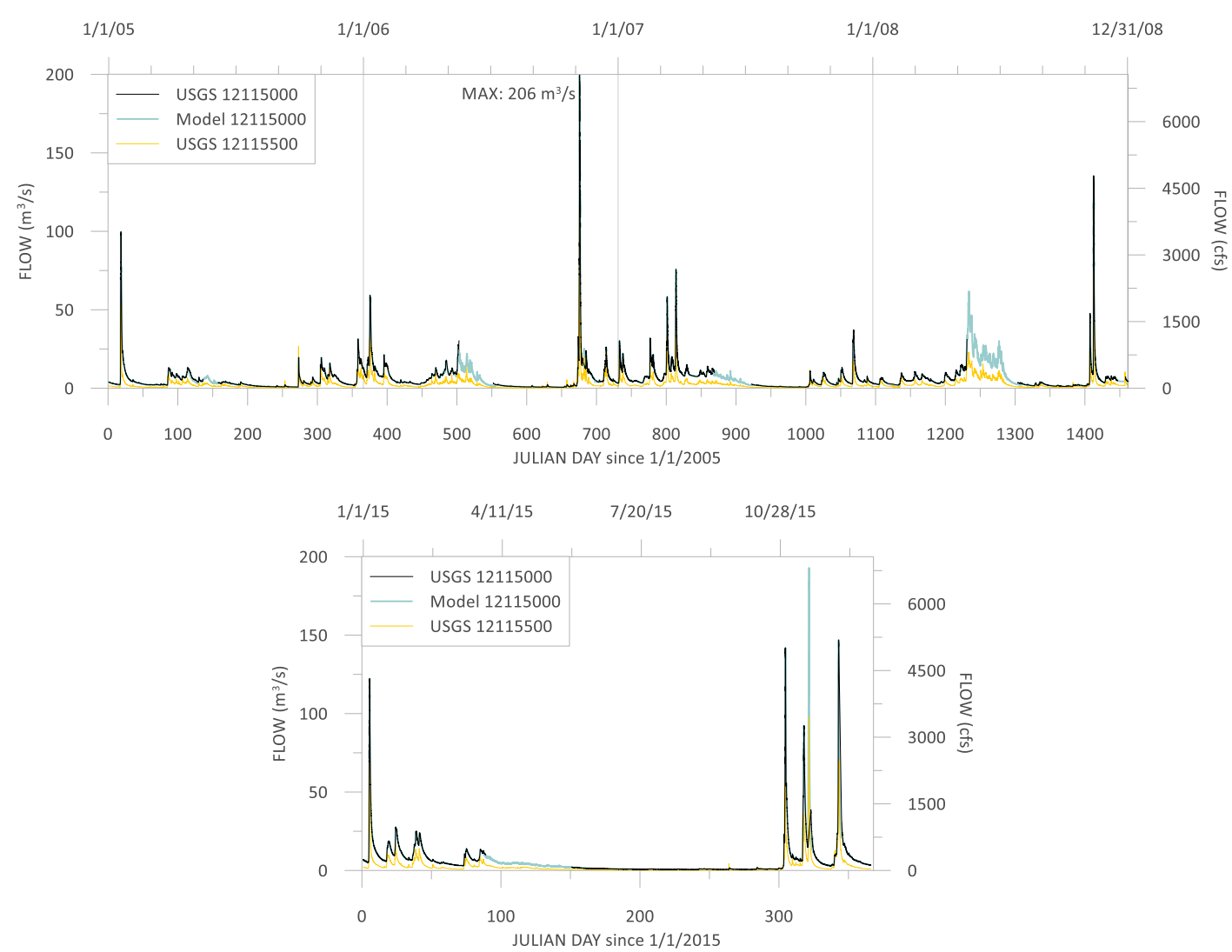

Figure 25. Observed streamflow at USGS 12115000 and USGS 12115500 relative to the branch 1 modeled inflow in 2005-2008 (top) and 2015 (bottom). Modeled inflow was corrected for backwater affects.

The ungaged drainage area was estimated using the drainage-area ratio method (Equation 2). This method is commonly used to estimate streamflow for ungaged sites with similar topographical and hydrological characteristics (Emerson, Vecchia, \& Dahl, 2005).

$$
Q_{\text {ungaged }}=Q_{\text {gaged }} \frac{A_{\text {ungaged }}}{A_{\text {gaged }}}
$$

Equation 2

The drainage-area ratios are presented in Table 5. Inflows for all ungaged streams were considered proportional to the backwater adjusted inflow from USGS 12115000 . The model inflows used for tributaries listed in Table 5 are shown in Figure 26. Observed 
data at USGS 12115700 were used as available for the Boulder Creek tributary. Missing values were filled in using the drainage-area ratio method. The model inflow for Rack Creek is representative of all modeled tributaries using the drainage-area ratio method. Each tributary follows the same trend observed at Rack Creek, scaled by their corresponding percentage of the backwater-corrected USGS 12115000 inflow.

Other ungaged flows were modeled using a distributed tributary and the drainage-area ratio method. The distributed tributary was refined during the water balance calibration discussed in Chapter 4.

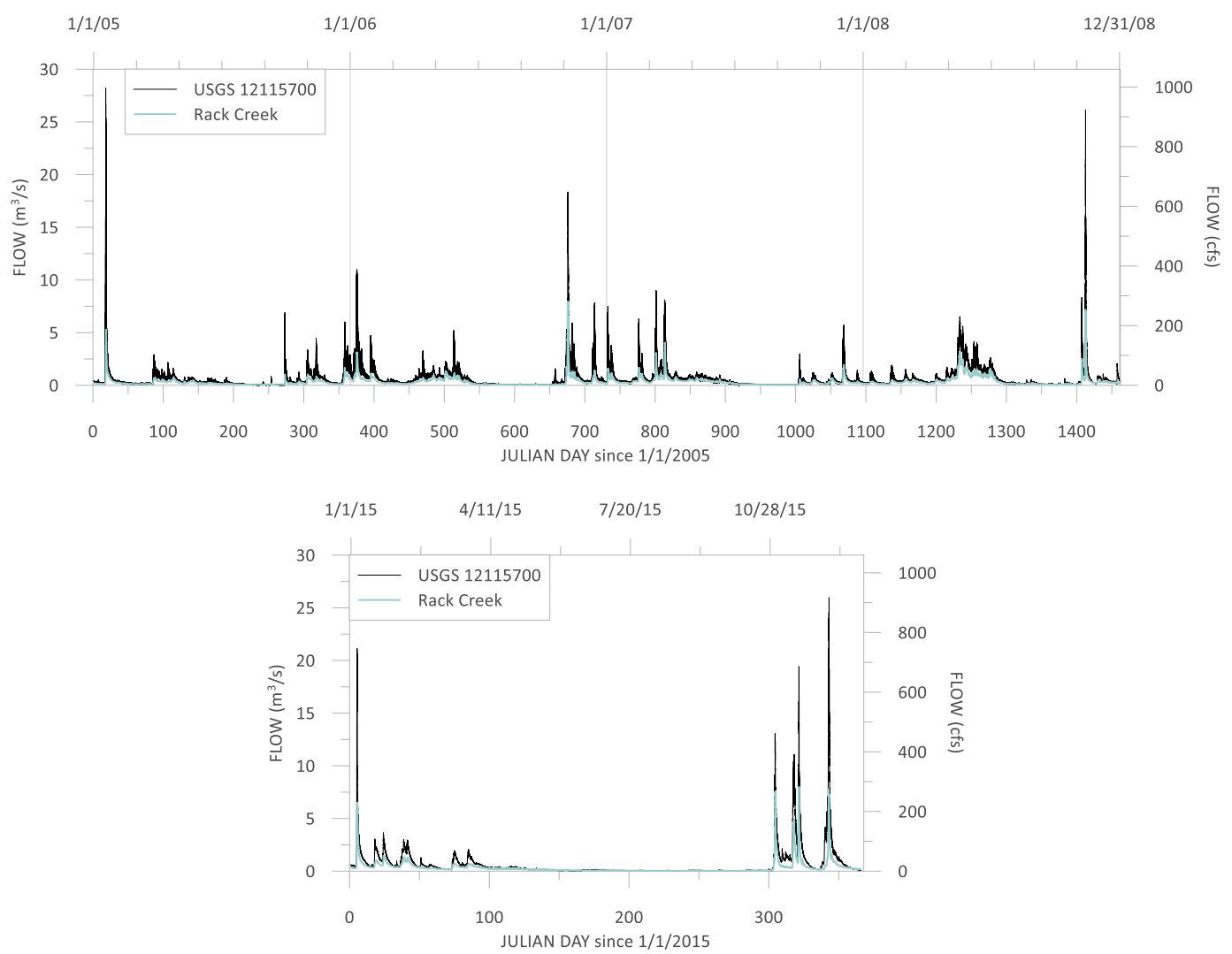

Figure 26. Observed streamflow at USGS 12115700 and modeled tributary inflow for Rack Creek. All reservoir tributaries not shown follow the same trend as Rack Creek adjusted by their respective scaling factors. 


\subsection{Stream Temperature}

Water temperature data were available at USGS 12115000 for both 2005-2008 and 2015. Partial water temperature records were available for Rex River, Boulder Creek, and Rack Creek for 2005-2008. Regression models were developed for inflows with partial water temperature records (Figure 28). Water temperature inputs were developed from the regression analysis using observed data as available and are shown in Figure 29 through Figure 31 for 2005-2008. In the previous study, V. Wells observed that USGS boundary condition temperature data was incorrect from May 5 to August 12,2008 . Water temperature data during this period from a temperature buoy were used in place of the USGS gaging station data in this study. Missing values prior to available buoy data were filled in using regression analysis with USGS 12116500 (Figure 27 and Figure 28).
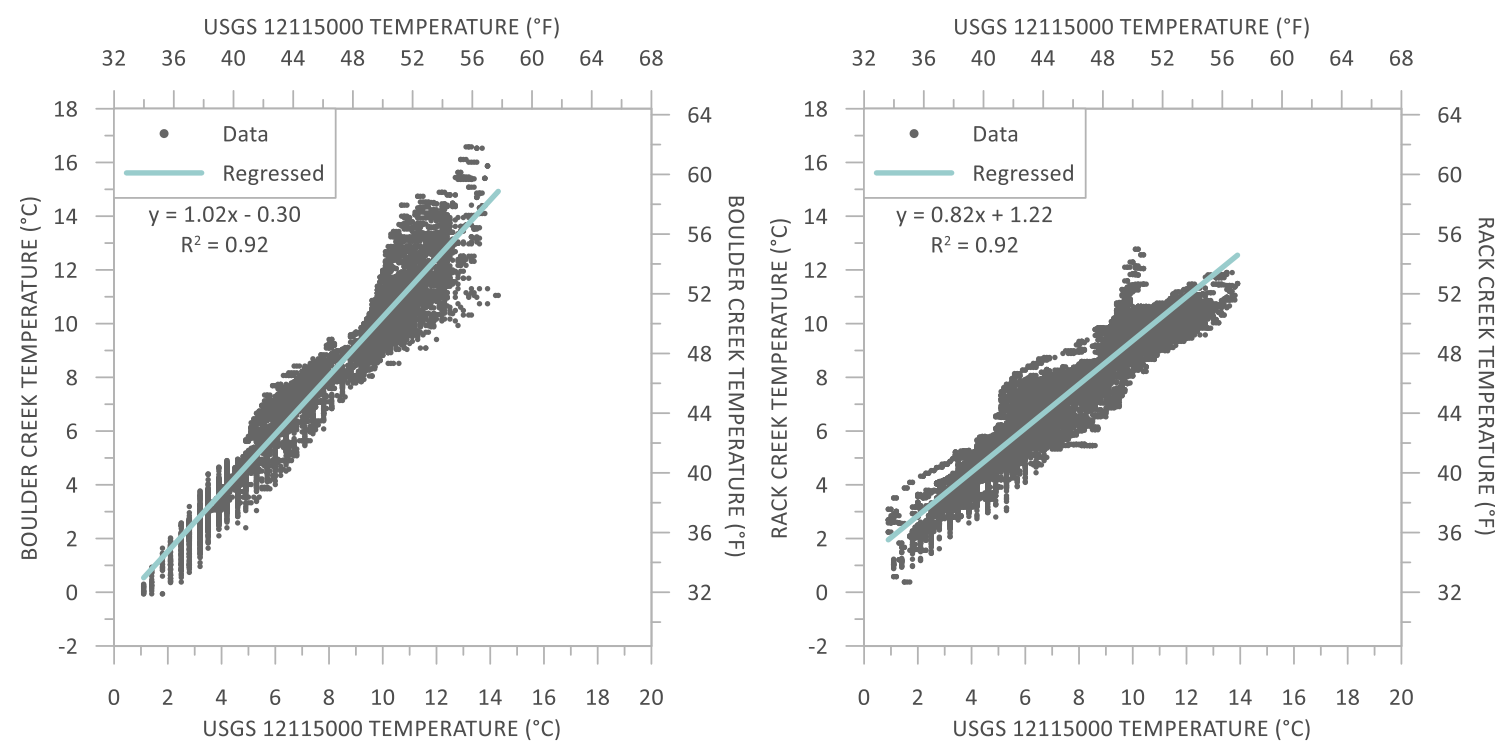

Figure 27. Regression models for water temperature in Boulder Creek (left, $n=12220$ ) and Rack Creek (right, $n=29168$ ) as a function of observed temperature at USGS 12115000. 

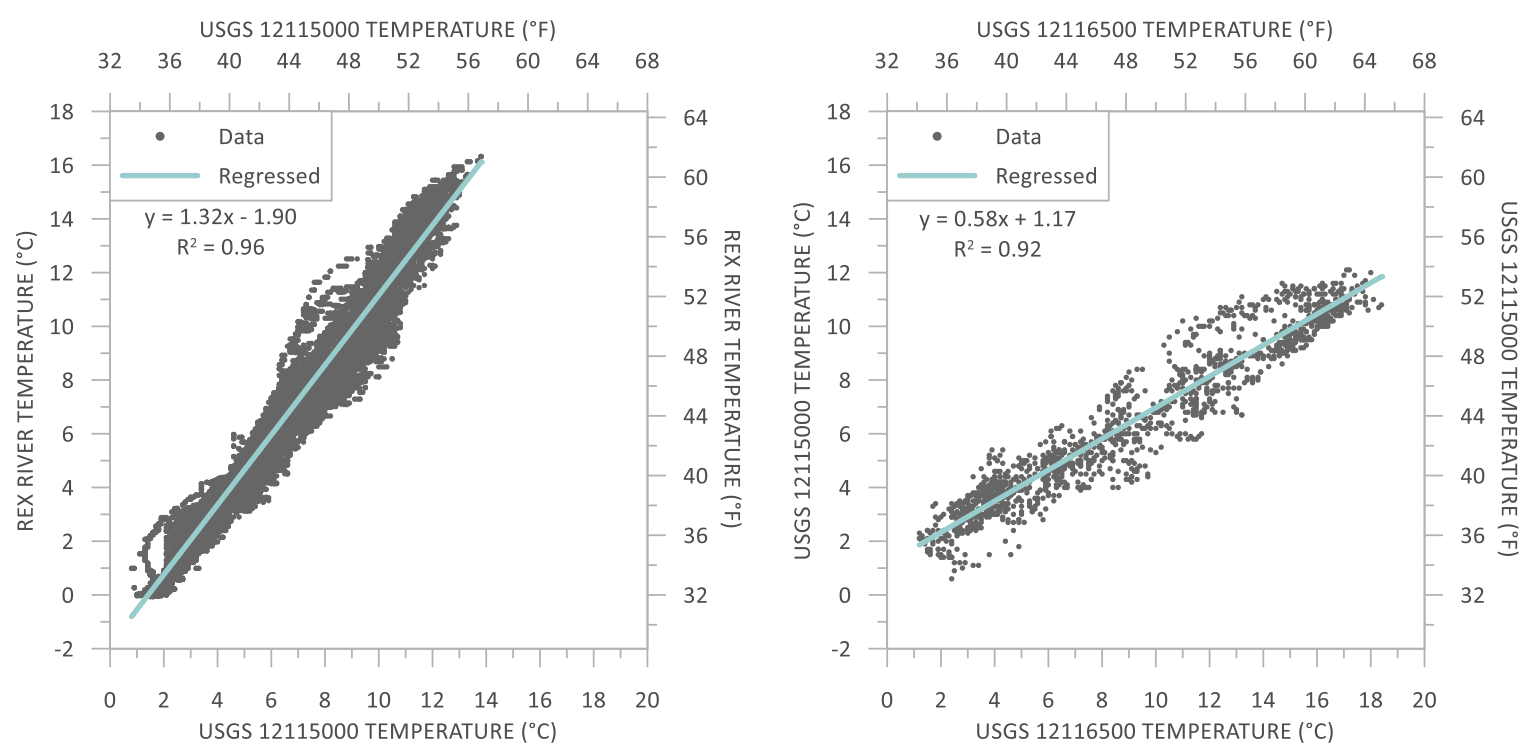

Figure 28. Regression model for water temperature in Rex River (left, $n=38530$ ) as a function of observed temperature at USGS 12115000. Regression model for water temperature at USGS 12115000 as a function of observed temperature at USGS 12116500 (right, $n=1415$ ).

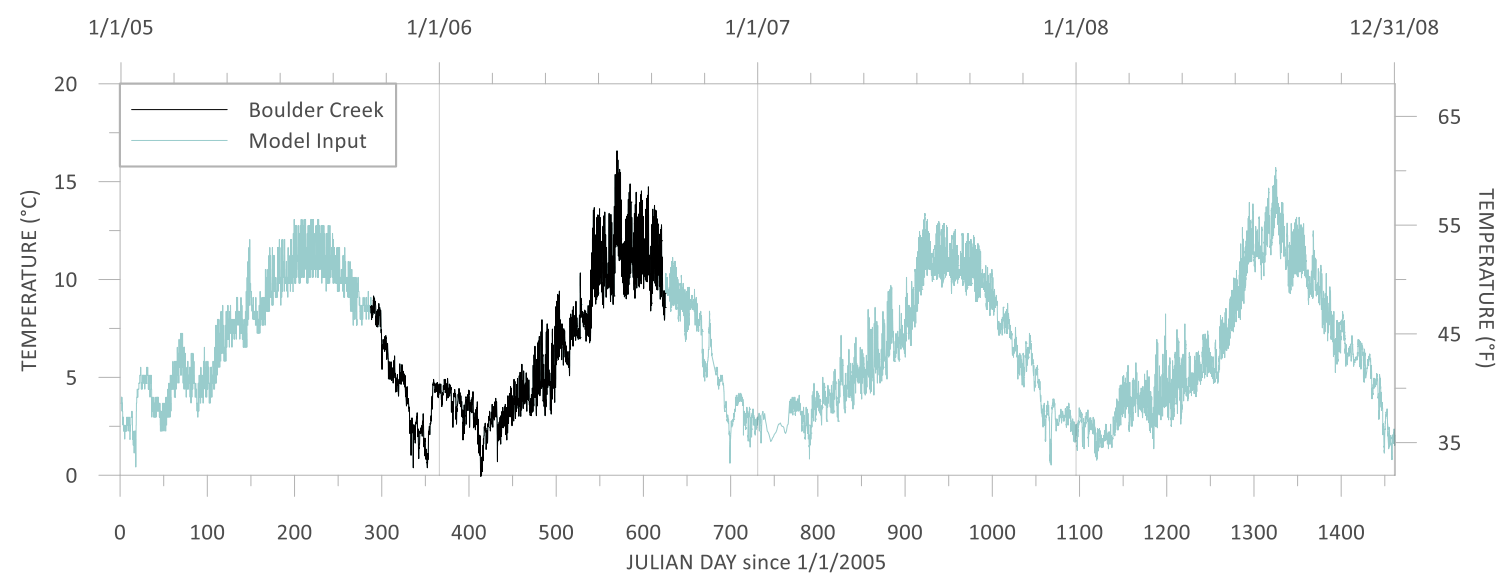

Figure 29. Observed water temperature at Boulder Creek and model input developed using regression analysis, 2005-2008. 


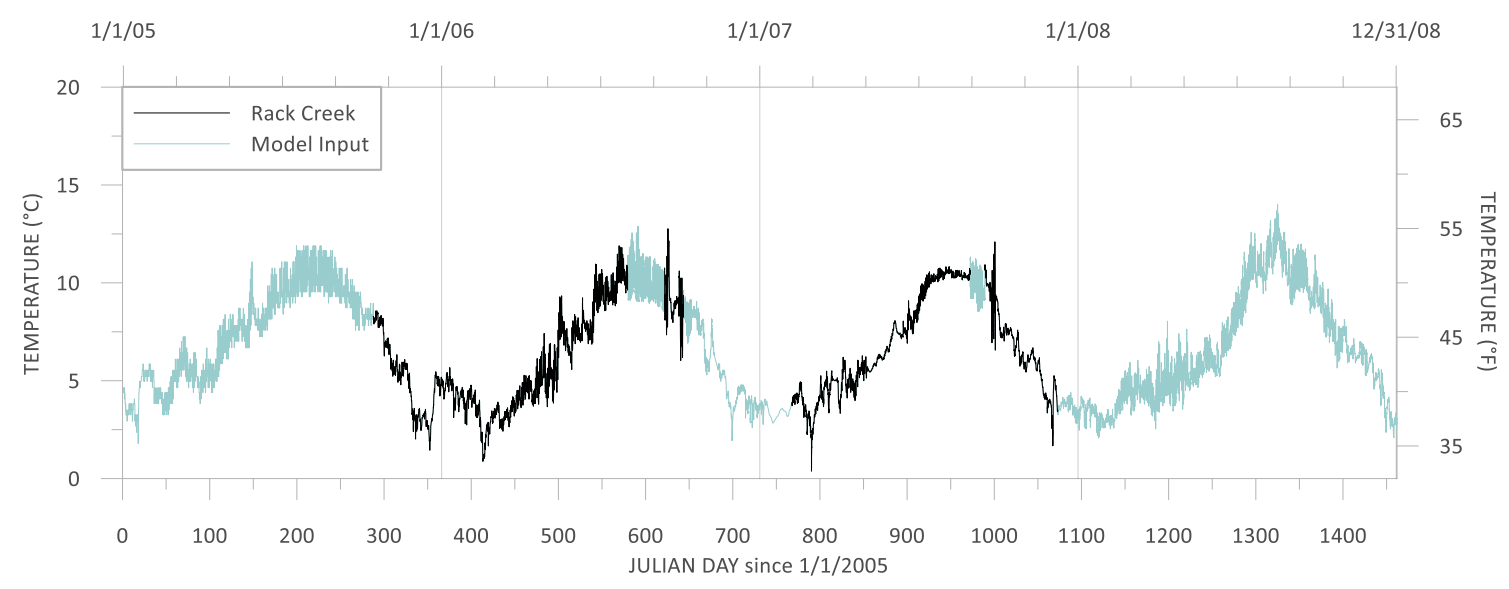

Figure 30. Observed water temperature at Rack Creek and model input developed using regression analysis, 2005-2008.

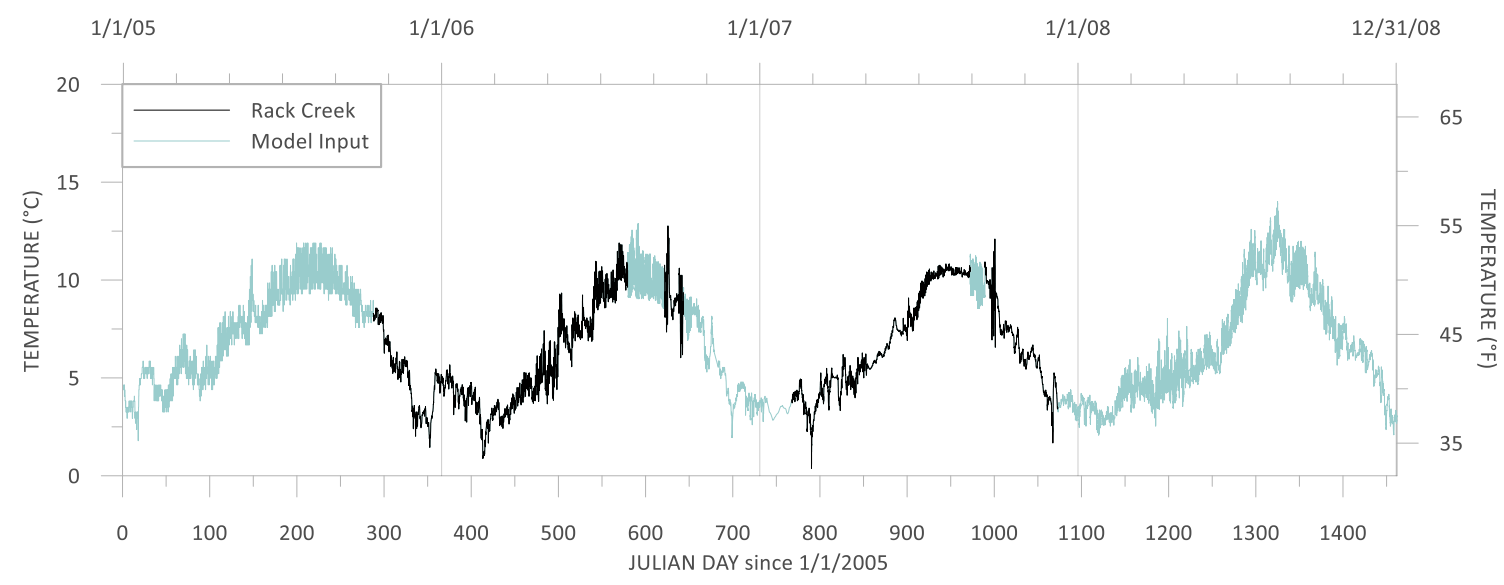

Figure 31. Observed water temperature at Rex River and model input developed using regression analysis, 2005-2008.

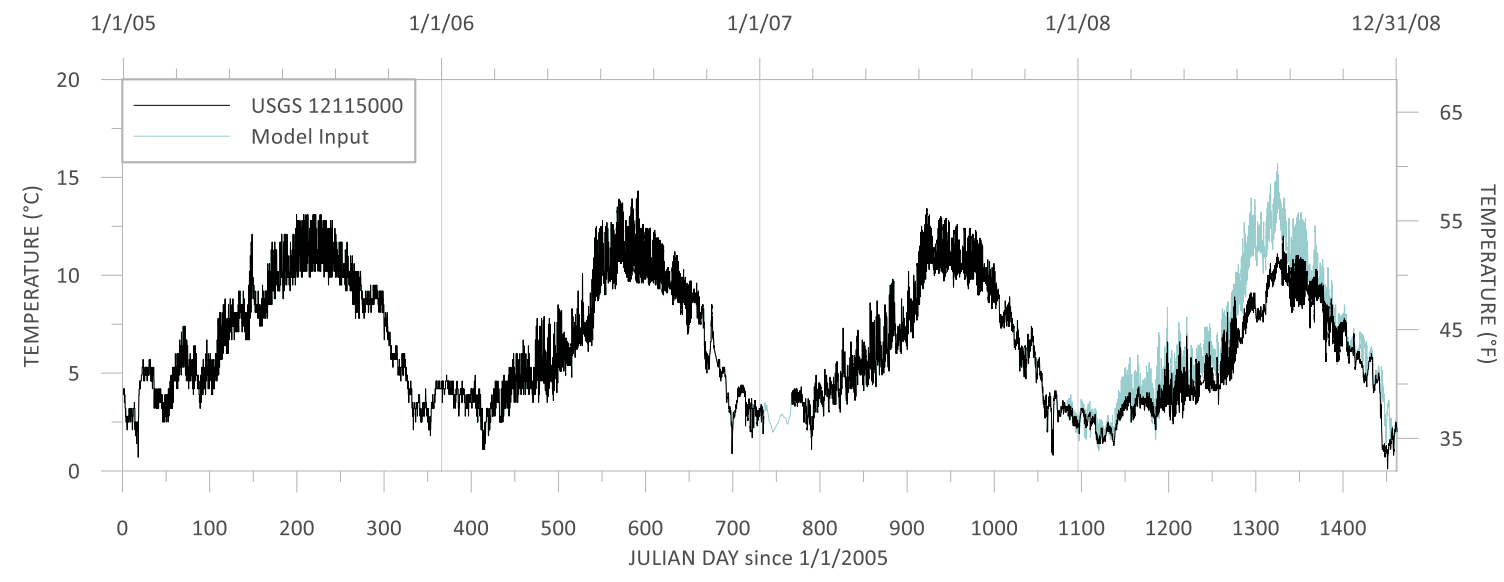

Figure 32. Observed water temperature data at USGS 12115000 and model input. Water temperature data at 6 meters from a buoy in close proximity were used for the later part of the model run, 2005-2008. 
Temperature input files for all inflows are shown in Figure 33. Water temperature files for Boulder Creek, Rack Creek, and Rex River were developed using the results of the 2005-2008 regression analysis. For tributaries lacking field data, inflow temperatures were assumed to be consistent with those observed at USGS 12115000.

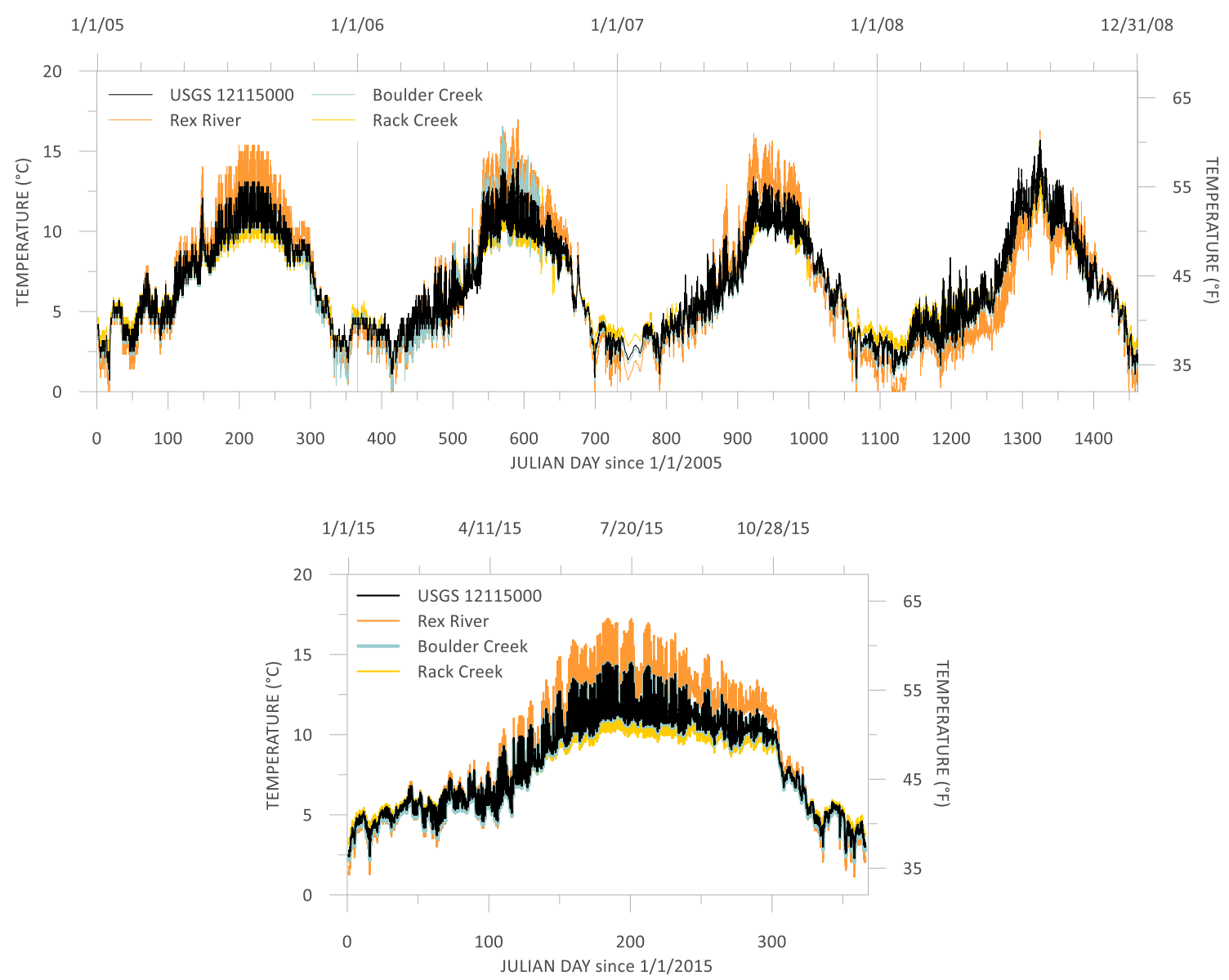

Figure 33. Water temperature inputs for all reservoir inflows in 2005-2008 (top) and 2015 (bottom). Inflow temperatures for tributaries lacking field observations were assumed to be consistent with USGS 12115000. 


\subsection{Model Outflow}

The main outflows from Chester Morse Lake are releases from the Masonry Dam and seepage loss through the glacial moraine. In the absence of direct measurements at the Masonry Dam, USGS gaging stations located downstream of the dam were used to estimate dam discharge (Figure 34). The powerhouse release was assumed to be the difference between USGS 12116500 and USGS 12116400. The powerhouse release has a maximum value of $21.2 \mathrm{~m}^{3} / \mathrm{s}$ (750 cfs). Excess flow was captured by the Rattlesnake Prairie tributary in the Cedar River model. The lower outlet release was assumed to be the difference between USGS 12116400, USGS 12116100, Lost Creek, and Fish Creek. The lower outlet has a maximum discharge of $18.4 \mathrm{~m}^{3} / \mathrm{s}$ (650 cfs). Excess flow was assumed to flow over the spillway. A comparison between the gaged flows and the model inputs is presented in Figure 34 for the $2005-2008$ model period and in Figure 35 for the 2015 model period. The seepage loss through the moraine was modeled using a distributed tributary for the Masonry Pool with flow rates estimated during the water balance calibration. This is discussed in the model calibration chapter. 

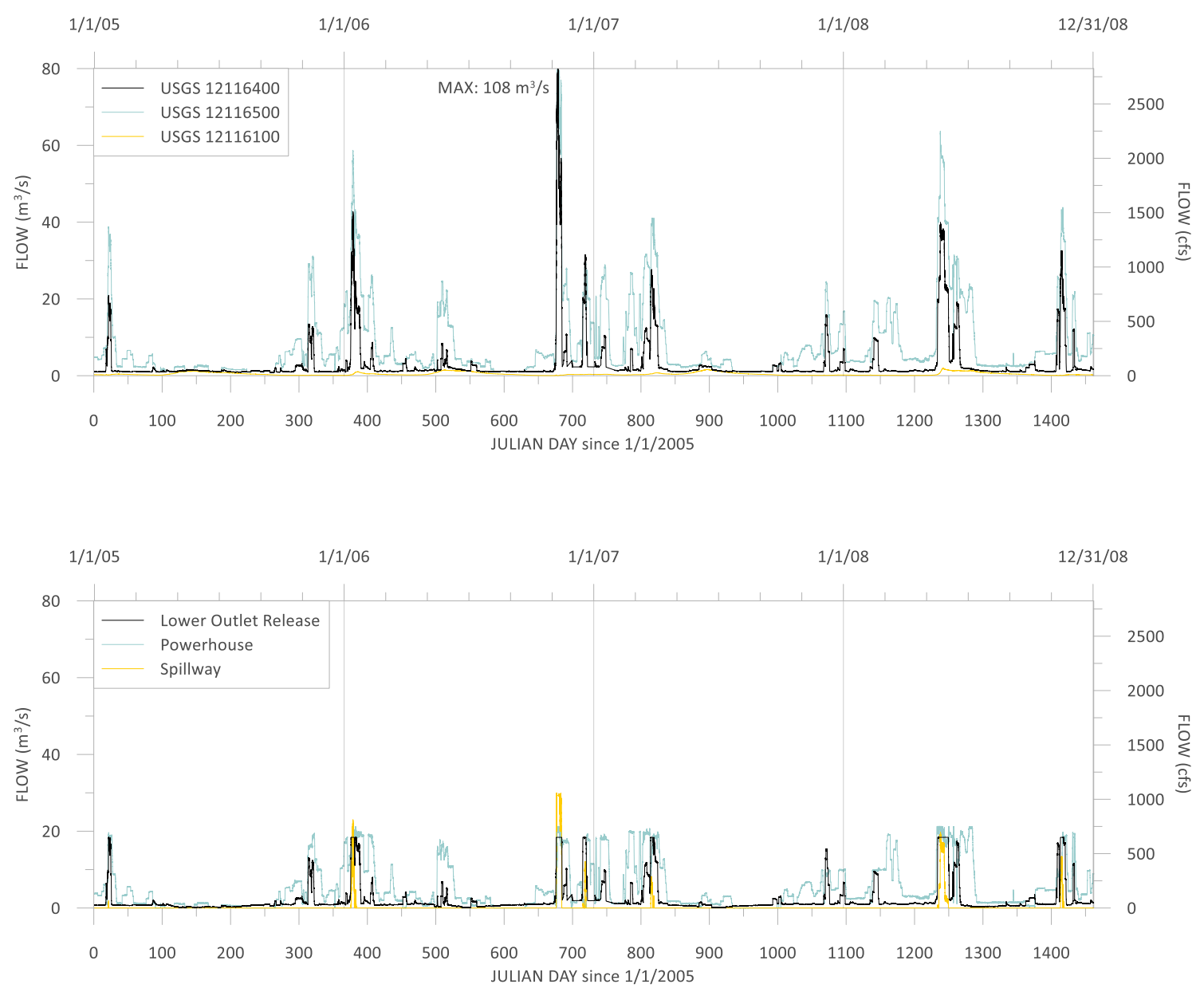

Figure 34. Observed streamflow below the Masonry Dam (top) and modeled outflows from the Masonry Dam (bottom), 2005-2008. 


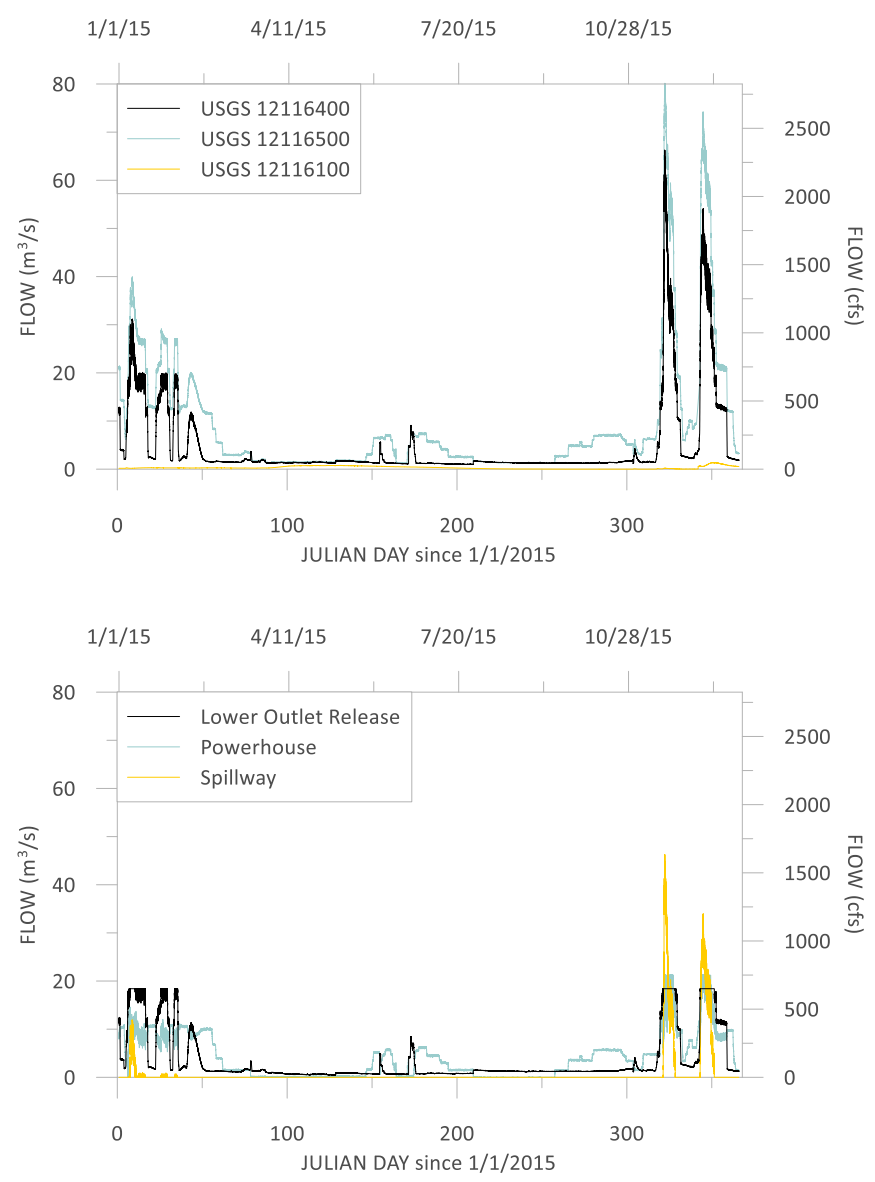

Figure 35. Observed streamflow below the Masonry Dam (top) and modeled outflows from the Masonry Dam (bottom), 2015.

\subsubsection{Cedar River}

The Cedar River drainage area accounts for 40 percent of the watershed with a 154-square-kilometer drainage area and is monitored by six USGS gaging stations. The Cedar River receives inflow from the three Masonry Dam releases and two gaged streams, Canyon Creek and Taylor Creek. The catchment area includes seven ungaged tributaries. A summary of the drainage areas and the corresponding location in the river model is presented in Table 6. The percent of basin area references the relation of the 
ungaged tributary basin area to the gaged basin area used to estimate inflow with the drainage-area ratio method.

Table 6. Summary of the drainage area of river tributaries, the percent of drainage basin area, and corresponding location in the Cedar River model.

\begin{tabular}{lccc}
\hline \multicolumn{1}{c}{ Stream } & Area $\left(\mathbf{k m}^{\mathbf{2}}\right)$ & \% of basin area & River Segment \\
\hline Lost Creek & 1.06 & 1.63 & 3 \\
Canyon Creek & 0.49 & --- & 9 \\
Fish Creek & 3.55 & 0.49 & 14 \\
De-Horn Creek & 4.56 & 6.10 & 28 \\
Unnamed Tributary & 2.75 & 3.68 & 28 \\
Steele Creek & 2.75 & 3.68 & 32 \\
Williams Creek & 6.24 & 8.36 & 45 \\
Taylor Creek & 44.83 & --- & 45 \\
Rock Creek & 14.23 & 19.04 & 83 \\
Distributed flow & 44.16 & 59.14 & Branch 4 \& 5 \\
\hline
\end{tabular}

\subsection{Streamflow}

The Cedar River receives its largest inflows from the dam releases and Taylor Creek. The simulated dam releases from the reservoir model were used as river model inputs. Data from USGS 12117000 were used for Taylor Creek (Figure 36). The Cedar River has eight additional perennial streams within the model domain. Canyon Creek is the only gaged inflow of the eight perennial streams. Data from USGS 12116100 were used as flow inputs for Canyon Creek as available. Data gaps were filled using the drainage-area ratio method relative to USGS 12116400. Streamflow for Lost Creek and Fish Creek were estimated using the drainage-area ratio method relative to USGS 12116500 . Streamflow for all remaining tributaries was estimated using the difference in observed flow between USGS 12117500 and USGS 12116500 with flows from USGS 12117000 accounted for. The drainage-area ratio method was then used to determine streamflow 
for each tributary. The model inflow for Rock Creek is representative of all modeled tributaries using the flow difference drainage-area ratio method. Each tributary follows the same trend observed at Rock Creek, scaled by their corresponding percentage of the flow difference (Table 6). Modeled streamflow inputs are shown in Figure 37. Other inflows were modeled using a distributed flow for branch 4 and branch 5 . Flow rates were estimated during the flow balance calibration. This is discussed in the model calibration chapter.

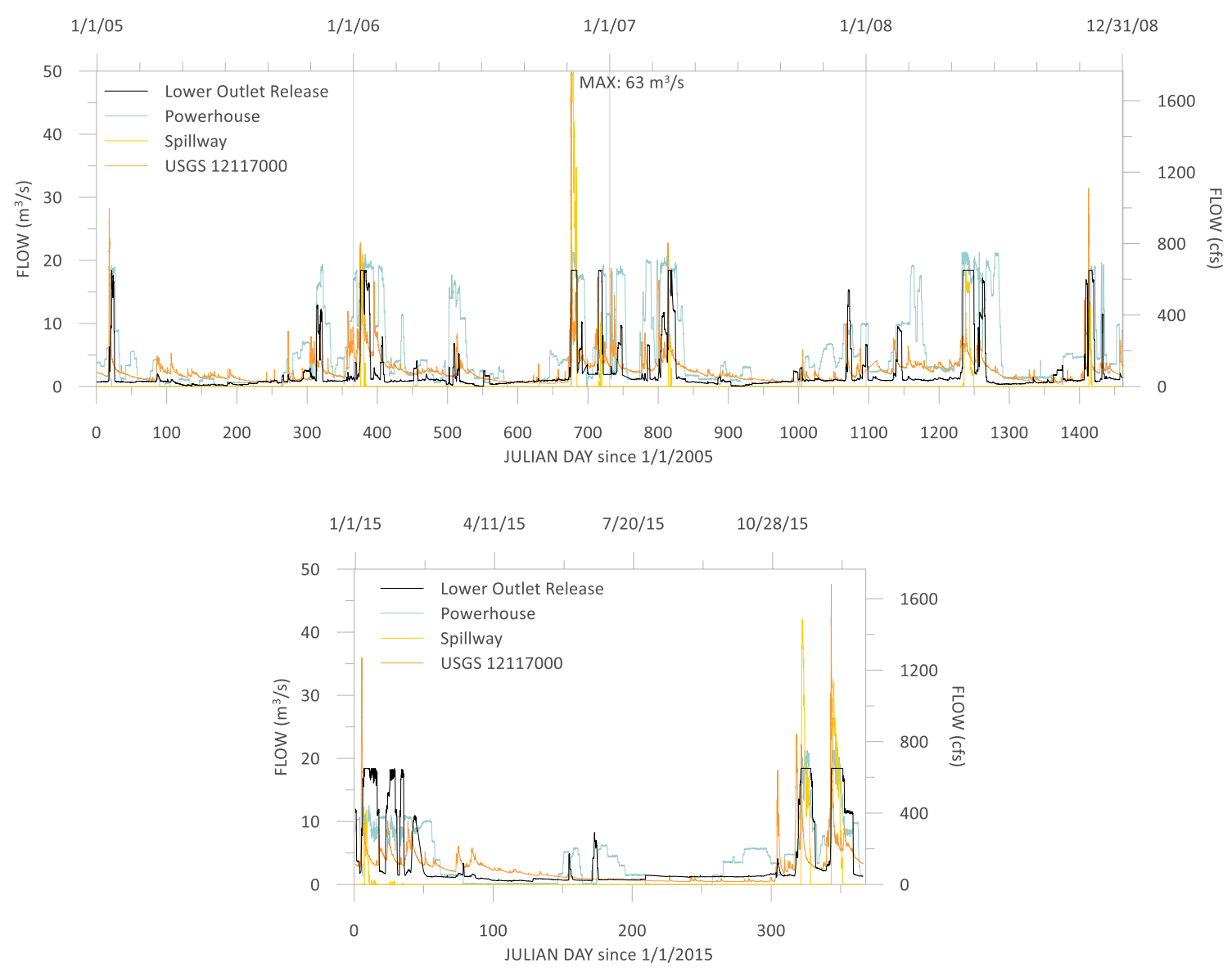

Figure 36. Larger inflows to the Cedar River in 2005-2008 (top) and 2015 (bottom). The dam releases were generated by the reservoir model. USGS 12117000 is the observed streamflow at Taylor Creek. 


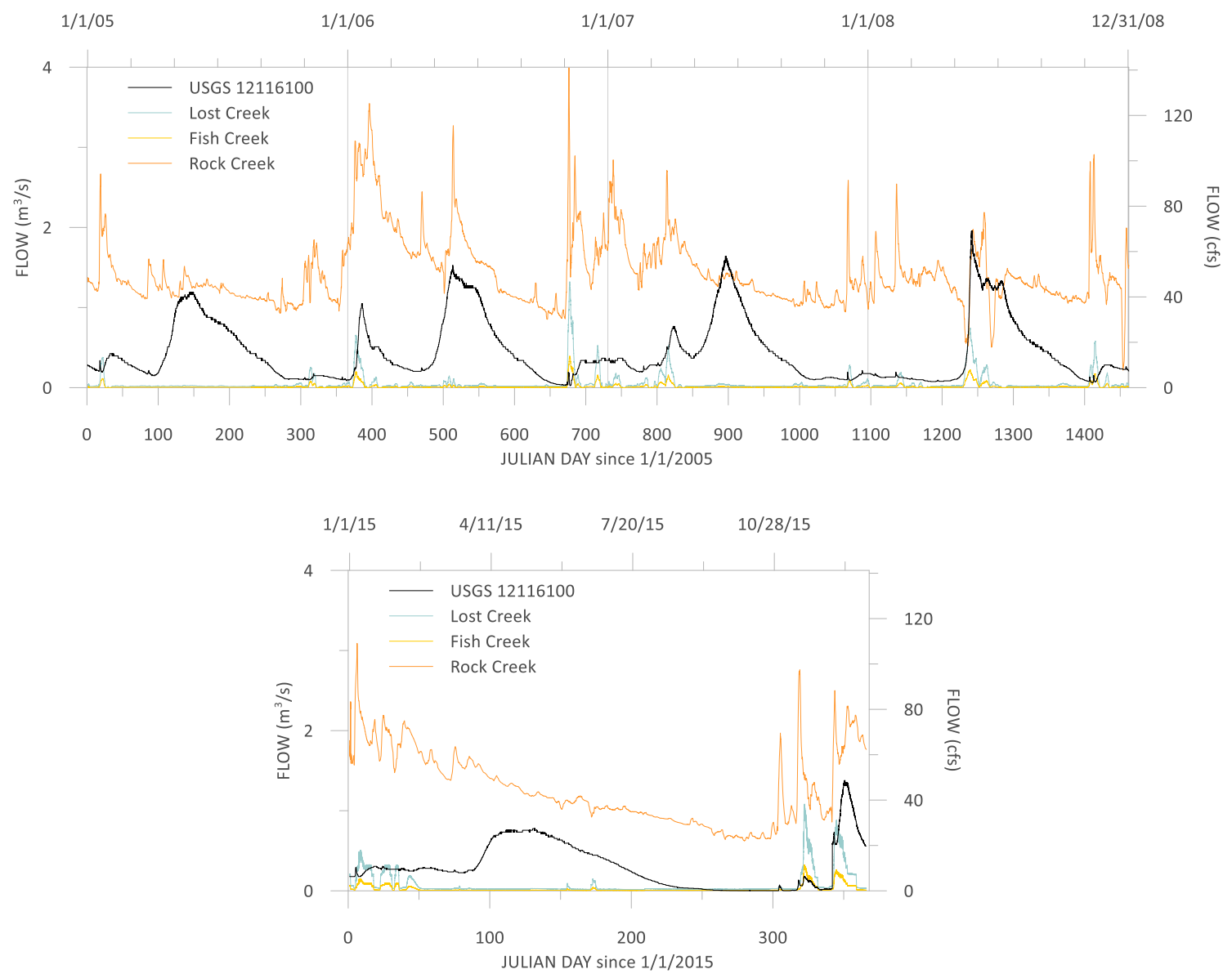

Figure 37. Smaller inflows to the Cedar River in 2005-2008 (top) and 2015 (bottom). USGS 12116100 is the observed streamflow at Canyon Creek. All other tributary inflows were estimated using the flow difference and drainage-area ratio method. Tributaries not shown follow the same trend as Rock Creek adjusted by their respective scaling factors. 


\subsection{Stream Temperature}

Temperature data were available at two locations for 2005-2008 and three locations for 2015 (Figure 38). The simulated temperature for the dam releases from the reservoir model were used as river model inputs (Figure 39). Temperature input files were developed during the water temperature calibration for the Cedar River, which is discussed in the model calibration chapter.

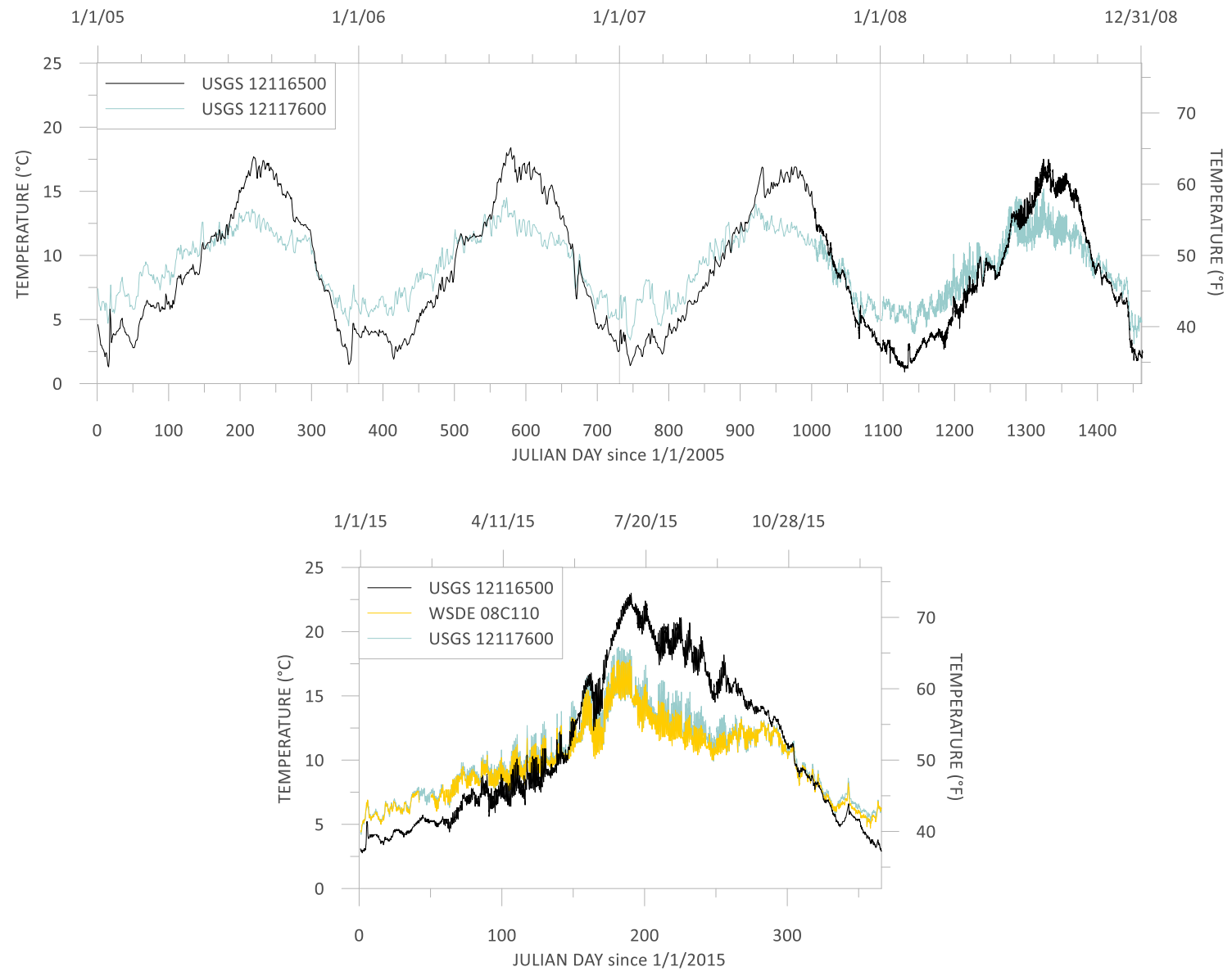

Figure 38. Observed water temperature in the Cedar River model domain for 2005-2008 (top) and 2015 (bottom). 


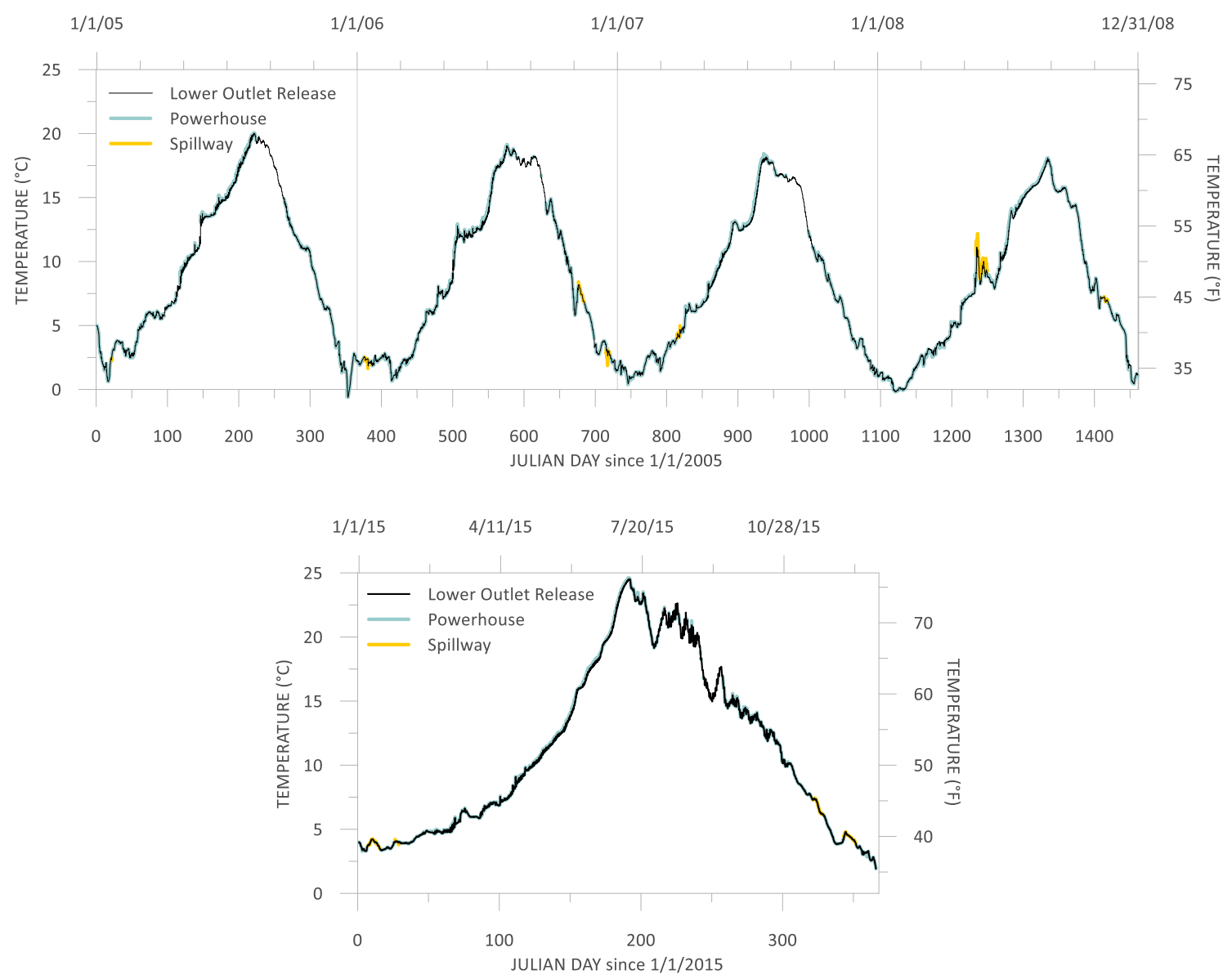

Figure 39. Simulated water temperature from the lower outlet release, the powerhouse release, and the spillway in the reservoir model for 2005-2008 (top) and 2015 (bottom). 


\subsubsection{Water Quality}

Water quality data were provided by SPU at various locations throughout the watershed. Additional data from Washington Department of Ecology (WSDE) were used for the Cedar River model. Water quality monitoring sites are shown in Figure 40.

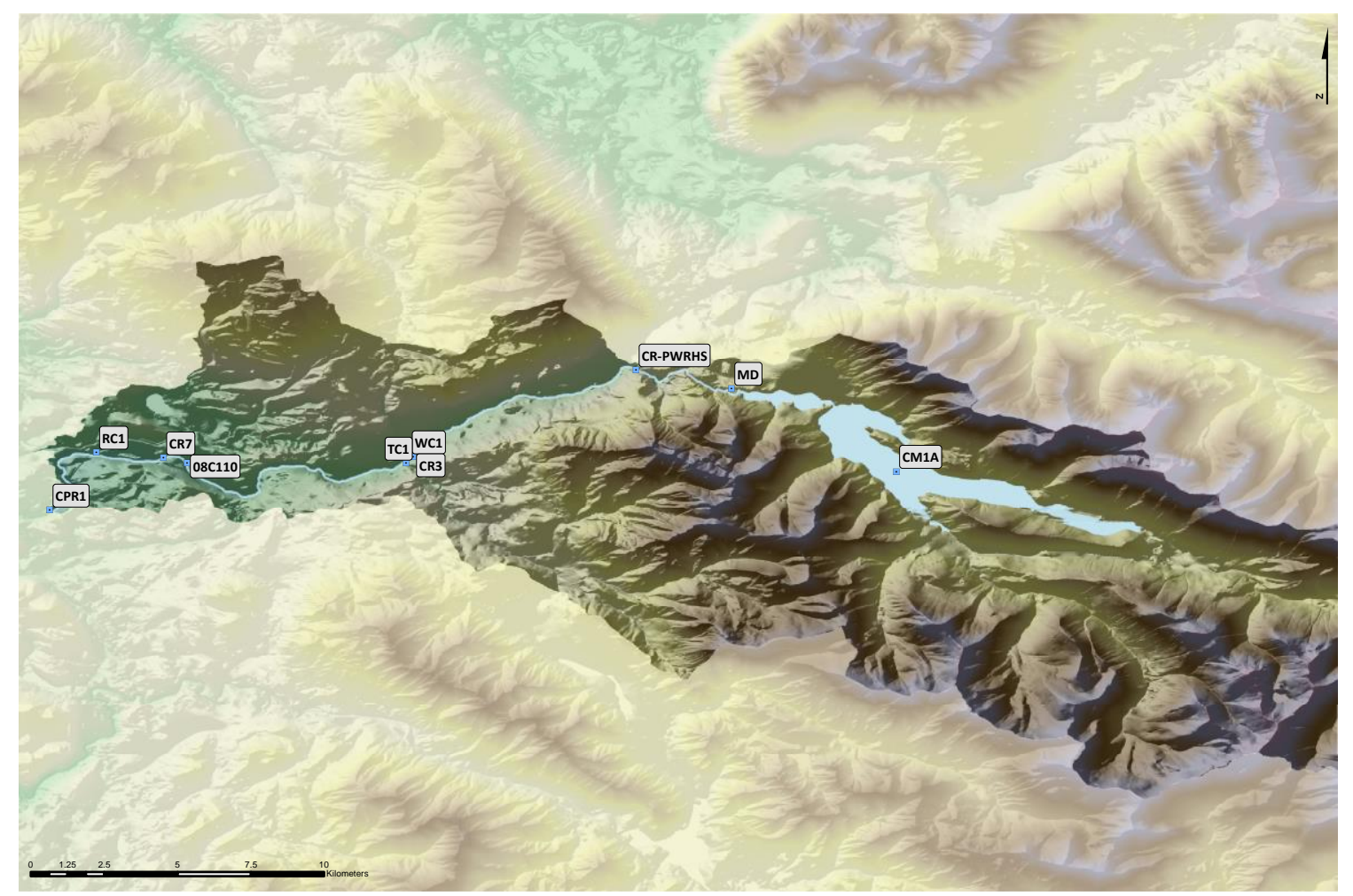

Figure 40. Map of water quality monitoring site locations within the Cedar River Municipal Watershed.

\subsubsection{Chester Morse Lake}

Water quality data provided by SPU was available for two locations in the reservoir model domain. Data were available from station $\mathrm{CM} 1 \mathrm{~A}$, located towards the middle of the main reservoir, and at station MD, located at the Masonry Dam. Measured data within the scope of this study included temperature, chlorophyll $a$, dissolved oxygen, 
total nitrogen, nitrate-nitrite, total phosphorus, and phosphate. Algae and zooplankton data were also collected as $\mathrm{mm}^{3} / \mathrm{L}$ and number of organisms per liter, respectively. CE-QUAL-W2 uses dry weight measurements of these constituents. A direct comparison between model and data was not possible for zooplankton and algae. Temperature and dissolved oxygen were collected at 1-meter intervals at station CM1A for 2005-2008. In 2015, chlorophyll $a$ was collected in addition to temperature and dissolved oxygen at 1-meter intervals at station CM1A. Other constituents at CM1A were collected and processed using a volume weighted approach by SPU. Data were provided as a single value for the epilimnion, hypolimnion, and metalimnion. Samples from the Masonry Dam were taken 1 meter below the surface in 2005-2008, and at 1 meter below the surface and at the lower level outlet elevation (457.2 m, $1500 \mathrm{ft})$ in 2015.

Water quality constituent files were developed using the available in-lake sampling data observed in the CM1A epilimnion-volume-weight-composite sample and the Masonry Dam 1-meter grab sample. Constituent files were adjusted during the water quality calibration to best match observed data. Assumptions used to estimate CE-QUAL-W2 input parameters from the available data are summarized in the Constituents section.

\subsubsection{Cedar River}

Water quality data were available at upwards of eight locations from two different sources in the river model domain. Data from WSDE were available from station 08C110, located at RM 25.4 (segment 74), for 2005-2008 and 2015. For 2005-2008, data 
from SPU were available at the powerhouse (CR-PWRHS, segment 16) and at the end of the model domain (CPR1, segment 95). In 2015, data from SPU were available at CR-PWRHS, at CPR1, near the mouth of Williams, Taylor and Rock Creeks (sampling sites WC1, TC1, RC1, respectively), at the Cedar River above Williams and Taylor Creeks (CR3), and at the Cedar River above Rock Creek (CR7). Due to limited data availability for 2005-2008, the concentration files developed for 2015 were used annually for the 2005-2008 model. Concentration input files were divided into five groups for the river boundary conditions. Group 1 was the Masonry Dam outflows, which were generated by the reservoir model. Group 2 was the Upper Cedar tributaries, which included Lost Creek, Fish Creek, Canyon Creek, and the Rattlesnake Prairie input. Concentration input files for group 2 were based off of the input file developed for the reservoir tributaries. Group 3 was the Middle Cedar tributaries, which included De-Horn Creek, the unnamed left-bank tributary, and Steele Creek. Constituent concentrations for group 3 were based off of the concentration input file developed for Taylor Creek. Group 4 was the distributed tributaries, which included the distributed tributary for branch 4 and branch 5 of the model. Concentration input files for group 4 were based off of the input file developed for the reservoir tributaries. Group 5 was the tributaries with field data in 2015, which included Williams Creek, Taylor Creek, and Rock Creek. Concentration input files for each tributary were developed using the field data collected in 2015 for both the 2005-2008 model and the 2015 model. 


\subsubsection{Constituents}

Constituent concentration files were developed for the reservoir model and river model using the assumptions stated below.

Total organic matter (TOM) was estimated using the following relationship where $\varphi_{T O C}$ is total organic carbon, from data; $\delta_{C}$ is the stoichiometric equivalent between organic matter and carbon, 0.45 ; and $\varphi_{\text {algae }}$ is the algae concentration, estimated using observed algae density.

$$
\varphi_{T O M}=\frac{\varphi_{T O C}}{\delta_{C}}-\varphi_{\text {algae }}
$$

The relative fractions of labile and refractory organic matter were treated as calibration parameters. Labile organic matter, estimated as 10 percent of the total organic matter, is readily decomposed and its source material includes algal and epiphyton excretion and mortality. Refractory organic matter, estimated as 90 percent of the total organic matter, is slowly decomposed and its source includes dissolved oxygen decay and labile organic matter. The following relationships were used to estimate model parameters for labile dissolved organic matter $\left(\varphi_{L D O M}\right)$, refractory dissolved organic matter $\left(\varphi_{R D O M}\right)$, labile particulate organic matter $\left(\varphi_{L P O M}\right)$, and refractory particulate organic matter $\left(\varphi_{\text {RPOM }}\right)$.

$$
\begin{gathered}
\varphi_{\text {LDOM }}=9 \% \times \varphi_{T O M} \\
\varphi_{\text {RDOM }}=81 \% \times \varphi_{T O M} \\
\varphi_{L P O M}=1 \% \times \varphi_{T O M} \\
\varphi_{R P O M}=9 \% \times \varphi_{T O M}
\end{gathered}
$$


The model simulated three algal groups. Inflow concentrations were estimated using data provided by SPU. Observed species data was classified into seven major groups (Figure 41). A monthly percentage of occurrence for each major group and the annual mean were calculated. The seven groups were simplified into three major groups of algae: diatoms, green algae, and cyanobacteria. Diatoms were estimated as $65 \%$ of observed density, green algae were estimated as $30 \%$ of the observed density, and cyanobacteria were estimated as $5 \%$ of the observed density. Concentrations of the zooplankton group were estimated as $0.001 \mathrm{mg} / \mathrm{L}$ in order to seed the reservoir and river in the absence of dry weight data. The zooplankton seed allowed the model to simulate zooplankton growth. Without the seed, no zooplankton growth would occur.

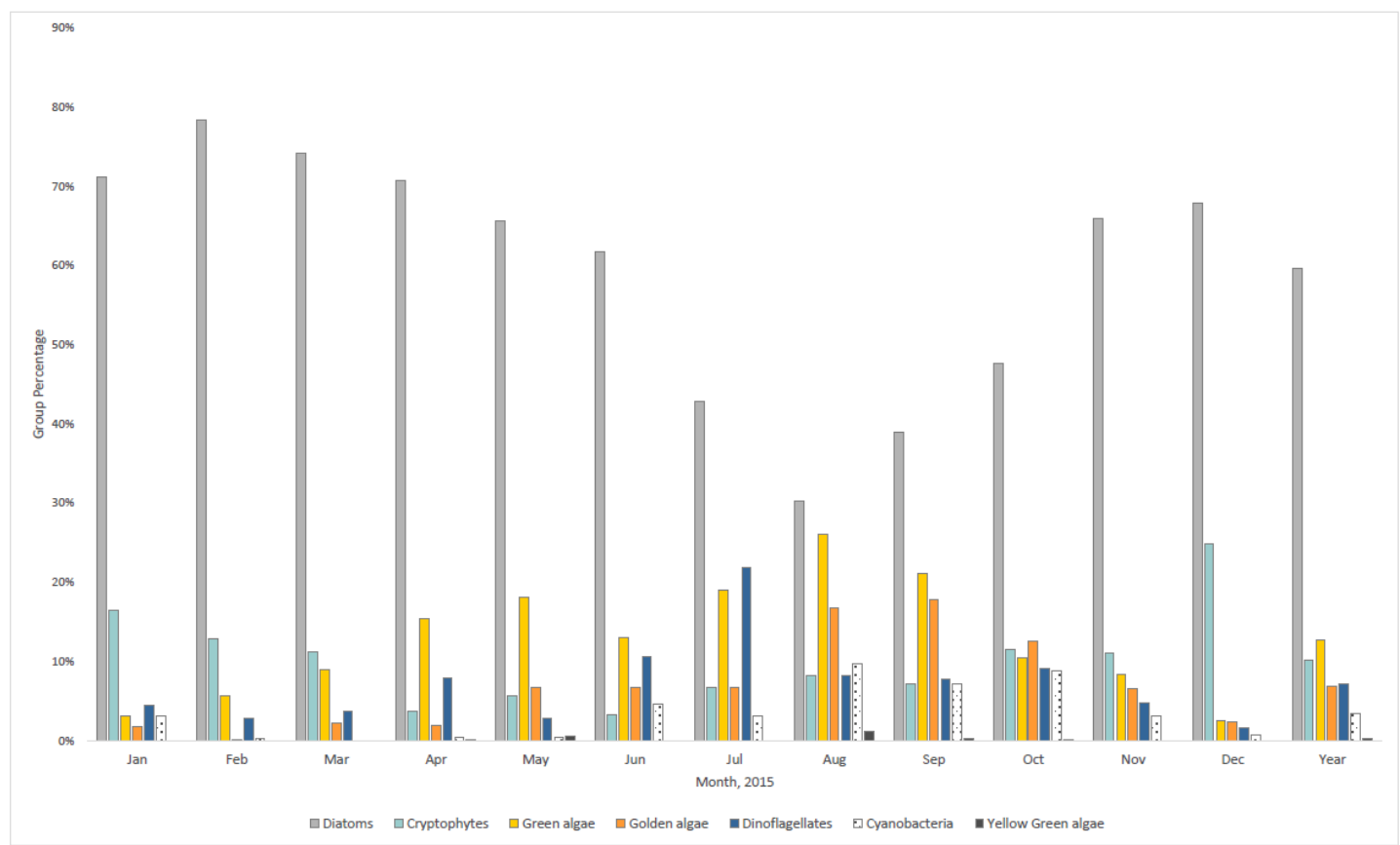

Figure 41. Monthly percentage of occurrence of observed algae groups in Chester Morse Lake, 2015. 
Total phosphorus data were used to estimate total phosphorus in labile dissolved organic matter $\left(\varphi_{L D O M-P}\right)$, refractory dissolved organic matter $\left(\varphi_{R D O M-P}\right)$, labile particulate organic matter $\left(\varphi_{L P O M-P}\right)$, and refractory particulate organic matter $\left(\varphi_{R P O M-P}\right)$. The total amount of phosphorus in organic matter $\left(\varphi_{T O M-P}\right)$ was estimated using the following relationship between total phosphorus from data $\left(\varphi_{T P}\right)$ and phosphate from data $\left(\varphi_{P_{O_{4}-P}}\right)$ where $\delta_{P_{\text {algae }}}$ is the stoichiometric equivalent between algal biomass and phosphorus, $0.005 ; \varphi_{\text {zooplankton }}$ is the zooplankton concentration, estimated; and $\delta_{P_{z o o p l a n k t o n}}$ is the stoichiometric equivalent between zooplankton biomass and phosphorus, 0.005 .

$$
\varphi_{T O M-P}=\varphi_{T P}-\varphi_{P_{4}-P}-\left(\varphi_{\text {algae }} \times \delta_{P_{\text {algae }}}\right)-\left(\varphi_{\text {zooplankton }} \times \delta_{P_{\text {zooplankton }}}\right)
$$

Fractions of LDOM-P, LROM-P, LPOM-P, and RPOM-P were assumed to follow the same relationship used to estimate LDOM, RDOM, LPOM, and RPOM.

Total nitrogen data were used to estimate total nitrogen in labile dissolved organic matter $\left(\varphi_{L D O M-N}\right)$, refractory dissolved organic matter $\left(\varphi_{R D O M-N}\right)$, labile particulate organic matter $\left(\varphi_{L P O M-N}\right)$, and refractory particulate organic matter $\left(\varphi_{R P O M-N}\right)$. The total amount of nitrogen in organic matter $\left(\varphi_{T O M-N}\right)$ was estimated using the following relationship between total nitrogen from data $\left(\varphi_{T N}\right)$, nitrate-nitrite nitrogen from data $\left(\varphi_{N O_{x}-N}\right)$, and estimated ammonia nitrogen $\left(\varphi_{N H_{4}-N}\right)$ where $\delta_{N_{a l g a e}}$ is the stoichiometric equivalent between algal biomass and nitrogen, 0.08 ; and $\delta_{N_{\text {zooplankton }}}$ is the stoichiometric equivalent between zooplankton biomass and nitrogen, 0.08. 
Ammonia nitrogen data were not available. Concentrations were assumed to be 20 percent of nitrate-nitrite concentrations.

$\varphi_{\text {TOM-N }}=\varphi_{T N}-\varphi_{N_{4}-N}-\varphi_{N O_{x}-N}-\left(\varphi_{\text {algae }} \times \delta_{N_{\text {algae }}}\right)-\left(\varphi_{\text {zooplankton }} \times \delta_{N_{\text {zooplankton }}}\right)$

Fractions of LDOM-N, LROM-N, LPOM-N, and RPOM-N were assumed to follow the same relationship used to estimate LDOM, RDOM, LPOM, and RPOM.

Dissolved oxygen was assumed to be at saturation. The equations developed by Benson and Krause were used to predict the solubility of dissolved oxygen accounting for the waterbody elevation and water temperature (1980).

Figure 42 through Figure 46 show the water quality constituents used for Chester Morse Lake and Cedar River in the 2005-2008 model. Figure 47 through Figure 51 show the water quality constituents used for Chester Morse Lake and Cedar River in the 2015 model. 


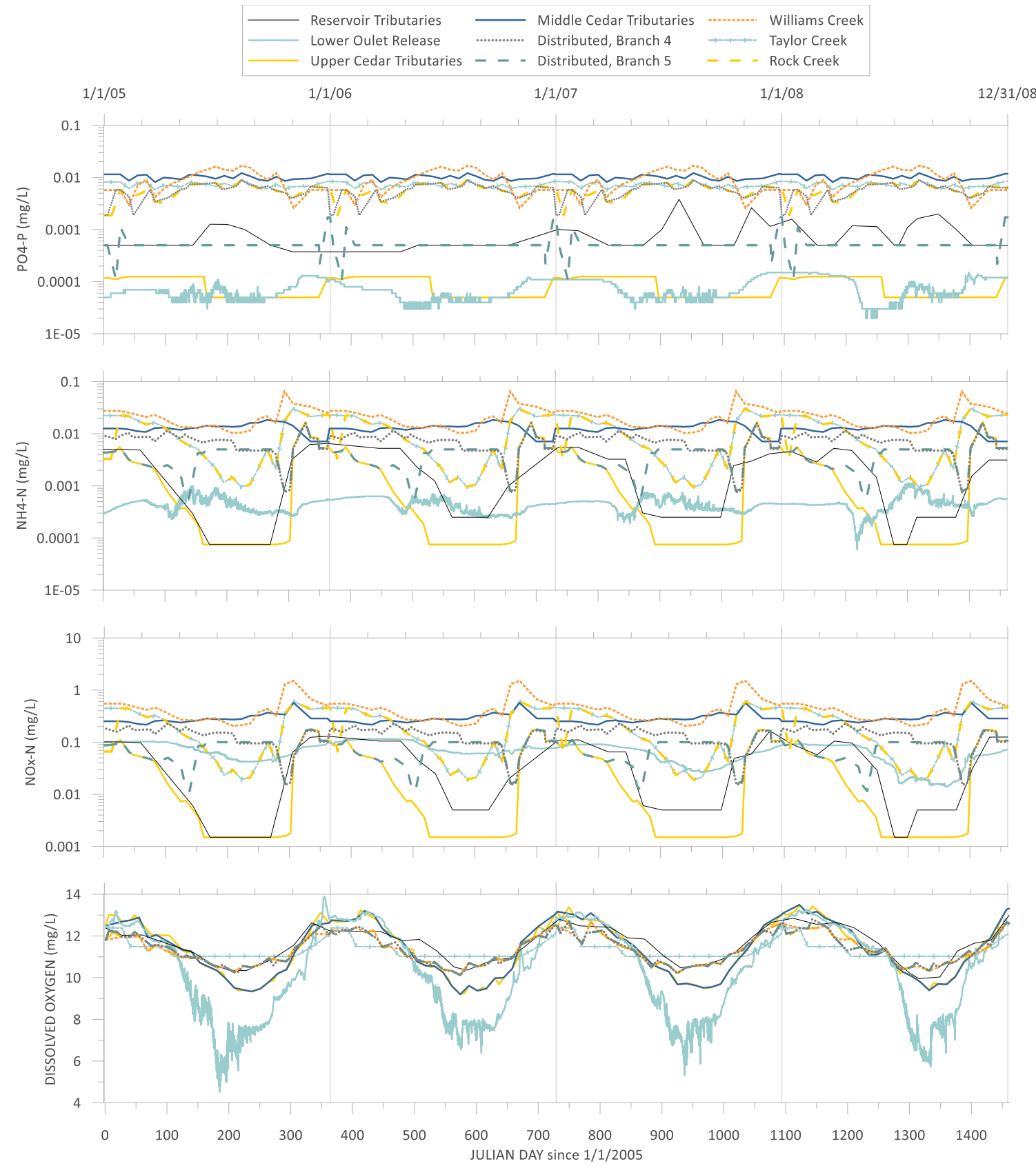

Figure 42. Constituent concentrations for phosphate, ammonia, nitrate-nitrite, and dissolved oxygen, 2005-2008. 


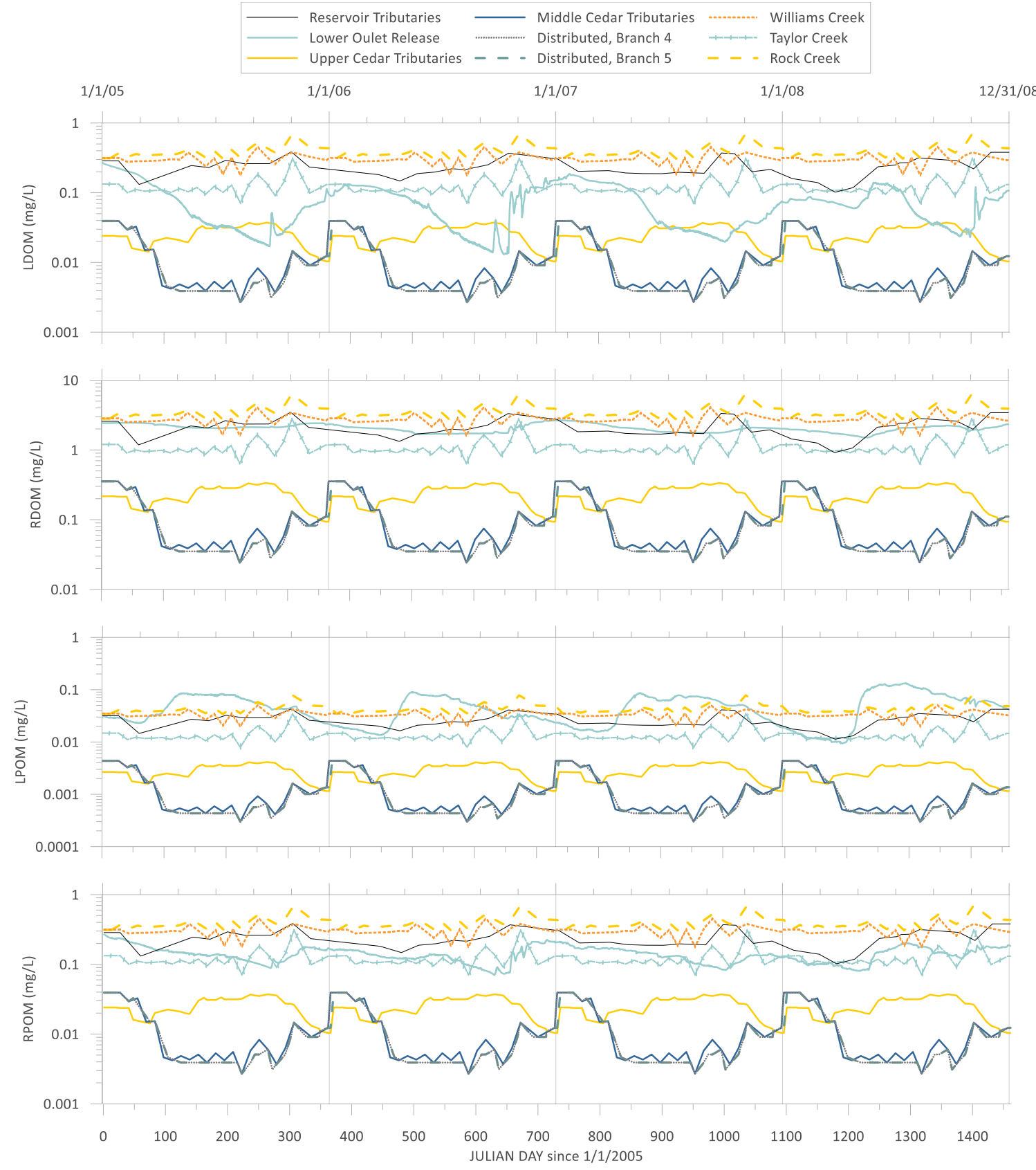

Figure 43. Constituent concentrations for LDOM, RDOM, LPOM, and RPOM, 2005-2008. 


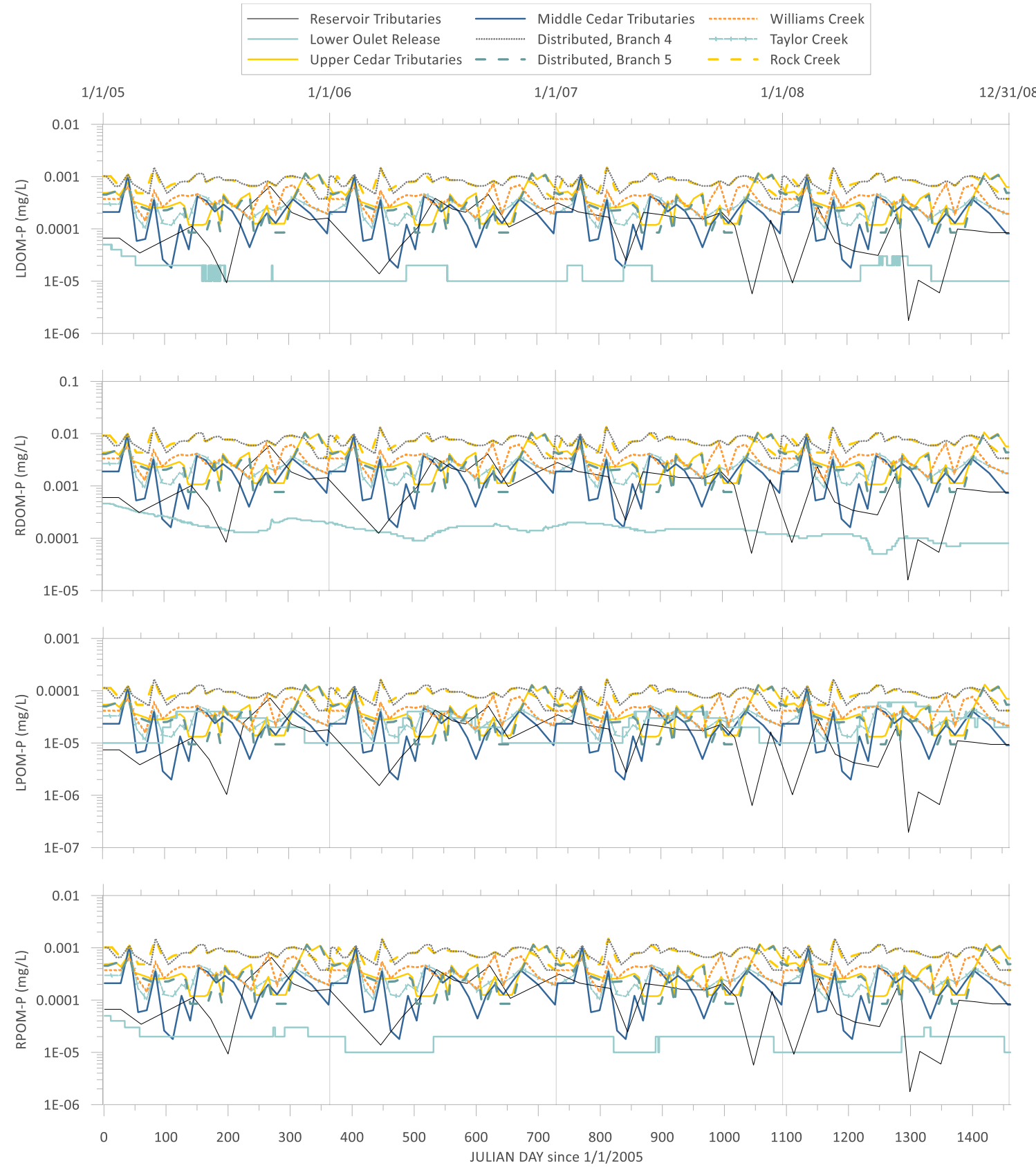

Figure 44. Constituent concentrations for LDOM-P, RDOM-P, LPOM-P, and RPOM-P, 2005-2008. 


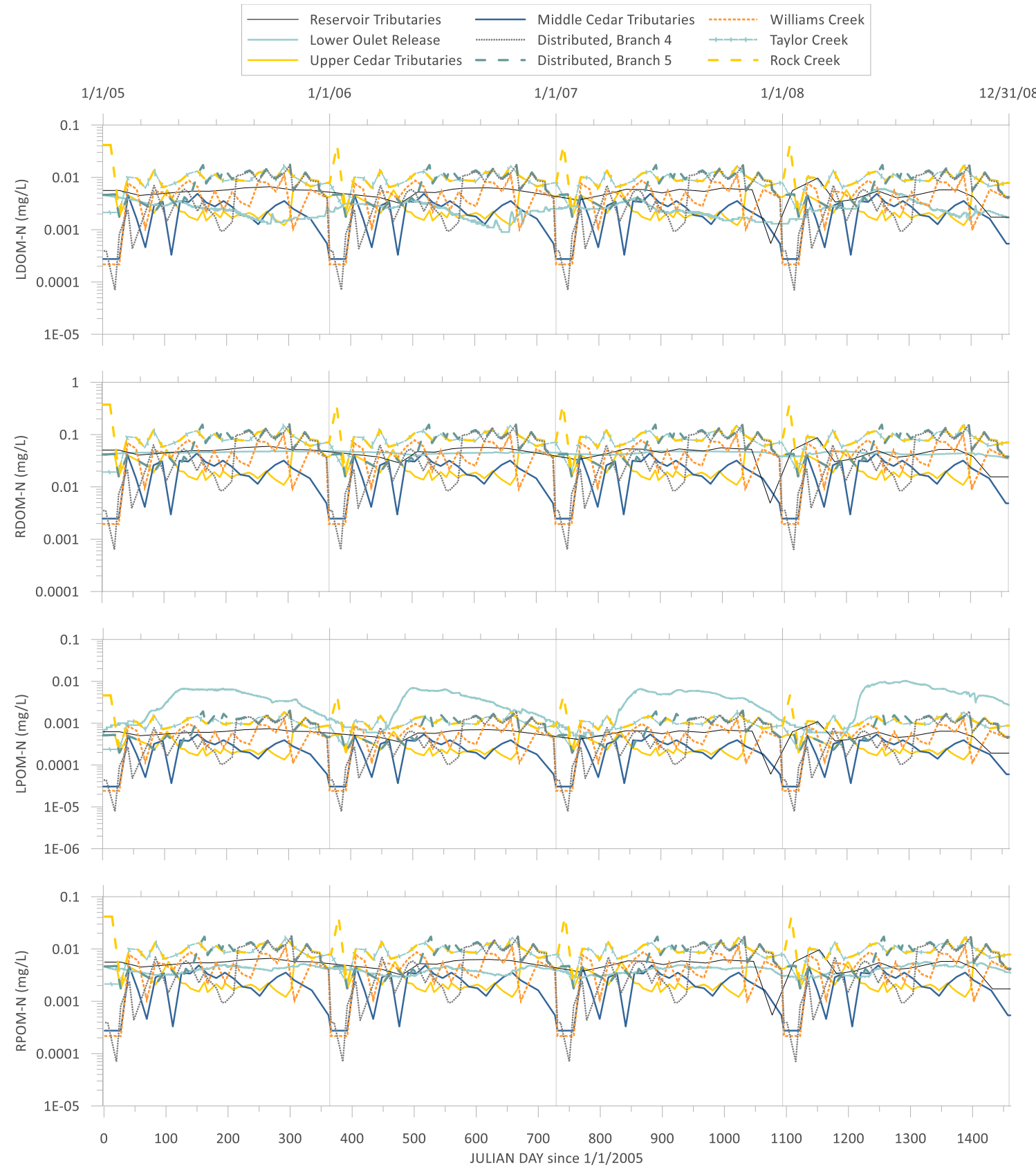

Figure 45. Constituent concentrations for LDOM-N, RDOM-N, LPOM-N, and RPOM-N, 2005-2008. 


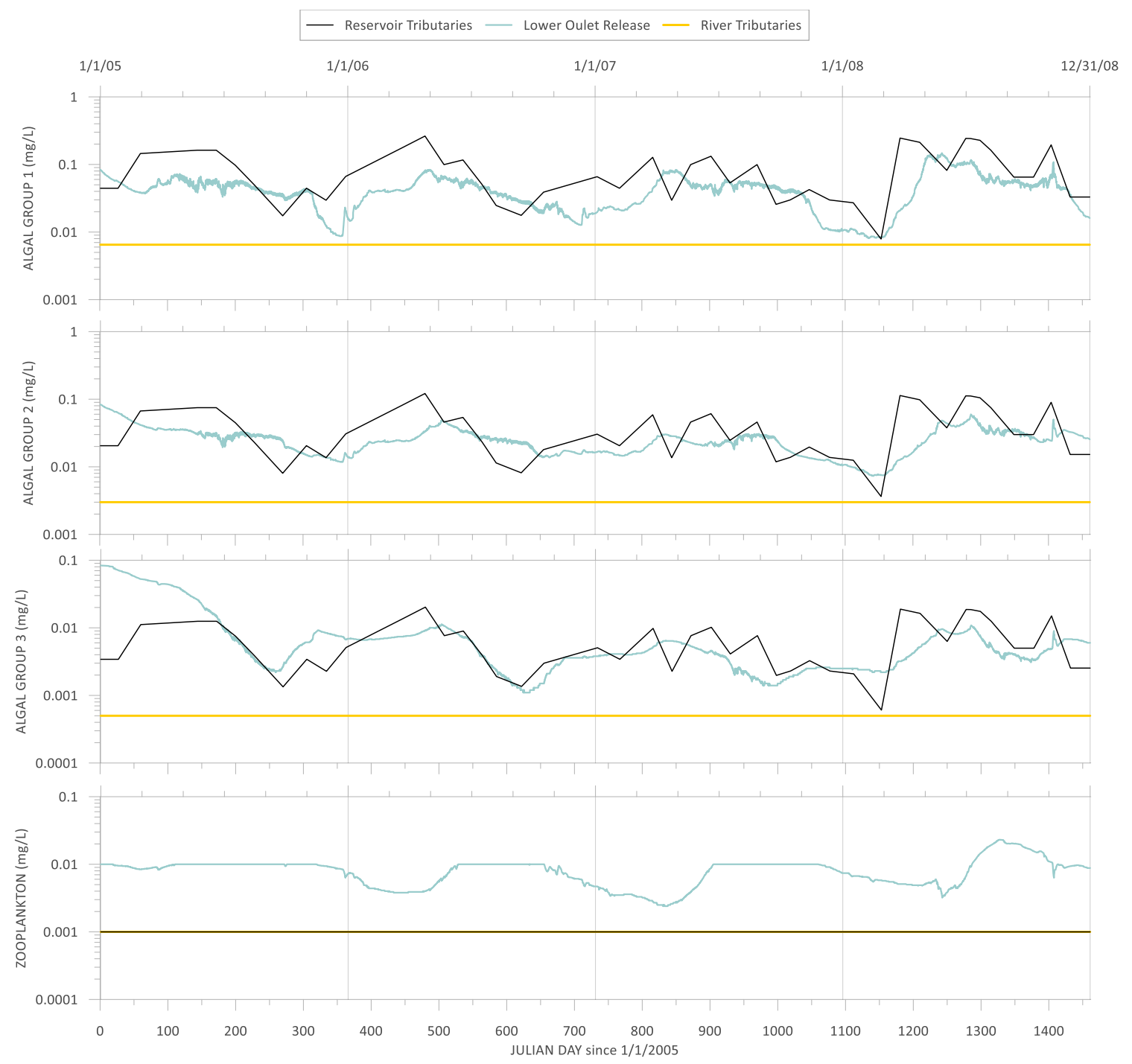

Figure 46. Constituent concentrations for algal group 1, algal group 2, algal group 3, and zooplankton, 2005-2008. 


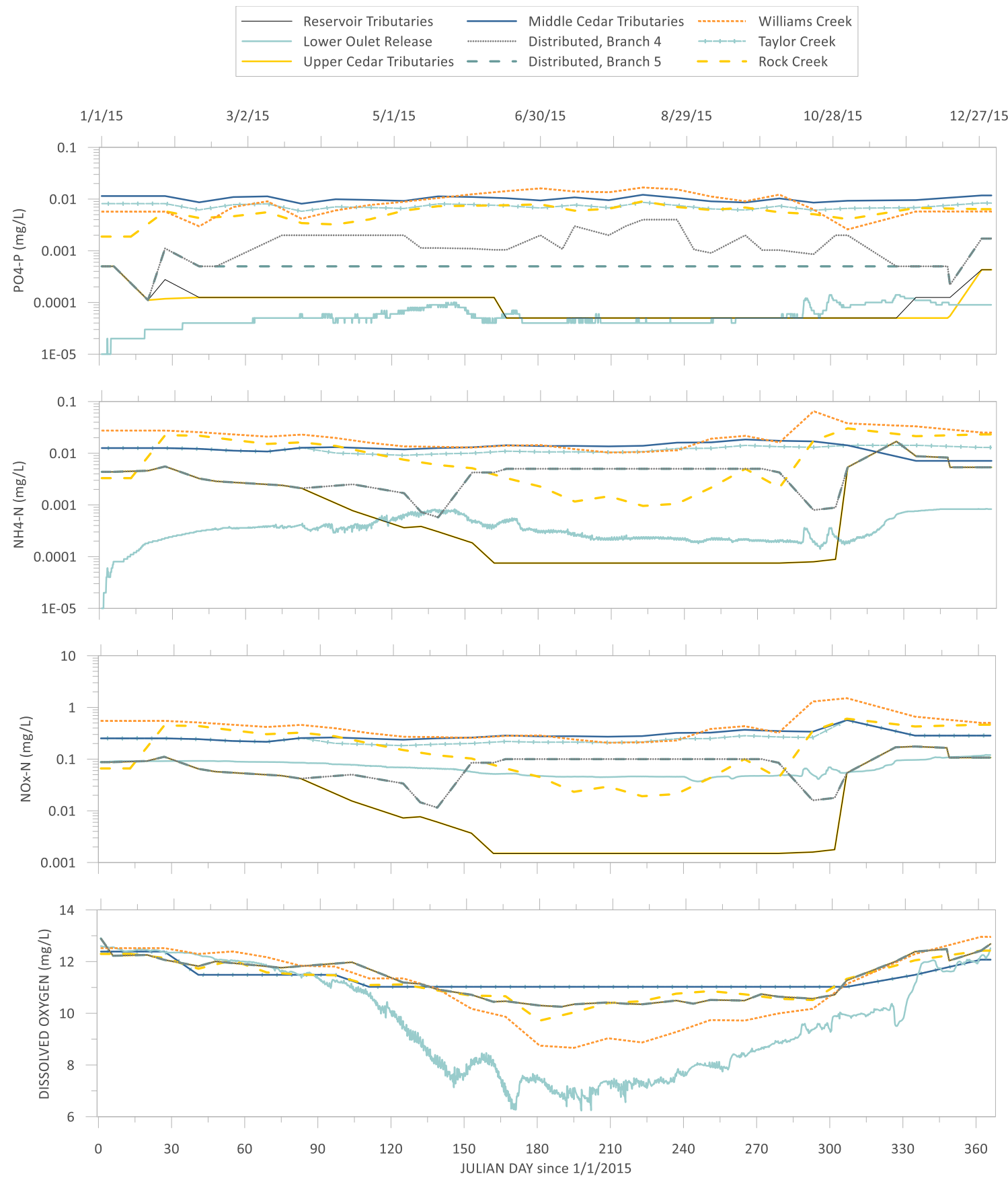

Figure 47. Constituent concentrations for phosphate, ammonia, nitrate-nitrite, and dissolved oxygen, 2015. 


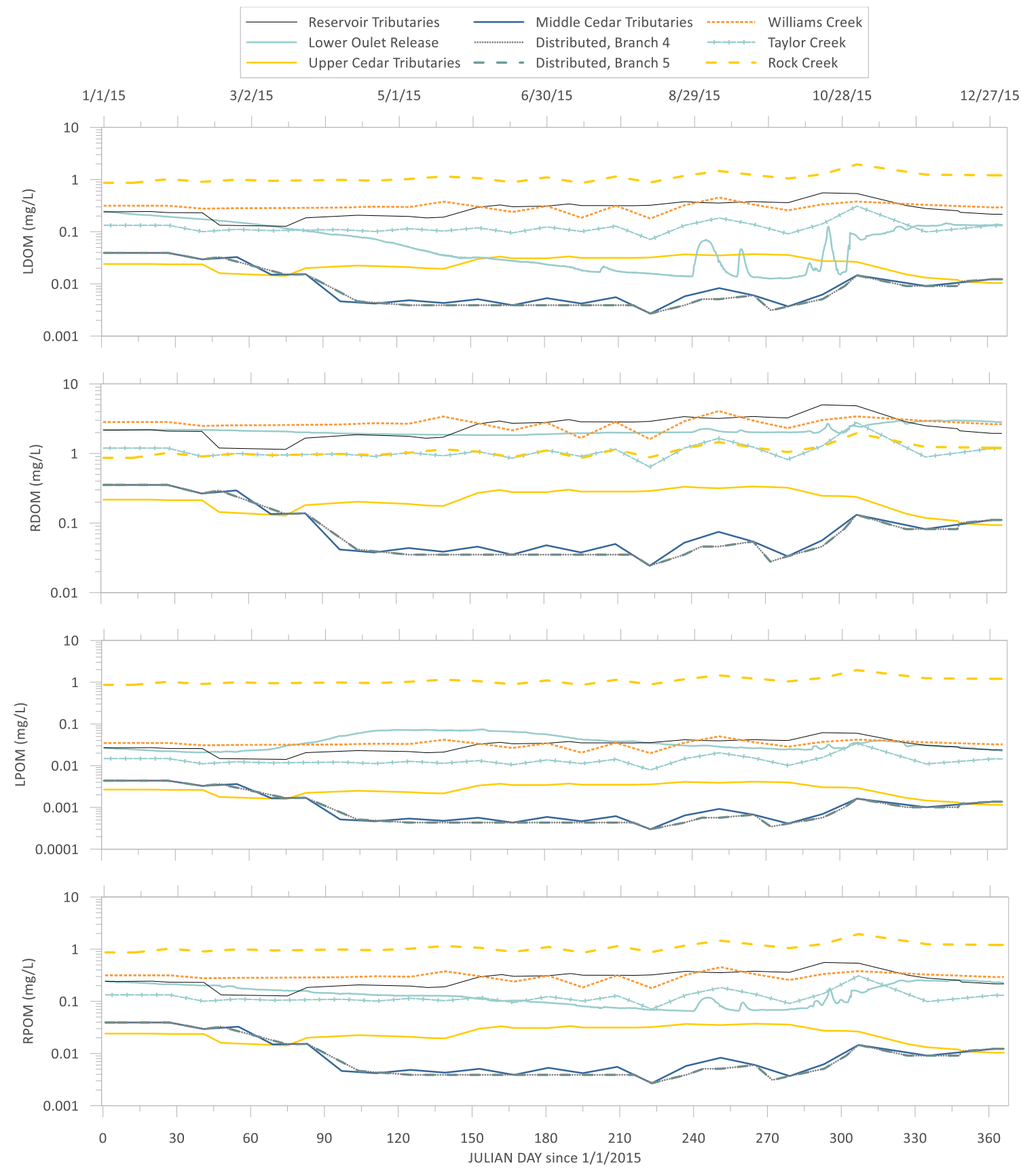

Figure 48. Constituent concentrations for LDOM, RDOM, LPOM, and RPOM, 2015. 

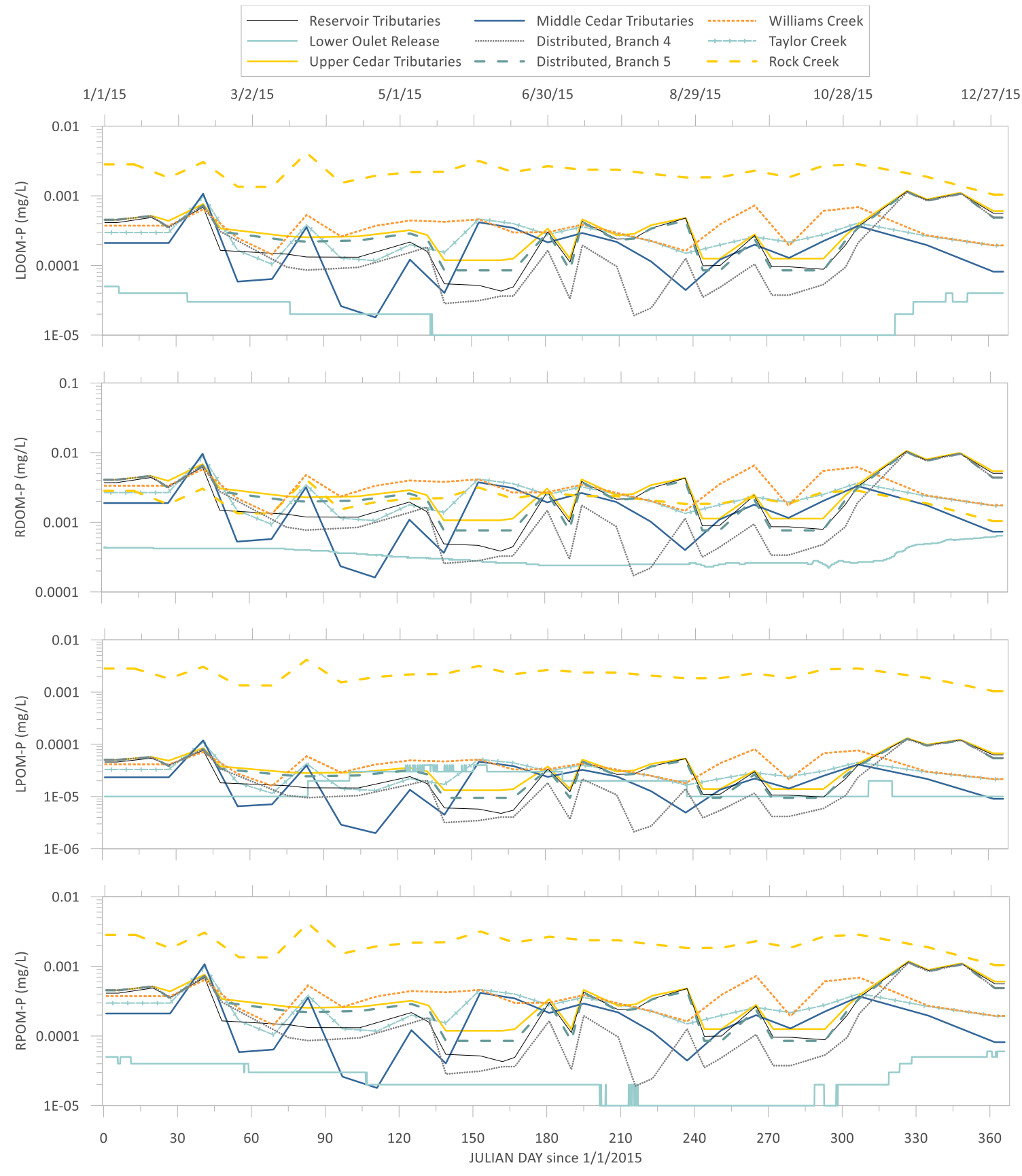

Figure 49. Constituent concentrations for LDOM-P, RDOM-P, LPOM-P, and RPOM-P, 2015. 

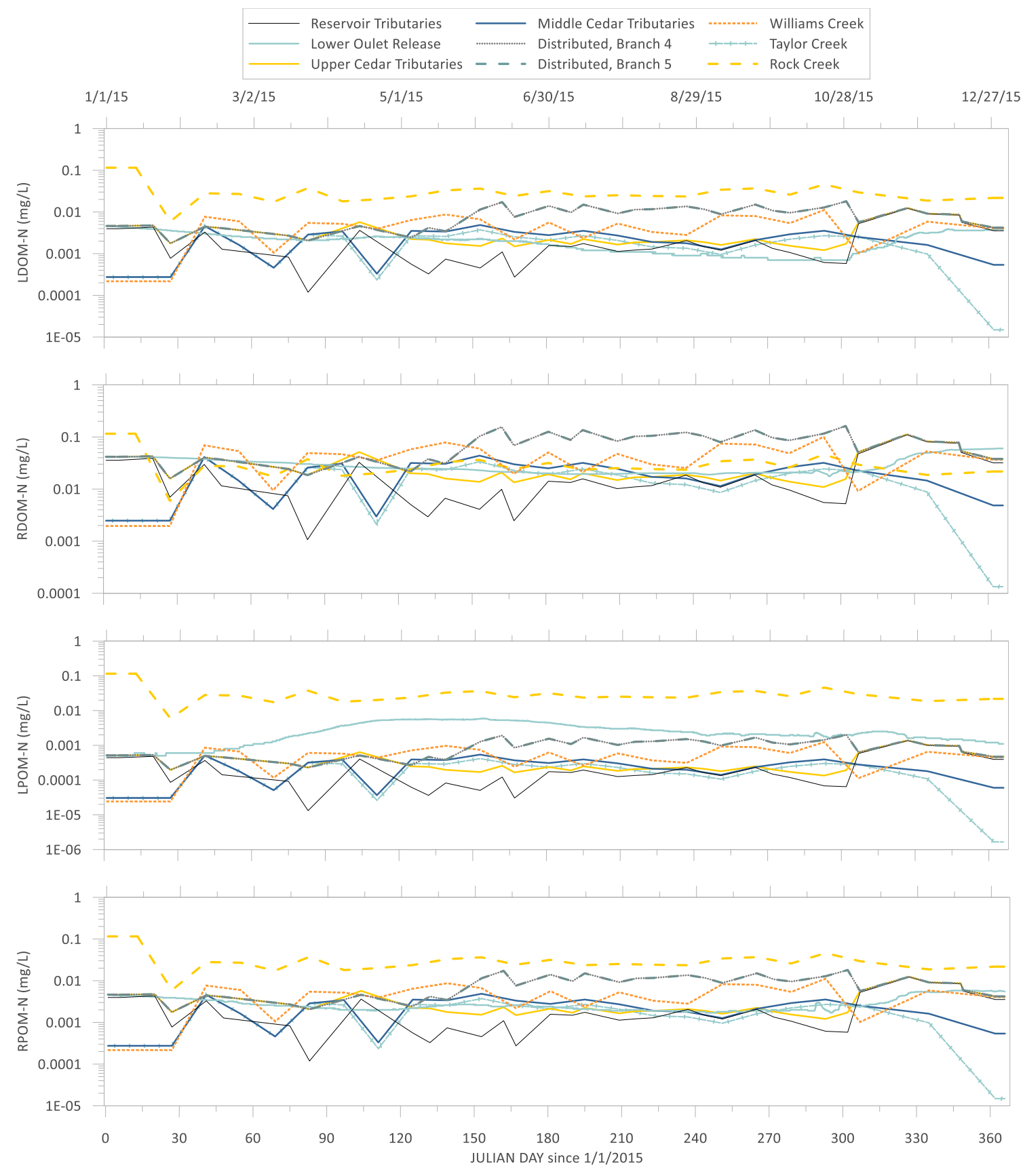

Figure 50. Constituent concentrations for LDOM-N, RDOM-N, LPOM-N, and RPOM-N, 2015. 


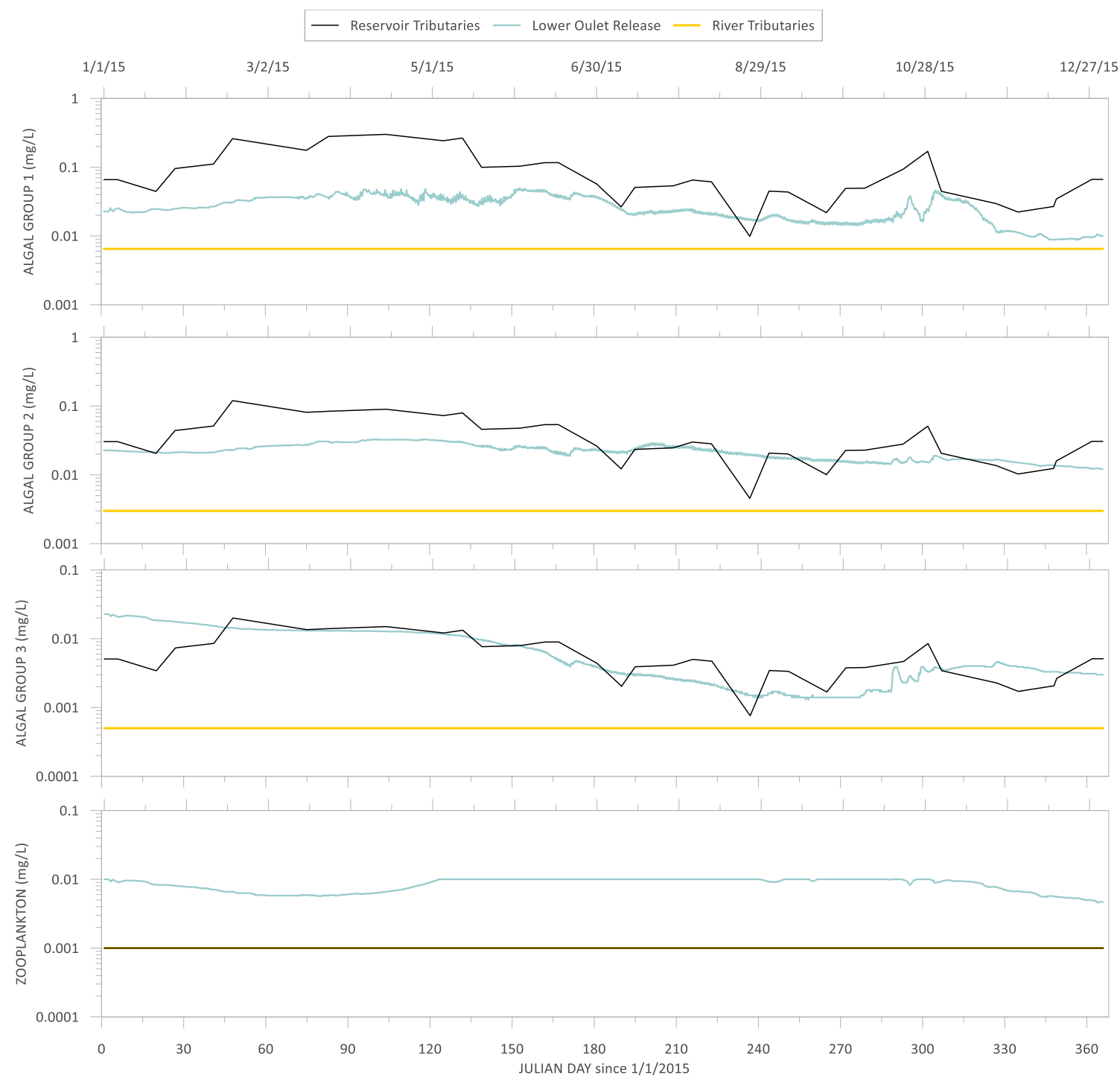

Figure 51. Constituent concentrations for algal group 1, algal group 2, algal group 3, and zooplankton, 2015. 


\subsubsection{Shading}

Topographic shading was calculated using DEMs for the reservoir and river models. The CE-QUAL-W2 shading algorithm calculates the position of the sun to determine which topographic inclination angle corresponds with the incoming solar radiation. When the angle of the incoming solar radiation is less than the angle of the surrounding topography, the short-wave solar radiation is reduced by 90 percent. Diffuse radiation is accounted for with the remaining 10 percent of incoming solar radiation. The shade file developed in the 2005-2008 study was used for this study.

\subsubsection{Outlet Structures and Pump Station}

Chester Morse Lake is impounded by the Masonry Dam and the Overflow Dike. The Masonry Dam, a 210-foot-high cyclopean concrete gravity dam, is the main outlet structure of the dam (Figure 52). The Overflow Dike, a roller compacted concrete (RCC) dam, splits the reservoir into two waterbodies at lower water elevations (Figure 53). It helps minimize water loss through the glacial moraine during low flow time periods. When water levels fall below 468.78 meters (1538 ft), the main reservoir is disconnected from the Masonry Pool. A portable floating pump station is used to ensure access to stored water and to meet in-stream flow requirements (Figure 54). 


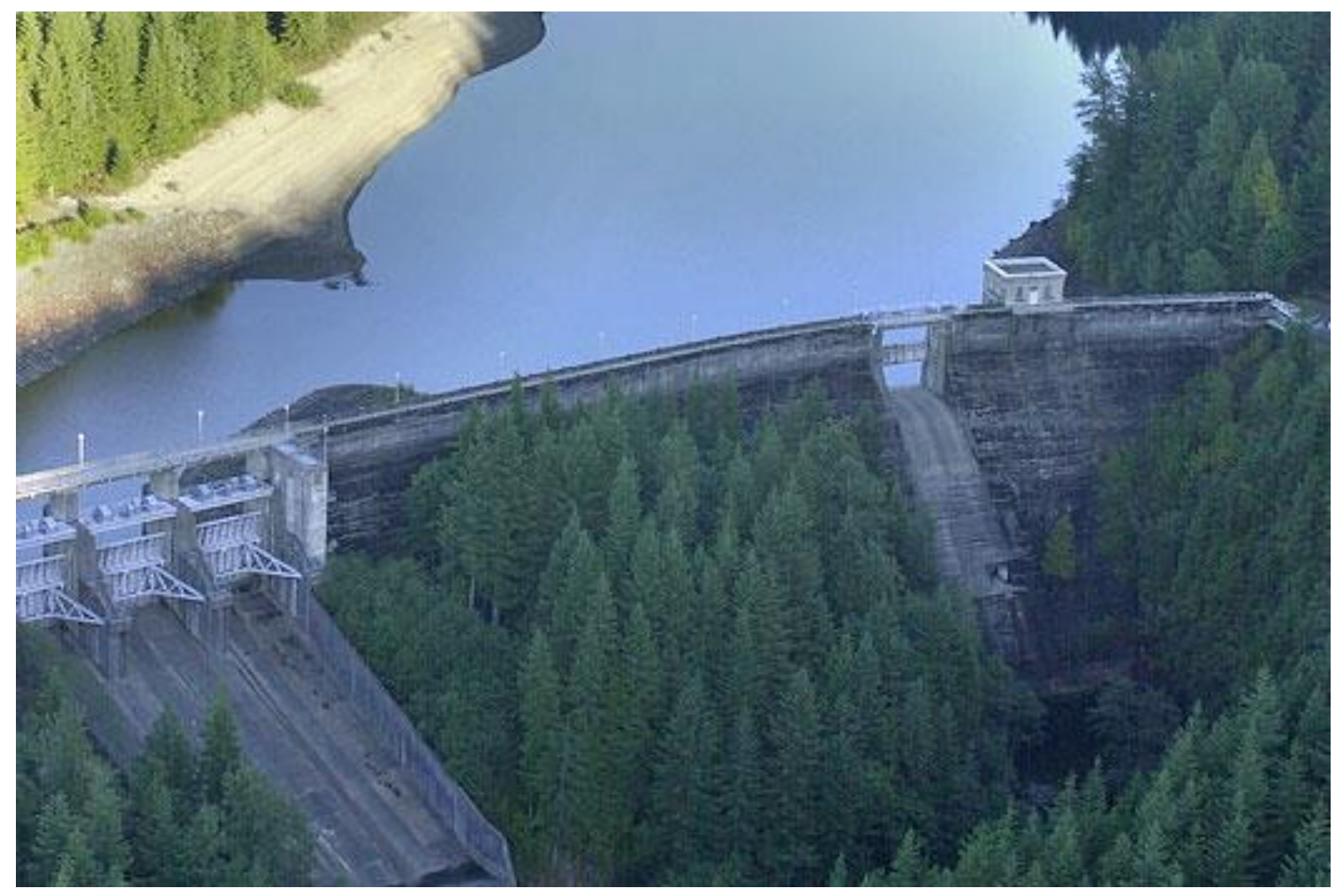

Figure 52. Aerial view of the Masonry Dam (Seattle Public Utilities, 2014).

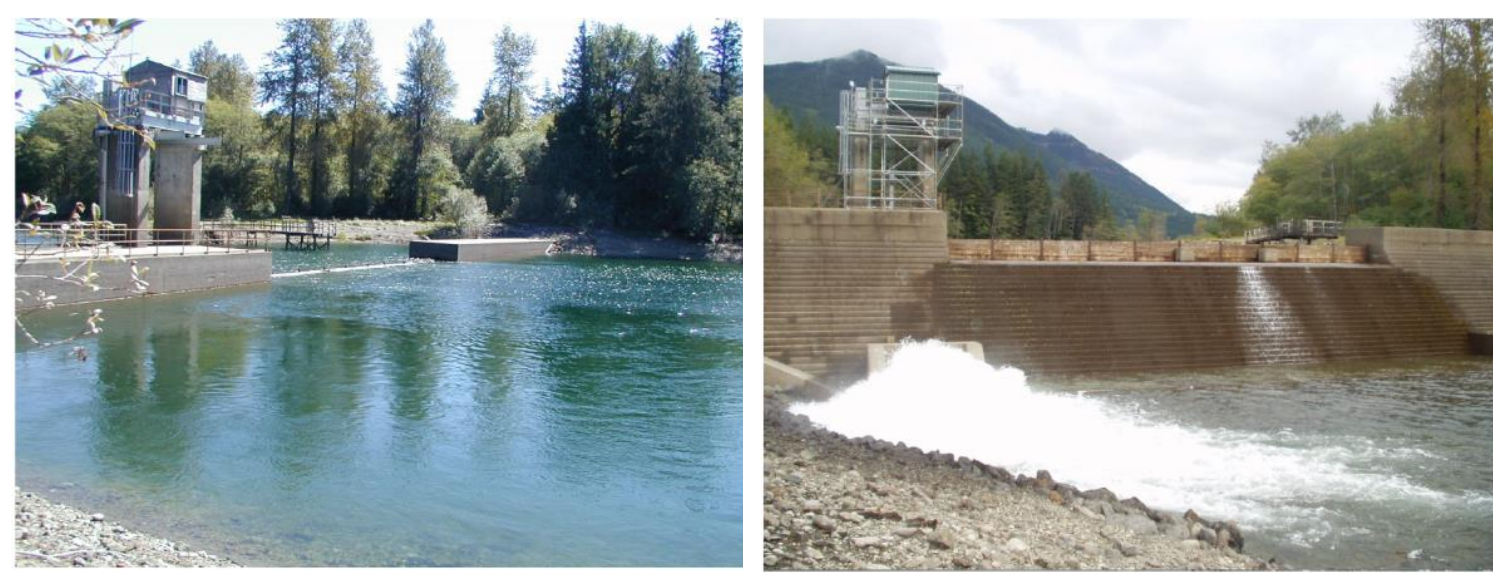

Figure 53. Overflow Dike at high water levels (left) and low water levels (right) (J. Edgerly, personal communication, July 12, 2019). 


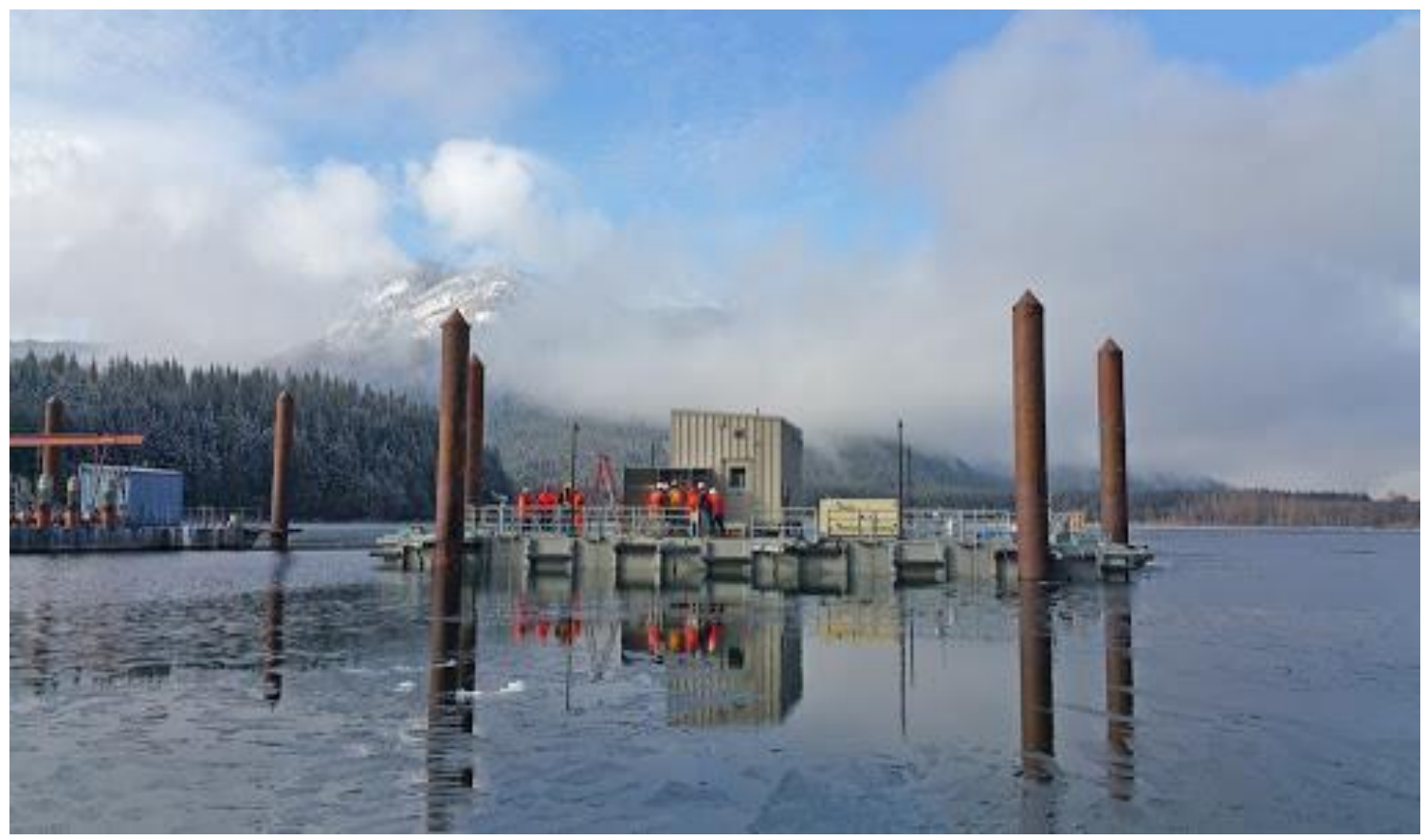

Figure 54. Chester Morse Lake Pumping Plant (Reid Middleton, n.d.)

\subsubsection{Overflow Dike}

The Overflow Dike is an RCC dam with flashboards, an underflow gate, and a bypass valve. It was modeled as a rectangular broad-crested weir with two underflow pipes (Figure 55). The weir was composed of two sections: the overflow dam (section A) and the notch with flashboards (section B). The underflow structure was modeled using the dynamic pipe algorithm. In the 2005-2008 model, two pipes were used to model the underflow gate and the bypass valve. In 2015, only the underflow gate was incorporated. SPU reported that the bypass valve was discontinued indefinitely for safety reasons as of August 22, 2007. The dynamic pipe algorithm allowed the pipes to be completely open, completely closed, or any fraction of open to model the flow being throttled by closing the gate valve. 


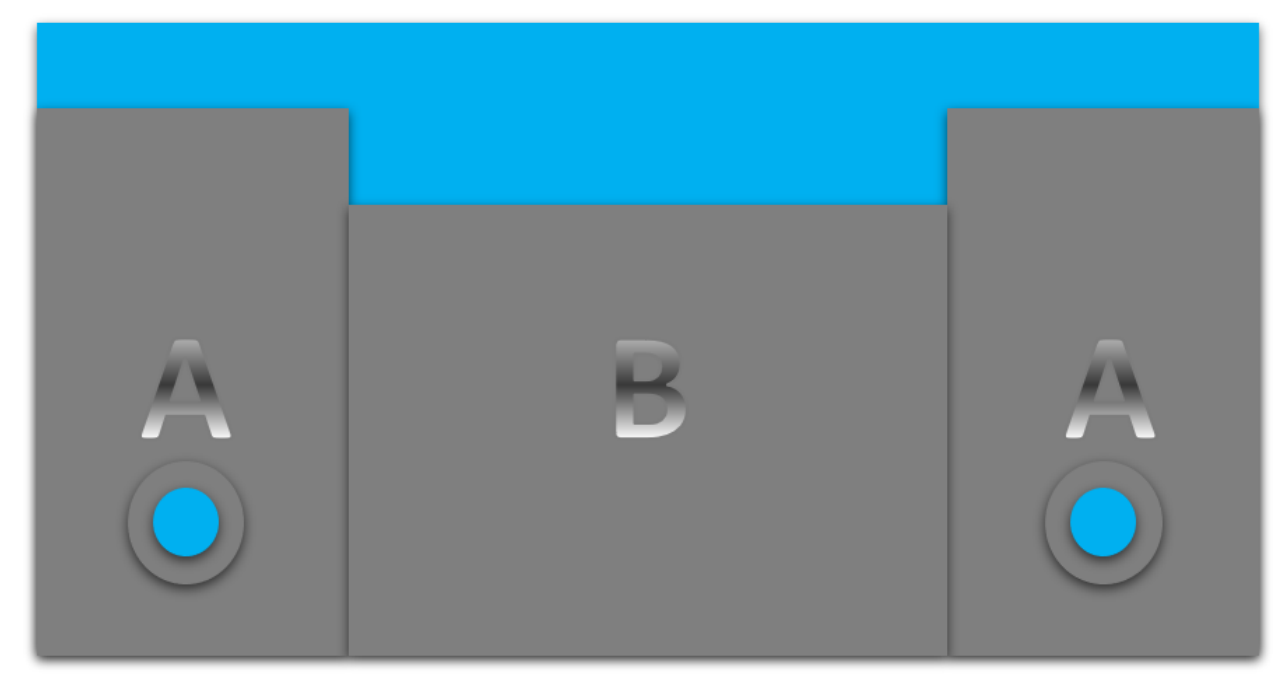

Figure 55. Schematic of Overflow Dike as modeled in CE-QUAL-W2. The weir was modeled using an overflow dam (section A) and a notch with flashboards (section B). The underflow structures were modeled as pipes.

Flow at the Overflow Dike was modeled using a rectangular broad-crested weir equation (Wells S. A., 2019). The equation takes the following form where $C_{D}$ is the discharge coefficient, $C_{v}$ is the velocity coefficient, $g$ is the gravitational acceleration, $W$ is the width at the surface, and $H$ is the upstream head above the spillway crest (Equation 3 ).

$$
Q=C_{D} C_{v} \frac{2}{3} \sqrt{\frac{2}{3}} g W H^{3 / 2}
$$

Equation 3 was solved for free flow conditions and for submerged conditions. During free flow conditions, the relationship shown in Equation 4 was used. During submerged conditions, the relationship shown in Equation 5 was used. 


$$
\begin{aligned}
& Q=\alpha_{1} H^{\beta_{1}}=C_{D} C_{v} \frac{2}{3} \sqrt{\frac{2}{3}} g W H^{3 / 2} \\
& Q=\alpha_{2} H^{\beta_{2}}=C_{D} C_{v} \frac{2}{3} \sqrt{\frac{2}{3}} g W H^{3 / 2}
\end{aligned}
$$

In order to have smooth transition between flow over a submerged weir and free flow, the flows must be equivalent at the transition point. The following relationship was used to determine the empirical coefficient $\alpha_{2}$ for submerged flow:

$$
\alpha_{2}=\frac{\alpha_{1} H^{\beta_{1}-\beta_{2}}}{(0.33)^{\beta_{2}}}
$$

Empirical coefficients for the rectangular broad-crested weir equation were estimated based on the physical characteristics of the Overflow Dike. Model parameters are summarized in Table 7.

Table 7. Summary of Overflow Dike weir characteristics.

\begin{tabular}{lcc}
\hline Parameter & Overflow Dam (A) & Notch with Flashboards (B) \\
\hline Elevation $(\mathrm{m})$ & 473.65 & 472.58 \\
Weir width $(\mathrm{m})$ & 90 & 30 \\
$\boldsymbol{\alpha}_{1}$ and $\boldsymbol{\alpha}_{2}$ & $153.4 ; 809.2$ & $51.1 ; 269.7$ \\
$\boldsymbol{\beta}$ & 1.5 & 1.5 \\
$\boldsymbol{C}_{\mathrm{d}}$ and $\mathrm{C}_{\mathrm{v}}$ & 1 & 1 \\
\hline
\end{tabular}

The underflow structures of the Overflow Dike were modeled using the dynamic pipe algorithm. The algorithm solves the one-dimensional Saint-Venant equations and includes the model segments that the pipe flows between, the invert and outlet 
elevations, pipe diameter, pipe length, and pipe roughness using Manning's friction factors. The model parameters for the underflow structures are summarized in Table 8.

Table 8. Summary of the underflow structure characteristics at the Overflow Dike.

\begin{tabular}{lcc}
\hline Parameter & Underflow Gate & Bypass Valve \\
\hline Pipe diameter $(\mathrm{m})$ & 1.98 & 1.75 \\
Pipe length $(\mathrm{m})$ & 8.23 & 64 \\
Invert elevation $(\mathrm{m})$ & 465.12 & 465.12 \\
Outlet elevation $(\mathrm{m})$ & 464.82 & 464.82 \\
Characteristics & $\begin{array}{l}\text { Concrete encased steel outlet pipe } \\
(f 0.015)\end{array}$ & $\begin{array}{l}\text { Wood stave and concrete encased } \\
\text { steel pipe }(f 0.015)\end{array}$ \\
\hline
\end{tabular}

\subsubsection{Chester Morse Lake Pumping Plant}

When water levels in the main reservoir fall below 468.78 meters ( $1538 \mathrm{ft}$ ) and gravity flow is no longer possible, a portable floating pump station is used to access stored water and ensure that in-stream flow agreements are met. The Morse Lake Pumping Plant (MLPP) has a 240 MGD capacity through four 1.22-meter (48 in) diameter HDPE pipelines. A discharge dike upstream of the Overflow Dike creates a head wall for the pumping plant discharge pipes. The discharge dike was characterized by the bathymetry and incorporated in the reservoir model grid. The pumping plant was modeled as a dynamic pump. The dynamic pump algorithm turns a pump on or off based on water surface elevation. The input parameters include the date, elevation to start pumping, elevation to stop pumping, and the pump rate. The withdrawal elevation for the pump was estimated at 3.05 meters ( $10 \mathrm{ft}$ ) below the water surface elevation based on dimensions from the pump platform schematic (Figure 56). In 2005 to 2008, the pump 
station was not used. In 2015, the pump station was used to test the pump replacement project.

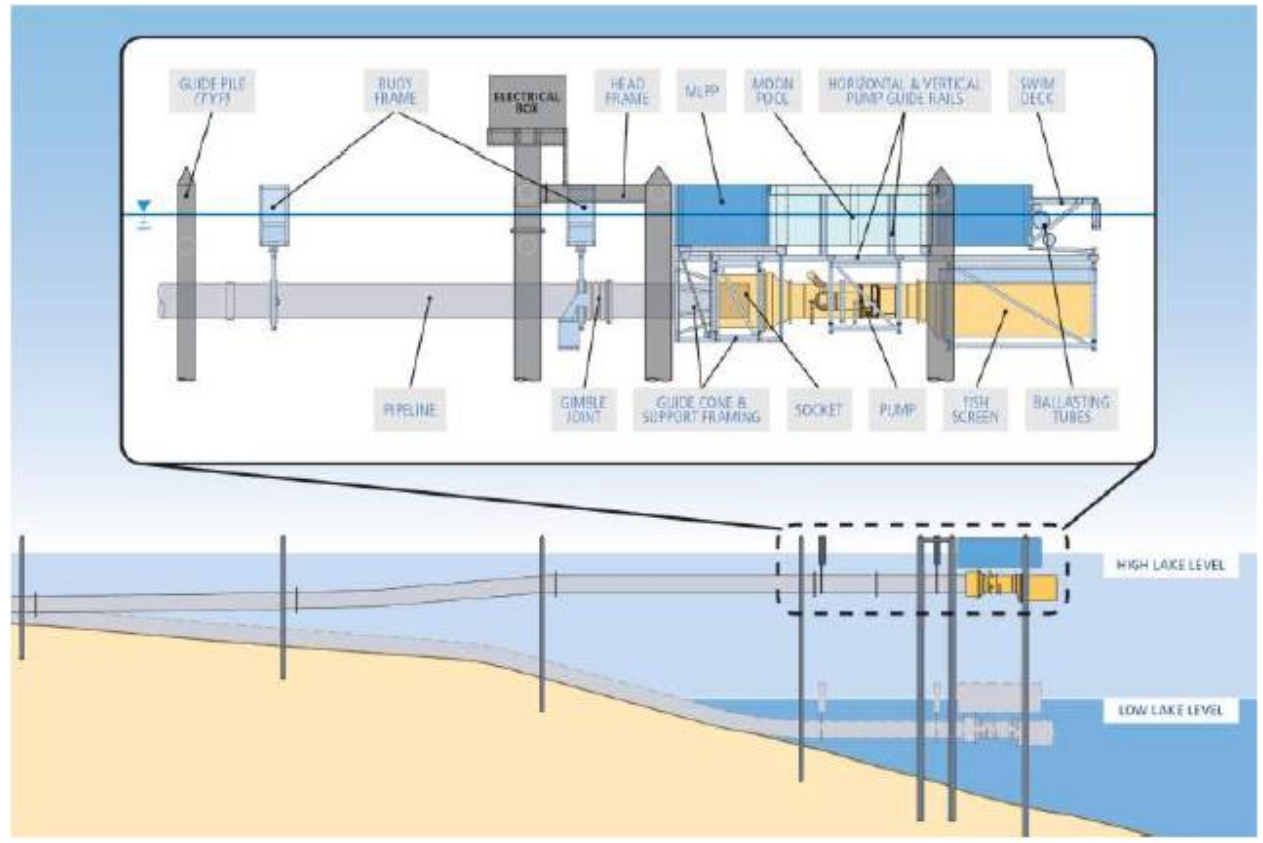

Figure 56. Schematic of the Chester Morse Lake floating portable pump station (Vail, Ochiltree, \& Bishop, 2016).

\subsubsection{Masonry Dam}

The Masonry Dam is the main outflow from Chester Morse Lake (Figure 57). The structure includes four outlets: the lower level outlet, the powerhouse outlet, the spillway, and the emergency spillway. The lower level outlet releases flow into the Cedar River and are the main source of water in the upper stretch of the river prior to the powerhouse. The lower level outlet has a maximum flow rate of $18.4 \mathrm{~m}^{3} / \mathrm{s}$ (650 cfs). The in-stream flow agreement requires a minimum release of $0.85 \mathrm{~m}^{3} / \mathrm{s}$ (30 cfs). The penstock for the powerhouse and water supply has a maximum flow rate of $21.2 \mathrm{~m}^{3} / \mathrm{s}$ 
(750 cfs). Flow from the powerhouse is diverted at the Masonry Dam and is released to the Cedar River $3.86 \mathrm{~km}$ (2.4 miles) downstream of the dam. A service spillway with a $124.6 \mathrm{~m}^{3} / \mathrm{s}$ (4400 cfs) capacity is utilized when the reservoir water level exceeds 474.6 meters (1557 ft). The spillway is typically closed from April to September. An emergency spillway with a $2123.8 \mathrm{~m}^{3} / \mathrm{s}$ (75000 cfs) capacity is used during high flow events. The current maximum operation level is 476.4 meters (1563 ft). The dam has not been filled to the originally intended refill level since the catastrophic landslide at Boxley Creek in 1918 caused by the significant seepage through the glacial moraine.

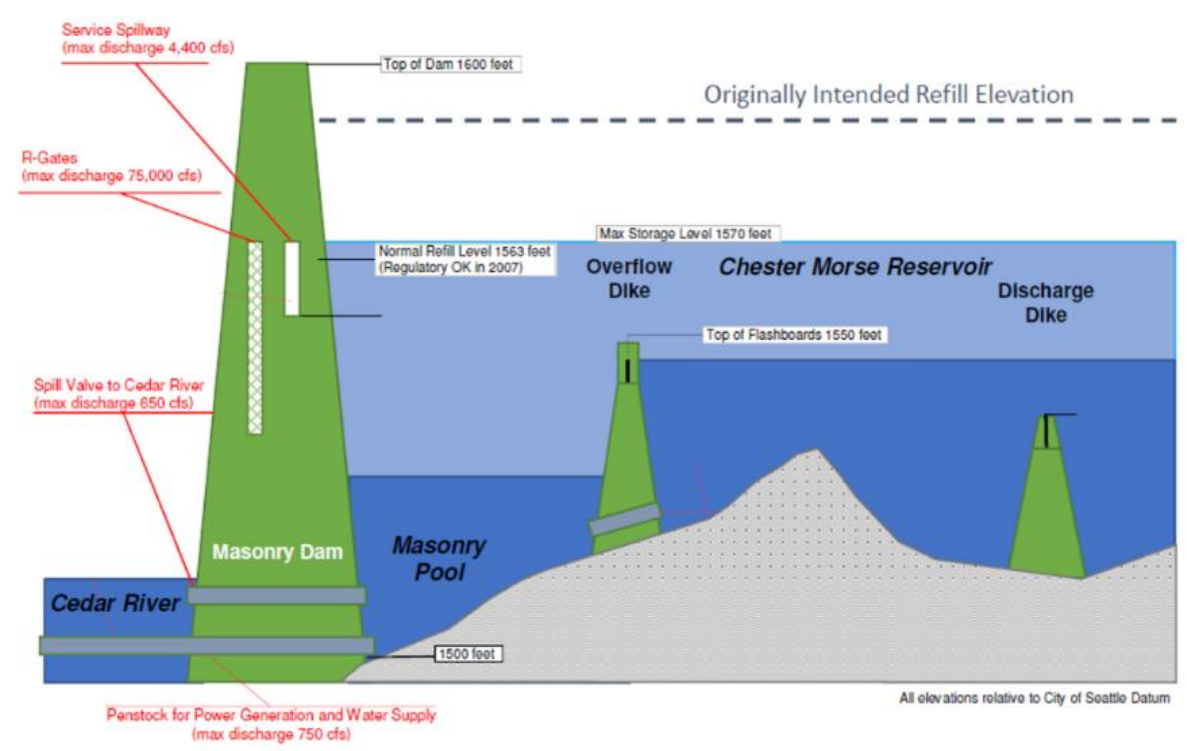

Figure 57. Schematic of the Overflow Dike and Masonry Dam. The schematic is not to scale (J. Edgerly, personal communication, July 7, 2019). 


\section{Chapter 4. Model Calibration}

The model calibration periods were January 1, 2005 through December 31, 2008 and January 1 through December 31, 2015. The first time period was chosen based on previous model work (Wells V. I., 2012). The second time period was chosen because it was a critical low-flow high-temperature year, and is considered representative of the "new normal" as climate changes. Calibration of the model included the following approach performed in the listed order.

- Development of model boundary conditions including meteorological inputs, boundary condition flows and temperature inputs, and dam outflows

- Hydrodynamic calibration to ensure correct water levels and flow rates were simulated

- Temperature calibration

- Water quality calibration including chlorophyll $a$, dissolved oxygen, total nitrogen, nitrate-nitrite, ammonia, total phosphorus, phosphate, and total organic carbon

Graphical comparisons of model simulations compared to measured field data were developed for water surface elevation, flow, temperature, and water quality constituents. Error statistics were calculated for all model parameters, and included mean error (ME), mean absolute error (MAE), and root mean square error (RMSE). The ME indicates average model bias direction with the sign of the error indicating 
over-prediction when positive or under-prediction when negative. MAE indicates the accuracy of continuous variables. RMSE places higher weight on large errors, and is useful when large errors are undesirable. If RMSE is greater than MAE, then there is more variance in individual errors. When RMSE is equal to MAE, then all errors are of similar magnitude. The ME is defined as:

$$
M E=\frac{\sum_{1}^{n}(\text { model }- \text { data })}{n}
$$

Equation 7

where $n$ is the number of observations, model is the model prediction, and data is the observed value. The MAE and RMSE are defined as:

$$
\begin{aligned}
& M A E=\frac{\sum_{1}^{n} \mid \operatorname{model}-\text { data } \mid}{n} \\
& \text { Equation } 8 \\
& R M S E=\sqrt{\frac{\sum_{1}^{n}(\text { model }- \text { data })^{2}}{n}}
\end{aligned}
$$

The goal for model calibration is to minimize all errors. ME should be as close to 0 as possible for all parameters. RMSE and MAE should be less than a measurable change for each parameter. For example, WSDE considers a measurable change in temperature to be $0.3^{\circ} \mathrm{C}$ and a measurable change in dissolved oxygen to be $0.2 \mathrm{mg} / \mathrm{L}$ (WSDE, 2019).

\subsection{Chester Morse Lake Water Balance}

Hydrodynamic calibration was completed to match observed water surface elevations in Chester Morse Lake and the Masonry Pool over the full model period. The reservoir inflow and outflow inputs carried a degree of uncertainty due to the assumptions made 
during their development. The water balance adjusted modeled water surface elevations using distributed flows to match observed water surface elevations at USGS 12115900 and USGS 12116060 . The gaging stations are located the upstream side of the Overflow Dike and at the Masonry Dam, respectively. Two distributed flows were used in the reservoir model in branch 1 and branch 4 . The main reservoir distributed flow for branch 1 accounted for ungaged inputs using the drainage area-ratio method as described in Chapter 3 with minor adjustments made to match observed water surface elevations in the main reservoir. The Masonry Pool water balance flow in branch 4 accounted for seepage loss through the moraine and other ungaged flows. The distributed flow calibration results are displayed in Figure 58 and Figure 59.

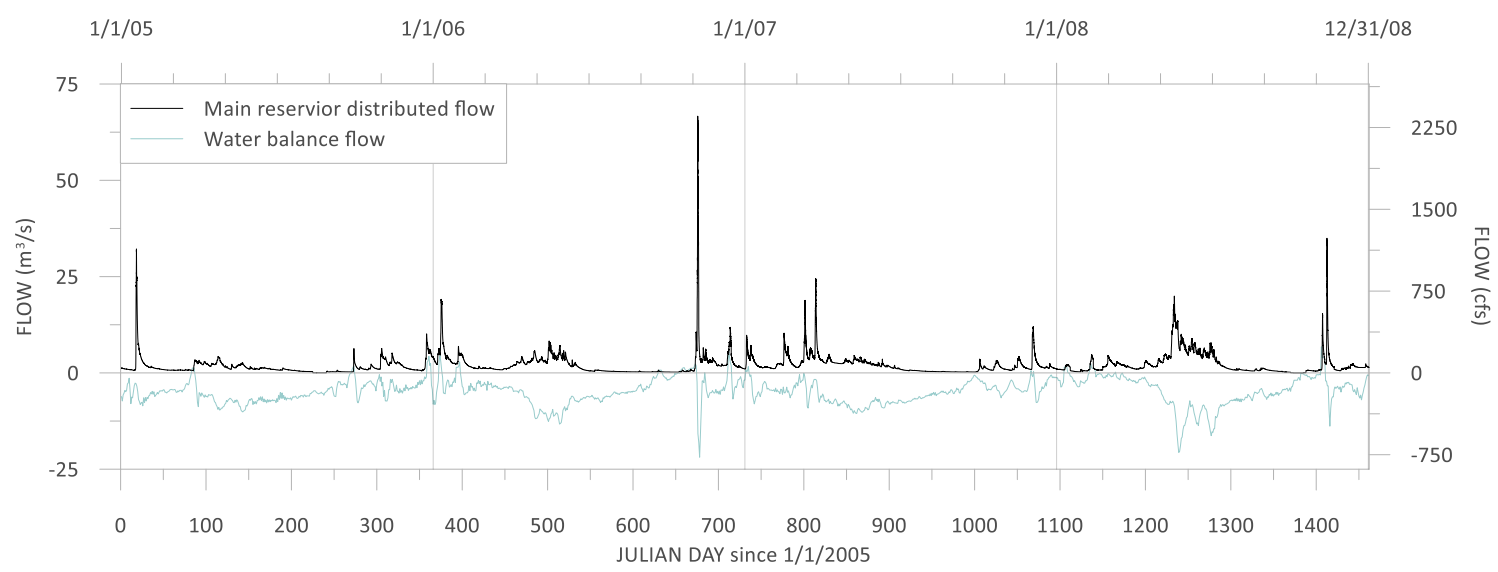

Figure 58. Main reservoir distributed flow (branch 1) and Masonry Pool water balance flow (branch 4) for 2005-2008. 


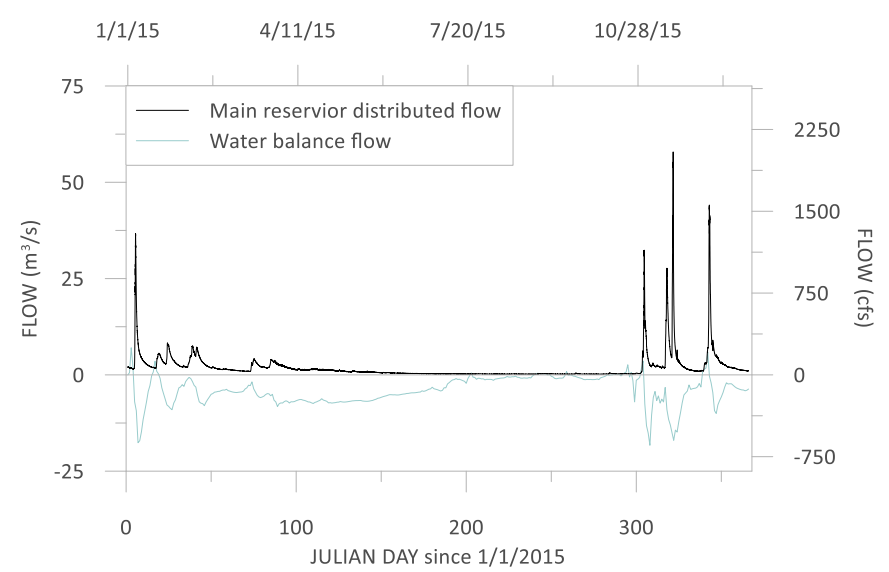

Figure 59. Main reservoir distributed flow (branch 1) and Masonry Pool water balance flow (branch 4) for 2015.

SPU uses the water surface elevation in the Masonry Pool to estimate average daily seepage loss through the glacial moraine where Masonry Pool water surface elevation is in feet (Equation 10).

$$
\text { Seepage }(c f s)=\left(\left(E L W S_{M P}-1500\right)^{2.3035} \times 0.023039\right)+35.47 \quad \text { Equation } 10
$$

The Masonry Pool water balance flow was compared to the water management equation used by SPU. The results are displayed in Figure 60 for 2005-2008 and in Figure 61 for 2015. The water management equation has a mean and standard deviation of $-4.95 \pm 2.12 \mathrm{~m}^{3} / \mathrm{s}$ compared to the water balance flow at $-4.86 \pm 3.74 \mathrm{~m}^{3} / \mathrm{s}$ for 2005-2008. The correlation coefficient between the water management equation and the water balance flow over the entire model period was 0.59 for $2005-2008$. When the influence from precipitation events was reduced by only considering the periods from March through October in the analysis, the correlation coefficient increased to 0.72 . The water management equation has a mean and standard deviation of $-4.31 \pm 3.34 \mathrm{~m}^{3} / \mathrm{s}$ 
compared to the water balance flow at $-3.94 \pm 3.63 \mathrm{~m}^{3} / \mathrm{s}$ for 2015 . The correlation coefficient between the water management equation and the water balance flow over the entire model period was 0.43 for 2015 . When the influence from precipitation events was reduced by only considering the period from March through October in the analysis, the correlation coefficient increased to 0.92 for 2015 . The water balance flow included seepage and other ungaged flows. This accounts for the underestimation trend relative to the SPU water management equation.
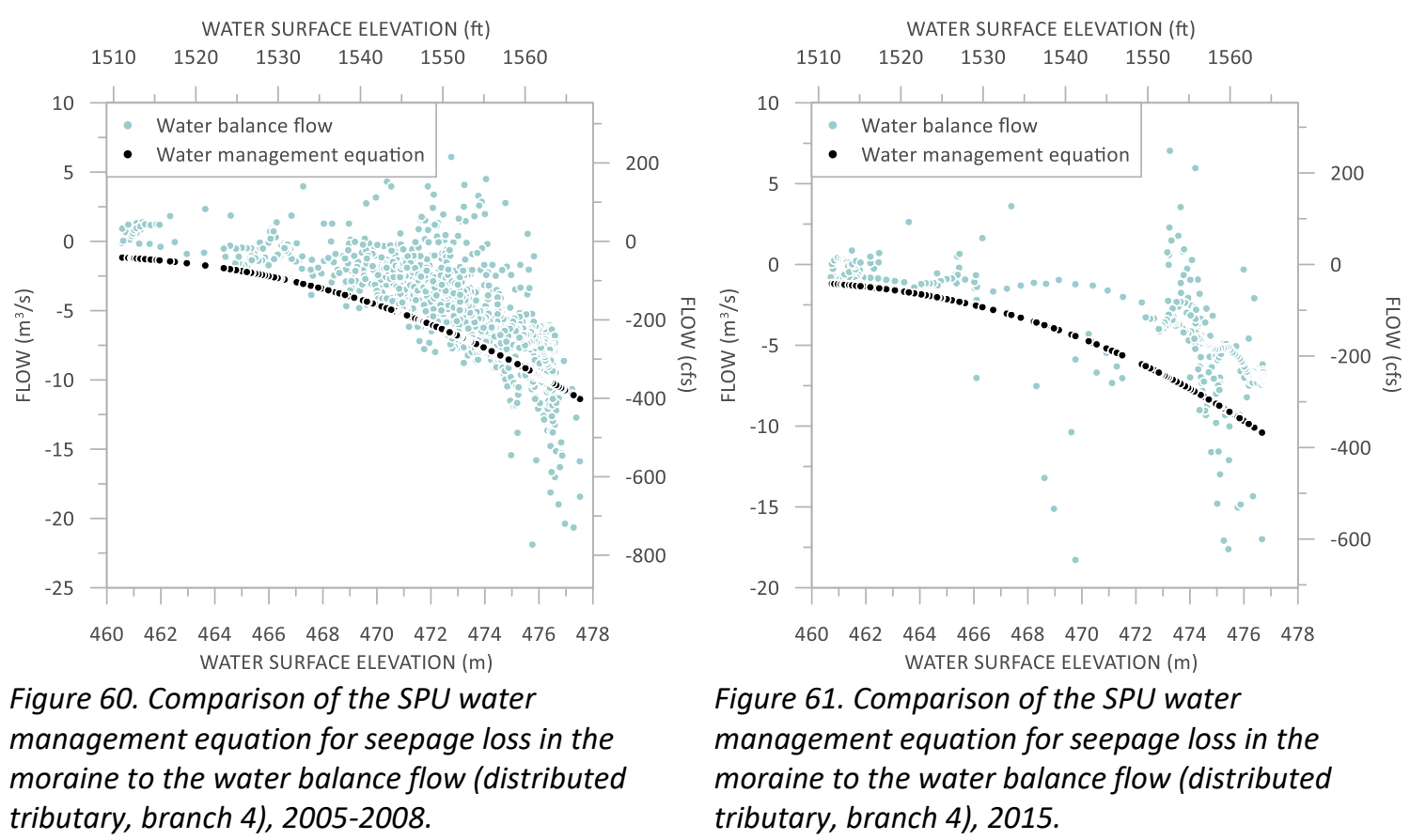

Figure 61. Comparison of the SPU water management equation for seepage loss in the moraine to the water balance flow (distributed tributary, branch 4), 2015.

The water level in the main reservoir is highly influenced by the water level in the Masonry Pool. The degree of openness of the pipe at the Overflow Dike was adjusted throughout the model run to match observed water levels in combination with changes to the distributed flow in branch 4 used to simulate seepage loss. Adjustments to the 
pipe were based off of the Overflow Dike outlet setting data provided by SPU. The modeled water surface elevations in the main reservoir and the Masonry Pool are compared to observations at USGS 12115900 and USGS 12116060 in Figure 62. Error statistics are summarized in Table 9 for 2005-2008 and Table 10 for 2015.

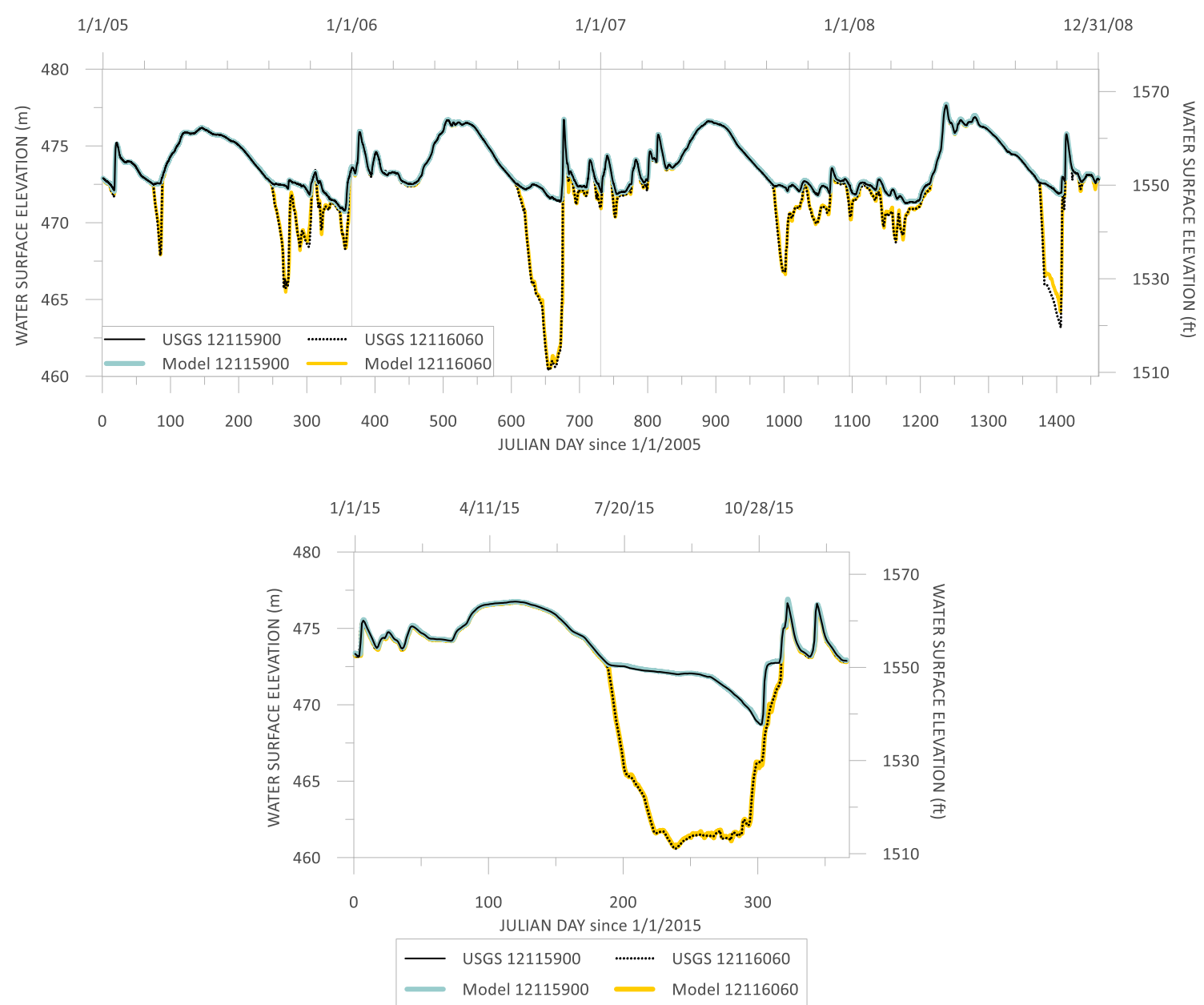

Figure 62. Comparison of modeled and observed water surface elevations in the main reservoir (USGS 12115900) and the Masonry Pool (USGS 12116060) in 2005-2008 (top) and 2015 (bottom). 
Table 9. Water surface elevation error statistics for the main reservoir (USGS 12115900) and the Masonry Pool (USGS 12116060), 2005-2008.

\begin{tabular}{lcccc}
\hline Sampling Location & ME $(\mathrm{m})$ & MAE $(\mathrm{m})$ & RMSE $(\mathrm{m})$ & Count \\
\hline 12115900, 2005-2008 & 0.02 & 0.04 & 0.05 & 34738 \\
12116060, 2005-2008 & 0.06 & 0.09 & 0.20 & 1447 \\
Weighted Average & 0.02 & 0.04 & 0.06 & 36185 \\
\hline
\end{tabular}

Table 10. Water surface elevation error statistics for the main reservoir (USGS 12115900) and the Masonry Pool (USGS 12116060), 2015.

\begin{tabular}{lcccc}
\hline Sampling Location & ME $(\mathrm{m})$ & MAE $(\mathrm{m})$ & RMSE $(\mathrm{m})$ & Count \\
\hline $\mathbf{1 2 1 1 5 9 0 0 , 2 0 1 5}$ & 0.03 & 0.05 & 0.06 & 9465 \\
12116060, 2015 & 0.01 & 0.08 & 0.13 & 365 \\
Weighted Average & 0.03 & 0.05 & 0.06 & 9830 \\
\hline
\end{tabular}

\subsection{Cedar River Flow Balance}

Modeled flows in the Cedar River were balanced using a mass balance approach. Three flow balances were completed along the length of the river. The first flow balance adjusted flows from Lost Creek and Fish Creek to match observed flow rates at USGS 12116400 (RM 33.7, segment 16). The second flow balance adjusted flows from the Rattlesnake Prairie to match observed flow rates at USGS 12116500 (RM 33.2, segment 22). The third flow balance adjusted flows in the distributed tributaries to match observed flows at USGS 12117500 (RM 23.4, segment 84). Comparisons of modeled flow and observed flow for each flow balance are show in Figure 63 for 2005-2008 and in Figure 64 for 2015. The calibrated flow inputs for Rattlesnake Prairie and the distributed flows for branch 4 and 5 are shown in Figure 65. Daily average flow error 
statistics at the three USGS gaging stations within the Cedar River model domain are summarized in Table 11 for 2005-2008 and Table 12 for 2015.

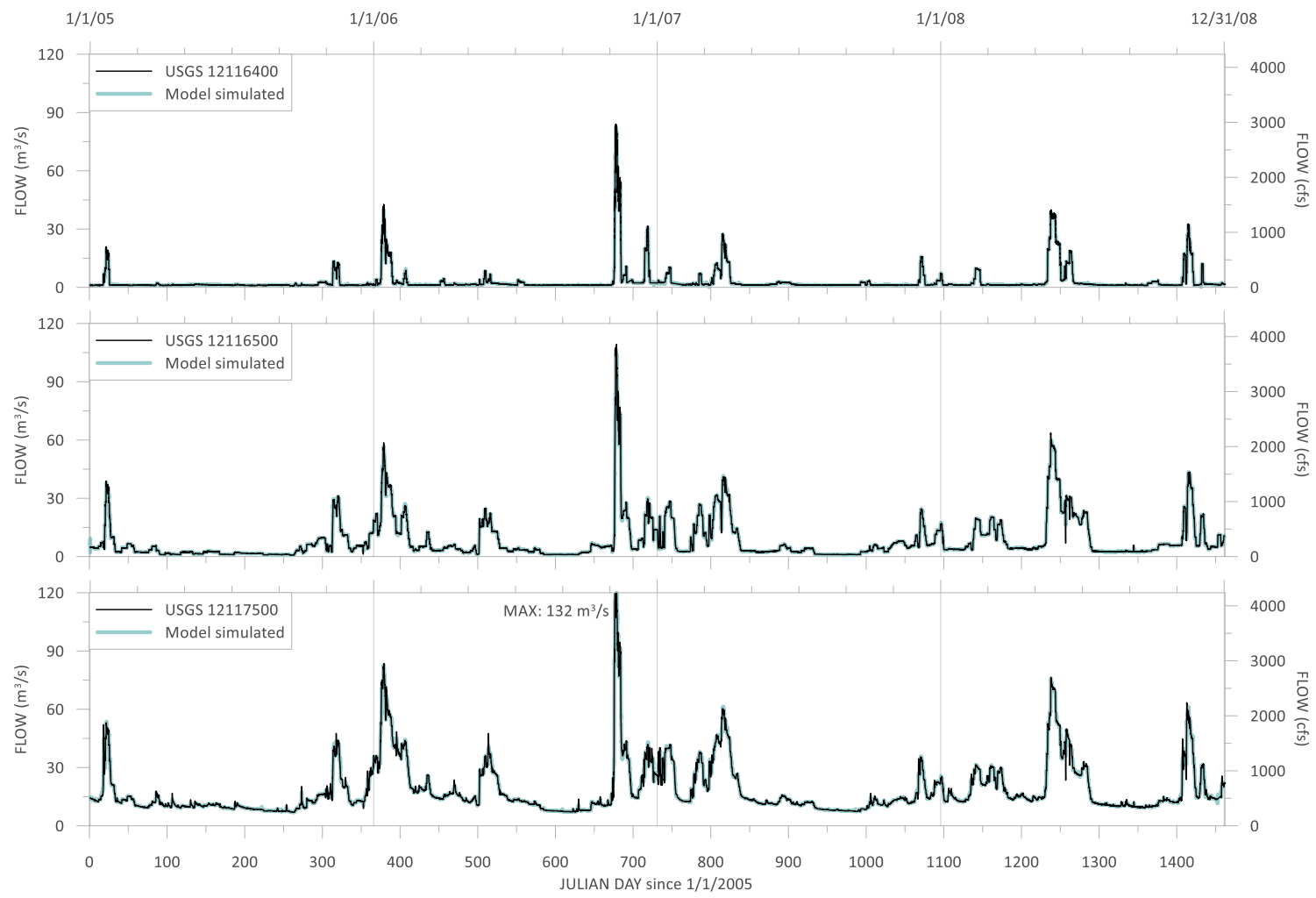

Figure 63. Modeled flow predictions compared to observed flow for 2005-2008 at USGS 12116400 (top), USGS 12116500 (middle), and USGS 12117500 (bottom). 


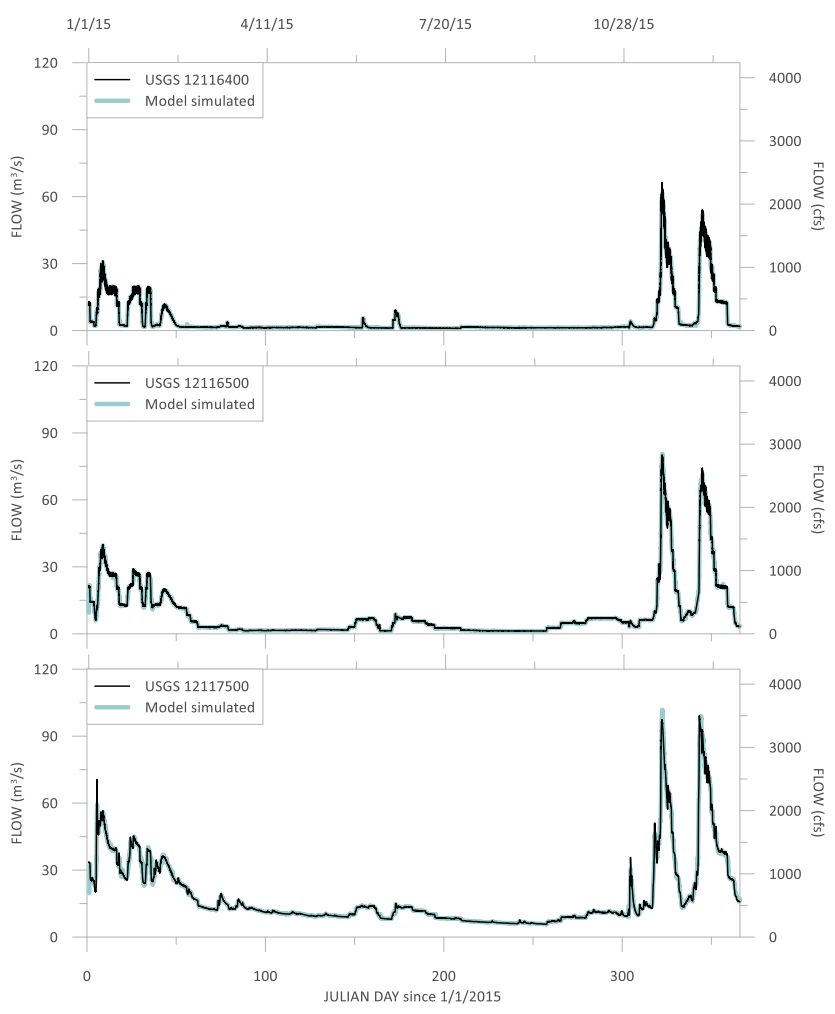

Figure 64. Modeled flow predictions compared to observed flow for 2015 at USGS 12116400 (top), USGS 12116500 (middle), and USGS 12117500 (bottom). 


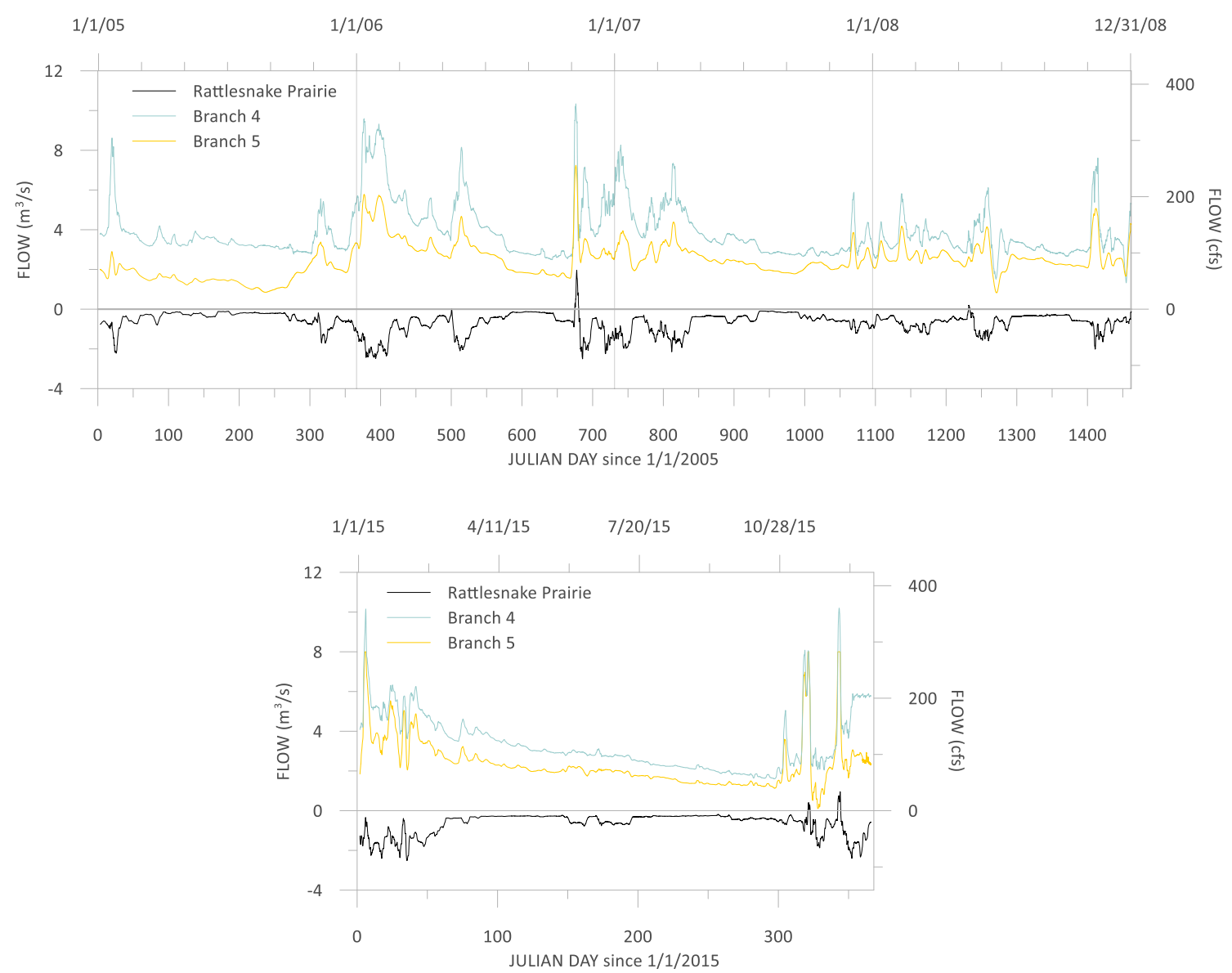

Figure 65. Flow inputs used for Rattlesnake Prairie and the distributed flows in branch 4 and branch 5 for 2005-2008 (top) and 2015 (bottom).

Table 11. Summary table of daily average flow error statistics at USGS 12116400, USGS 12116500, and USGS 12117500 for 2005-2008.

\begin{tabular}{lcccc}
\hline Sampling Location & $\mathrm{ME}\left(\mathrm{m}^{3} / \mathrm{s}\right)$ & $\mathrm{MAE}\left(\mathrm{m}^{3} / \mathrm{s}\right)$ & $\mathrm{RMSE}\left(\mathrm{m}^{3} / \mathrm{s}\right)$ & Count \\
\hline $\mathbf{1 2 1 1 6 4 0 0 , 2 0 0 5 - 2 0 0 8}$ & 0.00 & 0.03 & 0.09 & 1460 \\
$\mathbf{1 2 1 1 6 5 0 0 , 2 0 0 5 - 2 0 0 8}$ & -0.01 & 0.13 & 0.30 & 1460 \\
$\mathbf{1 2 1 1 7 5 0 0 , 2 0 0 5 - 2 0 0 8}$ & 0.01 & 0.35 & 0.89 & 1456 \\
Weighted Average & 0.00 & 0.17 & 0.43 & 4376 \\
\hline
\end{tabular}

Table 12. Summary table of daily average flow error statistics at USGS 12116400, USGS 12116500, and USGS 12117500 for 2015.

\begin{tabular}{lcccc}
\hline Sampling Location & $\mathrm{ME}\left(\mathrm{m}^{3} / \mathrm{s}\right)$ & $\mathrm{MAE}\left(\mathrm{m}^{3} / \mathrm{s}\right)$ & $\mathrm{RMSE}\left(\mathrm{m}^{3} / \mathrm{s}\right)$ & Count \\
\hline $\mathbf{1 2 1 1 6 4 0 0 , 2 0 1 5}$ & 0.00 & 0.06 & 0.16 & 364 \\
$\mathbf{1 2 1 1 6 5 0 0 , 2 0 1 5}$ & -0.07 & 0.11 & 0.20 & 365 \\
$\mathbf{1 2 1 1 7 5 0 0 , 2 0 1 5}$ & 0.00 & 0.25 & 0.69 & 361 \\
Weighted Average & -0.02 & 0.14 & 0.35 & 1090 \\
\hline
\end{tabular}




\subsection{Water Temperature}

In-lake temperature data were available at two sampling locations for the $2005-2008$ and 2015 models. SPU installed seven buoys and collected continuous data from December 19, 2007 through May 29, 2009. Continuous temperature data were available for the Cedar River at two USGS gaging stations for the 2005-2008 model and the 2015 model. Continuous temperature data were available at one WSDE location for the 2015 model.

\subsubsection{Chester Morse Lake}

Temperature profiles were collected at two sampling locations: mid-lake at site CM1A (segment 27) and at the Masonry Dam site MD (segment 64). During 2005 to 2008, 44 profiles were collected in 1-meter intervals at CM1A and 5 profiles were collected in 1-meter intervals at MD (Figure 66 and Figure 67). In 2015, 17 profiles were collected in 1-meter intervals at CM1A and 21 grab samples were collected at MD. Figure 68 shows the monthly trend in reservoir profiles collected during 2015. 

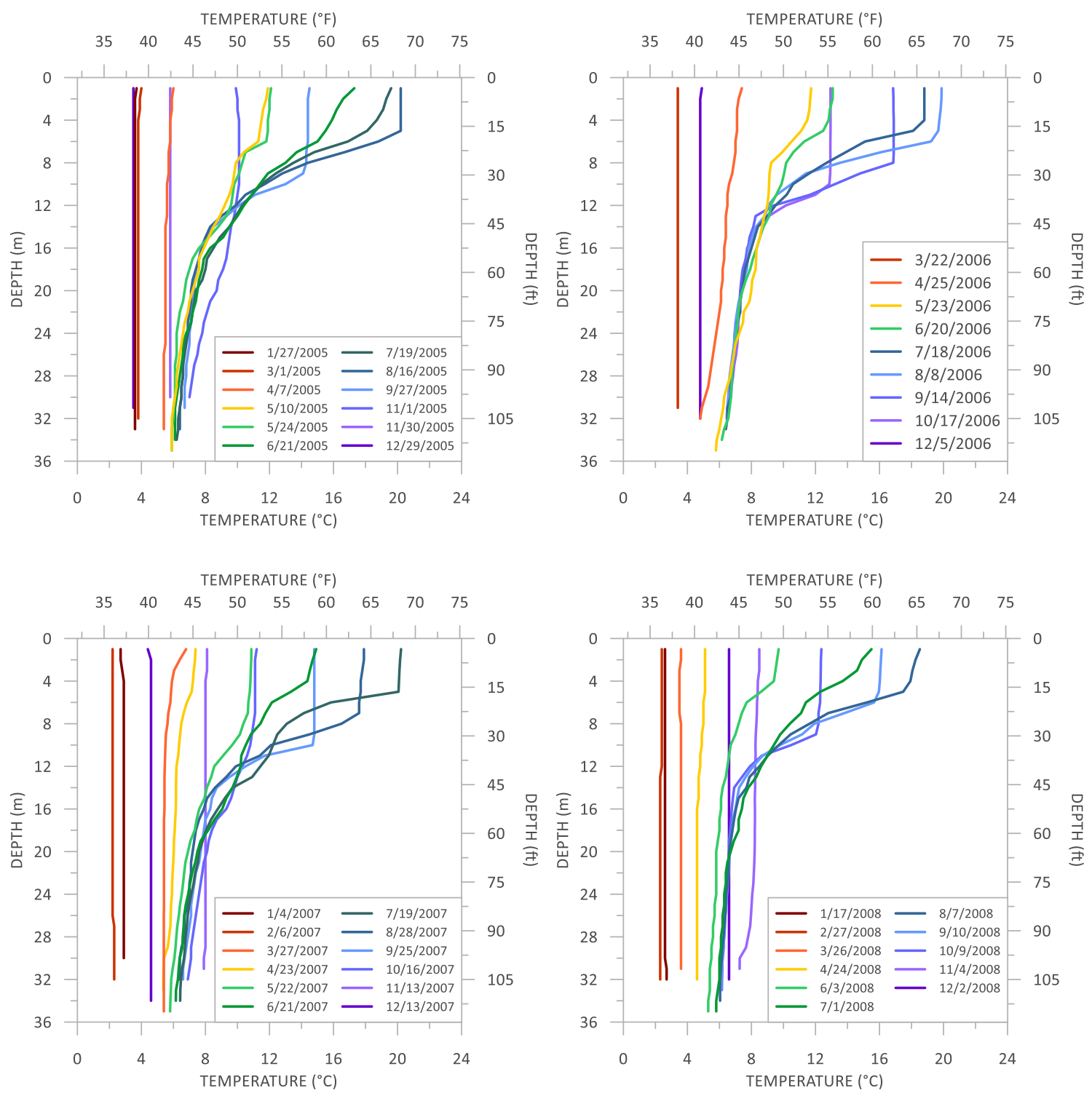

Figure 66. Temperature profiles from CM1A (segment 27), 2005 through 2008. 


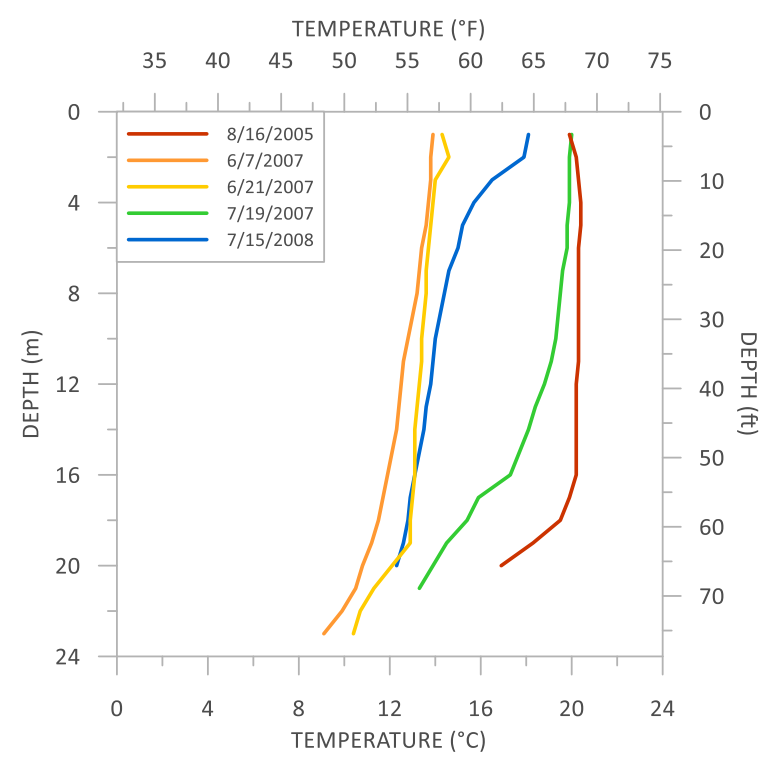

Figure 67. Temperature profiles at MD (segment 64), 2005-2008.
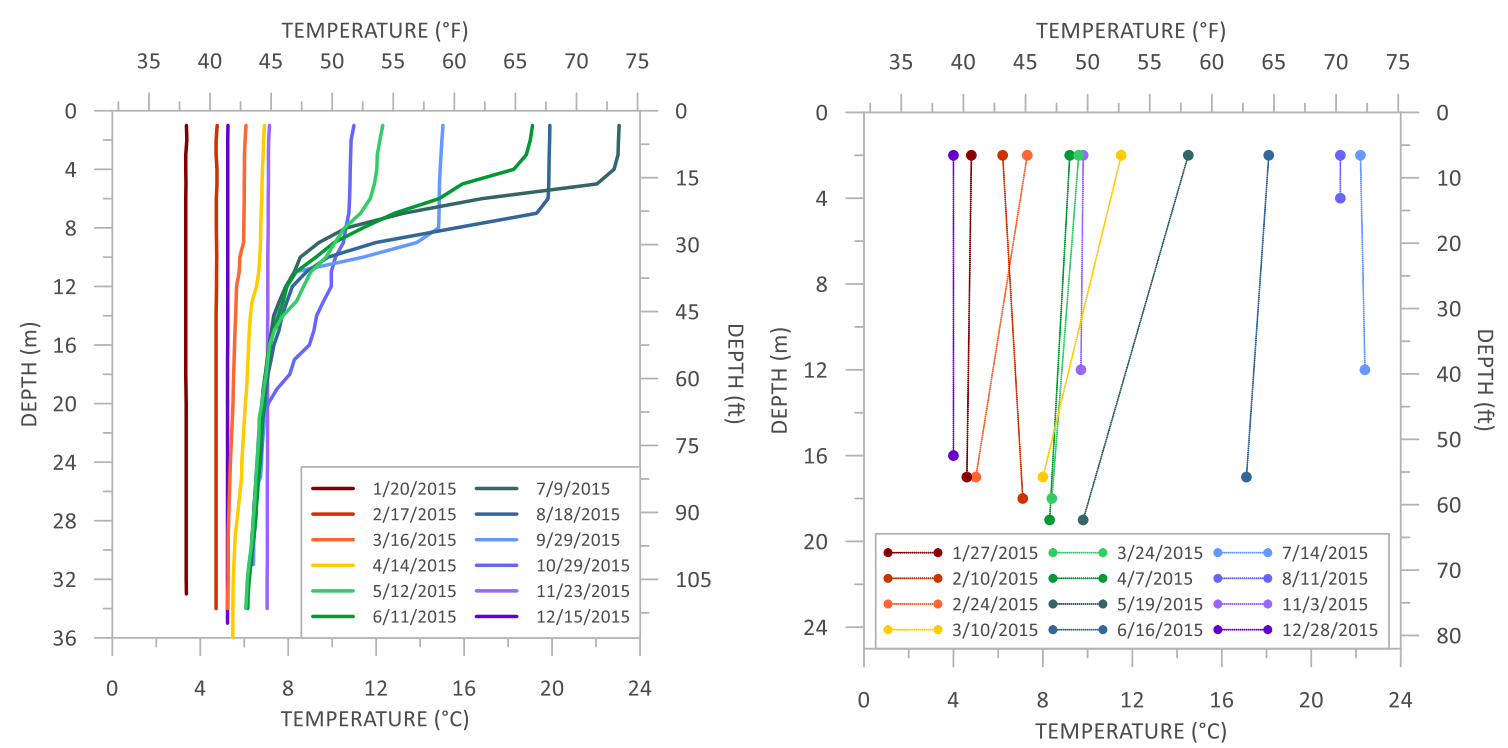

Figure 68. Temperature profiles from CM1A (left) and MD (right) during 2015. Grab samples were collected 2 meters below the surface and at the elevation of the lower level outlet at the Masonry Dam. The lines are for visual aid only in the MD figure. 
SPU deployed seven buoys with temperature probes from December 19, 2007 through

May 29, 2009. Table 13 summarizes the location, corresponding model segment, and

collection depths for each buoy. The temperature profiles at each location are shown in

Figure 69 through Figure 75.

Table 13. Summary of temperature buoy location and corresponding model segment.

\begin{tabular}{clcl}
\hline Buoy & Location & Model segment & Collection depths (m) \\
\hline $\mathbf{1}$ & Confluence with the Cedar River & 9 & $0: 2: 6$ \\
$\mathbf{2}$ & Green Point/McClellan inflow & 17 & $0: 2: 10 ; 15: 5: 25$ \\
$\mathbf{3}$ & Rex Delta drop-off & 47 & $0: 2: 10 ; 15: 5: 25$ \\
$\mathbf{4}$ & Cedar Delta drop-off & 13 & $0: 2: 10 ; 15: 5: 35$ \\
$\mathbf{5}$ & Chester Morse Lake, deepest & 23 & $0: 2: 10 ; 15: 5: 35$ \\
$\mathbf{6}$ & MLPP intake & 34 & $0: 2: 10 ; 15: 5: 25$ \\
$\mathbf{7}$ & Masonry Dam & 64 & $0: 2: 10 ; 15: 5: 20$ \\
\hline
\end{tabular}

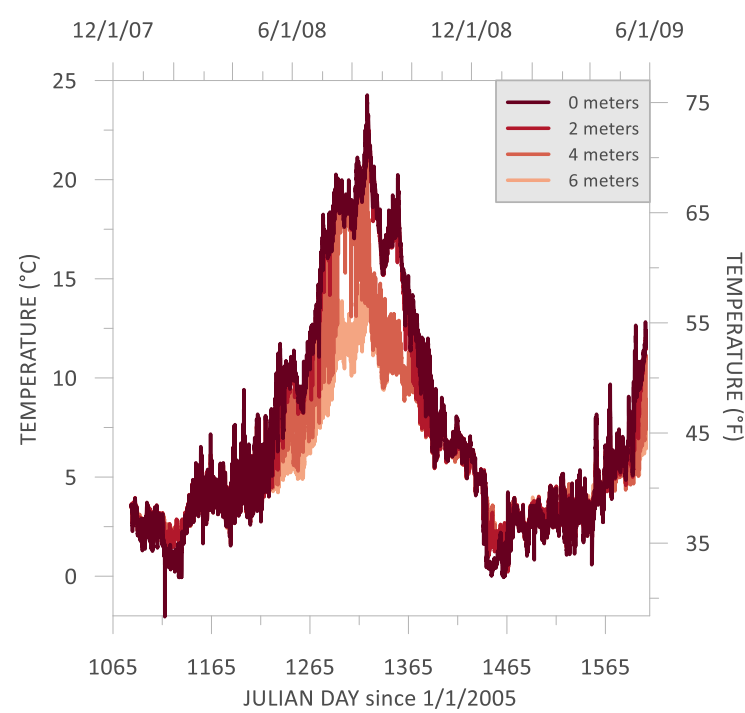

Figure 69. Continuous temperature collected at Buoy 1, Cedar River confluence (segment 9).

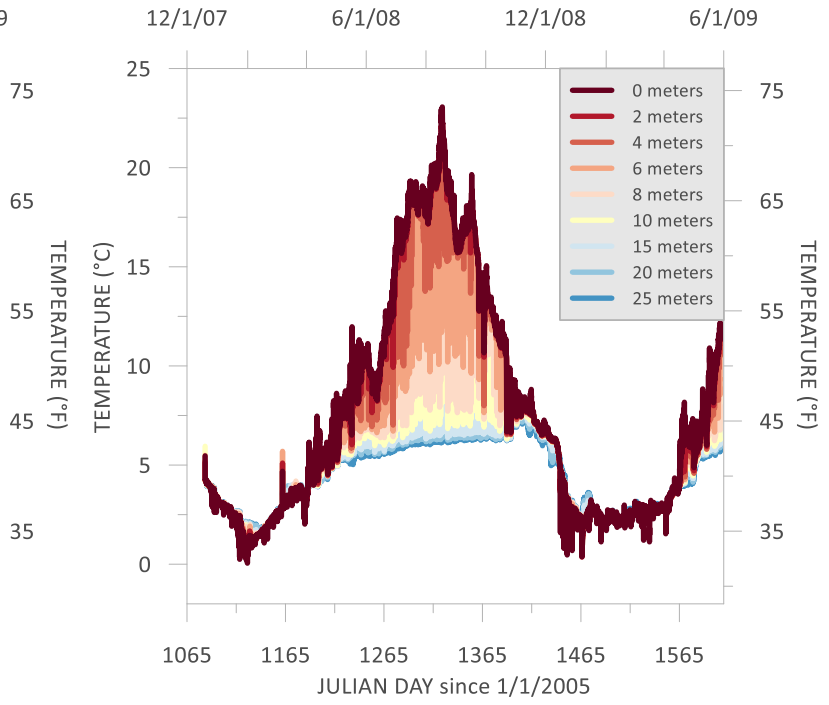

Figure 70. Continuous temperature collected at Buoy 2, Green Point/McClellan Creeks (segment 17). 


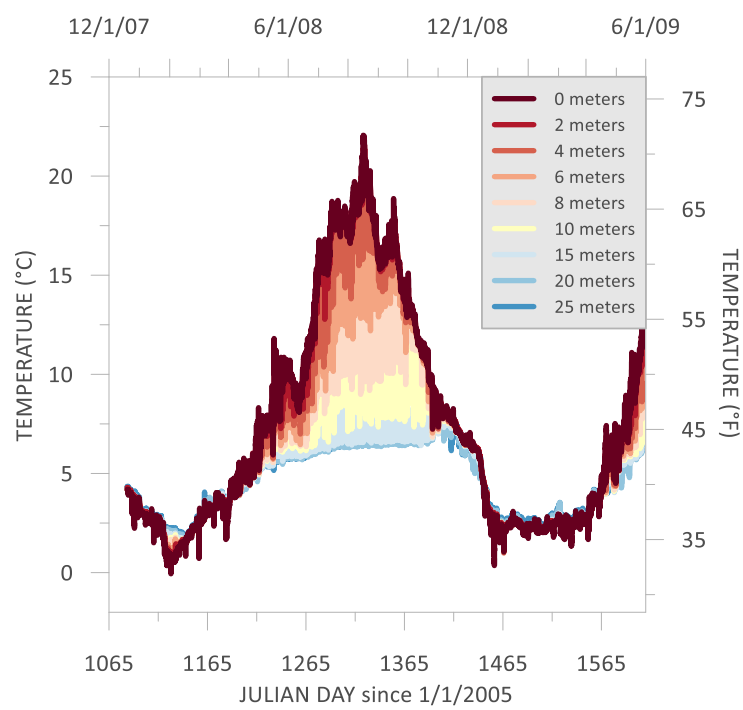

Figure 71. Continuous temperature collected at Buoy 3, Rex Delta drop-off (segment 47).

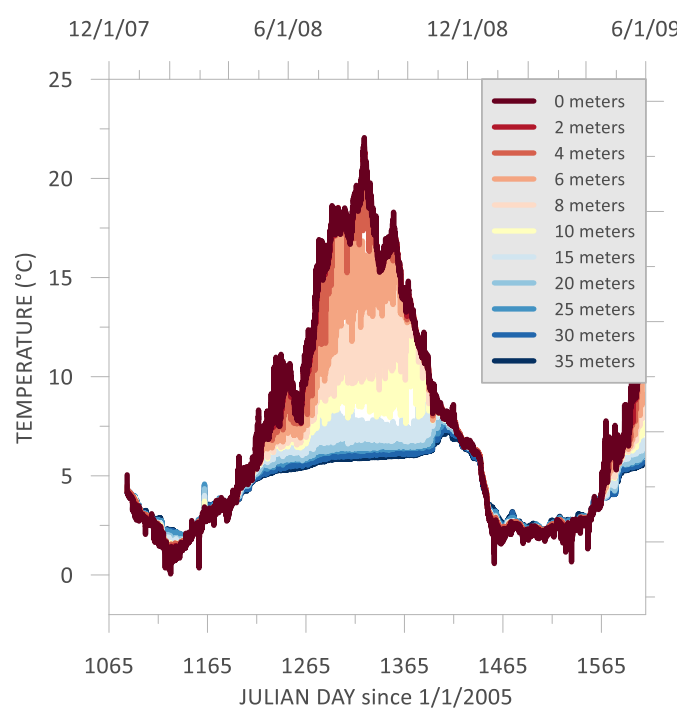

Figure 73. Continuous temperature collected at Buoy 5, Chester Morse Lake - Deepest (segment 23).

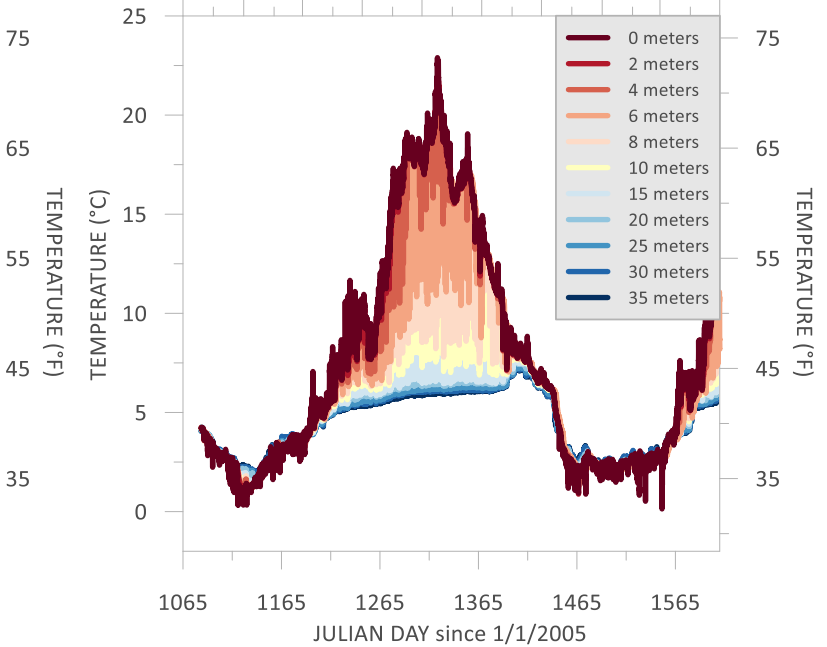

Figure 72. Continuous temperature collected at Buoy 4, Cedar Della drop-off (segment 13).
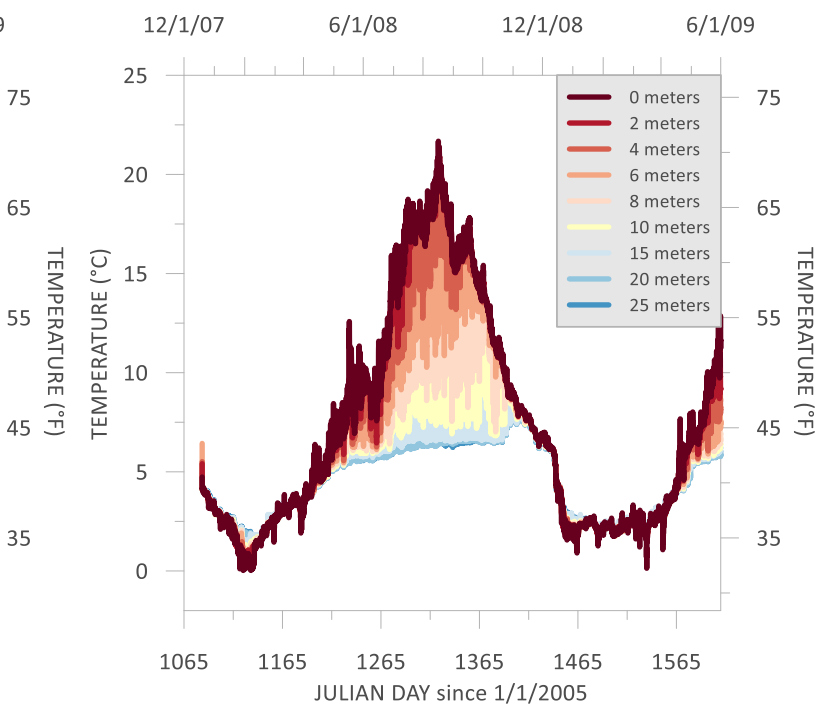

Figure 74. Continuous temperature collected at Buoy 6, MLPP intake (segment 34). 


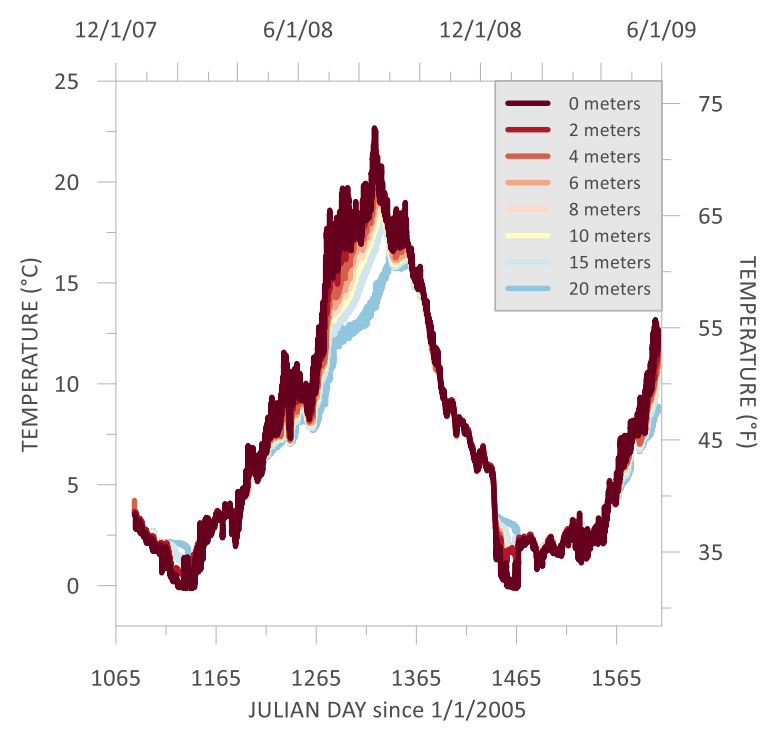

Figure 75. Continuous temperature collected at Buoy 7, Masonry Dam (segment 64).

Temperature calibration for Chester Morse Lake and the Masonry Pool used profile and buoy data as available to adjust model parameters and match observed data with all errors minimized. The main methods used during temperature calibration included adjusting the wind sheltering coefficient, specifying the light extinction coefficient, and selecting a representative theoretical solar radiation model.

The wind sheltering coefficient is a user-determined step function multiplication factor for the wind speed, which reduces or increases wind effects caused by terrain variation and error in observed data. The wind sheltering coefficient was adjusted based on observed mixing patterns within the reservoir. The depth of the thermocline and rate of change in the metalimnion guided calibration efforts with the wind sheltering coefficient. In 2005-2008, the wind sheltering coefficient ranged from 0.5 to 1.7 with an average value of 0.98 over the full model run. In 2015, the wind sheltering coefficient 
ranged from 0.2 to 1.2 with an average value of 0.90 over the full model run. The wind sheltering coefficient was applied uniformly over the entire reservoir model domain. The wind sheltering coefficient is shown as a function of time in Figure 76.

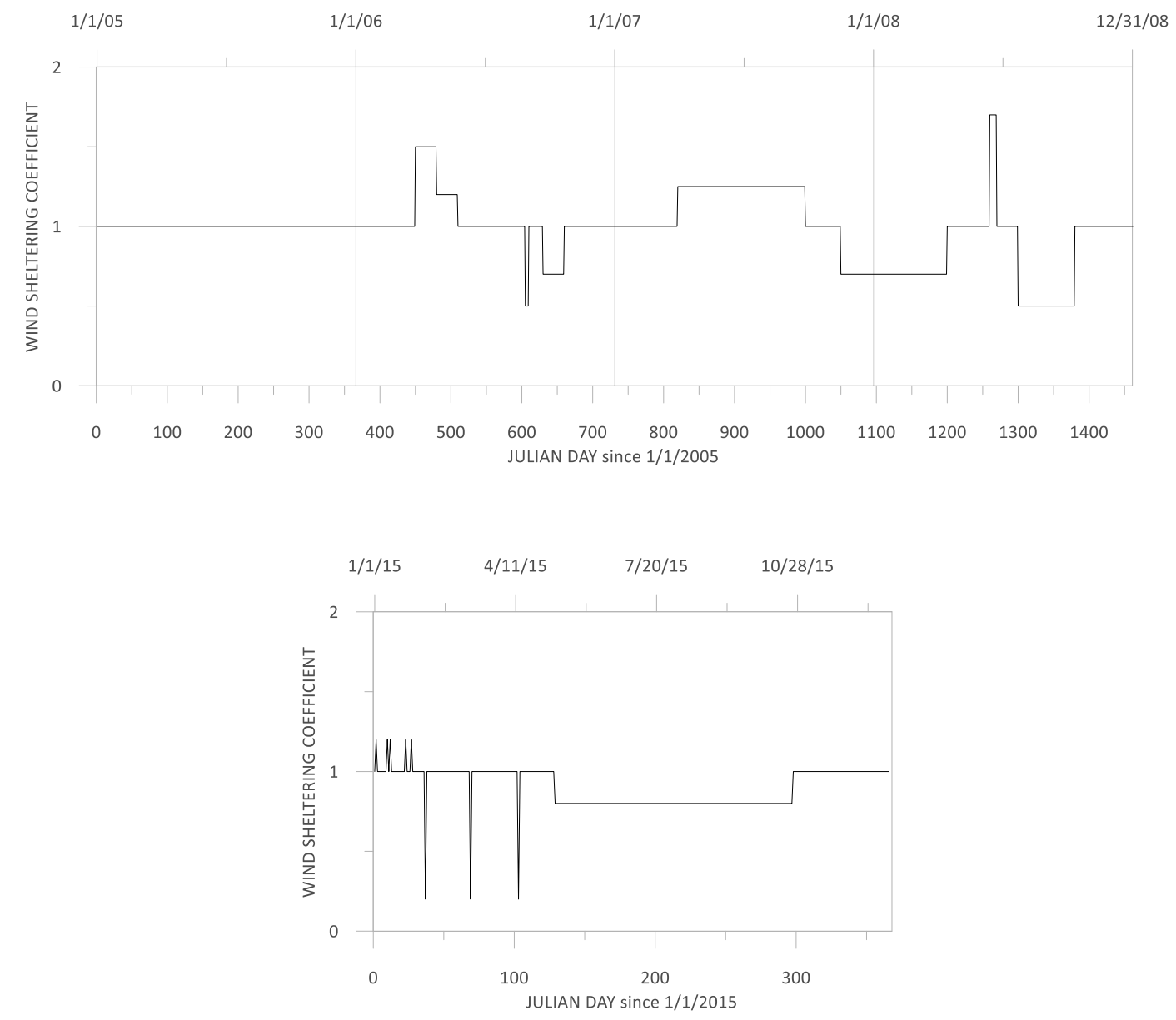

Figure 76. Wind sheltering coefficient as a function of time for the Chester Morse Lake model in 2005-2008 (top) and 2015 (bottom).

Temperature is impacted by the absorption and attenuation of light within the water column. The light extinction coefficient is the fraction of surface light absorbed over a depth of 1 meter. Low values of the light extinction coefficient indicate that light is able to penetrate deeper through the water column and that lower levels of organic 
compounds and suspended materials are present within the water column (Dodds \& Whiles, 2020). The 2005-2008 model was calibrated with a light extinction coefficient of 0.25. The 2015 model was calibrated with a light extinction coefficient of 0.30 . These values are consistent with literature values for oligotrophic and meso-oligotrophic systems (Wells S. A., 2019).

Solar radiation provides the major heat source for the water column and impacts wind patterns and hydrodynamics. The field data collected at Chester Morse Lake displayed a significant low bias in solar radiation data. Five theoretical solar models were tested with the 2015 model. The reservoir model performed best with the Meeus model. Solar radiation was estimated using the Meeus model for the 2005-2008 model and the 2015 model.

The temperature grab samples collected at the Masonry Dam in 2015 showed high variability relative to the temperature samples collected at CM1A. SPU confirmed that some of the grab samples could be inaccurate due to the sampling method. At the Masonry Dam, a sampler is lowered from the dam to the depth of the lower outlet and the sample is raised back up to the surface, transferred to a beaker, and measured with a thermometer. At CM1A, temperature is measured with a sonde. Eight observations at the Masonry Dam were excluded from error analysis due to sample inaccuracy.

The weighted average RMSE for all calibrated models estimated water temperature with an RMSE of less than $1^{\circ} \mathrm{C}$. The $2005-2008$ model displayed a cold bias with a weighted 
average ME of $-0.29^{\circ} \mathrm{C}$ at the $\mathrm{CM} 1 \mathrm{~A}$ and $\mathrm{MD}$ sites and a weighted average of $-0.19^{\circ} \mathrm{C}$ at the seven buoy locations. The 2015 model displayed no bias with a weighted average ME of $0.01^{\circ} \mathrm{C}$ at the $\mathrm{CM} 1 \mathrm{~A}$ and $\mathrm{MD}$ sites. The weighted average MAE was $0.56^{\circ} \mathrm{C}$ for the 2005-2008 model at the $\mathrm{CM} 1 \mathrm{~A}$ and $\mathrm{MD}$ sites and $0.74^{\circ} \mathrm{C}$ at the seven buoy locations. In 2015 , the weighted average MAE was $0.46^{\circ} \mathrm{C}$. Error statistics for all models are summarized in Table 14 through Table 16. Daily temperature at noon over time and depth as modeled mid-lake at station CM1A and in the Masonry Pool at station MD is shown in Figure 77 for 2005-2008. Daily temperature at noon over time and depth for 2015 is shown in Figure 78 for station CM1A and in Figure 79 for the Masonry Dam. Figure 80 through Figure 83 show the final model temperature calibration results for temperature profiles at $\mathrm{CM} 1 \mathrm{~A}$ and $\mathrm{MD}$. Comparisons of all buoy locations to the calibrated model are included in the Appendix.

Table 14. Summary of vertical profile temperature error statistics for CM1A and MD, 2005-2008.

\begin{tabular}{lcccc}
\hline Sampling Location & $\operatorname{ME}\left({ }^{\circ} \mathrm{C}\right)$ & $\operatorname{MAE}\left({ }^{\circ} \mathrm{C}\right)$ & $\mathrm{RMSE}\left({ }^{\circ} \mathrm{C}\right)$ & Count \\
\hline CM1A, 2005-2008 & -0.30 & 0.55 & 0.64 & 1435 \\
MD, 2005-2008 & -0.14 & 0.67 & 0.76 & 107 \\
Weighted Average & -0.29 & 0.56 & 0.65 & 1542 \\
\hline
\end{tabular}

Table 15. Summary of vertical profile temperature error statistics for CM1A and MD, 2015. * indicates that some data were excluded from analysis.

\begin{tabular}{lcccc}
\hline Sampling Location & $\mathrm{ME}\left({ }^{\circ} \mathrm{C}\right)$ & $\mathrm{MAE}\left({ }^{\circ} \mathrm{C}\right)$ & $\mathrm{RMSE}\left({ }^{\circ} \mathrm{C}\right)$ & Count \\
\hline CM1A, 2015 & 0.00 & 0.45 & 0.59 & 551 \\
\hline MD, 2015 & -0.28 & 1.27 & 1.36 & 36 \\
MD, 2015* & 0.16 & 0.73 & 0.77 & 28 \\
Weighted Average* & 0.01 & 0.46 & 0.60 & 579 \\
\hline
\end{tabular}


Table 16. Summary of vertical profile temperature error statistics for the seven temperature buoys, 2007-2008.

\begin{tabular}{lcccc}
\hline Sampling Location & $\mathrm{ME}\left({ }^{\circ} \mathrm{C}\right)$ & $\mathrm{MAE}\left({ }^{\circ} \mathrm{C}\right)$ & $\mathrm{RMSE}\left({ }^{\circ} \mathrm{C}\right)$ & Count \\
\hline Buoy 1 & 0.39 & 1.47 & 1.90 & 25689 \\
\hline Buoy 2 & -0.25 & 0.78 & 1.06 & 81552 \\
Buoy 3 & -0.19 & 0.68 & 0.89 & 74505 \\
\hline Buoy 4 & -0.13 & 0.76 & 1.05 & 74866 \\
Buoy 5 & -0.14 & 0.57 & 0.74 & 99659 \\
Buoy 6 & -0.18 & 0.72 & 0.95 & 81537 \\
Buoy 7 & -0.46 & 0.76 & 0.93 & 69250 \\
\hline Weighted Average & -0.19 & 0.74 & 0.98 & 507058 \\
\hline
\end{tabular}



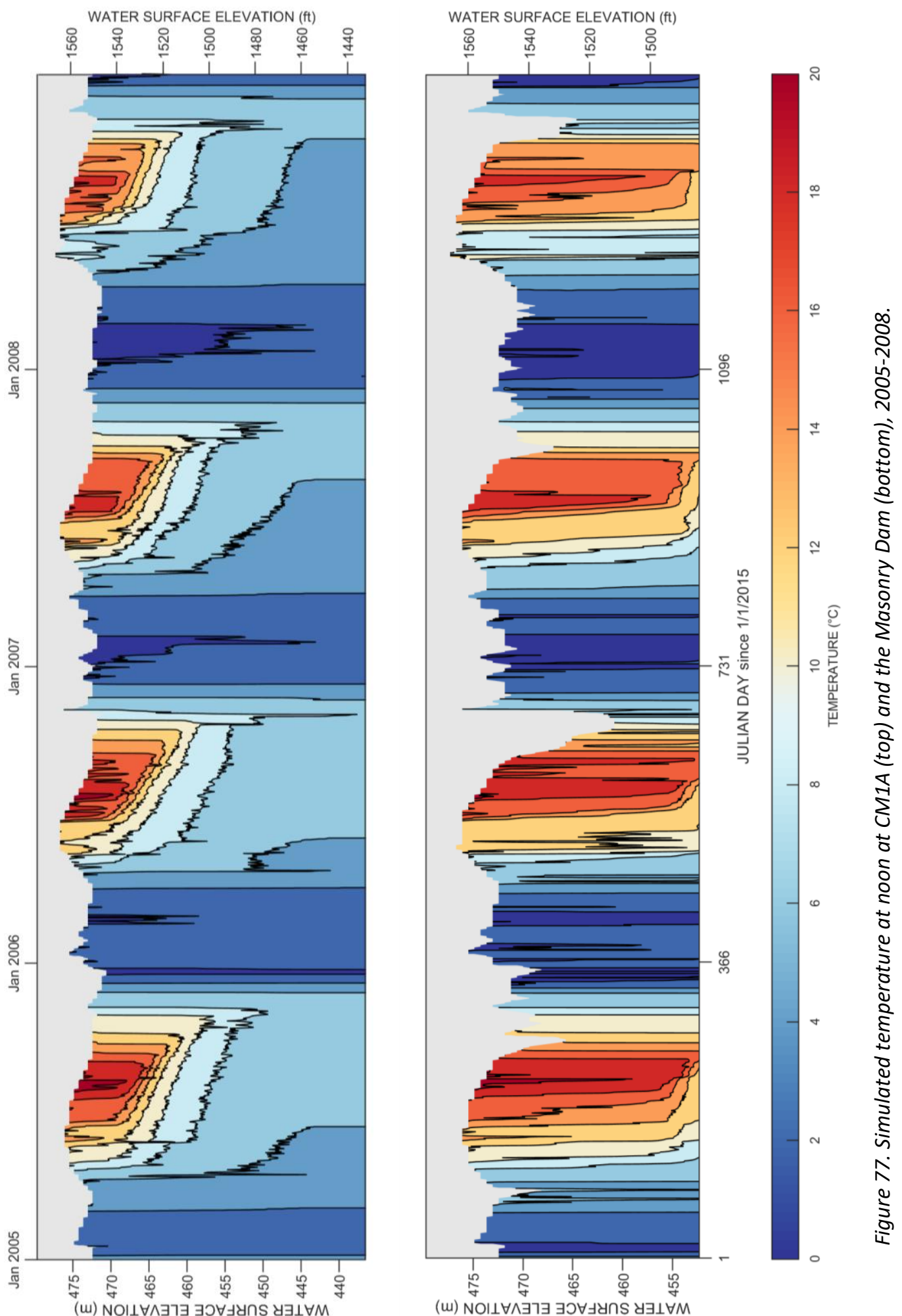

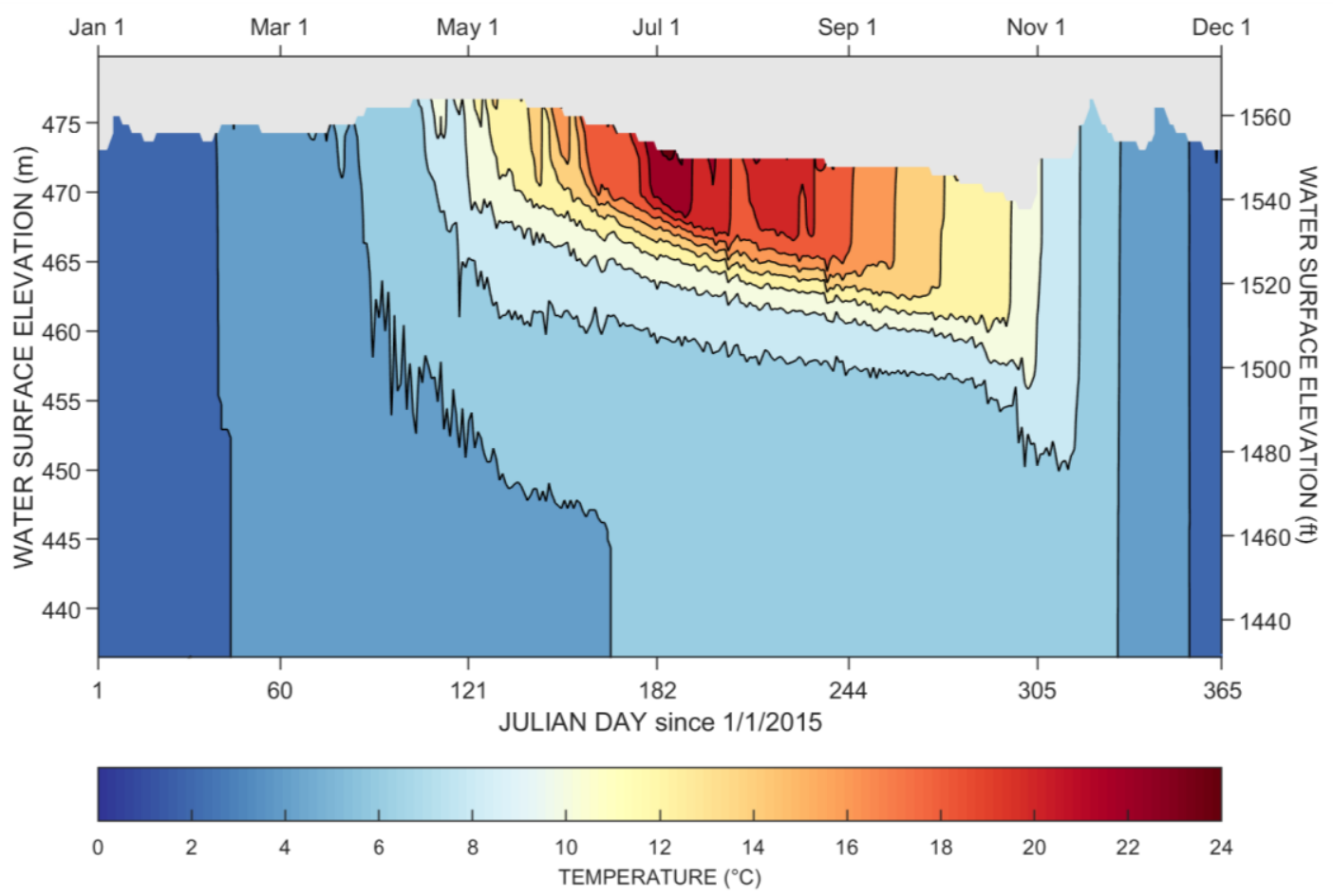

Figure 78. Simulated temperature at noon mid-lake at CM1A, 2015.

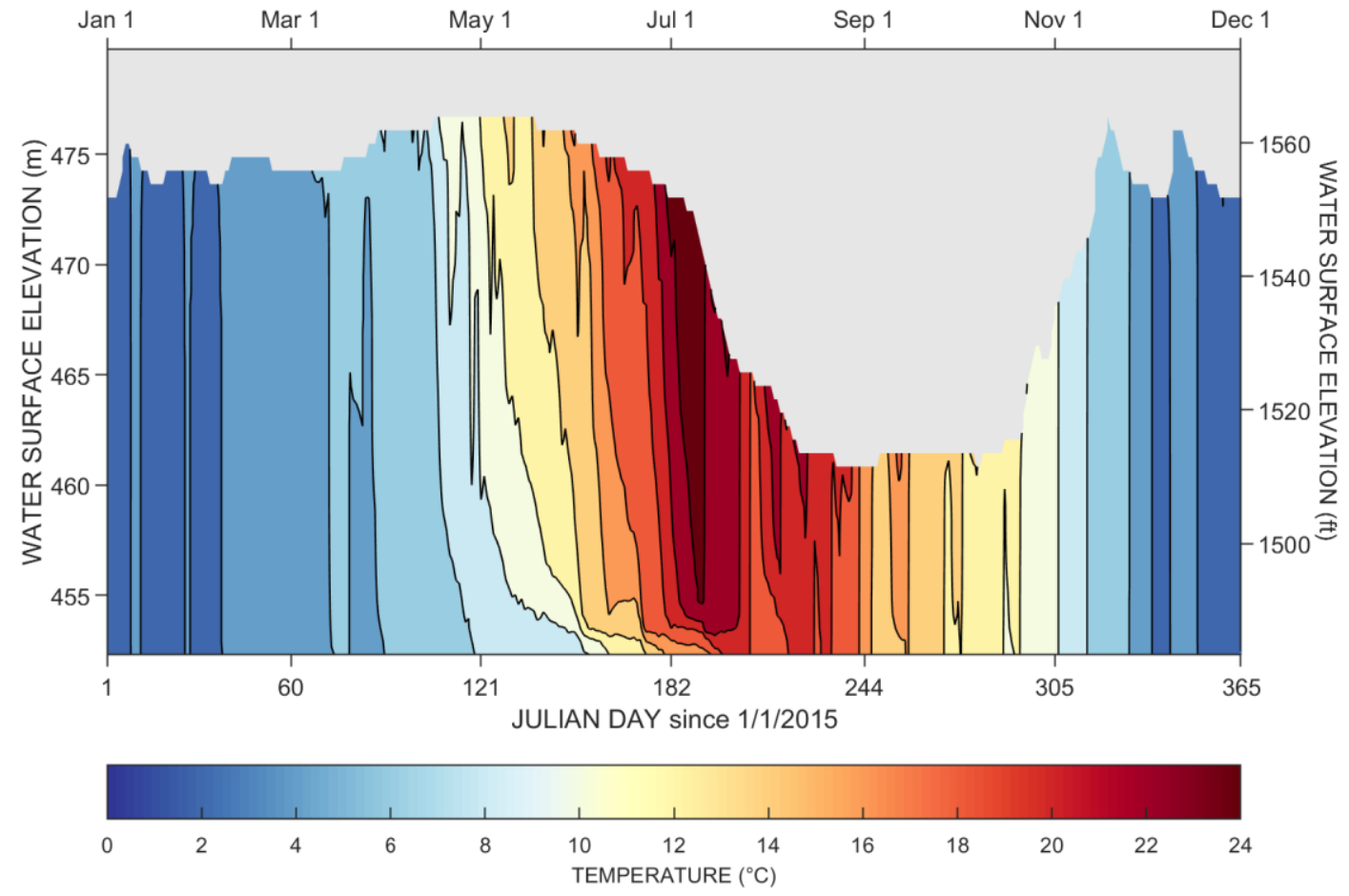

Figure 79. Simulated temperature at noon at the Masonry Dam, 2015. 


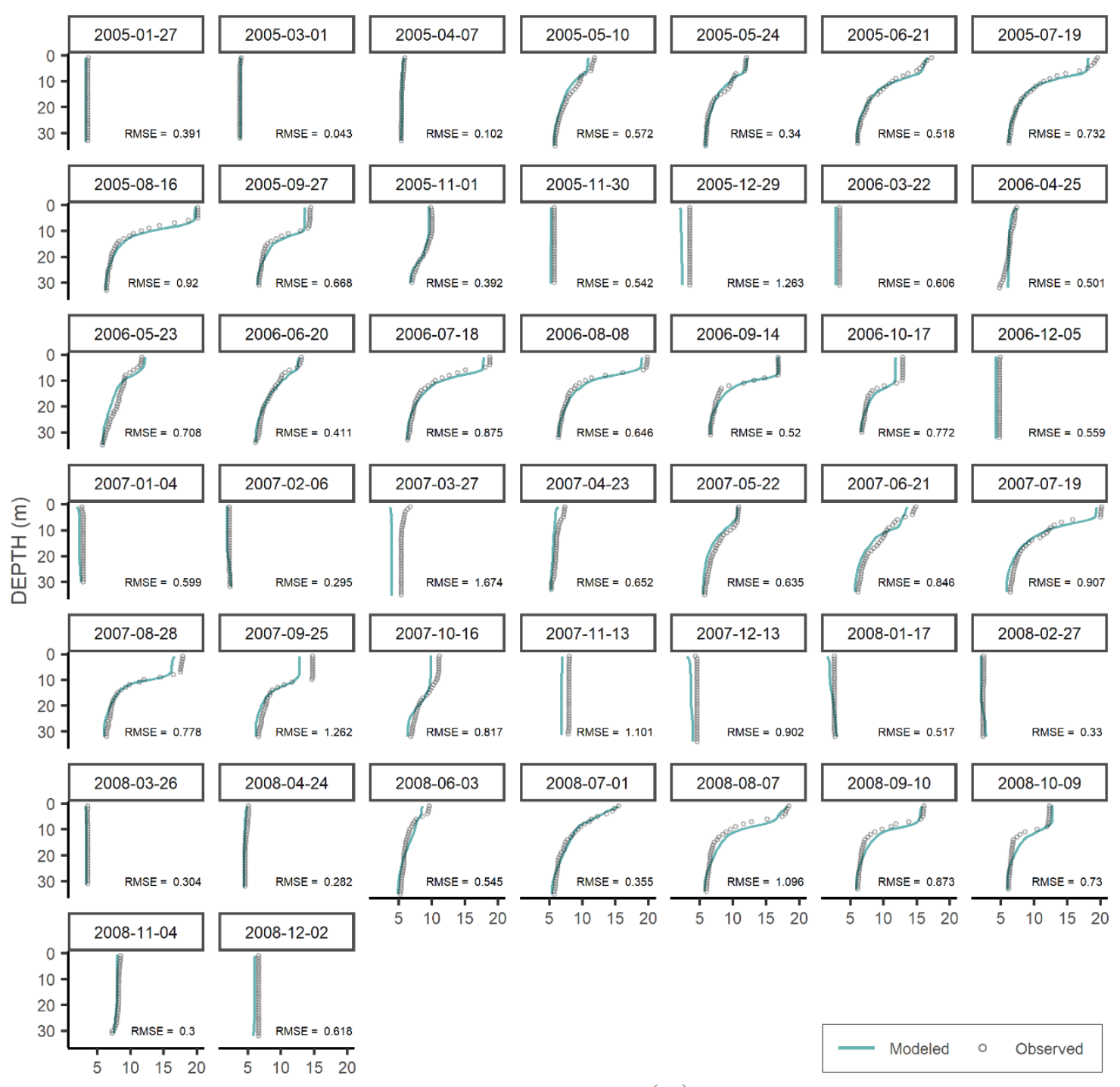

TEMPERATURE $\left({ }^{\circ} \mathrm{C}\right)$

Figure 80. Comparison of model temperature simulations to observed temperature data at CM1A, 2005-2008. 

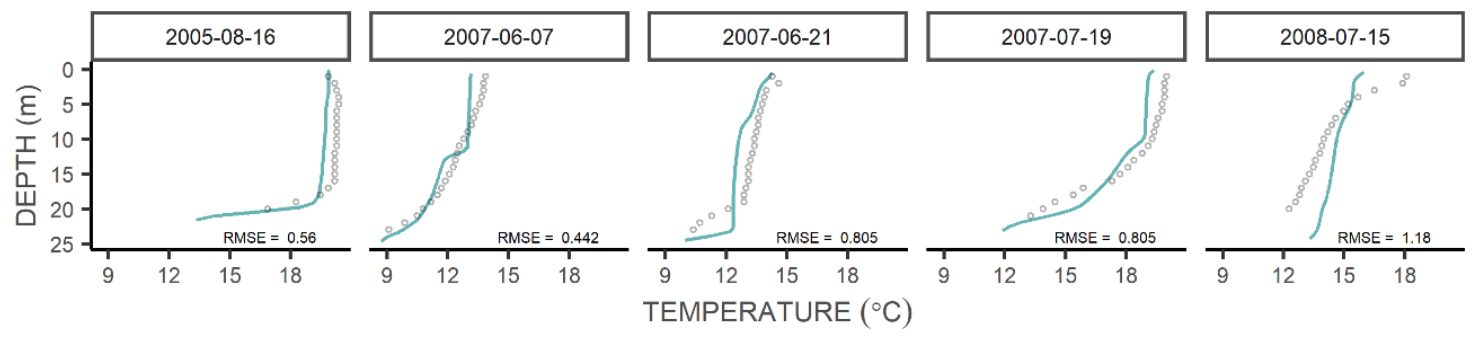

Modeled $\circ$ Observed

Figure 81. Comparison of model temperature simulations to observed temperature data at MD, 2005-2008.

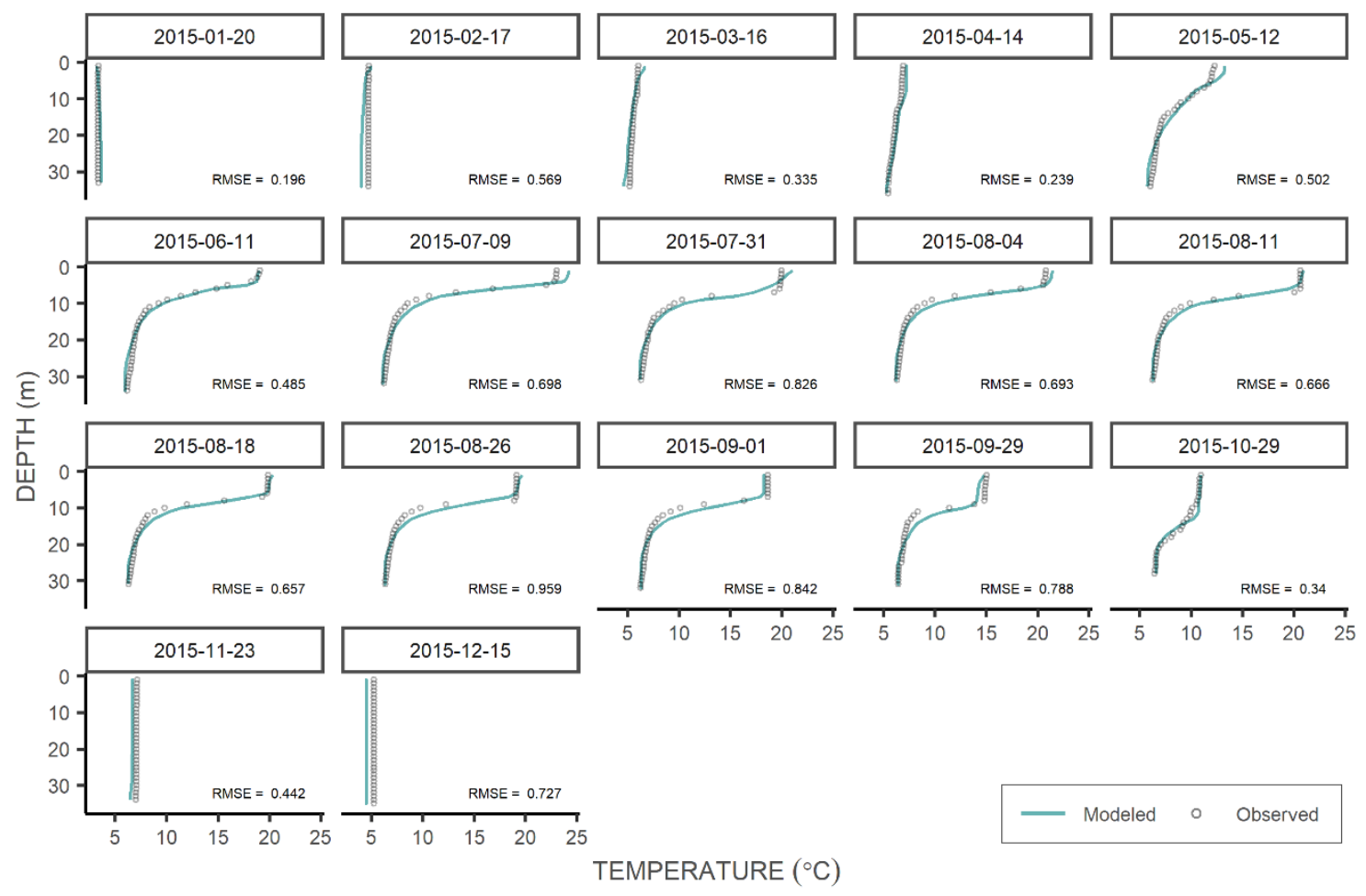

Figure 82. Comparison of model temperature simulations to observed temperature data at CM1A, 2015. 


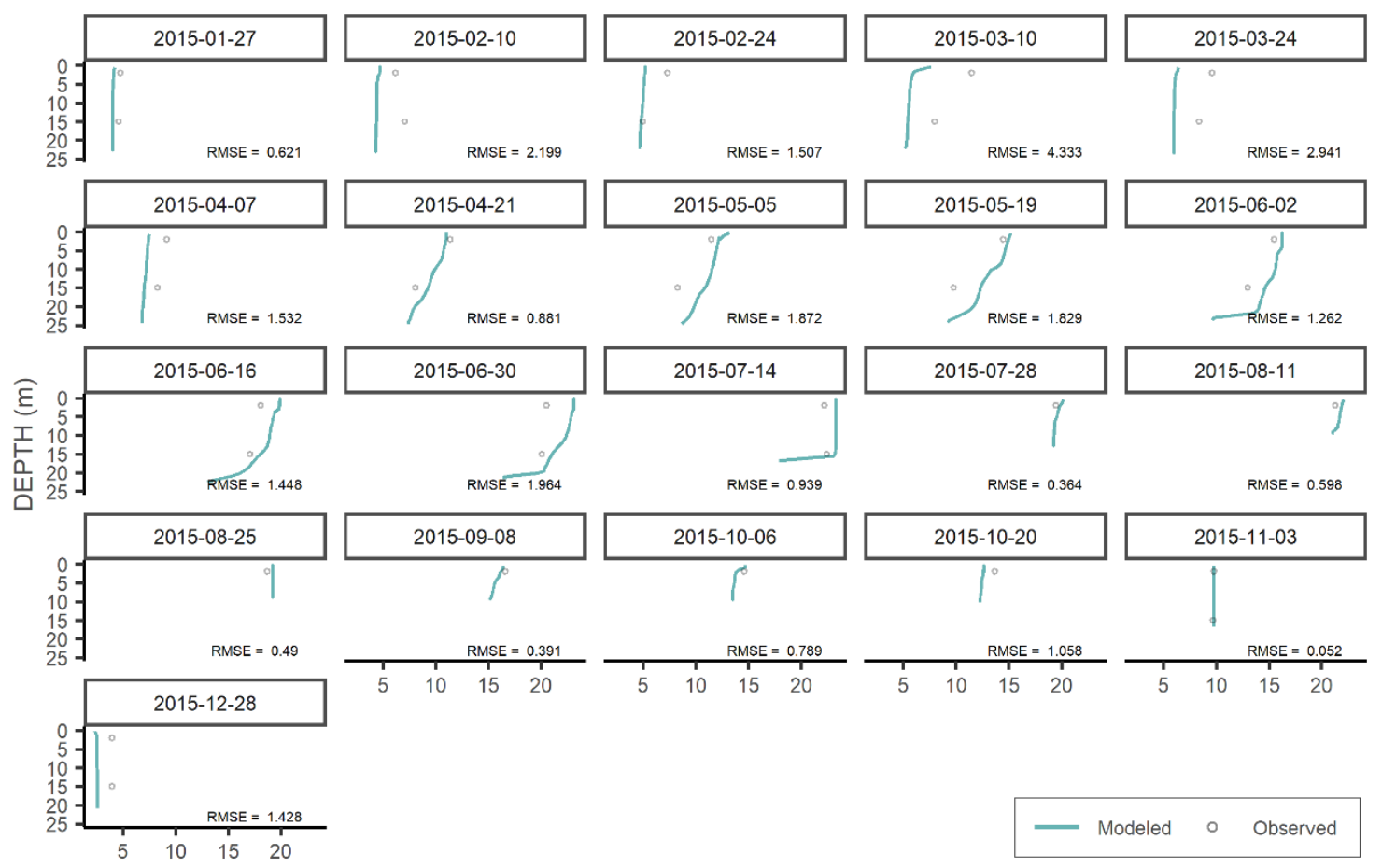

TEMPERATURE $\left({ }^{\circ} \mathrm{C}\right)$

Figure 83. Comparison of model temperature simulations to observed temperature data at MD, 2015.

\subsubsection{Cedar River}

Continuous temperature data were available for the Cedar River at two USGS gaging stations for the 2005-2008 model and the 2015 model. For the 2015 model, additional continuous temperature data were available at one WSDE location. The temperature calibration for the Cedar River used available data to adjust model parameters and match observed data with all errors minimized. The main component adjusted during temperature calibration was boundary condition inflow temperatures. Temperature inputs for all tributaries are shown relative to gaged temperatures in Figure 84. 

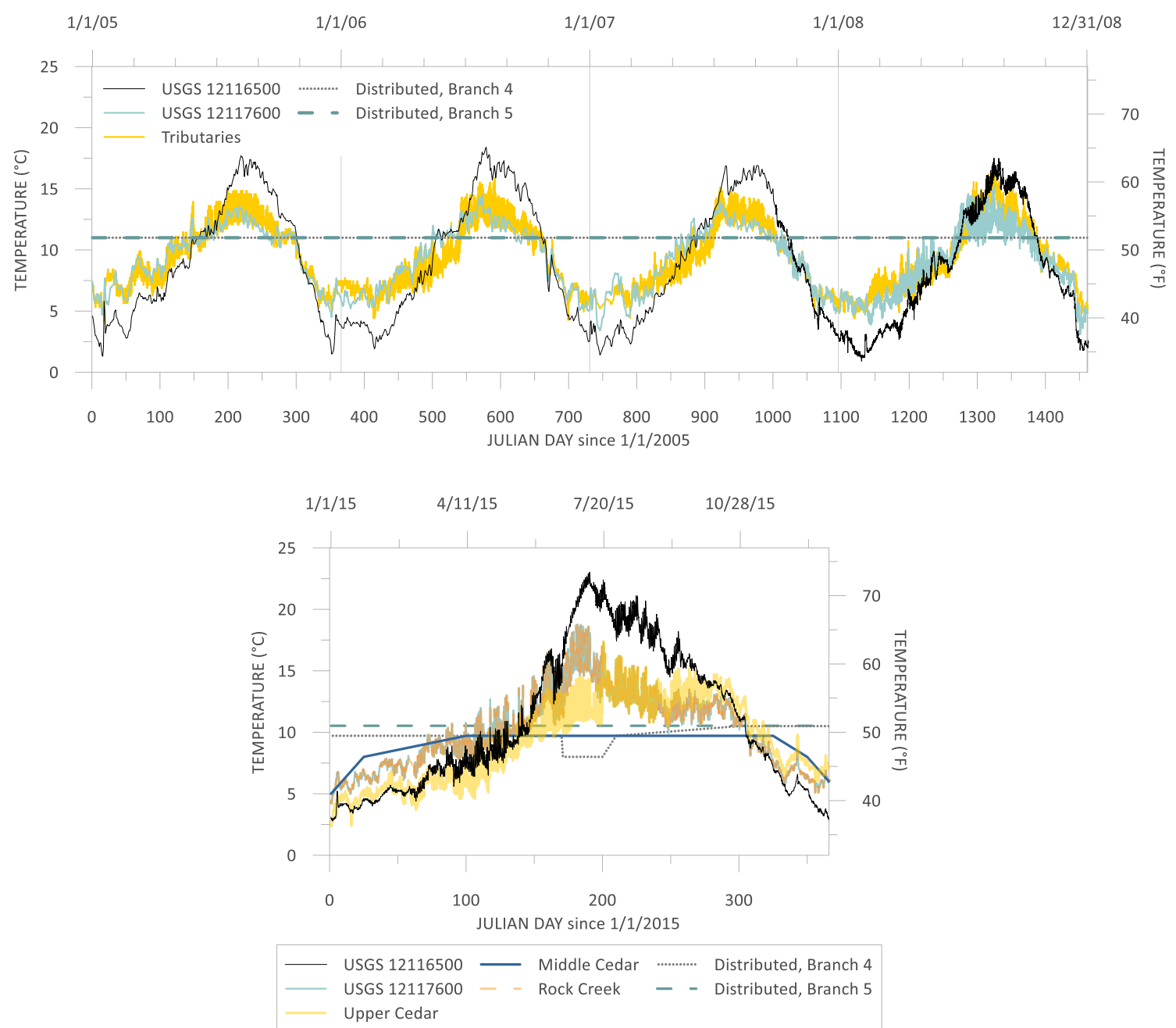

Figure 84. Water temperature inputs used for model tributaries in 2005-2008 (top) and 2015 (bottom). Upper Cedar tributaries included Lost Creek, Fish Creek, Canyon Creek, and Rattlesnake Prairie. Middle Cedar tributaries included De-Horn Creek, the unnamed left-bank input, Steele Creek, Williams Creek, and Taylor Creek.

The weighted average RMSE for all calibrated models estimated water temperature with an RMSE of less than $1^{\circ} \mathrm{C}$. The $2005-2008$ model had a weighted average RMSE of $0.71^{\circ} \mathrm{C}$ and the 2015 model had a weighted average RMSE of $0.48^{\circ} \mathrm{C}$. The river models showed no significant bias with a weighted average ME of $-0.02^{\circ} \mathrm{C}$ for $2005-2008$ and a weighted 
average ME of $-0.03^{\circ} \mathrm{C}$ for 2015 . The weighted average MAE was $0.56^{\circ} \mathrm{C}$ for the 2005-2008 model and $0.39^{\circ} \mathrm{C}$ for the 2015 model.

Temperature inputs for all tributaries in the 2005-2008 model were estimated using regression analysis between USGS 12115000 and USGS 12117600 . This was used in place of field data from USGS 12117600 as only daily average values were recorded for the majority of the model period at USGS 12117600 , while hourly values were available at USGS 12115000 . The observed temperatures at USGS 12115000 were adjusted using the regression analysis results. Distributed flows were modeled using a constant value to emulate groundwater flows. Simulated temperature over time for the entire river domain is displayed in Figure 85. Comparisons of modeled temperature and observed temperature for each USGS gaging station are show in Figure 86. Daily average temperature error statistics at the two USGS gaging stations within the Cedar River model domain are summarized in Table 17. 


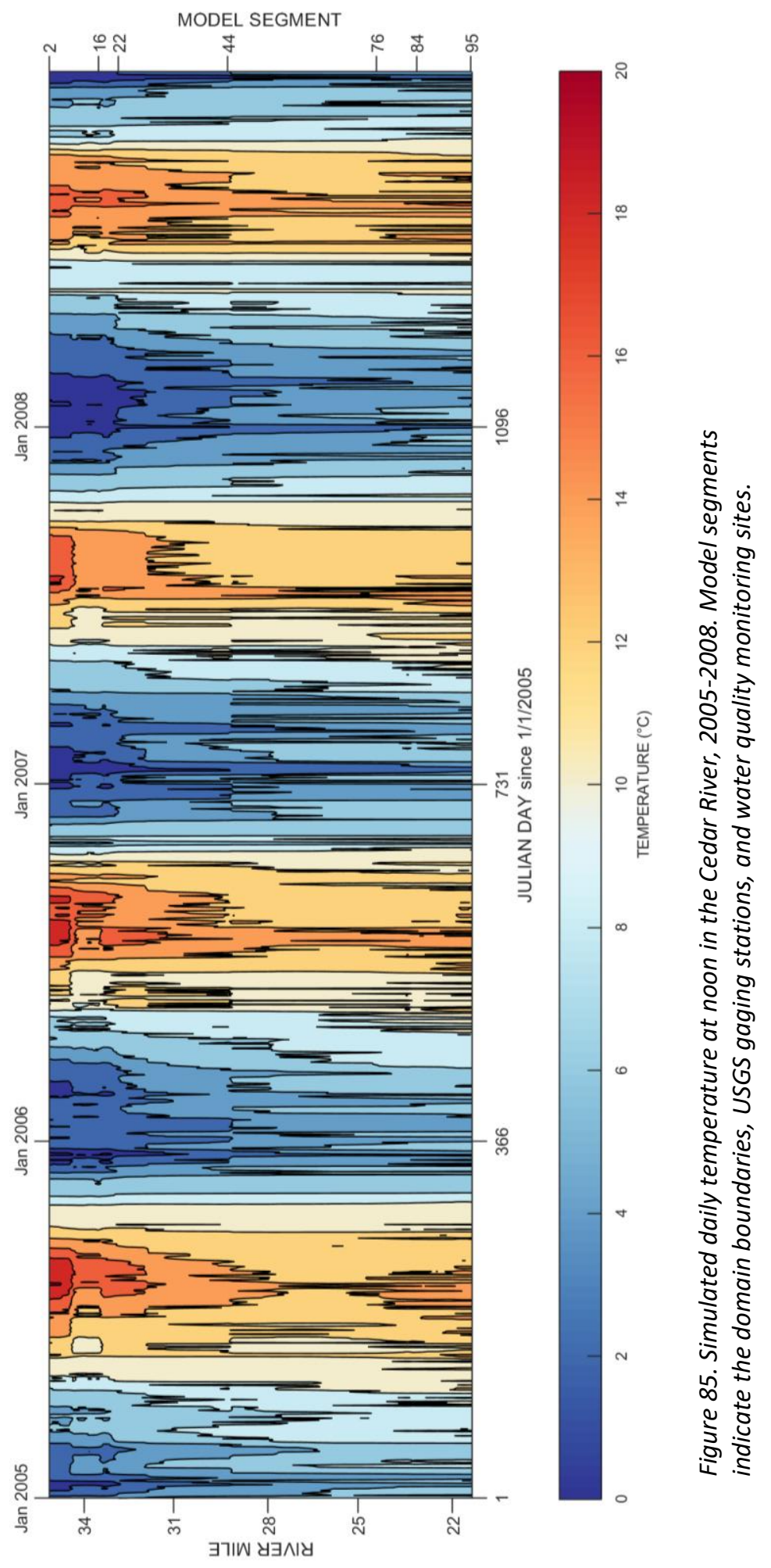




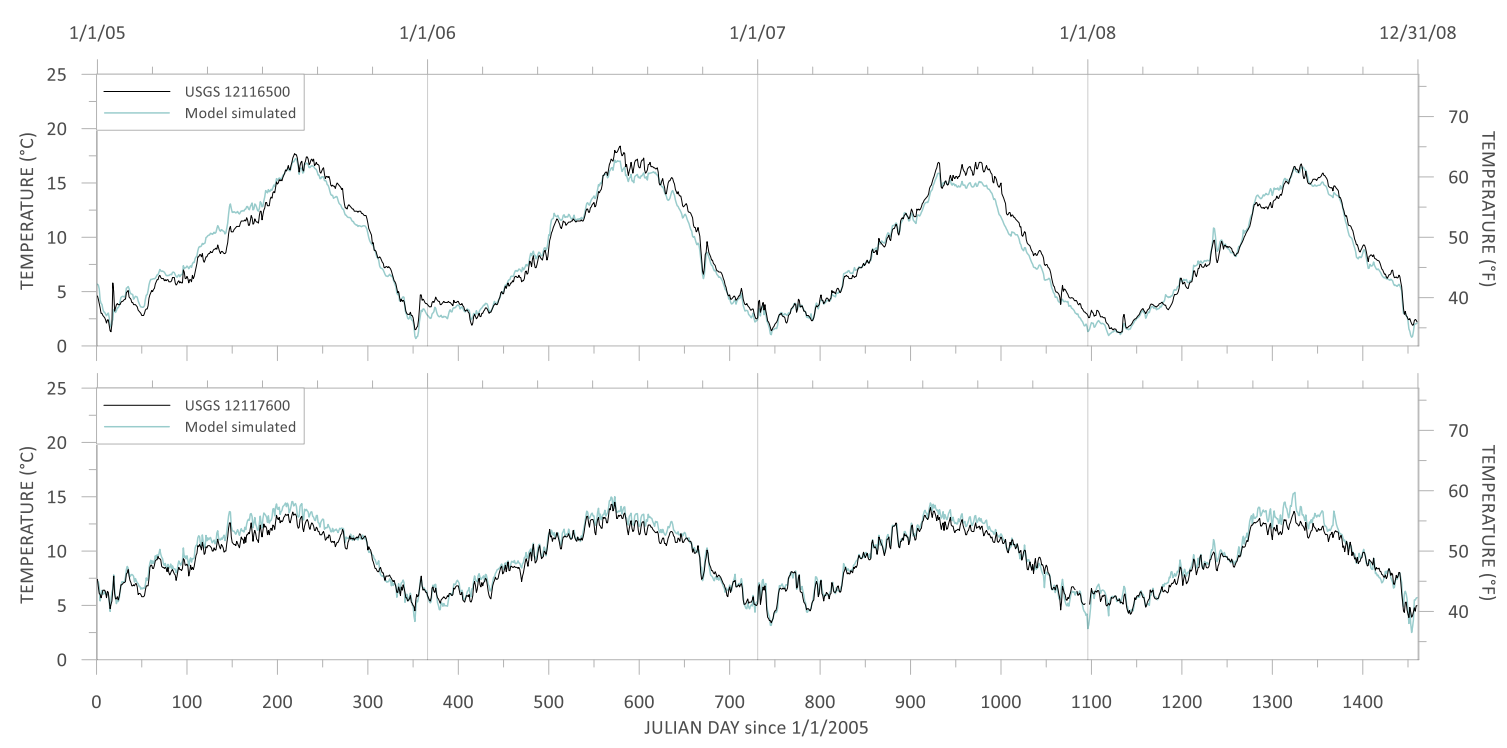

Figure 86. Modeled daily average temperature predictions compared to observed daily average temperature from 2005-2008 at USGS 12116500 (top) and USGS 12117600 (bottom).

Table 17. Summary of daily average temperature error statistics for USGS 12116500 and USGS 12117600 , 2005-2008.

\begin{tabular}{lcccc}
\hline Sampling Location & $\mathrm{ME}\left({ }^{\circ} \mathrm{C}\right)$ & $\mathrm{MAE}\left({ }^{\circ} \mathrm{C}\right)$ & $\mathrm{RMSE}\left({ }^{\circ} \mathrm{C}\right)$ & Count \\
\hline 12116500, 2005-2008 & -0.23 & 0.68 & 0.86 & 1455 \\
12117600, 2005-2008 & 0.19 & 0.44 & 0.56 & 1455 \\
Weighted Average & -0.02 & 0.56 & 0.71 & 2910 \\
\hline
\end{tabular}

Temperature inputs for tributaries in the $\mathbf{2 0 1 5}$ model were estimated using available data. The Upper Cedar River tributaries, which included Lost Creek, Fish Creek, Canyon Creek, and the Rattlesnake Prairie, were based off of USGS 12115000 during the first 200 days of the year and USGS 12116500 for the remainder of the year. The Middle Cedar tributaries, which included De-Horn Creek, the unnamed left-bank input, Steele Creek, Williams Creek, and Taylor Creek, and the distributed flow for branch 4 were generated using model response to arbitrary temperature inputs. Temperature at Rock Creek was assumed to be consistent with temperature observed at USGS 12117600. 
Distributed flow for branch 5 was modeled using a constant value to emulate groundwater flows. Simulated temperatures over time for the entire river domain are displayed in Figure 87. The influence of low flow during the summer months is seen with the highest temperatures closest to the dam. The river experienced a cooling effect as it moved downstream of the dam. This is likely due to groundwater exchange and hyporheic flow. Comparisons of modeled temperature and observed temperature for all gages within the river model domain are show in Figure 88. Daily average temperature error statistics for the three gages are summarized in Table 18.

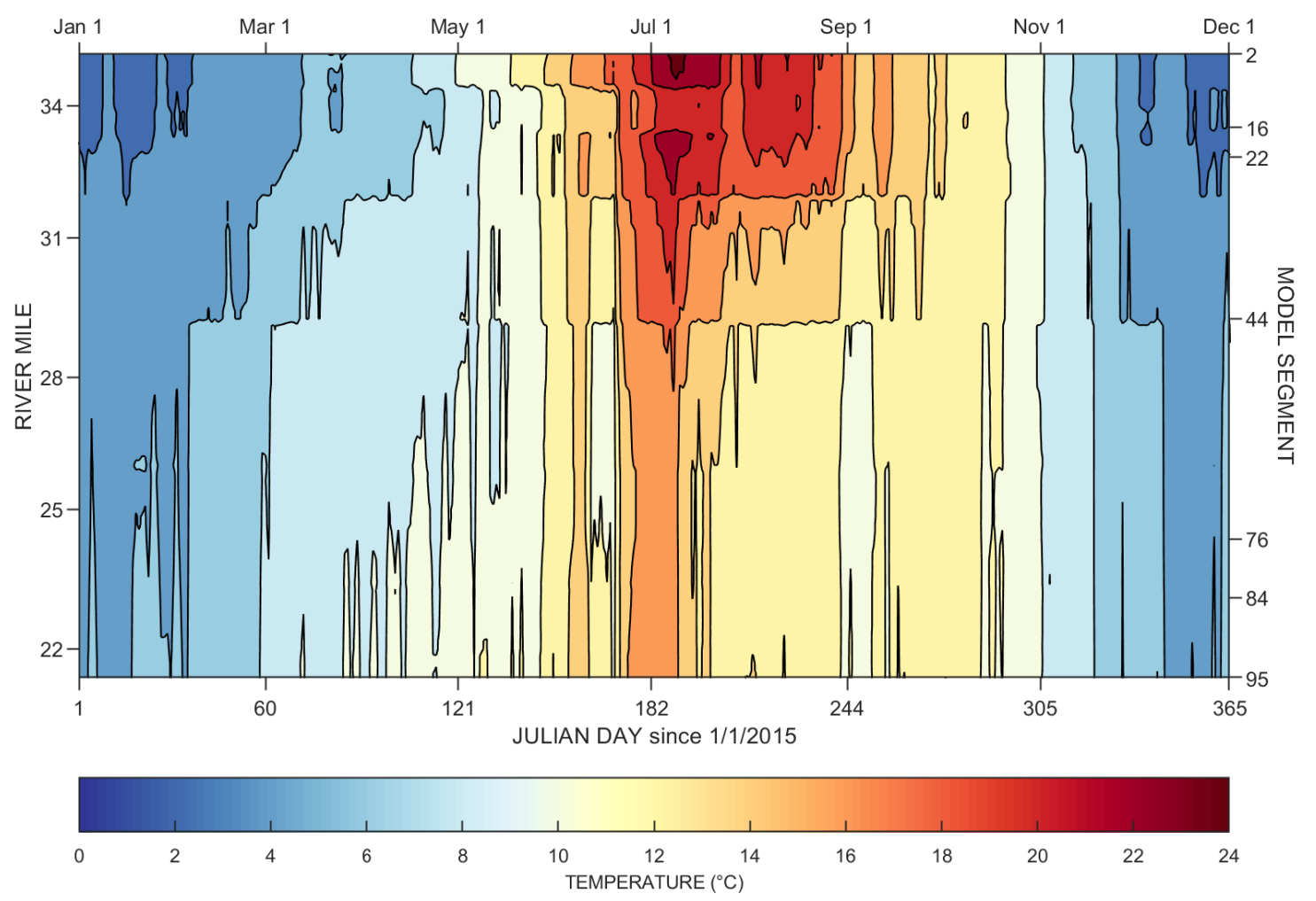

Figure 87. Simulated daily temperature at noon in the Cedar River, 2015. Model segments indicate the domain boundaries, USGS gaging stations, and water quality monitoring sites. 


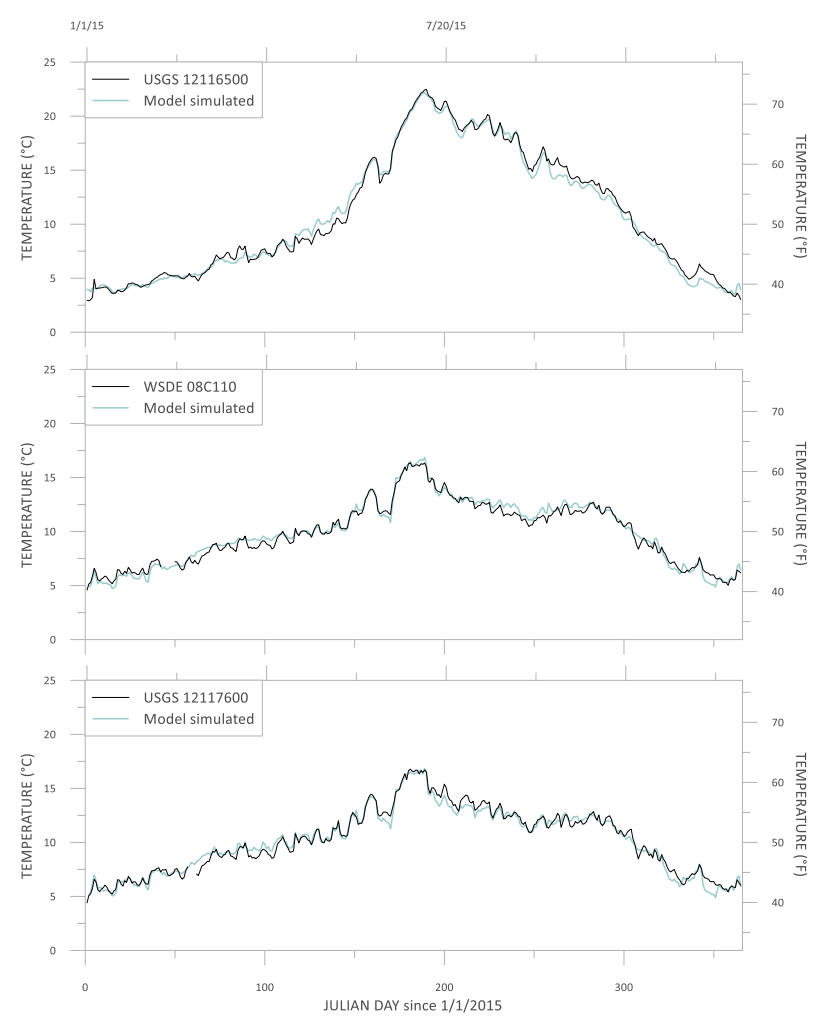

Figure 88. Modeled daily average temperature predictions compared to observed daily average temperature from 2015 at USGS 12116500 (top), WSDE $08 C 110$ (middle), and USGS 12117600 (bottom).

Table 18. Summary of daily average temperature error statistics for USGS 12116500, WSDE 08C110, and USGS 12117600, 2015.

\begin{tabular}{lcccc}
\hline Sampling Location & $\mathrm{ME}\left({ }^{\circ} \mathrm{C}\right)$ & $\operatorname{MAE}\left({ }^{\circ} \mathrm{C}\right)$ & $\mathrm{RMSE}\left({ }^{\circ} \mathrm{C}\right)$ & Count \\
\hline $\mathbf{1 2 1 1 6 5 0 0}, \mathbf{2 0 1 5}$ & -0.12 & 0.46 & 0.56 & 365 \\
$\mathbf{0 8 C 1 1 0 , 2 0 1 5}$ & 0.10 & 0.35 & 0.43 & 358 \\
$\mathbf{1 2 1 1 7 6 0 0 , 2 0 1 5}$ & -0.06 & 0.35 & 0.46 & 362 \\
Weighted Average & -0.03 & 0.39 & 0.48 & 1085 \\
\hline
\end{tabular}




\subsection{Water Quality}

Water quality data were available from two sites in the reservoir model domain and upwards of eight sites in the river domain. Measured data within the scope of this study included chlorophyll $a$, dissolved oxygen, total nitrogen, nitrate-nitrite, ammonia, total phosphorus, phosphate, total organic carbon, algae, and zooplankton.

\subsubsection{Chester Morse Lake}

Water quality calibration for Chester Morse Lake and the Masonry Pool used profile and grab sample data to adjust model parameters and match observed data with all errors minimized. The main methods used during water quality calibration included adjusting boundary condition concentrations, using model parameters to characterize three algal groups, and specifying the sediment oxygen demand.

Boundary condition field data were not available for any of the tributaries of Chester Morse Lake. In-lake concentrations were used as a reference point and adjustments to inflow concentrations were made iteratively based on model response. Constituent concentration inflows were developed using days corresponding to field data collection dates. The model linearly interpolated concentration values between sample dates.

The model simulated three major groups of algae: diatoms, green algae, and cyanobacteria. Model parameters for algal growth rate, algal temperature rate coefficients, and algal stoichiometric equivalent between algal biomass and 
chlorophyll $a$ were selected based on literature values and adjusted iteratively based on model response (Wells S. A., 2019).

Sediment oxygen demand was selected based on literature values and adjusted iteratively based on model response (Wells S. A., 2019).

Model parameters were determined using the 2015 reservoir model due to the shorter model duration and the wider breadth of available data. The calibration parameters developed during the 2015 reservoir calibration were used without alteration for the 2005-2008 reservoir model.

SPU provided grab sample data measured at the Masonry Dam station MD and vertical profile data measured mid-lake at station CM1A. Samples were collected approximately monthly. Dissolved oxygen was measured in 1-meter increments at CM1A for 2005-2008. Chlorophyll $a$ and dissolved oxygen were measured in 1-meter increments at $\mathrm{CM} 1 \mathrm{~A}$ for 2015. All other constituent samples at CM1A were measured using a volume weighted composite average for the epilimnion and hypolimnion with discrete values in the metalimnion. All samples at MD were discrete grab samples. Table 19 summarizes water quality error statistics for 2005-2008 and 2015. Error statistics were generated for all discrete samples. Error statistics were not generated between the model and the volume weighted composite average, as the data format did not allow for a direct comparison to the model outputs. Calibration results for chlorophyll $a$ are shown in Figure 89 for 2015. RMSE was below $1 \mu \mathrm{g} / \mathrm{L}$ for all sample days with the 
exception of three: March 16, April 14, and October 29. These days were excluded from analysis based on discrepancy between the vertical profile data and the volume weighted composite average data on these days. Daily dissolved oxygen concentrations at noon over time and depth as modeled mid-lake at station CM1A and in the Masonry Dam at station MD are shown in Figure 90 for 2005-2008. Daily dissolved oxygen concentrations at noon over time and depth for 2015 are shown in Figure 91 for station CM1A and in Figure 92 for the Masonry Dam. Water quality calibration results for dissolved oxygen are presented in Figure 93 for 2005-2008 and in Figure 94 for 2015. RMSE was below $1 \mathrm{mg} / \mathrm{L}$ for 85 percent of sample days in 2005-2008 and for all sample days in 2015.

Table 19. Summary of water quality error statistics for chlorophyll a and dissolved oxygen, 2005-2008 and 2015. * indicates that some data were excluded from analysis.

\begin{tabular}{lcccc}
\hline Parameter & ME (mg/L) & MAE (mg/L) & RMSE (mg/L) & Count \\
\hline Chlorophyll $a$, 2015 & $-3.3 e-4$ & $6.6 \mathrm{e}-4$ & $7.2 \mathrm{e}-4$ & 551 \\
Chlorophyll $a$, 2015* & $-0.3 \mathrm{e}-4$ & $4.2 \mathrm{e}-4$ & $4.8 \mathrm{e}-4$ & 454 \\
Dissolved oxygen, 2005-2008 & -0.17 & 0.59 & 0.66 & 1338 \\
Dissolved oxygen, 2015 & 0.14 & 0.43 & 0.51 & 551 \\
\hline
\end{tabular}




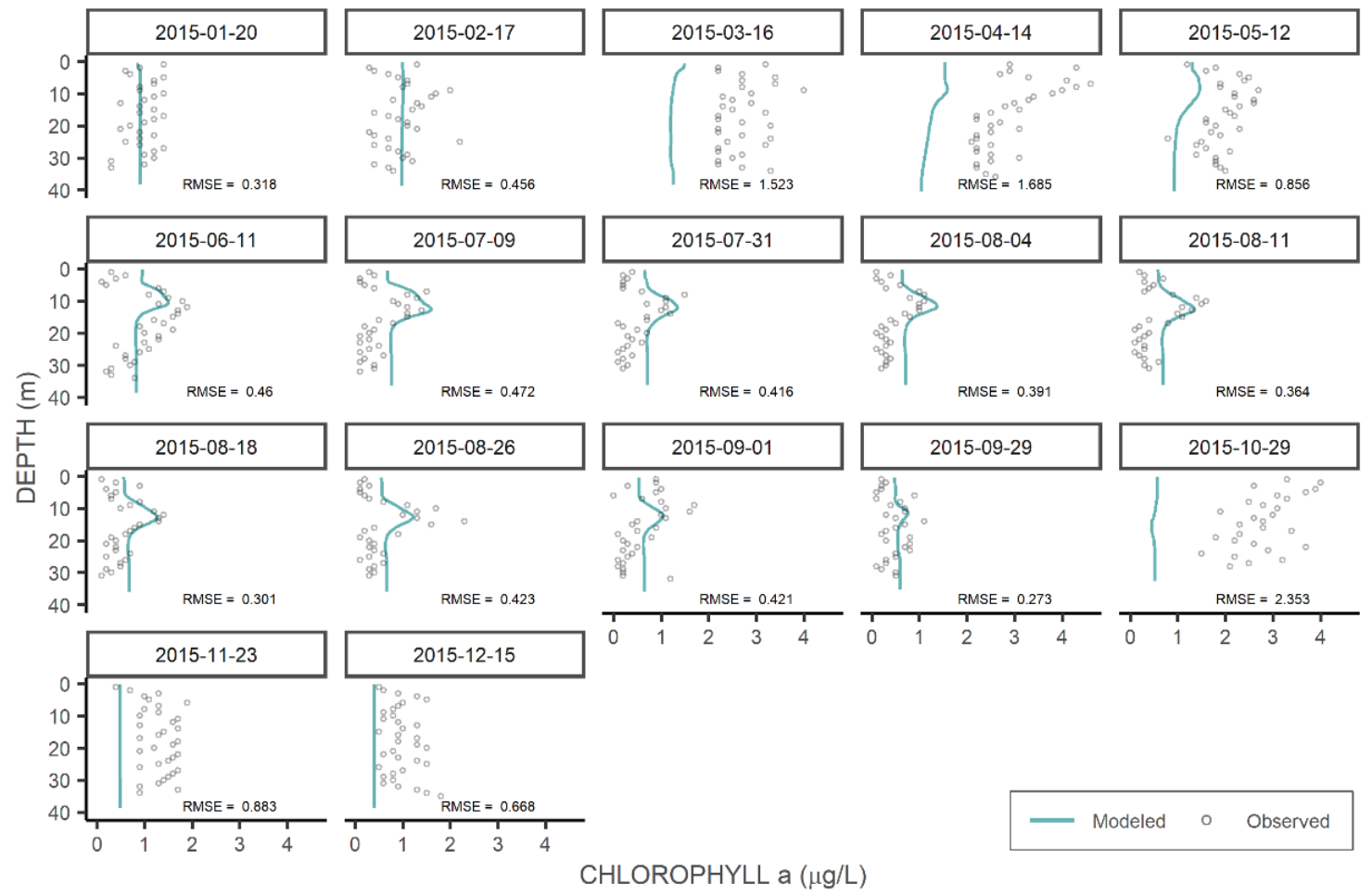

Figure 89. Comparison of modeled chlorophyll a concentrations to observed chlorophyll a data at CM1A, 2015. 

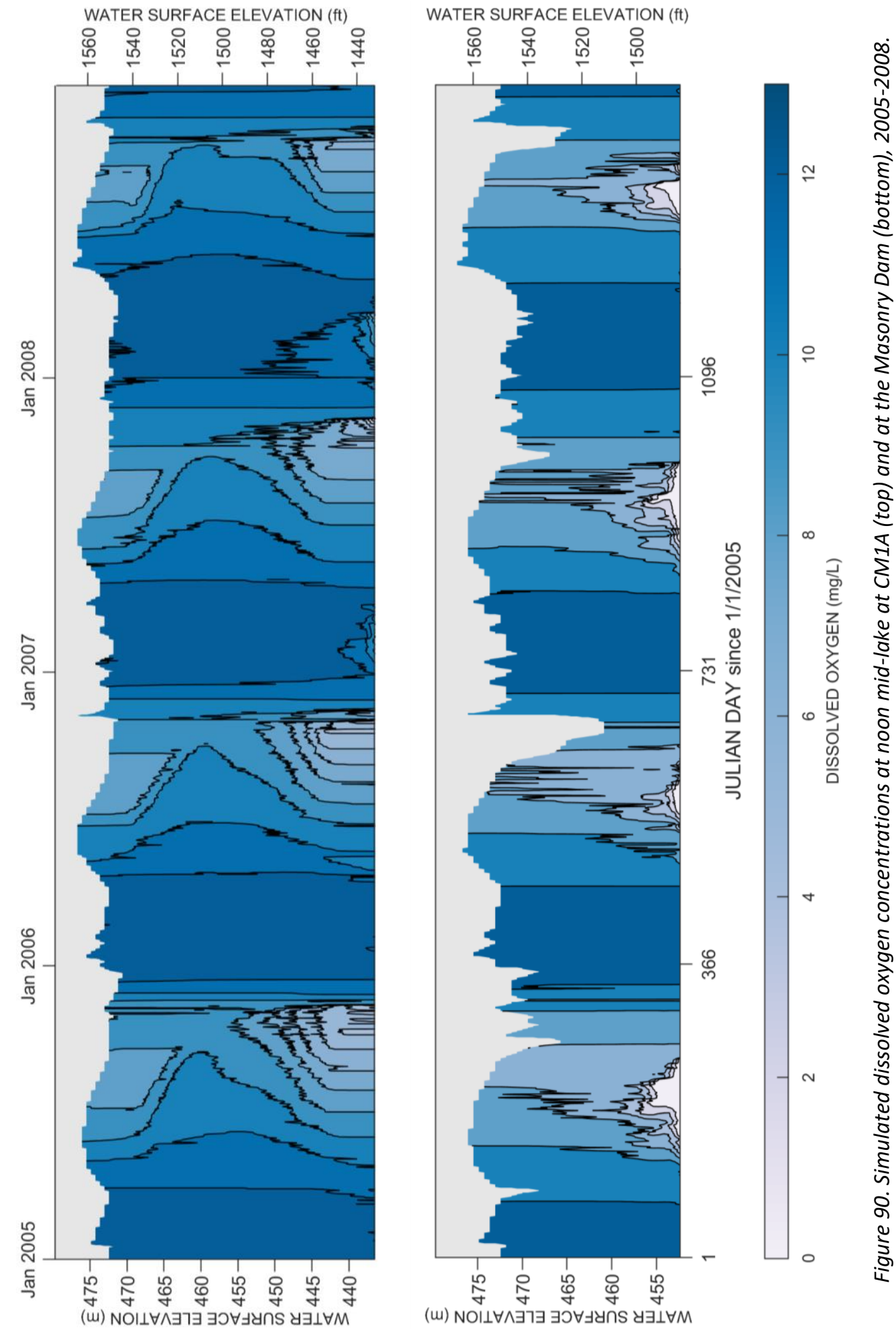

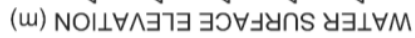



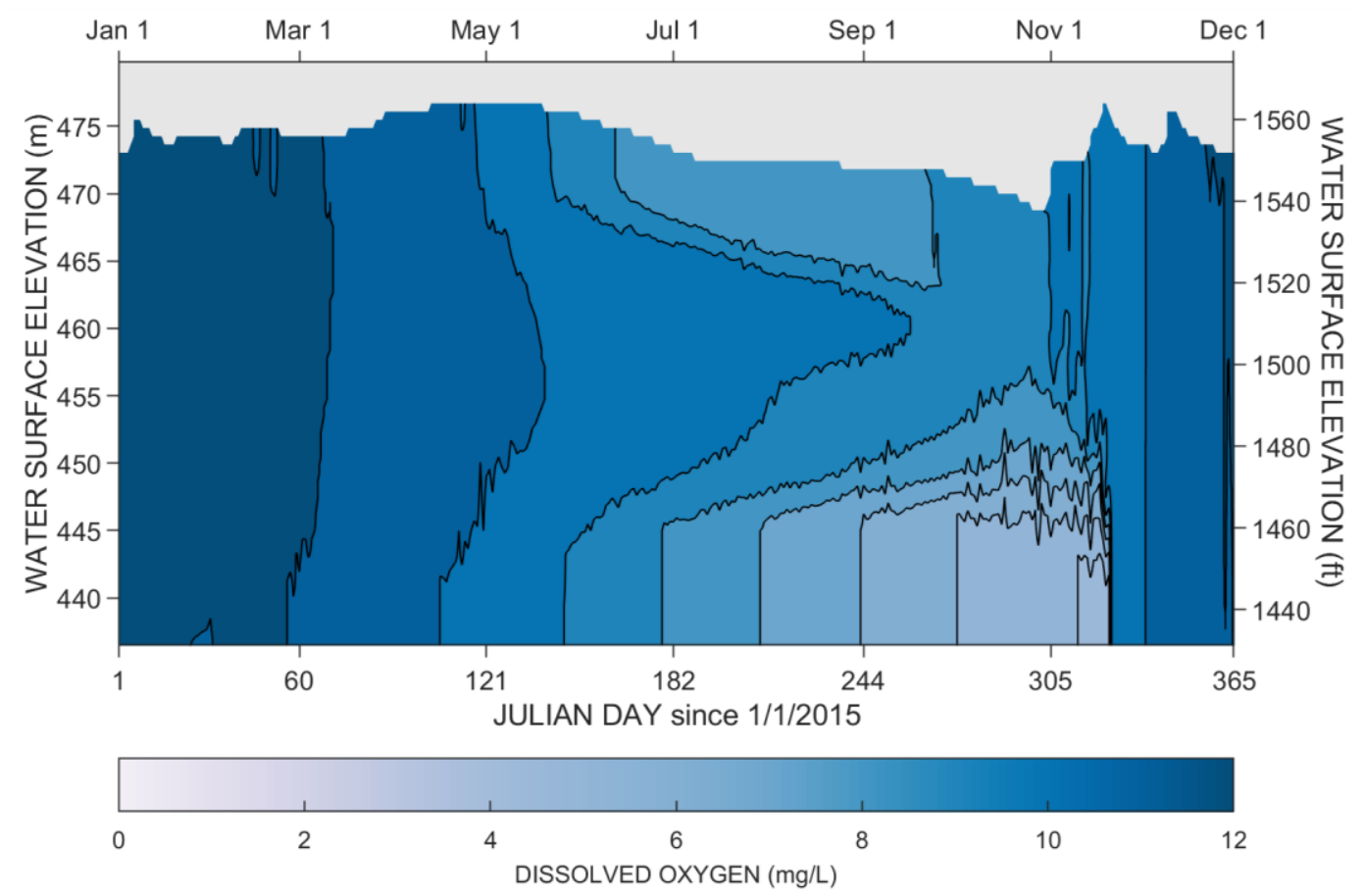

Figure 91. Simulated dissolved oxygen concentrations at noon mid-lake at CM1A, 2015.
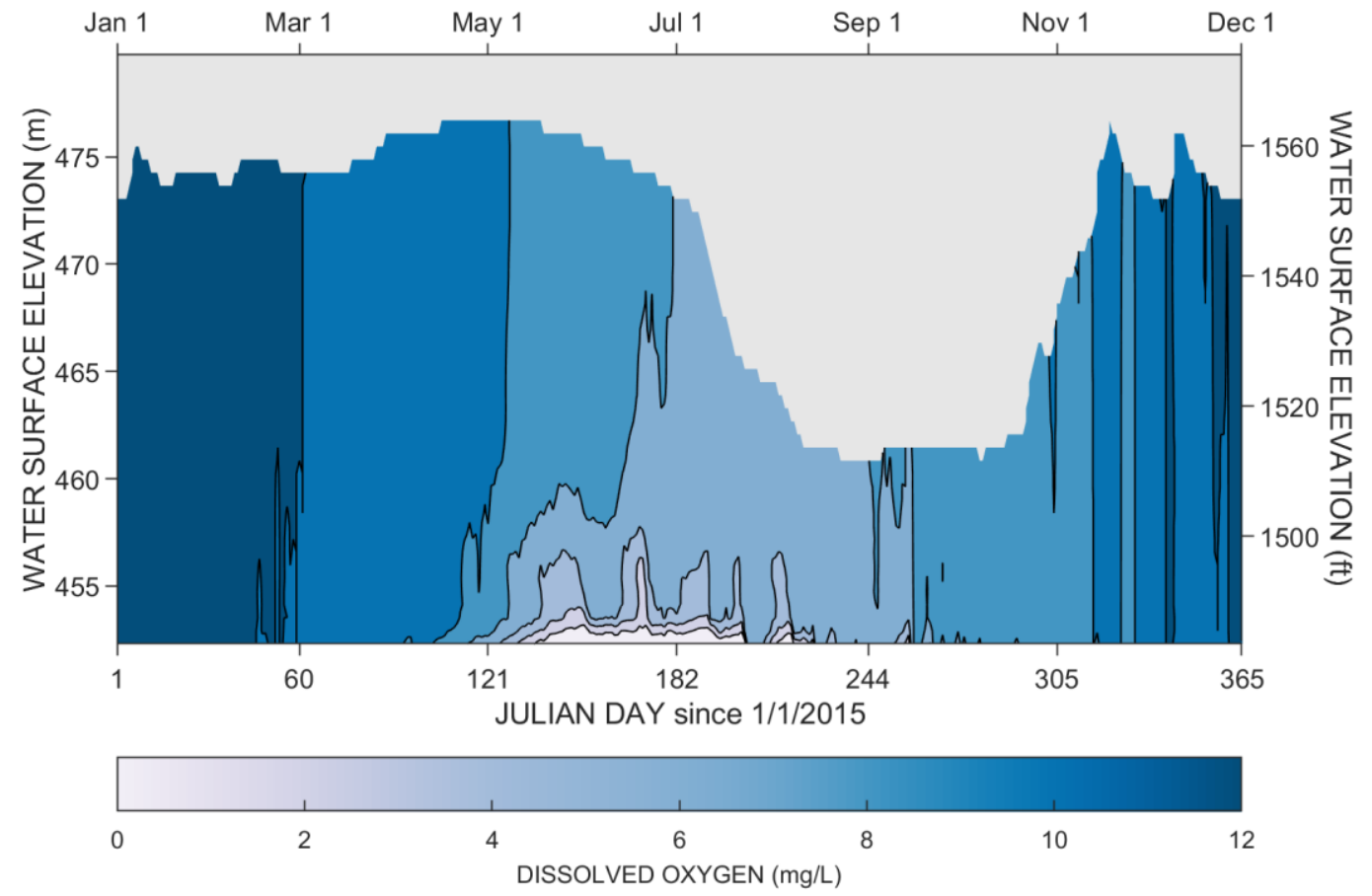

Figure 92. Simulated dissolved oxygen concentrations at noon at the Masonry Dam, 2015. 


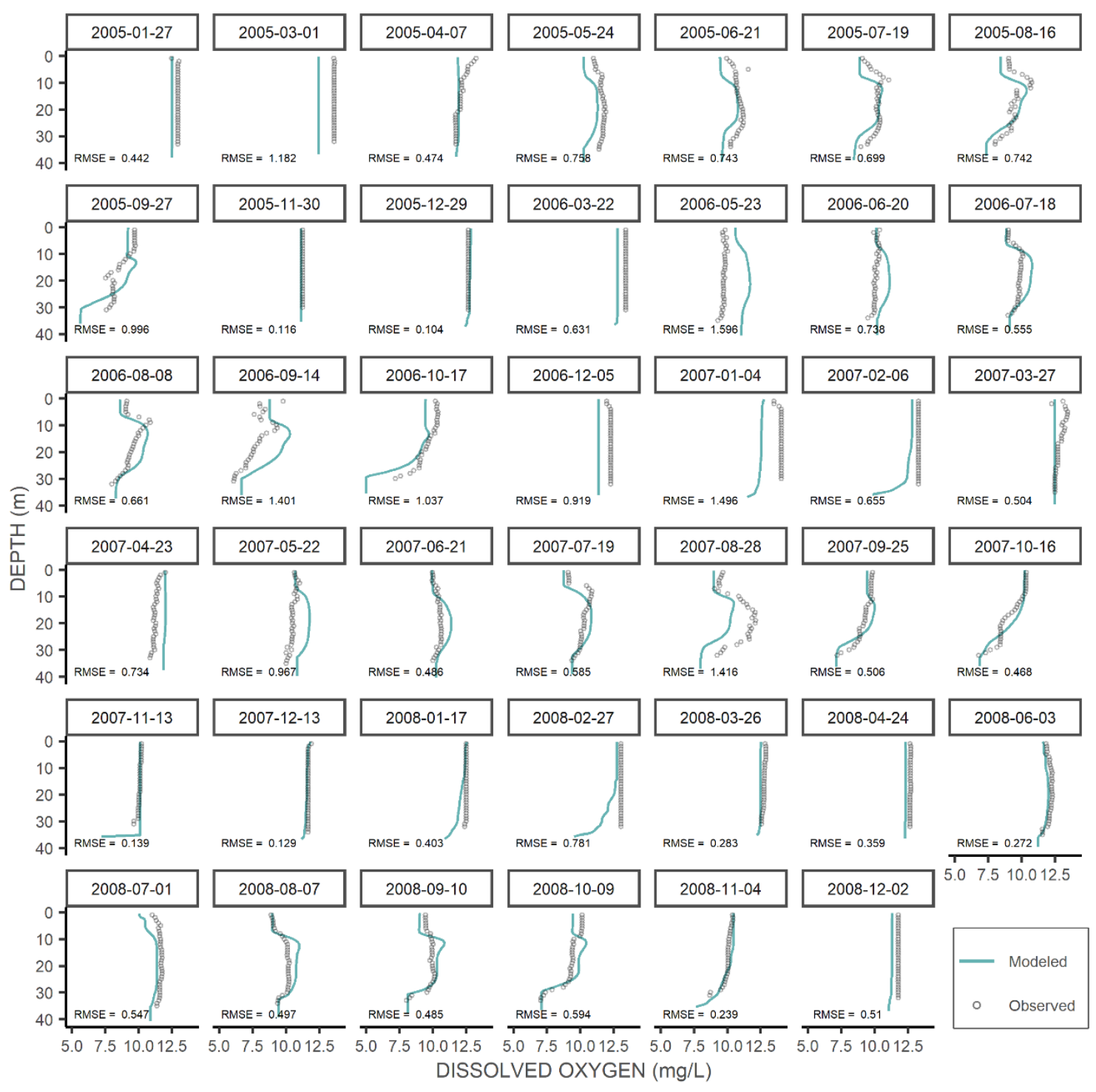

Figure 93. Comparison of modeled dissolved oxygen concentrations to observed dissolved oxygen data at CM1A, 2005-2008. 


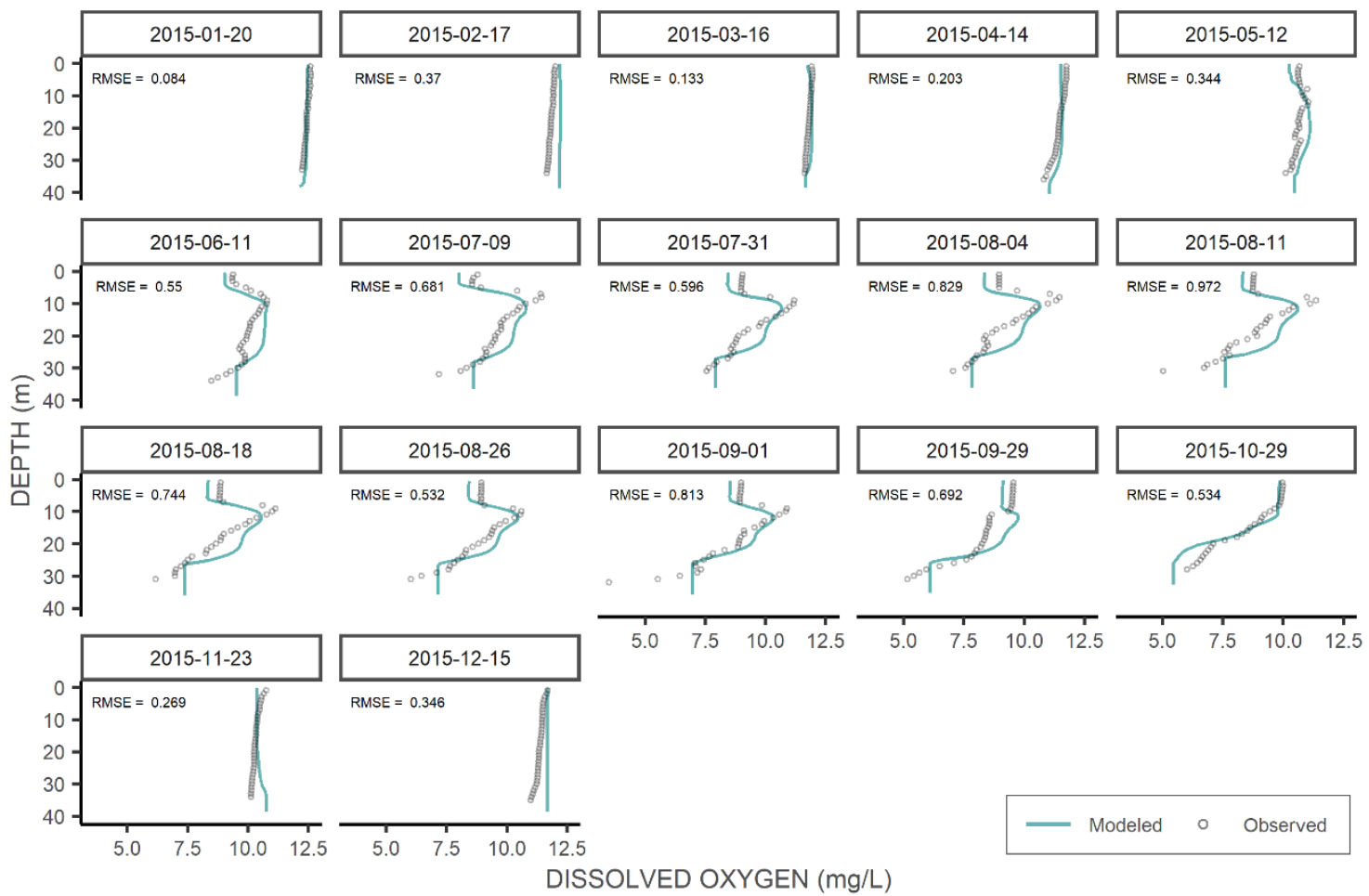

Figure 94. Comparison of modeled dissolved oxygen concentrations to observed dissolved oxygen data at CM1A, 2015.

Additional calibration results for all volume weighted composite average samples are included in the Appendix. Simulated concentrations of total nitrogen, nitrate-nitrite, total phosphorus, phosphate, and total organic carbon were compared to volume weighted composite average field data. The simulated ranges of constituent concentrations were consistent with the observed ranges with the exception of phosphate in the 2015 model. Concentration ranges are summarized in Table 20. 
Table 20. Summary of observed and modeled concentration ranges at CM1A in 2005-2008 and 2015.

\begin{tabular}{lcccc}
\hline Parameter & $\begin{array}{c}\text { Observed Range, } \\
\mathbf{2 0 0 5 - 2 0 0 8} \\
(\mathbf{m g} / \mathrm{L})\end{array}$ & $\begin{array}{c}\text { Modeled Range, } \\
\mathbf{2 0 0 5 - 2 0 0 8} \\
(\mathbf{m g} / \mathrm{L})\end{array}$ & $\begin{array}{c}\text { Observed Range, } \\
\mathbf{2 0 1 5}(\mathbf{m g} / \mathrm{L})\end{array}$ & $\begin{array}{c}\text { Modeled Range, } \\
\mathbf{2 0 1 5}(\mathbf{m g} / \mathrm{L})\end{array}$ \\
\hline Total nitrogen & $\mathrm{NA}$ & $0.08-0.19$ & $0.06-0.22$ & $0.07-0.20$ \\
\hline Nitrate-nitrite & $0.01-0.14$ & $0.01-0.13$ & $0.01-0.11$ & $0.04-0.12$ \\
\hline Total phosphorus & $1 \mathrm{e}-3-7.9 \mathrm{e}-3$ & $2 \mathrm{e}-3-6 \mathrm{e}-3$ & $1.5 \mathrm{e}-3-13.2 \mathrm{e}-3$ & $3.39 \mathrm{e}-3-8.36 \mathrm{e}-3$ \\
\hline Phosphate & $0.0-3.8 \mathrm{e}-3$ & $0.0-2.5 \mathrm{e}-3$ & $5.0 \mathrm{e}-4-2.19 \mathrm{e}-3$ & $2.8 \mathrm{e}-4-2.37 \mathrm{e}-3$ \\
\hline Total organic carbon & $0.74-1.54$ & $0.81-1.53$ & $0.97-1.63$ & $0.93-1.69$ \\
\hline
\end{tabular}

\subsubsection{Cedar River}

Water quality calibration for the Cedar River used grab sample data to adjust model parameters and match observed data with all errors minimized. The main methods used during water quality calibration included adjusting boundary condition concentrations.

The 2005-2008 and 2015 river models used the same model parameters as the reservoir models with the exception of sediment oxygen demand, which was reduced by 10 percent.

Limited water quality field data were available during 2005-2008. Dissolved oxygen, total nitrogen, nitrate-nitrite, ammonia, total phosphorus, and phosphate data were available at WSDE 08C110 (segment 74) with a monthly sample frequency throughout the modeled period. Total nitrogen, nitrate-nitrite, total phosphorus, phosphate, and total organic carbon data were available at two SPU sample locations, CR-PWRHS (segment 16) and CPR1 (segment 95). Collection at CR-PWRHS began on October 4, 2007 with a maximum of 26 samples per constituent collected during the modeled period. Data from CPR1 were available for the full model period. Sample count ranged 
from a low of 32 total nitrogen samples to a high of 287 phosphate samples. Due to the irregular sampling protocol, boundary condition data for all parameters developed for 2015 was used annually for the 2005-2008 model with the exception of dissolved oxygen. The method established by Benson and Krause was used to predict the solubility of dissolved oxygen accounting for the elevation and water temperature of each waterbody in the river model. Boundary condition concentrations were adjusted iteratively based on model response. Simulated dissolved oxygen concentrations at noon for the entire river domain are displayed in Figure 95. Error statistics are summarized in Table 21 . Water quality calibration results for all modeled parameters compared to the most downstream observed field data are presented in Figure 100 to Figure 102. Additional comparisons at all upstream observation sites are included in the Appendix. 


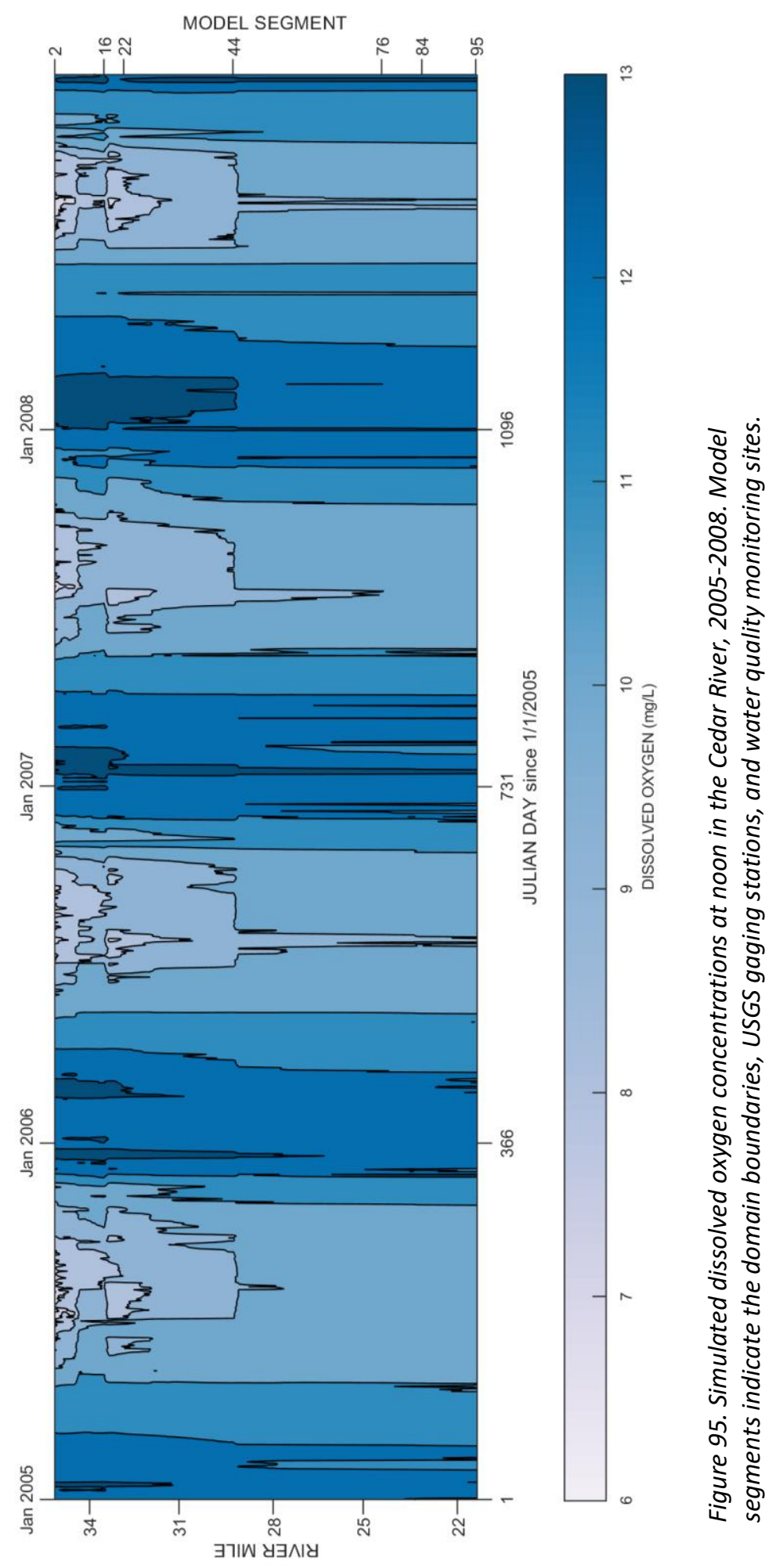


Table 21. Summary of weighted average concentration error statistics in the Cedar River, 2005-2008.

\begin{tabular}{lcccc}
\hline Parameter & ME $(\mathrm{mg} / \mathrm{L})$ & MAE $(\mathrm{mg} / \mathrm{L})$ & RMSE $(\mathrm{mg} / \mathrm{L})$ & Count \\
\hline Dissolved oxygen & -0.17 & 0.36 & 0.36 & 43 \\
\hline Total nitrogen & 0.04 & 0.05 & 0.05 & 75 \\
\hline Nitrate-nitrite & -0.02 & 0.03 & 0.03 & 172 \\
\hline Ammonia & -0.003 & 0.003 & 0.003 & 43 \\
\hline Total phosphorus & $3.13 \mathrm{e}-3$ & $3.89 \mathrm{e}-3$ & $3.89 \mathrm{e}-3$ & 152 \\
\hline Phosphate & $-4.9 \mathrm{e}-4$ & $1.13 \mathrm{e}-3$ & $1.13 \mathrm{e}-3$ & 193 \\
\hline Total organic carbon & -0.05 & 0.18 & 0.18 & 152 \\
\hline
\end{tabular}

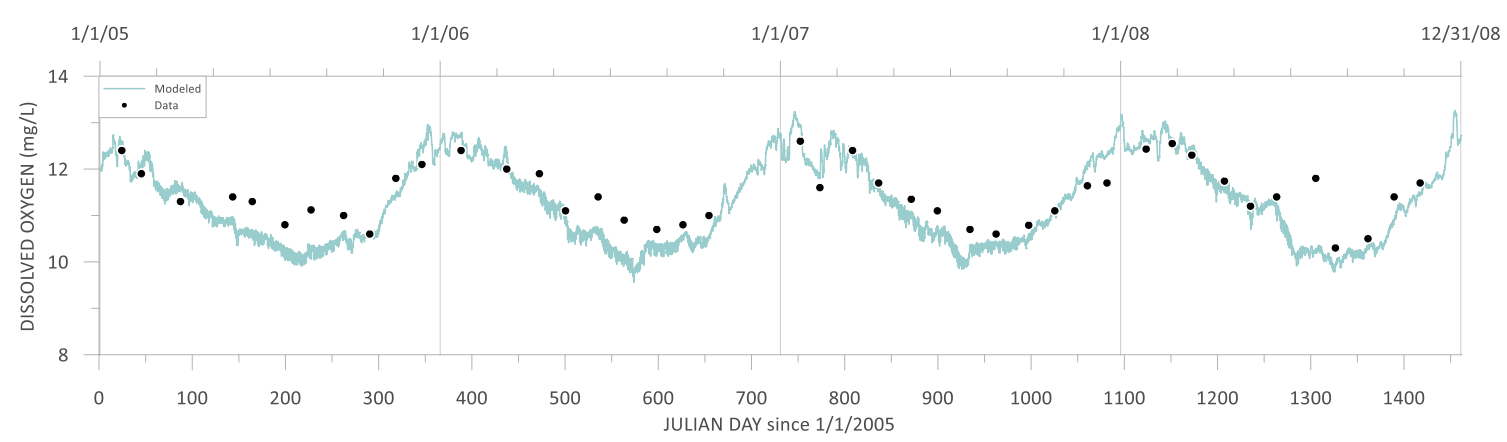

Figure 96. Comparison of modeled dissolved oxygen concentrations to observed concentrations at WSDE 08 C110 (segment 74), 2005-2008.

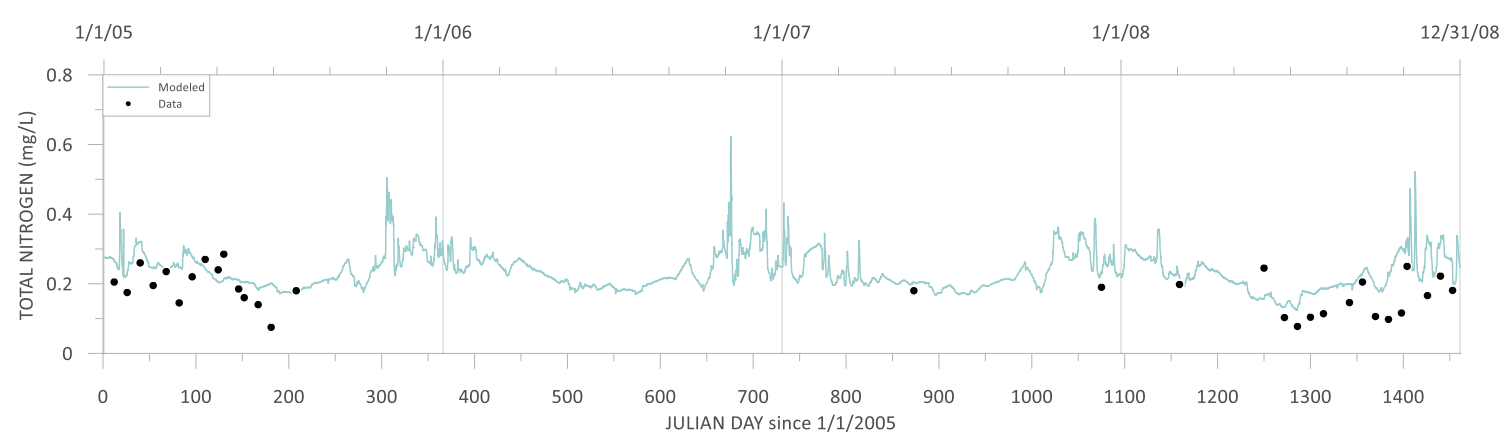

Figure 97. Comparison of modeled total nitrogen concentrations to observed concentrations at CPR1 (segment 95), 2005-2008. 


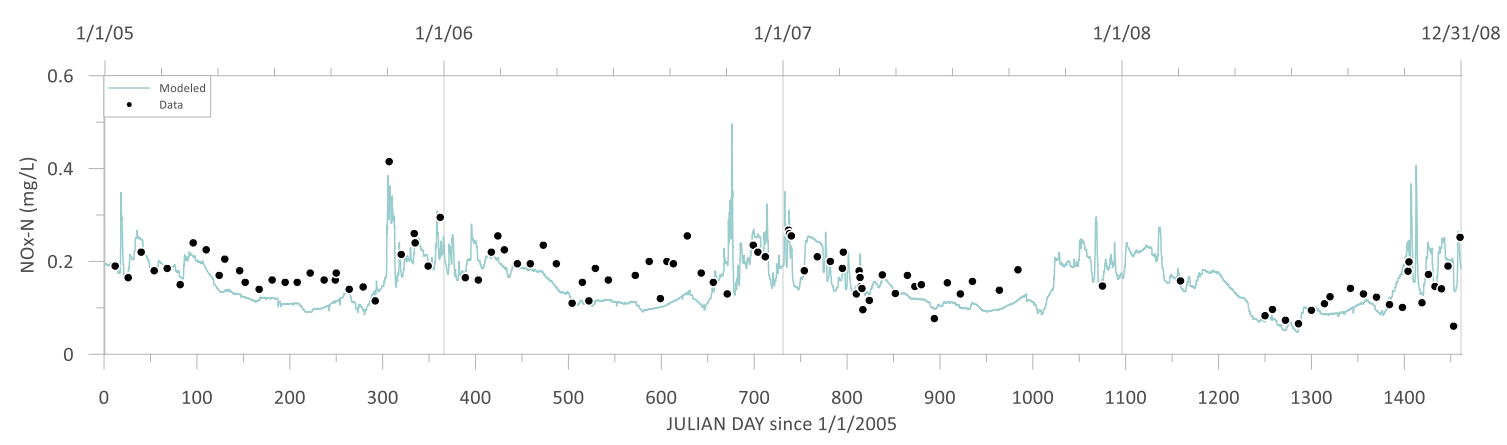

Figure 98. Comparison of modeled nitrate-nitrite concentrations to observed concentrations at CPR1 (segment 95), 2005-2008.

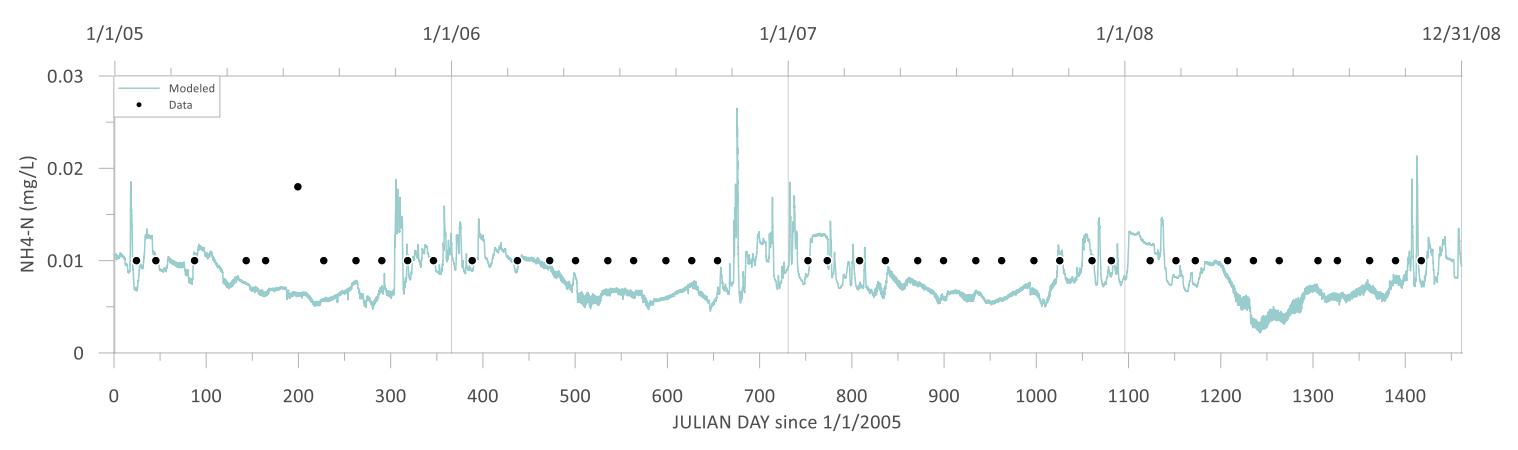

Figure 99. Comparison of modeled ammonia concentrations to observed concentrations at WSDE 08C110 (segment 74), 2005-2008.

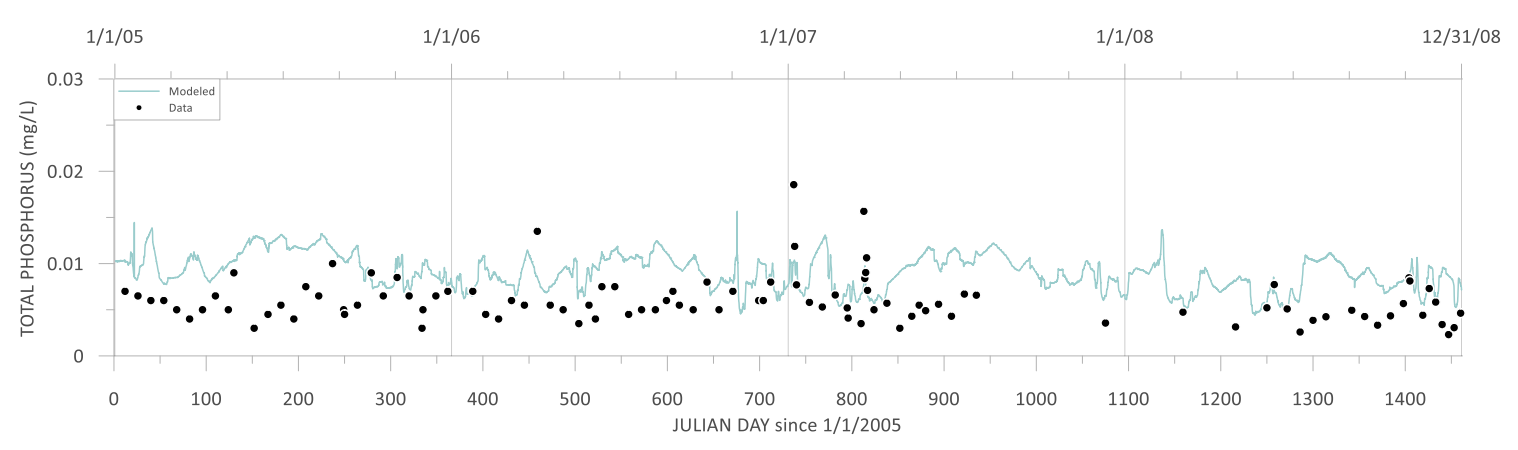

Figure 100. Comparison of modeled total phosphorus concentrations to observed concentrations at CPR1 (segment 95), 2005-2008. 


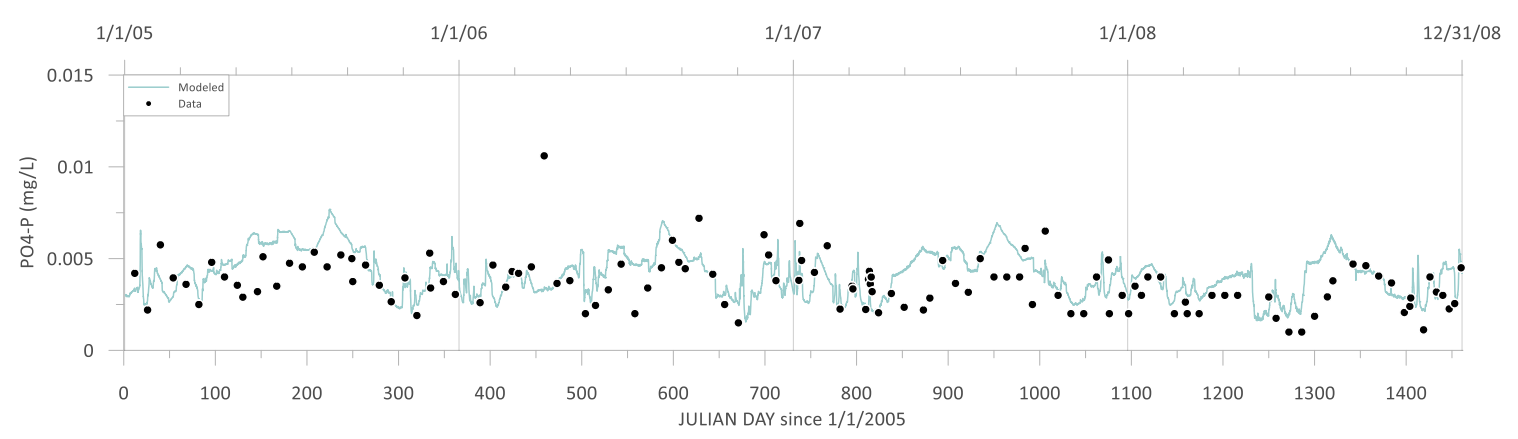

Figure 101. Comparison of modeled phosphate concentrations to observed concentrations at CPR1 (segment 95), 2005-2008.

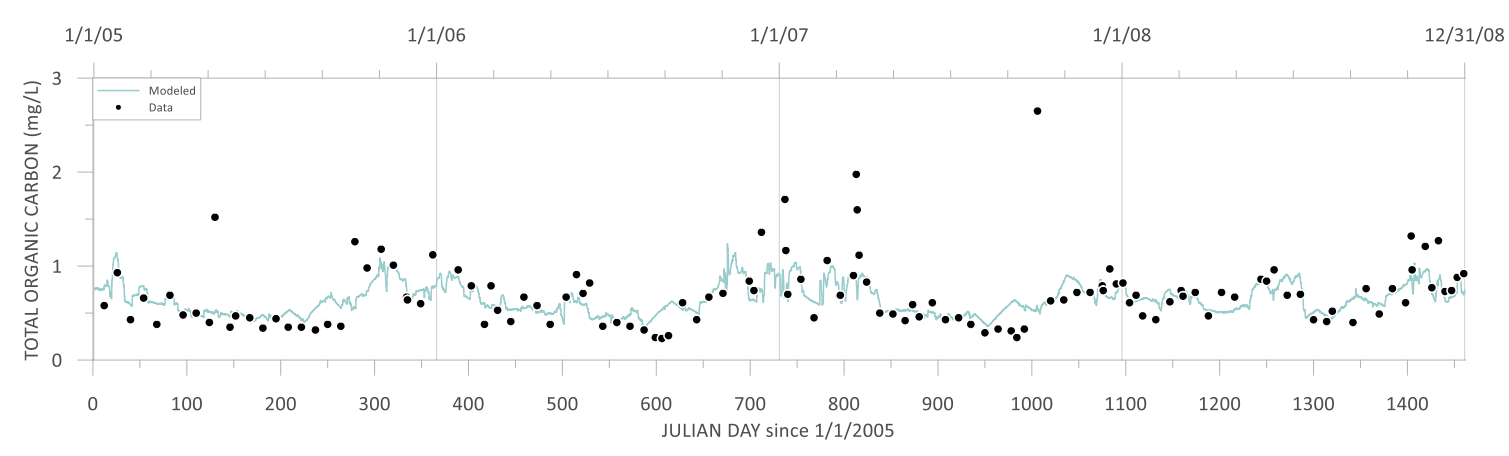

Figure 102. Comparison of modeled total organic carbon concentrations to observed concentrations at CPR1 (segment 95), 2005-2008.

Water quality data were available at five sites during 2015. Dissolved oxygen, total nitrogen, nitrate-nitrite, ammonia, total phosphorus, and phosphate were available approximately monthly at WSDE 08C110 (segment 74). Total nitrogen, nitrate-nitrite, total phosphorus, phosphate, and total organic carbon were available approximately bi-monthly at CR-PWRHS, CR3, CR7 and CPR1 (segments 16, 44, 76, and 95, respectively). Boundary condition concentrations were adjusted iteratively based on model response. Simulated dissolved oxygen concentrations at noon for the entire river domain are displayed in Figure 103. Error statistics are summarized in Table 22. Water quality calibration results for all modeled parameters compared to the most 
downstream observed field data are presented in Figure 108 through Figure 110.

Additional comparisons at all upstream observation sites are included in the Appendix.

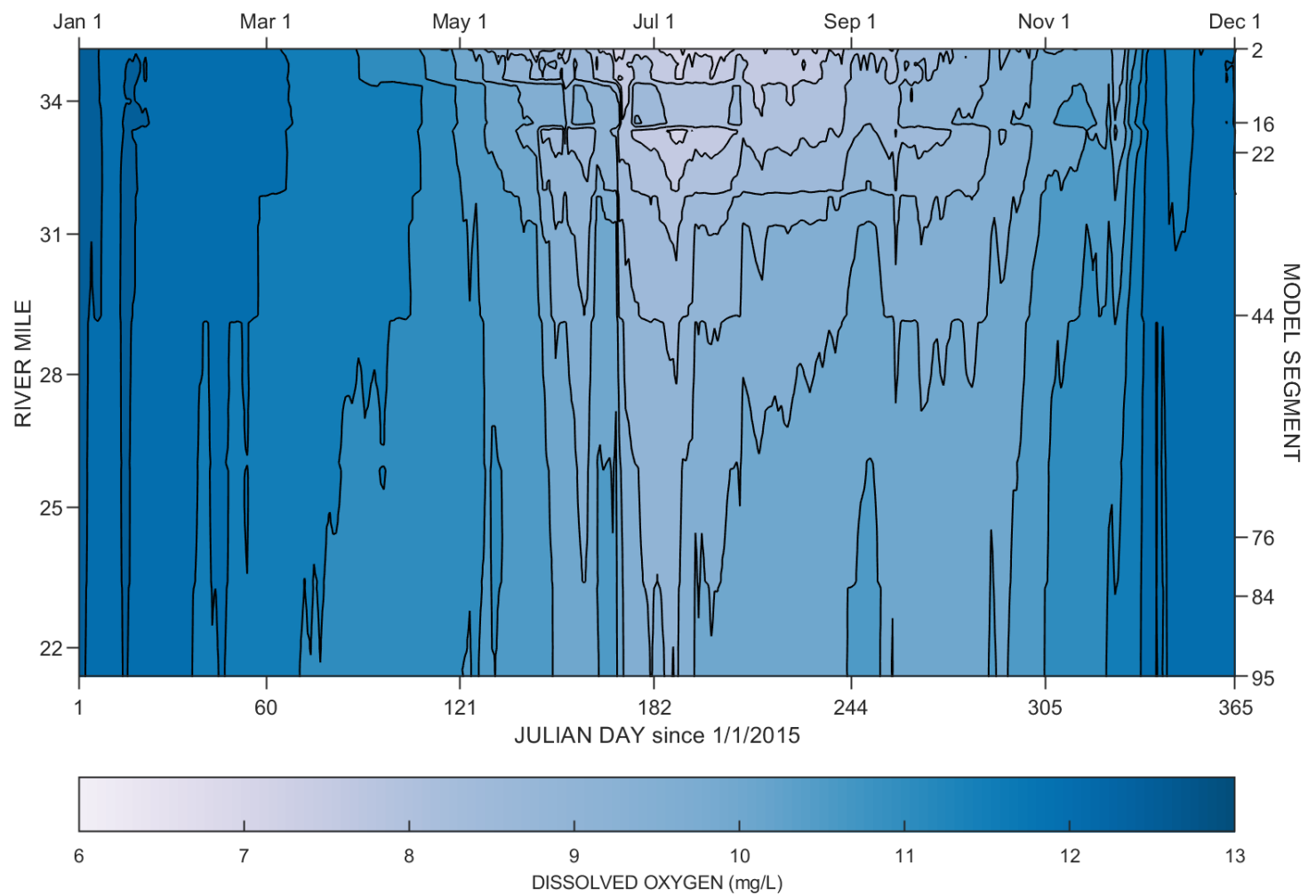

Figure 103. Simulated dissolved oxygen concentrations at noon in the Cedar River, 2015. Model segments indicate the domain boundaries, USGS gaging stations, and water quality monitoring sites.

Table 22. Summary of weighted average concentration error statistics in the Cedar River, 2015.

\begin{tabular}{lcccc}
\hline Parameter & ME $(\mathrm{mg} / \mathrm{L})$ & MAE $(\mathrm{mg} / \mathrm{L})$ & $\mathrm{RMSE}(\mathrm{mg} / \mathrm{L})$ & Count \\
\hline Dissolved oxygen & -0.21 & 0.32 & 0.32 & 12 \\
\hline Total nitrogen & 0.10 & 0.11 & 0.11 & 103 \\
Nitrate-nitrite & -0.007 & 0.018 & 0.018 & 103 \\
\hline Ammonia & -0.003 & 0.004 & 0.004 & 12 \\
\hline Total phosphorus & $-9.7 \mathrm{e}-6$ & $1.3 \mathrm{e}-3$ & $1.3 \mathrm{e}-3$ & 103 \\
Phosphate & $-1.1 \mathrm{e}-3$ & $1.3 \mathrm{e}-3$ & $1.3 \mathrm{e}-3$ & 103 \\
\hline Total organic carbon & 0.06 & 0.12 & 0.12 & 56 \\
\hline
\end{tabular}




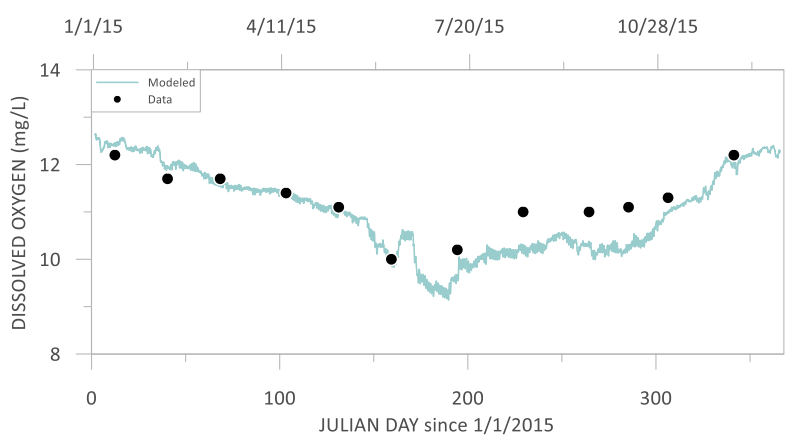

Figure 104. Comparison of modeled dissolved oxygen concentrations to observed concentrations at WSDE 08C110 (segment 74), 2015.

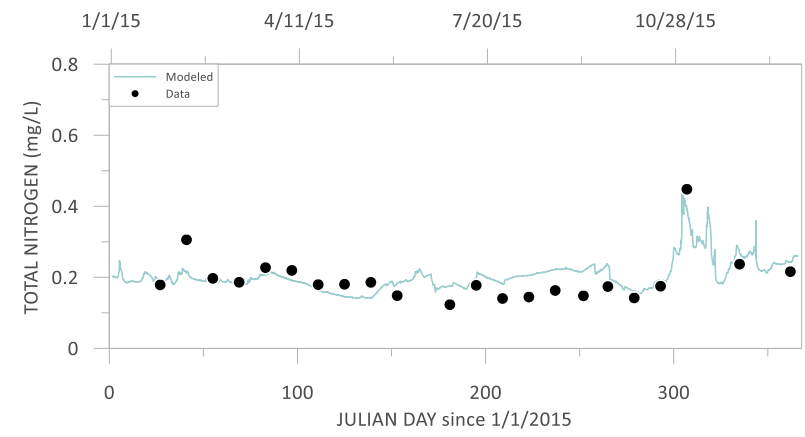

Figure 105. Comparison of modeled total nitrogen concentrations to observed concentrations at CPR1 (segment 95), 2015.

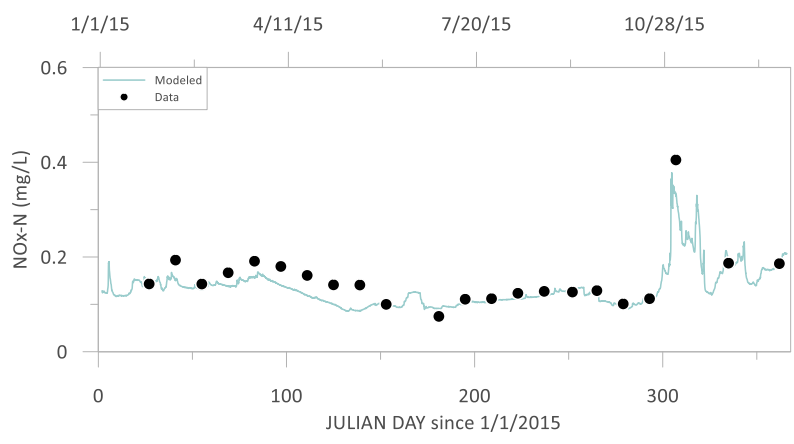

Figure 106. Comparison of modeled nitrate-nitrite concentrations to observed concentrations at CPR1 (segment 95), 2015. 


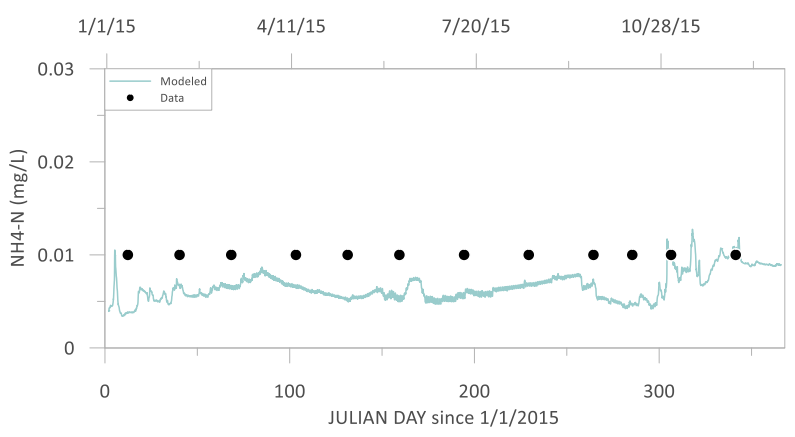

Figure 107. Comparison of modeled ammonia concentrations to observed concentrations at WSDE 08C110 (segment 74), 2015.

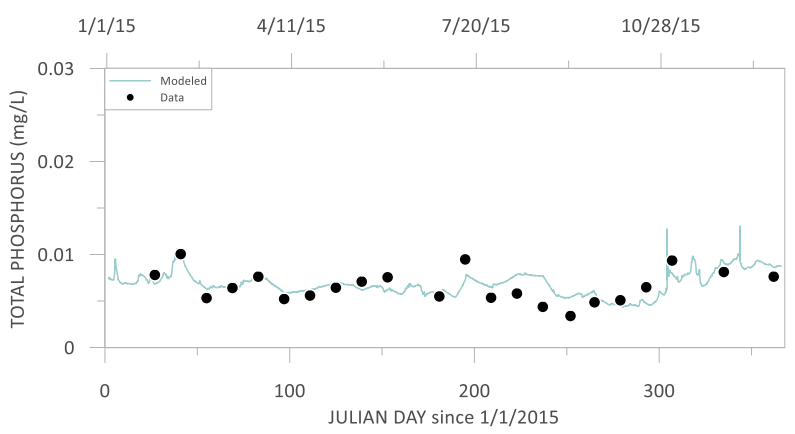

Figure 108. Comparison of modeled total phosphorus concentrations to observed concentrations at CPR1 (segment 95), 2015.

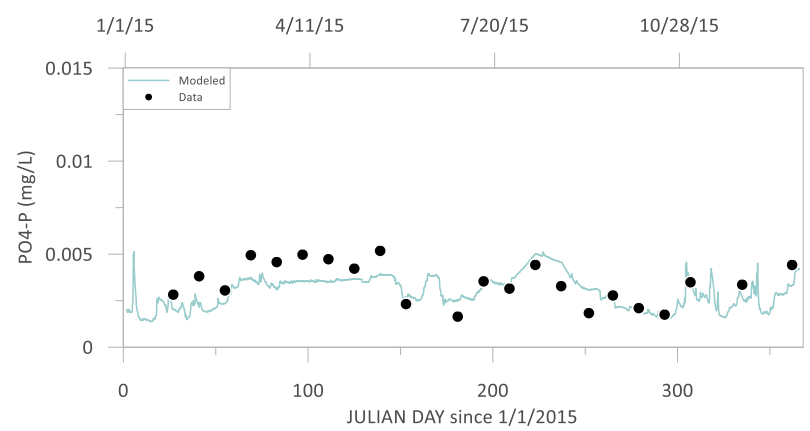

Figure 109. Comparison of modeled phosphate concentrations to observed concentrations at CPR1 (segment 95), 2015. 


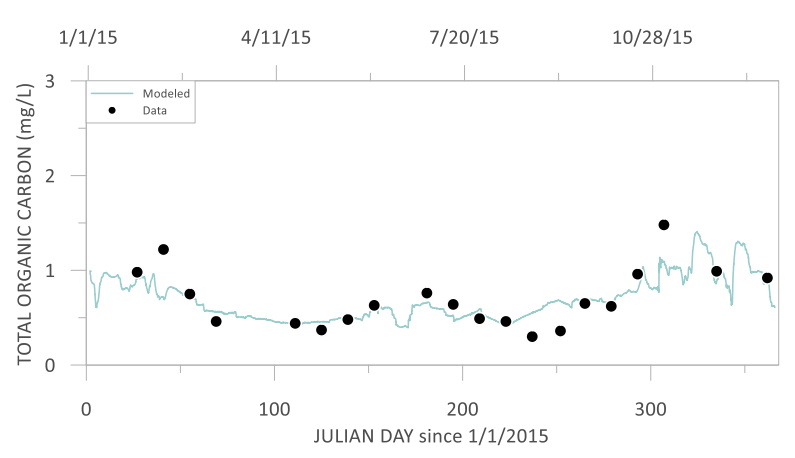

Figure 110. Comparison of modeled total organic carbon concentrations to observed concentrations at CPR1 (segment 95), 2015.

\subsection{Discussion of Model Calibration}

\subsubsection{Chester Morse Lake Water Balance}

The water balance in the reservoir models adjusted modeled water surface elevations using distributed flows to match observed water surface elevations at USGS 12115900 and USGS 12116060 . The process was complicated by numerous confounding factors including flow at the major reservoir structures, data availability in the Masonry Pool, and seepage loss through the glacial moraine. When inflows and outflows from a system are gaged and well-understood, the water balance becomes a simple mass balance calibration. In this study, the primary inflows for the system were gaged and other secondary inflows required little estimation. In contrast, outflows from the system were largely unknown and required extensive estimation. Flow rates were not available for any of the major structures on the reservoir. Outflows from the Masonry Dam were estimated using differences in gaged flow below the reservoir. Flow at the Overflow Dike was estimated using a weir equation and the dynamic pipe algorithm. Pumping flow rates and durations at the MLPP were estimated using observed water surface 
elevations. The water surface elevation in the Masonry Pool was sensitive to changes in the water surface elevation in the main reservoir. During lower water levels when the system had bifurcated, small adjustments in the degree of openness of the pipe connecting the two waterbodies strongly influenced the water level in the Masonry Pool. This was further complicated by data availability. Water surface elevations at the Overflow Dike (USGS 12115900) were available hourly for the 2005-2008 model and from January 1 through October 21, 2015. Water surface elevations were available every 15 minutes from October 21 through December 31, 2015. In contrast, water surface elevations at the Masonry Dam (USGS 12116060) were available daily for both the 2005-2008 model and the 2015 model.

The reservoir loses water via seepage through the glacial moraine abutting the Masonry Pool. Using methods consistent with the 1967 seepage evaluation (Hidaka \& Garrett, 1967), mean annual estimated seepage was $6.72 \pm 0.45 \mathrm{~m}^{3} / \mathrm{s}$ for WY 2005 to 2016 (Cervarich \& Scott, 2019). During this study, seepage and other ungaged flows in the Masonry Pool were estimated using differences in observed water surface elevations. Seepage loss impacts reservoir management strategy and slope stability. Current seepage loss is estimated using polynomial regression. No comparison to field data were available to corroborate seepage loss estimation. 


\subsubsection{Cedar River Flow Balance}

Modeled flows in the Cedar River were balanced using a mass balance approach at three USGS gaging stations along the length of the river model domain. The river has two gaging stations, USGS 12116400 and USGS 12116500, located within the first 3.86 kilometers (2.4 miles) from the Masonry Dam. The next gaging station, USGS 12117500, is located 15.77 kilometers (9.8 miles) downstream of USGS 12116500 . Inflows were estimated using differences between observed flow and the drainage-area ratio method. No field data were available to compare estimated tributary and groundwater inputs. Additionally, the Landsburg Diversion Dam, which is located approximately 1.8 kilometers upstream of USGS 12117600, formed the end of the model domain. As a result, model segments downstream of USGS 12117500 were excluded from the flow balance in the absence of diversion rates at the dam.

\subsubsection{Water Temperature Calibration Discussion}

\subsubsection{Chester Morse Lake}

Temperature calibration for the reservoir models was completed using in-lake temperature data and continuous temperature data from the USGS 12115000 . The 2015 reservoir model relied on regression equations developed by $\mathrm{V}$. Wells to estimate ungaged reservoir tributary temperatures relative to USGS 12115000 . No additional field data were available during the 2015 period for the Rex River, Rack Creek, or Boulder Creek to verify the regression estimations. In-lake profile data availability and 
quality limited calibration efforts in the Masonry Pool. In 2005-2008, temperature profiles were available at the Masonry Dam for four sample dates prior to the installation of the buoy on December $19,2007$. In 2015, no profile data were collected for the Masonry Pool. Grab samples were collected on 21 days throughout the year. The samples were always collected at the Masonry Pool surface and were collected at the elevation of the lower outlet approximately 71 percent of the time. The sampling protocol at the Masonry Dam in 2015 introduced a degree of uncertainty, as samples were brought to the surface rather than measured in situ. Buoy 7 in the Masonry Pool suggests the presence of a cold-water inflow during the summer months that V. Wells associated with the spring snow melt. In the absence of additional field data in the Masonry Pool, it was not possible to account for cooler water stored at depth during the summer months in the Masonry Pool.

\subsubsection{Cedar River}

Temperature calibration for the river models was completed using continuous temperature data from gaging stations along the Cedar River. In 2015, data were available at three gaging stations, which provided important spatial resolution. WSDE 08C110 provided additional spatial resolution that was not available for the 2005-2008 model. During temperature calibration, temperatures at WSDE 08C110 were the most challenging to calibrate. The model was sensitive to boundary condition inflow temperatures in the branch 4 distributed flow and the Middle Cedar tributaries, which included De-Horn Creek, the unnamed left-bank input, Steele Creek, Williams Creek, and 
Taylor Creek. In the final calibration, a simply arbitrary temperature input file was developed for the distributed flow and the Middle Cedar tributaries. Figure 111 shows the sensitivity of the model to the boundary condition inflow temperatures at WSDE 08C110 (segment 74). When the Middle Cedar tributaries were modeled using the input temperatures developed for the Upper tributaries, the model had a cold bias in the winter and spring and a warm bias in the fall. When the Middle Cedar tributaries were modeled using the input temperatures developed for Rock Creek, the model over-predicted temperatures during the summer. When the branch 4 distributed flow was modeled using the mean annual air temperature for waterbody 2 with a constant value of $9.96^{\circ} \mathrm{C}$, the model over-predicted the summer maxima. The weighted average error statistics comparing the final model calibration to the sensitivity analysis are summarized in Table 23.

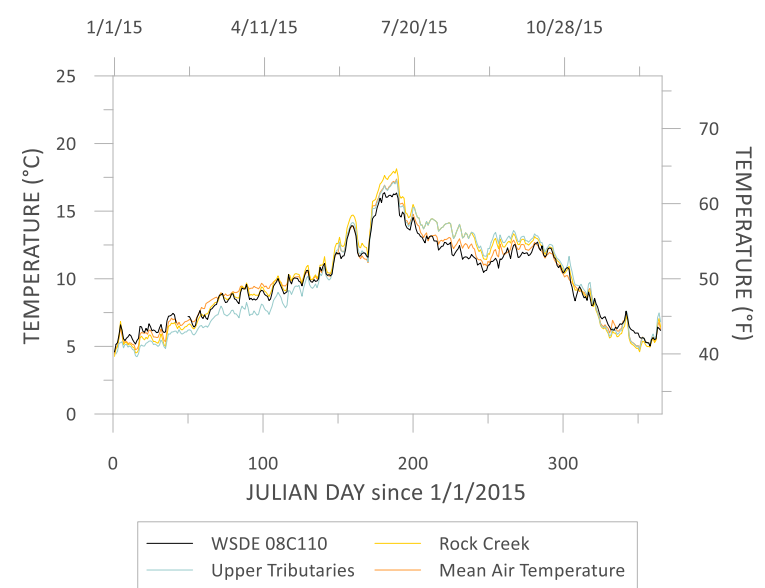

Figure 111. Comparison of observed daily average temperature at WSDE $08 \mathrm{C} 110$ to calibration model runs using different temperature inputs for the Middle Cedar tributaries and the branch 4 distributed flow. In the Upper tributaries model run, the Upper tributaries temperature file was used for the Middle tributaries. In the Rock Creek run, the Rock Creek temperature file was used for the Middle tributaries. In the mean air temperature run, the mean annual air temperature for waterbody 2 was used as the temperature value for the branch 4 distributed flow. 
Table 23. Summary of weighted average daily temperature error statistics comparing the final calibration to the boundary condition temperature sensitivity analysis model runs for the 2015 Cedar River model.

\begin{tabular}{lcccc}
\hline Model & $\mathrm{ME}\left({ }^{\circ} \mathrm{C}\right)$ & $\mathrm{MAE}\left({ }^{\circ} \mathrm{C}\right)$ & $\mathrm{RMSE}\left({ }^{\circ} \mathrm{C}\right)$ & Count \\
\hline Final Calibration & -0.03 & 0.39 & 0.48 & 1085 \\
Upper Tributaries & -0.07 & 0.56 & 0.67 & 1085 \\
Rock Creek & 0.11 & 0.49 & 0.61 & 1085 \\
Mean Annual Air Temperature & 0.02 & 0.39 & 0.50 & 1085 \\
\hline
\end{tabular}

\subsubsection{Water Quality Calibration Discussion}

\subsubsection{Chester Morse Lake}

Water quality data were available at two sites in the reservoir domain. Calibration limitations included lack of boundary condition data, lack of discrete and continuous data, and absence of field collection notes. No data were available for the reservoir tributaries. Water quality calibration was completed iteratively with boundary condition inflow concentrations adjusted based on model response. Limited continuous depth data were available. Dissolved oxygen profile data at CM1A were available for 2005-2008. Chlorophyll $a$ and dissolved oxygen profile data at CM1A were available for 2015. No other profile data were available for CM1A. No profile data were available in the Masonry Pool. All other parameters collected mid-lake at CM1A were volume weighted composite samples in the hypolimnion and epilimnion. Discrete samples were collected from the metalimnion. All samples collected at the Masonry Dam were discrete grab samples. No total nitrogen data were collected at CM1A and only 11 samples were collected at the Masonry Dam for 2005-2008. Total nitrogen was estimated using regression analysis of the 2015 total nitrogen and nitrate-nitrite data. 
No ammonia data were collected for the reservoir domain during 2005-2008 or 2015. Ammonia concentrations were estimated as a percentage of nitrate-nitrite concentrations.

Field collection notes did not include exact depths or collection times. The epilimnion and hypolimnion depths were provided as a depth range based on time of year. The depth associated with the metalimnion sample was not provided. The field observation sample time was not provided. Model outputs were difficult to compare to field data due to the volume weighted sampling protocol and the difference in sampling method for algae and zooplankton. The model calculated dry weight for algae and zooplankton. The data were collected as $\mathrm{mm}^{3} / \mathrm{L}$ and number of organisms per liter, respectively.

The data collected in the reservoir displayed some variation at each sample location and between each sample location. Data were compared using a correlation matrix and Pearson correlation coefficients (Figure 112 and Figure 113). Data collected in 2015 had a strong relationship between total nitrogen and nitrate-nitrite with a Pearson correlation coefficient of 0.95 at $\mathrm{CM} 1 \mathrm{~A}$ and 0.92 at the Masonry Dam. The relationship between total phosphorus and phosphate had a lower correlation coefficient of 0.62 at CM1A and an insignificant relationship at the Masonry Dam. The relationship between algae and chlorophyll $a$ in the reservoir was insignificant compared to a 0.75 correlation coefficient at the Masonry Dam. 


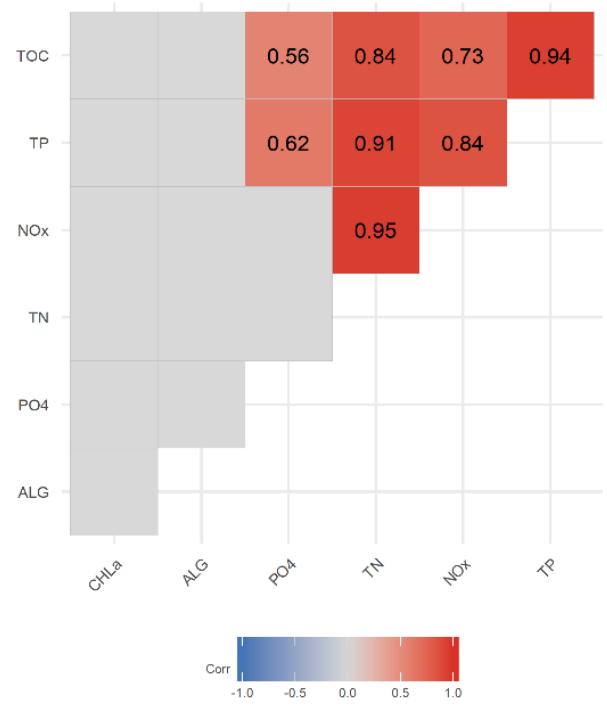

Figure 112. Correlation matrix of water quality constituents mid-lake at CM1A, 2015. Negative numbers indicate a negative correlation and positive numbers indicate a positive correlation. Insignificance is indicated by a blank.

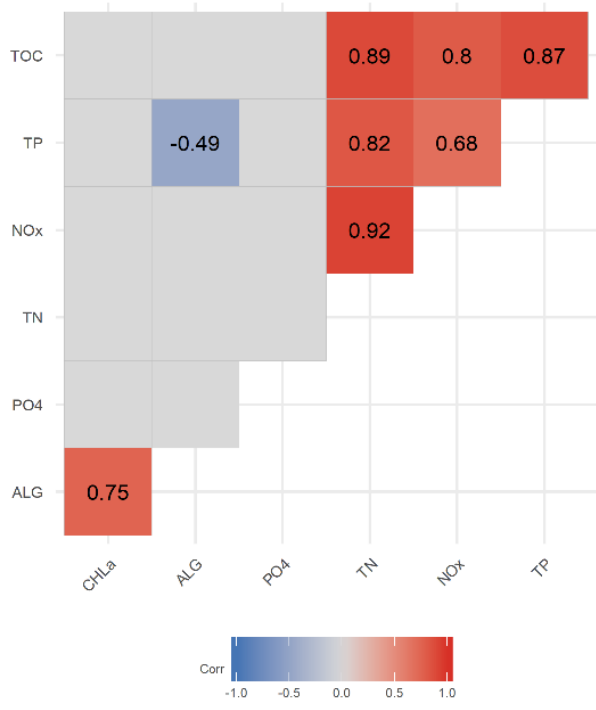

Figure 113. Correlation matrix of water quality constituents at the Masonry Dam, 2015. Negative numbers indicate a negative correlation and positive numbers indicate a positive correlation. Insignificance is indicated by a blank.

A comparison between observed data at $\mathrm{CM} 1 \mathrm{~A}$ and observed data in the Masonry Pool showed that total nitrogen, nitrate-nitrite, total phosphorus, and total organic carbon were well-correlated with coefficients equal to or greater than 0.85 . Phosphate had the lowest correlation with a coefficient of 0.46 , followed by chlorophyll $a$ with a coefficient of 0.68 . Results of the correlation matrix between nutrient concentrations at $\mathrm{CM} 1 \mathrm{~A}$ and MD are summarized in Table 24.

Table 24. Comparison of Pearson correlation coefficients for water quality parameters, 2015. Coefficients were calculated for the relationship between parameters at CM1A and the Masonry Dam (MD).

\begin{tabular}{lc}
\hline Parameter & MD vs CM1A \\
\hline Chlorophyll $a$ & 0.68 \\
Total nitrogen & 0.95 \\
Nitrate-nitrite & 0.99 \\
Total phosphorus & 0.85 \\
Phosphate & 0.46 \\
Total organic carbon & 0.94 \\
\hline
\end{tabular}


The lower phosphate correlations between $\mathrm{CM} 1 \mathrm{~A}$ and $\mathrm{MD}$ in concert with the low correlation of total phosphorus and phosphate within $\mathrm{CM} 1 \mathrm{~A}$ and the insignificant relationship at the Masonry Dam suggest error in some data values. The lower correlation of chlorophyll $a$ between the waterbodies and the insignificant relationship between algae and chlorophyll $a$ at $\mathrm{CM} 1 \mathrm{~A}$ also suggest error in some of the data. Limited temporal resolution made it difficult to identify individual data samples as outliers or as indicative of seasonal and diurnal trends. The variation in correlation values and potential data error could explain the discrepancy in chlorophyll $a$ data and modeled phosphate ranges in the 2015 model.

\subsubsection{Cedar River}

Water quality calibration for the Cedar River used grab sample data from upwards of eight monitoring sites. Calibration limitations for the 2005-2008 model included lack of boundary condition data and data availability. From 2005 to 2008, data for total nitrogen, nitrate-nitrite, total phosphorus, phosphate, and total organic carbon were available at CPR1, the monitoring site at the end of the model domain, for a total of 31 days. Data for nitrate-nitrite, total phosphorus, phosphate, and total organic carbon were available at the monitoring site at the powerhouse for a total of eight days with data collection beginning in October 2007. No boundary condition inflow concentrations or chlorophyll $a$ were available for 2005-2008. Dissolved oxygen and ammonia concentration data were limited to approximately monthly observations at WSDE $08 \mathrm{C} 110$. 
During 2015, calibration limitations included data availability and lack of field notes.

Dissolved oxygen and ammonia concentration data were limited to approximately monthly observations at WSDE 08C110. No chlorophyll $a$ data were available and algae data were limited to approximately bi-monthly observations at the monitoring site located at the end of the model domain. Data collected at all SPU sampling locations did not include the time of observation. 


\section{Chapter 5. Model Scenarios}

The calibrated 2015 Chester Morse Lake and Cedar River models were used to explore how the impacts of climate change and shifts in reservoir management would affect the watershed. SPU developed five different scenarios to evaluate using the calibrated models.

\subsection{Scenario Descriptions}

The model scenarios for Chester Morse Lake and the Cedar River fell into two major categories: climate change and reservoir management. The climate change scenarios modeled the impact of shifts in air temperature, water temperature, flow volumes, and flow timing. The reservoir management scenarios modeled the impact of increasing water storage and increasing the spring refill level. The modeled scenarios and their general description are summarized in Table 25.

Table 25. Summary table of modeled scenarios.

\begin{tabular}{cl}
\hline Scenario & Description \\
\hline $\mathbf{1}$ & $3^{\circ} \mathrm{C}$ temperature increase \\
$\mathbf{2}$ & $25 \%$ flow decrease \\
$\mathbf{3}$ & Shift flows 4 weeks earlier \\
$\mathbf{4}$ & $1.2 \mathrm{~m}(4 \mathrm{ft})$ increase in flashboard elevation \\
$\mathbf{5}$ & Increase spring refill level to $477.3 \mathrm{~m}(1566 \mathrm{ft})$ \\
\hline
\end{tabular}

The scenarios were applied to the reservoir and river model using the 2015 observed water levels in the Masonry Pool as the reservoir management strategy. The original model was calibrated using measured outflows. For the scenarios, dam releases were unknown and the following assumptions were made in order to run the scenarios. The 
scenario reservoir outflows maintained the 2015 observed Masonry Pool water surface elevations. The Instream Flow Agreement (IFA) of $0.85 \mathrm{~m}^{3} / \mathrm{s}$ (30 cfs) for the bypass reach between the Masonry Dam and the powerhouse was always met. The 2015 observed daily average ratio between the lower outlet release and the powerhouse release was maintained, and simulated reservoir scenario outflows were distributed accordingly.

The climate change scenarios included scenarios 1 through 3. Scenario 1 evaluated the impact of an increase in air temperature and water temperature. All water temperatures and air temperatures were increased by a uniform $3^{\circ} \mathrm{C}$. All dew point temperatures were calculated based on the increased air temperature and the historically observed relative humidity using Equation 1. The temperate of the distributed tributaries in the river model, which simulated ground water flow and other ungaged inputs, were not adjusted. Changes in air temperature are damped and delayed in the subsurface (Menberg, Blum, Kurylyk, \& Bayer, 2014). As a result, temperature changes in groundwater change more gradually than in surface waters. Scenario 2 reduced all inflows by 25 percent. Scenario 3 shifted all inflows 4 weeks earlier to simulate a shift from a snow-dominated system to a rain-dominated system. All reservoir operations were also shifted 4 weeks earlier, including the reservoir pumping station, underflow gate at the Overflow Dike, Masonry Pool water surface elevations, and daily average ratio between the lower outlet release and the powerhouse release. The flows for the last four weeks of the simulated scenario were assumed to be equivalent to the flows observed during the first four weeks. 
The reservoir management scenarios included scenarios 4 and 5. Scenario 4 increased the flashboard elevation at the Overflow Dike from 472.4 meters (1550 ft) to 473.7 meters (1554 ft). Scenario 5 increased the spring refill level from 476.4 meters (1563 ft) to 477.3 meters (1566 ft). The model setup assumed that the reservoir was refilled starting the third week of February and that it reached its maximum level on the same day observed in 2015. It was assumed that the system bifurcated on the same day observed in 2015. The observed Masonry Pool elevations from 2015 were scaled accordingly to facilitate the increase in spring refill level. The observed Masonry Pool elevations from 2015 were maintained once the system bifurcated.

\subsection{Temperature Predictions}

Simulated temperatures for each scenario were analyzed using two methods. The first method considered changes in the percent of reservoir or river volume within specified temperature ranges. This method analyzed all model segments of the reservoir and river for all days from May 1 to September 30. The second method considered changes in daily temperature at noon for the reservoir and the river. Changes in the reservoir were analyzed mid-lake at CM1A (segment 27) over the total depth of the segment and at the Masonry Dam (segment 64). Changes in the river were analyzed for all model segments.

\subsubsection{Chester Morse Lake}

The change in the percent of reservoir volume for each scenario is shown relative to the base model in Figure 114. Temperature changes in the reservoir were most significant 
under Scenario 1. From May through September, temperature changes at the lower and upper temperature limits were most noticeable. Scenario 1 resulted in a 27 percent decrease in simulated temperatures equal to or less than $6^{\circ} \mathrm{C}$ and a 7 percent increase in simulated temperatures equal to or greater than $22^{\circ} \mathrm{C}$. Changes in temperature under all other scenarios were negligible from May to September.

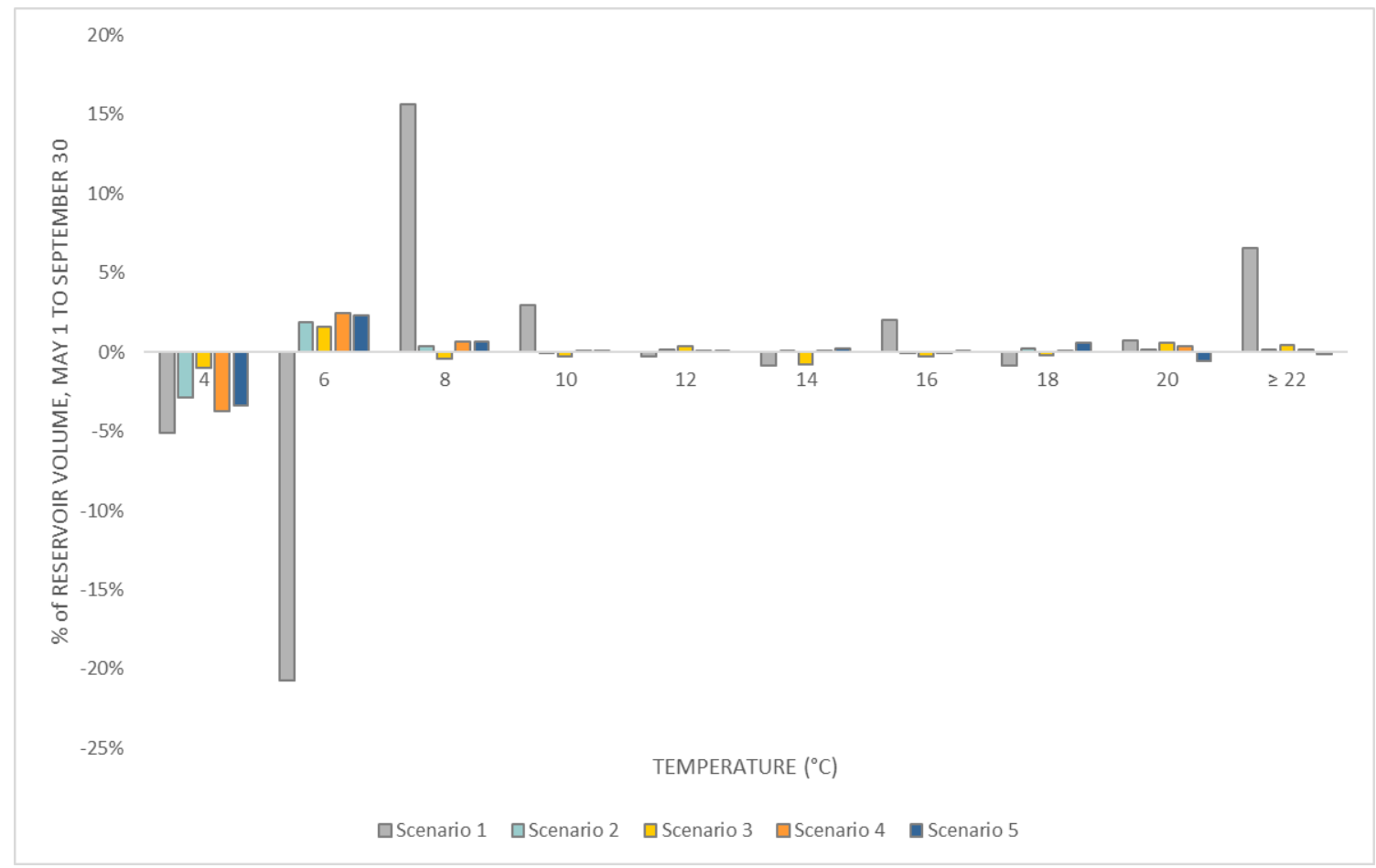

Figure 114. Change in percent of reservoir volume from May 1 to September 30 within the indicated temperature range relative to the base model for all segments on all days. 
The change in daily temperature at noon was considered over depth at CM1A (segment 27) for the entire model run. The monthly average temperature at noon, the weighted averages from May through September, and the overall weighted averages are summarized in Table 26 . The climate change scenarios showed more change in temperature than the reservoir management scenarios. Scenario 1 had the highest change in temperature with an overall average increase of $1.92^{\circ} \mathrm{C}$. Scenario 5 had the lowest change in temperature with an overall average increase of $0.04^{\circ} \mathrm{C}$. Contour plots of predicted change in temperature relative to the base model are shown in Figure 115 through Figure 119.

Table 26. Summary of the average monthly temperature in degrees Celsius at noon in the Chester Morse Lake base model and the change in the average for each scenario modeled at CM1A (segment 27). Weighted averages are calculated for May through September and annually.

\begin{tabular}{lcccccc}
\hline Month & Base & Scenario 1 & Scenario 2 & Scenario 3 & Scenario 4 & Scenario 5 \\
\hline Jan & 3.67 & 1.00 & 0.01 & 0.00 & 0.00 & 0.00 \\
\hline Feb & 4.15 & 1.98 & 0.01 & -0.08 & 0.08 & 0.08 \\
\hline Mar & 5.05 & 2.30 & 0.02 & -0.08 & 0.09 & 0.08 \\
\hline Apr & 6.35 & 2.26 & 0.12 & 0.02 & 0.12 & 0.10 \\
\hline May & 8.04 & 2.07 & 0.21 & 0.16 & 0.12 & 0.07 \\
\hline Jun & 9.18 & 1.87 & 0.23 & 0.50 & 0.13 & 0.02 \\
\hline Jul & 9.88 & 1.76 & 0.18 & 0.40 & 0.09 & -0.01 \\
\hline Aug & 10.21 & 1.70 & 0.12 & 0.28 & 0.04 & 0.01 \\
\hline Sep & 9.59 & 1.72 & 0.08 & 0.13 & 0.03 & 0.01 \\
\hline Oct & 8.91 & 1.72 & 0.06 & -0.22 & 0.04 & 0.01 \\
\hline Nov & 7.33 & 2.16 & 0.14 & 0.20 & 0.12 & 0.03 \\
\hline Dec & 4.30 & 2.48 & 0.07 & 0.10 & 0.04 & 0.02 \\
May-Sep & 9.38 & 1.83 & 0.16 & 0.29 & 0.08 & 0.02 \\
\hline Overall & 7.24 & 1.92 & 0.10 & 0.12 & 0.08 & 0.04 \\
\hline
\end{tabular}



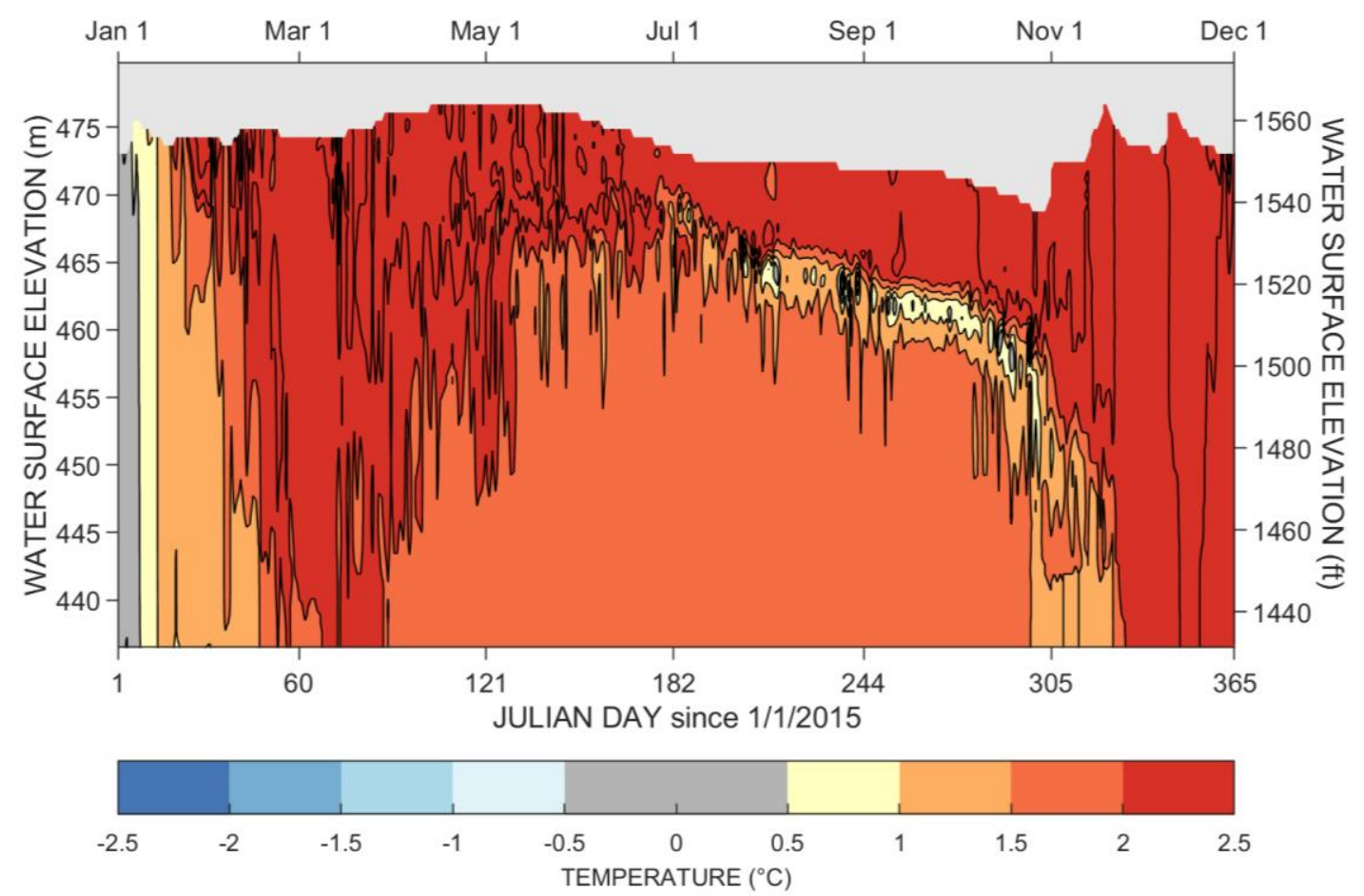

Figure 115. Comparison of the base condition daily temperature at noon to Scenario 1, CM1A (segment 27).
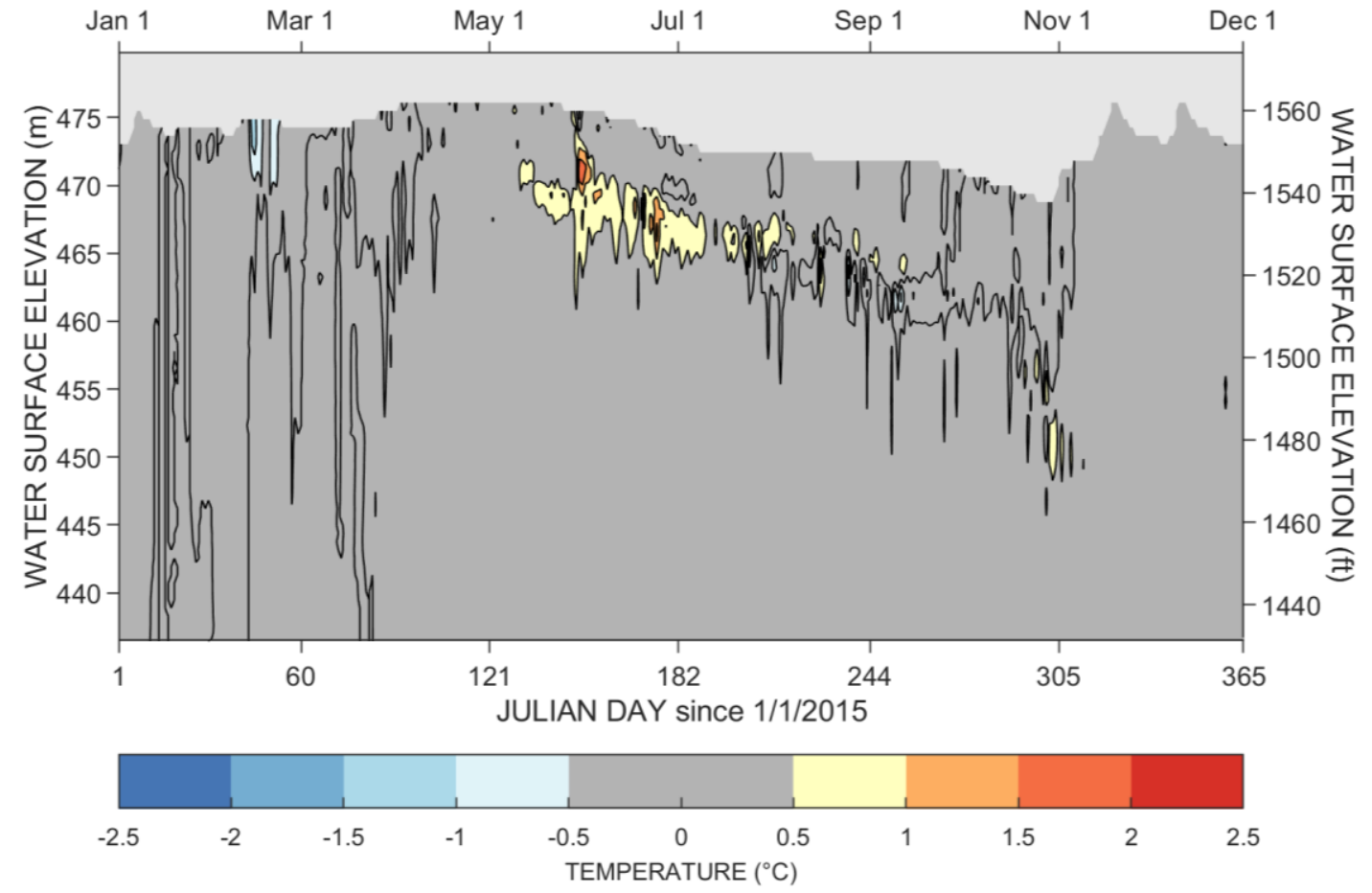

Figure 116. Comparison of the base condition daily temperature at noon to Scenario 2, CM1A (segment 27). 


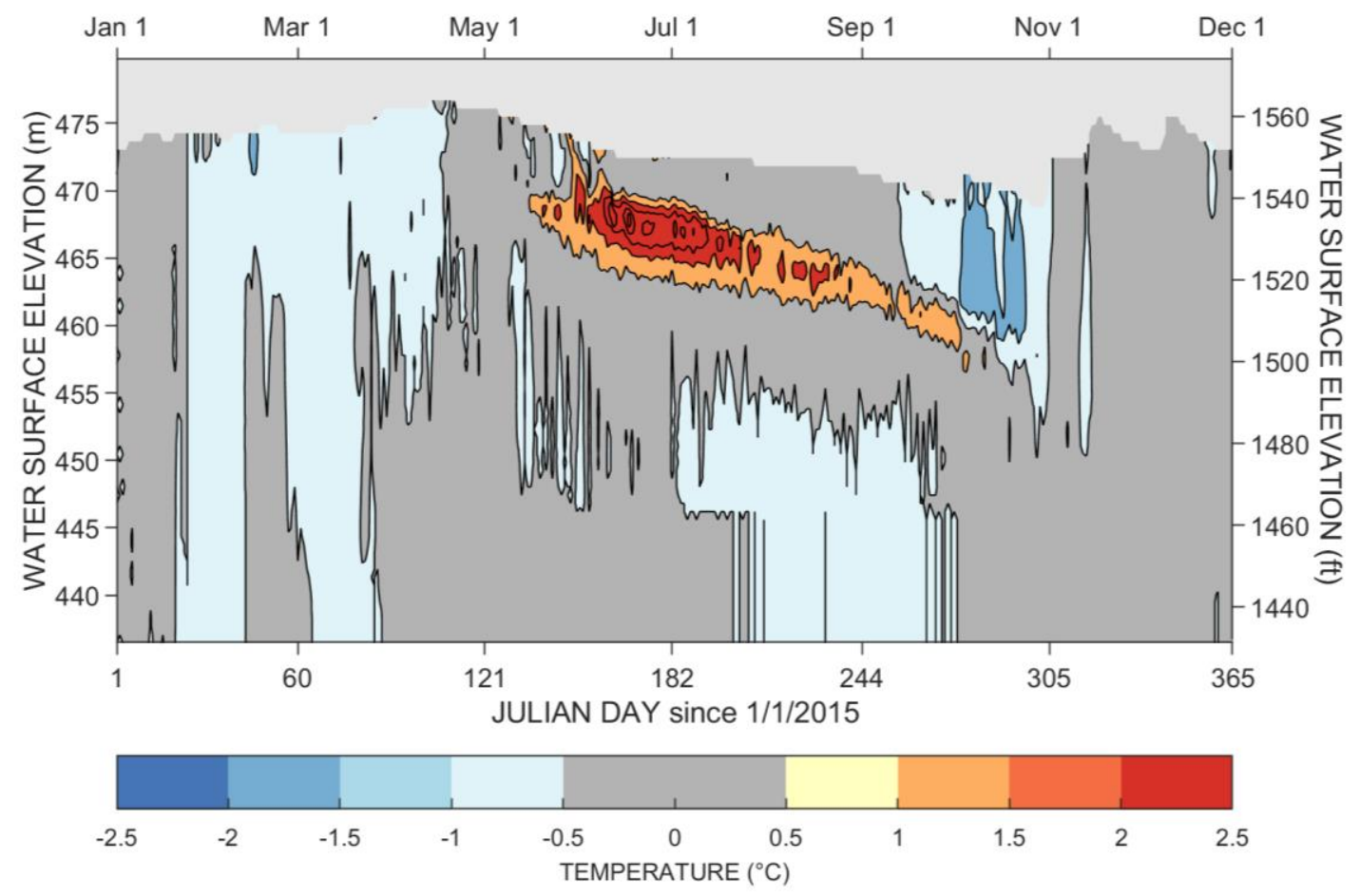

Figure 117. Comparison of the base condition daily temperature at noon to Scenario 3, CM1A (segment 27).

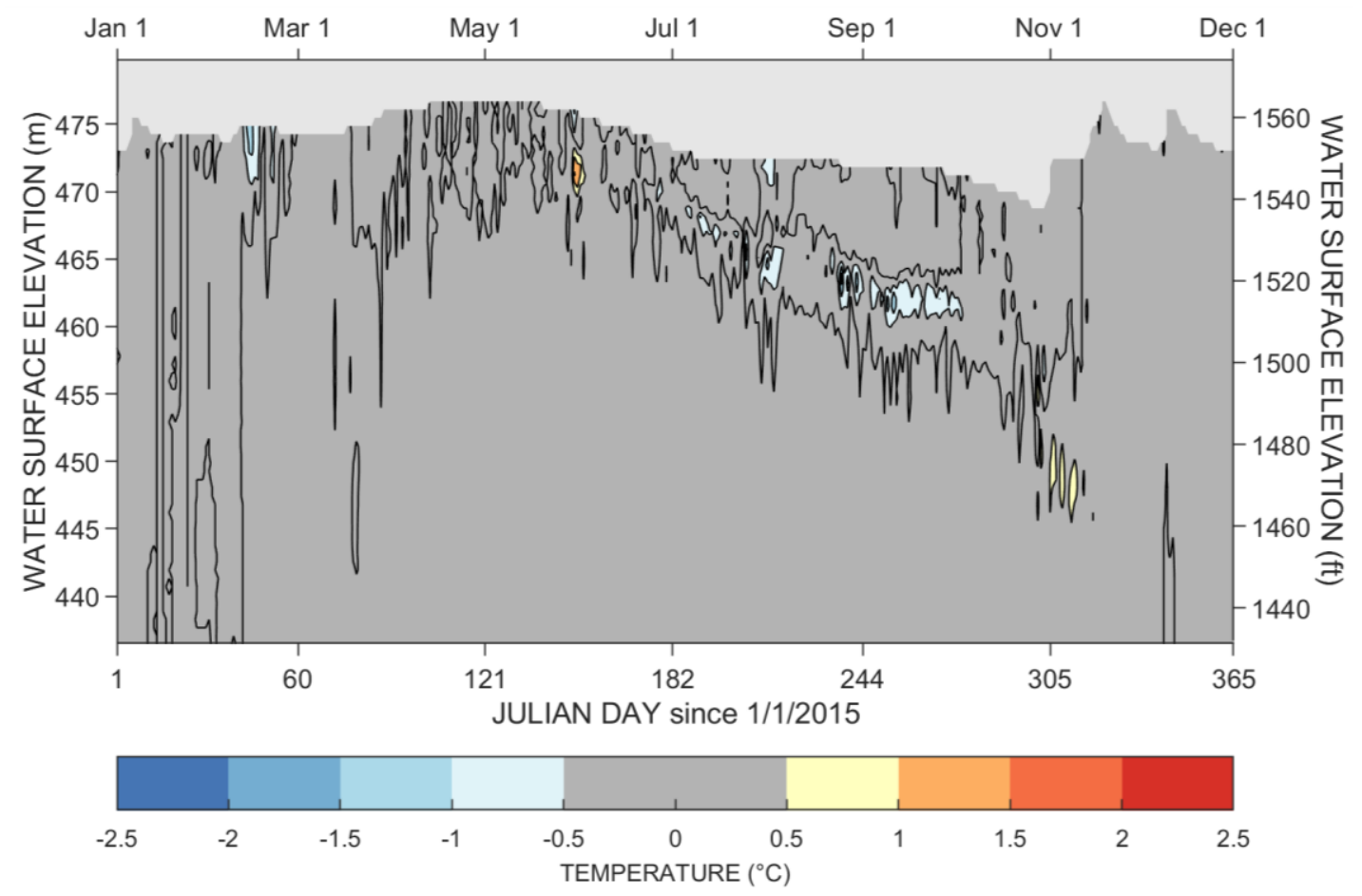

Figure 118. Comparison of the base condition daily temperature at noon to Scenario 4, CM1A (segment 27). 


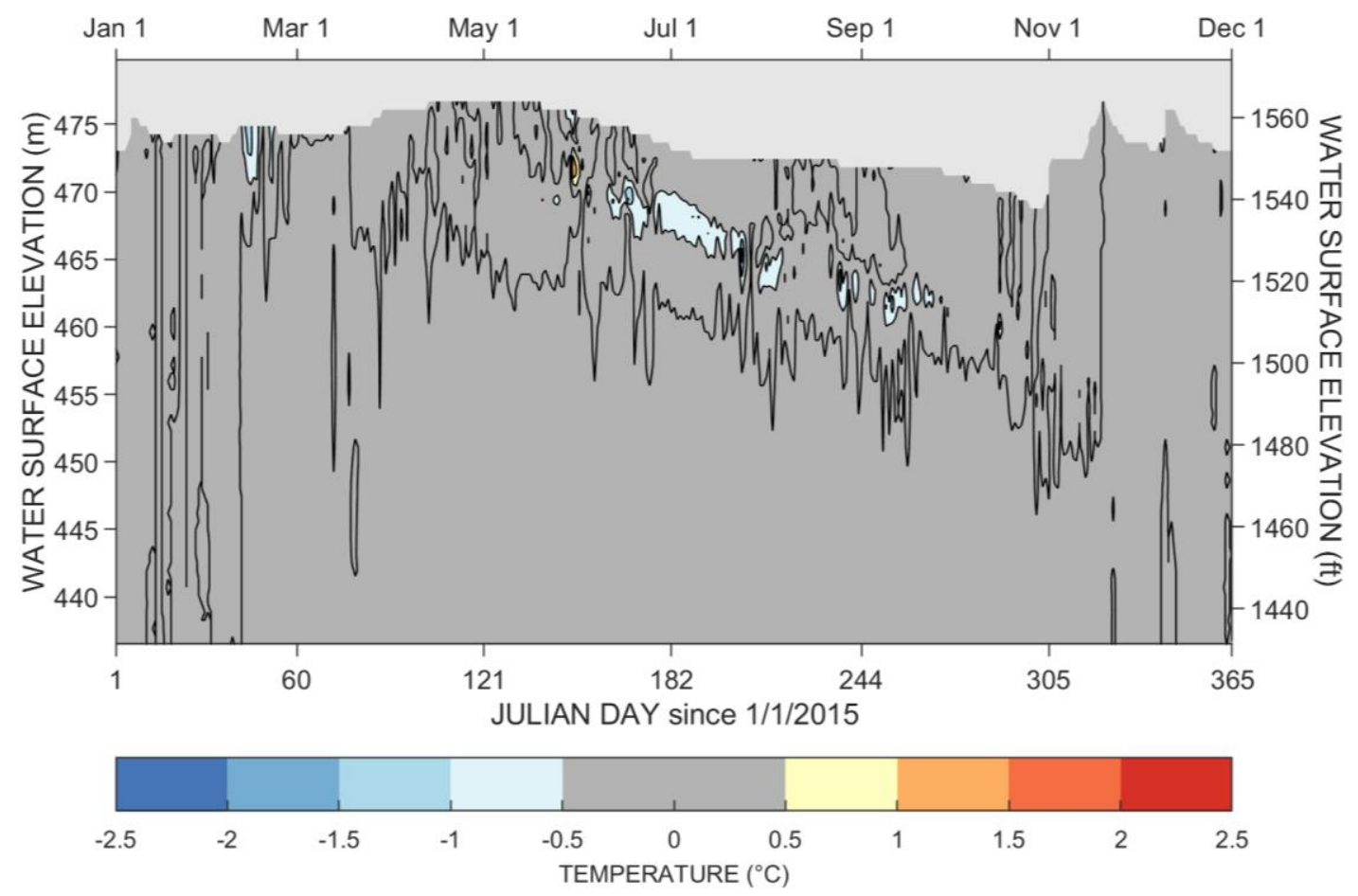

Figure 119. Comparison of the base condition daily temperature at noon to Scenario 5, CM1A (segment 27).

The change in daily temperature at noon was considered over depth at the Masonry Dam (MD, segment 64) for the entire model run. The monthly average temperature at noon, the weighted averages from May through September, and the overall weighted averages are summarized in Table 27. The climate change scenarios showed more change in temperature than the reservoir management scenarios. Scenario 1 had the highest change in temperature with an overall average increase of $2.25^{\circ} \mathrm{C}$. Scenario 4 had the lowest change in temperature with an overall average decrease of $-0.02^{\circ} \mathrm{C}$. Contour plots of predicted change in temperature relative to the base model are shown in Figure 120 through Figure 124. 
Table 27. Summary of the average monthly temperature in degrees Celsius at noon in the Masonry Pool base model and the change in the average for each scenario modeled at MD (segment 64). Weighted averages are calculated for May through September and annually.

\begin{tabular}{lcccccc}
\hline Month & Base & Scenario 1 & Scenario 2 & Scenario 3 & Scenario 4 & Scenario 5 \\
\hline Jan & 3.73 & 1.02 & 0.00 & 0.02 & 0.02 & 0.01 \\
\hline Feb & 4.44 & 2.24 & -0.01 & 0.10 & 0.01 & 0.01 \\
\hline Mar & 5.83 & 2.52 & 0.05 & -0.13 & 0.04 & 0.03 \\
\hline Apr & 8.16 & 2.58 & 0.09 & -0.06 & 0.03 & -0.02 \\
\hline May & 12.39 & 2.38 & 0.17 & 0.88 & 0.02 & -0.08 \\
\hline Jun & 18.11 & 2.21 & -0.08 & 1.57 & 0.03 & 0.00 \\
\hline Jul & 22.42 & 2.08 & 0.14 & -0.12 & -0.36 & 0.07 \\
\hline Aug & 20.54 & 2.08 & -0.07 & -0.12 & -0.10 & -0.09 \\
\hline Sep & 15.36 & 2.32 & 0.06 & 0.25 & 0.05 & -0.08 \\
\hline Oct & 12.37 & 2.62 & -0.03 & -0.45 & -0.04 & -0.05 \\
\hline Nov & 7.48 & 2.53 & -0.06 & 0.11 & 0.00 & 0.00 \\
\hline Dec & 3.67 & 2.47 & -0.02 & 0.06 & 0.04 & 0.04 \\
May-Sep & 17.78 & 2.21 & 0.04 & 0.48 & -0.07 & -0.04 \\
\hline Overall & 11.25 & 2.25 & 0.02 & 0.17 & -0.02 & -0.01 \\
\hline
\end{tabular}

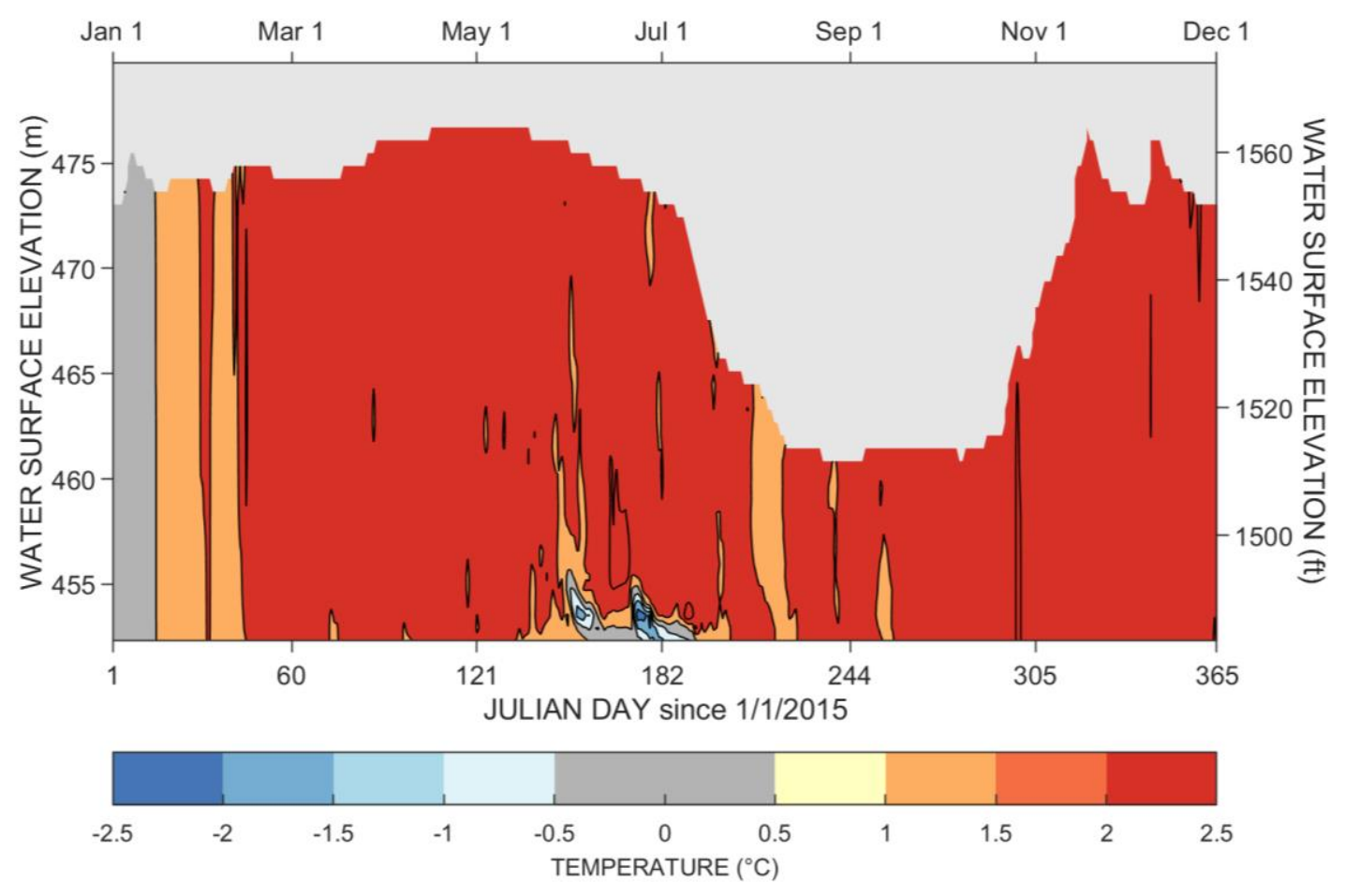

Figure 120. Comparison of the base condition daily temperature at noon to Scenario 1, MD (segment 64). 


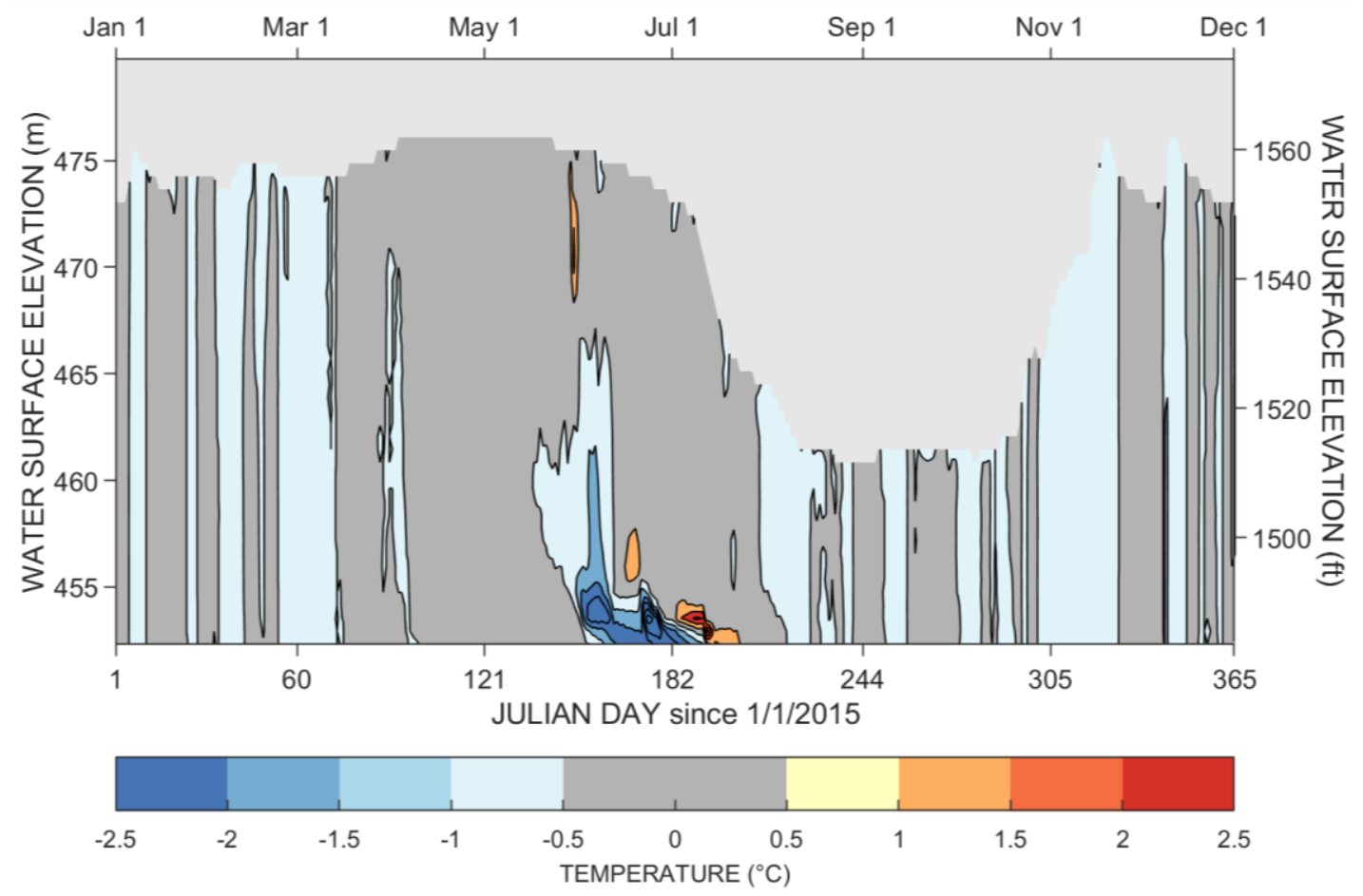

Figure 121. Comparison of the base condition daily temperature at noon to Scenario 2, MD (segment 64).
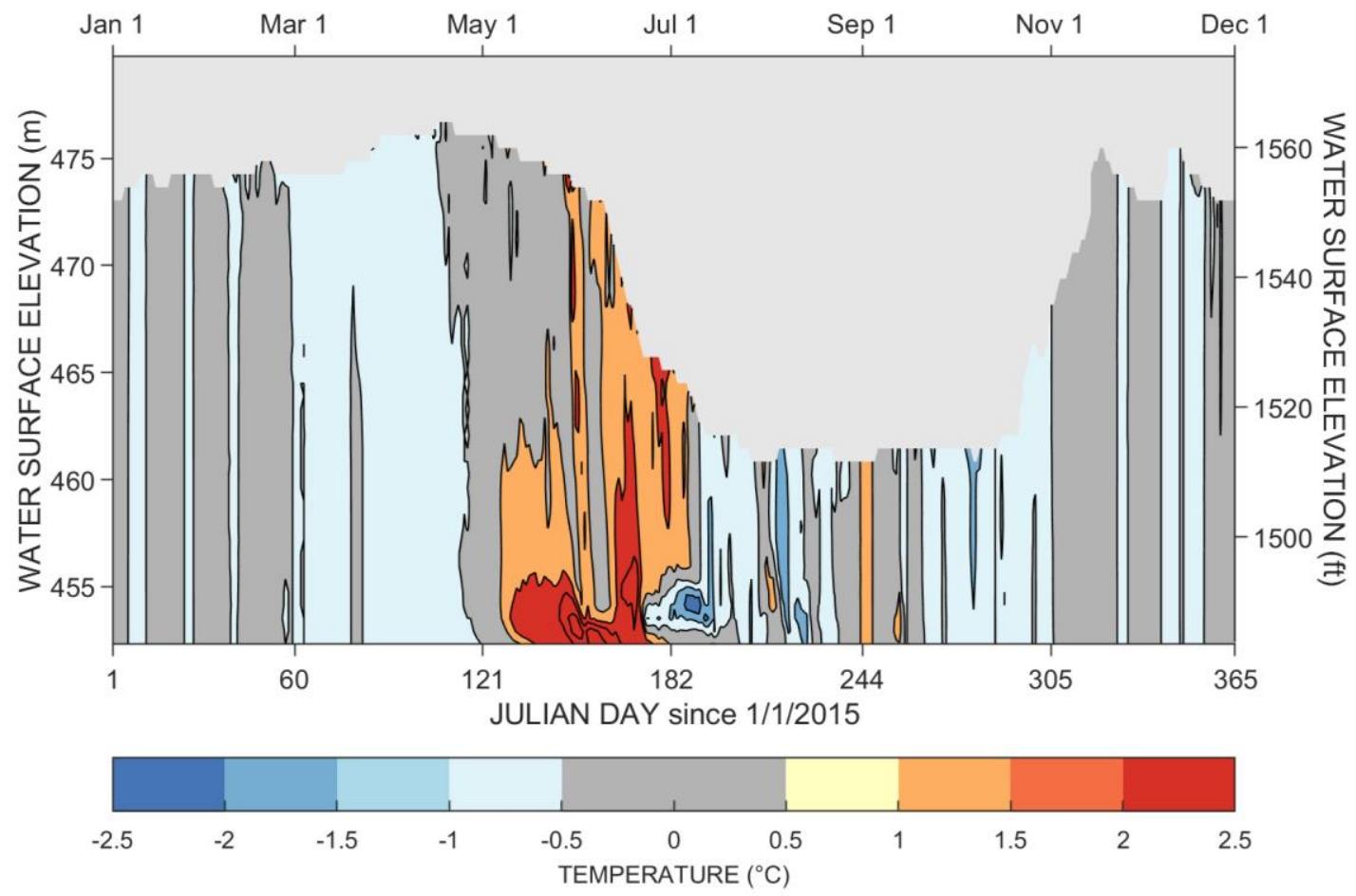

Figure 122. Comparison of the base condition daily temperature at noon to Scenario 3, MD (segment 64). 


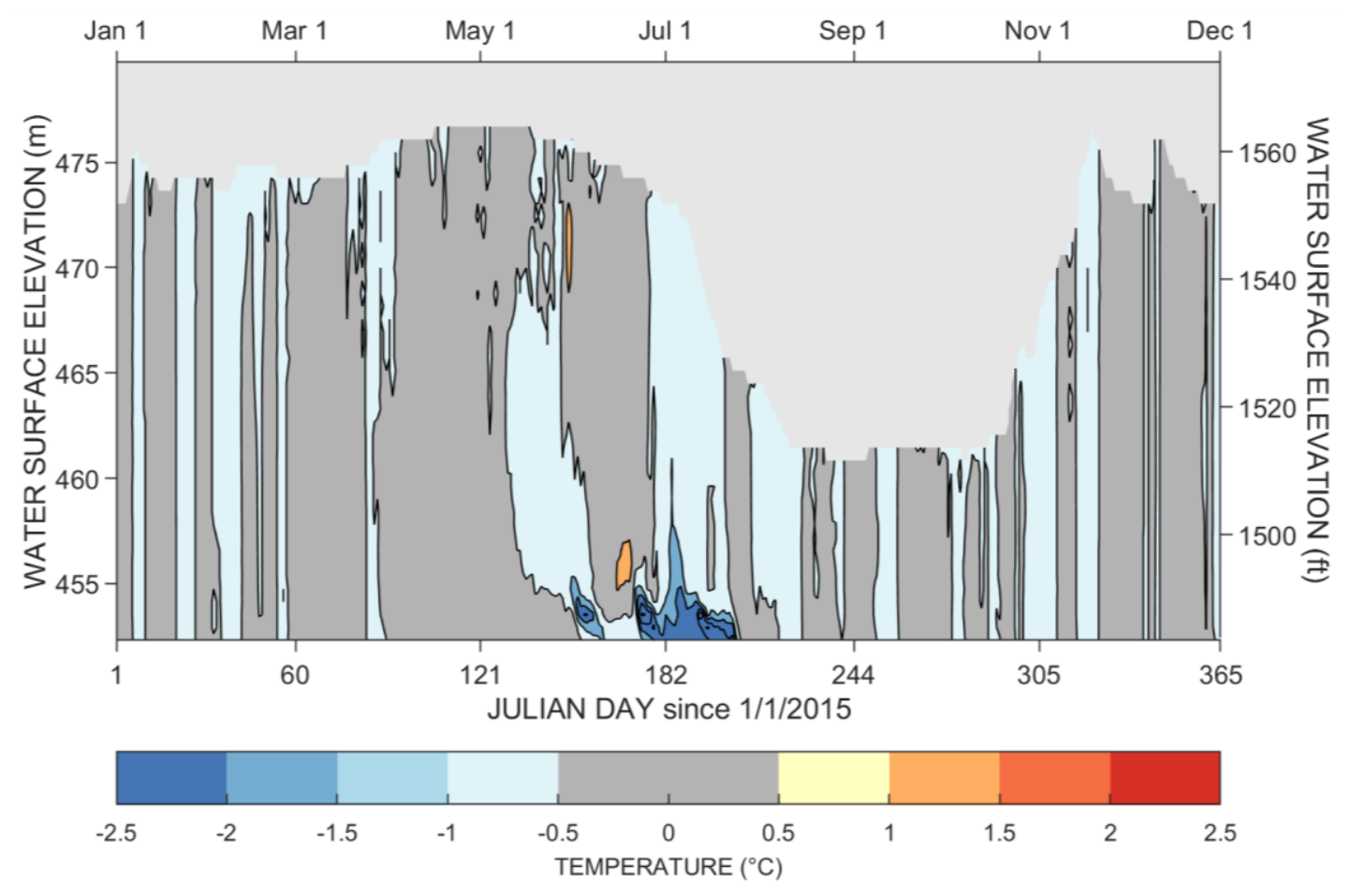

Figure 123. Comparison of the base condition daily temperature at noon to Scenario 4, MD (segment 64).

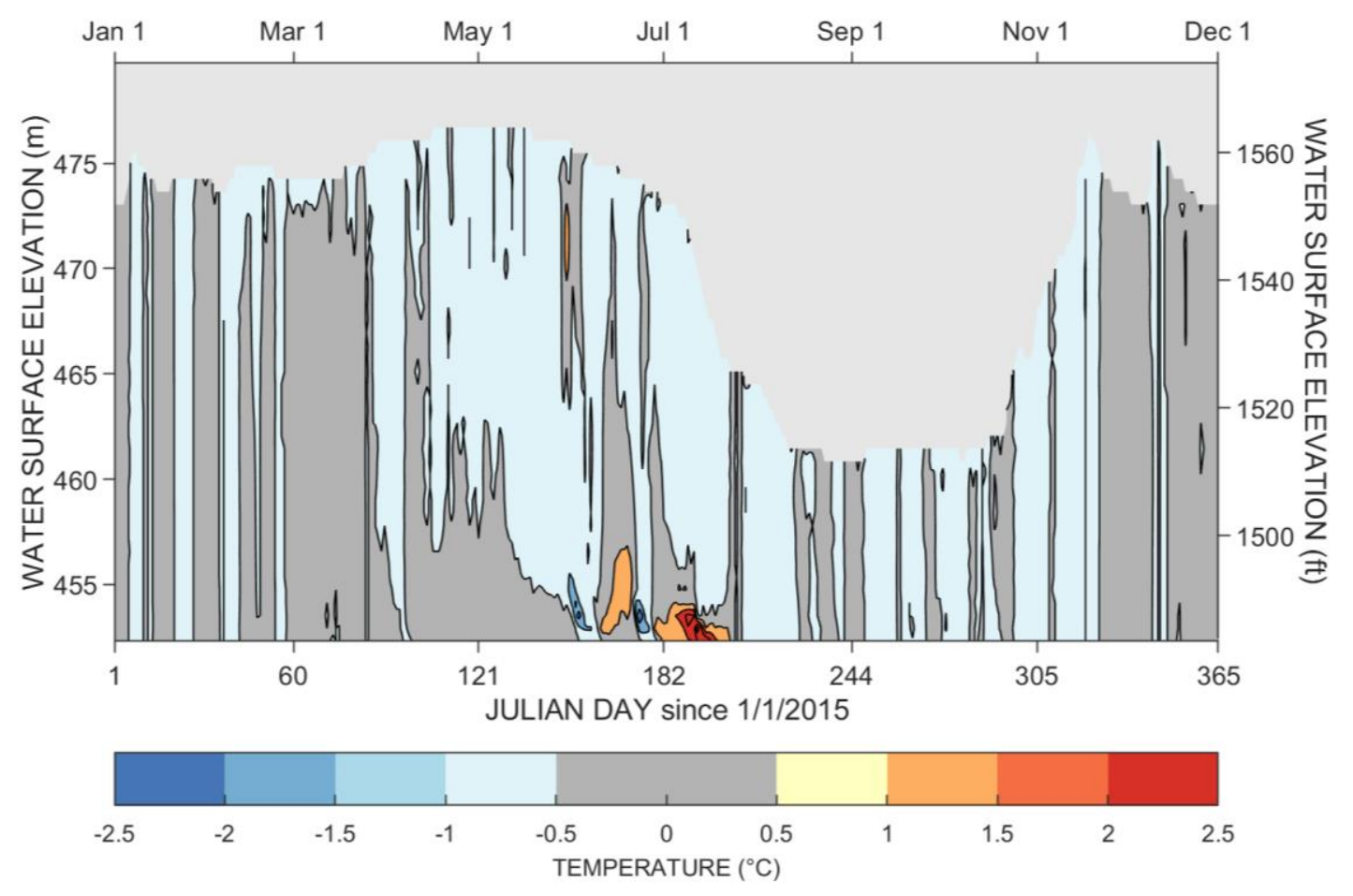

Figure 124. Comparison of the base condition daily temperature at noon to Scenario 5, MD (segment 64). 


\subsubsection{Cedar River}

The change in the percent of river volume for each scenario from May to September is shown relative to the base model in Figure 125 . Temperature changes in the river were most significant under the climate change scenarios. Scenario 1 resulted in a 20 percent decrease in modeled temperatures equal to or less than $10^{\circ} \mathrm{C}$ and a 5 percent increase in modeled temperatures equal to or greater than $22^{\circ} \mathrm{C}$. Scenario 2 resulted in a 5 percent decrease in modeled temperatures equal to or less than $10^{\circ} \mathrm{C}$ and a 2 percent increase in modeled temperatures equal to or greater than $22^{\circ} \mathrm{C}$. Scenario 3 resulted in a 7 percent decrease in modeled temperatures equal to or less than $10^{\circ} \mathrm{C}$ and a 1 percent increase in modeled temperatures equal to or greater than $22^{\circ} \mathrm{C}$. Changes in temperature under the reservoir management scenarios were negligible from May to September.

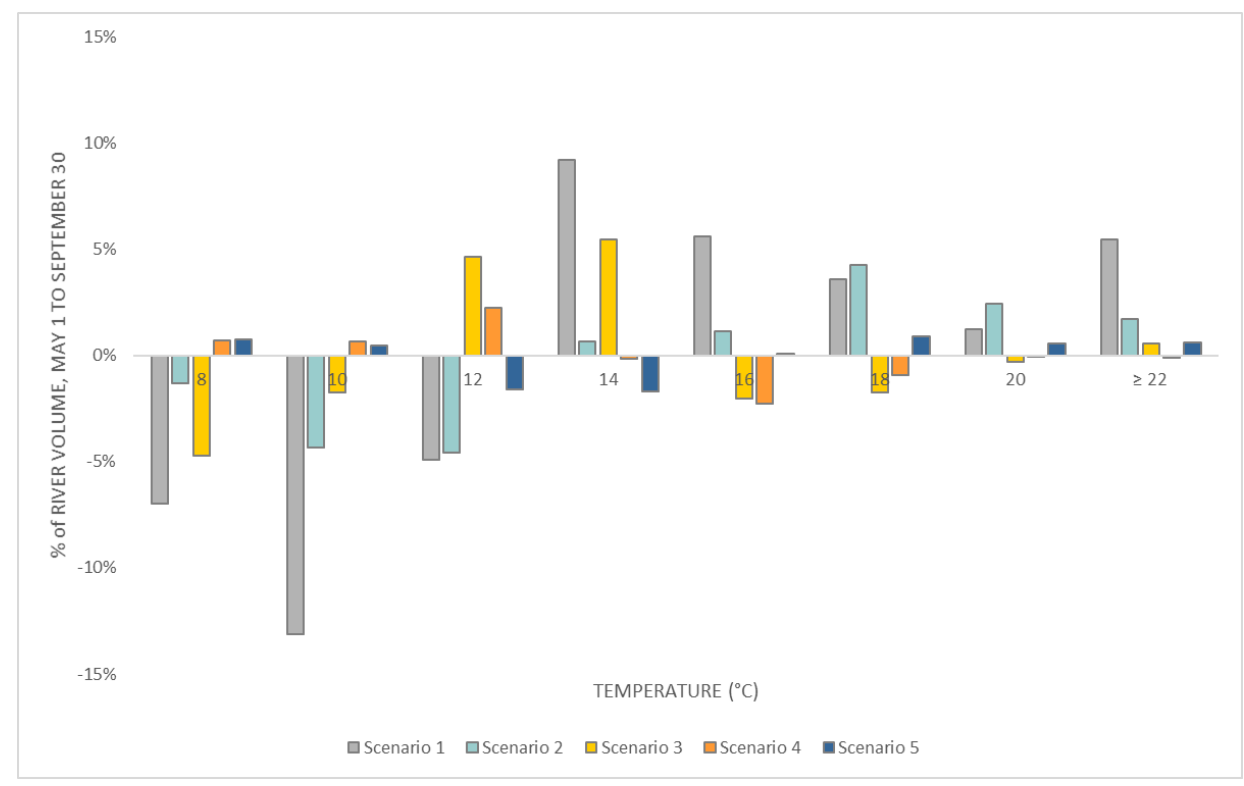

Figure 125. Change in percent of river volume from May 1 to September 30 within the indicated temperature range relative to the base model for all segments on all days. 
The change in daily temperature at noon was considered for all river model segments for the entire model run. The monthly average temperature at noon, the weighted averages from May through September, and the overall weighted averages are summarized in Table 28 . The climate change scenarios showed more change in temperature than the reservoir management scenarios. Scenario 1 had the highest change in temperature with an overall average increase of $1.97^{\circ} \mathrm{C}$. Scenario 4 had the lowest change in temperature with an overall average decrease of $-0.03^{\circ} \mathrm{C}$. Contour plots of predicted change in temperature relative to the base model are shown in Figure 126 through Figure 130.

Table 28. Summary of the average monthly temperature in degrees Celsius at noon in the Cedar River base model and the change in the average for each scenario modeled at all segments. Weighted averages are calculated for May through September and annually.

\begin{tabular}{lcccccc}
\hline Month & Base & Scenario 1 & Scenario 2 & Scenario 3 & Scenario 4 & Scenario 5 \\
\hline Jan & 5.00 & 1.38 & 0.16 & 0.46 & 0.08 & 0.05 \\
\hline Feb & 6.13 & 2.00 & -0.04 & 0.91 & -0.05 & -0.03 \\
\hline Mar & 8.10 & 1.97 & 0.02 & 0.11 & -0.07 & 0.06 \\
\hline Apr & 9.21 & 2.06 & 0.02 & -0.09 & 0.02 & 0.00 \\
\hline May & 10.87 & 1.90 & -0.02 & 1.04 & -0.05 & -0.17 \\
\hline Jun & 14.85 & 2.09 & 0.43 & 0.73 & 0.11 & 0.40 \\
\hline Jul & 16.95 & 1.87 & 1.05 & -1.60 & -0.49 & 0.12 \\
\hline Aug & 15.14 & 1.64 & 0.63 & 0.87 & -0.16 & -0.32 \\
\hline Sep & 13.22 & 1.96 & 0.37 & 1.18 & 0.09 & -0.03 \\
\hline Oct & 12.07 & 2.34 & 0.05 & -0.51 & 0.05 & 0.01 \\
\hline Nov & 8.03 & 2.29 & 0.24 & 0.17 & 0.01 & -0.03 \\
\hline Dec & 5.31 & 2.21 & -0.10 & 0.16 & 0.12 & -0.04 \\
May-Sep & 14.21 & 1.89 & 0.49 & 0.44 & -0.10 & 0.00 \\
Overall & 10.43 & 1.97 & 0.24 & 0.28 & -0.03 & 0.00 \\
\hline
\end{tabular}



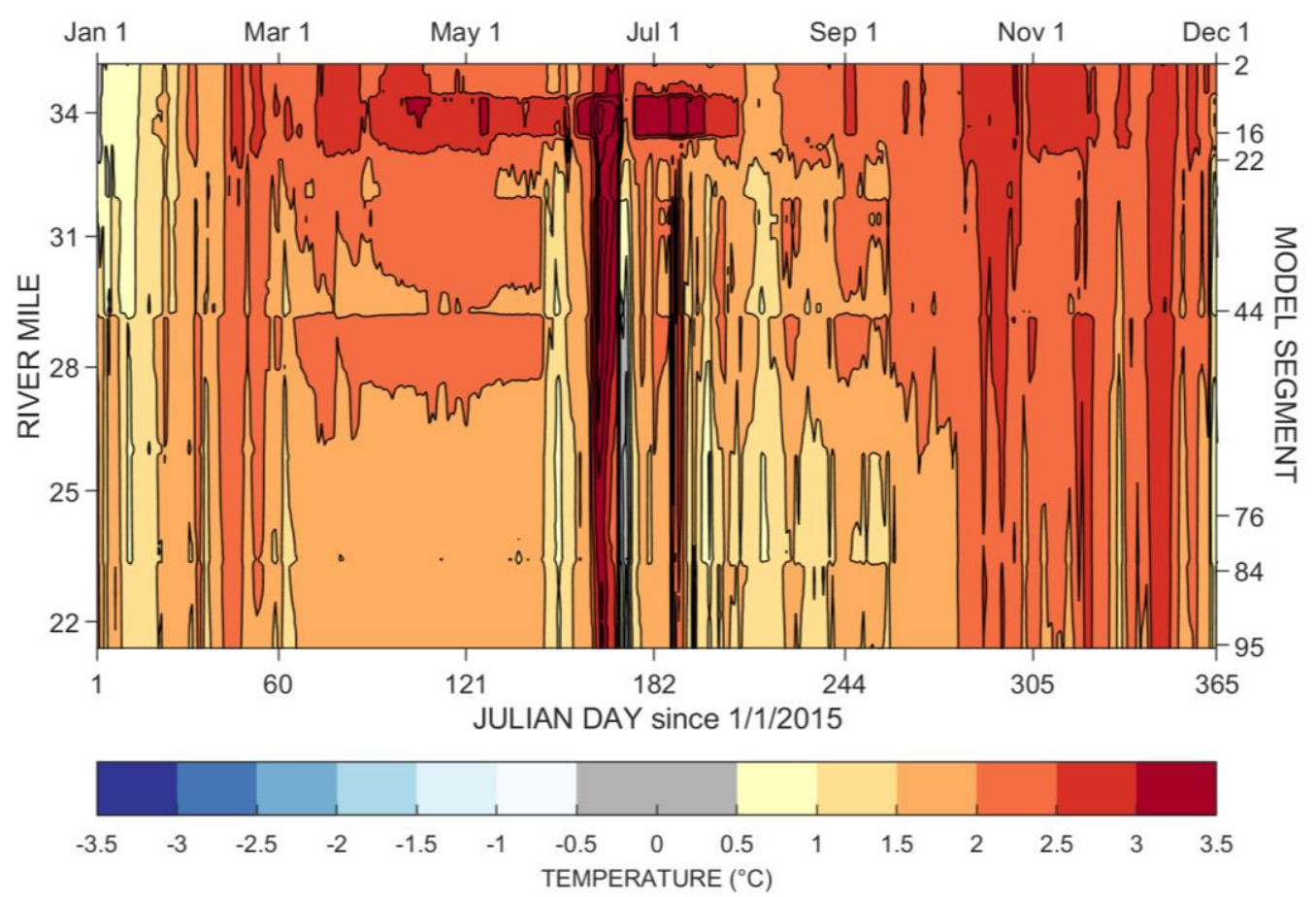

Figure 126. Comparison of the base condition daily temperature at noon to Scenario 1 for all segments on all days, Cedar River.

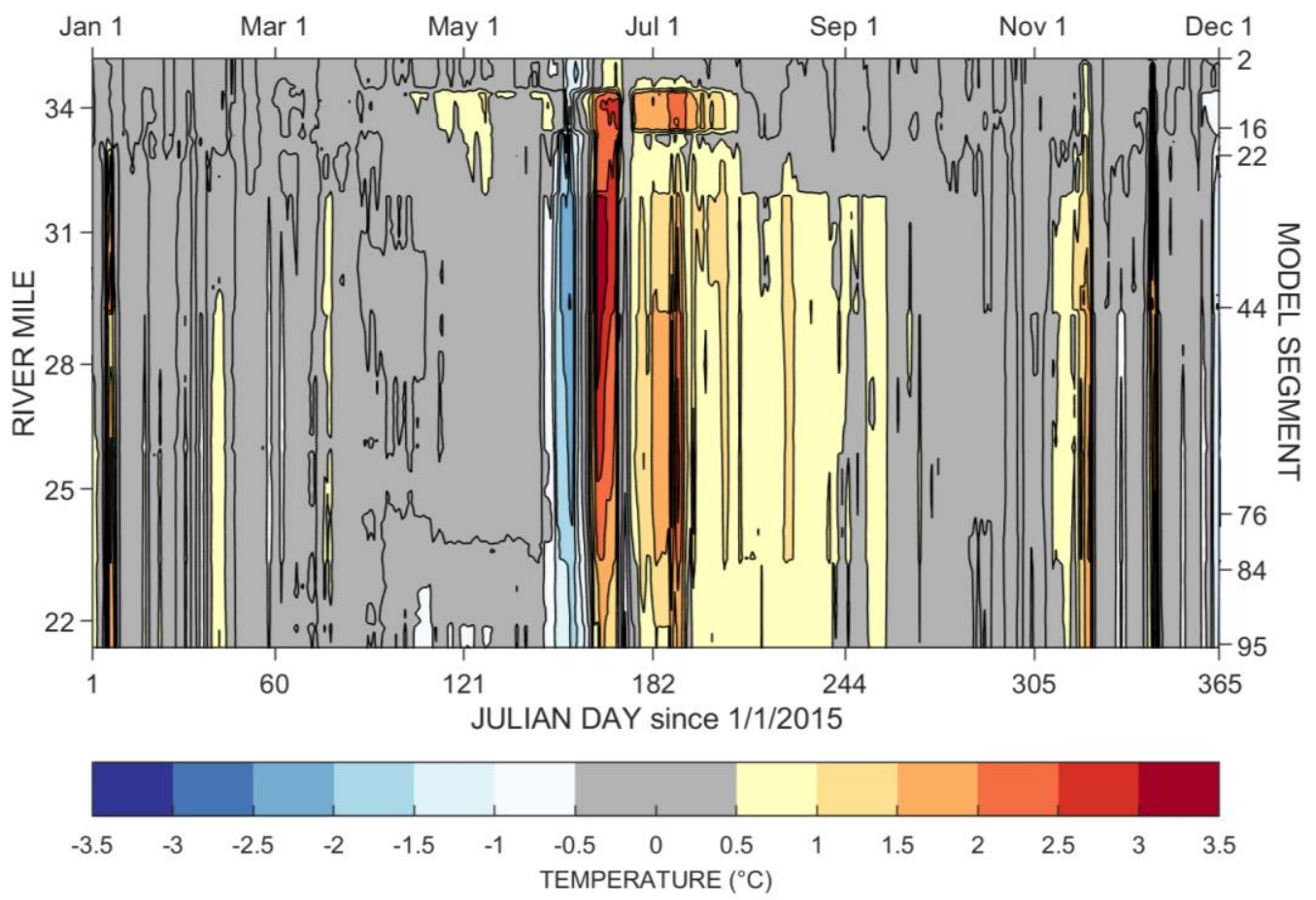

Figure 127. Comparison of the base condition daily temperature at noon to Scenario 2 for all segments on all days, Cedar River. 


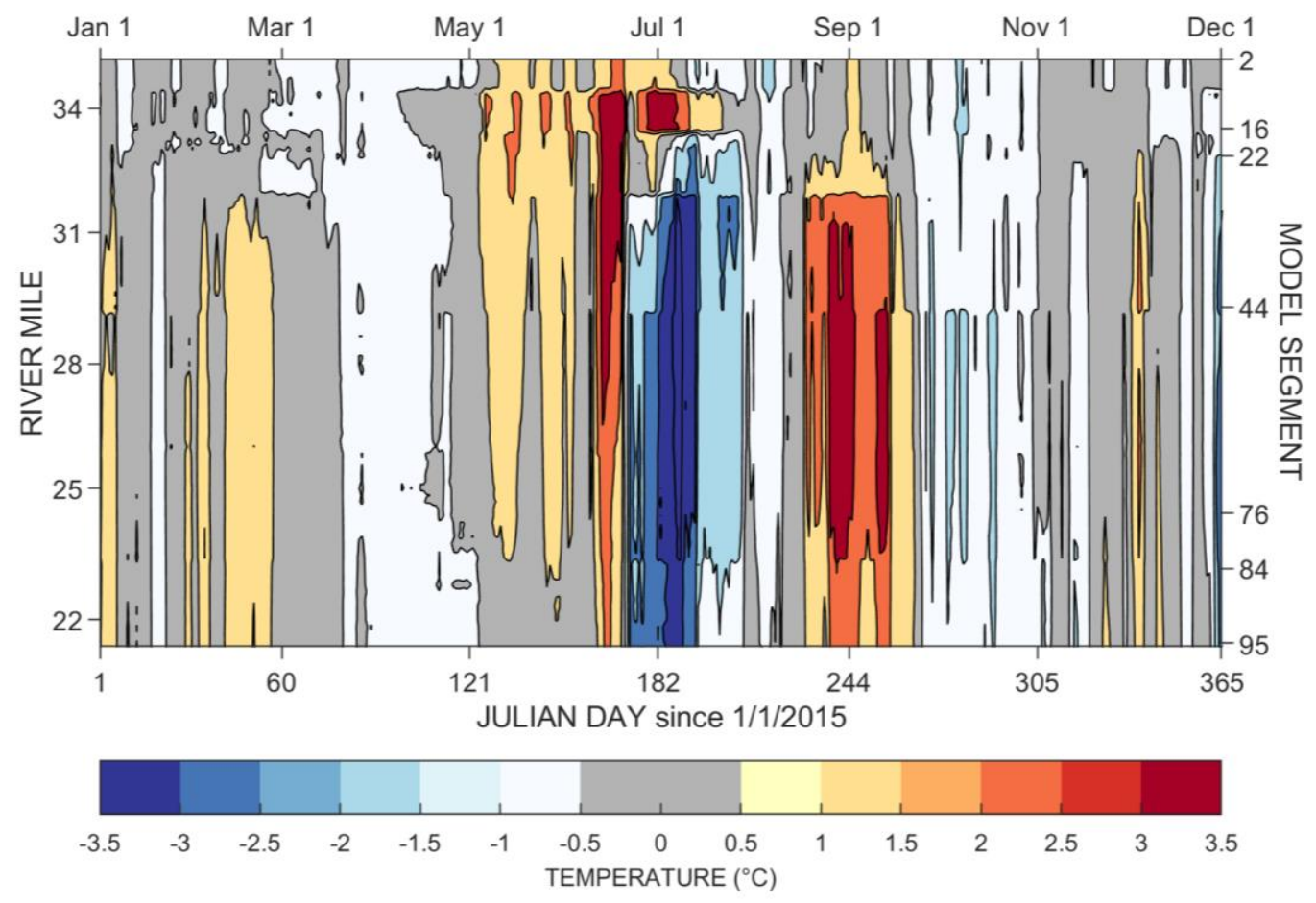

Figure 128. Comparison of the base condition daily temperature at noon to Scenario 3 for all segments on all days, Cedar River.
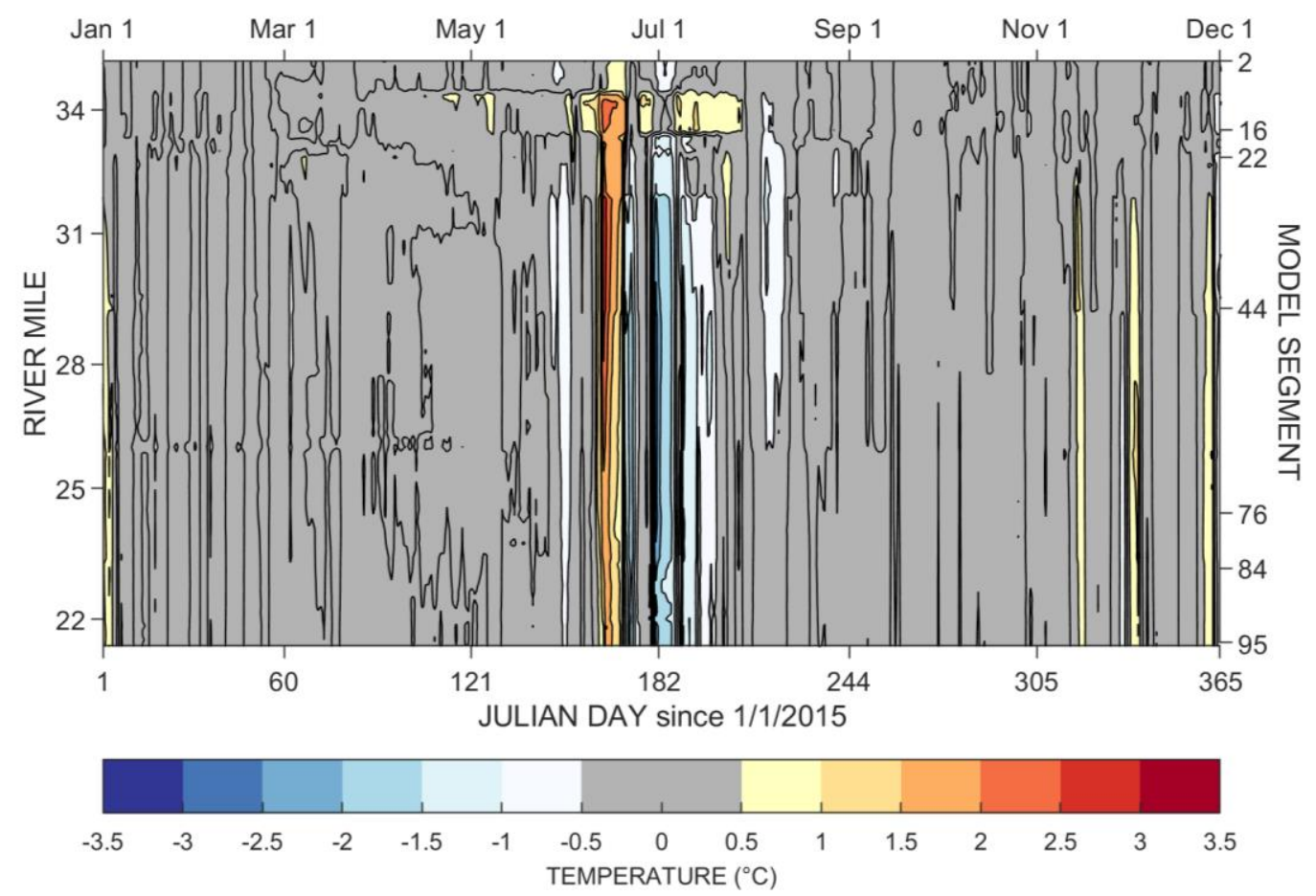

Figure 129. Comparison of the base condition daily temperature at noon to Scenario 4 for all segments on all days, Cedar River. 


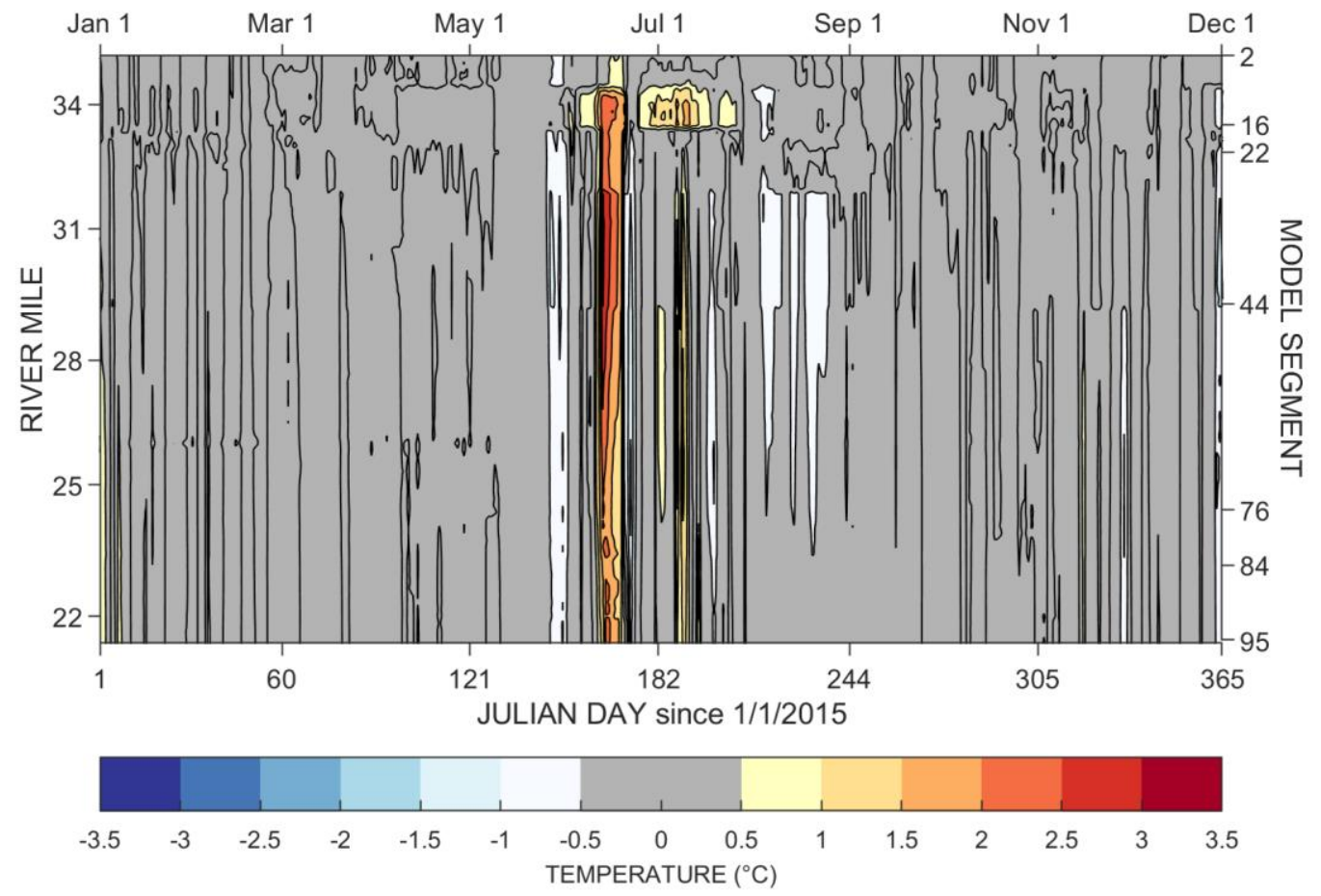

Figure 130. Comparison of the base condition daily temperature at noon to Scenario 5 for all segments on all days, Cedar River. 


\subsection{Water Quality Predictions}

Water quality parameters were simulated for all scenarios. Chlorophyll $a$ and dissolved oxygen were analyzed using two methods in the reservoir. The first method considered changes in the percent of reservoir volume within specified concentration ranges. This method analyzed all model segments of the reservoir for all days from May 1 to September 30 . The second method considered changes in daily concentrations at noon for the reservoir. Changes in the reservoir were analyzed mid-lake at CM1A (segment 27) and at the Masonry Dam (segment 64) over the total depth of the segment. The first method was used for all other water quality parameters in the reservoir. Water quality parameters in the river were evaluated using the second method for all model segments.

\subsubsection{Chester Morse Lake}

The change in the percent of reservoir volume in chlorophyll $a$ and dissolved oxygen for each scenario is shown relative to the base model in Figure 132 and Figure 131. No significant changes in chlorophyll a concentrations were observed from May to September in any of the scenarios. Dissolved oxygen changes were most significant in Scenario 1. Scenario 1 resulted in a 9 percent increase in simulated dissolved oxygen concentrations equal to or less than $6 \mathrm{mg} / \mathrm{L}$ and a 39 percent decrease in simulated dissolved oxygen concentrations equal to or greater than $10 \mathrm{mg} / \mathrm{L}$. Changes in dissolved 
oxygen concentrations under all other scenarios were negligible from May to

\section{September.}

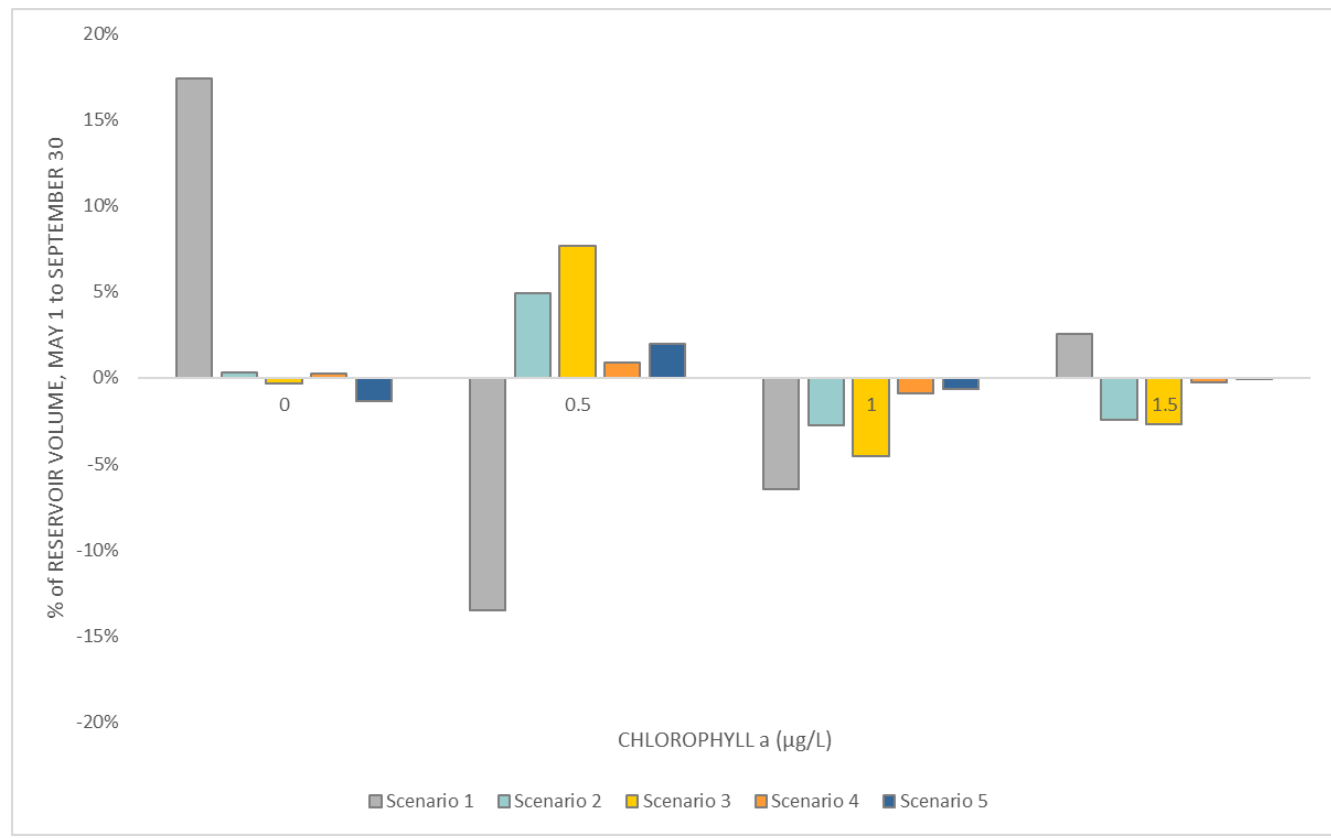

Figure 131. Change in percent of reservoir volume from May 1 to September 30 within the indicated chlorophyll a range relative to the base model for all segments on all days.

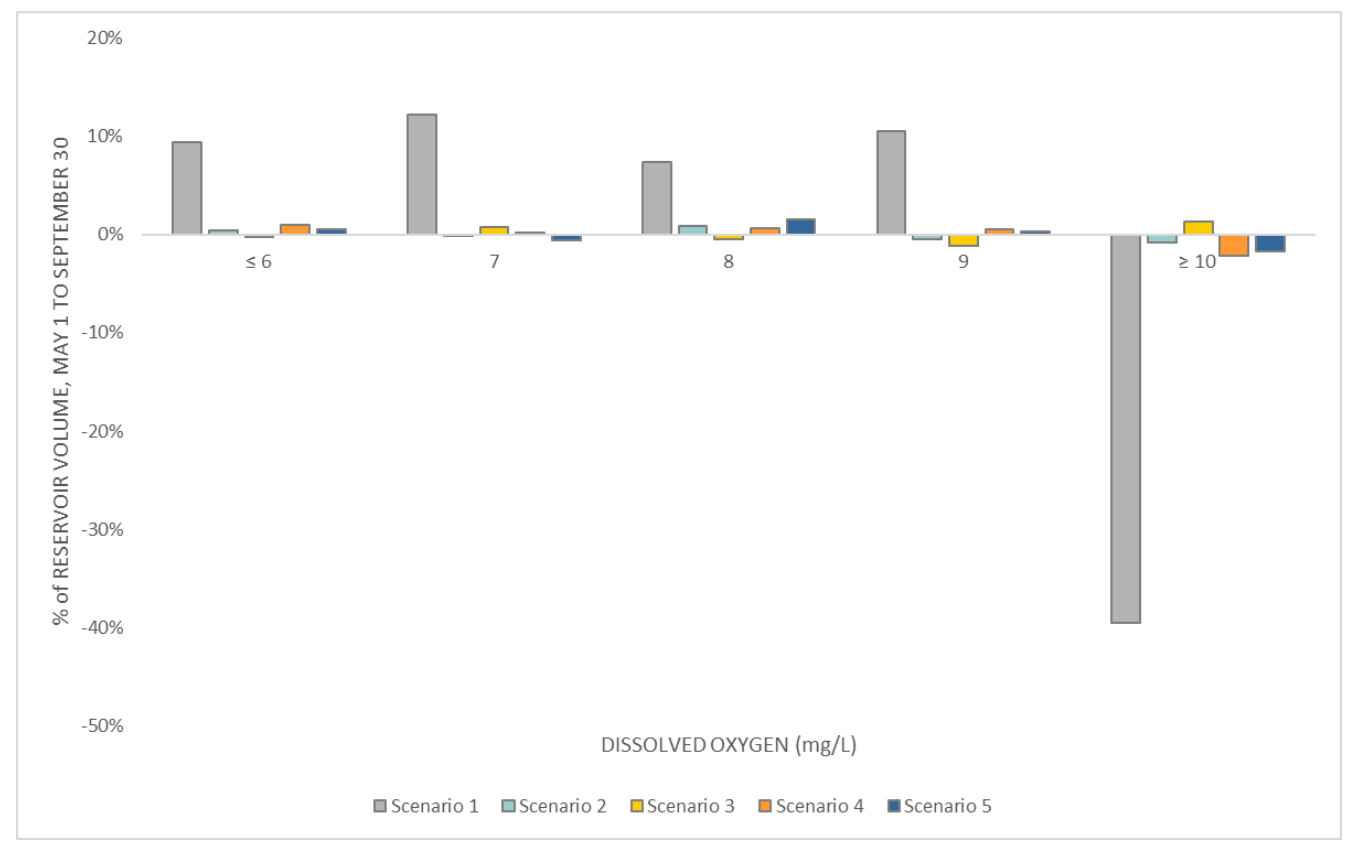

Figure 132. Change in percent of reservoir volume from May 1 to September 30 within the indicated dissolved oxygen range relative to the base model for all segments on all days. 
Additional water quality parameters were evaluated using the weighted average change in percent of reservoir volume from May through September. Results are summarized in Table 29. No significant changes in constituent concentrations were observed from May to September in any of the scenarios.

Table 29. Weighted average change in percent of reservoir volume from May 1 to September 30 relative to the Chester Morse Lake base model for all segments on all days.

\begin{tabular}{|c|c|c|c|c|c|c|}
\hline Parameter (mg/L) & Base & Scenario 1 & Scenario 2 & Scenario 3 & Scenario 4 & Scenario 5 \\
\hline $\begin{array}{l}\text { Chlorophyll } a \\
(\mu \mathrm{g} / \mathrm{L})\end{array}$ & $9.15 \mathrm{E}-01$ & $-1.03 E-01$ & $-8.08 \mathrm{E}-02$ & $-9.10 \mathrm{E}-02$ & $-1.71 \mathrm{E}-02$ & $-8.60 \mathrm{E}-03$ \\
\hline Dissolved Oxygen & 9.57 & $-1.32 \mathrm{E}+00$ & $-4.10 \mathrm{E}-02$ & 4.90E-02 & $-7.60 \mathrm{E}-02$ & $-3.60 \mathrm{E}-02$ \\
\hline Total nitrogen & $1.11 \mathrm{E}-01$ & $3.70 \mathrm{E}-03$ & $6.60 \mathrm{E}-03$ & $9.20 \mathrm{E}-03$ & $-3.00 E-04$ & $5.00 \mathrm{E}-04$ \\
\hline Nitrate-nitrite & $6.80 \mathrm{E}-02$ & 4.24E-03 & $4.85 \mathrm{E}-03$ & 7.01E-03 & $-6.00 E-05$ & 3.80E-04 \\
\hline Ammonia & 4.60E-02 & $-8.12 \mathrm{E}-03$ & $-3.24 \mathrm{E}-03$ & $-3.29 E-03$ & $-6.00 E-04$ & $-4.90 E-04$ \\
\hline Total phosphorus & $4.96 \mathrm{E}-02$ & $1.80 \mathrm{E}-03$ & $1.25 \mathrm{E}-03$ & $-3.50 E-04$ & $-2.90 \mathrm{E}-04$ & 3.00E-05 \\
\hline Phosphate & 8.96E-03 & 2.10E-03 & $-2.31 \mathrm{E}-04$ & $-4.21 E-04$ & $1.06 \mathrm{E}-04$ & 5.40E-05 \\
\hline $\begin{array}{l}\text { Total organic } \\
\text { carbon }\end{array}$ & 9.93E-01 & $-1.39 E-02$ & 7.00E-03 & $-1.41 \mathrm{E}-02$ & $-2.90 \mathrm{E}-03$ & $-9.00 E-04$ \\
\hline
\end{tabular}

The change in daily dissolved oxygen concentrations at noon was considered over depth for the entire model run at CM1A (segment 27). The monthly average dissolved oxygen concentrations at noon, the weighted averages from May through September, and the overall weighted averages are summarized in Table 30. Scenario 1 showed the greatest change in dissolved oxygen concentrations with an overall average decrease of 1.47 $\mathrm{mg} / \mathrm{L}$. Contour plots of predicted change in dissolved oxygen concentrations relative to the base model are shown in Figure 133 through Figure 137. 
Table 30. Summary of the average monthly dissolved oxygen concentration $(\mathrm{mg} / \mathrm{L})$ at noon in the Chester Morse Lake base model and the change in the average for each scenario modeled at CM1A (segment 27). Weighted averages are calculated for May through September and annually.

\begin{tabular}{lcccccc}
\hline Month & Base & Scenario 1 & Scenario 2 & Scenario 3 & Scenario 4 & Scenario 5 \\
\hline Jan & 12.45 & -0.19 & 0.00 & 0.03 & 0.01 & 0.01 \\
\hline Feb & 12.21 & -0.62 & 0.03 & 0.08 & 0.00 & 0.00 \\
Mar & 11.85 & -0.89 & 0.05 & 0.09 & 0.01 & 0.01 \\
\hline Apr & 11.37 & -1.09 & 0.01 & 0.05 & -0.02 & -0.02 \\
May & 10.67 & -1.28 & -0.02 & 0.03 & -0.04 & -0.03 \\
\hline Jun & 9.95 & -1.52 & -0.04 & 0.02 & -0.07 & -0.05 \\
\hline Jul & 9.37 & -1.78 & -0.06 & 0.03 & -0.10 & -0.06 \\
Aug & 8.82 & -2.04 & -0.05 & 0.03 & -0.11 & -0.07 \\
Sep & 8.32 & -2.29 & -0.05 & 0.06 & -0.14 & -0.09 \\
Oct & 7.92 & -2.65 & -0.05 & 0.25 & -0.15 & -0.10 \\
Nov & 9.14 & -2.29 & -0.10 & -0.04 & 0.04 & -0.07 \\
Dec & 11.66 & -0.96 & -0.09 & -0.12 & -0.03 & -0.02 \\
May-Sep & 9.43 & -1.78 & -0.04 & 0.03 & -0.09 & -0.06 \\
\hline Overall & 10.30 & -1.47 & -0.03 & 0.04 & -0.05 & -0.04 \\
\hline
\end{tabular}
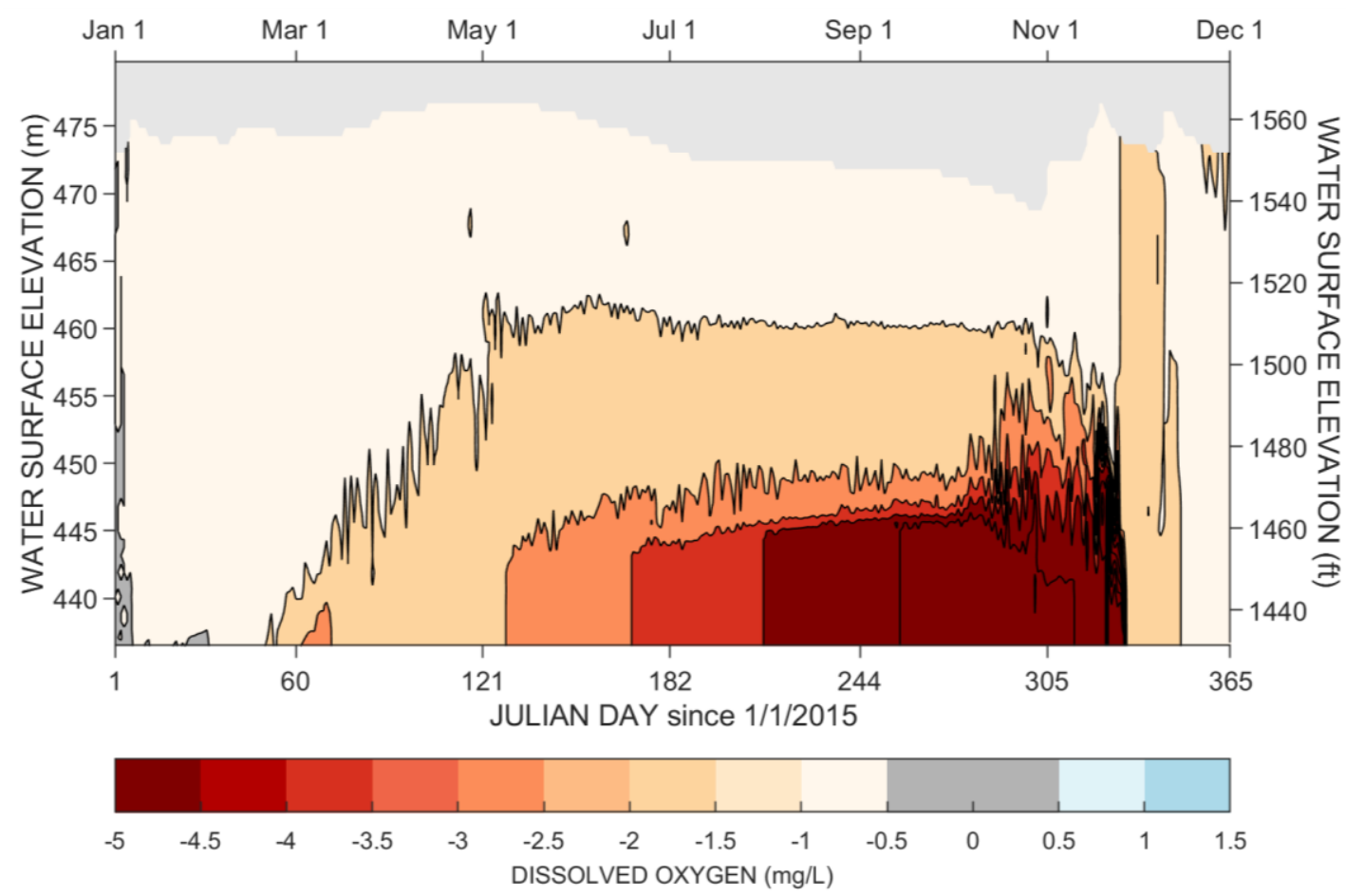

Figure 133. Comparison of the base condition daily dissolved oxygen concentration at noon to Scenario 1 , CM1A (segment 27). 

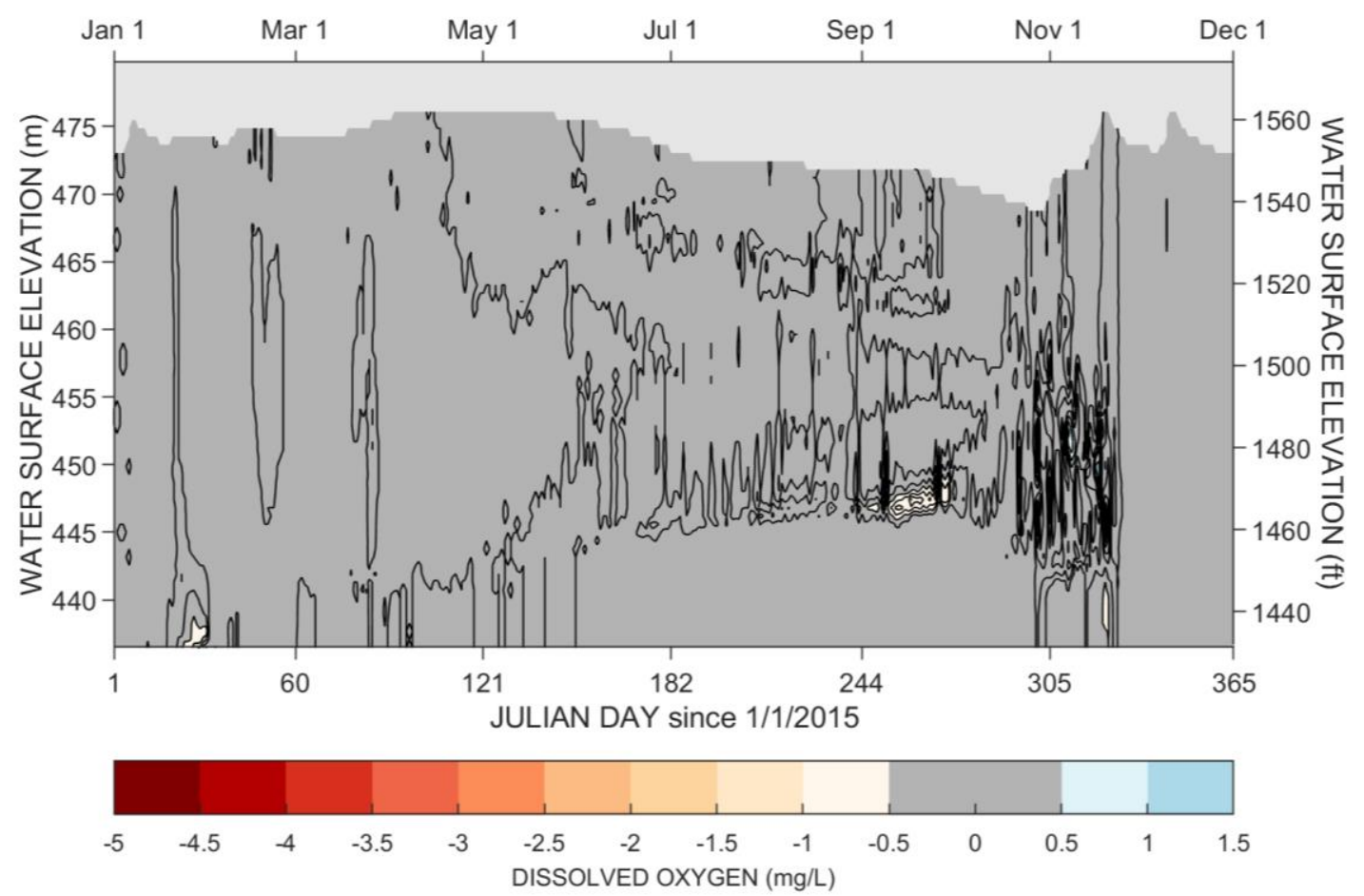

Figure 134. Comparison of the base condition daily dissolved oxygen concentration at noon to Scenario 2, CM1A (segment 27).
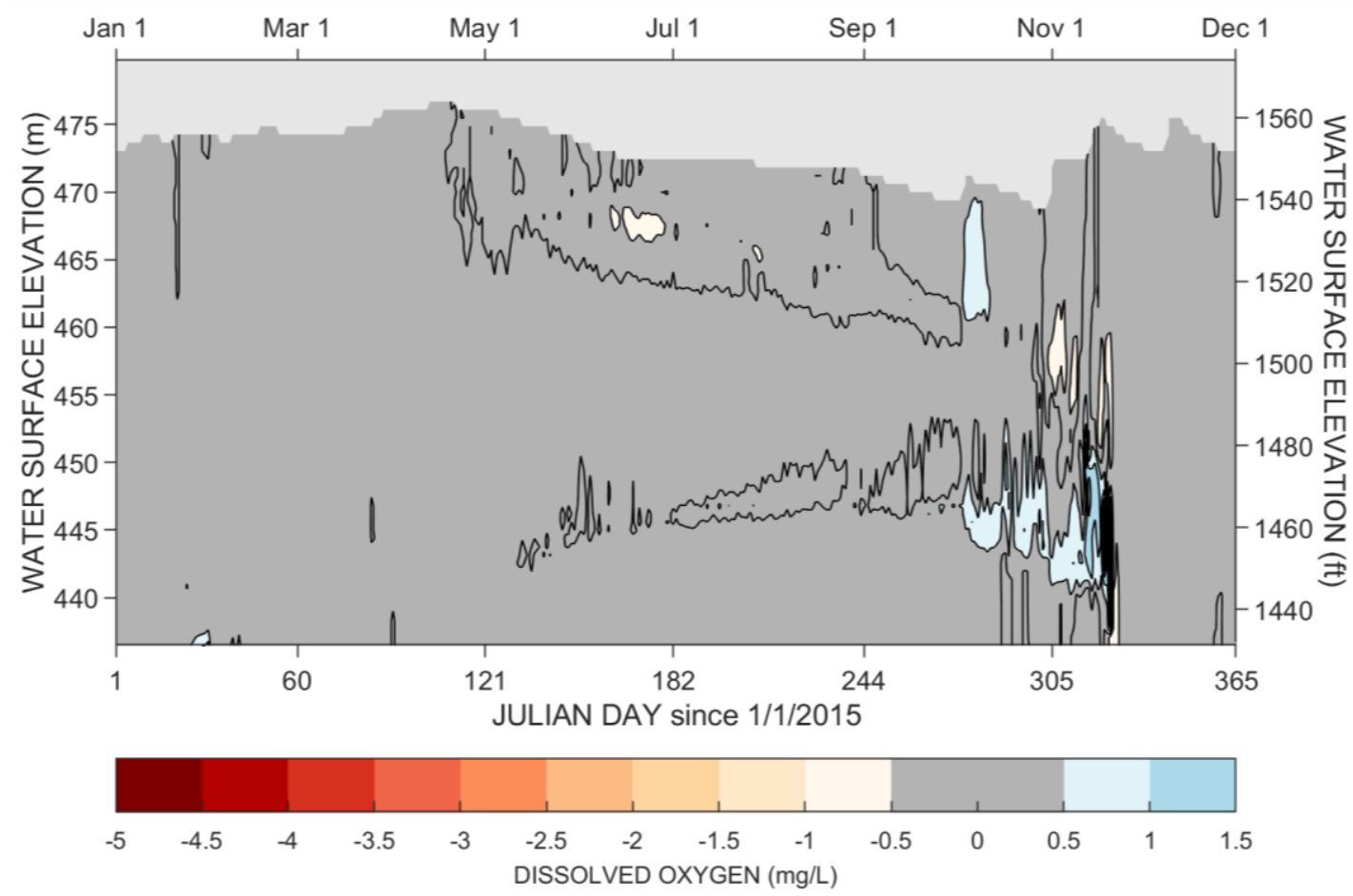

Figure 135. Comparison of the base condition daily dissolved oxygen concentration at noon to Scenario 3, CM1A (segment 27). 

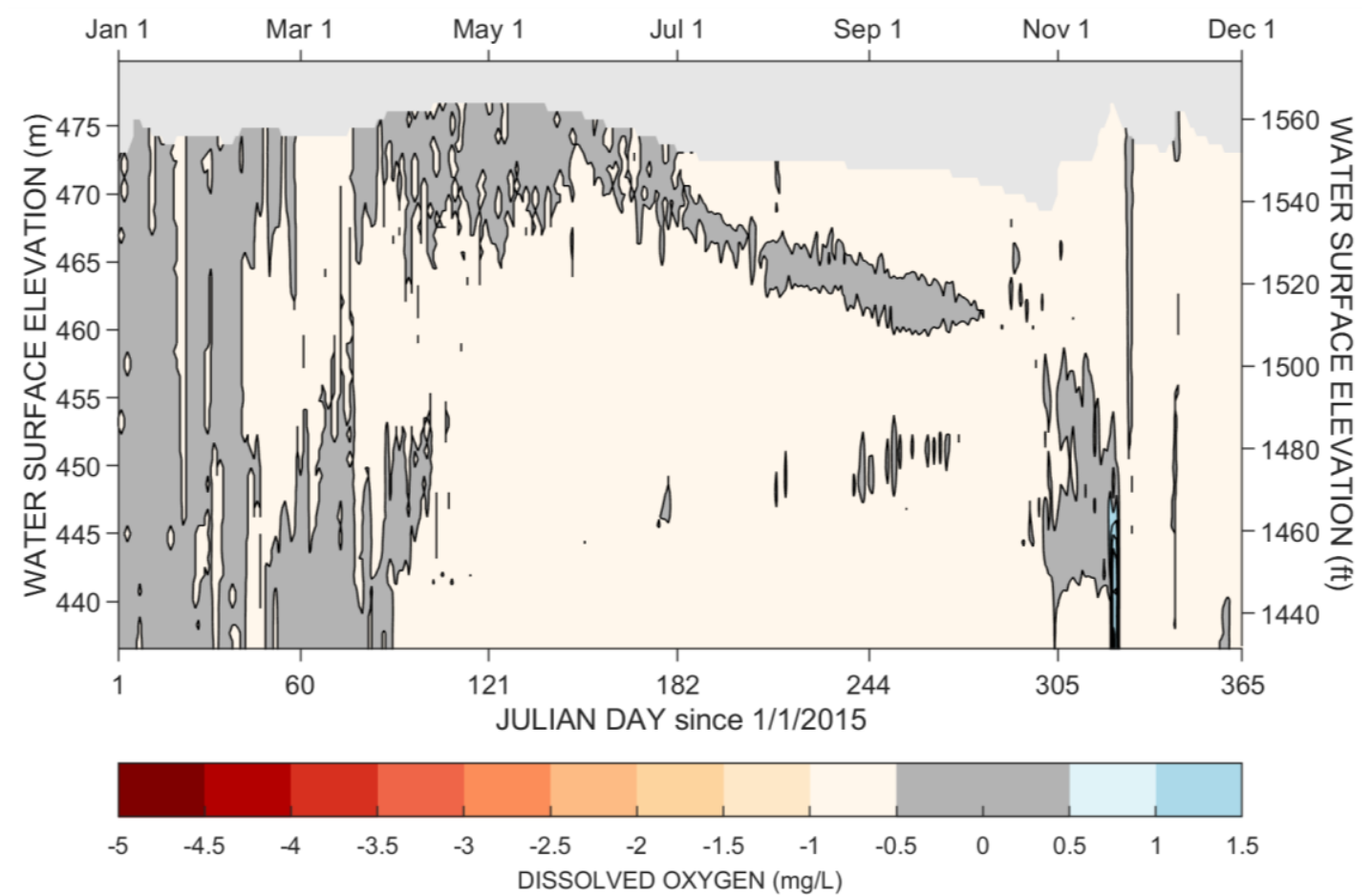

Figure 136. Comparison of the base condition daily dissolved oxygen concentration at noon to Scenario 4, CM1A (segment 27).
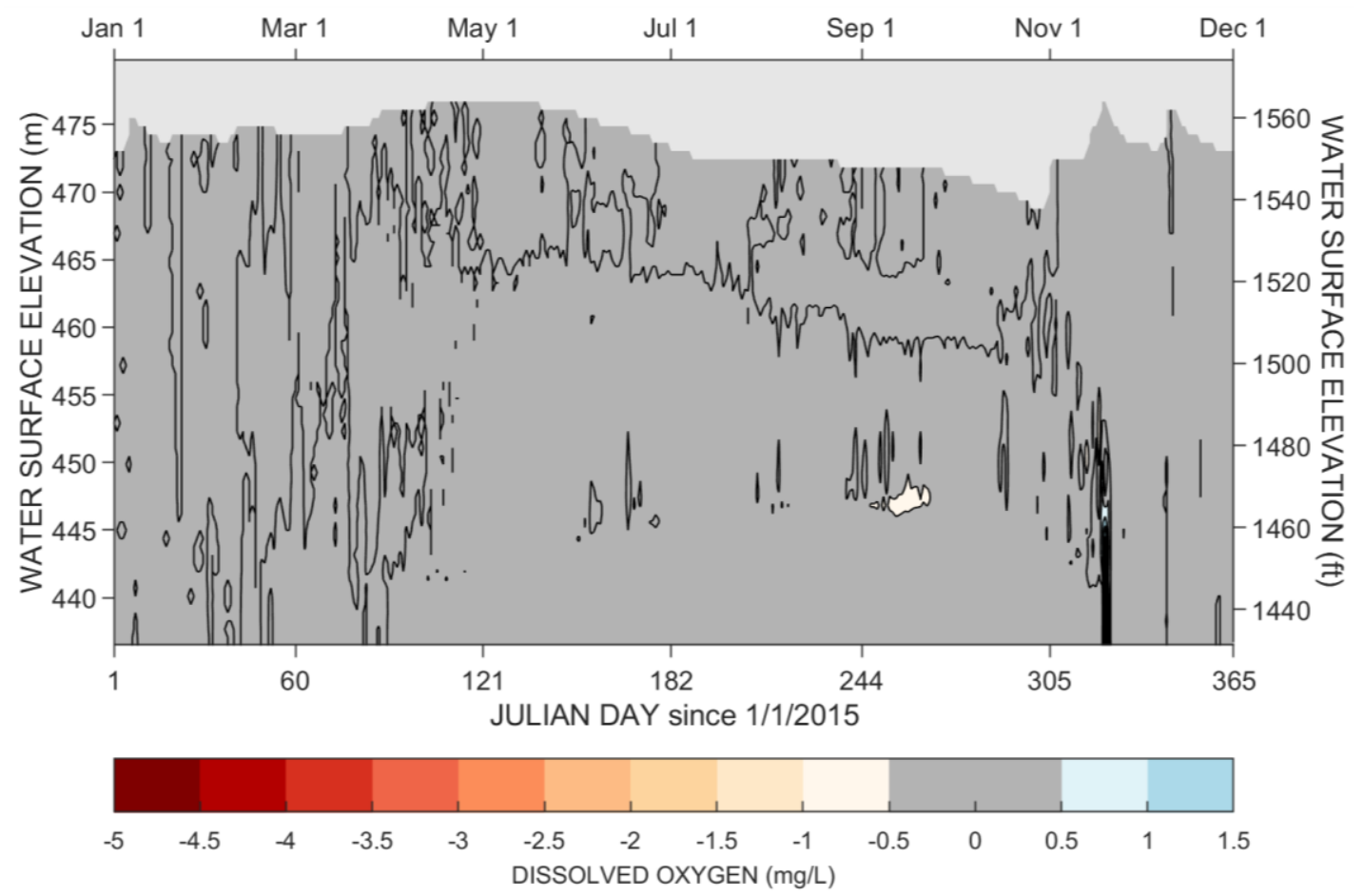

Figure 137. Comparison of the base condition daily dissolved oxygen concentration at noon to Scenario 5 , CM1A (segment 27). 
The change in daily dissolved oxygen concentrations at noon was considered over depth for the entire model run at the Masonry Dam (MD, segment 64). The monthly average dissolved oxygen concentrations at noon, the weighted averages from May through September, and the overall weighted averages are summarized in Table 31. Scenario 1 showed the greatest change in dissolved oxygen concentrations with an overall average decrease of $-0.72 \mathrm{mg} / \mathrm{L}$. Contour plots of predicted change in dissolved oxygen concentrations relative to the base model are shown in Figure 138 through Figure 142.

Table 31. Summary of the average monthly dissolved oxygen concentration $(\mathrm{mg} / \mathrm{L})$ at noon in the Masonry Pool base model and the change in the average for each scenario modeled at MD (segment 64). Weighted averages are calculated for May through September and annually.

\begin{tabular}{lcccccc}
\hline Month & Base & Scenario 1 & Scenario 2 & Scenario 3 & Scenario 4 & Scenario 5 \\
\hline Jan & 12.45 & -0.24 & 0.00 & 0.00 & 0.00 & 0.00 \\
\hline Feb & 12.16 & -0.71 & 0.02 & 0.00 & 0.01 & 0.01 \\
\hline Mar & 11.70 & -0.96 & -0.01 & 0.05 & 0.00 & -0.01 \\
\hline Apr & 10.84 & -1.31 & -0.06 & 0.02 & 0.00 & -0.01 \\
May & 8.67 & -1.23 & -0.12 & 0.43 & -0.03 & -0.02 \\
\hline Jun & 7.47 & -0.66 & -0.34 & 0.20 & -0.10 & 0.04 \\
Jul & 6.79 & -0.29 & 0.09 & 0.08 & -0.12 & 0.18 \\
\hline Aug & 7.09 & -0.43 & -0.06 & 0.26 & -0.05 & -0.09 \\
\hline Sep & 8.08 & -0.55 & -0.04 & 0.33 & -0.10 & -0.07 \\
\hline Oct & 9.21 & -0.64 & -0.03 & -0.09 & -0.04 & 0.02 \\
\hline Nov & 10.08 & -0.80 & 0.06 & 0.02 & 0.05 & 0.06 \\
\hline Dec & 11.90 & -0.85 & 0.00 & -0.03 & -0.01 & -0.02 \\
May-Sep & 7.62 & -0.63 & -0.09 & 0.26 & -0.08 & 0.01 \\
\hline Overall & 9.69 & -0.72 & -0.04 & 0.10 & -0.03 & 0.01 \\
\hline
\end{tabular}



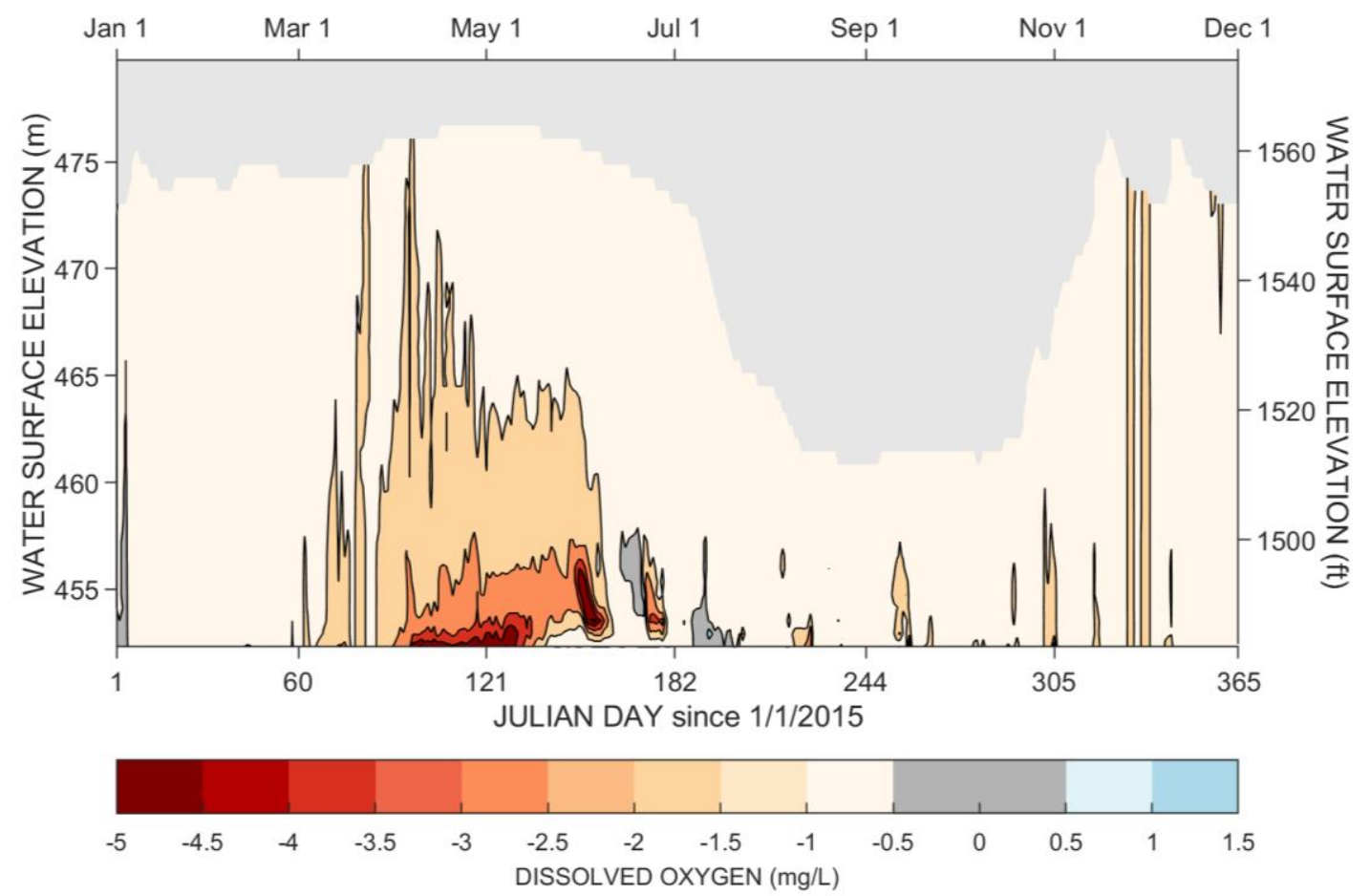

Figure 138. Comparison of the base condition daily dissolved oxygen concentration at noon to Scenario 1 , MD (segment 64).
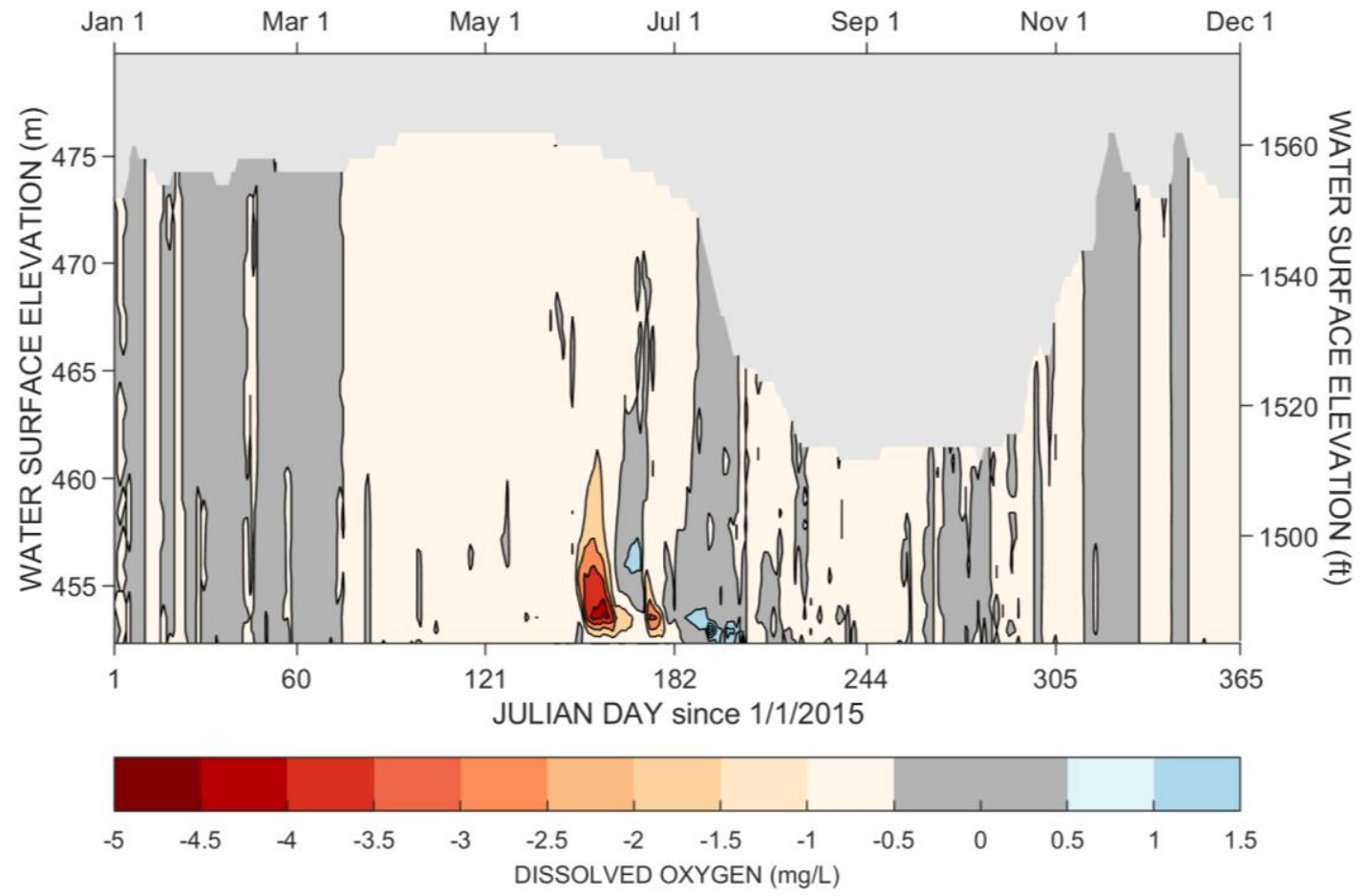

Figure 139. Comparison of the base condition daily dissolved oxygen concentration at noon to Scenario 2, $M D$ (segment 64). 

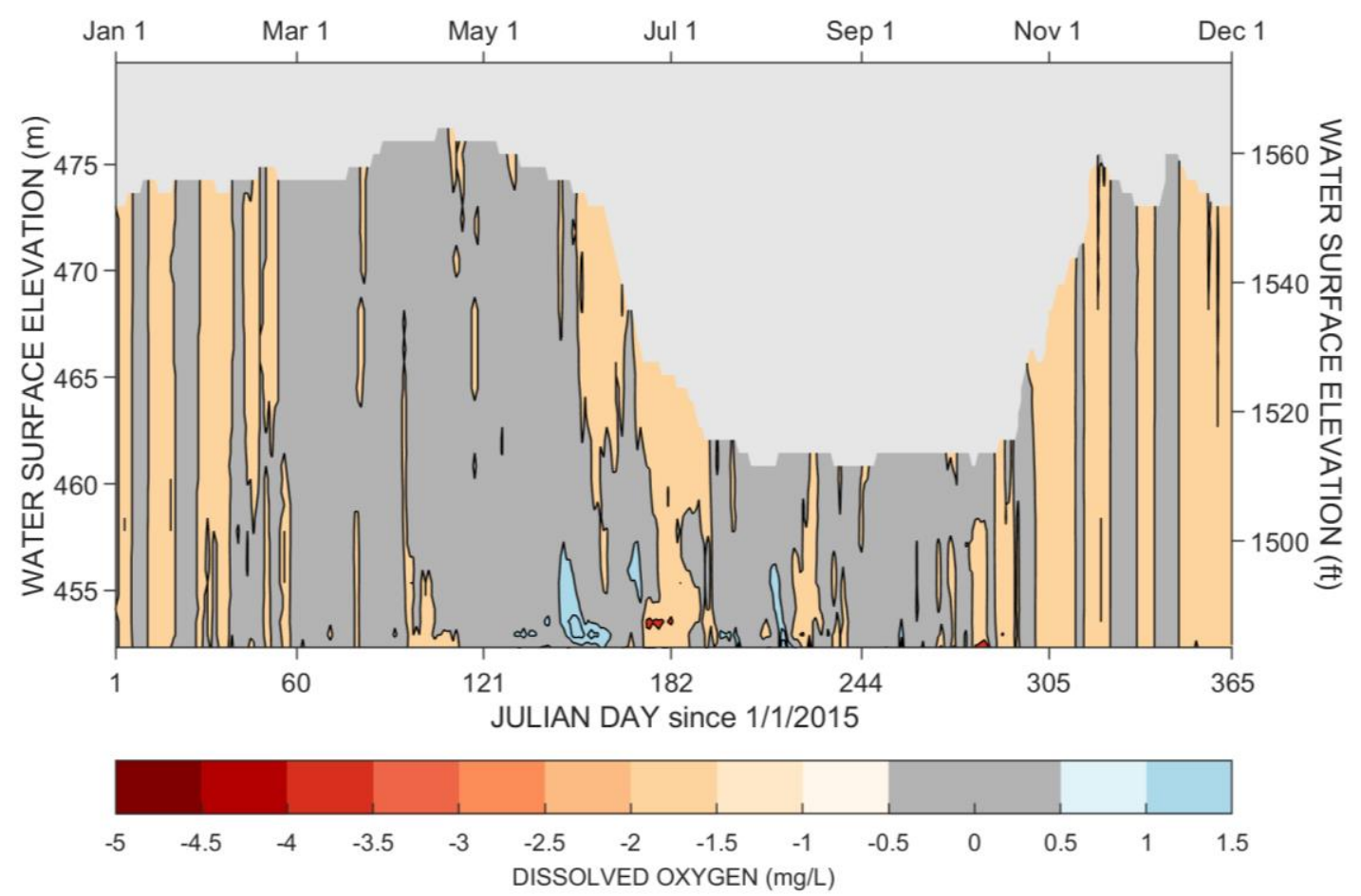

Figure 140. Comparison of the base condition daily dissolved oxygen concentration at noon to Scenario 3 , MD (segment 64).
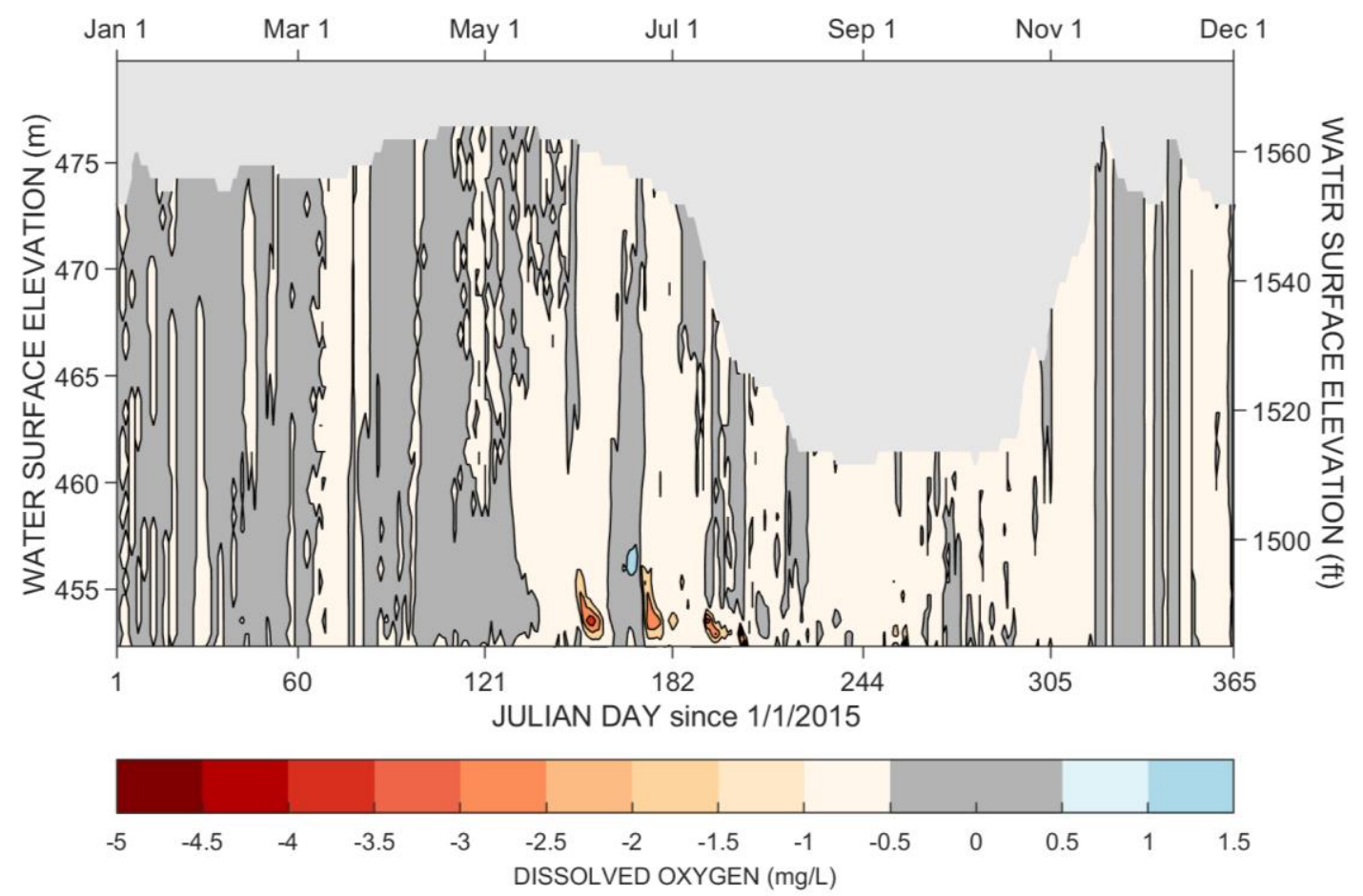

Figure 141. Comparison of the base condition daily dissolved oxygen concentration at noon to Scenario 4 , $M D$ (segment 64). 


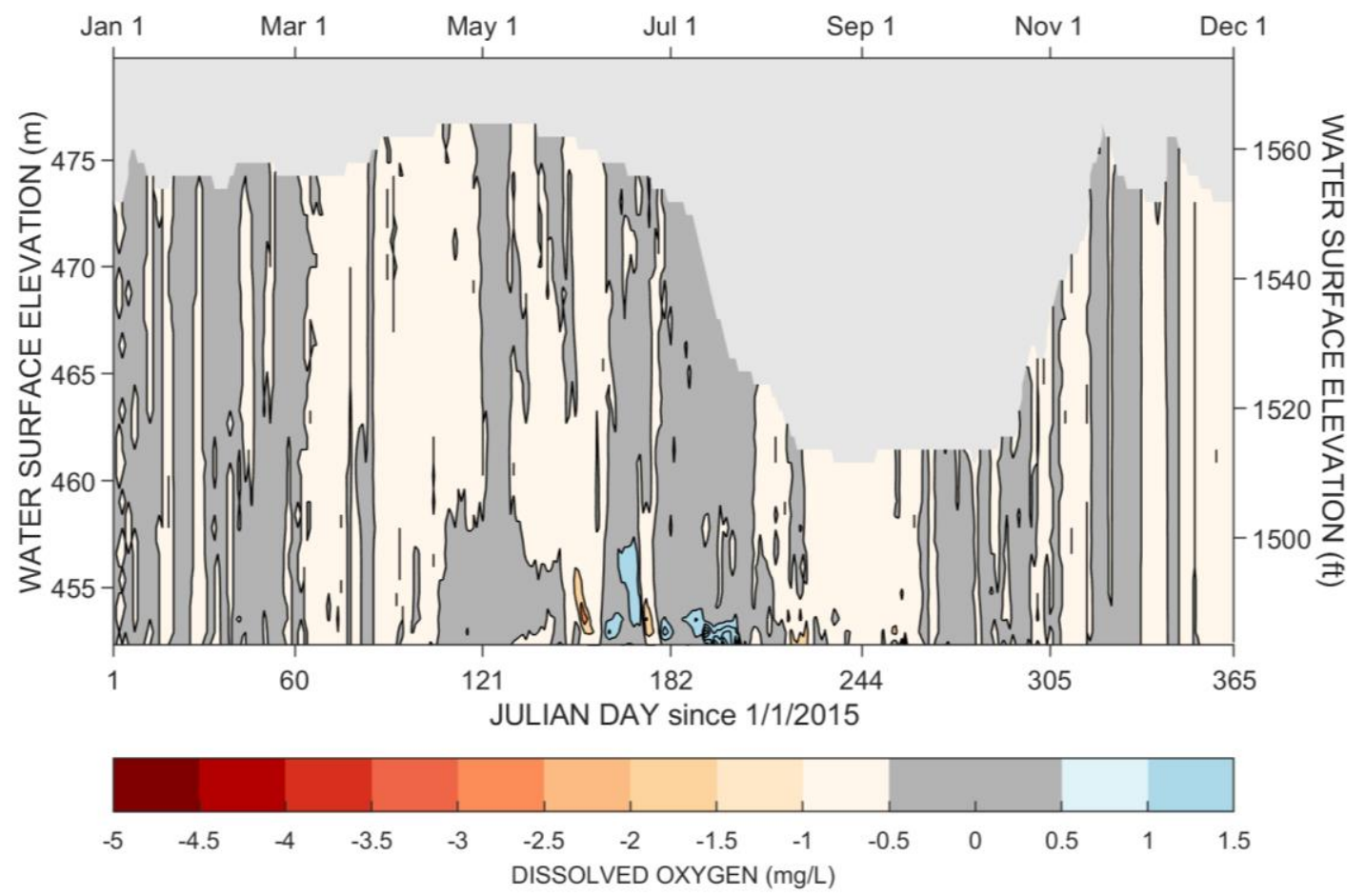

Figure 142. Comparison of the base condition daily dissolved oxygen concentration at noon to Scenario 5, MD (segment 64).

\subsubsection{Cedar River}

The change in daily concentration at noon for each water quality parameter was considered for all river segments for the entire model run. The weighted averages from May through September and for the year are summarized in Table 32. No significant changes in constituent concentrations were observed in any of the scenarios. A visual comparison of the base condition daily dissolved oxygen at noon to each scenario is included in the Appendix. 
Table 32. Summary of the change in weighted average concentration at noon relative to the base model for all segments calculated for May through September (M-S) and annually.

\begin{tabular}{lcccccc}
\hline Parameter $(\mathbf{m g} / \mathrm{L})$ & Base & $\begin{array}{c}\text { Scenario } \\
\mathbf{1}\end{array}$ & $\begin{array}{c}\text { Scenario } \\
\mathbf{2}\end{array}$ & $\begin{array}{c}\text { Scenario } \\
\mathbf{3}\end{array}$ & $\begin{array}{c}\text { Scenario } \\
\mathbf{4}\end{array}$ & $\begin{array}{c}\text { Scenario } \\
\mathbf{5}\end{array}$ \\
\hline Chlorophyll $\boldsymbol{a}(\boldsymbol{\mu \mathrm { g }} / \mathrm{L}), \mathrm{M}-\mathrm{S}$ & $\mathbf{0 . 4 3}$ & $3.89 \mathrm{E}-04$ & $7.65 \mathrm{E}-03$ & $3.90 \mathrm{E}-02$ & $-7.88 \mathrm{E}-03$ & $-3.63 \mathrm{E}-03$ \\
$\quad$ Overall & 0.45 & $5.68 \mathrm{E}-04$ & $-1.38 \mathrm{E}-02$ & $-2.72 \mathrm{E}-02$ & $1.69 \mathrm{E}-03$ & $-2.11 \mathrm{E}-03$ \\
Dissolved oxygen, M-S & 9.78 & -0.31 & -0.11 & -0.09 & 0.01 & 0.00 \\
$\quad$ Overall & 10.81 & -0.40 & -0.04 & -0.05 & 0.00 & 0.00 \\
\hline Total nitrogen, M-S & 0.16 & $1.61 \mathrm{E}-04$ & $-1.04 \mathrm{E}-03$ & $8.80 \mathrm{E}-04$ & $2.36 \mathrm{E}-03$ & $1.00 \mathrm{E}-03$ \\
$\quad$ Overall & 0.17 & $-1.46 \mathrm{E}-04$ & $3.52 \mathrm{E}-03$ & $-2.78 \mathrm{E}-03$ & $5.45 \mathrm{E}-04$ & $4.07 \mathrm{E}-04$ \\
\hline Nitrate-nitrite, M-S & 0.10 & $1.26 \mathrm{E}-04$ & $-4.88 \mathrm{E}-04$ & $2.11 \mathrm{E}-04$ & $1.41 \mathrm{E}-03$ & $9.30 \mathrm{E}-04$ \\
$\quad$ Overall & 0.11 & $-9.97 \mathrm{E}-05$ & $3.71 \mathrm{E}-03$ & $-1.39 \mathrm{E}-03$ & $2.44 \mathrm{E}-04$ & $3.73 \mathrm{E}-04$ \\
\hline Ammonia, M-S & $5.24 \mathrm{E}-03$ & $1.72 \mathrm{E}-05$ & $-2.10 \mathrm{E}-04$ & $-4.81 \mathrm{E}-04$ & $8.41 \mathrm{E}-05$ & $5.02 \mathrm{E}-05$ \\
$\quad$ Overall & $5.60 \mathrm{E}-03$ & $-6.43 \mathrm{E}-05$ & $-5.00 \mathrm{E}-05$ & $-1.33 \mathrm{E}-04$ & $9.94 \mathrm{E}-06$ & $2.82 \mathrm{E}-05$ \\
\hline Total phosphorus, M-S & $5.49 \mathrm{E}-03$ & $3.50 \mathrm{E}-06$ & $7.11 \mathrm{E}-06$ & $-3.07 \mathrm{E}-05$ & $5.95 \mathrm{E}-05$ & $4.53 \mathrm{E}-05$ \\
$\quad$ Overall & $6.11 \mathrm{E}-03$ & $4.34 \mathrm{E}-05$ & $8.02 \mathrm{E}-05$ & $-9.46 \mathrm{E}-05$ & $2.63 \mathrm{E}-05$ & $2.49 \mathrm{E}-05$ \\
\hline Phosphate, M-S & $2.79 \mathrm{E}-02$ & $6.45 \mathrm{E}-05$ & $-1.80 \mathrm{E}-04$ & $-2.80 \mathrm{E}-04$ & $6.32 \mathrm{E}-05$ & $3.59 \mathrm{E}-05$ \\
$\quad$ Overall & $2.44 \mathrm{E}-02$ & $5.25 \mathrm{E}-05$ & $-2.29 \mathrm{E}-05$ & $-3.19 \mathrm{E}-05$ & $1.34 \mathrm{E}-05$ & $1.59 \mathrm{E}-05$ \\
\hline Total organic carbon, M-S & 0.60 & $-9.13 \mathrm{E}-03$ & $3.51 \mathrm{E}-02$ & $5.32 \mathrm{E}-02$ & $-6.74 \mathrm{E}-03$ & $2.40 \mathrm{E}-03$ \\
$\quad$ Overall & 0.76 & $-6.19 \mathrm{E}-03$ & $-1.09 \mathrm{E}-03$ & $3.68 \mathrm{E}-02$ & $1.78 \mathrm{E}-04$ & $2.50 \mathrm{E}-03$ \\
\hline
\end{tabular}

\subsubsection{Water Quality Discussion and Conclusions}

The relationship between input parameters and water quality constituents was

evaluated using a correlation matrix and Pearson correlation coefficients (Figure 143).

The mean daily air temperature at USGS 12115900, water temperature at USGS

12115000, flow at USGS 12115000, and Masonry Pool water surface elevation at USGS

121160606 were calculated for each day in 2015 with a corresponding water quality

constituent field sample from SPU. Water quality parameters generally showed positive

correlation between each other with values ranging from 0.56 to 0.95 . Air temperature

and water temperature showed the highest positive correlation of 0.93 for boundary

condition parameters. Air temperature and water temperature generally showed 
negative correlation or a statistically insignificant correlation to water quality parameters.

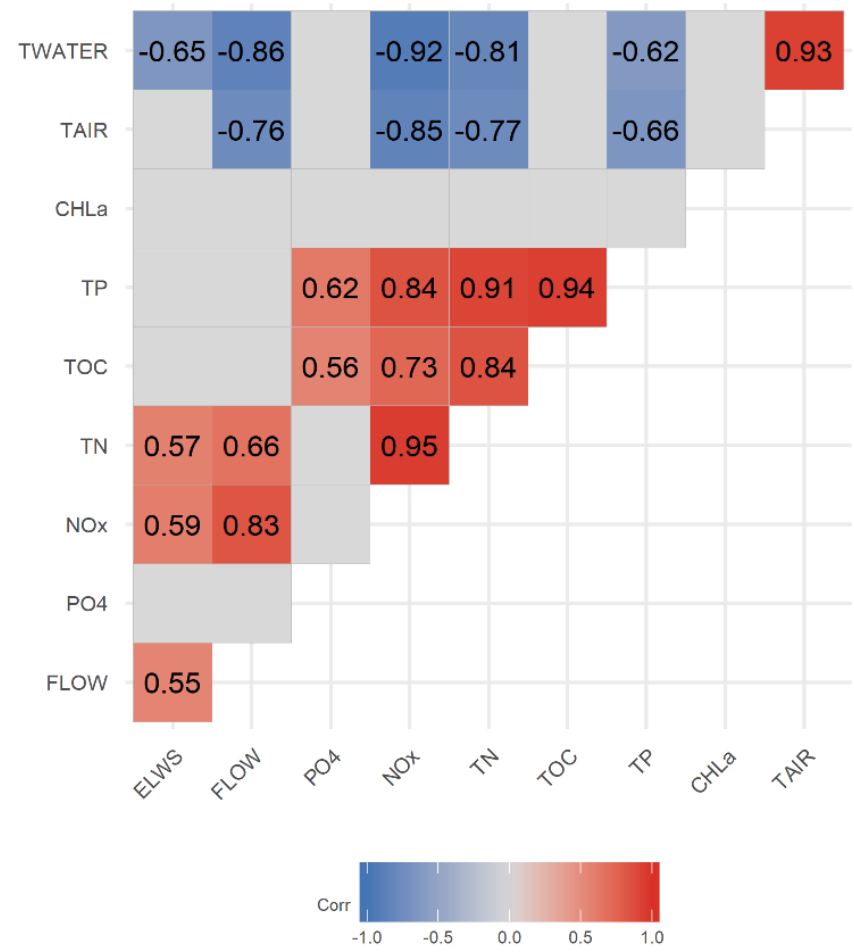

Figure 143. Correlation matrix of water quality constituents and input parameters changed in scenarios. Negative numbers indicate a negative correlation and positive numbers indicate a positive correlation. Insignificance is indicated by a blank.

In Scenario 1, the correlation matrix suggests that the greatest change would occur in modeled water temperatures due to the positive correlation with air temperature. Changes in air temperature and water temperature would be unlikely to significantly modify chlorophyll $a$, phosphate, or total organic carbon. Under Scenario 2 and Scenario 3 , changes in flow would be unlikely to significantly modify chlorophyll $a$, total phosphate, phosphate, or total organic carbon. Total nitrogen and nitrate-nitrite were 
positively correlated, which corresponds to the greatest modeled increase in these parameters relative to the base model. In Scenario 4 and Scenario 5, changes in water surface elevation would be unlikely to significantly modify chlorophyll $a$, total phosphate, phosphate, or total organic carbon. Total nitrogen and nitrate-nitrite were positively correlated, which corresponds to the increase simulated in Scenario 5. Scenario 4 showed a decrease in these parameters.

\subsection{Environmental Impact on Fish Habitat}

The Cedar River Municipal Watershed is home to a variety of fish species from the Salmonidae family. Species known to exist within the watershed include Chinook salmon, sockeye salmon, coho salmon, steelhead and rainbow trout, cutthroat trout, bull trout, pygmy whitefish, and mountain whitefish (City of Seattle, April 2000). The geographic regions relevant to this study include the reservoirs and their tributaries and the Cedar River from the Masonry Dam to the Landsburg Diversion Dam. Each area provides habitat for different fish species. The upper geographic region of the watershed is separated from the lower geographic region by two waterfalls downstream of the Masonry Dam that act as a natural barrier to upstream fish passage. The upper watershed is home to bull trout, pygmy whitefish, and rainbow trout. Fish habitat in the lower watershed has been severely altered by the construction of the Landsburg Diversion Dam in 1900 and the rerouting of the Cedar River in 1916 (City of Seattle, April 2000). The Cedar River was rerouted from the Black River into Lake Washington when the Lake Washington Ship Canal was constructed, which caused the extinction of pink 
salmon and chum salmon in the Cedar River. The Landsburg Diversion Dam did not allow for fish passage until the construction of the fish ladder in 2003. Prior to the construction of the fish ladder, the lower watershed provided habitat for rainbow trout and cutthroat trout. Since the completion of the fish ladder, coho salmon, Chinook salmon, and steelhead trout have returned to the lower watershed. Sockeye salmon, due to their high numbers, are denied passage at the fish ladder to protect water quality.

The change in fish habitat under each scenario relative to the 2015 calibrated model was determined for the reservoir model and the river model. The volume of fish habitat based on temperature and dissolved oxygen limits was calculated using the CE-QUAL-W2 fish habitat module.

\subsubsection{Chester Morse Lake}

The species of greatest concern in the upper watershed is bull trout. Bull trout are listed as a threatened species under the Federal Endangered Species Act (Seattle Public Utilities, n.d.). In the fish-bioenergetics study conducted by V. Wells, growth potential zones were determined using the relationship between temperature and growth potential. Bull trout habitat was classified into five major growth potential zones. The zones are summarized in Table 33. 
Table 33. Summary of growth potential zones for bull trout in Chester Morse Lake.

\begin{tabular}{lcc}
\hline Growth Potential Zone & Temperature Criteria $\left({ }^{\circ} \mathrm{C}\right)$ & Dissolved oxygen minimum (mg/L) \\
\hline Optimal Growth & $11.4-15.2$ & 5 \\
\hline High Growth & $9.8-17$ & 4 \\
Medium Growth & $8.7-18$ & 4 \\
Low Growth & $6-20$ & 4 \\
\hline Non-lethal (no growth) & $0-26.4$ & 4 \\
\hline
\end{tabular}

The reservoir volume of bull trout habitat was determined for each growth potential zone under the base model and in each of the scenarios. The scenario with the greatest impact was Scenario 1. Non-lethal growth potential was reduced from 100 percent for all months in the base model by a monthly average of 2 to 20 percent under Scenario 1. No other scenarios resulted in a decrease of non-lethal growth potential. Optimal growth increased by 14 percent under Scenario 1 during April and November, but decreased by 4 to 10 percent during May, October, and September. Scenarios 2, 4, and 5 did not undergo significant change in optimal growth potential. Scenario 3 resulted in a 3 percent increase during September and a 5 percent decrease during October. The change in optimal and non-lethal bull trout habitat for each scenario is summarized in Table 35 and Table 34. Results for all other growth potential zones are presented in the Appendix. 
Table 34. Summary of the average monthly percent of reservoir volume with non-lethal growth potential for bull trout in the Chester Morse Lake base model and the change in the average for each scenario.

\begin{tabular}{lcccccc}
\hline Month & Base & Scenario 1 & Scenario 2 & Scenario 3 & Scenario 4 & Scenario 5 \\
\hline Jan & 100 & 0 & 0 & 0 & 0 & 0 \\
\hline Feb & 100 & 0 & 0 & 0 & 0 & 0 \\
Mar & 100 & 0 & 0 & 0 & 0 & 0 \\
\hline Apr & 100 & 0 & 0 & 0 & 0 & 0 \\
May & 100 & 0 & 0 & 0 & 0 & 0 \\
Jun & 100 & 0 & 0 & 0 & 0 & 0 \\
Jul & 100 & -2 & 0 & 0 & 0 & 0 \\
Aug & 100 & -12 & 0 & 0 & 0 & 0 \\
Sep & 100 & -15 & 0 & 0 & 0 & 0 \\
Oct & 100 & -20 & 0 & 0 & 0 & 0 \\
Nov & 100 & -12 & 0 & 0 & 0 & 0 \\
Dec & 100 & 0 & 0 & 0 & 0 & 0 \\
\hline
\end{tabular}

Table 35. Summary of the average monthly percent of reservoir volume with optimal growth potential for bull trout in the Chester Morse Lake base model and the change in the average for each scenario.

\begin{tabular}{lcccccc}
\hline Month & Base & Scenario 1 & Scenario 2 & Scenario 3 & Scenario 4 & Scenario 5 \\
\hline Jan & 0 & 0 & 0 & 0 & 0 & 0 \\
\hline Feb & 0 & 0 & 0 & 0 & 0 & 0 \\
Mar & 0 & 0 & 0 & 0 & 0 & 0 \\
\hline Apr & 0 & 14 & 0 & 0 & 0 & 0 \\
May & 26 & -4 & 0 & -1 & 0 & 0 \\
\hline Jun & 9 & 1 & 0 & -1 & 0 & 0 \\
Jul & 6 & 3 & 0 & 0 & 0 & 0 \\
\hline Aug & 6 & 3 & 0 & 0 & 0 & -1 \\
Sep & 19 & -10 & -1 & 3 & -1 & 0 \\
\hline Oct & 35 & -8 & -1 & -5 & 0 & 0 \\
\hline Nov & 0 & 14 & 0 & 0 & 0 & 0 \\
\hline Dec & 0 & 0 & 0 & 0 & 0 & 0 \\
\hline
\end{tabular}




\subsubsection{Cedar River}

The species of greatest concern in the lower watershed are Chinook salmon, coho salmon, and steelhead trout. The aquatic life temperature and dissolved oxygen criteria outlined by the Washington State Legislature were used to evaluate changes in fish habitat in the river model (WSDE, 2019). The criteria are summarized in Table 36.

Table 36. Summary of WAC 173-201A-200 aquatic life temperature and dissolved oxygen criteria for fresh surface waters.

\begin{tabular}{lccc}
\hline Category & Season & Highest 7-DADMax $\left({ }^{\circ} \mathrm{C}\right)$ & Lowest 1-Day DO min (mg/L) \\
\hline $\begin{array}{l}\text { Core summer salmonid } \\
\text { habitat }\end{array}$ & $6 / 15-9 / 15$ & 16 & 9.5 \\
$\begin{array}{l}\text { Salmonid spawning, } \\
\text { rearing, and migration }\end{array}$ & $9 / 16-6 / 14$ & 17.5 & 8 \\
$\begin{array}{l}\text { Salmonid rearing and } \\
\text { migration only }\end{array}$ & $9 / 16-6 / 14$ & 17.5 & 6.5 \\
\hline
\end{tabular}

The highest 7-day average of the daily maximum temperature (7-DADMax) was used as the temperature maximum in the fish habitat analysis. The temperature minimum for each category was estimated as $6^{\circ} \mathrm{C}$ based on the average temperature of the lower limit within the optimum range for Chinook salmon, coho salmon, and steelhead trout (Bell, 1990). The core summer salmonid habitat aquatic life use was the most impacted category. Fish volume habitat decreased by 1 to 13 percent from mid-June through mid-September under Scenario 1 and Scenario 2. Fish volume habitat decreased by 14 to 22 percent from August through mid-September under Scenario 3. Habitat volume increased by 11 to 12 percent from mid-June through July in Scenario 4 . Scenario 5 saw minimal change in core summer salmonid habitat. Results are summarized in Table 37. 
Table 37. Summary of the average monthly percent of river volume with core summer salmonid habitat aquatic life use in the Cedar River base model and the change in the average for each scenario.

\begin{tabular}{lcccccc}
\hline Month & Base & Scenario 1 & Scenario 2 & Scenario 3 & Scenario 4 & Scenario 5 \\
\hline Jun 15-30 & 49 & -9 & -10 & 20 & 12 & 2 \\
Jul & 48 & -13 & -13 & 25 & 11 & -2 \\
Aug & 76 & -6 & -8 & -14 & -1 & 2 \\
Sep 1-15 & 77 & -1 & -4 & -22 & -1 & 1 \\
\hline
\end{tabular}

The monthly average values for the spawning, rearing, and migration category and the rearing and migration only category were nearly identical for each scenario. Under the salmonid spawning, rearing, and migration aquatic life use category, fish habitat generally increased under all scenarios with the major exception of decreases observed for all scenarios in early June. The largest predicted increase and decrease occurred under Scenario 1. The maximum predicted increase was 71 percent in December. The maximum observed decrease was 14 percent in early June. Results for the salmonid spawning, rearing, and migration category are summarized in Table 38. Results for the salmonid rearing and migration only category are summarized in the Appendix.

Table 38. Summary of the average monthly percent of river volume with salmonid spawning, rearing, and migration aquatic life use in the Cedar River base model and the change in the average for each scenario.

\begin{tabular}{lcccccc}
\hline Month & Base & Scenario 1 & Scenario 2 & Scenario 3 & Scenario 4 & Scenario 5 \\
\hline Jan & 13 & 48 & 11 & 24 & 1 & 0 \\
\hline Feb & 57 & 39 & -2 & 23 & -3 & -2 \\
\hline Mar & 91 & 9 & -1 & 0 & 0 & 1 \\
\hline Apr & 100 & 0 & 0 & -1 & 0 & 0 \\
\hline May & 100 & -3 & -1 & 0 & 0 & 0 \\
\hline Jun 1-14 & 99 & -14 & -4 & -4 & -1 & -1 \\
\hline Jul & -- & -- & -- & -- & -- & -- \\
\hline Aug & -- & -- & -- & -- & 0 & -- \\
\hline Sep 16-30 & 100 & -2 & 0 & 0 & 0 & 0 \\
\hline Oct & 100 & 0 & 0 & 0 & -2 & -3 \\
\hline Nov & 91 & 9 & -5 & 4 & 6 & -4 \\
\hline Dec & 25 & 71 & -3 & 4 & - \\
\hline
\end{tabular}




\section{Chapter 6. Model Improvements}

The calibrated model for the Cedar River Municipal Watershed required parameter estimation that introduced a degree of uncertainty. Additionally, use of the dynamic pipe algorithm required extensive manual adjustment. Suggestions for model improvements are outlined in the following sections and focus on improvements for the 2015 model as SPU data collection methods have been updated since the $2005-2008$ model.

\subsection{Chester Morse Lake}

The Chester Morse Lake model could be improved by increasing temporal and spatial data resolution, reducing parameter estimation, and increasing model stability. Components to consider include boundary condition data, flow at reservoir structures, temperature data and water quality data, meteorological inputs, and the dynamic pipe algorithm.

Limited boundary condition data were collected for the reservoir. Flow data were available for the major tributaries and temperature data were available at one upstream location. No water quality data were collected. In future studies, it would be beneficial to increase spatial and temporal resolution for major reservoir tributaries. Water temperature data collection efforts on the major tributaries could verify the regression relationships developed using the partial temperature records from 2005 to 2008. 
Water quality data collection for the major tributaries would allow for an increased understanding of nutrient sources in the reservoir.

The dearth of flow data at all major reservoir structures required extensive estimation and introduced uncertainty into the model. The model could be improved with known outflows from the Masonry Dam, known flows at the Overflow Dike, documented flow rates and durations at the MLPP, and an increased understanding of seepage from the Masonry Pool. It would require extensive gaging of the system to obtain higher outflow resolution. An alternative would be higher temporal resolution of the Masonry Pool water surface elevation collected at the same datum as USGS 12116060.

Additional water quality data would improve model performance. No ammonia data were collected for 2015. The relationship between ammonia and other nitrogenous species is complex. The estimation of ammonia as a percentage of the nitrate-nitrite concentrations introduced model uncertainty. The sampling method and spatial resolution at the Masonry Dam limited model calibration efforts. In future studies, it would be beneficial to have profile data at 1-meter increments collected in situ at the Masonry Dam. This would provide an increased understanding of temperature and nutrient dynamics at the dam. Since the outflows from the reservoir model were used as inputs into the river model, both the river and reservoir model would be improved with increased data frequency at the Masonry Dam. Additionally, data collection methods more consistent with CE-QUAL-W2 model capabilities would allow for a more direct comparison of observations and predictions. The model provides laterally 
averaged outputs for each vertical layer over each model timestep, which allowed for a depth resolution every 0.61 meters and a temporal resolution every 15 minutes in this study. Vertical profile data of all water quality constituents at a 1-meter depth resolution with a timestamp would allow for a more direct comparison to model predictions. CE-QUAL-W2 also uses specific units for each modeled parameter. It was not possible to accurately compare algae and zooplankton data in this study due to the sampling method and reported units.

The meteorological inputs relied on neighboring meteorological stations and estimation of parameter input. No on-site cloud cover data were available for the model and the observed solar data were inconsistent with theoretical solar models. Cloud cover from Stampede Pass, Renton Municipal Airport, and Boeing Field were used as model inputs. This does not capture cloud development caused by orographic lift that would be expected over the model domain. The model was highly sensitive to solar radiation. It would be exceedingly valuable to collect high quality solar radiation data on-site. This would reduce model uncertainty and reliance on theoretical models. Additionally, the wind speed data required data quality screening due to data irregularities. It would be beneficial to collect on-lake wind speed and direction observations to better understand wind dynamics on the water in addition to the observations collected at USGS 12115900. Wind provides the dominate mixing mechanism for lakes. A single wind event can have a substantial impact on temperature dynamics. 
The underflow gate at the Overflow Dike was modeled using the dynamic pipe algorithm. The model was highly sensitive to changes in the degree of openness of the pipe and required extensive iterative calibration during the water balance. The dynamic pipe created numerical instabilities that were resolved with reduced timesteps. Future efforts should consider using a steady state algorithm for the dynamic pipe or modeling the underflow gate with an alternative method. This could greatly improve efficiency during the water balance calibration and reduce the manual effort of opening and closing the pipe in increments as small as one percent.

\subsection{Cedar River}

The Cedar River model could be improved by increasing temporal and spatial data resolution and reducing parameter estimation. Components to consider include boundary condition data, temperature data, and water quality data.

Boundary condition data were estimated for seven of the nine perennial streams included in the river model domain. The remainder of the ungaged inputs were captured using distributed flows. The ungaged inputs totaled approximately 64 percent of the contributing drainage basin area. The flow difference method accurately captured the total volume of ungaged flows within the Cedar River, but it does not provide accurate spatial resolution of those flows. The majority of the ungaged flows are likely groundwater inputs from glacial moraine return flow. It would be beneficial to conduct a seepage study on the Cedar River to better understand the groundwater inputs. 
The Cedar River is unique in that it cools as it flows downstream. This is likely the results of two main factors. At the dam, higher temperature water is released from the Masonry Pool, which does not completely stratify. Downstream from the dam, the Cedar River is cooled by groundwater inputs from the return flow of seepage through the glacial moraine. Temperature data were available at three locations along the river domain. The WSDE monitoring site, located at RM 25.4, captured important temperature dynamics in the Cedar River. Temperature in the corresponding model segment was highly sensitive to temperature inputs from De-Horn Creek, Steele Creek, the unnamed left-bank input, Williams Creek, Taylor Creek, and the branch 4 distributed tributary. Field observations of surface and groundwater temperatures along this stretch would improve model performance.

Additional water quality data would also improve model performance. Limited ammonia and dissolved oxygen data were collected for 2015. No chlorophyll $a$ data were collected during 2015. The majority of the available data did not include a field observation timestamp. Model calibration would be improved with additional data. A more direct comparison of model outputs could be made with the addition of a data timestamp. 


\section{Chapter 7. Conclusion}

A CE-QUAL-W2 model of the Cedar River Municipal Watershed was developed and calibrated for two periods: January 1, 2005 through December 31, 2008 and January 1 to December 31, 2015. The model simulated water temperature on the hourly timescale with an RMSE of $0.60-0.65^{\circ} \mathrm{C}$ in the reservoir models and an RMSE of $0.48-0.71^{\circ} \mathrm{C}$ in the river models. The model simulated water surface elevation on the hourly timescale in Chester Morse Lake with an RMSE of 0.05 - 0.06 meters in the reservoir models. The model simulated water surface elevation on the daily timescale in the Masonry Pool with an RMSE of $0.13-0.20$ meters in the reservoir models. The model simulated flow on the daily average timescale in the Cedar River with an RMSE of $0.35-0.43 \mathrm{~m}^{3} / \mathrm{s}$ in the river models. The model simulated water quality parameters on the daily timescale within observed ranges for all parameters.

The Masonry Dam released warm water from the Masonry Pool in the summer, and river temperatures were warmest near the dam from June through September. Water temperatures decreased an average of $5.6^{\circ} \mathrm{C}$ from the dam to end of the river domain over this period with a maximum modeled decrease of $9.8^{\circ} \mathrm{C}$ on July 21,2015 . The river model was most sensitive to changes in tributary input temperatures during the temperature calibration. This suggests that groundwater and hyporheic flow play a critical role in determining water temperature in the Cedar River. 
The impact of climate change and reservoir management scenarios was investigated under five scenarios using the 2015 model. The scenario with the greatest modeled impact was Scenario 1, in which air temperature and water temperature were increased by a uniform $3^{\circ} \mathrm{C}$. Temperature change of the average monthly temperature at noon in the reservoir ranged from $1.0-2.6^{\circ} \mathrm{C}$ with a weighted average annual change of $1.92^{\circ} \mathrm{C}$ mid-lake and $2.25^{\circ} \mathrm{C}$ at the Masonry Dam. Temperature change of the average monthly temperature at noon in the river ranged from $1.4-2.3^{\circ} \mathrm{C}$ with a weighted average annual change of $1.97^{\circ} \mathrm{C}$. Dissolved oxygen concentrations in the reservoir experienced the greatest simulated change under Scenario 1. Levels were equal to or less than 6 $\mathrm{mg} / \mathrm{L}$ for 9 percent of the time from May to September compared to 0 percent in the base model and all other scenarios. Levels were equal to or greater than $10 \mathrm{mg} / \mathrm{L}$ for 0 percent of the time from May to September compared to an average of 5 percent of the time in the base model and all other scenarios.

The change in fish habitat under each scenario relative to the 2015 calibrated model was determined for the reservoir model and the river model. The volume of fish habitat based on temperature and dissolved oxygen limits was calculated using the CE-QUAL-W2 fish habitat module. In the reservoir, Scenario 1 had the greatest impact on fish habitat. The average monthly decrease in non-lethal growth conditions for bull trout in Scenario 1 ranged from 2 to 20 percent of reservoir volume from June through October. In the river, the core summer salmonid habitat aquatic life use was the most 
impacted category. Fish volume habitat decreased by 1 to 13 percent from mid-June through mid-September under Scenario 1 and Scenario 2.

Other water quality parameters did not experience significant change under the modeled scenarios. This is likely due to the fact that the concentrations were well-correlated to one another, but not well-correlated to temperature, flow, and water surface elevation. Concentrations in the scenarios were assumed to be equivalent to concentrations in the base model. The model was most sensitive to changes in boundary condition concentrations during calibration. Since no changes were made to input concentrations for the scenarios, it is reasonable that little change was observed in scenario-simulated water quality concentrations.

The developed models provide a management tool to evaluate the impacts of climate change and changes in reservoir operation. Future work includes a more detailed investigation of the impact of climate change. Climate change scenarios using regional climate models and hydrological models would provide more insight on potential changes in the system. The climate change scenarios modeled in this study provide a broad understanding of the model's sensitivity to changes in temperature and flow. It would be beneficial to use the flow outputs from hydrologic models as inputs rather than changing flows by a single percentage factor or generic shift in days. The meteorological data from regional climate models would provide more detailed insight as the model is most sensitive to changes in boundary condition data. The major challenge in incorporating predictions from regional climate models is timestep. 
Regional climate models currently predict on the daily level. CE-QUAL-W2 requires sub-daily inputs, with hourly or sub-hourly inputs considered optimal.

Additional future work includes dynamically incorporating SPU operation logic into the model. The scenarios currently use the historically observed Masonry Pool water levels to control outflows from the reservoir, which captures the SPU operation logic statically rather than dynamically. This assumes that the reservoir would be managed similarly to management strategies in 2015 under all scenarios. While 2015 is a critical low-flow high-temperature year and it is unlikely that the Masonry Pool would be drawn down below the levels observed in 2015, it is unlikely that the reservoir would be managed with the same water surface levels observed in 2015 under varying climate change and reservoir operation scenarios. Model logic that incorporates minimal and supplemental flow commitments at the Landsburg Diversion Dam and that allows for dynamic change in reservoir water surface elevations should be developed. With additional input from SPU, more refined model logic can be developed to adjust management strategies under each scenario. This would de-couple the model from the historically observed Masonry Pool water surface elevations and allow the model to be a more useful management tool based on operation logic rather than observed operation strategy. 


\section{References}

Annear, R. L., and Wells, S. A. (2007). A comparison of five models for estimating clearsky solar radiation. Water Resources Research, 43(W10415). doi:10.1029/2006WR005055

Association of State Dam Safety Officials. (2020). Dam safety 2018: Masonry Dam and Cedar River Watershed field trip. Retrieved from Association of State Dam Safety Officials: https://damsafety.org/basic-page/dam-safety-2018-masonry-dam-andcedar-river-watershed-field-trip

Bell, M. (1990). Fisheries handbook of engineering requirements and biological criteria. (Fish Passage Development and Evaluation Program), Third edition, 353. Portland, OR: U.S. Army Corps of Engineers, North Pacific Division.

Benson, B., and Krause, D. (1980). The concentration and isotopic fractionation of gases dissolved in freshwater in equilibrium with the atmosphere. 1. Oxygen. Limnology and Oceanography, 25(4), 662-671. doi:10.4319/lo.1980.25.4.0662

Cervarich, A., and Scott, M. (2019). Seepage from Chester Morse Lake and Masonry Pool: A water balance comparison of current seepage rates to historic rates. Hydrology, ESM 525 Watershed, 12 Jun 2019. Portland State University, student paper.

City of Seattle. (April 2000). Cedar River Watershed habitat conservation plan for the issuance of a permit to allow incidental take of threatened and endangered species. Seattle. Retrieved from https://ecos.fws.gov/docs/plan_documents/thcp/thcp_1130.pdf

Dodds, W. K., and Whiles, M. R. (2020). Movement of light, heat, and chemicals in water. In Freshwater ecology: Concepts and environmental applications of limnology (Third edition ed., pp. 49-72). San Diego, CA: Academic Press. doi:10.1016/B978-0-12-813255-5.00003-X

Emerson, D. G., Vecchia, A. V., and Dahl, A. L. (2005). Evaluation of drainage-area ratio method used to estimate streamflow for the Red River of the North Basin, North Dakota and Minnesota. U.S. Geological Services. Scientific Investigations Report 2005-5017. doi:10.3133/sir20055017

Hidaka, F., and Garrett, A. (1967). Evaluation of seepage from Chester Morse Lake and Masonry Pool King County, Washington. Geological Survey Water-Supply Paper 1839-J. Washington, D.C.: U.S. Government Printing Office. doi:10.3133/wsp1839J 
Hirsch, R. M. (1975). Glacial geology and geomorphology of the Upper Cedar River Watershed, Cascade Range, Washington (M.S. thesis). University of Washington, Seattle.

Landau Associates. (2019). Cedar moraine safety studies. Retrieved from Landau Associates: https://www.landauinc.com/our-work/geotechnicalengineering/cedar-moraine-safety-studies

Mateus, M., da Silva Vieira, R., Almeida, C., Silva, M., and Reis, F. (2018). ScoRE-A simple approach to select a water quality model. Water, 10(12). doi:10.3390/w10121811

McDonald, L. (2017, 11 10). Cedar River: It may be short, but it is vital. Retrieved from Black Diamond History: https://blackdiamondhistory.wordpress.com/2017/11/10/cedar-river-it-may-beshort-but-it-is-vital/

Meek, D., and Hatfield, J. (1994). Data quality checking for single station meteorological databases. Agricultural and Forest Meteorology, 69(1-2), 85-109. doi:10.1016/0168-1923(94)90083-3

Menberg, K., Blum, P., Kurylyk, B. L., and Bayer, P. (2014). Observed groundwater temperature response to recent climate change. Hydrology and Earth System Sciences, 18(11), 4453-4466. doi:10.5194/hess-18-4453-2014

Northwest Hydraulic Consultants Inc. (2007). Chester Morse Lake - Spawning impedance study. Seattle. Retrieved from https://www.seattle.gov/Documents/Departments/SPU/EnvironmentConservati on/ChesterMorseSpawningImpedanceStudy.pdf

Pluhowski, E. J. (1970). Urbanization and its effect on temperature of the streams on Long Island, New York. Washington, D.C.: U.S. Geological Survey, Professional Paper 627-D. doi:10.3133/pp627D

Reid Middleton. (n.d.). Award winning - Morse Lake Pump Plant. Retrieved from http://www.reidmiddleton.com/awards/award-winning-morse-lake-pumpplant/

Savor Snoqualmie Valley. (2017, 10 18). The town that slowly sank. Retrieved from https://savorsnoqualmievalley.org/blog/the-town-that-slowly/

Seattle Public Utilities. (2014). Explore the watershed: Family tap water tour. Retrieved from https://atyourservice.seattle.gov/2014/06/04/explore-the-watershedfamily-tap-water-tour/ 
Seattle Public Utilities. (n.d.). Cedar River Watershed: Streams. Retrieved from http://www.seattle.gov/utilities/environment-and-conservation/ourwatersheds/cedar-river-watershed/biodiversity/habitats/streams

Singh, V. P. (1992). Elementary hydrology. Englewood Cliffs, New Jersey: Prentice Hall.

Stein, A. J. (2000, 5 31). Cedar River Watershed (King County) - Environmental overview. Retrieved from HistoryLink.org: https://www.historylink.org/File/2486

USGS StreamStats. (n.d.). Retrieved from https://streamstats.usgs.gov/ss/

Vail, S., Ochiltree, C., and Bishop, E. (2016). Morse Lake Pumping Plant (MLPP) replacement project. Retrieved from Morse-Lake-Pump-Plant Portable-FloatingPump-Station-Improved-Water-Supply-Reliability-for-Seattle-PublicUtilities\%20.pdf

Wells, S. A. (2019). CE-QUAL-W2: A two-dimensional, laterally averaged, hydrodynamic and water quality model, version 4.2, user manual. Portland: Department of Civil and Environmental Engineering, Portland State University.

Wells, V. I. (2012). CE-QUAL-W2 water quality and fish-bioenergetics model of Chester Morse Lake and the Cedar River (M.S. thesis). Portland State University, Portland. doi:10.15760/etd.324

WSDE. (2018, June). Inventory of dams report for selected Washington counties and selected dam hazard categories. Publication \#94-16. Dam Safety Office. Olympia: Water Resources Program, Washington State Department of Ecology. Retrieved from https://fortress.wa.gov/ecy/publications/publications/94016.pdf

WSDE. (2019). Water quality standards for surface waters of the State of Washington, Chapter 173-201A WAC. Publication \#06-10-091. Watershed Management Section. Olympia: Water Quality Program, Washington State Department of Ecology. Retrieved from https://fortress.wa.gov/ecy/publications/documents/0610091.pdf 


\section{Appendix A. Temperature Profiles: Buoys, 2007-2008}
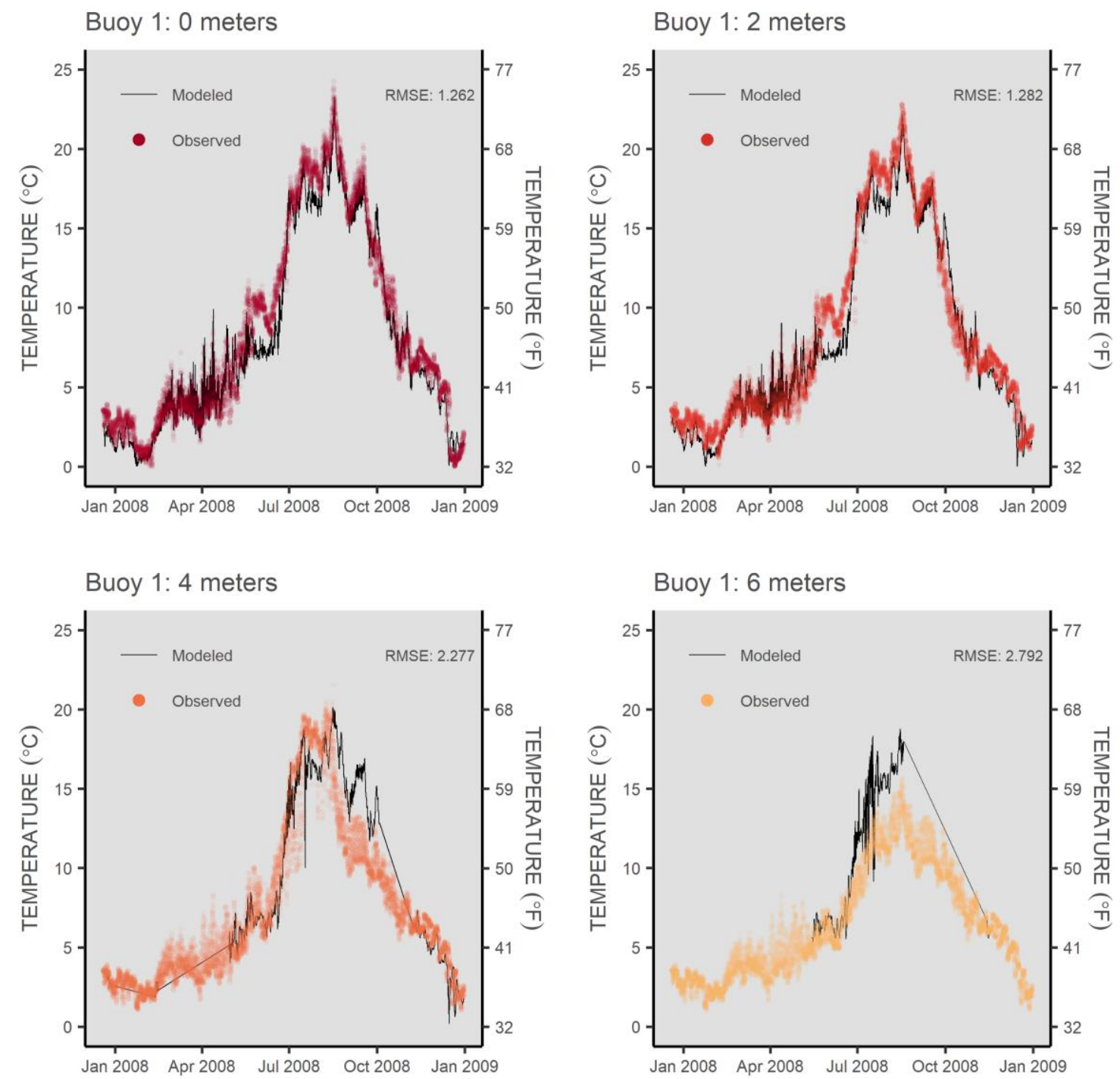

Figure A-1. Comparison of modeled and observed temperatures from depths 0 to 6 meters at buoy 1 (segment 9), Cedar River confluence, 2007-2008. 


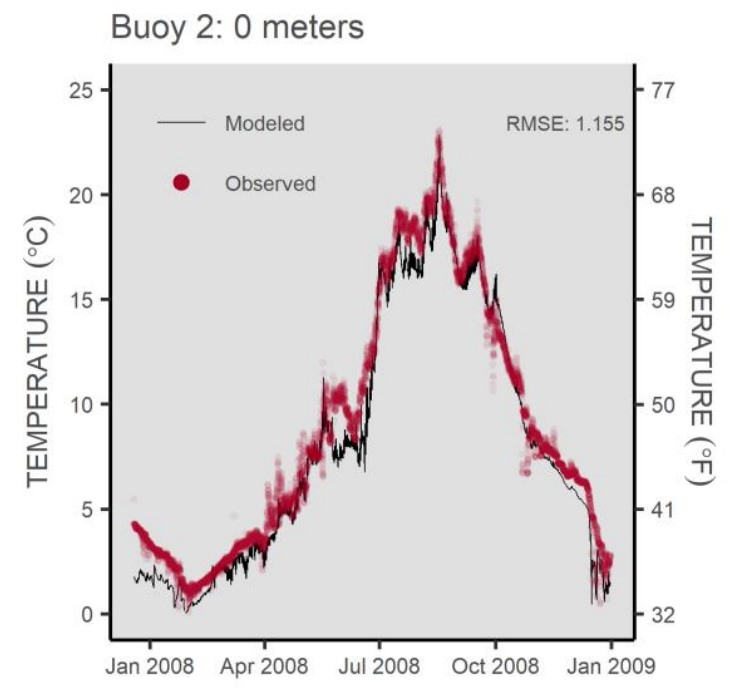

Buoy 2: 4 meters

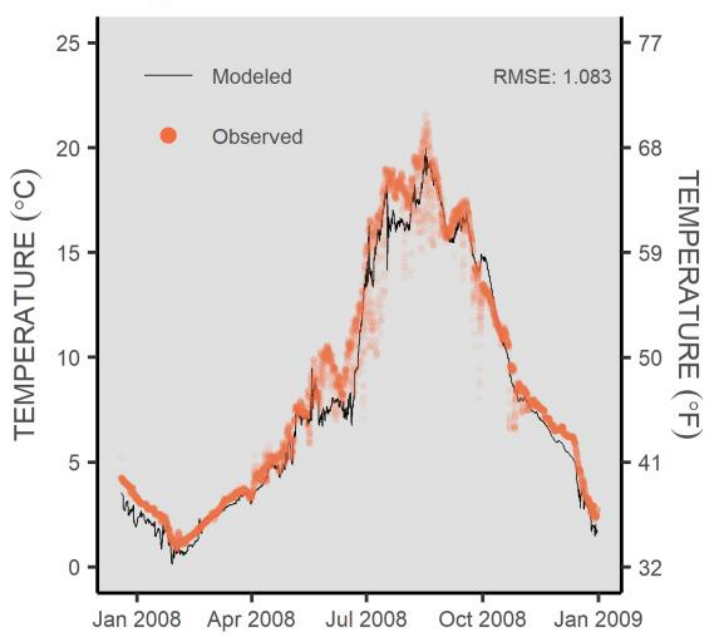

Buoy 2: 2 meters

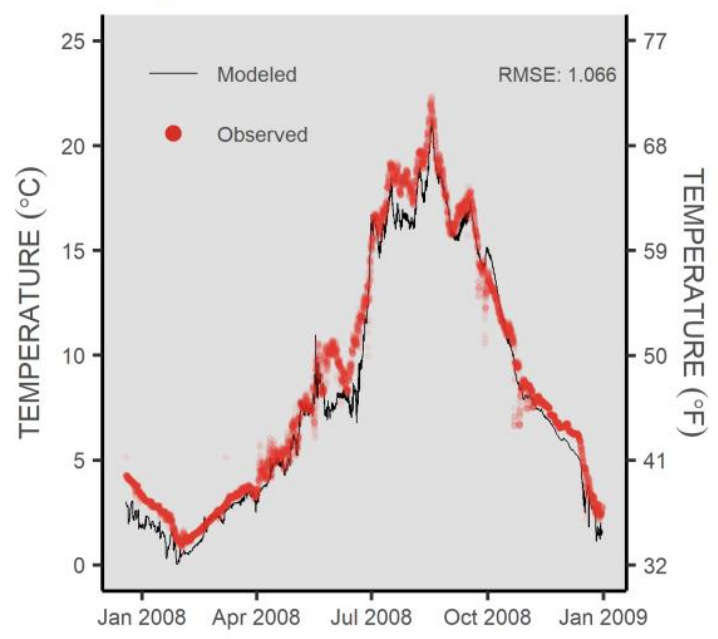

Buoy 2: 6 meters

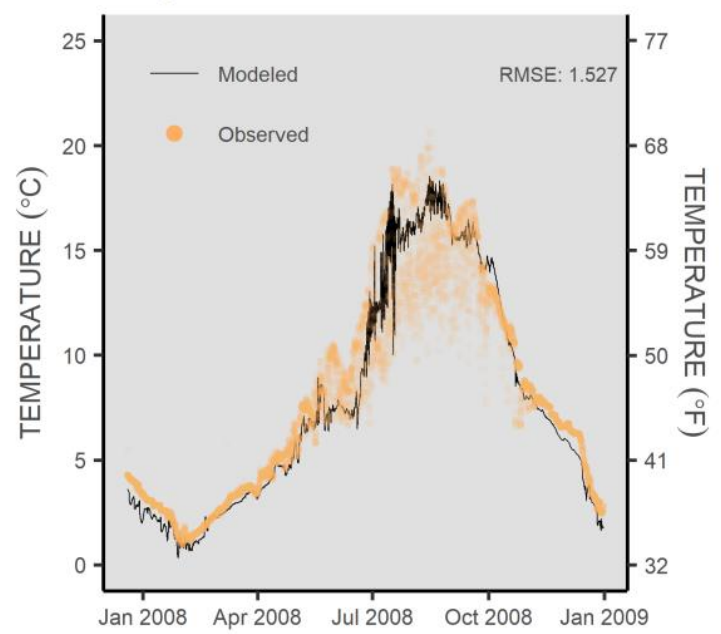

Figure A-2. Comparison of modeled and observed temperatures from depths 0 to 6 meters at buoy 2 (segment 17), Green Point/McClellan, 2007-2008. 


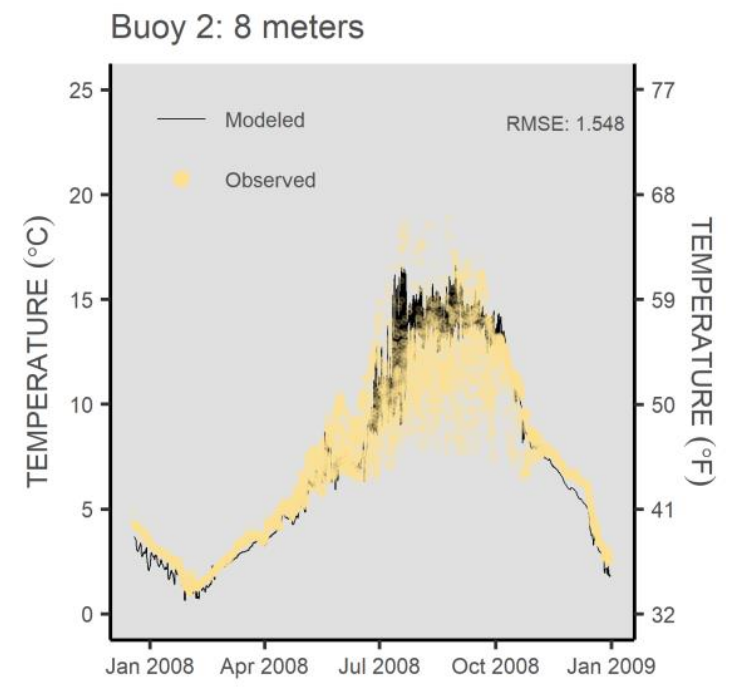

Buoy 2: 15 meters

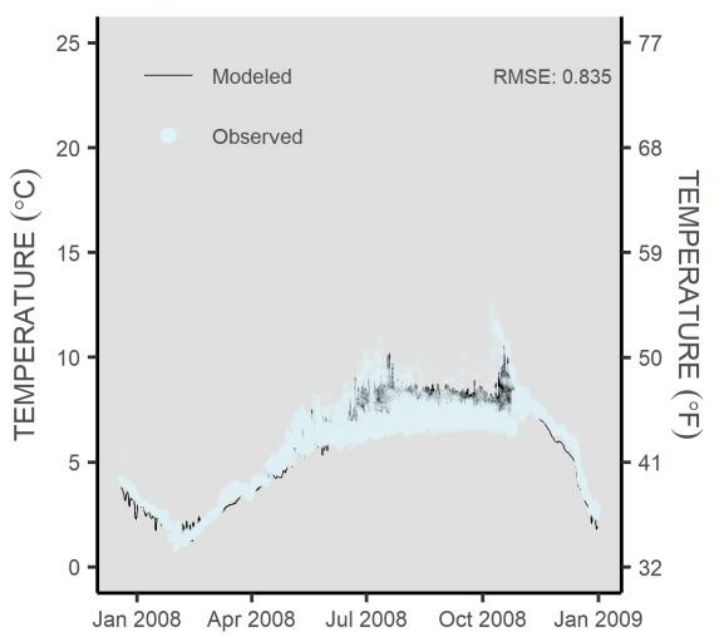

Buoy 2: 10 meters

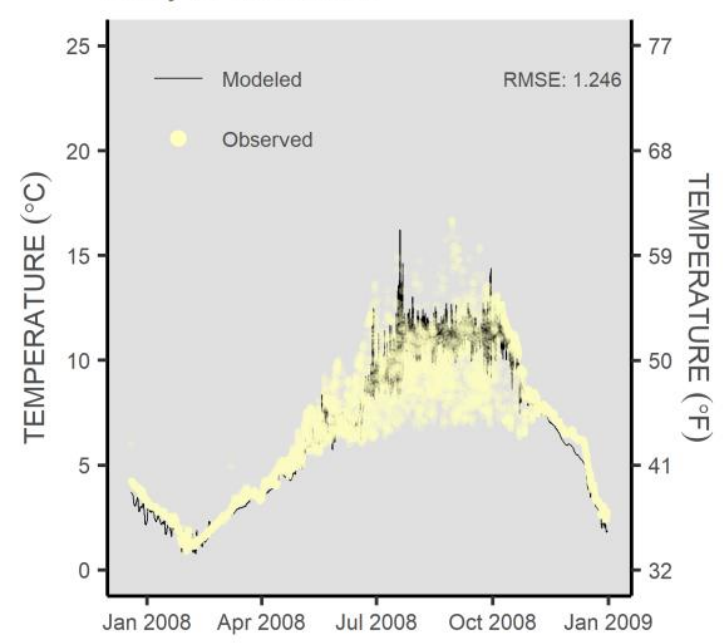

Buoy 2: 20 meters

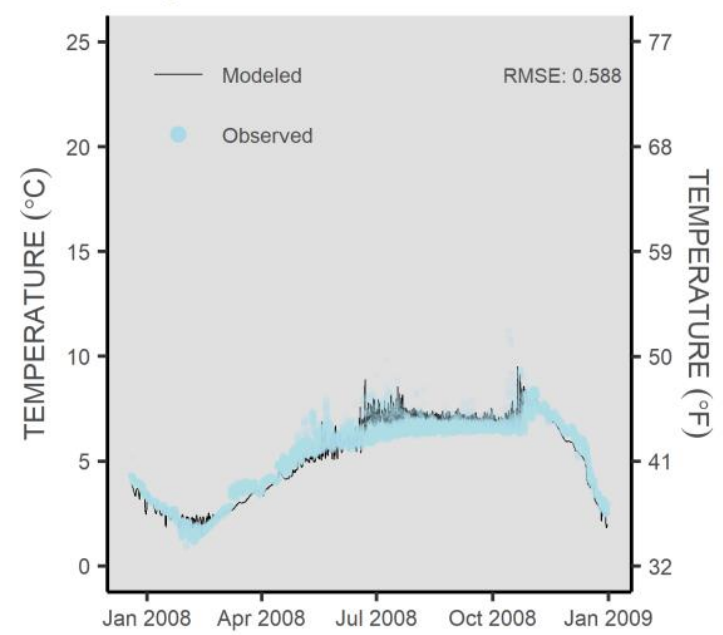

Figure A-3. Comparison of modeled and observed temperatures from depths 8 to 20 meters at buoy 2 (segment 17), Green Point/McClellan, 2007-2008. 


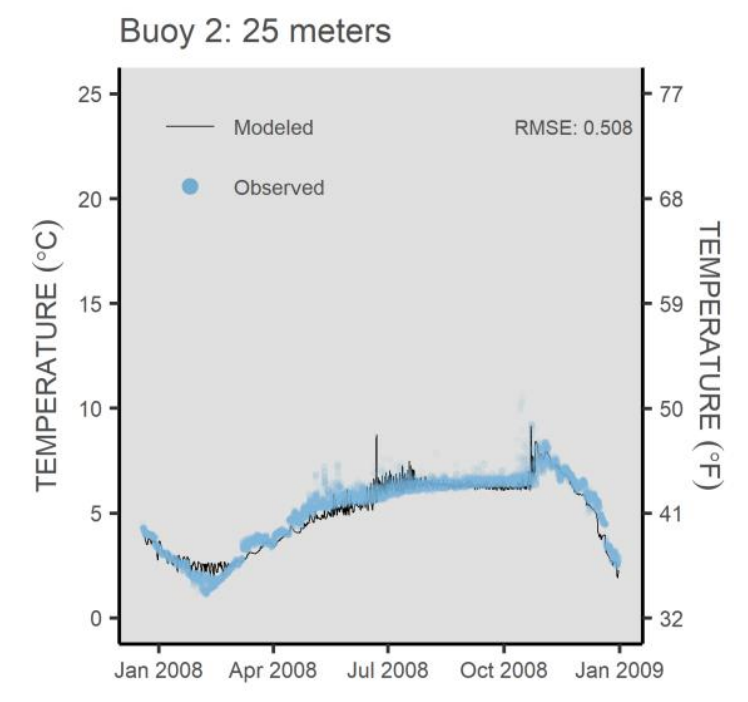

Figure A-4. Comparison of modeled and observed temperatures from depth of 25 meters at buoy 2 (segment 17), Green Point/McClellan, 2007-2008. 


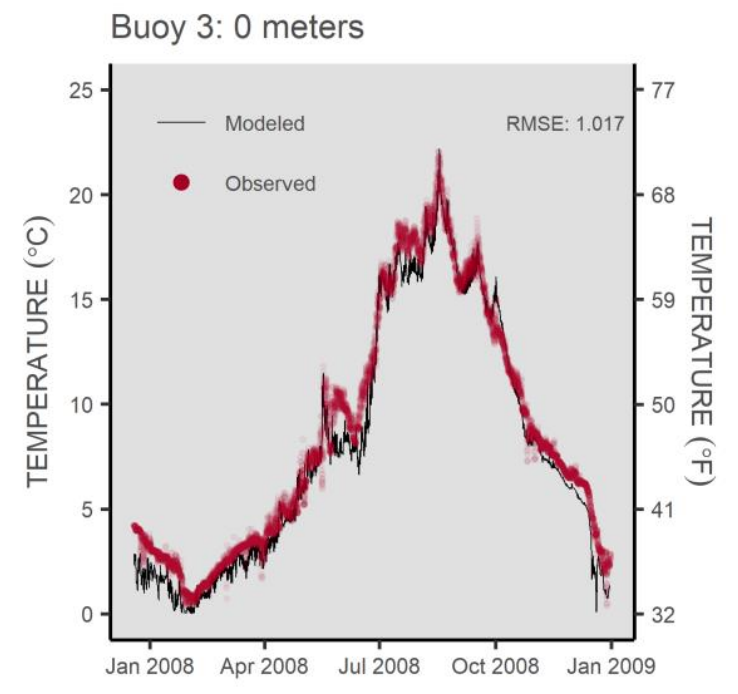

Buoy 3: 4 meters

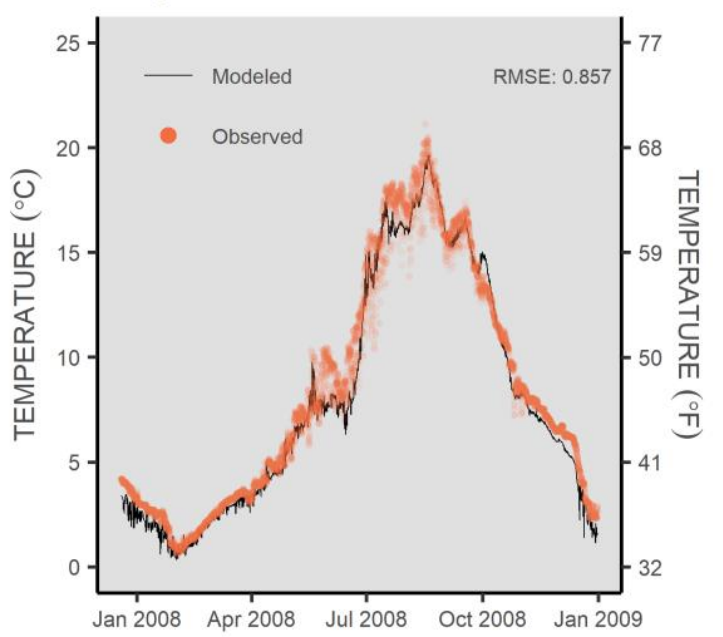

Buoy 3: 2 meters

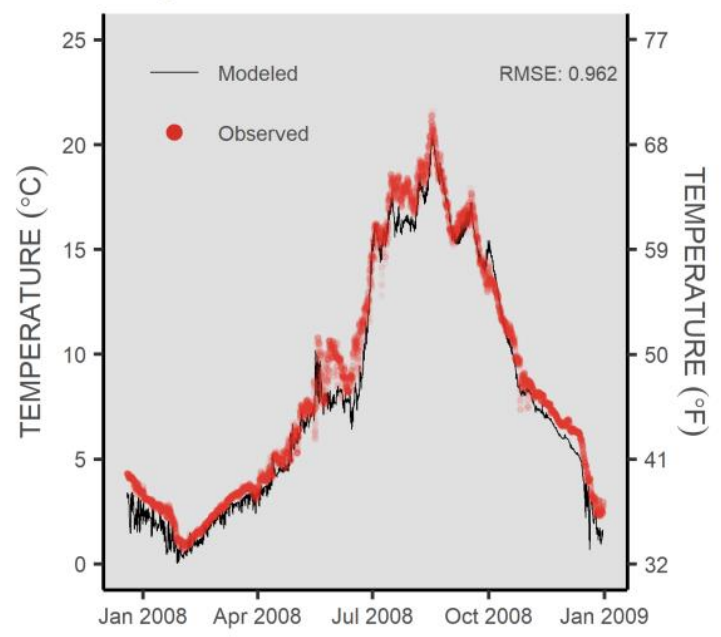

Buoy 3: 6 meters

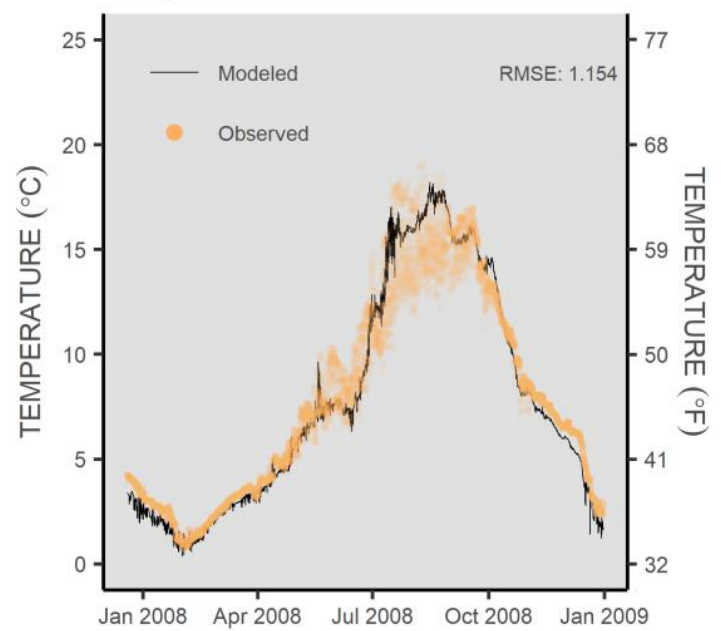

Figure A-5. Comparison of modeled and observed temperatures from depths 0 to 6 meters at buoy 3 (segment 47), Rex Delta Drop-off, 2007-2008. 


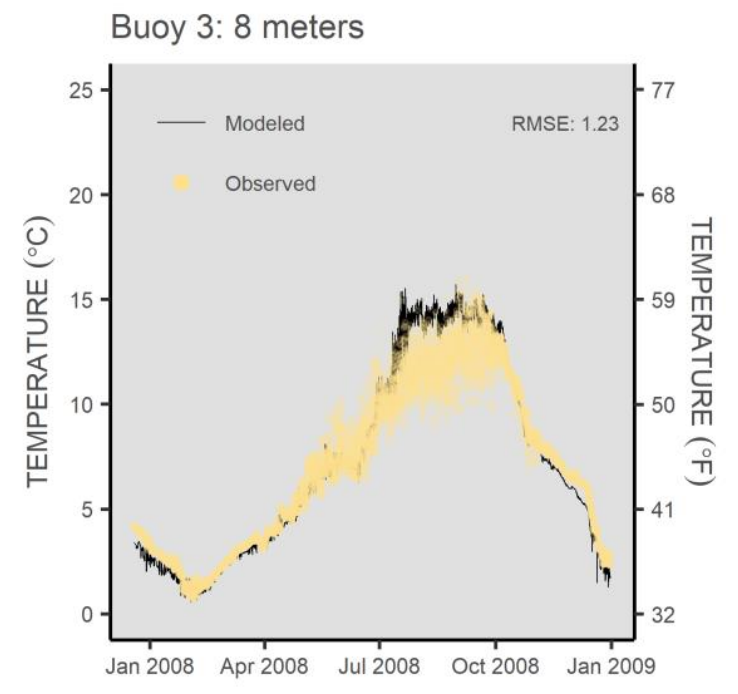

Buoy 3: 15 meters

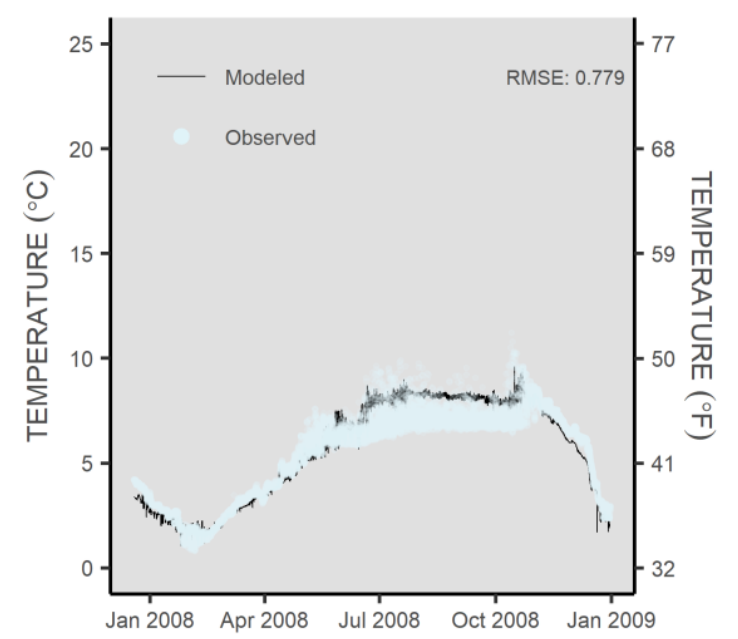

Buoy 3: 10 meters

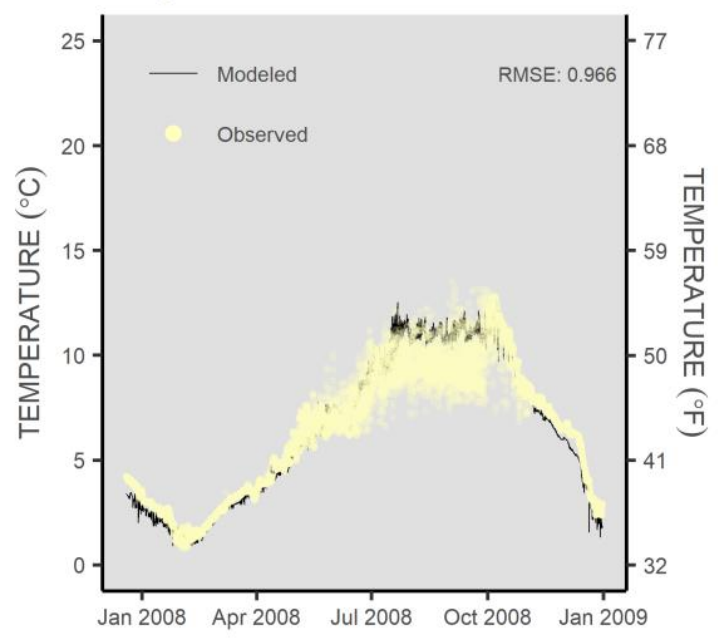

Buoy 3: 20 meters

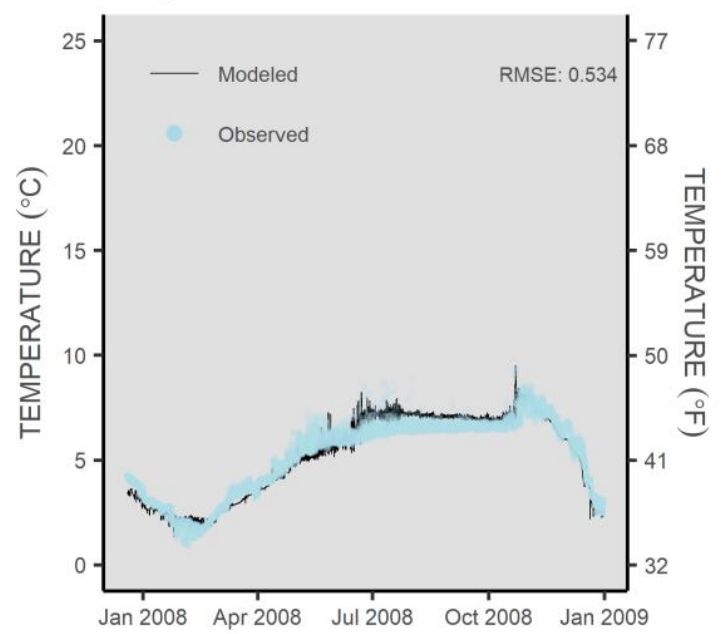

Figure A-6. Comparison of modeled and observed temperatures from depths 8 to 15 meters at buoy 3 (segment 47), Rex Delta Drop-off, 2007-2008. 


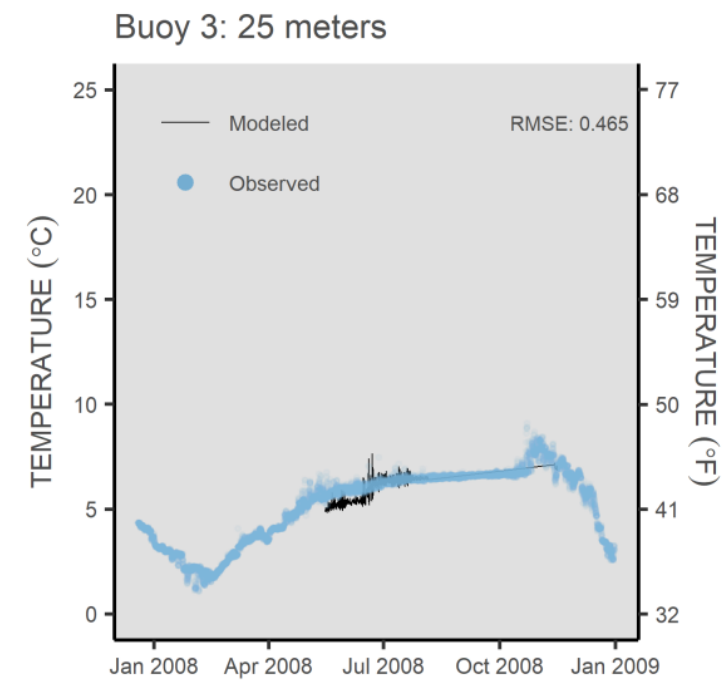

Figure A-7. Comparison of modeled and observed temperatures from depth of 25 meters at buoy 3 (segment 47), Rex Delta Drop-off, 2007-2008. 

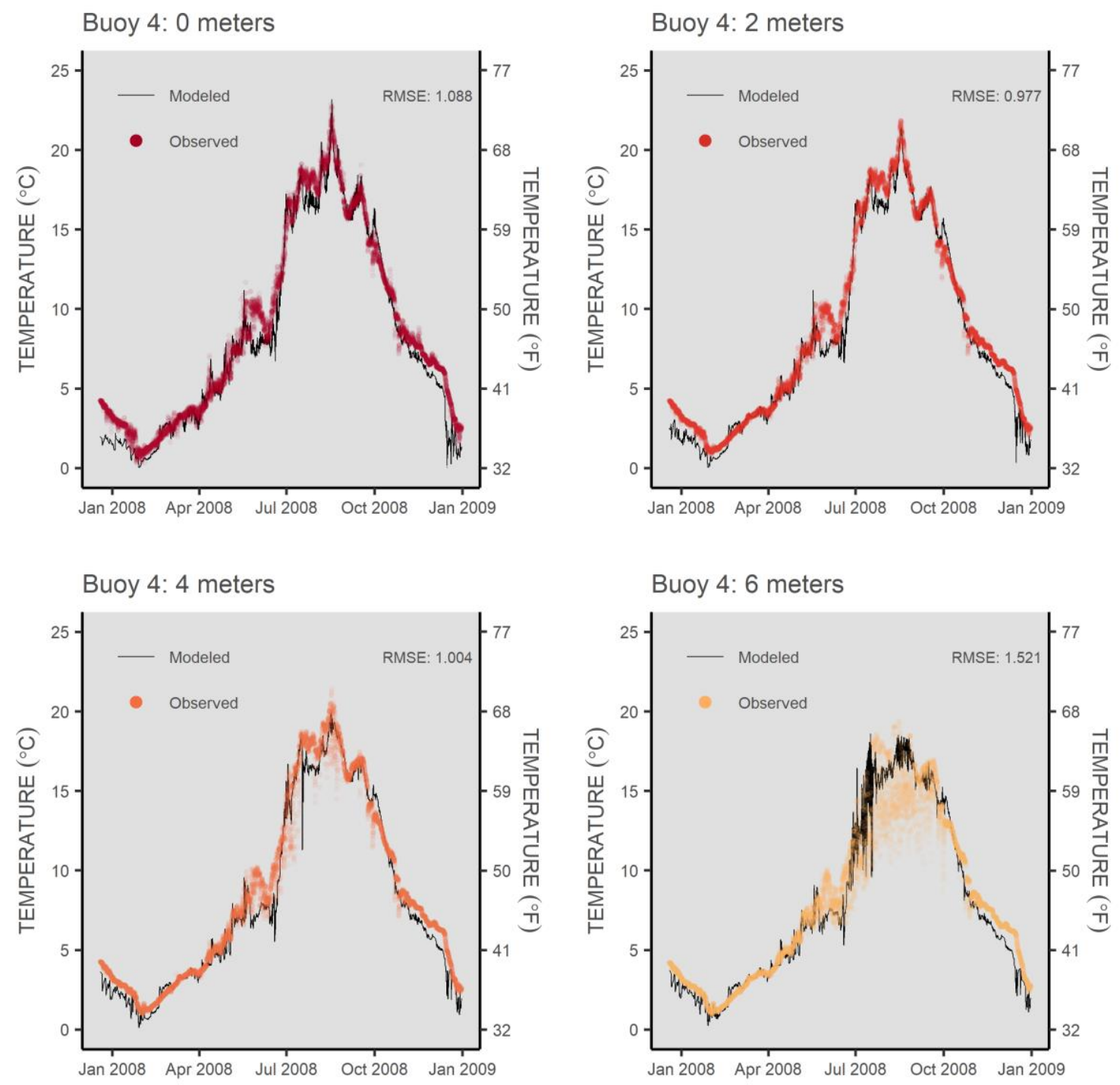

Figure A-8. Comparison of modeled and observed temperatures from depths 0 to 6 meters at buoy 4 (segment 13), Cedar Delta Drop-off, 2007-2008. 

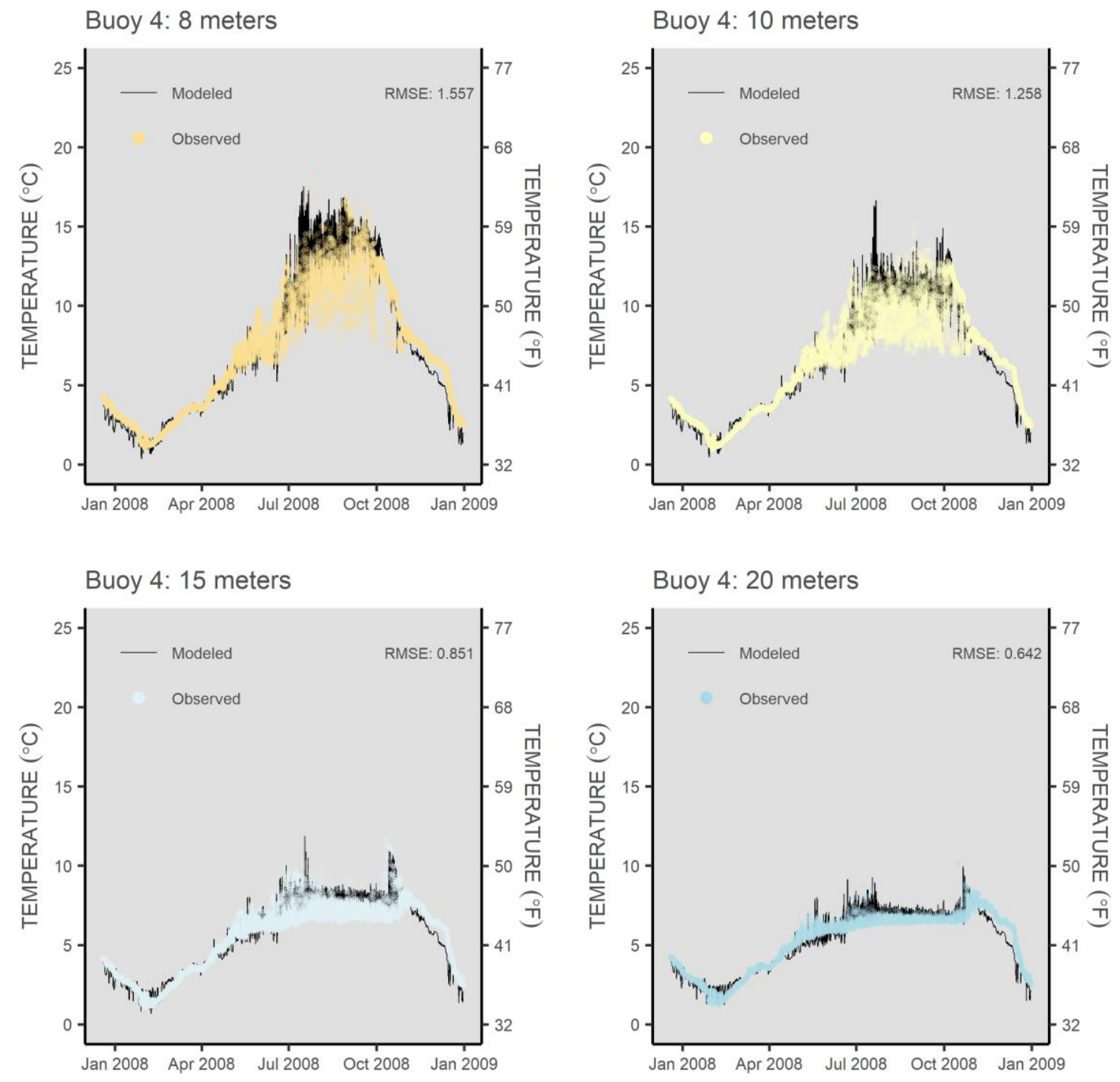

Figure A-9. Comparison of modeled and observed temperatures from depths 8 to 20 meters at buoy 4 (segment 13), Cedar Delta Drop-off, 2007-2008. 

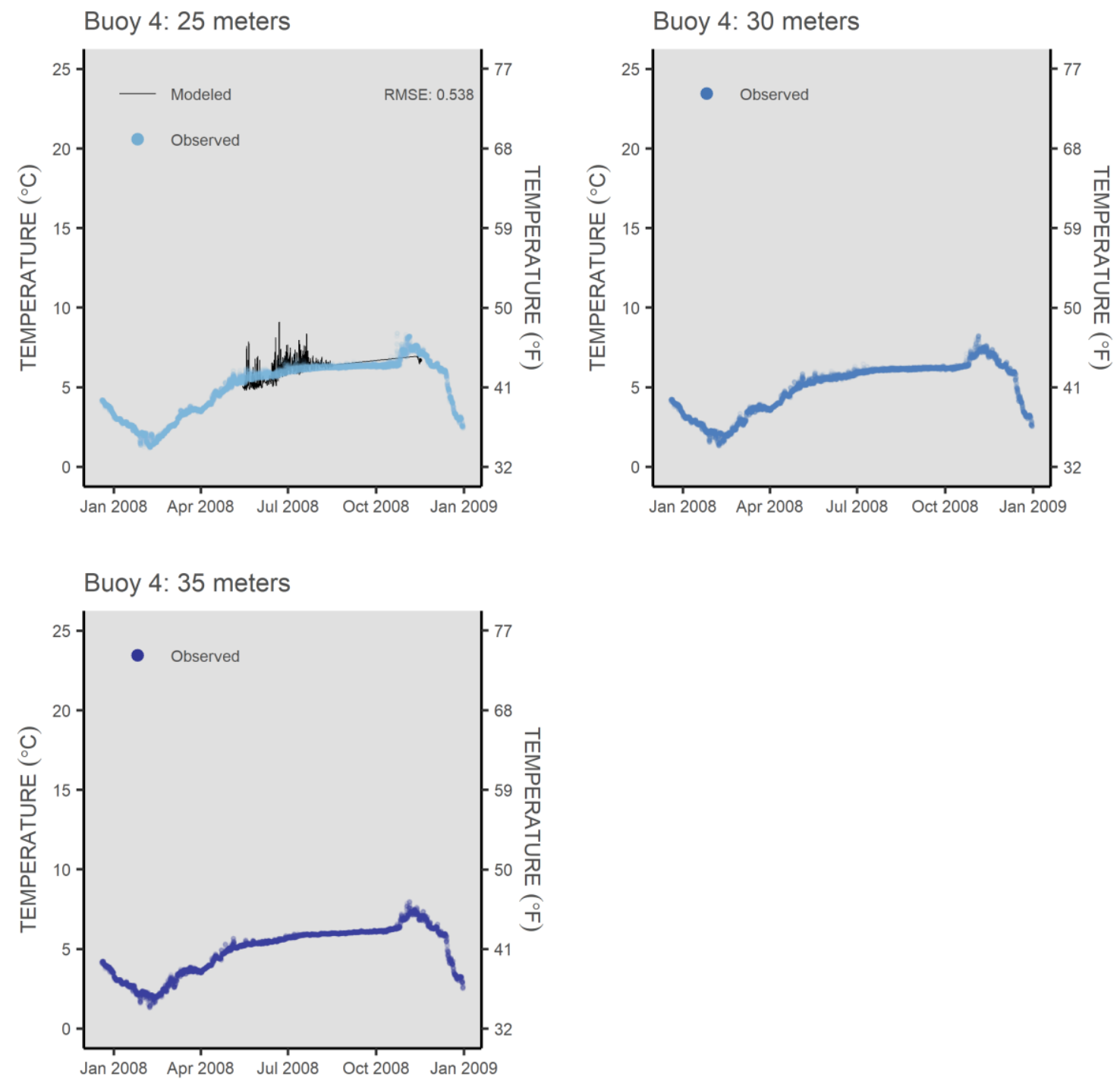

Figure A-10. Comparison of modeled and observed temperatures from depths 25 to 35 meters at buoy 4 (segment 13), Cedar Delta Drop-off, 2007-2008. 


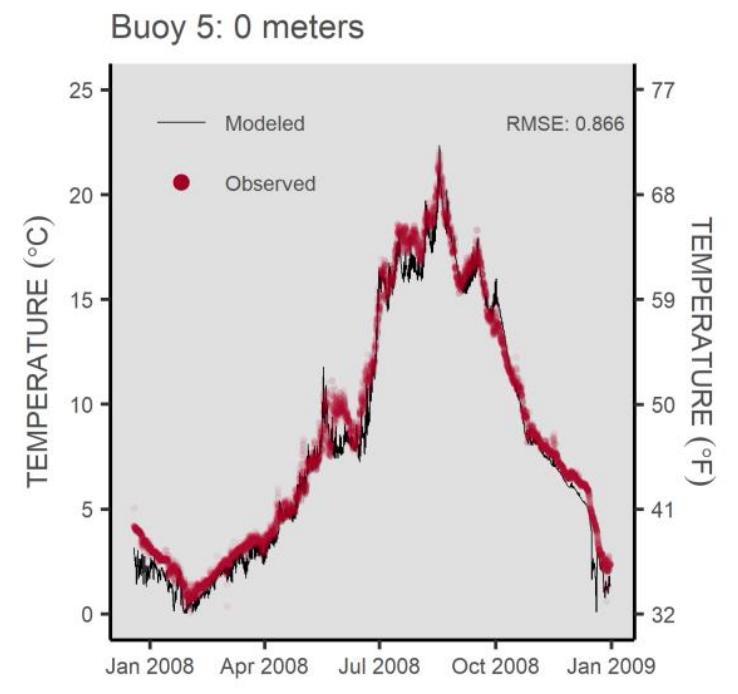

Buoy 5: 4 meters

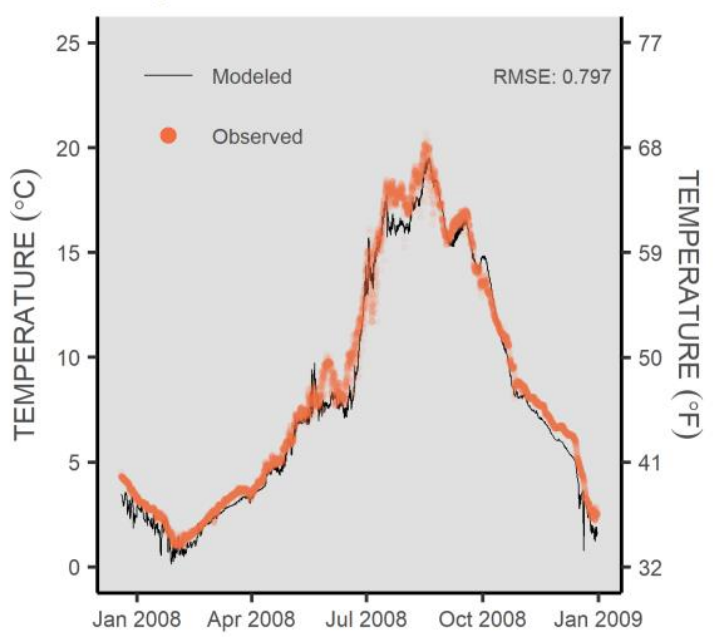

Buoy 5: 2 meters

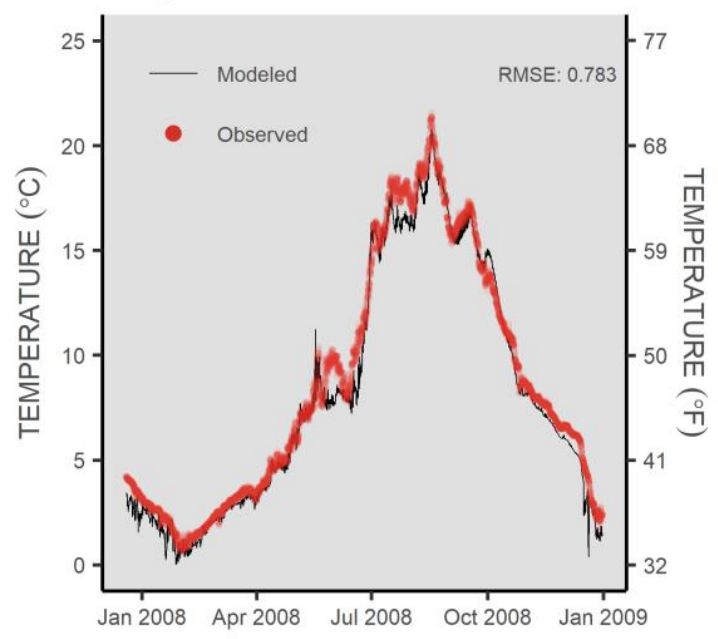

Buoy 5: 6 meters

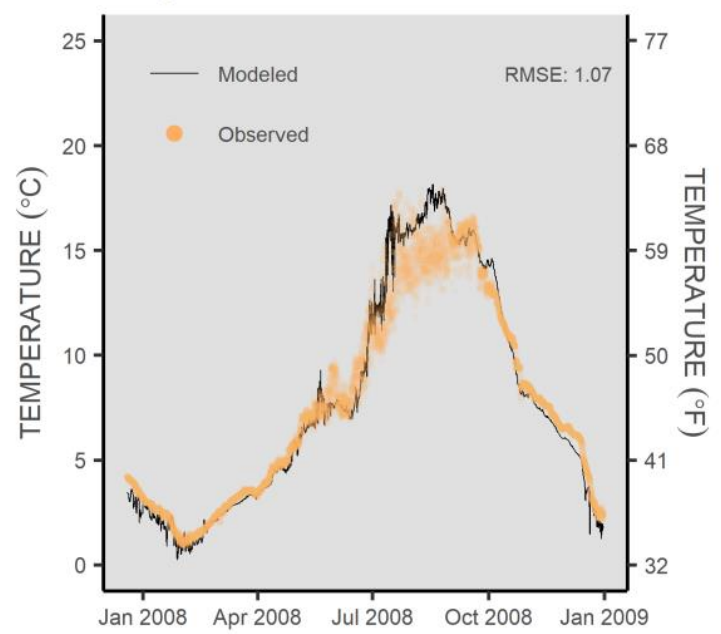

Figure A-11. Comparison of modeled and observed temperatures from depths 0 to 6 meters at buoy 5 (segment 23), Chester Morse Lake - Deepest, 2007-2008. 


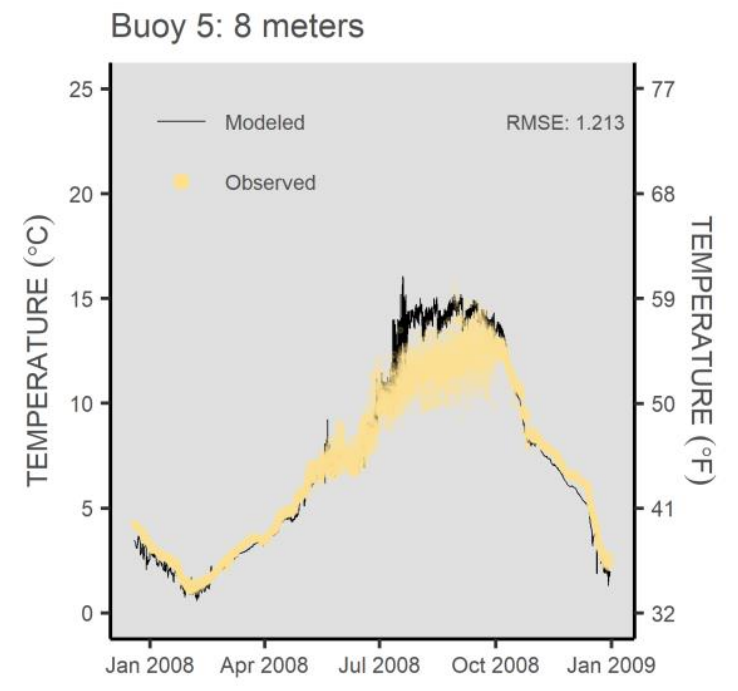

Buoy 5: 15 meters

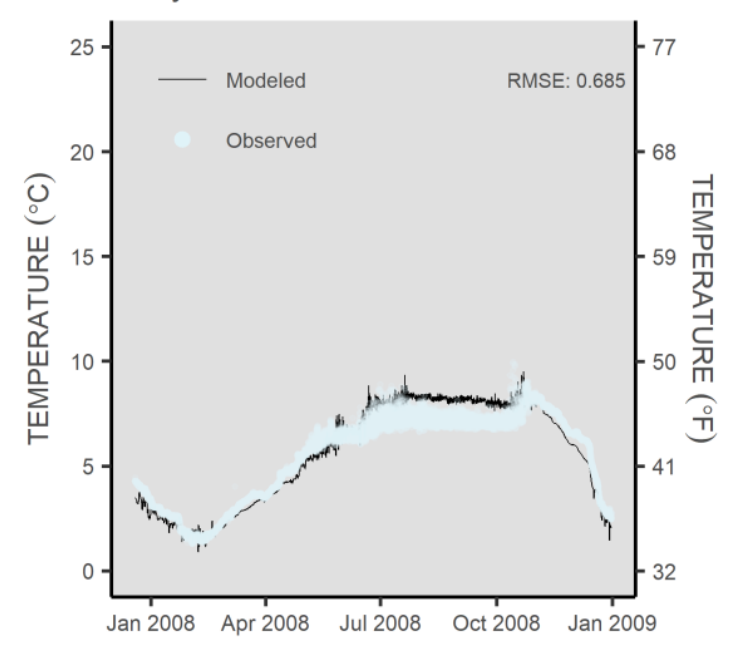

Buoy 5: 10 meters

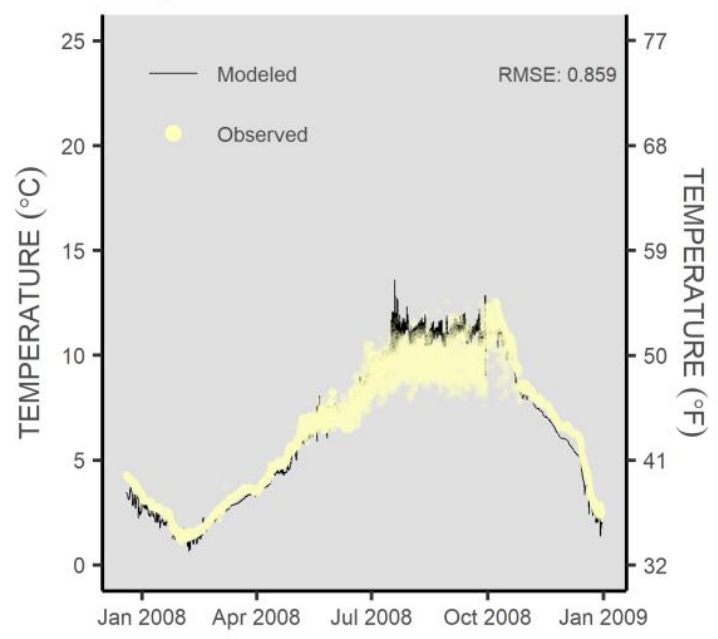

Buoy 5: 20 meters

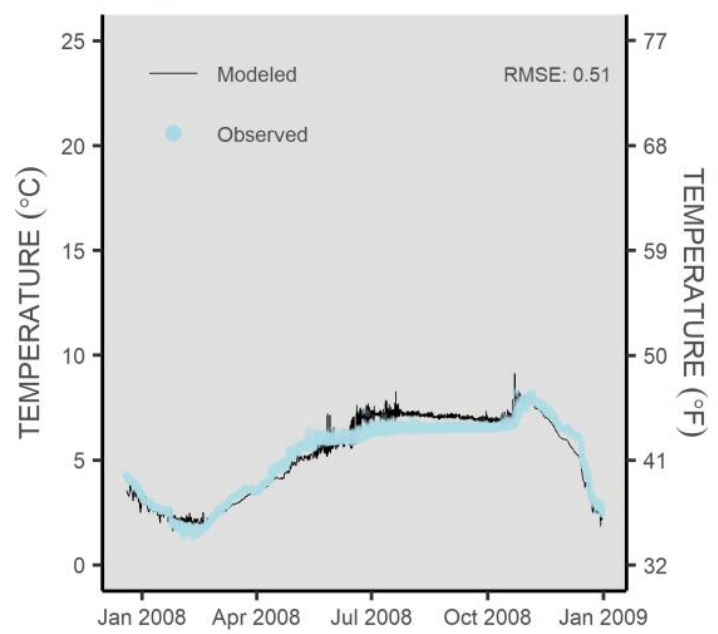

Figure A-12. Comparison of modeled and observed temperatures from depths 8 to 15 meters at buoy 5 (segment 23), Chester Morse Lake - Deepest, 2007-2008. 

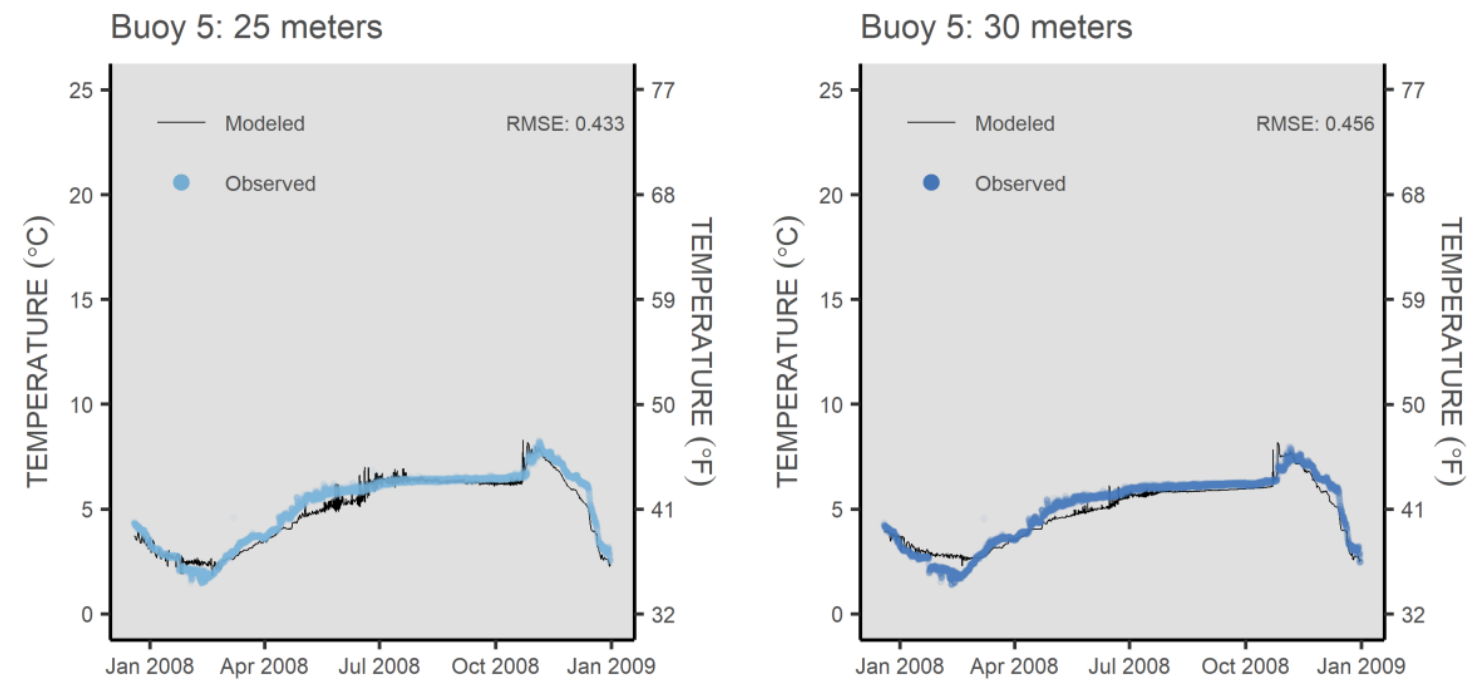

Buoy 5: 35 meters

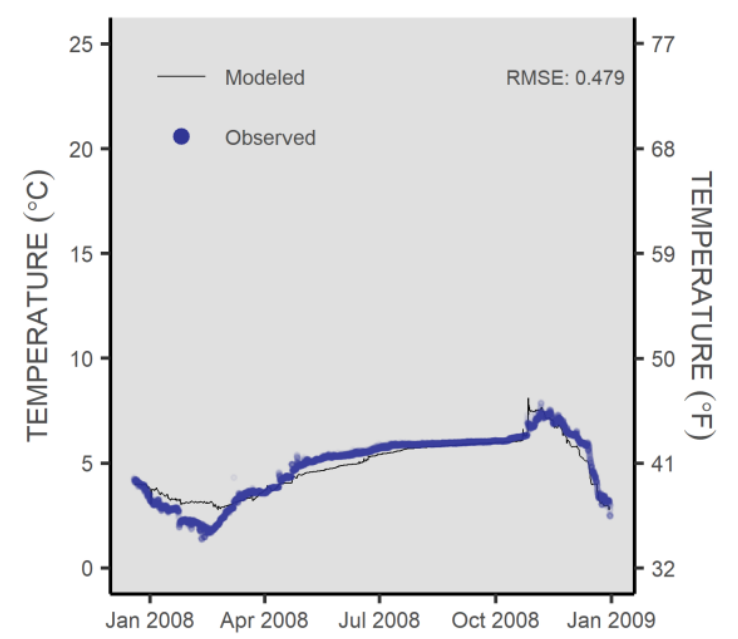

Figure A-13. Comparison of modeled and observed temperatures from depths 25 to 35 meters at buoy 5 (segment 23), Chester Morse Lake - Deepest, 2007-2008. 


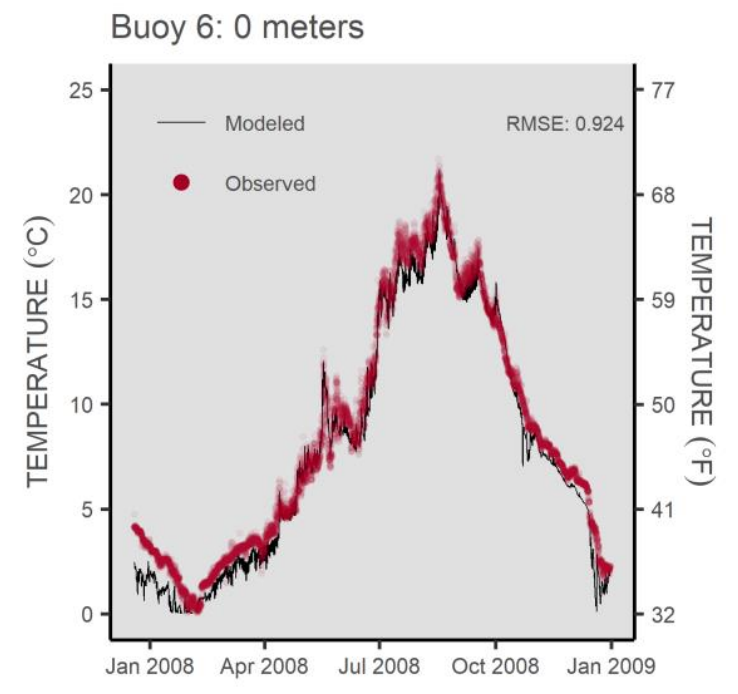

Buoy 6: 4 meters

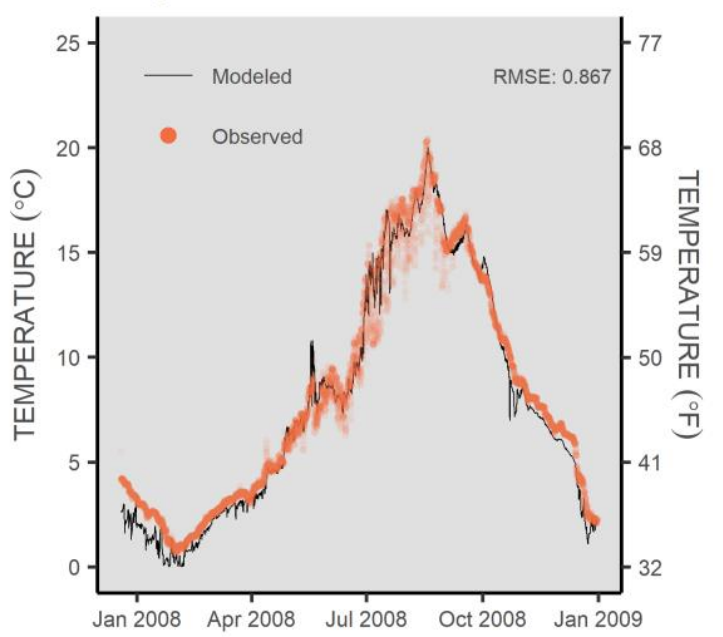

Buoy 6: 2 meters

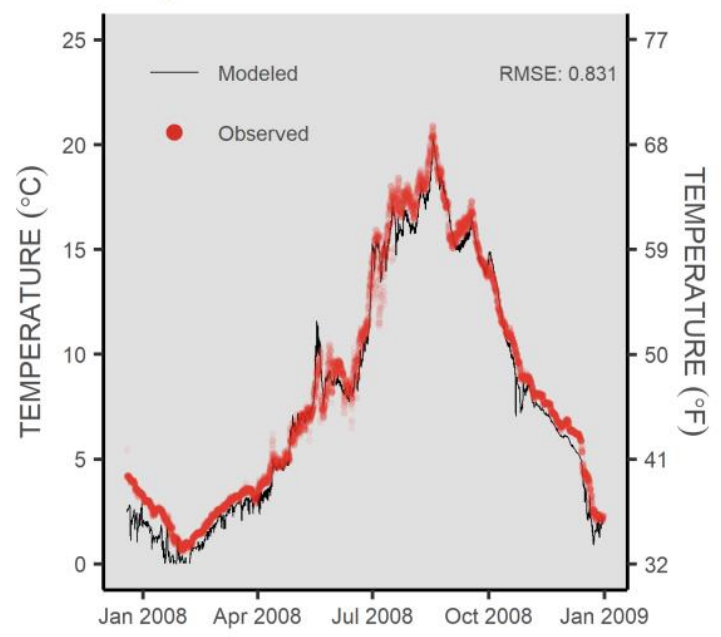

Buoy 6: 6 meters

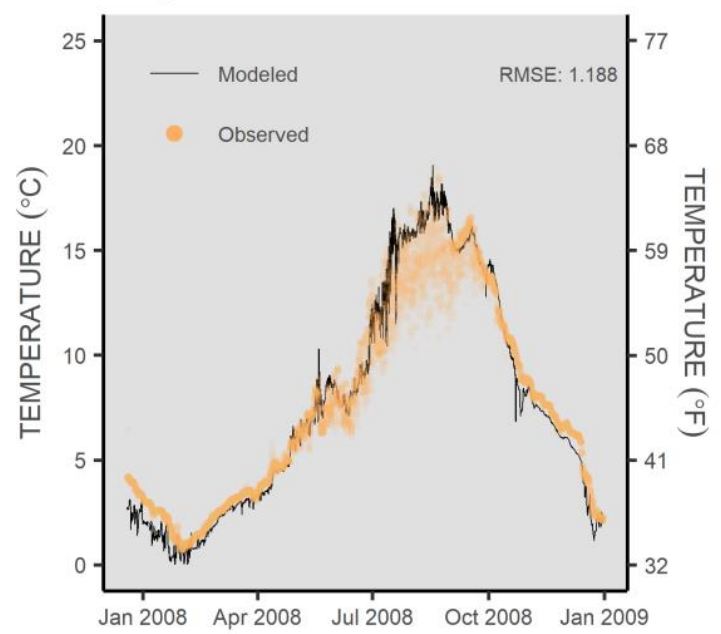

Figure A-14. Comparison of modeled and observed temperatures from depths 0 to 6 meters at buoy 6 (segment 34), MLPP intake, 2007-2008. 


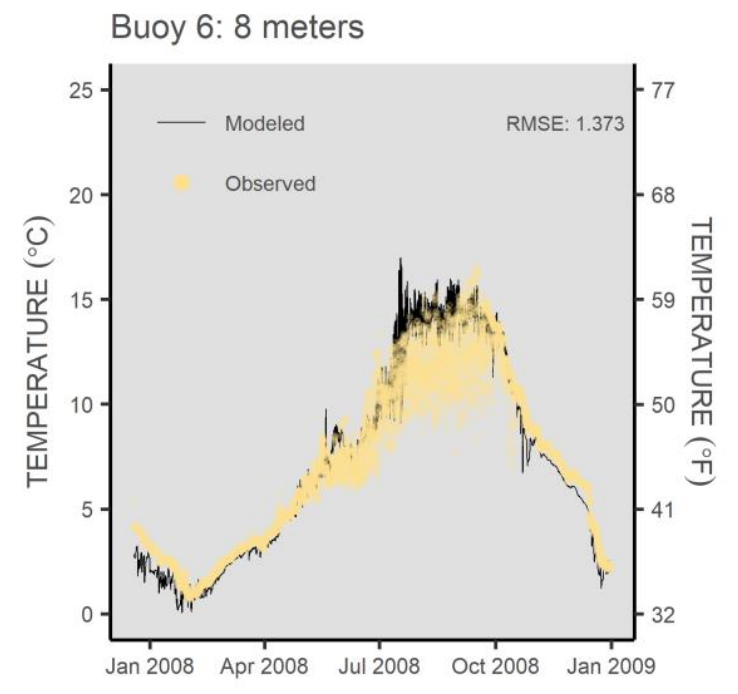

Buoy 6: 15 meters

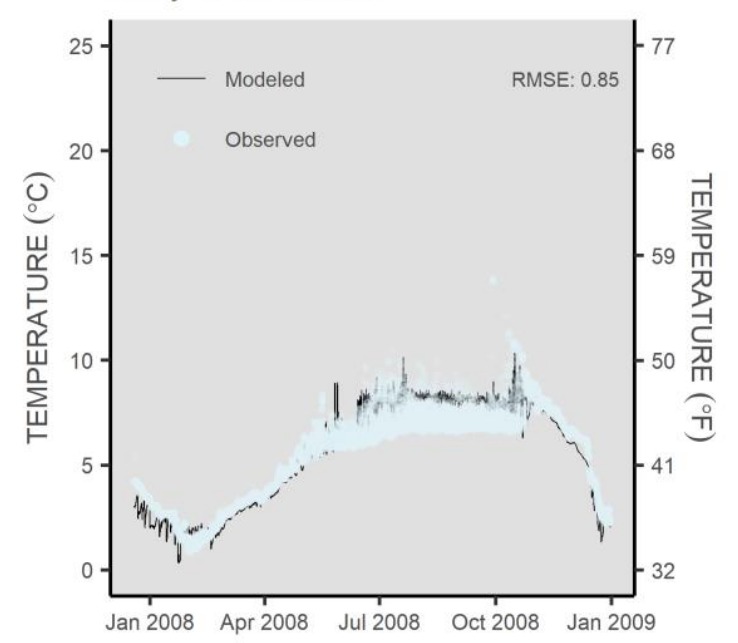

Buoy 6: 10 meters

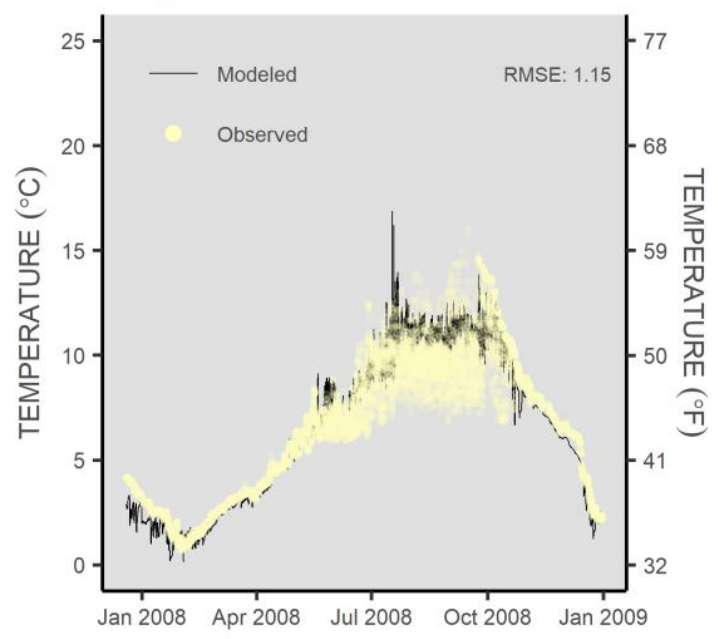

Buoy 6: 20 meters

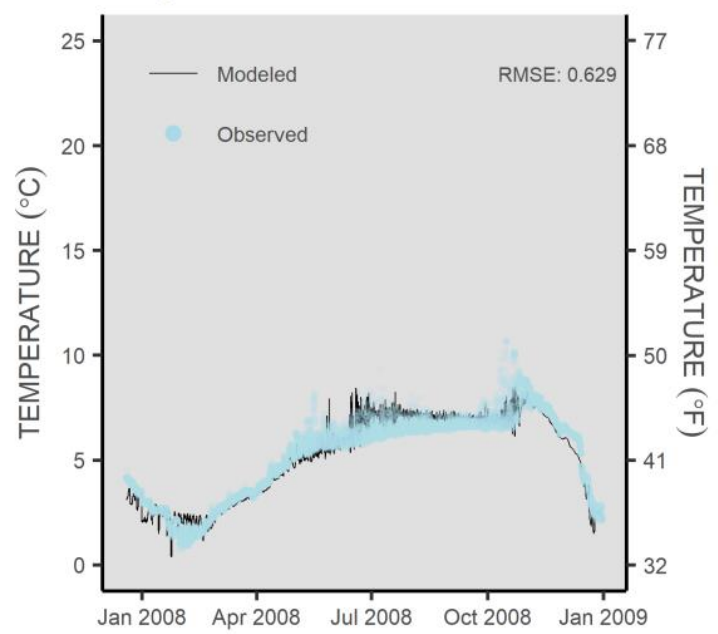

Figure A-15. Comparison of modeled and observed temperatures from depths 8 to 20 meters at buoy 6 (segment 34), MLPP intake, 2007-2008. 


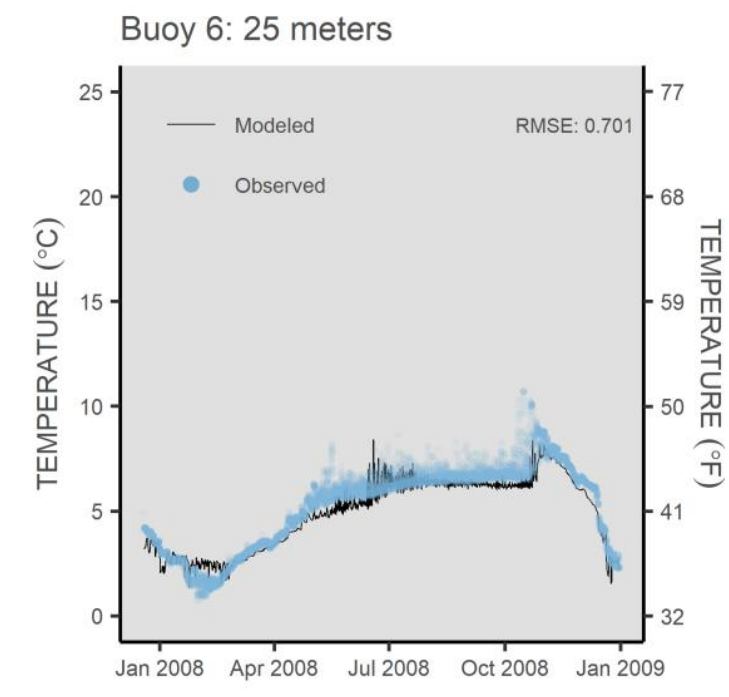

Figure A-16. Comparison of modeled and observed temperatures from depth of 25 meters at buoy 6 (segment 34), MLPP intake, 2007-2008. 

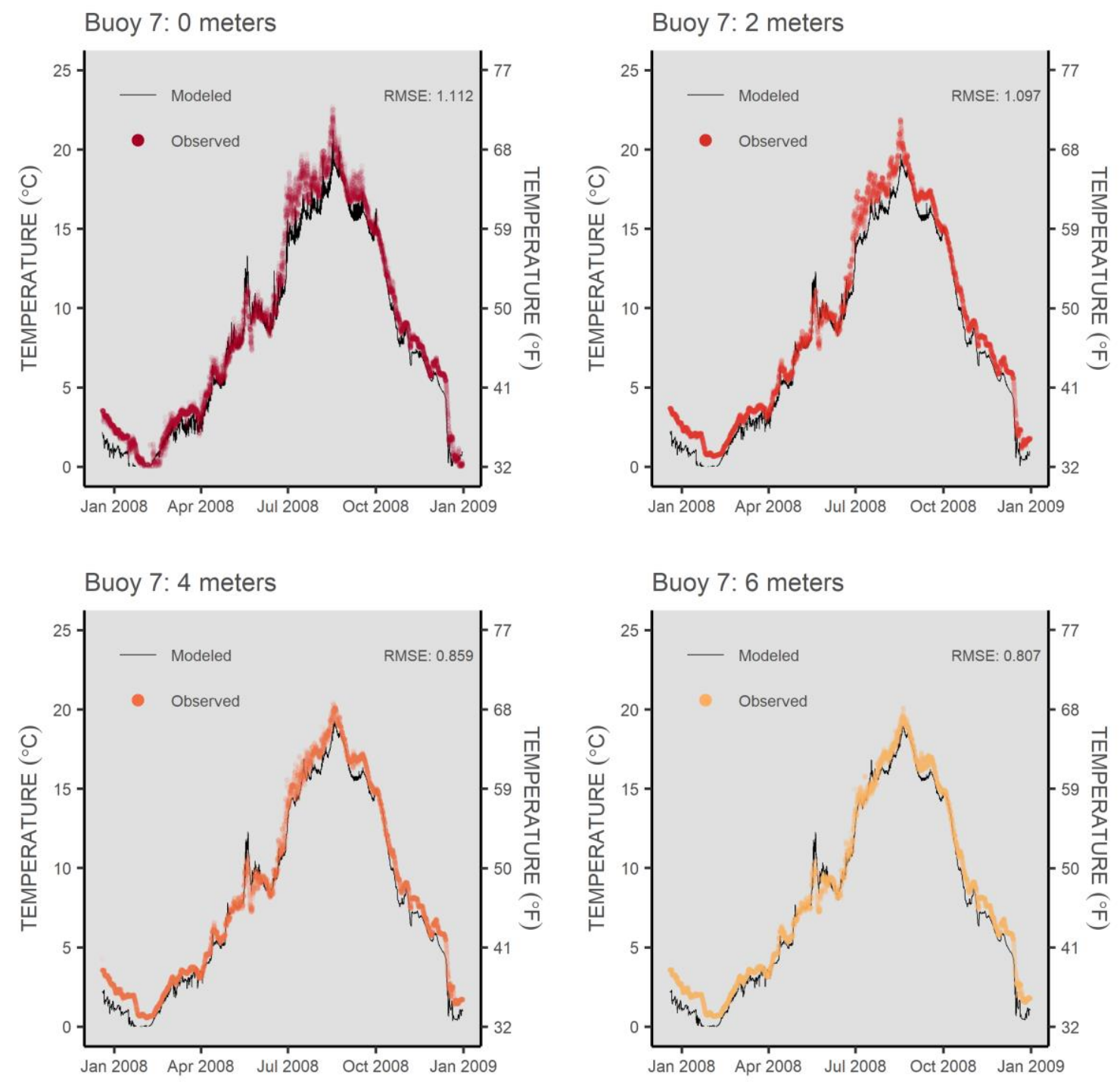

Figure A-17. Comparison of modeled and observed temperatures from depths 0 to 6 meters at buoy 7 (segment 64), Masonry Dam, 2007-2008. 


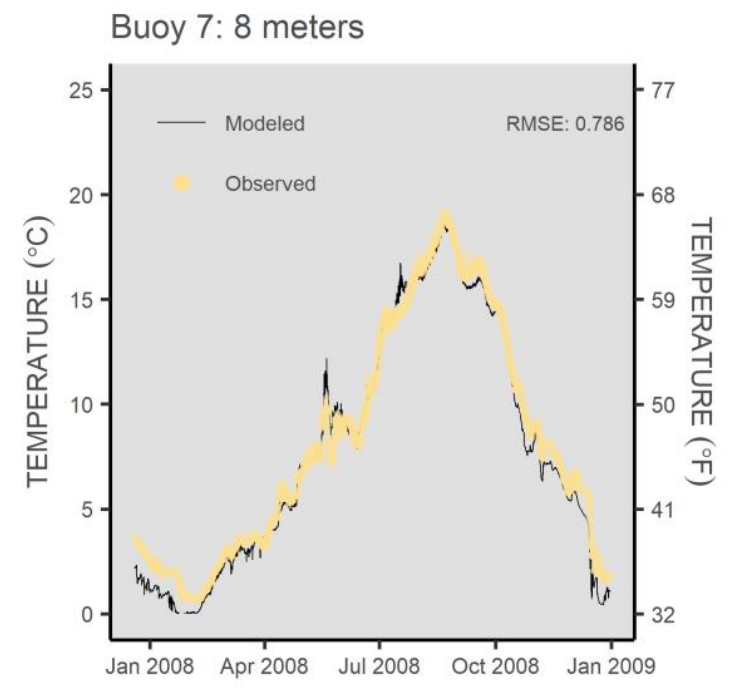

Buoy 7: 15 meters

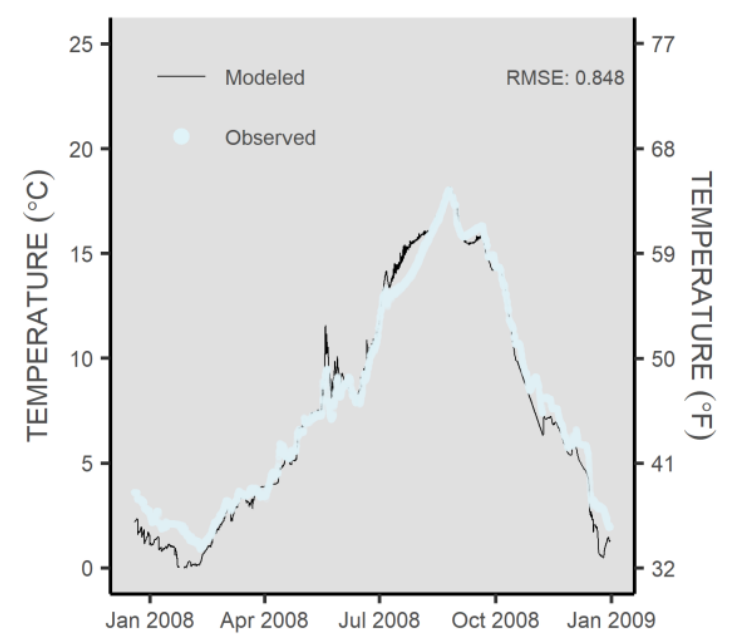

Buoy 7: 10 meters

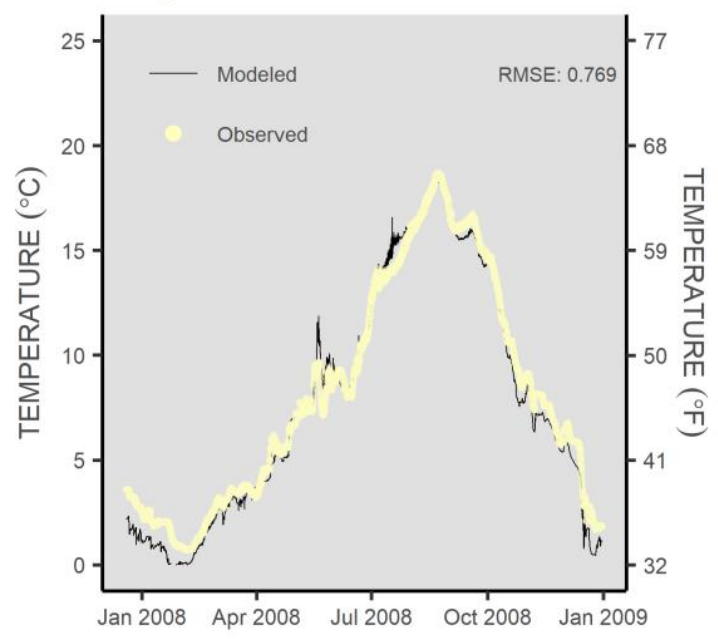

Buoy 7: 20 meters

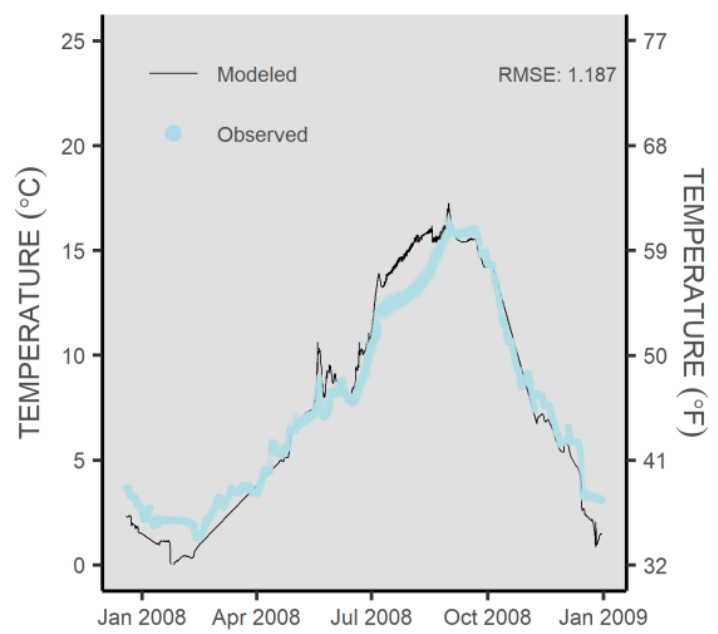

Figure A-18. Comparison of modeled and observed temperatures from depths 8 to 20 meters at buoy 7 (segment 64), Masonry Dam, 2007-2008. 


\section{Appendix B. Water Quality Constituents: Reservoir Model, 2005-2008}
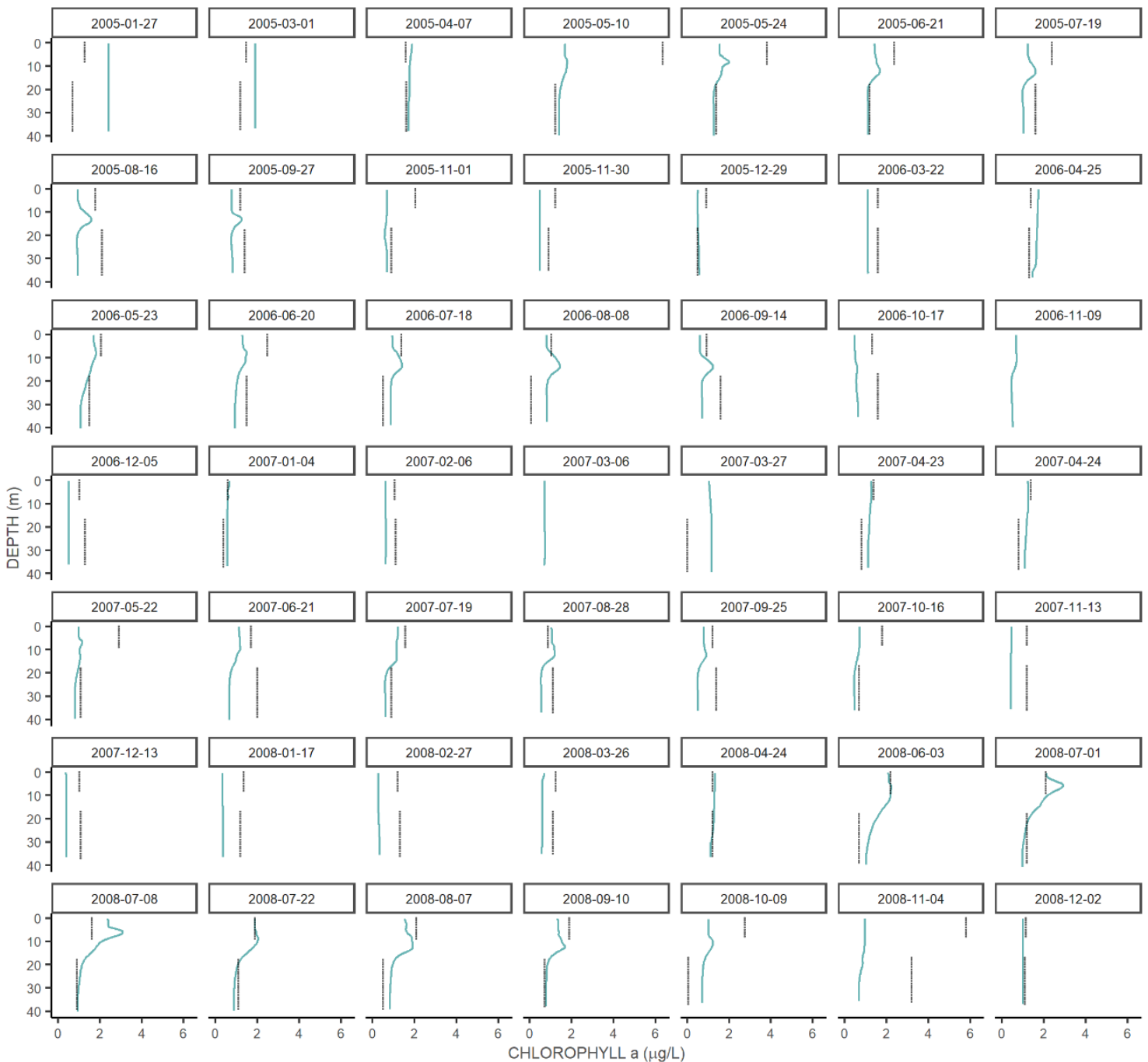

- Modeled - Observed

Figure B-1. Comparison of modeled and observed chlorophyll a concentrations at CM1A (segment 27), 2005-2008. Observed concentrations were calculated using a volume weighted method. Modeled results were concentration over depth in 0.61-meter increments. 


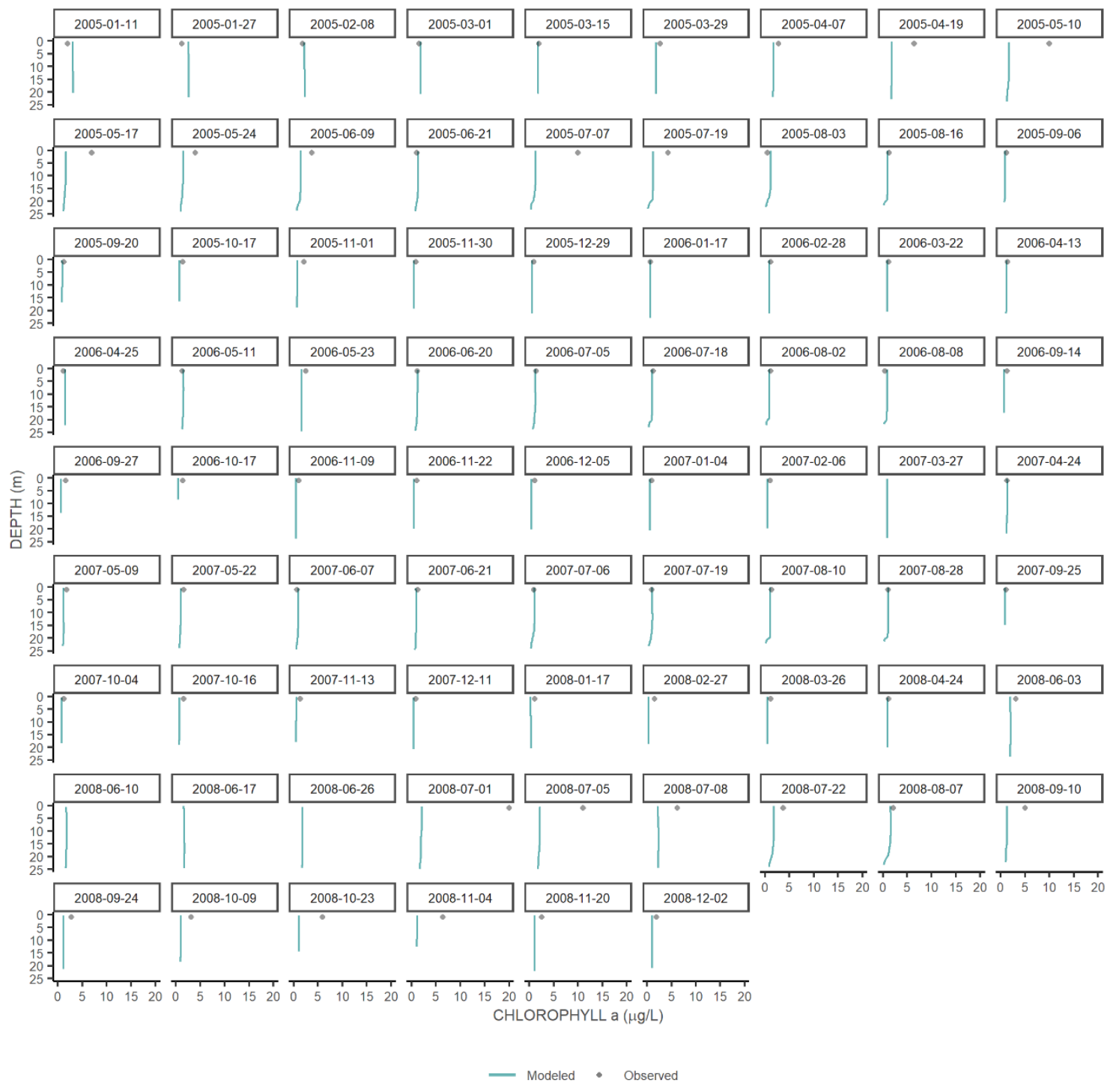

Figure B-2. Comparison of modeled and observed chlorophyll a concentrations at MD (segment 64), 2005-2008. 


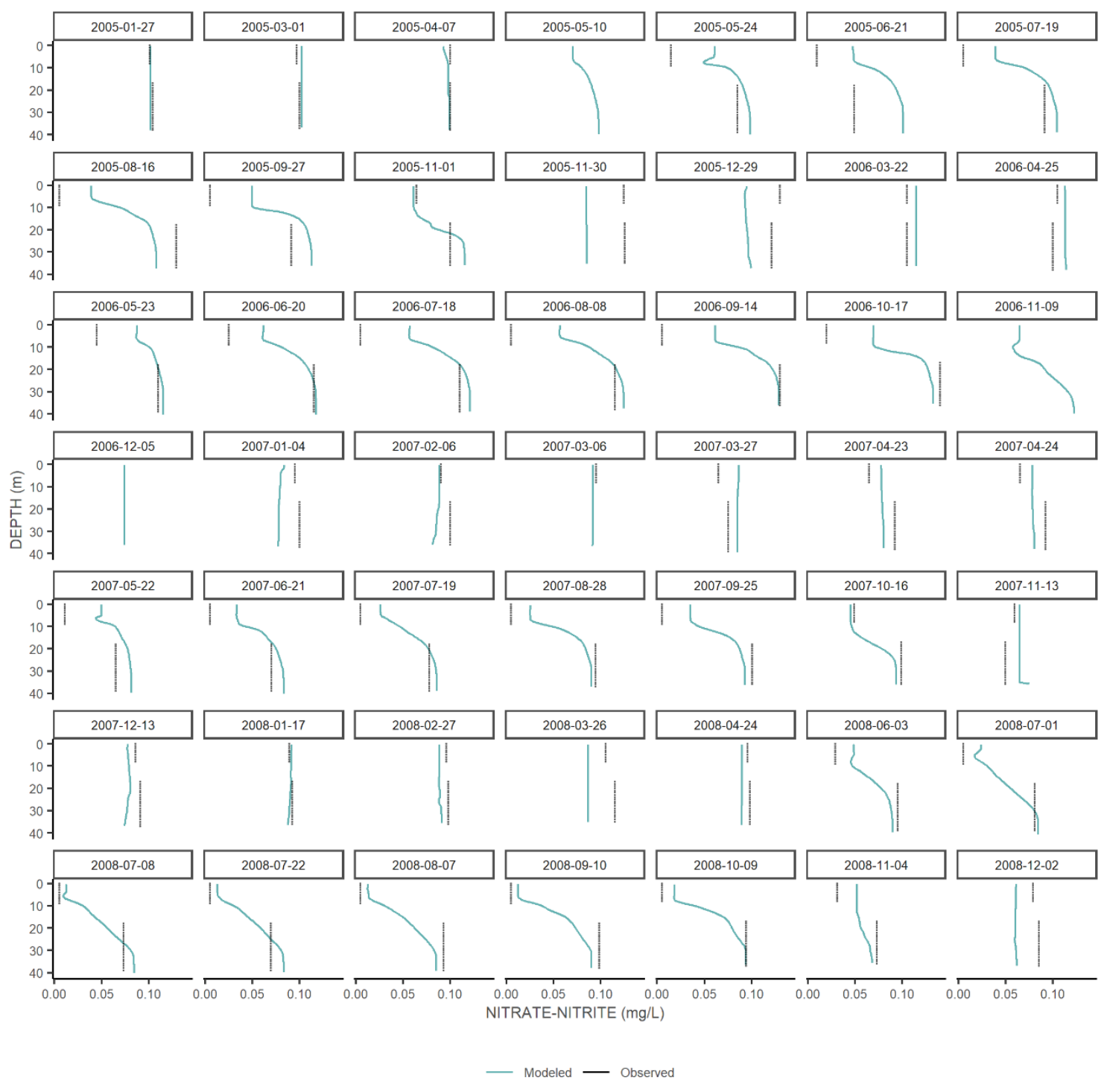

Figure B-3. Comparison of modeled and observed nitrate-nitrite concentrations at CM1A (segment 27), 2005-2008. Observed concentrations were calculated using a volume weighted method. Modeled results were concentration over depth in 0.61-meter increments. 

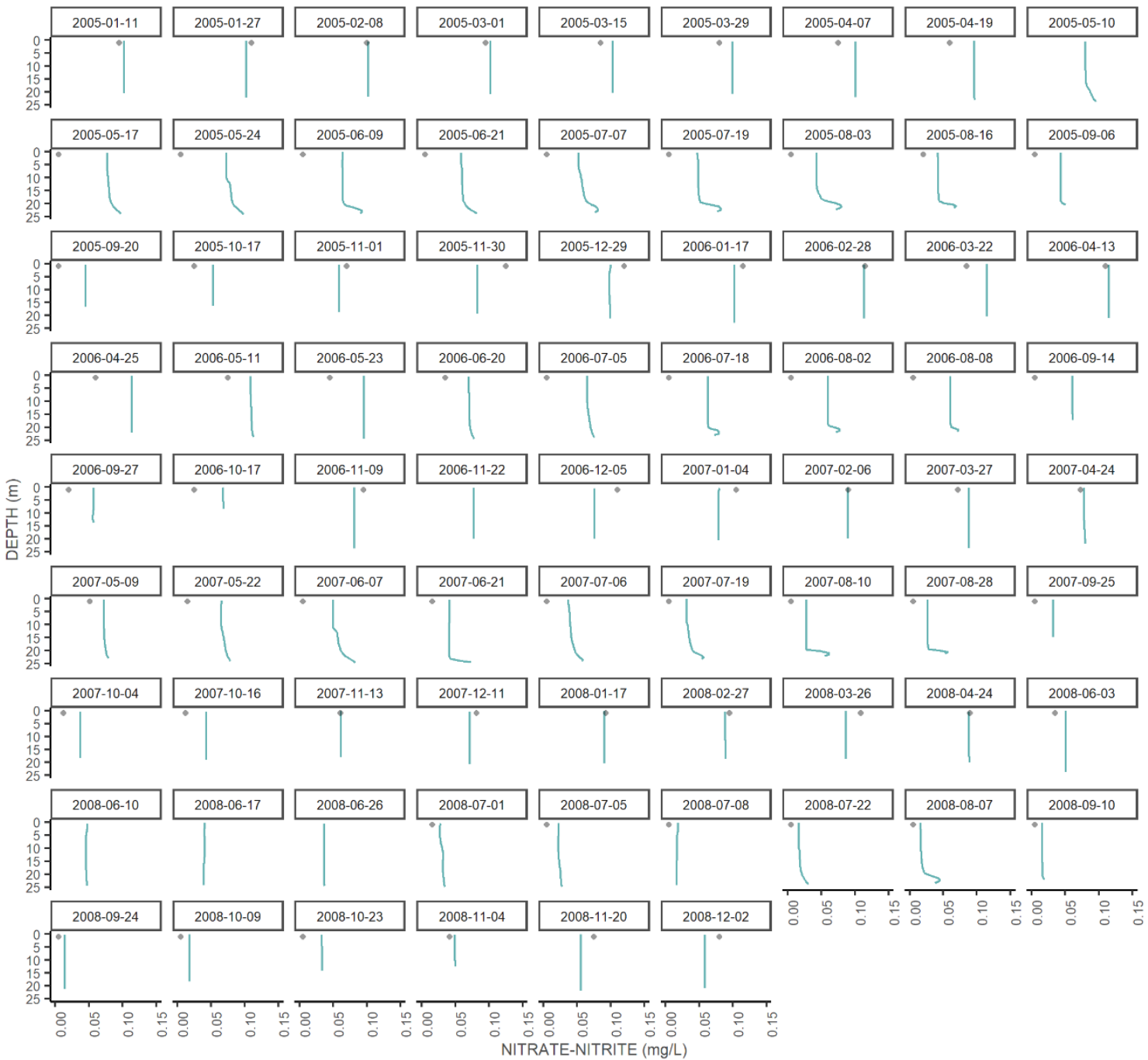

- Modeled • Observed

Figure B-4. Comparison of modeled and observed nitrate-nitrite concentrations at MD (segment 64), 2005-2008. 


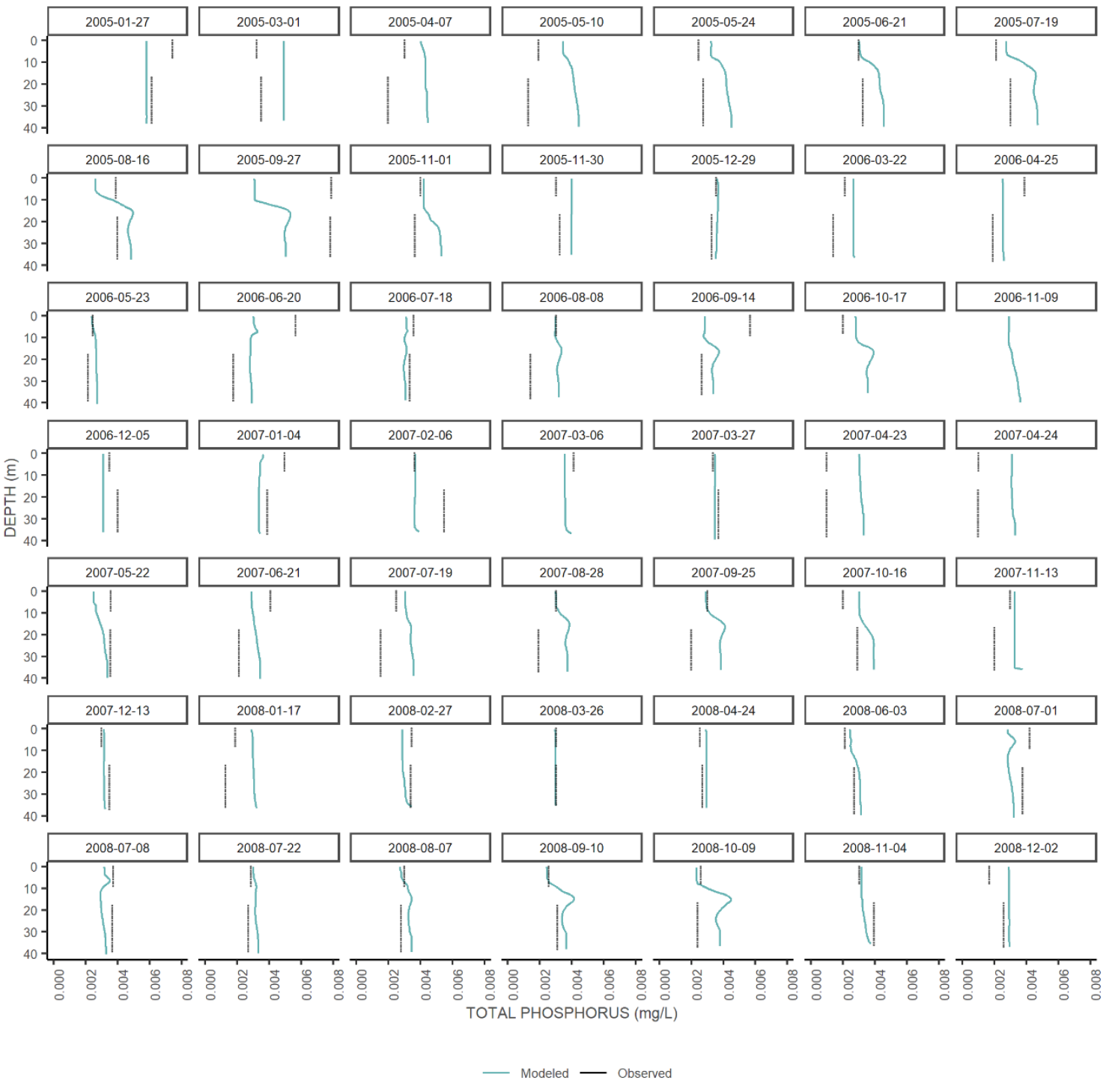

Figure B-5. Comparison of modeled and observed total phosphorus concentrations at CM1A (segment 27), 2005-2008. Observed concentrations were calculated using a volume weighted method. Modeled results were concentration over depth in 0.61-meter increments. 


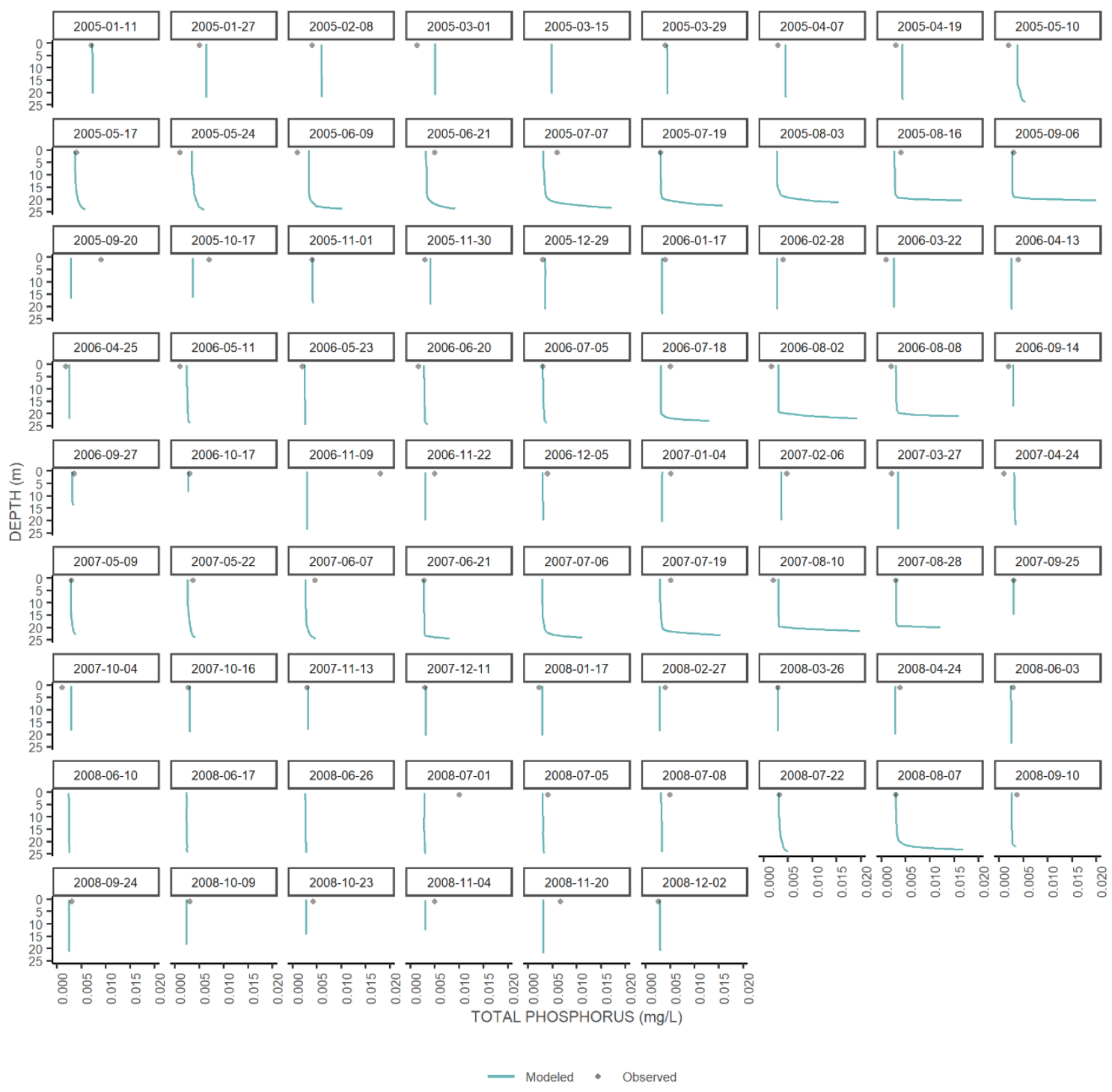

Figure B-6. Comparison of modeled and observed total phosphorus concentrations at MD (segment 64), 2005-2008. 


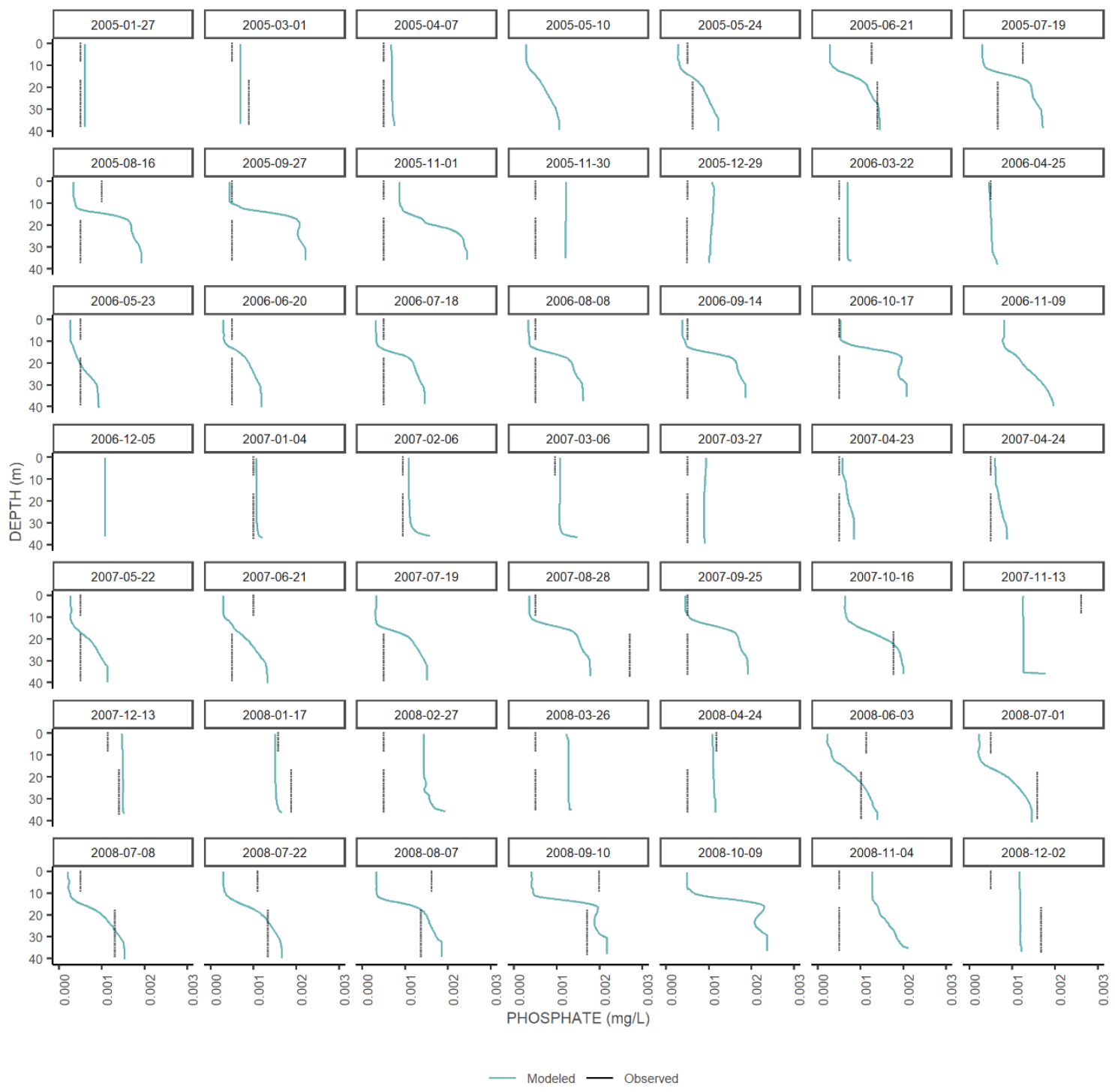

Figure B-7. Comparison of modeled and observed phosphate concentrations at CM1A (segment 27), 2005-2008. Observed concentrations were calculated using a volume weighted method. Modeled results were concentration over depth in 0.61-meter increments. 


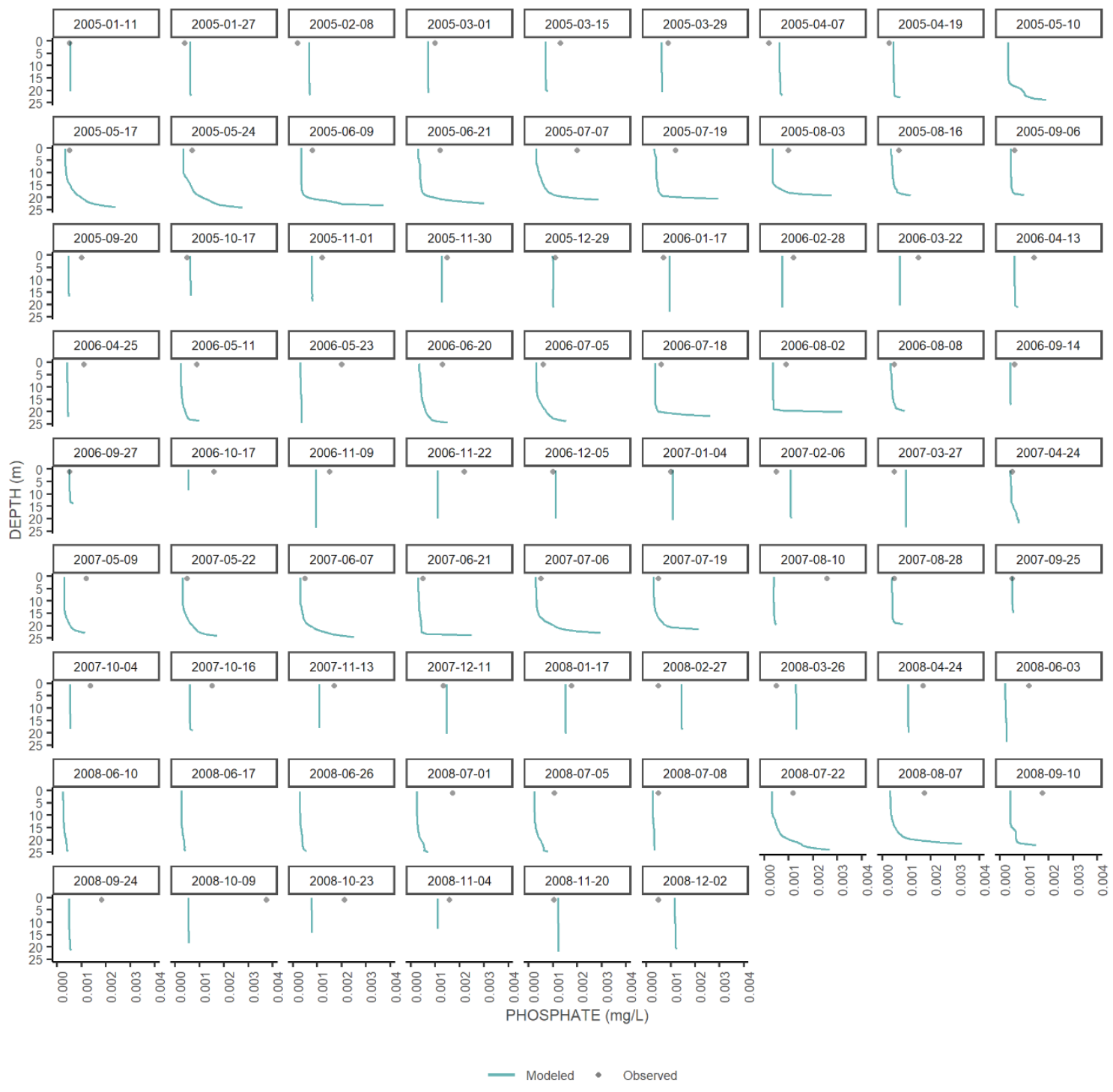

Figure B-8. Comparison of modeled and observed phosphate concentrations at MD (segment 64), 2005-2008. 


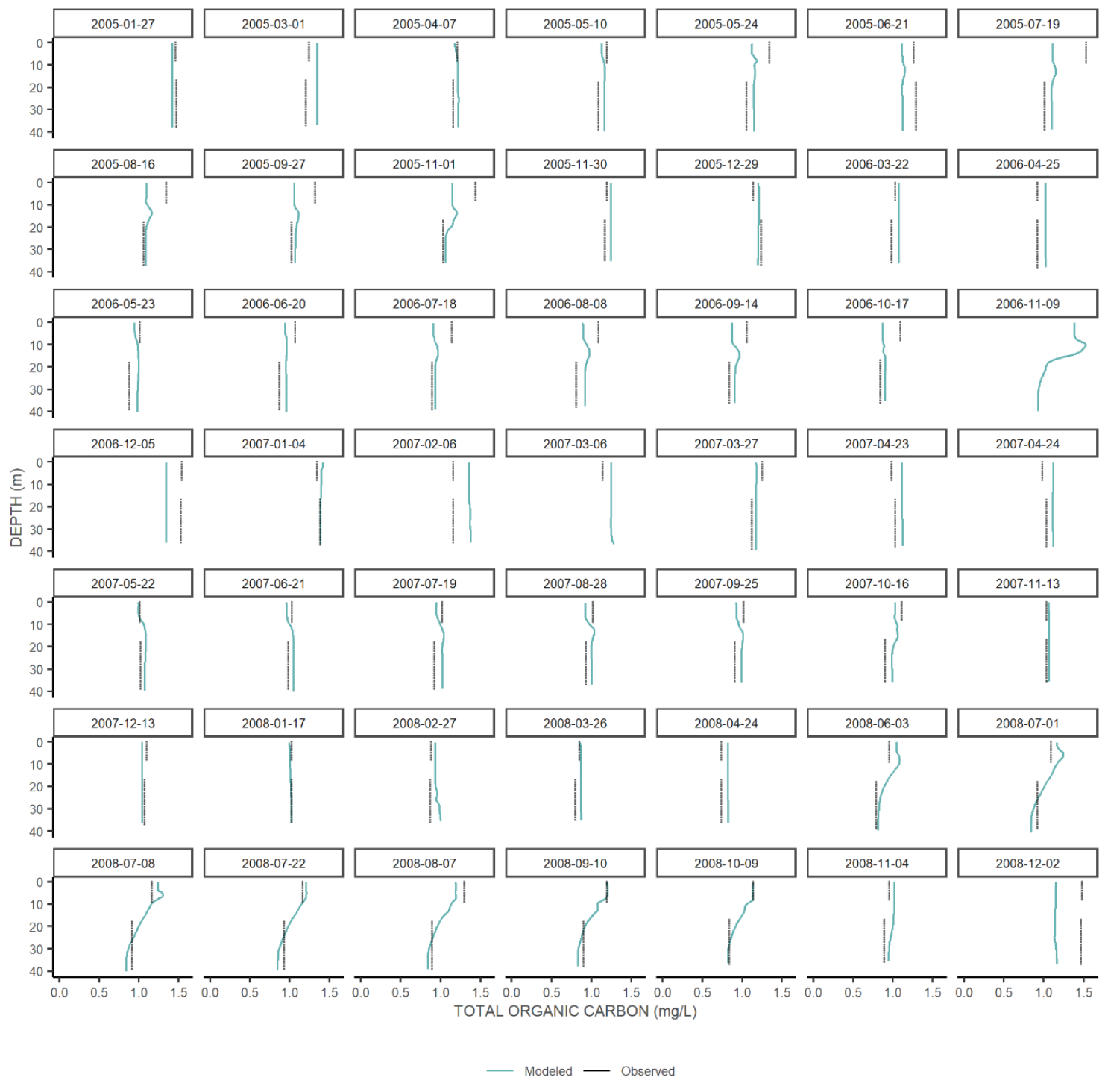

Figure B-9. Comparison of modeled and observed total organic carbon concentrations at CM1A (segment 27), 2005-2008. Observed concentrations were calculated using a volume weighted method. Modeled results were concentration over depth in 0.61-meter increments. 


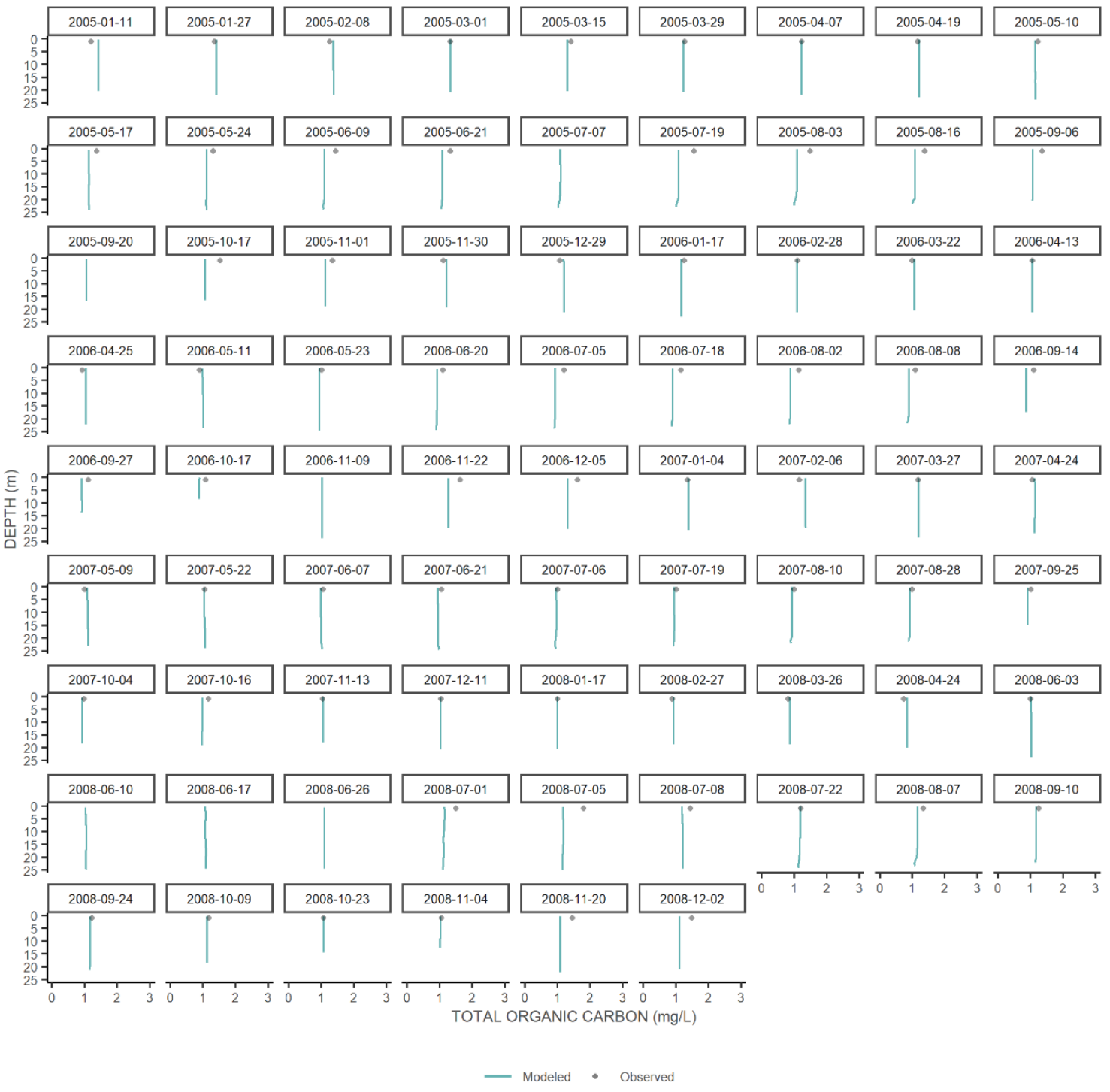

Figure B-10. Comparison of modeled and observed total organic carbon concentrations at MD (segment 64), 2005-2008. 
Appendix C. Water Quality Constituents: Reservoir Model, 2015
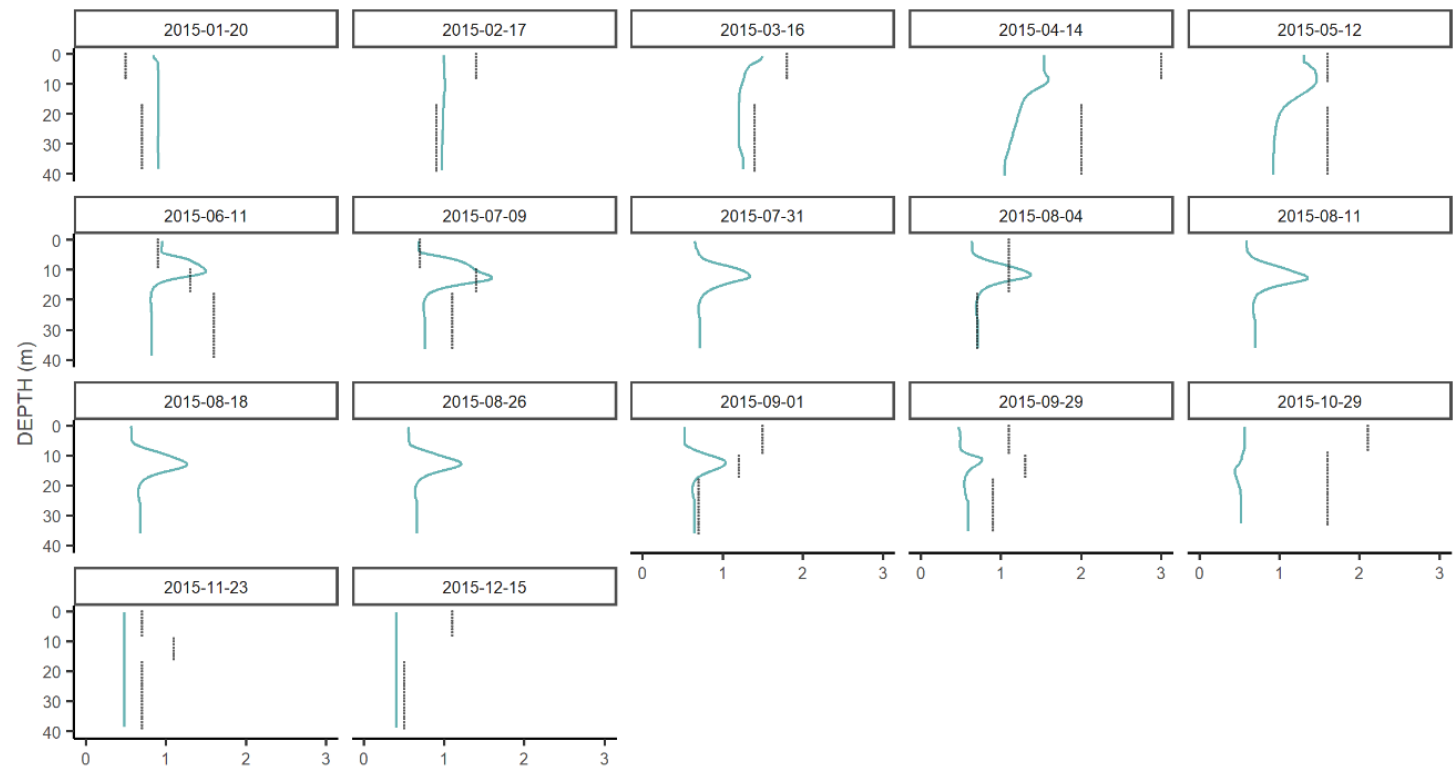

CHLOROPHYLL a ( $\mu \mathrm{g} / \mathrm{L})$

- Modeled — Observed

Figure C-1. Comparison of modeled and observed chlorophyll a concentrations at CM1A (segment 27), 2015. Observed concentrations were calculated using a volume weighted method. Modeled results were concentration over depth in 0.61-meter increments.
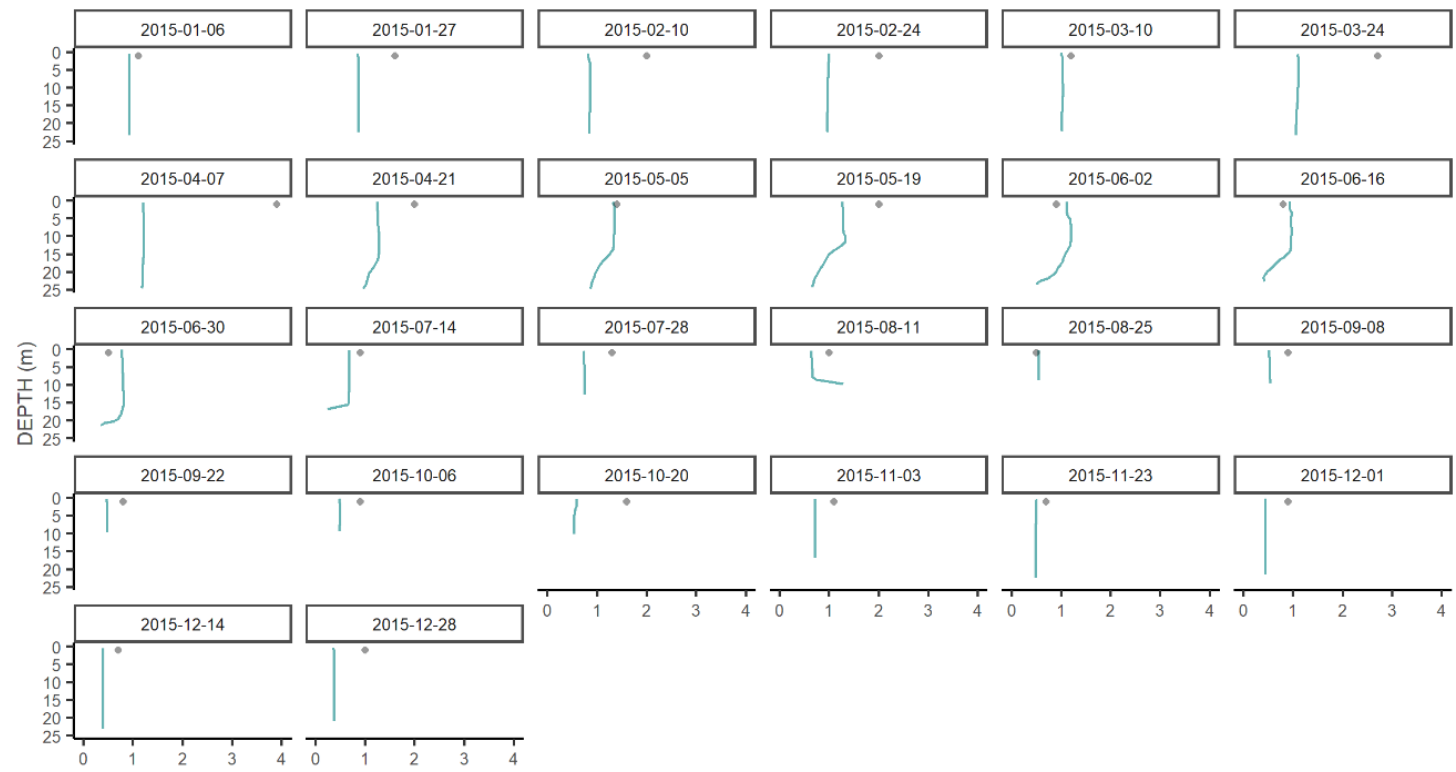

CHLOROPHYLL a $(\mu \mathrm{g} / \mathrm{L})$

— Modeled • Observed

Figure C-2. Comparison of modeled and observed chlorophyll a concentrations at MD (segment 64), 2015. 


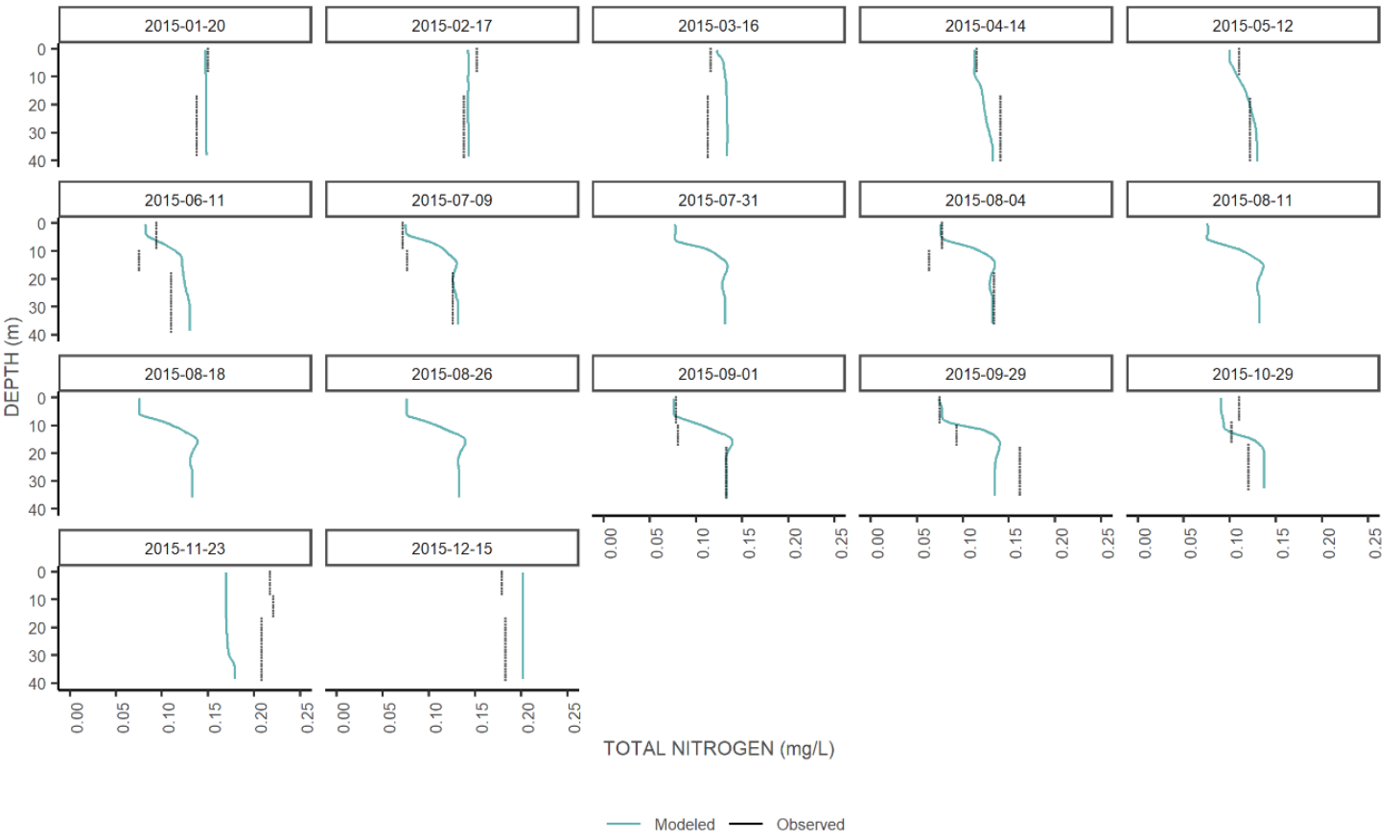

Figure C-3. Comparison of modeled and observed total nitrogen concentrations at CM1A (segment 27), 2015. Observed concentrations were calculated using a volume weighted method. Modeled results were concentration over depth in 0.61-meter increments.

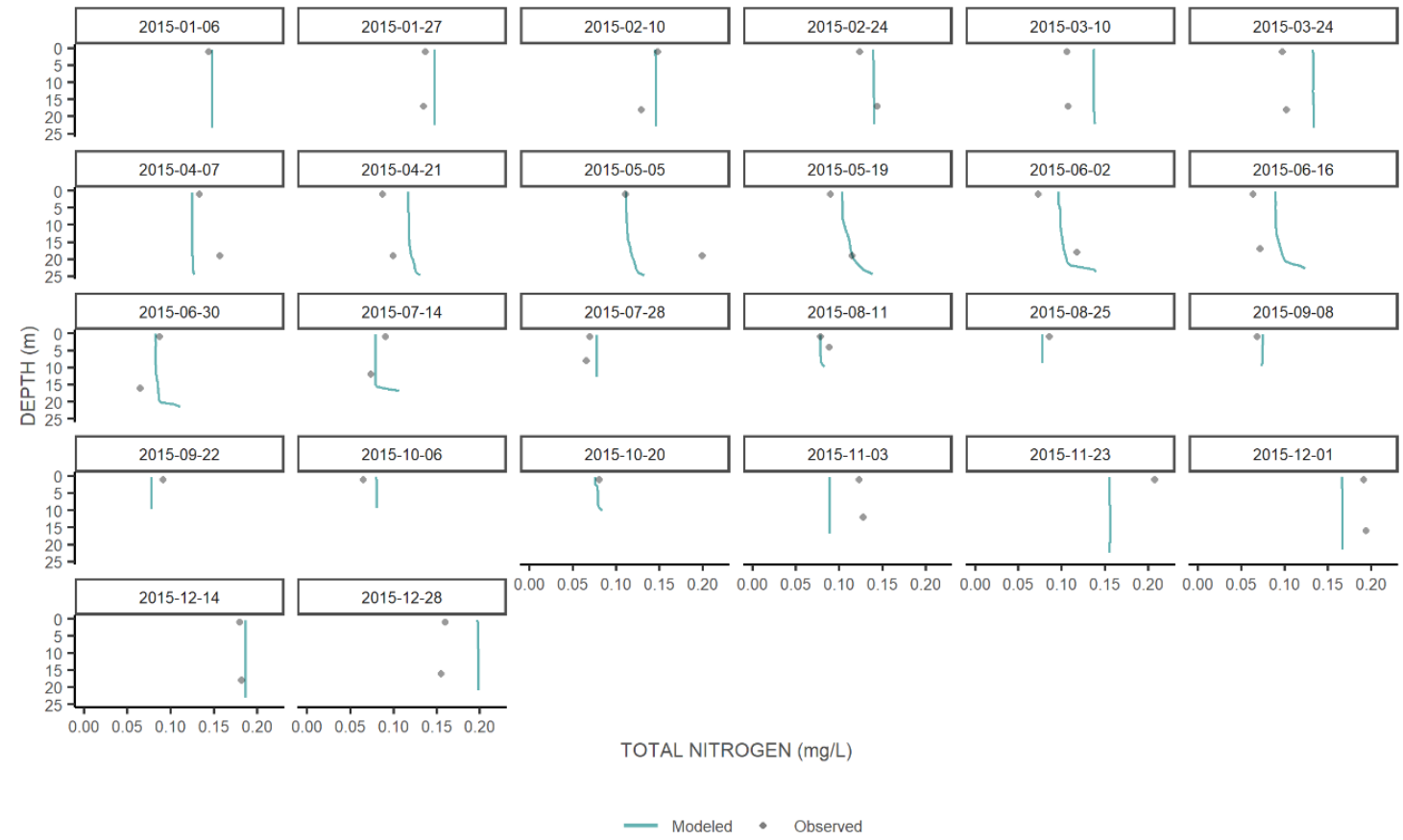

Figure C-4. Comparison of modeled and observed total nitrogen concentrations at MD (segment 64), 2015. 


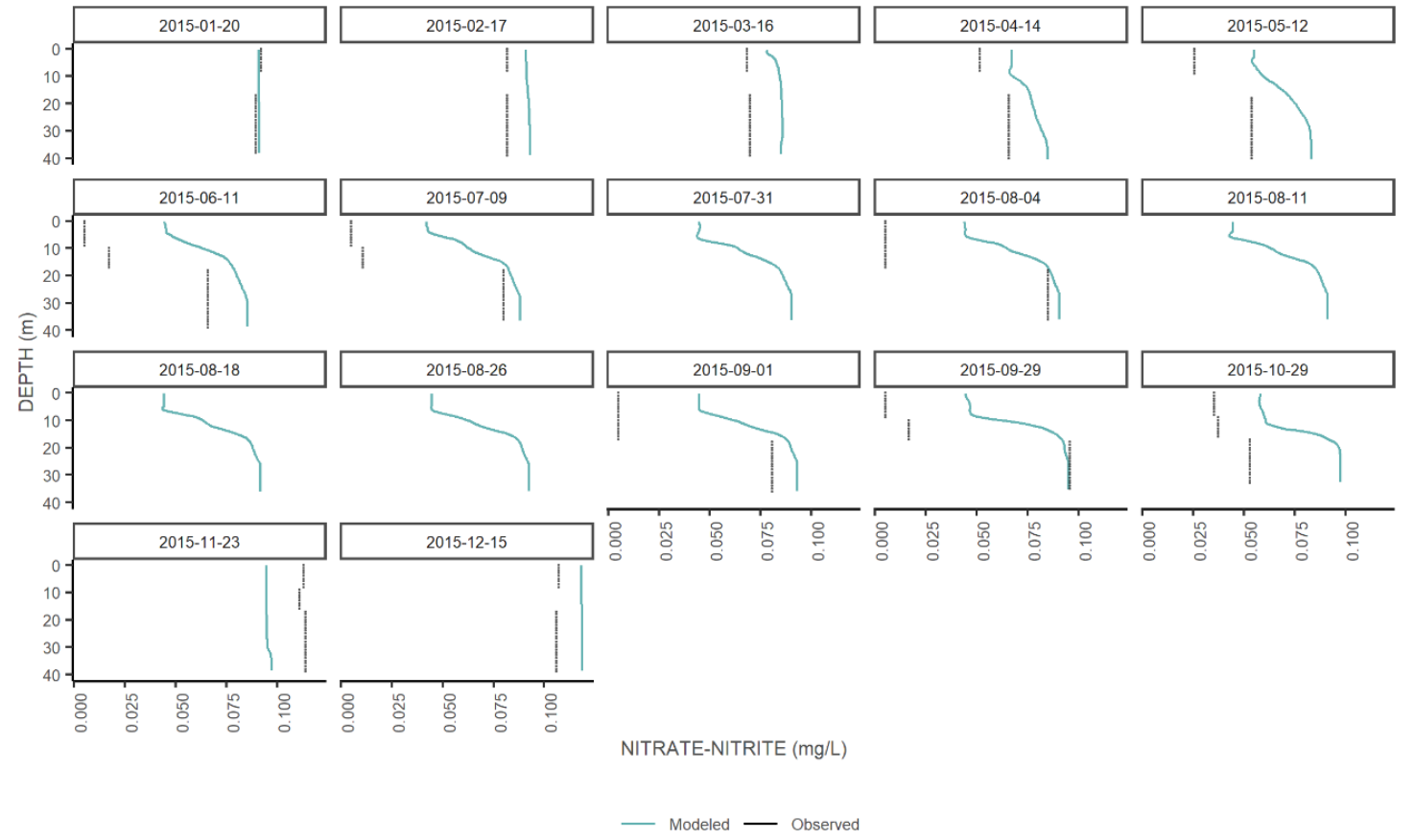

Figure C-5. Comparison of modeled and observed nitrate-nitrite concentrations at CM1A (segment 27), 2015. Observed concentrations were calculated using a volume weighted method. Modeled results were concentration over depth in 0.61-meter increments.

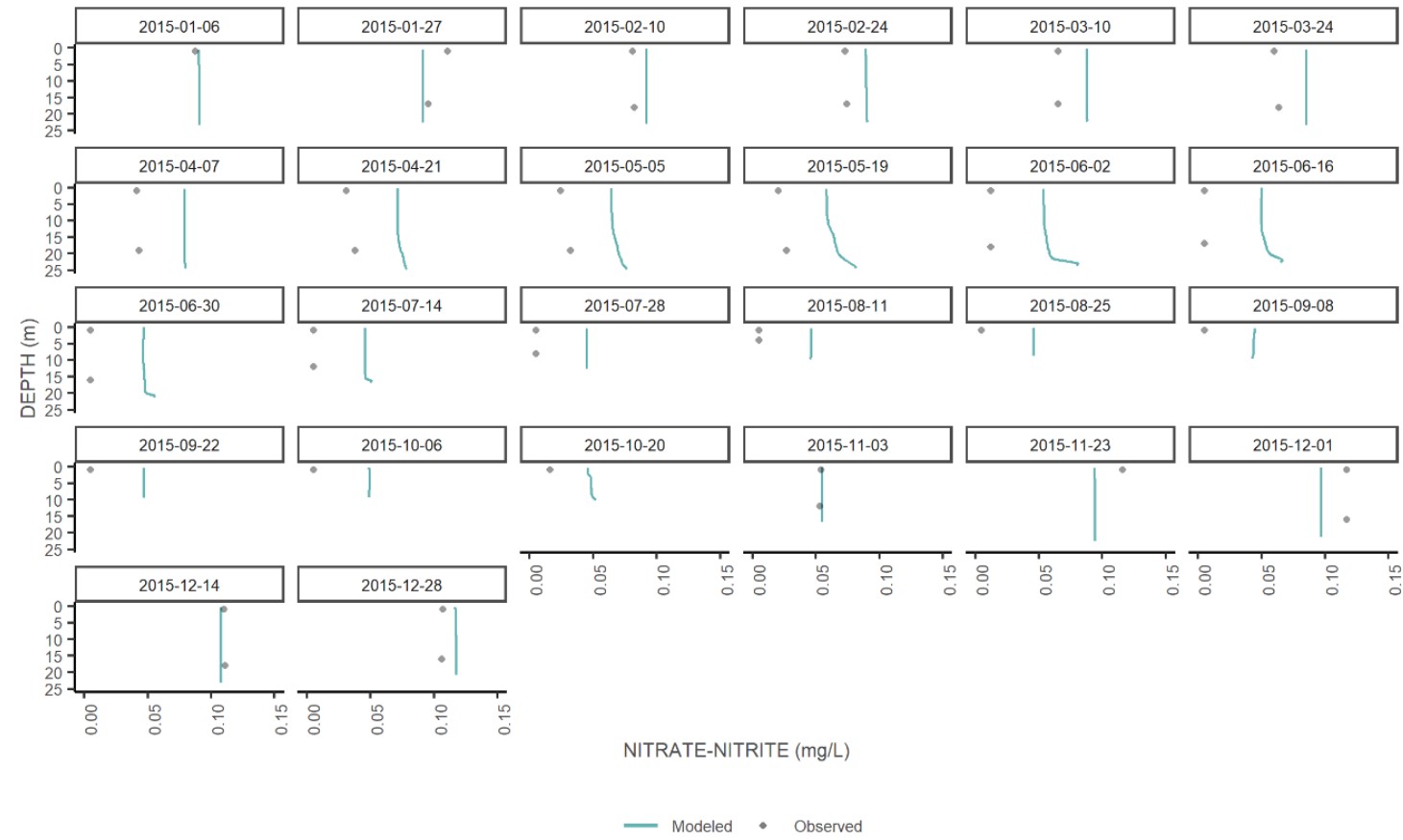

Figure C-6. Comparison of modeled and observed nitrate-nitrite concentrations at MD (segment 64), 2015. 


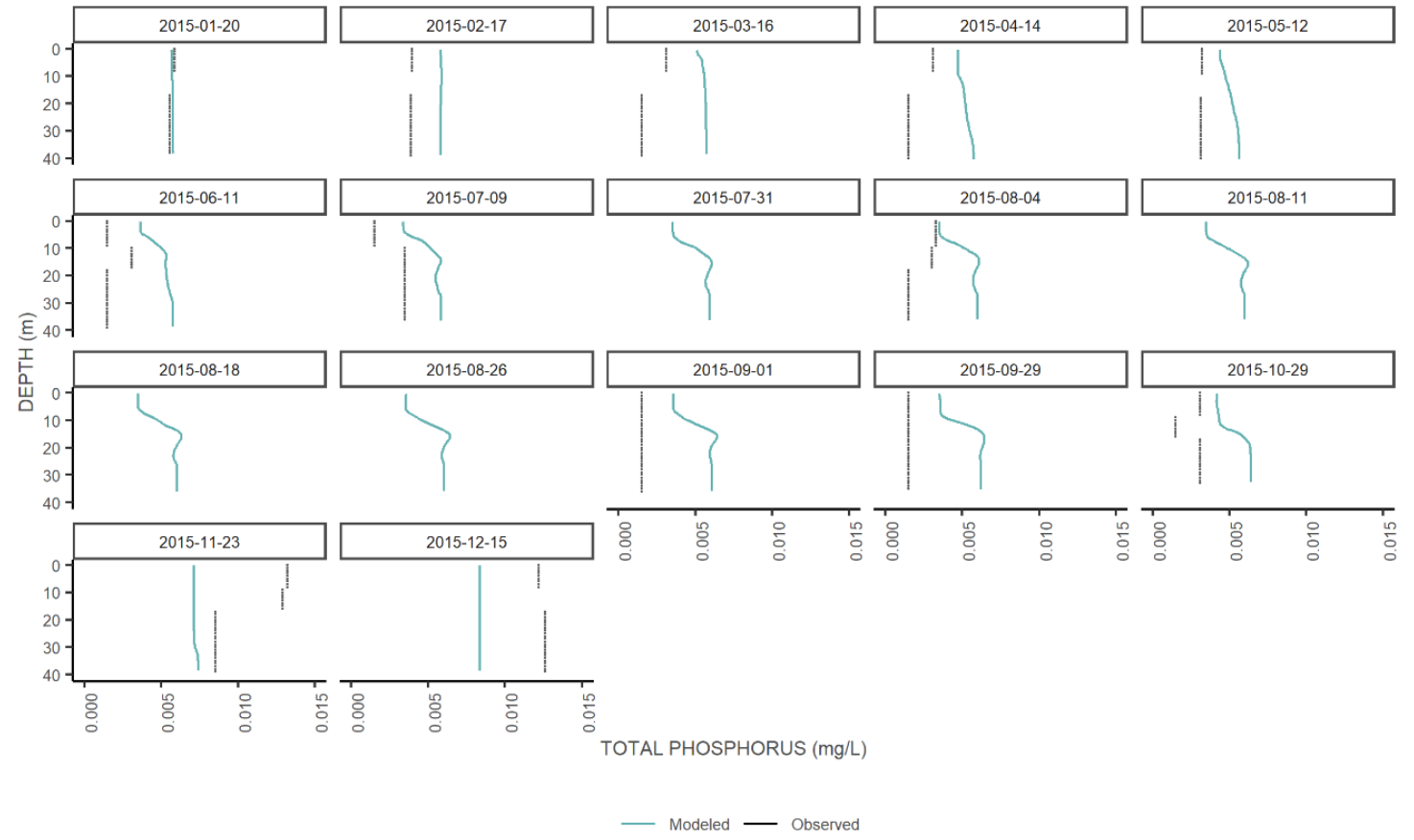

Figure C-7. Comparison of modeled and observed total phosphorus concentrations at CM1A (segment 27), 2015. Observed concentrations were calculated using a volume weighted method. Modeled results were concentration over depth in 0.61-meter increments.

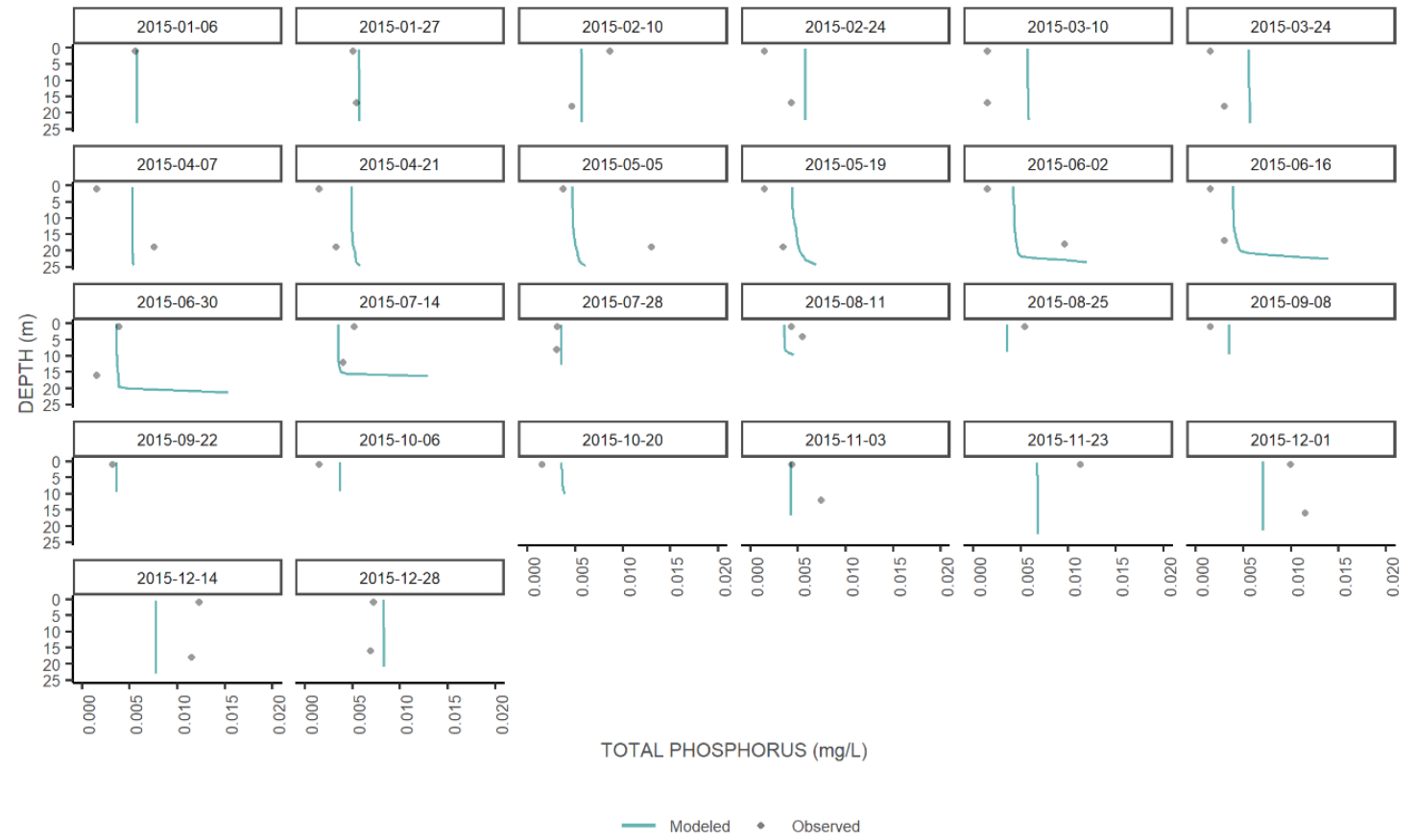

Figure C-8. Comparison of modeled and observed total phosphorus concentrations at MD (segment 64), 2015. 


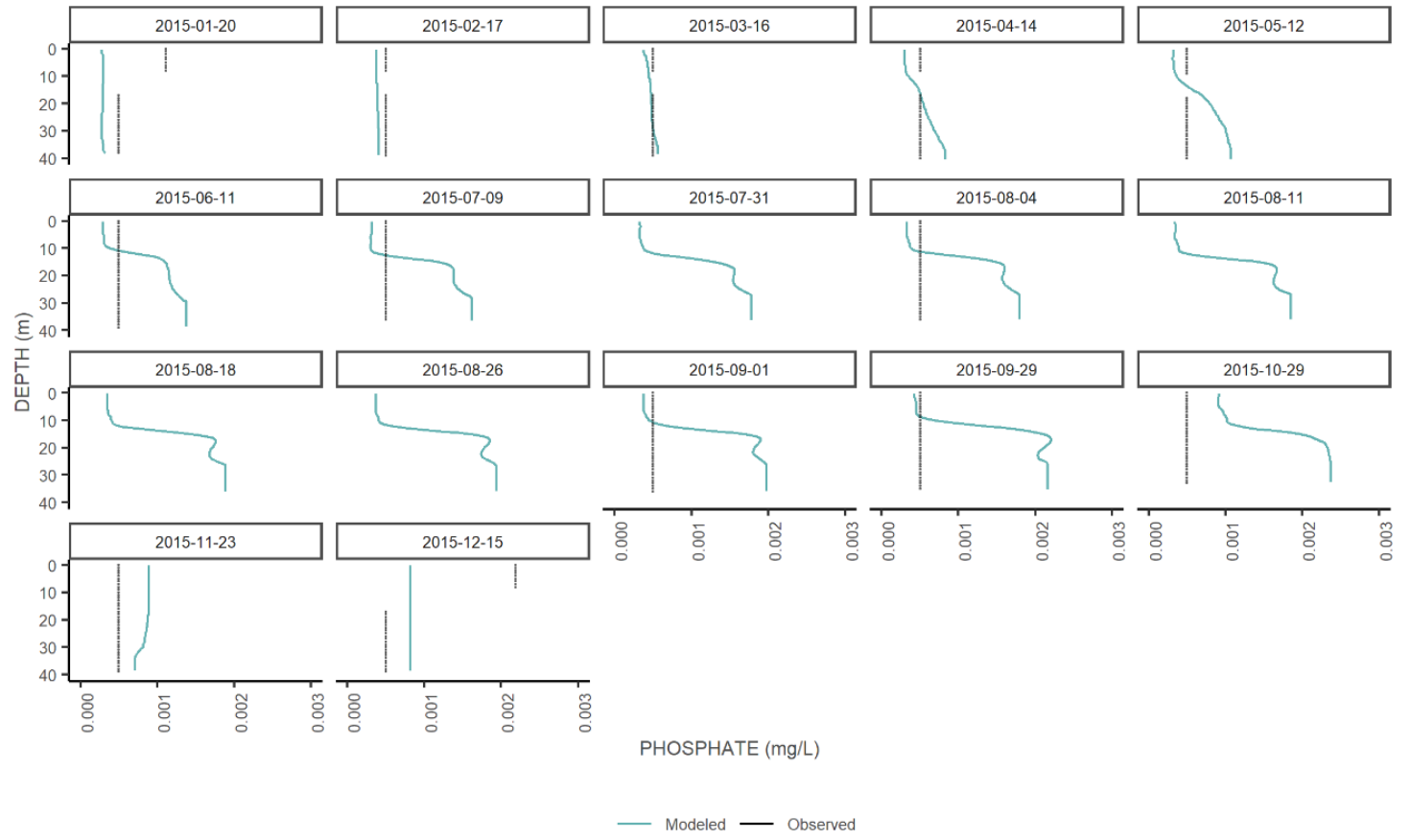

Figure C-9. Comparison of modeled and observed phosphate concentrations at CM1A (segment 27), 2015. Observed concentrations were calculated using a volume weighted method. Modeled results were concentration over depth in 0.61-meter increments.

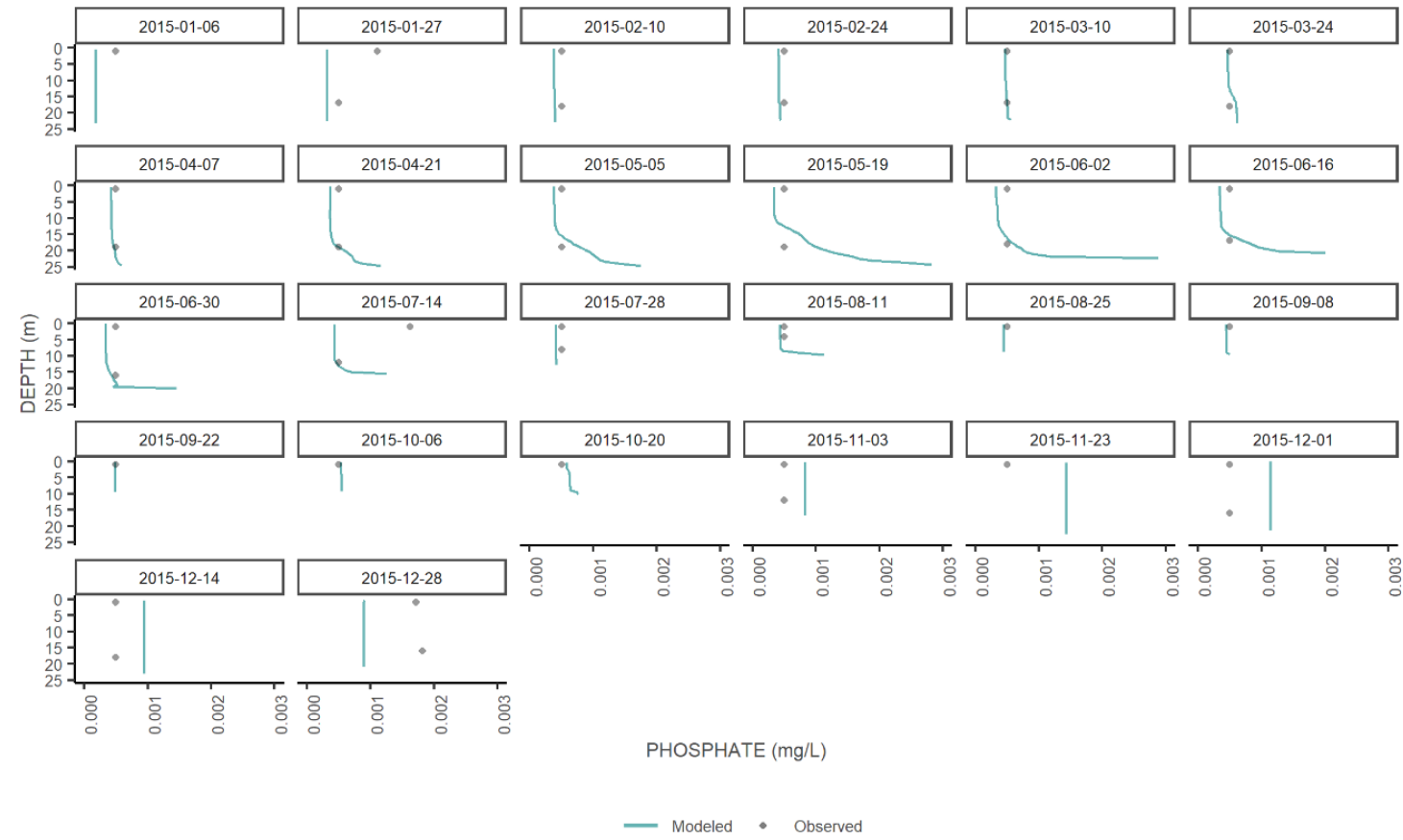

Figure C-10. Comparison of modeled and observed phosphate concentrations at MD (segment 64), 2015. 


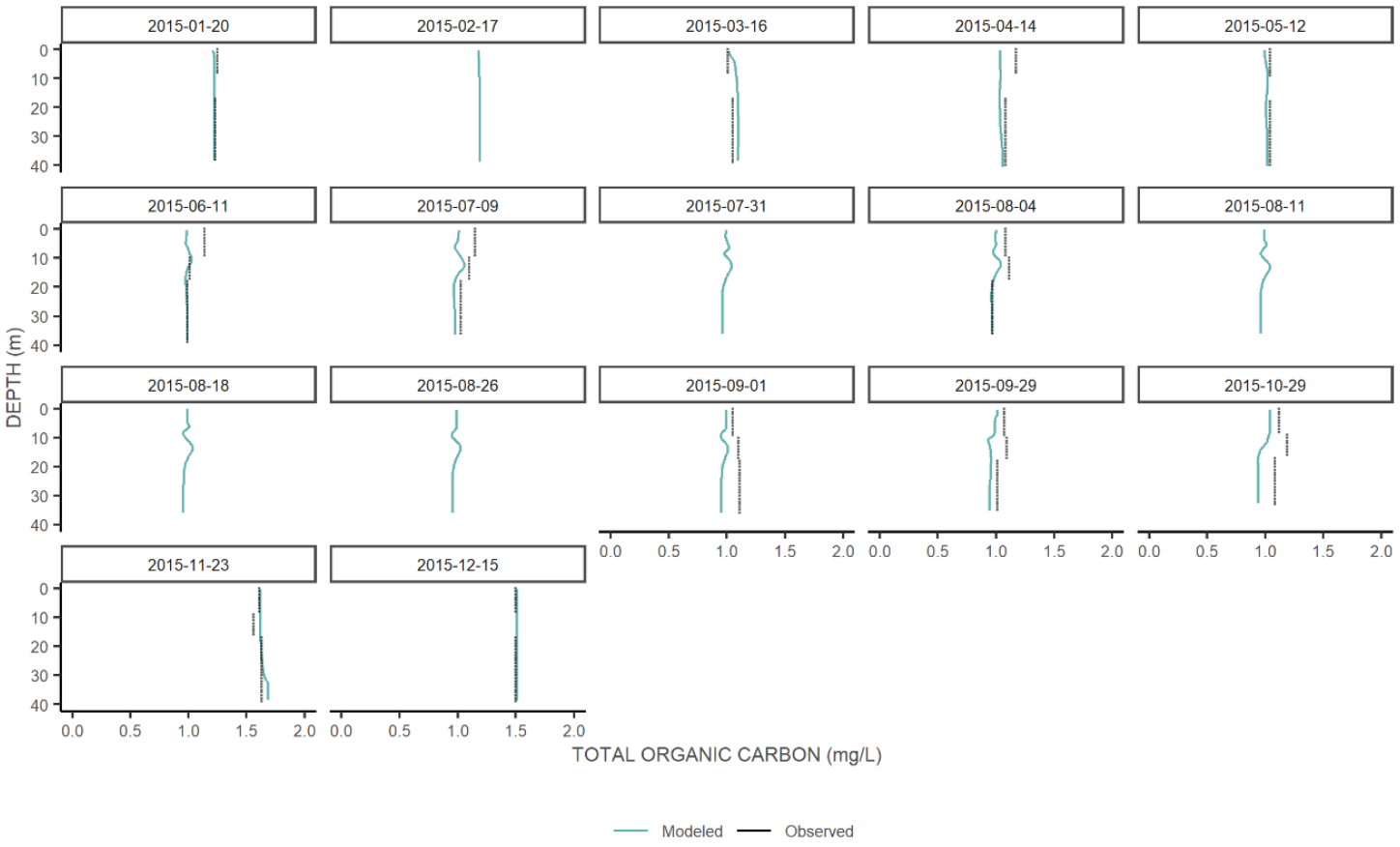

Figure C-11. Comparison of modeled and observed total organic carbon concentrations at CM1A (segment 27), 2015. Observed concentrations were calculated using a volume weighted method. Modeled results were concentration over depth in 0.61-meter increments.

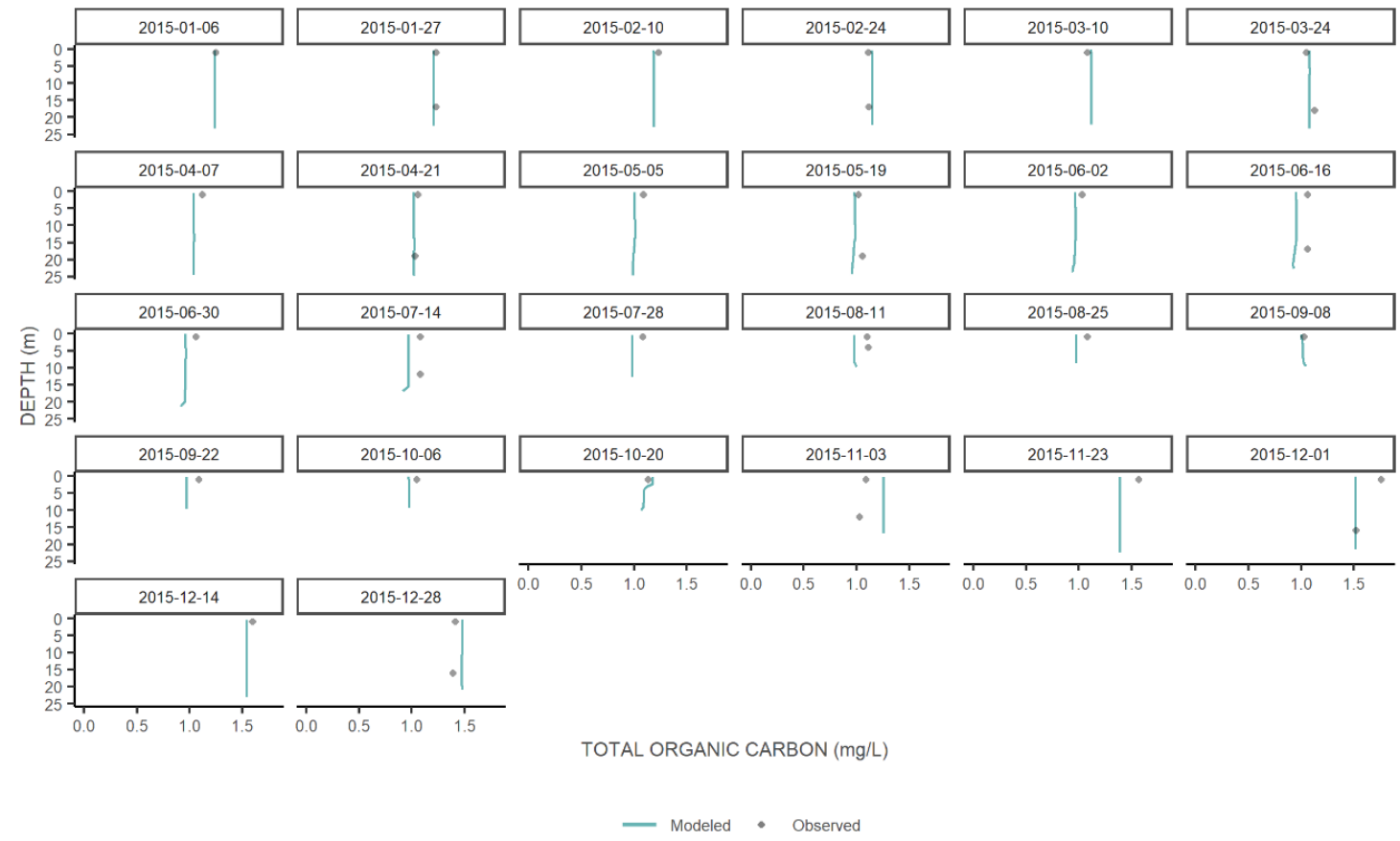

Figure C-12. Comparison of modeled and observed total organic carbon concentrations at MD (segment 64), 2015. 


\section{Appendix D. Water Quality Constituents: River Model, 2005-2008}

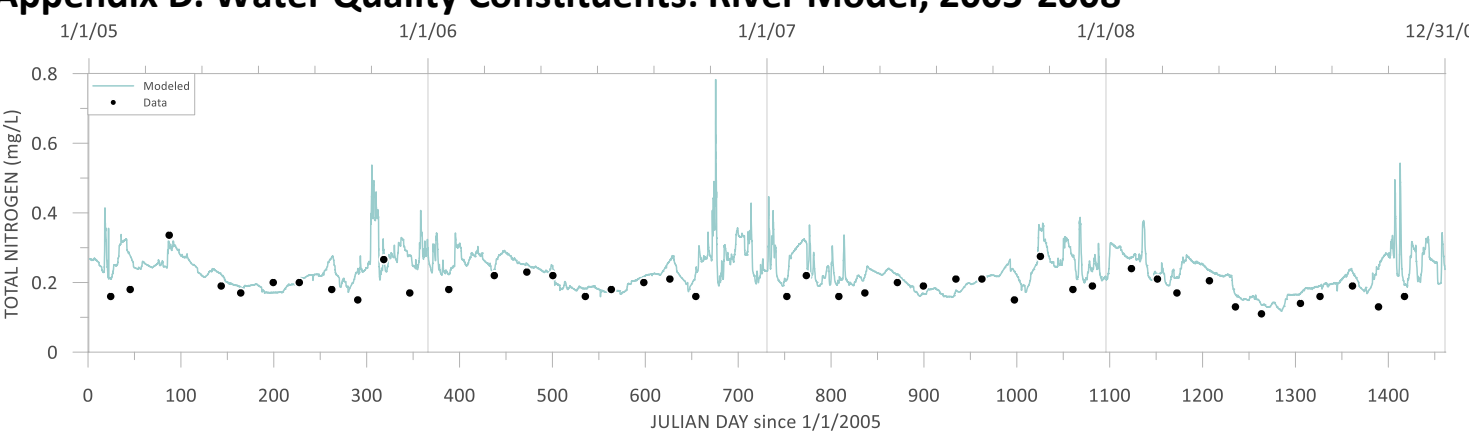

Figure D-1. Comparison of modeled total nitrogen concentrations to observed concentrations at WSDE 08 C110 (segment 74), 2005-2008.

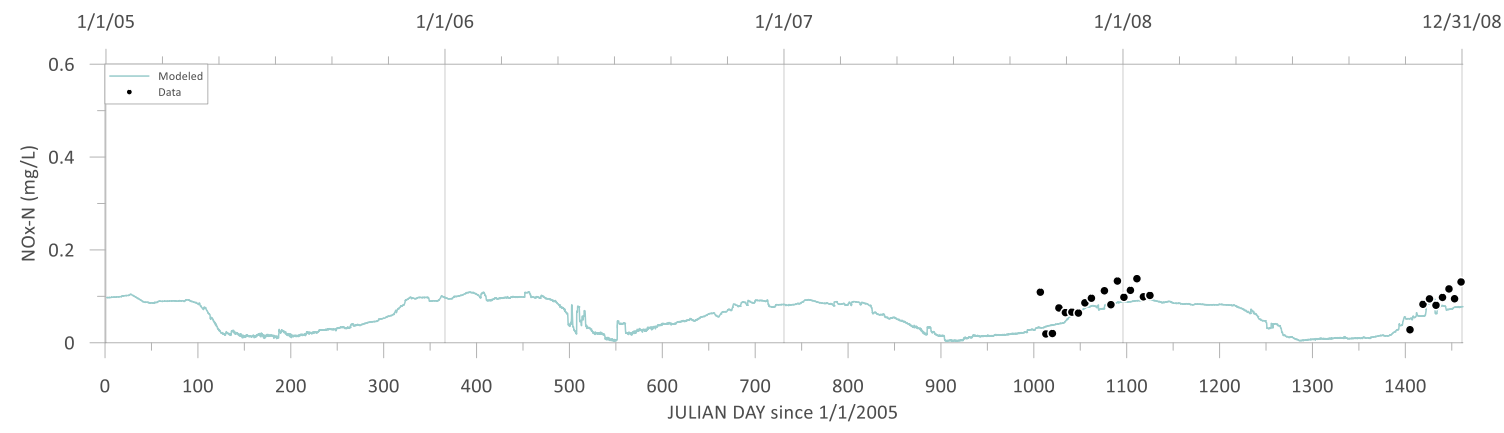

Figure D-2. Comparison of modeled nitrate-nitrite concentrations to observed concentrations at CR-PWRHS (segment 16), 2005-2008.

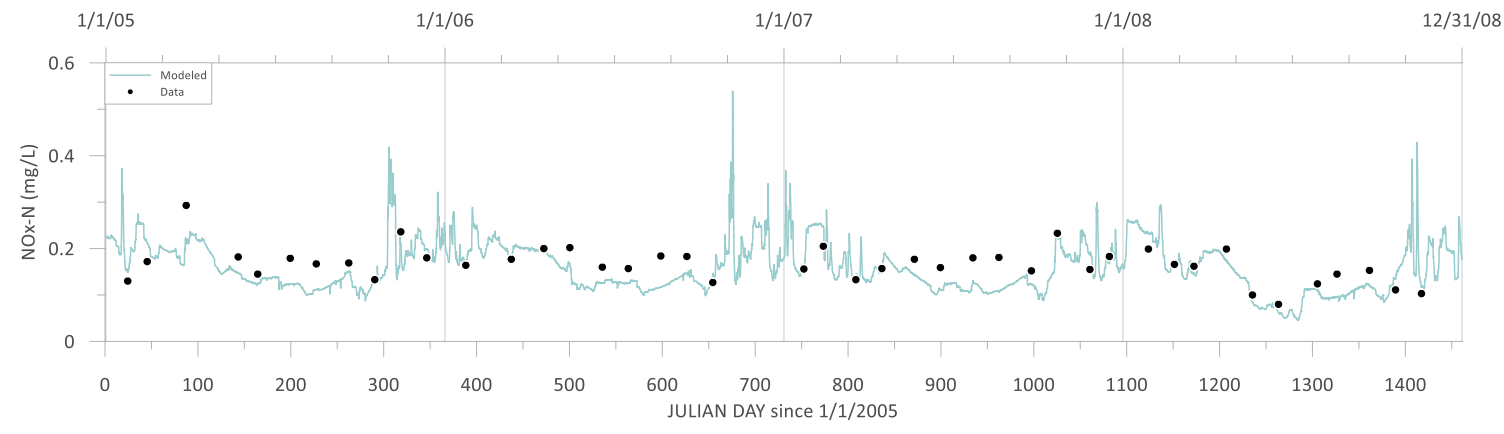

Figure D-3. Comparison of modeled nitrate-nitrite concentrations to observed concentrations at WSDE 08 C110 (segment 74), 2005-2008. 


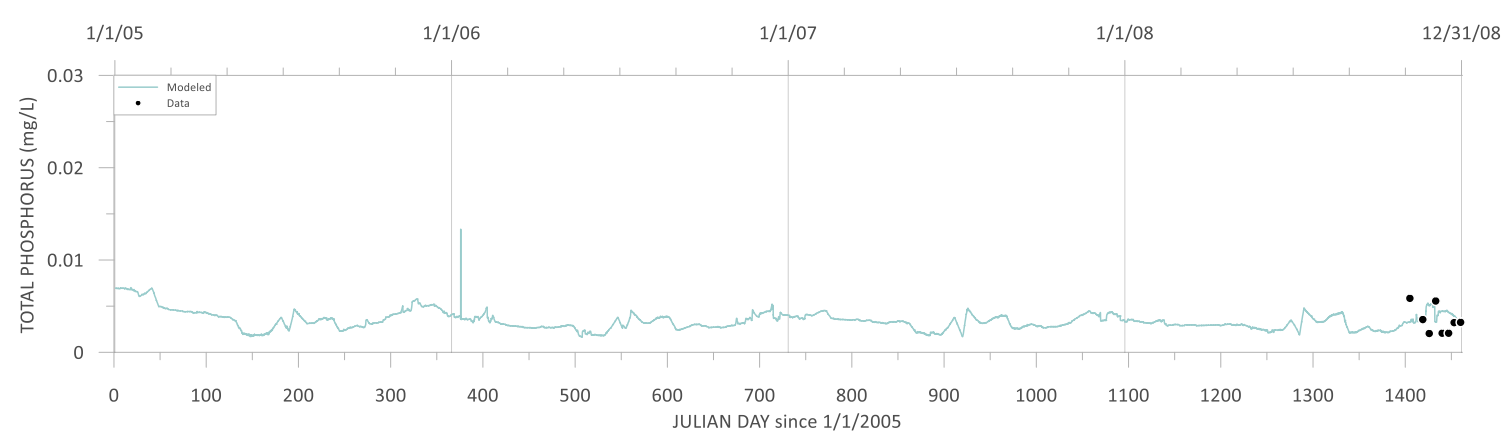

Figure D-4. Comparison of modeled total phosphorus concentrations to observed concentrations at CR-PWRHS (segment 16), 2005-2008.

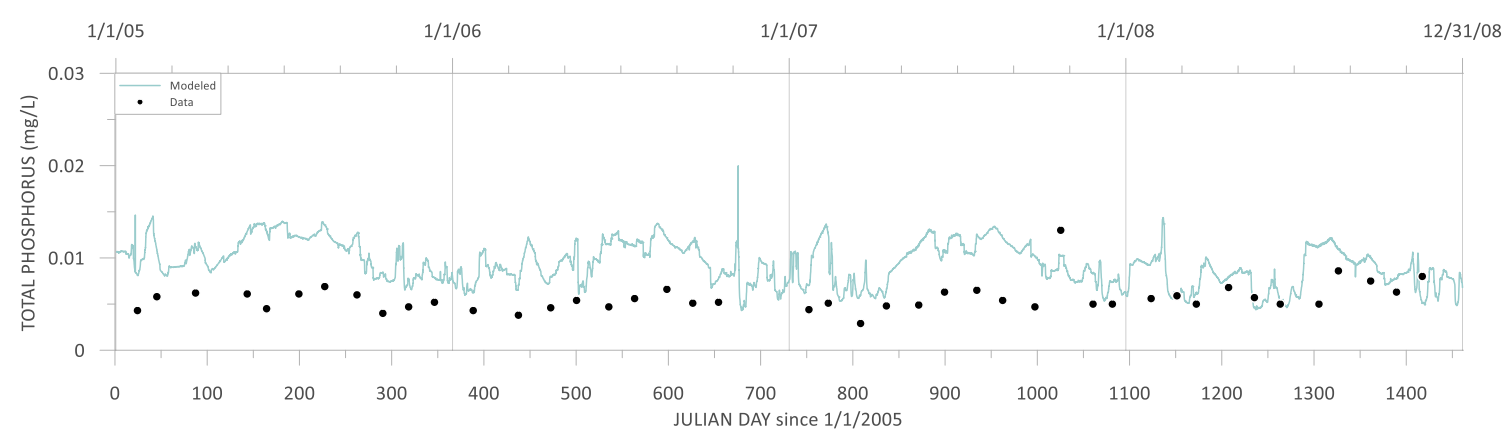

Figure D-5. Comparison of modeled total phosphorus concentrations to observed concentrations at WSDE 08 C110 (segment 74), 2005-2008.

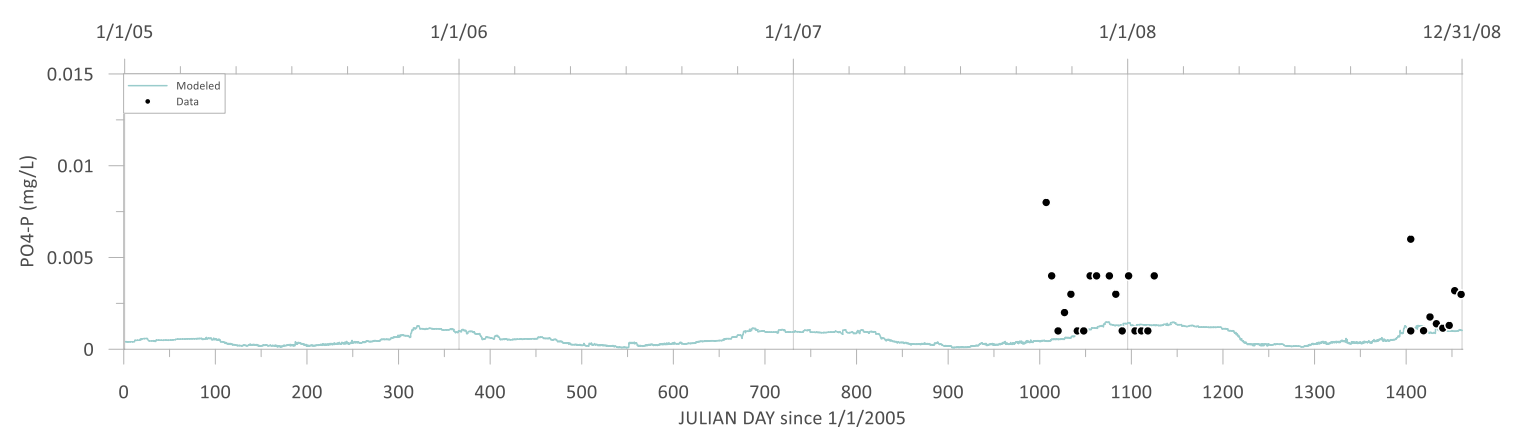

Figure D-6. Comparison of modeled phosphate concentrations to observed concentrations at CR-PWRHS (segment 16), 2005-2008. 


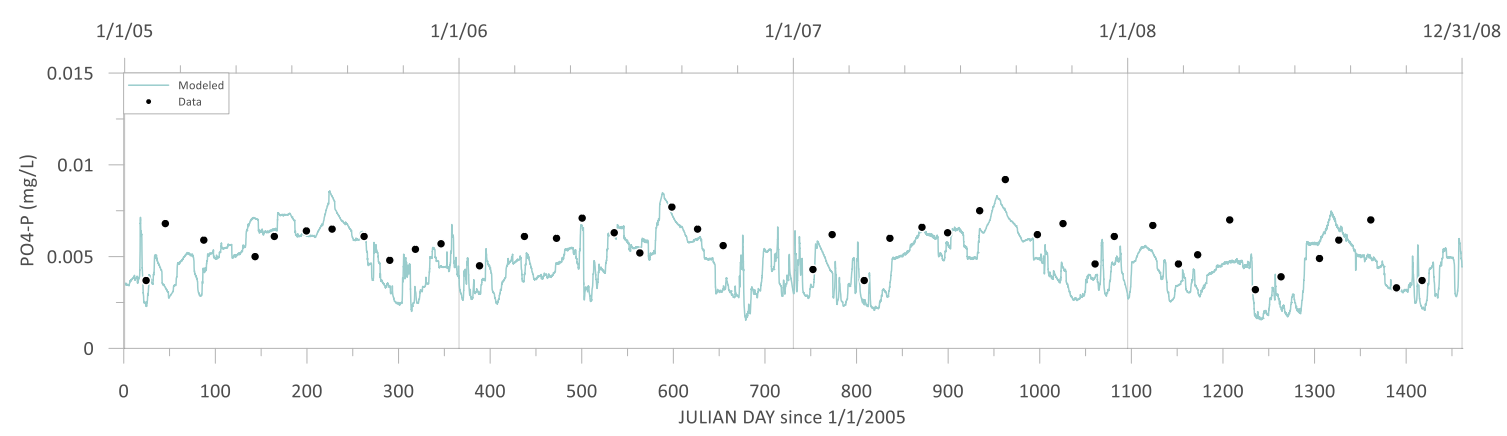

Figure D-7. Comparison of modeled phosphate concentrations to observed concentrations at WSDE 08 C110 (segment 74), 2005-2008.

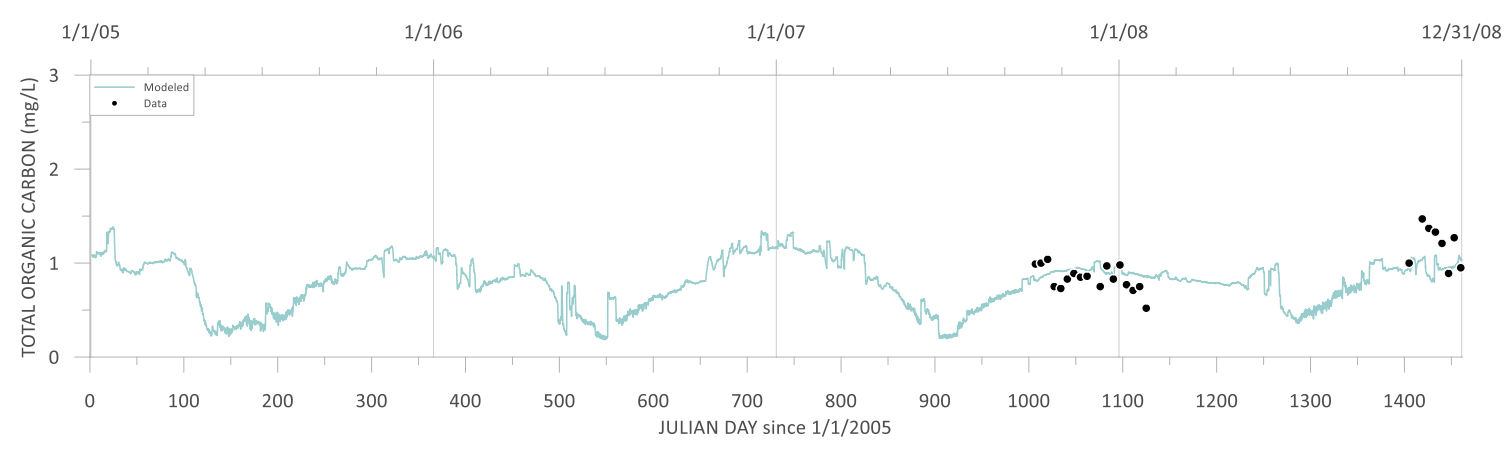

Figure D-8. Comparison of modeled total organic carbon concentrations to observed concentrations at CR-PWRHS (segment 16), 2005-2008. 


\section{Appendix E. Water Quality Constituents: River Model, 2015}

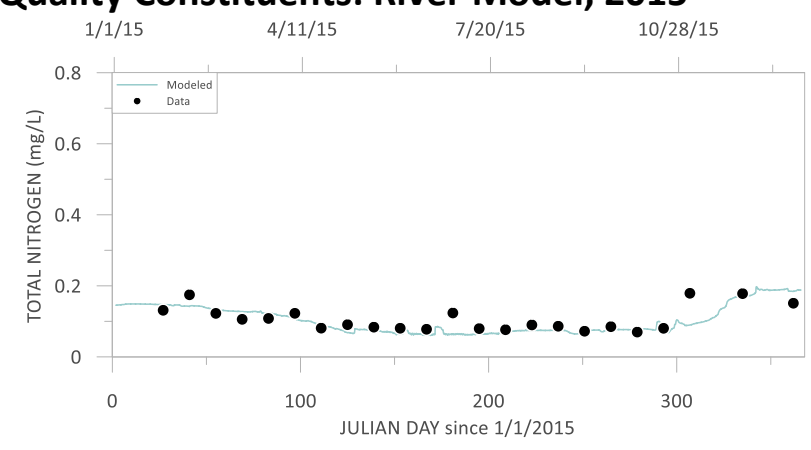

Figure E-1. Comparison of modeled total nitrogen concentrations to observed concentrations at CR-PWRHS (segment 16), 2015.

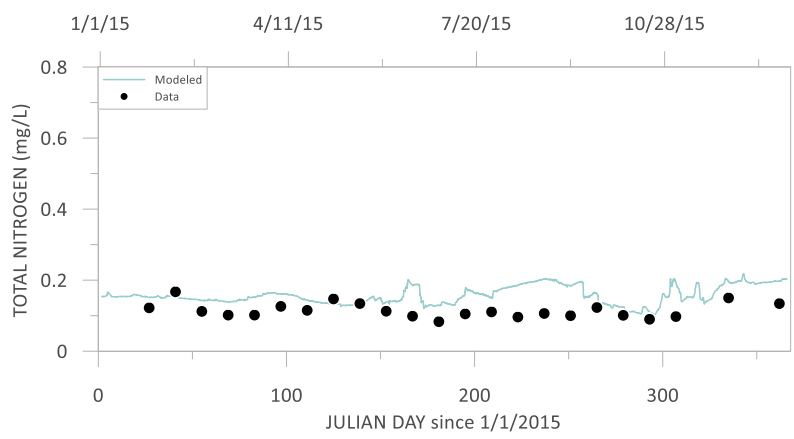

Figure E-2. Comparison of modeled total nitrogen concentrations to observed concentrations at CR3 (segment 44), 2015.

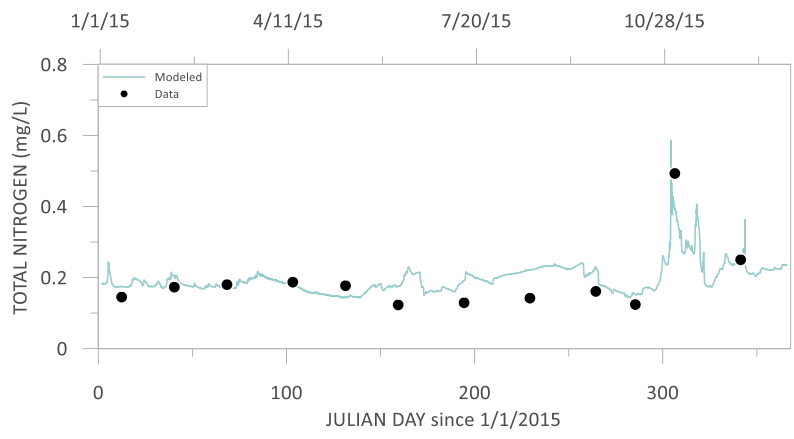

Figure E-3. Comparison of modeled total nitrogen concentrations to observed concentrations at WSDE 08C110 (segment 74), 2015. 


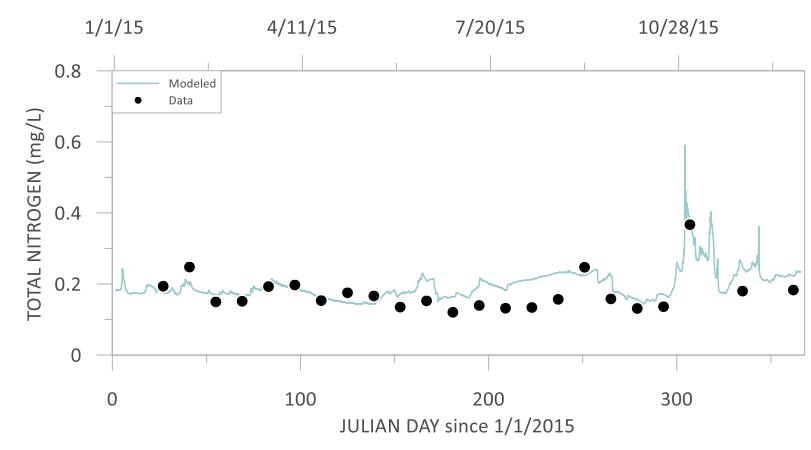

Figure E-4. Comparison of modeled total nitrogen concentrations to observed concentrations at CR7 (segment 76), 2015.

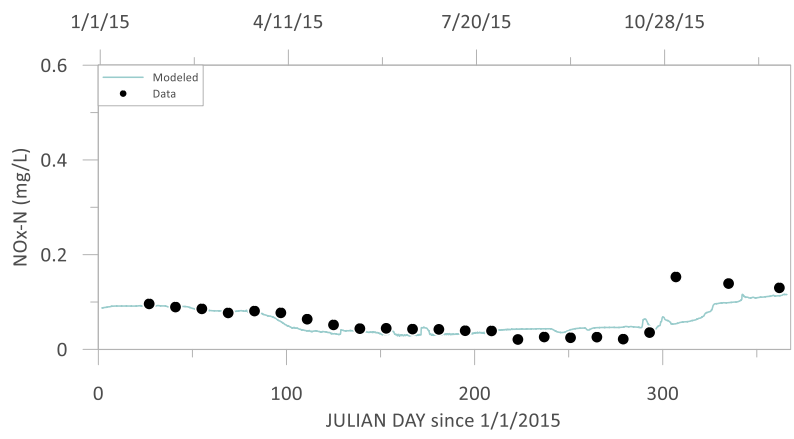

Figure E-5. Comparison of modeled nitrate-nitrite concentrations to observed concentrations at CR-PWRHS (segment 16), 2015.

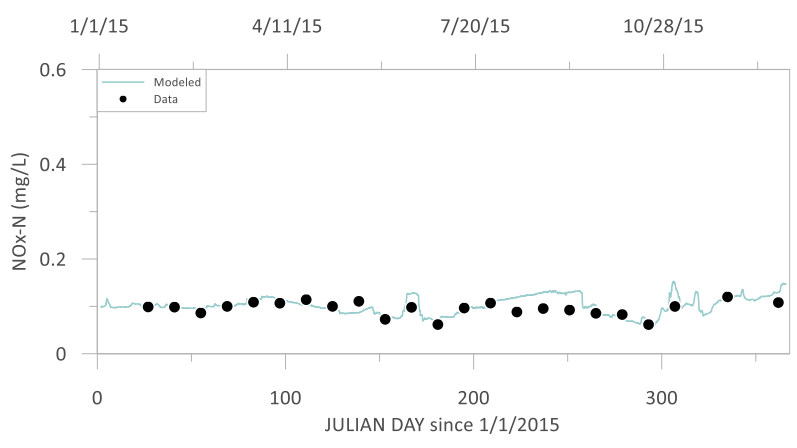

Figure E-6. Comparison of modeled nitrate-nitrite concentrations to observed concentrations at CR3 (segment 44), 2015. 


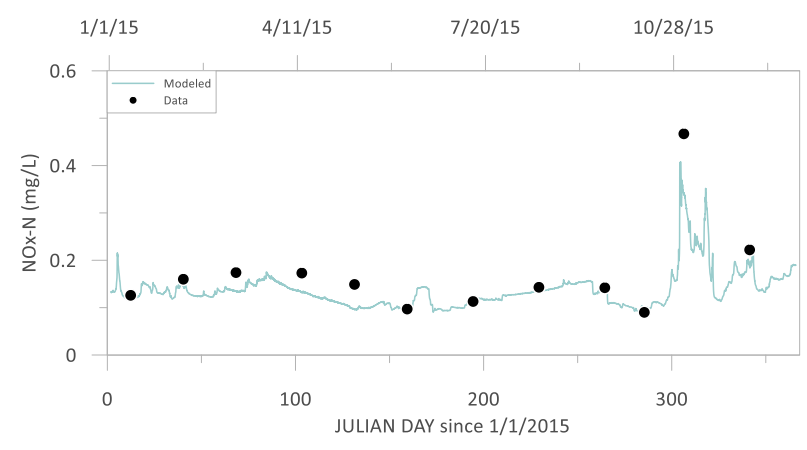

Figure E-7. Comparison of modeled nitrate-nitrite concentrations to observed concentrations at WSDE 08C110 (segment 74), 2015.

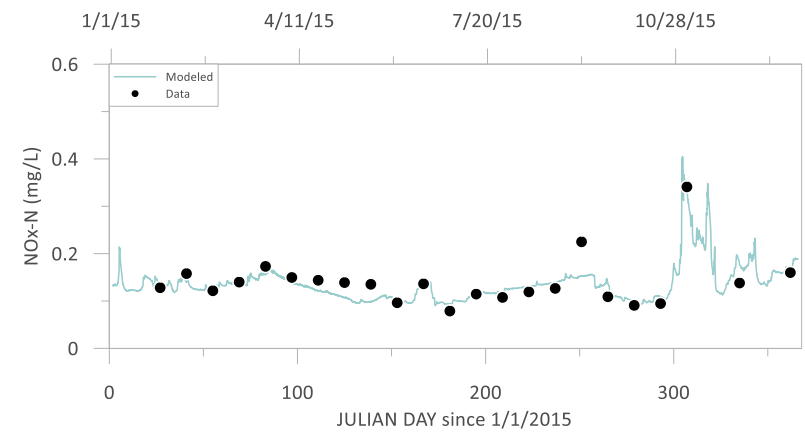

Figure E-8. Comparison of modeled nitrate-nitrite concentrations to observed concentrations at CR7 (segment 76), 2015.

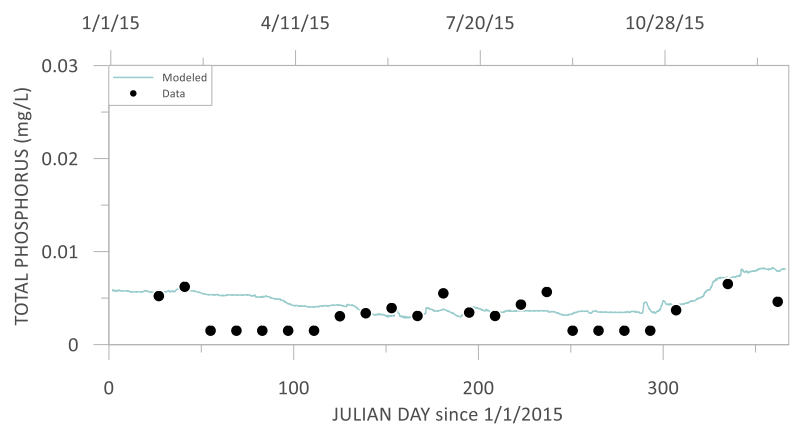

Figure E-9. Comparison of modeled total phosphorus concentrations to observed concentrations at CR-PWRHS (segment 16), 2015. 


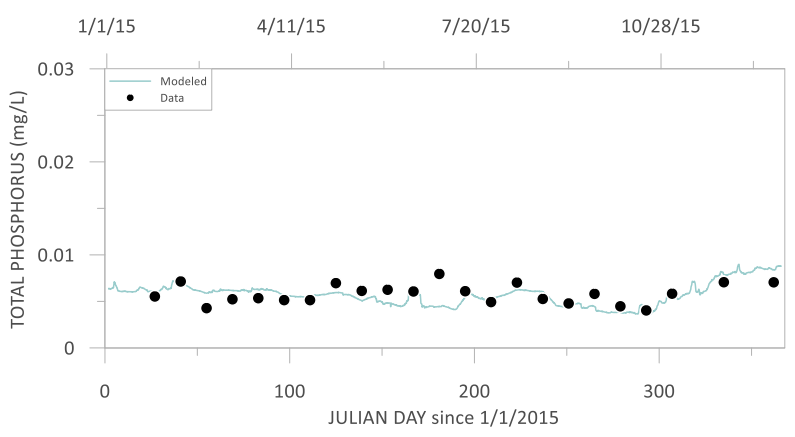

Figure E-10. Comparison of modeled total phosphorus concentrations to observed concentrations at CR3 (segment 44), 2015.

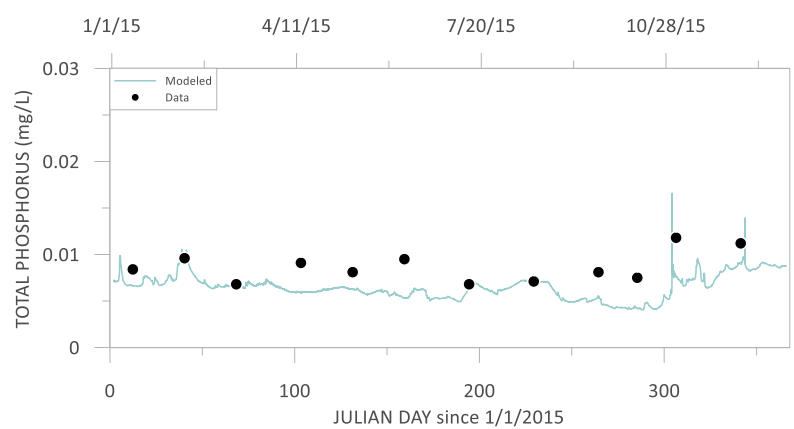

Figure E-11. Comparison of modeled total phosphorus concentrations to observed concentrations at WSDE 08C110 (segment 74), 2015.

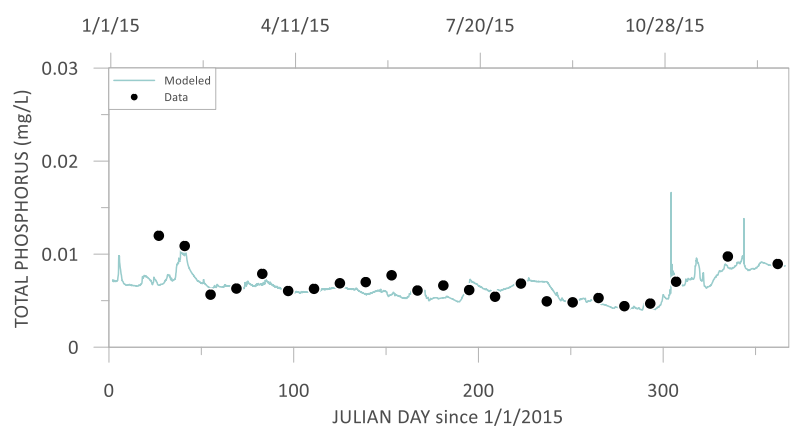

Figure E-12. Comparison of modeled total phosphorus concentrations to observed concentrations at CR7 (segment 76), 2015. 


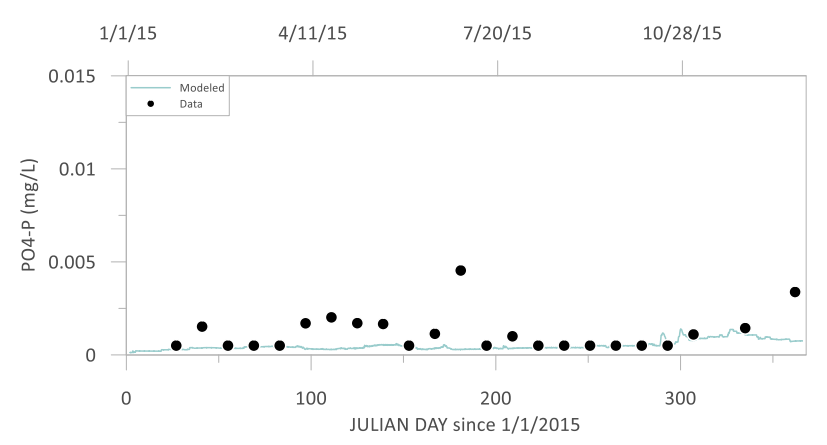

Figure E-13. Comparison of modeled phosphate concentrations to observed concentrations at CR-PWRHS (segment 16), 2015.

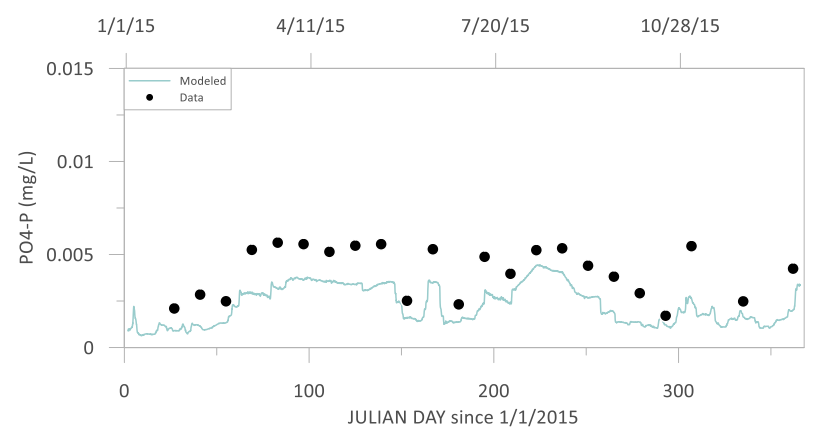

Figure E-14. Comparison of modeled phosphate concentrations to observed concentrations at CR3 (segment 44), 2015.

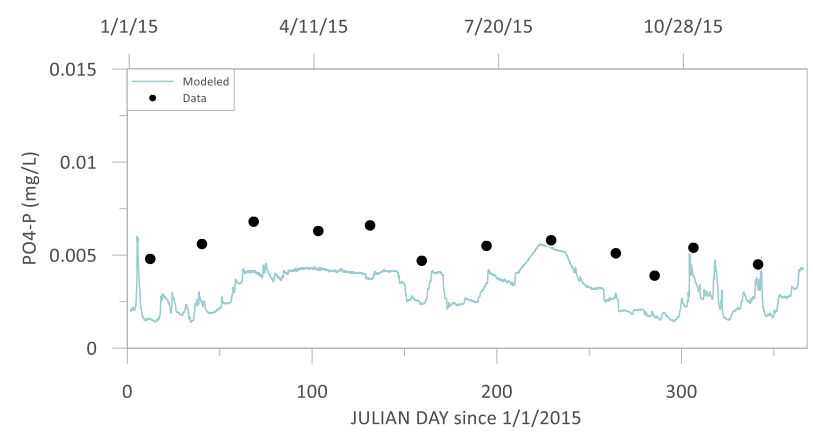

Figure E-15. Comparison of modeled phosphate concentrations to observed concentrations at WSDE $08 C 110$ (segment 74), 2015. 


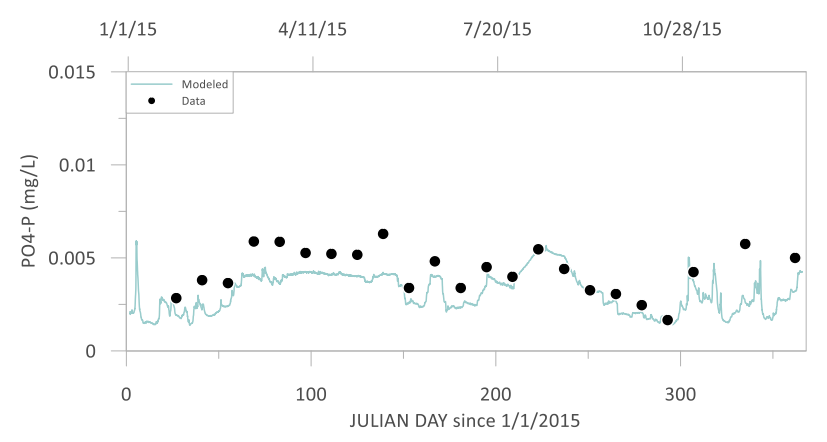

Figure E-16. Comparison of modeled phosphate concentrations to observed concentrations at CR7 (segment 76), 2015.

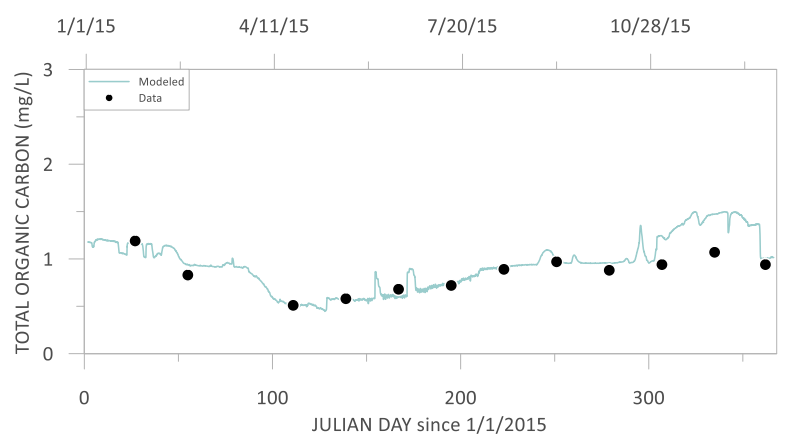

Figure E-17. Comparison of modeled total organic carbon concentrations to observed concentrations at CR-PWRHS (segment 16), 2015.

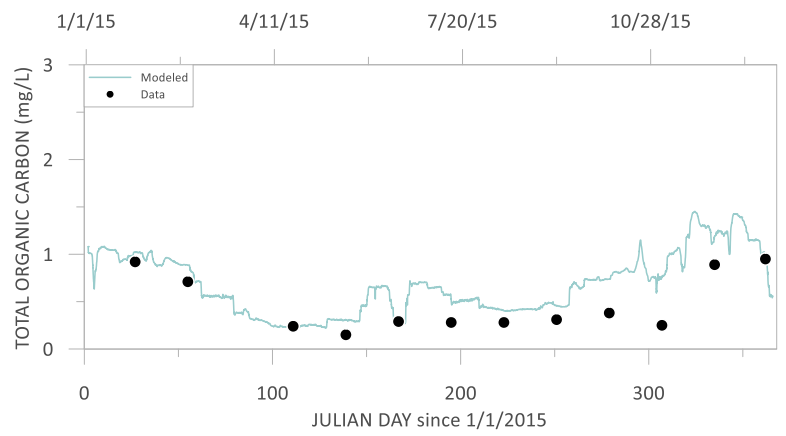

Figure E-18. Comparison of modeled total organic carbon concentrations to observed concentrations at CR3 (segment 44), 2015. 


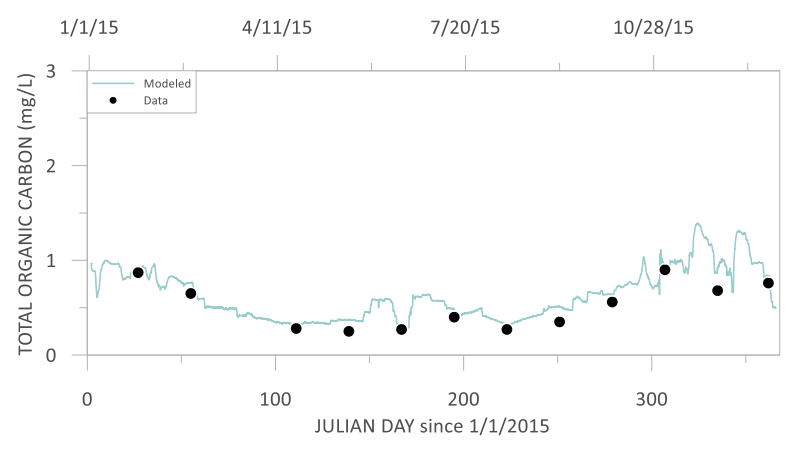

Figure E-19. Comparison of modeled total organic carbon concentrations to observed concentrations at CR7 (segment 76), 2015. 
Appendix F. Change in Dissolved Oxygen Concentrations under Scenarios, Cedar River
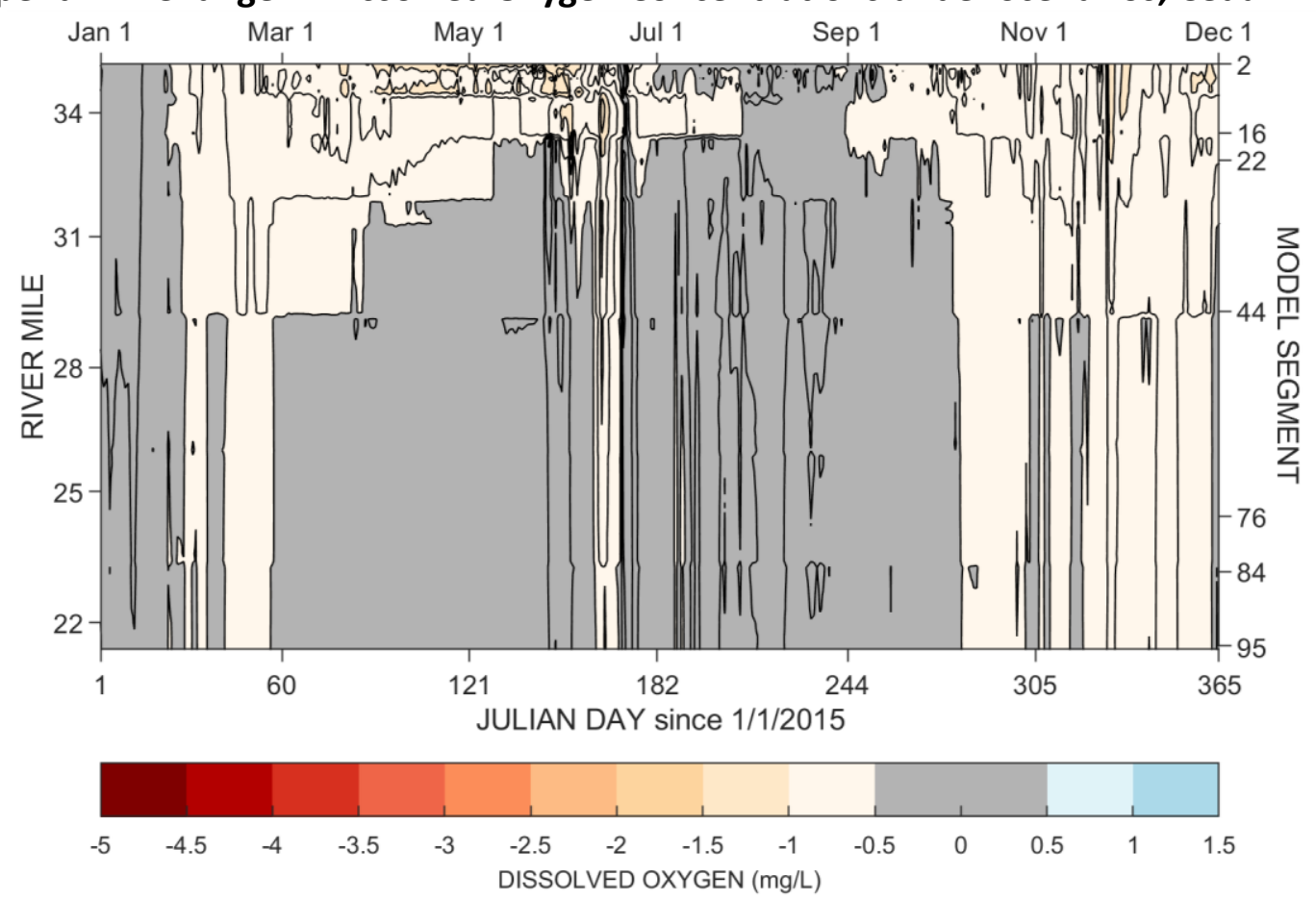

Figure F-1. Comparison of the base condition daily dissolved oxygen concentration at noon to Scenario 1 for all segments on all days, Cedar River.
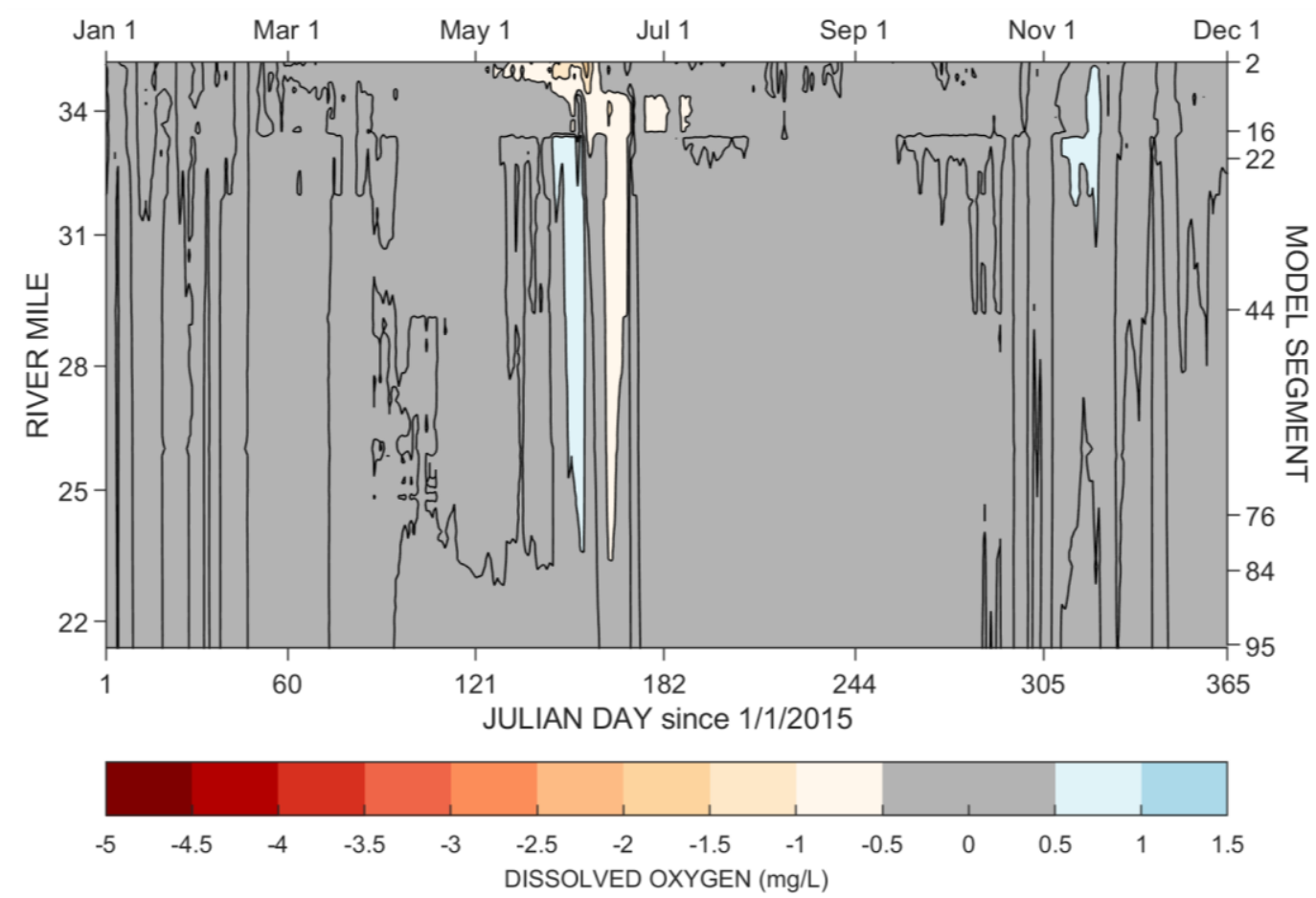

Figure F-2. Comparison of the base condition daily dissolved oxygen concentration at noon to Scenario 2 for all segments on all days, Cedar River. 

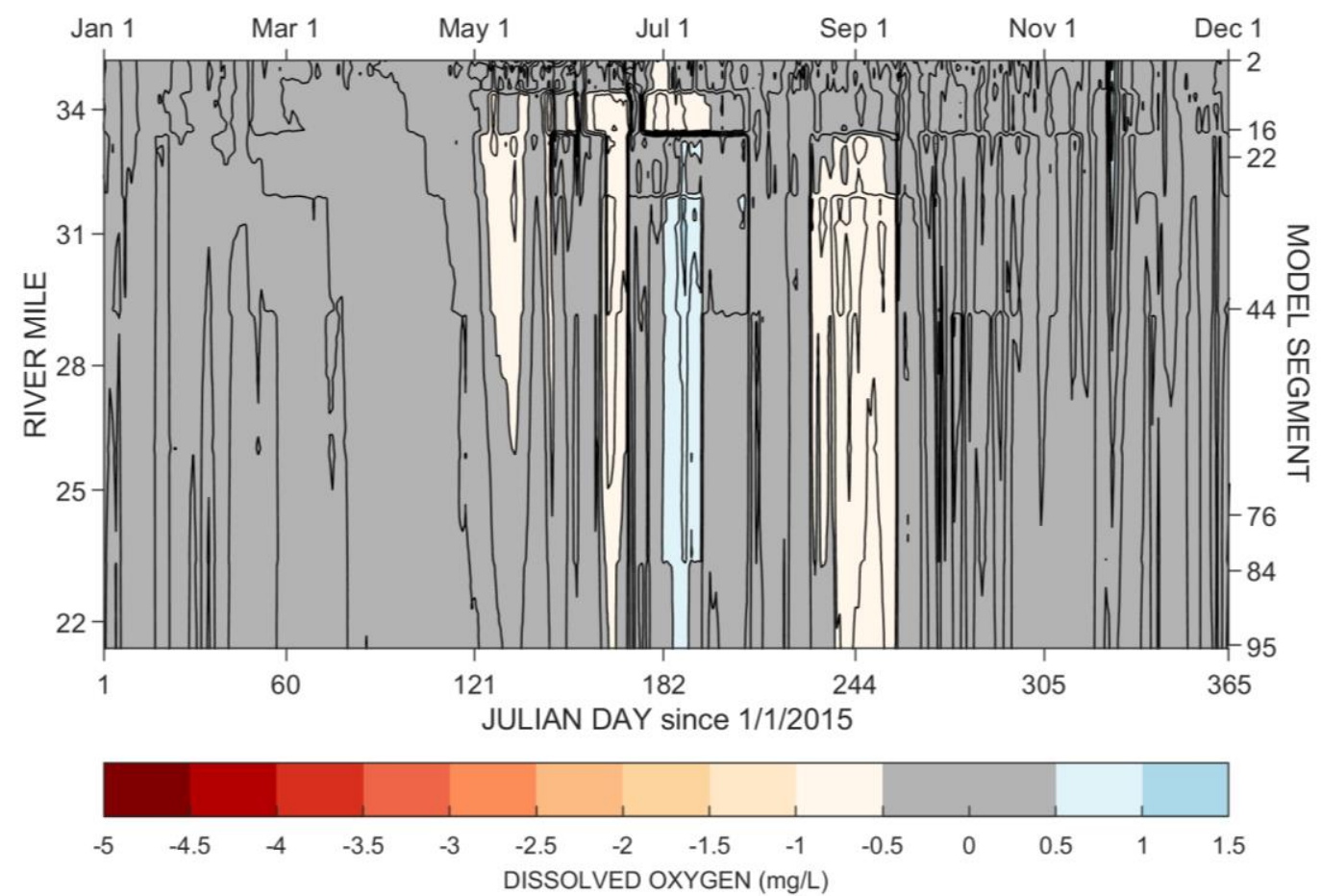

Figure F-3. Comparison of the base condition daily dissolved oxygen concentration at noon to Scenario 3 for all segments on all days, Cedar River.
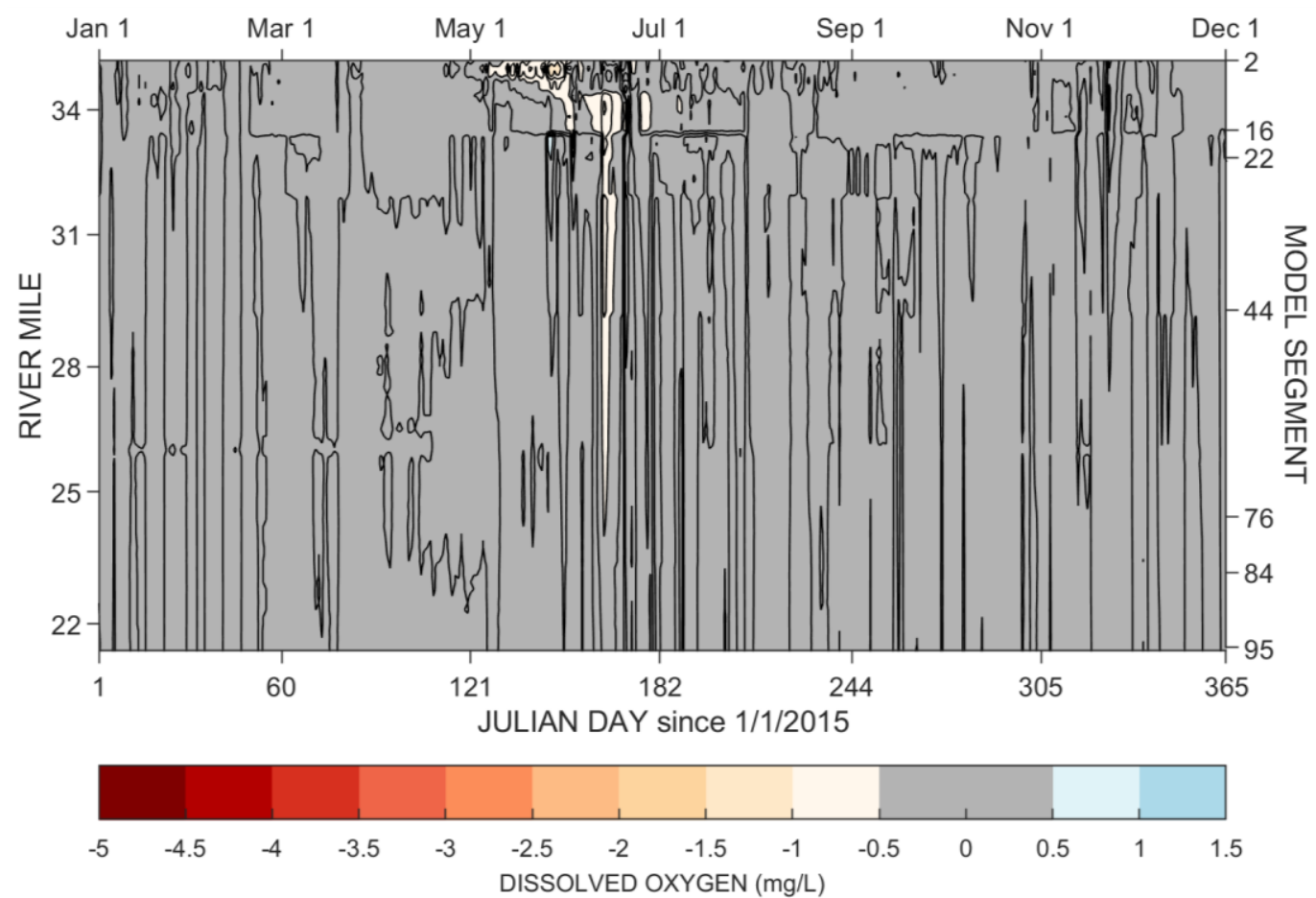

Figure F-4. Comparison of the base condition daily dissolved oxygen concentration at noon to Scenario 4 for all segments on all days, Cedar River. 

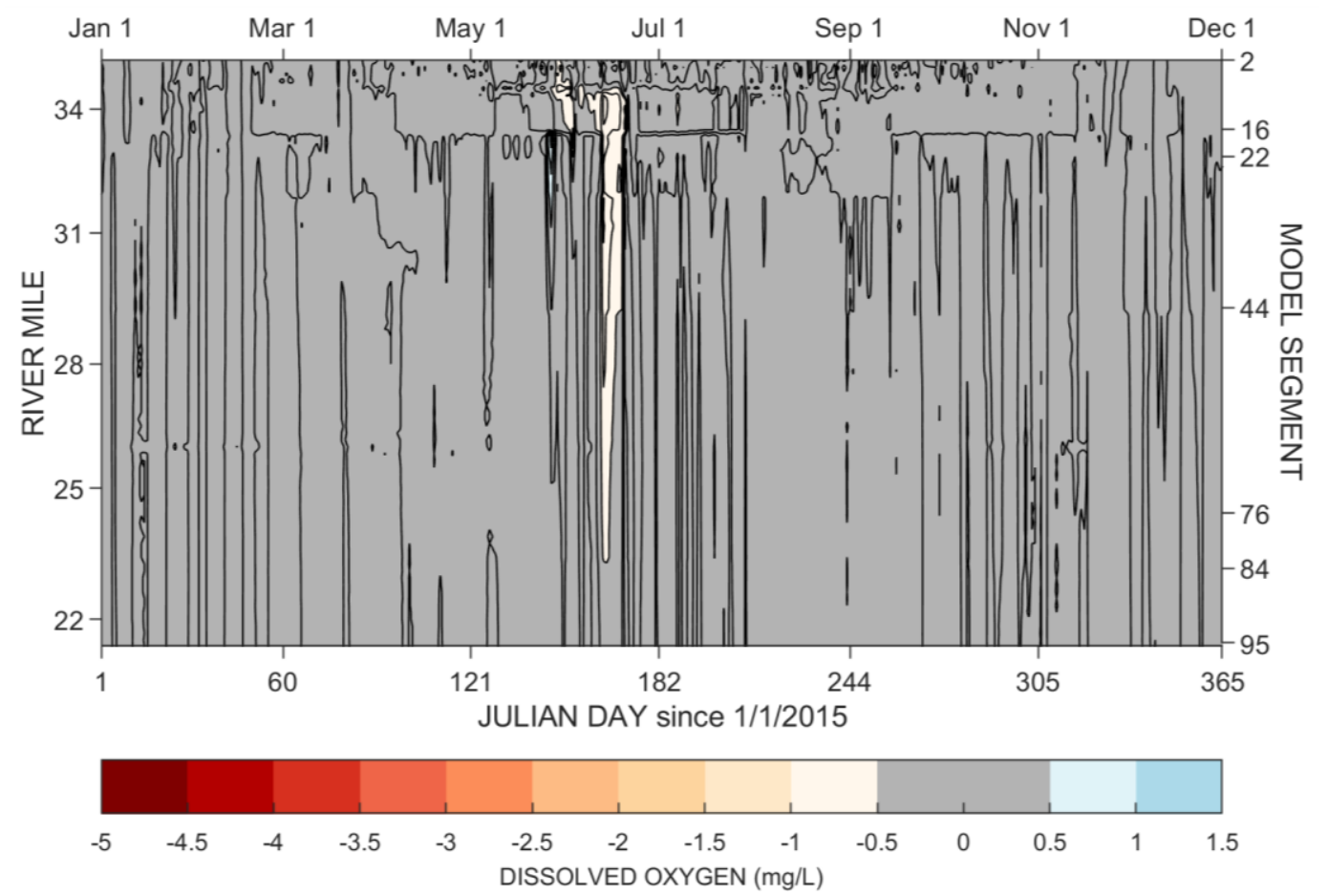

Figure F-5. Comparison of the base condition daily dissolved oxygen concentration at noon to Scenario 5 for all segments on all days, Cedar River. 


\section{Appendix G. Fish Habitat Volume}

Table G-1. Summary of the average monthly percent of reservoir volume with high growth potential for bull trout in the Chester Morse Lake base model and the change in the average for each scenario.

\begin{tabular}{lcccccc}
\hline Month & Base & Scenario 1 & Scenario 2 & Scenario 3 & Scenario 4 & Scenario 5 \\
\hline Jan & 0 & 0 & 0 & 0 & 0 & 0 \\
Feb & 0 & 0 & 0 & 0 & 0 & 0 \\
Mar & 0 & 3 & 0 & 0 & 0 & 0 \\
\hline Apr & 5 & 31 & 1 & 0 & 0 & 0 \\
May & 39 & 9 & 1 & -2 & 1 & 1 \\
\hline Jun & 22 & 2 & 0 & -2 & 0 & 0 \\
Jul & 14 & 8 & 0 & 0 & 0 & 0 \\
Aug & 13 & 7 & 1 & 0 & 0 & 0 \\
Sep & 42 & -16 & -1 & -2 & -1 & 0 \\
Oct & 50 & 6 & 0 & 9 & 0 & -1 \\
Nov & 4 & 43 & 0 & 2 & -1 & 0 \\
Dec & 0 & 0 & 0 & 0 & 0 & 0 \\
\hline
\end{tabular}

Table G-2. Summary of the average monthly percent of reservoir volume with medium growth potential for bull trout in the Chester Morse Lake base model and the change in the average for each scenario.

\begin{tabular}{lcccccc}
\hline Month & Base & Scenario 1 & Scenario 2 & Scenario 3 & Scenario 4 & Scenario 5 \\
\hline Jan & 0 & 0 & 0 & 0 & 0 & 0 \\
\hline Feb & 0 & 1 & 0 & 0 & 0 & 0 \\
Mar & 0 & 13 & 0 & 0 & 0 & 0 \\
\hline Apr & 13 & 44 & 0 & 0 & 0 & 0 \\
May & 48 & 18 & 1 & -3 & 1 & 1 \\
Jun & 31 & 8 & 0 & -2 & 1 & 1 \\
Jul & 21 & 16 & 0 & -1 & 1 & 1 \\
Aug & 21 & 15 & 1 & -1 & 0 & 0 \\
Sep & 50 & -1 & 0 & -2 & 0 & 0 \\
Oct & 55 & 14 & 1 & 11 & 1 & 0 \\
Nov & 18 & 52 & 2 & 5 & 1 & 0 \\
\hline Dec & 0 & 0 & 0 & 0 & 0 & 0 \\
\hline
\end{tabular}


Table G-3. Summary of the average monthly percent of reservoir volume with low growth potential for bull trout in the Chester Morse Lake base model and the change in the average for each scenario.

\begin{tabular}{lcccccc}
\hline Month & Base & Scenario $\mathbf{1}$ & Scenario $\mathbf{2}$ & Scenario 3 & Scenario 4 & Scenario 5 \\
\hline Jan & 0 & 7 & 0 & 0 & 0 & 0 \\
Feb & 1 & 67 & -1 & -1 & 0 & 0 \\
Mar & 15 & 85 & -1 & -2 & 1 & 1 \\
Apr & 70 & 30 & 3 & 0 & 5 & 5 \\
May & 84 & 15 & 6 & -1 & 10 & 9 \\
Jun & 89 & -9 & 4 & 0 & 5 & 6 \\
Jul & 80 & -8 & -1 & -2 & -1 & 1 \\
Aug & 86 & -27 & -2 & -3 & -2 & 0 \\
Sep & 100 & -18 & 0 & 0 & 0 & 0 \\
Oct & 100 & -20 & 0 & 0 & 0 & 0 \\
Nov & 87 & 0 & 3 & 4 & 2 & 1 \\
Dec & 0 & 81 & 0 & 0 & 0 & 0 \\
\hline
\end{tabular}

Table G-4. Summary of the average monthly percent of river volume with salmonid rearing and migration only aquatic life use in the Cedar River base model and the change in the average for each scenario.

\begin{tabular}{lcccccc}
\hline Month & Base & Scenario $\mathbf{1}$ & Scenario 2 & Scenario 3 & Scenario 4 & Scenario 5 \\
\hline Jan & 13 & 48 & 11 & 24 & 1 & 0 \\
Feb & 57 & 39 & -2 & 23 & -3 & -2 \\
Mar & 91 & 9 & -1 & 0 & 0 & 1 \\
\hline Apr & 100 & 0 & 0 & -1 & 0 & 0 \\
May & 100 & -1 & 0 & 0 & 0 & 0 \\
Jun 1-14 & 100 & -12 & -1 & -4 & -1 & -1 \\
Jul & -- & -- & -- & -- & -- & - \\
\hline Aug & -- & -- & -- & -- & -- & -- \\
Sep 16-30 & 100 & -1 & 0 & 0 & 0 & 0 \\
Oct & 100 & 0 & 0 & 0 & 0 & 0 \\
Nov & 91 & 9 & -5 & 4 & -2 & -3 \\
Dec & 25 & 71 & -3 & 4 & 6 & -4 \\
\hline
\end{tabular}

